William Oliveira Bessa

\title{
ANÁLISE EXPERIMENTAL E NUMÉRICA DE LIGAÇÕES VIGA MISTA-PILAR COM CANTONEIRAS DE ALMA E ASSENTO - PAVIMENTO TIPO E LIGAÇÕES ISOLADAS
}

\begin{abstract}
Tese apresentada à Escola de Engenharia de São Carlos, da Universidade de São Paulo, como parte dos requisitos para obtenção do título de Doutor em Engenharia de Estruturas.
\end{abstract}

Orientador: Professor associado Roberto Martins Gonçalves 
AUTORIZO A REPRODUÇÃO E DIVULGAÇÃO TOTAL OU PARCIAL DESTE TRABALHO, POR QUALQUER MEIO CONVENCIONAL OU ELETRÔNICO, PARA FINS DE ESTUDO E PESQUISA, DESDE QUE CITADA A FONTE.

Ficha catalográfica preparada pela Seção de Tratamento da Informação do Serviço de Biblioteca - EESC/USP

Bessa, William Oliveira
B557a Análise experimental e numérica de ligações viga mista-pilar com cantoneiras de alma e assento-pavimento tipo e ligações isoladas / William Oliveira Bessa ; orientador Roberto Martins Gonçalves. -- São Carlos, 2009 .

Tese (Doutorado-Programa de Pós-Graduação e Área de Concentração em Engenharia de Estruturas) -- Escola de Engenharia de São Carlos da Universidade de São Paulo, 2009 .

1. Ligações viga-pilar. 2. Ligações mistas.

3. Pavimento tipo. 4. Cantoneiras de alma e assento.

I. Título. 
Candidato: Engenheiro WILLIAM OLIVEIRA BESSA

Tese defendida e julgada em 8.12.2009 perante a Comissão Julgadora:

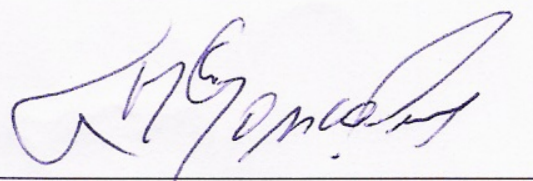

Prof. Associado ROBERTO MARTINS GONÇALVES (Orientador)

(Escola de Engenharia de São Carloś/USP)

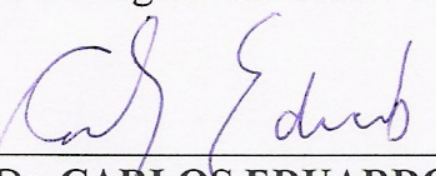

\section{Prof. Dr. CARLOS EDUARDO JAVARONI}

(Universidade Estadual Paulista "Julio de Mesquita Filho"/UNESP-Campus de Bauru)

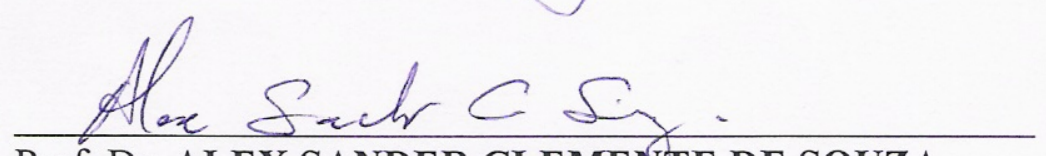

APROUADO

Prof. Dr. ALEX SANDER CLEMENTE DE SOUZA

(Universidade Federal de São Carlos/UFSCar)

\section{ABROVADO}
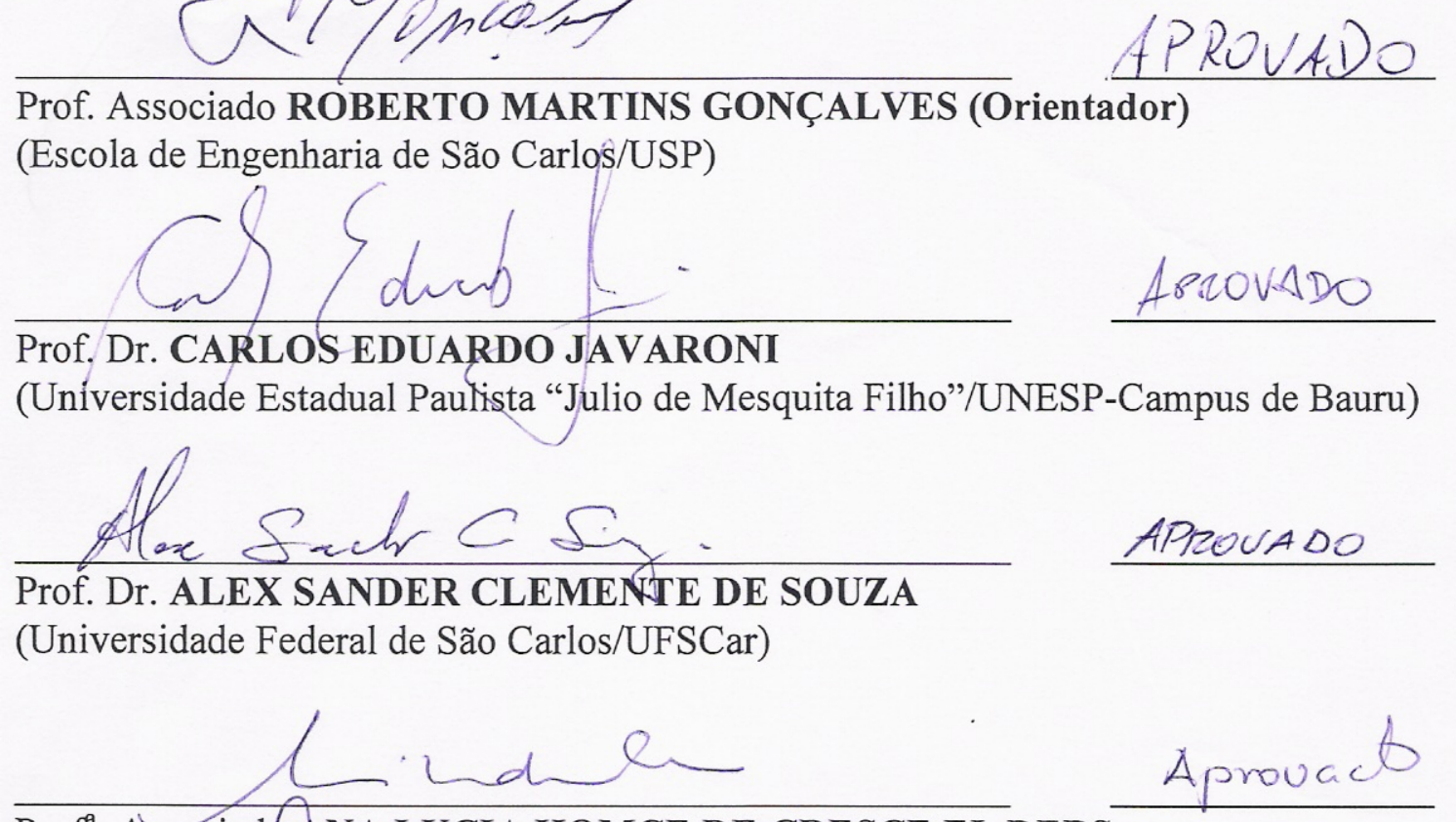

Prof ${ }^{\natural}$. Associada ANA LUCIA HOMCE DE CRESCE EL DEBS

(Escola de Engenharia de São Carlos/USP)

Prof. Dr. JORGE MUNAIAR NETO

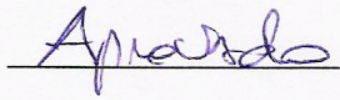

(Escola de Engenharia de São-Carlos/USP)

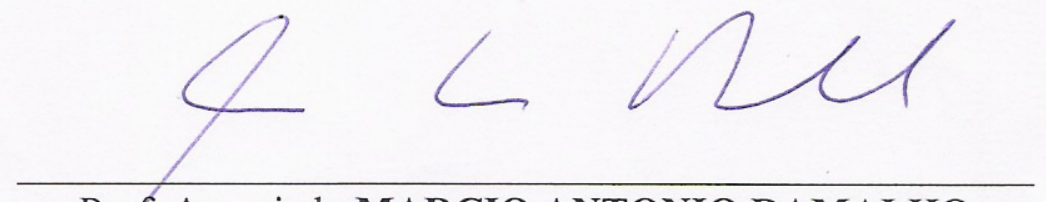

Prof. Associado MARCIO ANTONIO RAMALHO

Coordenador do Programa de Pós-Graduação em

Engenharia Civil (Engenharia de Estruturas)

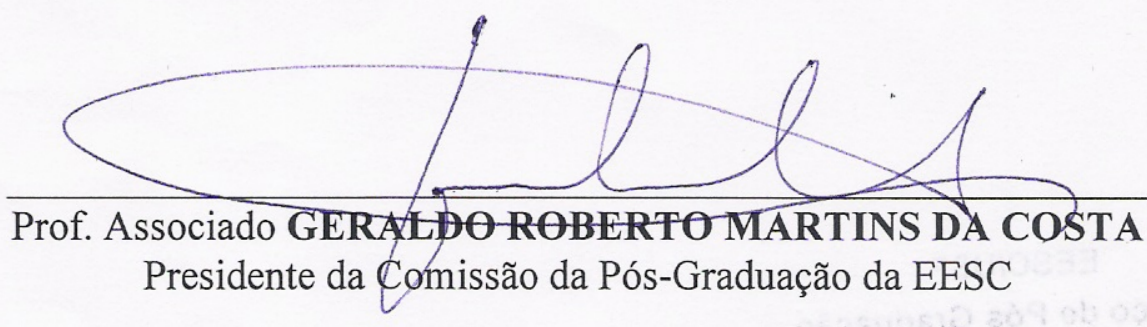


"The only limit to our realization of tomorrow will be our doubts of today. Let us move forward with strong and active faith"

President Franklin D. Roosevelt 


\section{AGRADECIMENTOS}

Ao professor Roberto Martins Gonçalves pela confiança, incentivo, amizade e pela dedicação com a qual sempre pude contar não só para o desenvolvimento deste trabalho, mas principalmente para o meu amadurecimento pessoal e profissional como engenheiro.

Agradeço a todos os meus familiares pelo incentivo durante este período. Aos meus queridos sobrinhos Luis Felipe e Eduardo e, em especial, para a minha mãe Cleusa, pela confiança e ajuda na superação dos momentos difíceis.

A CAPES, CNPq e FAPESP pelo auxílio financeiro ao longo de todo o desenvolvimento deste trabalho de pesquisa.

Aos professores Toshiaki Takeya e José Samuel Giongo pela contribuição ao desenvolvimento da abrangente análise experimental.

Ao desenhista Francisco Brito, cuja contribuição foi fundamental no processo de concepção e elaboração dos desenhos do programa experimental.

Um agradecimento especial aos amigos Pedro César, Calil Zumerle e Bruno Higaki pela convivência e contribuição durante o longo processo de concepção e desenvolvimento da análise experimental.

A todos os funcionários da Secretária do Departamento de Estruturas pela disponibilidade de ajudar no dia-dia de nosso trabalho.

A todos os funcionários do Laboratório de Estruturas.

Aos grandes amigos Leonardo, Junio, Osvaldo e Márcia, pela gratificante e prazerosa convivência ao longo destes anos em São Carlos.

Por fim, aos novos colegas e amigos do Departamento de Arquitetura e Engenharia do MPDFT. 


\section{RESUMO}

BESSA, W. O. (2009). Análise Teórica e Experimental de Ligações Viga MistaPilar com Cantoneiras de Alma e Assento - Pavimento Tipo e Ligações Isoladas. São Carlos. Tese (Doutorado). Escola de Engenharia de São Carlos, Universidade de São Paulo, Brasil.

Esta pesquisa apresenta um amplo programa experimental de ligações viga mista-pilar com cantoneiras de alma e assento, incluindo protótipos isolados e ligações inseridas num pavimento tipo constituído de laje prémoldada com vigotas e lajotas cerâmicas. Os objetivos do trabalho foram avaliar os efeitos da fissuração da laje no comportamento da ligação (rigidez inicial e momento resistente), o acréscimo da taxa de armadura secundária e os detalhes propostos para a ancoragem das armaduras longitudinais.

Nos ensaios experimentais foram analisadas as rotações das ligações, deslocamentos e deformações nos elementos. Para o estudo teórico, tomou-se como referência o Método das Componentes do EUROCODE 3 e 4. Paralelamente, um estudo numérico para ligações mistas foi desenvolvido com o objetivo de incluir a laje de concreto, as armaduras longitudinais e transversais, além da não linearidade física e geométrica na análise por elementos finitos.

De acordo com os resultados, a condição prévia de fissuração da laje mostrou-se menos relevante que a continuidade das vigas na direção do eixo de menor inércia do pilar, no que se refere à determinação da rigidez inicial e resistência das ligações mista inseridas num pavimento tipo. A metodologia de modelagem numérica foi capaz de representar de forma satisfatória os mecanismos plásticos e os estados limites últimos da ligação.

Palavras-chave: estruturas mistas, pavimento tipo, ligações mistas, método das componentes, vigotas pré-moldadas, ligações com cantoneiras. 


\begin{abstract}
BESSA, W. O. (2009). Theoretical and Experimental Analysis of Beam-toColumn Composite Connections with Bottom and Web Angle - Typical Floor and Isolated Prototypes. São Carlos. Thesis (Doctorate). São Carlos School of Engineering, University of São Paulo, Brazil.
\end{abstract}

This research presents an extensive experimental study of the structural behavior of the beam-to-column composite connections with bottom and web angle, including isolated prototypes and typical floor with slab made of precast joist with lattice and bricks. The objectives were to evaluate concrete slab cracking effects in the composite connections behavior (initial stiffness and resistant moment), the secondary steel ratio increase and the proposed details for the longitudinal steel bars anchorage.

In the experimental tests, it was analyzed the connection total rotation, the displacements and deformations in the connection components. The theoretical study was developed based on EURODODE 3 and 4 methodologies. Besides, a numerical study was developed with the purpose of including the concrete slab modelling, the longitudinal and transversal steel bars, and the geometrical and material non-linearity in the finite element analysis.

According to the results, the beam continuity through to the column minor axis showed to be more important than the concrete slab previous cracking, for the initial stiffness and resistant moment composite connections behavior in the typical floor. The numerical models represented satisfactorily the plastic mechanism connection and the ultimate limit states.

keywords: composite structures, typical floor, composite connections, component method, lattice girder, angle connections. 


\section{SUMÁRIO}

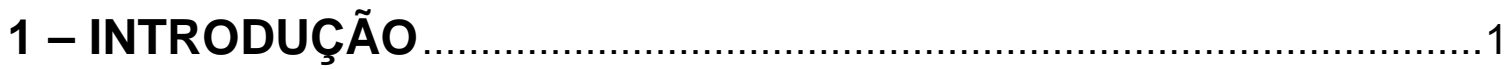

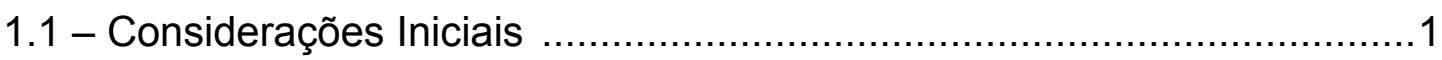

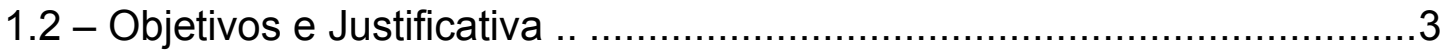

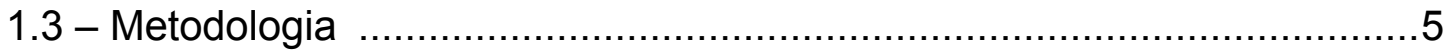

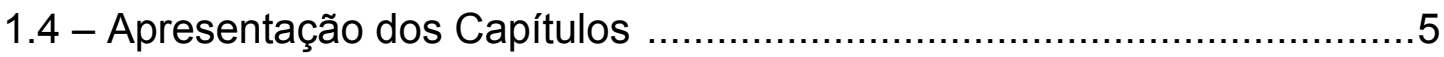

2 - REVISÃO BIBLIOGRÁFICA E CONCEITOS GERAIS $\ldots \ldots \ldots \ldots \ldots \ldots \ldots \ldots \ldots . . \ldots$

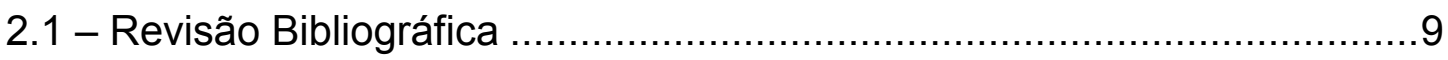

2.1 .1 - Considerações gerais ................................................ 9

2.1.2 - Aspectos gerais das ligações mistas .................................10

2.1.3 - Comportamento $M-\theta$ das ligações mistas aço concreto ........... 17

2.1.4 - Resistência e rigidez das ligações .................................. 21

2.2 - Conceitos Gerais ............................................................. 27

2.2.1 - Consideração da não-linearidade dos materiais ....................27

2.2.1.1 - Análise elástica linear para estado limite último .......... 28

2.2.1.2 - Análise elástica linear para estado limite de serviço.......31

2.2.1.3 - Análise rígido-plástica .............................................32

2.2.1.4 - Análise elasto-plástica .............................................34

2.2.2 - Vigas mistas aço-concreto ...................................................36

2.2.2.1 - Largura efetiva............................................... 38

2.2.2.2 - Comportamento em estado limite último .....................39

2.2.2.3 - Comportamento em estado limite de serviço .................43

2.2.2.4 - Grau de conexão de cisalhamento ............................44

2.2.2.5 - Armaduras transversais na laje.................................46

2.2.2.6 - Armaduras longitudinais..........................................49

2.3 - Considerações Finais ..................................................... 49

\section{3 - DIMENSIONAMENTO DAS LIGAÇÕES MISTAS COM CANTONEIRAS}

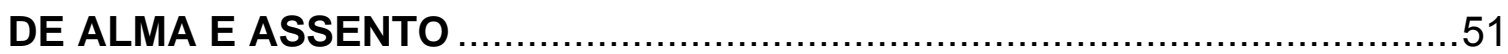

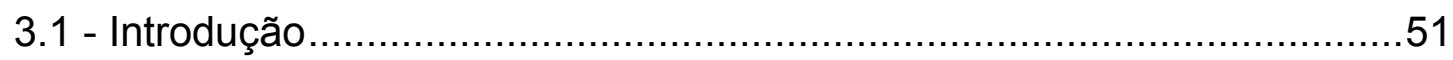


3.2 - Método Analítico Proposto pelo EUROCODE 3 .52

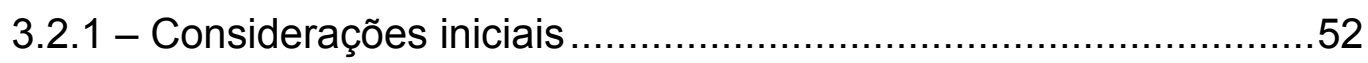

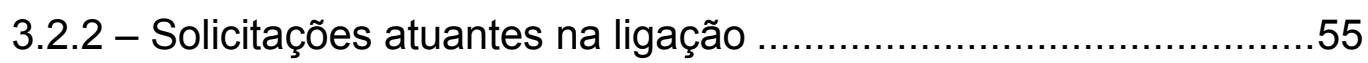

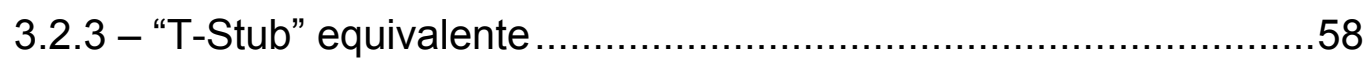

3.2.4 - Componentes básicos tracionados ........................................62

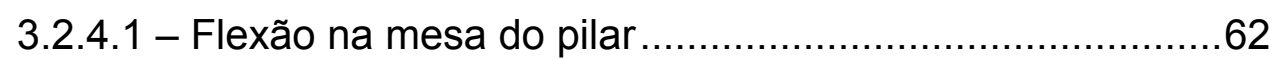

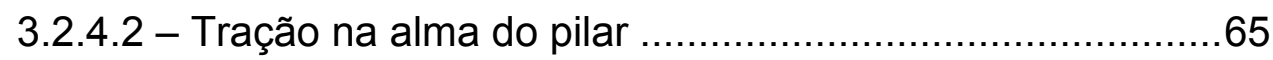

3.2.4.3 - Tração na alma da viga..................................................66

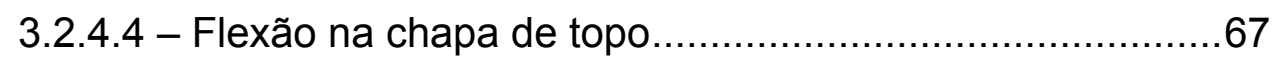

3.2.4.5 - Tração na armadura longitudinal da laje .........................68

3.2.5 - Componentes individuais em compressão ...............................70

3.2.5.1 - Compressão transversal na alma do pilar .......................70

3.2.5.2 - Compressão na mesa e alma da viga ………………......72

3.2.5.3 - Compressão na aba da cantoneira de assento ................72

3.2.6 - Componente individual em cisalhamento horizontal...................73

3.2.7 - Determinação do momento resistente .......................................75

3.2.8 - Determinação da rigidez inicial da ligação.................................. 80

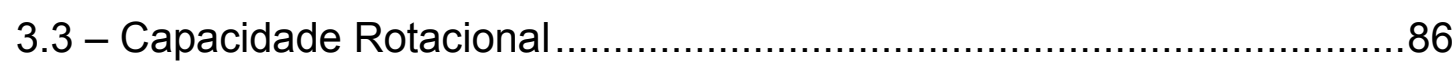

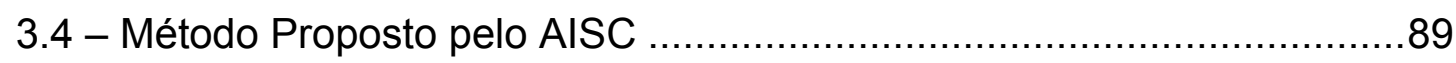

3.5 - Considerações Finais sobre os Métodos de Cálculo .............................91

4 - ENSAIOS EXPERIMENTAIS DOS PROTÓTIPOS ISOLADOS E

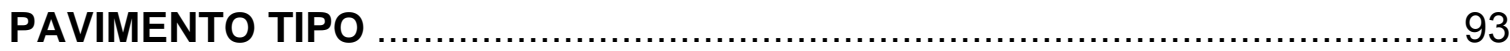

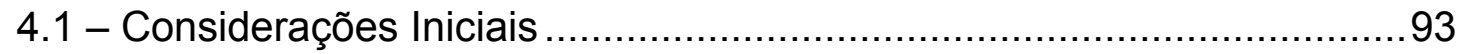

4.2 - Modelos Isolados: Pilar de Canto e de Centro......................................94

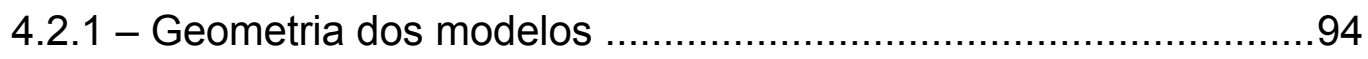

4.2.2 - Armaduras e montagem dos modelos .....................................96

4.2.3 - Sistemas de aplicação dos carregamentos ..............................100

4.2 .4 - Instrumentação................................................................102

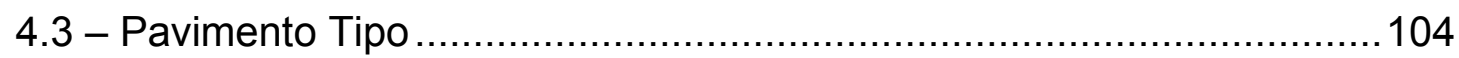

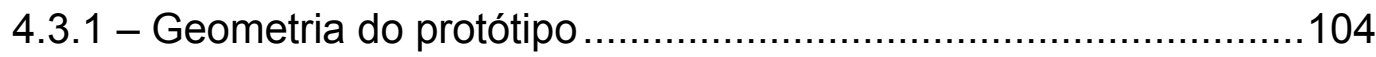

4.3.2 - Montagem do pavimento tipo …...........................................107 
4.3.3 - Etapas de aplicação do carregamento 111

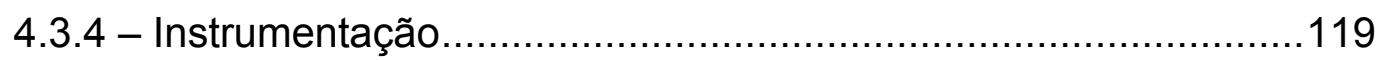

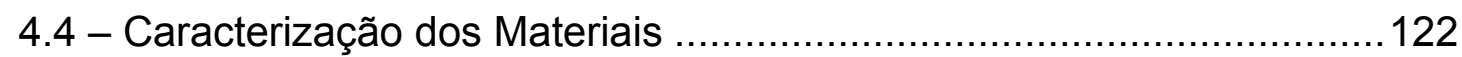

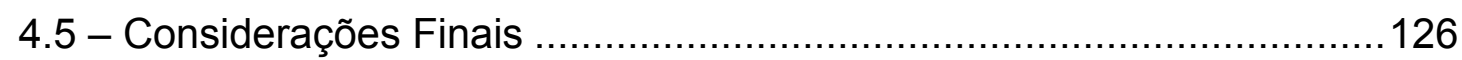

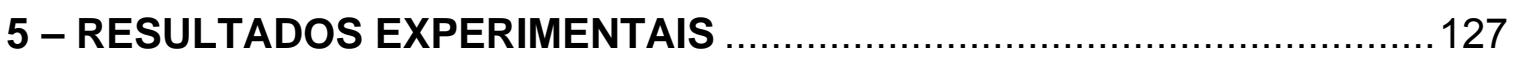

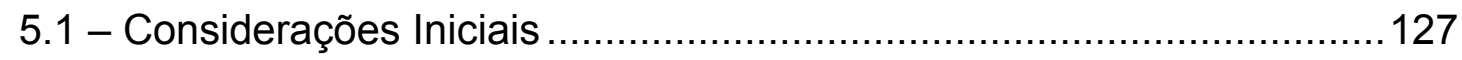

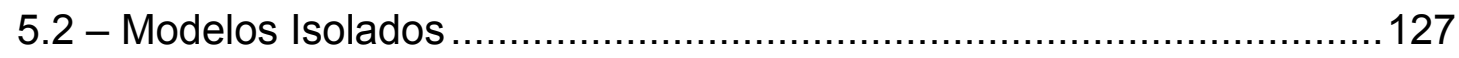

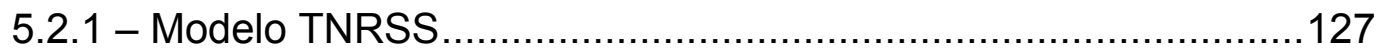

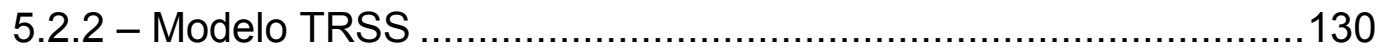

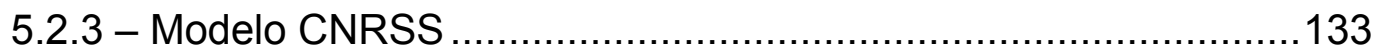

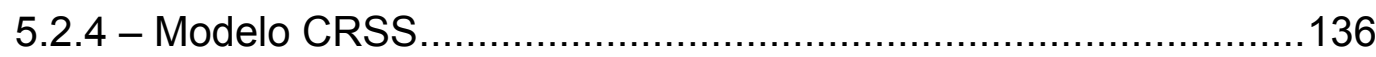

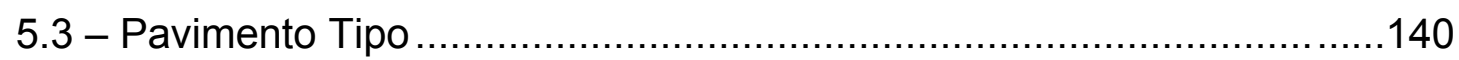

5.3.1 - Resultados da etapa de carregamento distribuído ....................140

5.3.2 - Resultados da etapa de carregamento concentrado .................142

5.3.2.1 - Ligação [1] ..........................................................145

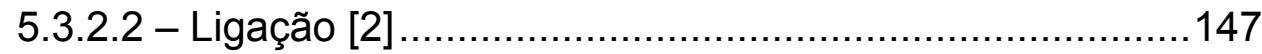

5.3.2.3 - Ligação [3] .........................................................149

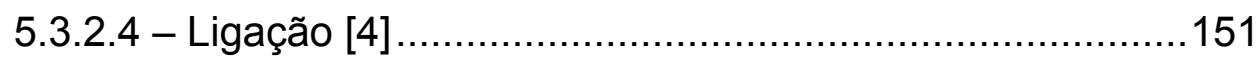

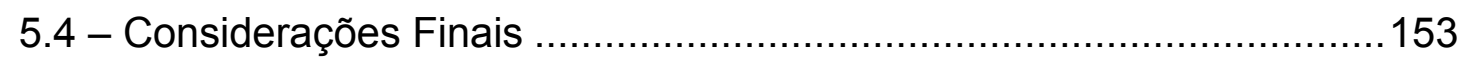

6 - DESCRIÇÃO E RESULTADOS DA MODELAGEM NUMÉRICA ...............155

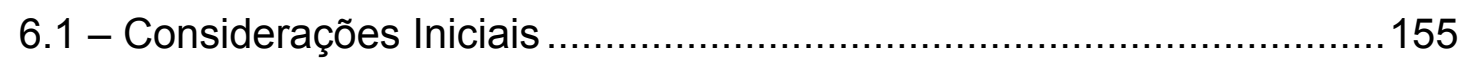

6.2 - Critérios Adotados na Análise Numérica ………..............................155

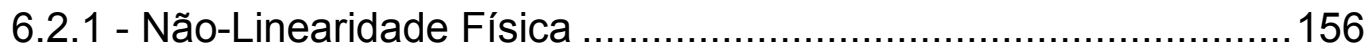

6.2.2 - Descontinuidade Geométrica ...............................................157

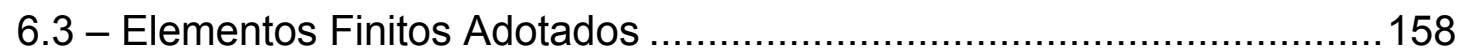

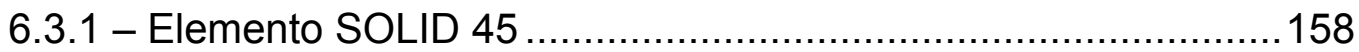

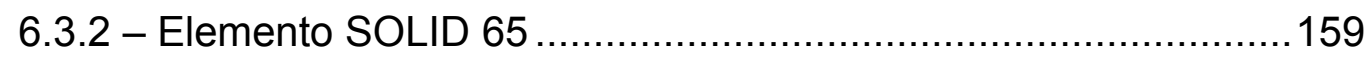

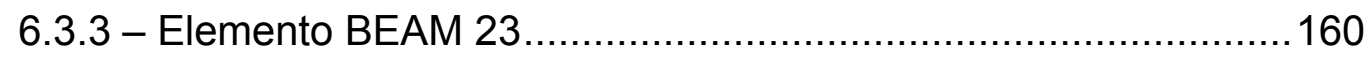

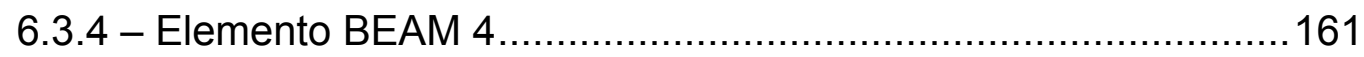

6.3.5 - Elemento BEAM 189...........................................................162 
6.3.6 - Elemento COMBIN 39 162

6.3.7 - Elementos de contato TARGE 170 e CONTA 173..................163

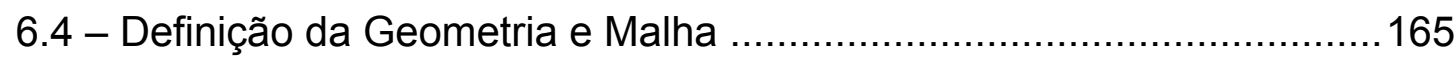

6.5 - Modelos Constitutivos para os Materiais ............................................. 168

6.6 - Condições de Contorno e Carregamento ……….............................171

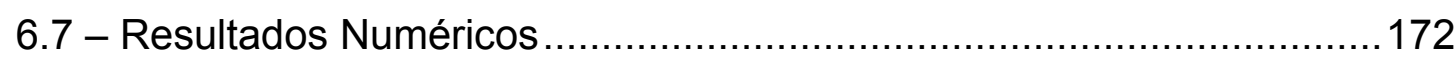

6.7.1 - Comportamento global da ligação ........................................173

6.7.2 - Modelos numéricos de pilar de borda ..................................175

6.7.3 - Modelos numéricos de pilar de centro ..................................182

6.8 - Comentários Finais a respeito da Modelagem Numérica ...................187

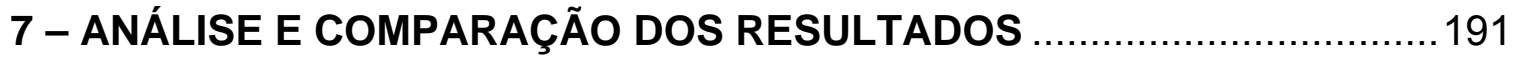

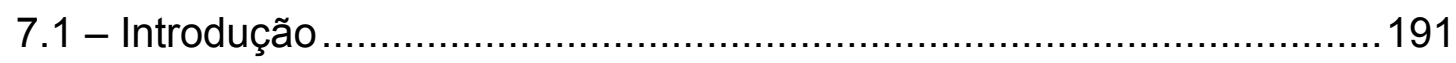

7.2 - Análise e Comparação dos Resultados Numéricos e Experimentais .191

7.2.1 - Comportamento momento-rotação total da ligação .................. 192

7.2.2 - Análise dos elementos da ligação..........................................196

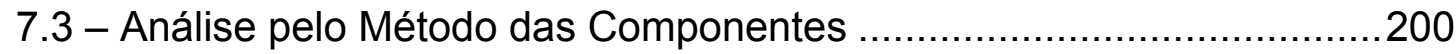

7.4 - Discussão dos Resultados de Acordo com as Três Análises .............205

7.5 - Fissuração na Laje do Pavimento Tipo............................................214

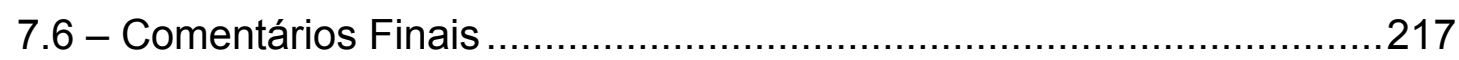

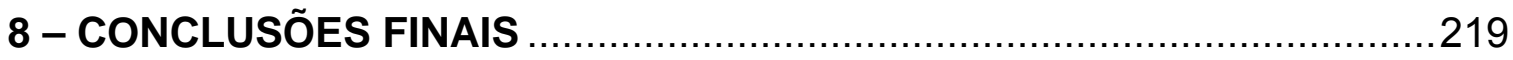

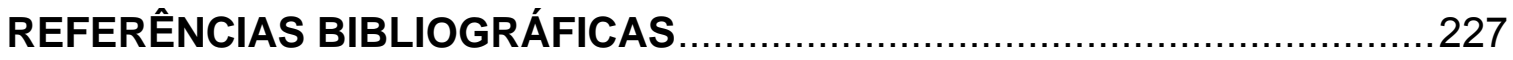

APÊNDICE A - DETALHAMENTO DOS PROTÓTIPOS EXPERIMENTAIS...235

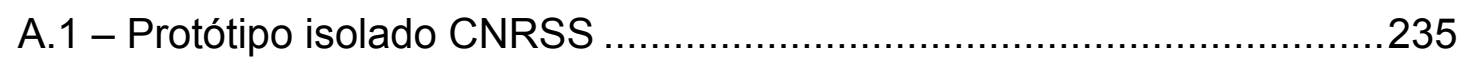

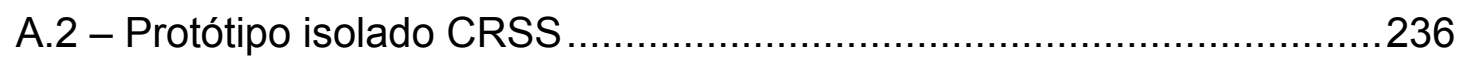

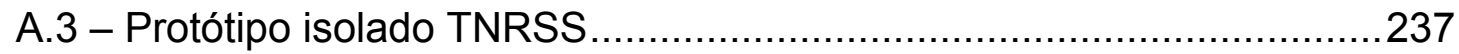

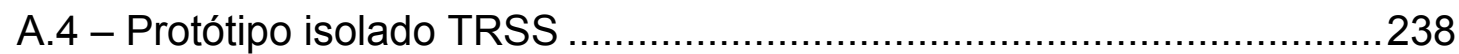

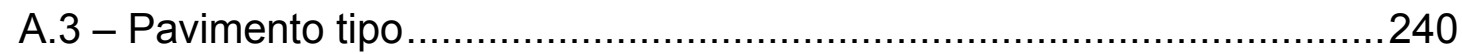

APÊNDICE B - RESULTADOS COMPLEMENTARES DA ETAPA DE CARREGAMENTO CONCENTRADO NO PAVIMENTO TIPO …..................245 


\section{1 \\ INTRODUÇÃO}

\section{1 - Considerações Iniciais}

As estruturas mistas, tal como as estruturas metálicas, têm seu comportamento global influenciado pelo tipo de ligação entre vigas e pilares. Esta influência é ainda mais relevante devido à grande variedade de configurações e dispositivos que podem ser utilizados, introduzindo, dessa forma, descontinuidades geométricas que, associadas à não linearidade dos materiais, propicia o comportamento não linear da estrutura como um todo.

O desenvolvimento da tecnologia de materiais e de recursos computacionais voltados para a análise estrutural tem possibilitado o surgimento de novas técnicas construtivas e análise de edifícios de andares múltiplos.

As vigas de aço ligadas por conectores de cisalhamento à laje de concreto (vigas mistas) vêm ocupando cada vez mais espaço no mercado. Estes elementos possuem grande capacidade de resistir a momentos positivos, possibilitando a concepção de projetos com vãos maiores, menor número de pilares e uma melhor relação custo/benefício.

$\mathrm{Na}$ região de momento negativo, a laje de concreto estará tracionada e, preponderantemente, a armadura longitudinal contribuirá para a resistência da laje ao momento fletor.

Uma ligação mista é aquela caracterizada pela participação da laje de concreto da viga mista e, consequentemente, de sua armadura longitudinal na transmissão de momento fletor para o pilar ou para a viga mista do vão adjacente. As ligações mistas são mais rígidas e resistentes se comparadas com a mesma em aço (mesmos perfis sem a consideração da armadura 
longitudinal da laje na resistência da ligação), com uma capacidade rotacional compatível. A participação da laje na concepção de pórticos metálicos visa um melhor equilíbrio entre economia e eficiência estrutural.

Dentre os benefícios das ligações mistas, podemos destacar a redução do peso próprio das vigas e um melhor desempenho em serviço, diminuindo as fissuras da laje nas regiões próximas aos pilares devido à presença de armaduras.

Nas ligações mistas, com transmissão de momentos fletores da viga para o pilar, deve-se considerar à contribuição da laje de concreto e da armadura longitudinal, no comportamento da ligação metálica.

Dessa forma, as ligações metálicas viga-pilar podem ser concebidas como mistas, com maior capacidade de transmissão de momentos fletores, sem grandes alterações no projeto estrutural e na técnica construtiva.

$\mathrm{Na}$ análise estrutural convencional, os projetos consideram a estrutura como sendo um conjunto de barras unidimensionais, interligadas através de pontos nodais, cujo comportamento é considerado idealmente articulado ou engastado.

A consideração do comportamento das ligações como articulada ou engastada é inadequada com a realidade, fazendo-se necessário o estabelecimento de um comportamento intermediário denominado de ligações semi-rígidas ou semi-contínuas.

Para descrever o comportamento semi-rígido, faz-se necessário conhecer a resposta rotacional da mesma por meio do comportamento $M-\phi 1$. Dessa forma, as pesquisas voltadas para o estudo das ligações mistas têm como principal objetivo a previsão do comportamento desta curva, dado este que deve ser considerado nas diferentes etapas do projeto estrutural.

É devido a tal resposta que podemos estabelecer que o comportamento do pórtico, em termos de deslocamento e esforços, será dependente também da resposta rotacional de cada nó (ligação). Adicionalmente, é possível

\footnotetext{
${ }^{1}$ Relação momento x rotação onde:

M é o momento na ligação;

$\phi$ é a rotação relativa entre eixos do pilar e da viga
} 
também prever de forma mais precisa os esforços atuantes em cada elemento da ligação, contribuindo para a otimização no dimensionamento. Essa relação $M-\phi$ pode ser obtida através de expressões analíticas, ensaios experimentais ou modelos numéricos.

\section{2 - Objetivos e Justificativas}

O presente trabalho de doutorado teve como proposta contribuir para uma melhor caracterização do comportamento das ligações mistas e, consequentemente, das estruturas mistas aço-concreto, assim como a correlação de suas respectivas variáveis. Neste sentido, os principais objetivos do trabalho foram:

- Investigação do comportamento da ligação viga mista-pilar com cantoneiras de alma e assento, em estado limite último e de serviço, considerando as ligações mistas inseridas em um pavimento tipo e em protótipos isolados;

- Avaliação do comportamento das ligações mistas considerando várias condições de carregamento monotônico, em particular, a deterioração da rigidez da ligação mista em função da fissuração da laje para as várias fases de carregamento do pavimento tipo;

- Avaliação da eficiência da proposta de detalhamento das armaduras da ligação mista, com a dispensa da armadura de contorno do pilar para a ancoragem da armadura longitudinal nas ligações de pilar de borda, e acréscimo da taxa de armadura secundária da laje. Em todos os modelos foi considerando laje mista pré-moldada com vigotas e lajotas cerâmicas, técnica construtiva amplamente empregada no Brasil;

- Correlacionar os resultados observados nas ligações de um pavimento tipo e os obtidos a partir de protótipos isolados (pilar de borda e de centro);

- Realização da análise numérica de ligações viga mista-pilar com cantoneiras de alma e assento, submetido a carregamento 
monotônico, com a consideração da laje de concreto, armaduras longitudinais e transversais;

- Avaliação da metodologia de dimensionamento apresentada pelo EUROCODE 3 (2005) e EUROCODE 4 (2004) para determinação da rigidez inicial e momento resistente de ligações com cantoneiras de alma e assento.

Nas últimas décadas, estudos de caráter analítico, experimental e numéricos vêm sendo desenvolvidos, principalmente na Europa e Estados Unidos, com o objetivo de avaliar o real comportamento das ligações mistas aço-concreto.

Em relação aos ensaios experimentais, a maioria dos trabalhos foi direcionada para modelos cruciformes, que consiste num pilar interno isolado submetido a carregamentos simétricos ou desbalanceados, utilizando principalmente, ligações com chapa de topo e com cantoneiras de alma e assento, sendo a laje maciça ou mista com forma de aço incorporada (steel deck). Aqui vale ressaltar o caráter pioneiro desta pesquisa em termos de Brasil, no que se refere ao estudo experimental de um pavimento tipo de ligações mistas e laje pré-moldada com vigotas e lajotas cerâmicas.

O protótipo composto de um pavimento tipo permite avaliar com melhor precisão a influência da fissuração da laje no comportamento da rigidez da ligação, a interação de suas componentes com os carregamentos atuantes nos dois planos de cada nó, a influência do momento volvente da laje e a conseqüente fissuração provocada por esta solicitação na resistência da ligação mista.

A análise numérica teve como objetivo contribuir e complementar a análise experimental. A opção de uma modelagem 3D permite uma avaliação mais precisa do comportamento de cada componente da ligação, o que vai de encontro ao modelo analítico proposto pelo EUROCODE 3 (2005), denominado de Método das Componentes.

A incorporação da laje de concreto, das armaduras longitudinais, transversais e de suas respectivas não linearidades, permitiram avaliar os 
estados limites de serviço e últimos da ligação mista. Os resultados obtidos pelos modelos numéricos visam uma futura utilização em estudos paramétricos e na consideração de carregamentos cíclicos.

\section{3 - Metodologia}

A metodologia adotada neste trabalho envolveu abordagens teóricas e experimentais. A revisão bibliográfica foi realizada num processo contínuo ao longo do trabalho, com o objetivo de aprimorar os principais conceitos relativos ao comportamento das vigas mistas e das ligações viga mista-pilar, além de contribuir para o embasamento teórico, no que se refere às investigações numéricas e experimentais, e análise de todo o histórico dos trabalhos mais importantes relativos ao objeto desta pesquisa.

Os ensaios experimentais seguiram as mesmas técnicas e procedimentos empregados em trabalhos anteriores do Departamento de Engenharia de Estruturas da Escola de Engenharia de São Carlos, dentre estes trabalhos destacam-se: Ribeiro (1998), Maggi (2004), Figueiredo (2004) e Tristão(2006). A primeira etapa consistiu na definição dos modelos a serem ensaiados, cuja fundamentação vem da revisão bibliográfica, experiência obtida em trabalhos anteriores e nos objetivos da pesquisa.

Neste sentido, devido aos recursos obtidos para a realização do programa experimental, optou-se pela concepção de um pavimento tipo e quatro protótipos isolados, estes por sua vez constituídos de dois modelos cruciformes e dois modelos em "T" de pilares de canto, com laje mista composta de vigotas pré-moldadas treliçadas, técnica construtiva amplamente empregada no Brasil.

Os modelos numéricos foram desenvolvidos e analisados utilizando os programas comerciais TRUEGRID e ANSYS. A comprovação da confiabilidade da análise numérica e a verificação dos resultados analíticos foi estabelecida pela comparação dos resultados numéricos, experimentais e analíticos, o que permitiu a elaboração das conclusões finais do trabalho. 


\section{4 - Apresentação dos Capítulos}

O trabalho foi estruturado em oito capítulos, abrangendo a revisão bibliográfica e conceitos gerais, os aspectos normativos relativos ao dimensionamento das ligações mistas, os ensaios experimentais dos protótipos isolados e o pavimento tipo, resultados dos protótipos experimentais, descrição e resultados da modelagem numérica, comparação dos resultados e as conclusões finais.

Adicionalmente, dois apêndices foram considerados com o objetivo de complementar e detalhar a abordagem referente aos ensaios experimentais. Os apêndices consistem, respectivamente, no detalhamento das armaduras dos protótipos experimentais, e dos resultados complementares da etapa de carregamento concentrado no pavimento tipo.

Neste capítulo introdutório foram definidos os objetivos, justificativas e metodologias de trabalho, após uma breve apresentação do tema da pesquisa.

O capítulo 2 apresenta a revisão bibliográfica do tema, com os principais parâmetros que influenciam as ligações mistas aço-concreto e o histórico das principais pesquisas. Adicionalmente, considerou-se uma abordagem dos conceitos gerais relativos às vigas mistas e o comportamento não-linear das ligações mistas aço-concreto.

No capítulo 3 têm-se os principais aspectos normativos de dimensionamento das ligações mistas, introduzindo os conceitos relativos ao Método das Componentes proposto pelos EUROCODE 3 (2005) e EUROCODE 4 (2004) e discussão. Este método foi utilizado como base para o estudo analítico das ligações viga mista-pilar com cantoneira de alma e assento.

O Capítulo 4 apresenta e descreve os ensaios experimentais, com os respectivos procedimentos, considerações, instrumentação e caracterização dos materiais.

No Capítulo 5 têm-se os principais resultados experimentais dos modelos isolados e do pavimento tipo. Os resultados descritos referem-se ao comportamento força $x$ deslocamento, momento $x$ rotação $(M-\phi)$ global das 
ligações, além das deformações nas vigas e armaduras.

O Capítulo 6 aborda a descrição da metodologia de modelagem numérica, bem como os resultados principais em termos do comportamento momento $\mathrm{x}$ rotação, deformações e tensões nas cantoneiras, vigas, pilares $\mathrm{e}$ armaduras longitudinais das ligações dos protótipos isolados.

No capítulo 7 faz-se a análise e comparação dos resultados experimentais, numéricos e analíticos, com enfoque nos principais aspectos que influenciaram no comportamento dos protótipos experimentais isolados e do pavimento tipo.

Finalmente, no Capítulo 8 são apresentadas as análises dos resultados e conclusões obtidas neste trabalho, além de sugestões para a continuidade das pesquisas. 


\section{2}

\section{REVISÃO BIBLIOGRÁFICA E CONCEITOS GERAIS}

\section{1 - Revisão Bibliográfica}

\subsection{1 - Considerações gerais}

A primeira parte do capítulo é dedicado a revisão bibliográfica relativa às ligações viga mista-pilar, com abordagem voltada para os aspectos gerais das ligações mistas, histórico dos principais estudos desenvolvidos, além das características de resistência e rigidez das ligações.

Da mesma forma que para as estruturas metálicas, o comportamento das estruturas mistas também está diretamente relacionado com o desempenho das ligações entre as vigas e pilares, já que estas são as origens das descontinuidades geométricas e mecânicas da estrutura.

A consideração das características reais de resistência e de deformabilidade das ligações pode conduzir a uma diminuição do custo global das estruturas metálicas, através da diminuição do peso da estrutura (devido às simplificações ou mesmo eliminação de sistemas de contraventamento) ou pela redução da parcela referente à mão-de-obra.

Segundo Neves (1996), a obtenção das vantagens descritas acima depende dos seguintes fatores:

- Relação custo da mão-de-obra/custo do aço;

- Grau de contraventamento (contraventada ou não contraventada);

- Base de cálculo.

O estudo realizado por Neves (1996) englobou os aspectos econômicos proporcionado pela adoção de ligações semi-rígidas em seu país, Portugal, 
com base em estudos semelhantes realizados em outros países europeus, considerando estruturas contraventadas e não contraventadas; com mesma geometria e carregamento.

Os elementos adotados foram perfis I laminados a quente (HE para colunas e IPE para as vigas), conectados segundo o eixo de maior inércia do pilar.

Não foram considerados os custos de projeto, transporte dos elementos e de execução de sistemas de contraventamento.

Os resultados obtidos, de modo geral, apontaram para um resultado vantajoso quanto à consideração do comportamento semi-rígido das ligações, obtendo-se uma economia de cerca de $5 \%$ e $2 \%$ do preço global da estrutura para, respectivamente, estruturas não contraventadas e contraventadas.

O autor ressalta ainda que a redução do preço global da estrutura pode ser mais significativa com a parcela do custo da mão-de-obra sobre o custo total. No Brasil, o custo da mão de obra é baixo se comparados aos países da Europa ou Estados Unidos, porém, deve-se sempre levar em consideração uma melhor qualificação do trabalhador com objetivo de evitar problemas de fabricação e montagem da estrutura, principalmente no que se refere às ligações.

\subsection{2 - Aspectos gerais das ligações mistas}

As ligações mistas são mais rígidas e resistentes se comparadas com a mesma ligação em aço, sem a laje de concreto. Dessa forma, o projeto estrutural que considera a participação da laje de concreto visa buscar um maior equilíbrio entre economia e eficiência estrutural. Na etapa de análise e dimensionamento, além de conhecer o comportamento dos elementos estruturais como lajes, pilares, vigas e conectores de cisalhamento, é necessário avaliar o comportamento da ligação.

Os detalhes de ligações em aço mais utilizadas nas ligações mistas estão apresentados na Figura 2.1, na qual se utiliza conector do tipo pino com cabeça para a ligação da viga com a laje de concreto. 


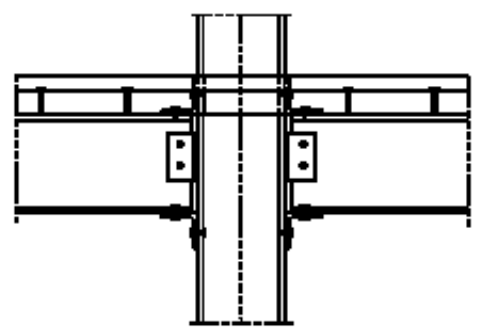

(a)

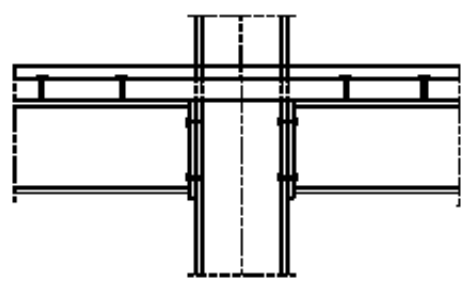

(d)

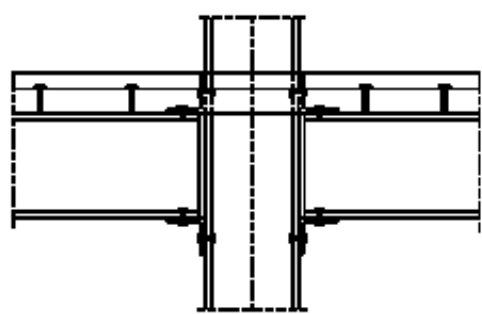

(b)

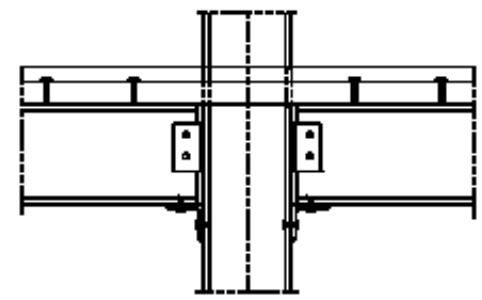

(e)

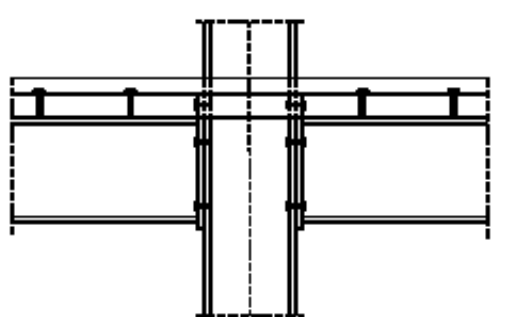

(c)

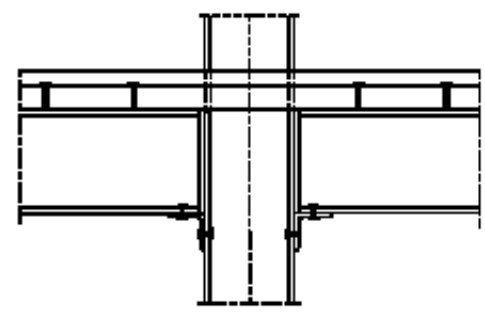

(f)

Figura 2.1: Exemplos de ligação viga mista-pilar: (a) dupla cantoneira de alma e cantoneira de assento e topo; (b) cantoneira de assento e topo; (c) chapa de topo estendida; (d) chapa de topo não estendida; (e) dupla cantoneira de alma e cantoneira de assento; (f) cantoneira de assento.

$\mathrm{Na}$ análise experimental de ligações em aço ou mista é usual a utilização de modelos cruciformes que simulam o pilar interno de um pórtico, que consiste de um pilar com dois trechos de viga conectados em cada lado. Os modelos que simulam os pilares de extremidade possuem a forma de um "T", sendo o pilar com apenas uma viga conectada a ele. A Figura 2.2 ilustra estes esquemas de ensaio.

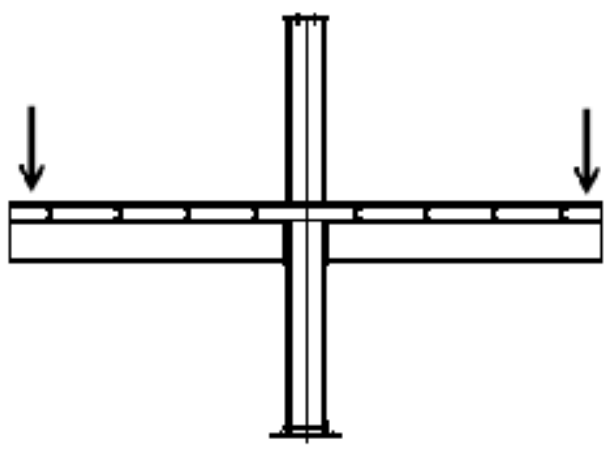

(a)

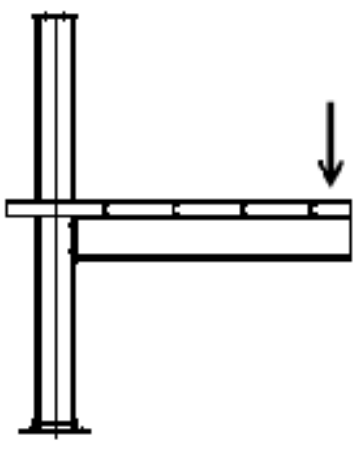

(b)

Figura 2.2: Modelos experimentais cruciformes (a) e pilar de extremidade (b). 
Pesquisadores, principalmente na Europa e Estados Unidos, vem desenvolvendo trabalhos de caráter numérico, analítico e experimental de diferentes tipos de ligações, principalmente com cantoneiras de alma e assento, visando quantificar a participação de cada componente da ligação no comportamento global e os principais modos de falha. O conjunto desses estudos tem auxiliado na elaboração de procedimentos normativos que considerem estes comportamentos de modo mais próximo possível da realidade.

A tabela 2.1 apresenta os principais trabalhos (experimentais $\mathrm{e}$ numéricos) desenvolvidos a partir da década de 70 do século passado, enfatizando de que se tratam, na grande maioria, de ligações mistas com carregamento monotônico.

Tabela 2.1: Resumo dos principais estudos envolvendo as ligações mistas.

\begin{tabular}{|c|c|c|c|}
\hline Trabalho & Investigação & Descrição & Objetivos \\
\hline $\begin{array}{l}\text { Johnson } \\
\text { and Hope } \\
\text { Gill (1972) }\end{array}$ & Experimental & $\begin{array}{c}5 \text { ensaios de modelos cruciformes } \\
\text { de ligações mistas com duas } \\
\text { cantoneiras fixadas } \\
\text { simetricamente na mesa } \\
\text { comprimida da viga; } \\
\text { carregamento simétrico. }\end{array}$ & $\begin{array}{l}\text { Obtenção da relação } \\
\text { entre a força na } \\
\text { armadura e na mesa } \\
\text { comprimida da viga. }\end{array}$ \\
\hline $\begin{array}{l}\text { Van Dalen } \\
\text { and Godoy } \\
\text { (1982) }\end{array}$ & Experimental & $\begin{array}{l}4 \text { ensaios em modelos } \\
\text { cruciformes de ligação com } \\
\text { cantoneira de assento e topo; } \\
\text { enrijecedores de alma no pilar; } \\
\text { carregamento simétrico; taxa de } \\
\text { armadura de } 0,46 \% \text { e } 0,80 \% \text {. }\end{array}$ & $\begin{array}{l}\text { Avaliar o deslizamento } \\
\text { relativo entre a viga e } \\
\text { laje de concreto, com } \\
\text { diferentes taxas de } \\
\text { armadura. }\end{array}$ \\
\hline Law (1983) & Experimental & $\begin{array}{c}6 \text { modelos cruciformes com } 12 \\
\text { ensaios de ligações mistas com } \\
\text { chapa de topo. }\end{array}$ & $\begin{array}{l}\text { Ligação no eixo de } \\
\text { maior e menor inércia } \\
\text { do pilar; avaliação da } \\
\text { distribuição dos } \\
\text { conectores de } \\
\text { cisalhamento; relação } \\
\text { entre alturas da viga de } \\
\text { aço e da laje; momento } \\
\text { desbalanceado na } \\
\text { ligação e força de } \\
\text { compressão no pilar. }\end{array}$ \\
\hline $\begin{array}{l}\text { Benussi et. } \\
\text { Al. (1986) }\end{array}$ & Experimental & $\begin{array}{l}\text { Ligações com chapa de topo com } \\
4 \text { modelos cruciformes com } \\
\text { momentos desbalanceados }\end{array}$ & $\begin{array}{l}\text { Comportamento da } \\
\text { ligação metálica e taxa } \\
\text { de armadura. }\end{array}$ \\
\hline
\end{tabular}




\begin{tabular}{|c|c|c|c|}
\hline $\begin{array}{l}\text { Ammerman } \\
\text { \& Leon } \\
(1987)\end{array}$ & Experimental & $\begin{array}{l}2 \text { ensaios em modelos cruciformes; } \\
\text { ligações mistas com um lado do } \\
\text { pilar com cantoneira de assento, } \\
\text { alma e topo e, no outro, com } \\
\text { cantoneira de alma e assento; sem } \\
\text { enrijecedor de alma do pilar. }\end{array}$ & $\begin{array}{l}\text { Avaliação da ligação } \\
\text { com cantoneiras. }\end{array}$ \\
\hline Leon (1990) & Experimental & $\begin{array}{l}\text { Ligação com cantoneira de alma e } \\
\text { assento, sendo a alma do pilar } \\
\text { enrijecida. }\end{array}$ & $\begin{array}{l}\text { Avaliação do } \\
\text { comportamento da } \\
\text { armadura. }\end{array}$ \\
\hline $\begin{array}{l}\text { Altmann, } \\
\text { Maquoi, } \\
\text { Jaspart } \\
(1991)\end{array}$ & Experimental & $\begin{array}{c}\text { Ligações com cantoneiras de alma } \\
\text { e assento; ligações com } \\
\text { cantoneiras de alma, assento e } \\
\text { topo, totalizando } 38 \text { ensaios de } \\
\text { modelos cruciformes. }\end{array}$ & $\begin{array}{c}\text { Análise do tipo de } \\
\text { ligação metálica; perfis } \\
\text { para pilares e vigas; } \\
\text { rigidez relativa entre } \\
\text { viga e pilar; espessura } \\
\text { das cantoneiras; taxa } \\
\text { de armadura. }\end{array}$ \\
\hline $\begin{array}{l}\text { Xiao, Choo } \\
\text { and } \\
\text { Nethercot } \\
\text { (1994) }\end{array}$ & Experimental & $\begin{array}{c}\text { Interação completa entre laje e viga } \\
\text { em ensaios de modelos cruciformes } \\
\text { e modelos em "T". }\end{array}$ & $\begin{array}{c}\text { Tipo de ligação; taxa de } \\
\text { armadura; } \\
\text { enrijecedores de alma } \\
\text { no pilar; razão } \\
\text { cortante/momento; } \\
\text { comportamento da } \\
\text { ligação em nó interno e } \\
\text { externo. }\end{array}$ \\
\hline $\begin{array}{l}\text { Benussi, } \\
\text { Nethercot \& } \\
\text { Zandonini } \\
\text { (1995) }\end{array}$ & Experimental & $\begin{array}{c}\text { Ensaios em modelos de pórtico } \\
\text { misto com dois vãos e dois } \\
\text { andares. }\end{array}$ & $\begin{array}{l}\text { Análise das ligações } \\
\text { mistas em pórtico; } \\
\text { comparação com } \\
\text { resultados de modelos } \\
\text { cruciformes. }\end{array}$ \\
\hline $\begin{array}{l}\text { Li, Nethercot } \\
\text { and Choo } \\
\text { (1996a) }\end{array}$ & Experimental & $\begin{array}{c}7 \text { ensaios em modelos cruciformes; } \\
\text { ligação com chapa de topo; vigas } \\
\text { foram conectadas segundo o eixo } \\
\text { de menor inércia do pilar. }\end{array}$ & $\begin{array}{l}\text { Análise da influência do } \\
\text { carregamento } \\
\text { assimétrico; relação } \\
\text { cortante/momento. }\end{array}$ \\
\hline $\begin{array}{l}\text { Benussi, } \\
\text { Bernuzi, } \\
\text { Noe \& } \\
\text { Zandonini } \\
(1996)\end{array}$ & Experimental & $\begin{array}{l}\text { Ensaios em pórtico misto com } 1 \\
\text { andar, composto de } 2 \text { vigas e } 3 \\
\text { pilares; ligações com chapa de } \\
\text { topo. }\end{array}$ & $\begin{array}{l}\text { Comportamento de um } \\
\text { pórtico com ligação } \\
\text { mista. }\end{array}$ \\
\hline $\begin{array}{l}\text { Ahmed and } \\
\text { Nethercot } \\
(1996)\end{array}$ & Numérica & $\begin{array}{c}\text { Análise numérica de ligações } \\
\text { mistas com chapa de topo; modelo } \\
\text { validado por comparações de } \\
\text { resultados experimentais por Li et. } \\
\text { al. (1996) }\end{array}$ & $\begin{array}{l}\text { Taxa de armadura; } \\
\text { interação viga-laje; } \\
\text { espessura da chapa de } \\
\text { topo; espessura da } \\
\text { mesa inferior e da alma } \\
\text { do pilar. }\end{array}$ \\
\hline $\begin{array}{l}\text { Alves and } \\
\text { Queiroz } \\
(2000)\end{array}$ & Experimental & $\begin{array}{l}\text { Ensaios de ligações mistas viga- } \\
\text { viga e viga-pilar, ambas com } \\
\text { cantoneiras de alma e assento. }\end{array}$ & $\begin{array}{l}\text { Comportamento da } \\
\text { ligação com } \\
\text { cantoneiras. }\end{array}$ \\
\hline $\begin{array}{l}\text { Brow and } \\
\text { Anderson } \\
(2001)\end{array}$ & Experimental & $\begin{array}{l}4 \text { ensaios em modelos cruciformes; } \\
\text { ligações com chapa de topo; altura } \\
\text { da seção de aço de } 457 \text { e } 533 \text { mm. }\end{array}$ & $\begin{array}{l}\text { Comportamento da } \\
\text { ligação em função da } \\
\text { altura da seção de aço; } \\
\text { posição da armadura } \\
\text { na laje; espessura da } \\
\text { chapa de topo. }\end{array}$ \\
\hline
\end{tabular}




\begin{tabular}{|c|c|c|c|}
\hline $\begin{array}{l}\text { Figueiredo } \\
\text { (2004) }\end{array}$ & Experimental & $\begin{array}{l}2 \text { ensaios em modelos cruciformes; } \\
\text { ligação com chapa de topo } \\
\text { estendida (espessura de } 22,4 \mathrm{~mm} \text { ); } \\
\text { taxa de armadura de } 1 \% .\end{array}$ & $\begin{array}{l}\text { Avaliação do detalhe da } \\
\text { ligação de aço. }\end{array}$ \\
\hline $\begin{array}{l}\text { Tristão } \\
(2006)\end{array}$ & $\begin{array}{l}\text { Experimental } \\
\text { e Numérico }\end{array}$ & $\begin{array}{l}5 \text { protótipos monotônicos e } 1 \text { cíclico } \\
\text { de ligação mista com cantoneira de } \\
\text { alma e assento; pilar de } \\
\text { extremidade. }\end{array}$ & $\begin{array}{c}\text { Avaliação da influência } \\
\text { da força axial no pilar; } \\
\text { do enrijecedor de alma } \\
\text { do pilar; eficiência da } \\
\text { ancoragem nas barras } \\
\text { da armadura } \\
\text { longitudinal. }\end{array}$ \\
\hline $\begin{array}{l}\text { Wang and Li } \\
\quad(2006)\end{array}$ & Experimental & $\begin{array}{c}2 \text { pórticos; com } 3 \text { pilares e dois } \\
\text { vãos, laje com forma de aço } \\
\text { incorporada, ligação semi-rígida } \\
\text { com chapa de topo e carregamento } \\
\text { simétrico e assimétrico para cada } \\
\text { pórtico. }\end{array}$ & $\begin{array}{l}\text { Avaliação da ligação } \\
\text { mista semi-rígida, } \\
\text { comportamento da laje } \\
\text { e da viga submetido a } \\
\text { ações verticais em } \\
\text { pórticos, }\end{array}$ \\
\hline $\begin{array}{l}\text { David } \\
(2007)\end{array}$ & $\begin{array}{l}\text { Experimental } \\
\text { e Numérico }\end{array}$ & $\begin{array}{l}17 \text { corpos de prova de ensaios de } \\
\text { cisalhamento direto com conectores } \\
\text { de perfis U formados a frio; } 9 \text { vigas } \\
\text { mistas biapoiadas com variação do } \\
\text { grau de interação, posição dos } \\
\text { conectores em relação à vigota, } \\
\text { taxa e posição da armadura, altura } \\
\text { e espessura do conector. }\end{array}$ & $\begin{array}{c}\text { Avaliação do } \\
\text { posicionamento dos } \\
\text { conectores e armadura } \\
\text { de costura em vigas } \\
\text { biapoiadas. } \\
\text { Caracterização dos } \\
\text { conectores de U de } \\
\text { perfis formados a frio. }\end{array}$ \\
\hline $\begin{array}{l}\text { Vasdravellis, } \\
\text { Valente and } \\
\text { Castiglioni } \\
\text { (2008) }\end{array}$ & $\begin{array}{l}\text { Experimental } \\
\text { e Numérico }\end{array}$ & $\begin{array}{c}4 \text { protótipos cíclicos de ligações } \\
\text { mistas de pilar de canto ( } 2 \text { com } \\
\text { armaduras de contorno do pilar e } 2 \\
\text { com armaduras ancoradas nas } \\
\text { vigas intermediárias), laje steel- } \\
\text { deck, pilar parcialmente preenchido } \\
\text { de concreto e ligação com chapa de } \\
\text { topo na mesa do pilar. }\end{array}$ & $\begin{array}{c}\text { Avaliação dos detalhes } \\
\text { de ancoragem proposta } \\
\text { para as armaduras, da } \\
\text { perda de rigidez e } \\
\text { resistência da ligação } \\
\text { parcialmente resistente } \\
\text { submetida a } \\
\text { carregamento cíclico e } \\
\text { influência do painel de } \\
\text { alma do pilar. }\end{array}$ \\
\hline
\end{tabular}

As principais conclusões obtidas por esses estudos são apresentadas a seguir:

- A rigidez e resistências das ligações mistas estão diretamente relacionadas com a taxa de armadura longitudinal da laje. Entretanto, para taxas muito elevadas (acima de 5\%), o comportamento da ligação fica condicionado as componentes da zona comprimida, tal como a alma e a mesa do pilar, quando não enrijecida;

- A capacidade rotacional da ligação mista maior que $30 \mathrm{mrad}$ é o suficiente para realizar uma análise plástica de estruturas. Alguns cuidados devem ser tomados para evitar a ruptura da viga mista na 
região adjacente à ligação, tal como prevenir a ruptura dos conectores de cisalhamento, a flambagem local da alma e da mesa da viga na região comprimida, além do cisalhamento longitudinal da laje da viga.

- O aumento da razão força cortante/momento fletor leva a uma redução do momento resistente e da rigidez da ligação mista..

- As ligações mistas com cantoneiras de alma e assento possuem elevada resistência e rigidez. A flambagem da mesa comprimida torna-se improvável de acontecer, uma vez que a cantoneira confere uma resistência adicional à mesa da viga.

- Nas ligações com cantoneiras é importante o controle do deslizamento dos parafusos na fase inicial de carregamento. Em vários ensaios, foi observada uma perda de rigidez inicial devido ao deslizamento dos parafusos.

- A altura da seção da viga está diretamente relacionada com a resistência e rigidez da ligação mista;

- O efeito do carregamento não simétrico na resistência da ligação só é significativo quando a força na armadura é maior que a resistência à força cortante do pilar ou que a resistência ao contato entre o concreto da laje e a face do pilar.

- Com a taxa de armadura em torno de $1 \%$, a espessura da chapa de topo não altera significamente a rigidez inicial e o momento último da ligação mista.

- Os ensaios realizados por Aribert (1995) mostraram que a conexão parcial de cisalhamento entre a viga e a laje de concreto diminui o momento de plastificação da ligação.

- Para os casos de utilização de enrijecedores de alma do pilar, normalmente a plastificação ocorre devido à flambagem da mesa comprimida da viga ou plastificação da armadura longitudinal.

- A rigidez inicial das ligações mistas é influenciada pela ancoragem da armadura na laje, principalmente nos pilares de extremidade, na qual se obtém uma ancoragem eficiente quando cerca de $40 \%$ da armadura longitudinal efetiva contorna o pilar. 
- As ligações mais flexíveis e com conexão de cisalhamento menos efetiva permitem uma distribuição mais uniforme das fissuras na laje, segundo a direção perpendicular ao eixo longitudinal da viga. Alguns autores recomendam uma taxa de armadura de no mínimo 0,80\% para que a distribuição das fissuras seja mais uniforme, outros, no entanto, recomendam $1 \%$.

- A influência da força de compressão no pilar, para a rigidez inicial da ligação, é maior para ligações sem enrijecedor do que para ligações com enrijecedor de alma.

Nos últimos anos, alguns trabalhos experimentais, principalmente na Europa, foram direcionados para a análise de ligações mistas submetidas a carregamentos cíclicos, com modelos de ligações isoladas (cruciformes ou "T") e também modelos de ligações em pórticos. Os principais objetivos desses estudos são:

i) Investigar o comportamento $M-\phi$ das principais configurações de ligações mistas em pórticos, submetido a carregamentos cíclicos, tal como de seus componentes isolados;

ii) Desenvolver novas tipologias de ligações, de modo a permitir um melhor comportamento dúctil quando submetido a carregamentos sísmicos;

iii) Propor métodos de avaliação de danos e procedimentos de reparo em estruturas mistas, para serem incorporados na prática construtiva.

De maneira geral, os parâmetros que mais influenciam as ligações mistas são:

- Relação de inércia entre perfis da viga e do pilar;

- Elementos de ligação entre a viga e o pilar (cantoneiras, chapa de topo, parafusos, solda);

- Laje de concreto armado, principalmente a taxa de armadura e a resistência do concreto;

- Presença ou não de enrijecedores na alma do pilar;

- $\quad$ Tipo de carregamento (simétrico ou não-simétrico); 
- Conexão de cisalhamento entre a viga e a laje (distribuição e quantidade de conectores).

\subsection{3 - Comportamento $M$ - $\theta$ das ligações mistas aço concreto}

O comportamento $M-\phi$ de uma ligação, seja ela em aço ou mista, é caracterizado por sua rigidez inicial, momento resistente e capacidade rotacional, e podem ser obtidas via análise experimental, modelagem numérica ou métodos analíticos.

A Figura 2.3 apresenta que o comportamento de uma ligação mista pode ser dividido em duas fases:

i)Fase elástica: considera as etapas relativas a antes e depois da fissuração da laje de concreto. Ensaios experimentais mostram que as fissuras no concreto começam na região próxima a face do pilar, e propagam para as extremidades das vigas.

ii) Fase não linear: a não linearidade no comportamento da ligação mista pode ter como causa um dos motivos citados abaixo:

- Aumento do tamanho e extensão das fissuras da laje;

- Plastificação da armadura, dos componentes do pilar ou da viga ou elementos da ligação (parafusos, cantoneiras, chapa de topo);

- Deslizamento dos parafusos na ligação viga-pilar ou do conector de cisalhamento na interface laje-viga;

- Imperfeições devido ao processo de fabricação ou tensões residuais.

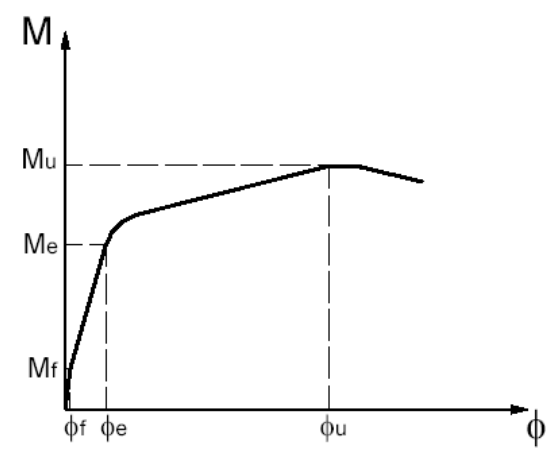

Figura 2.3: Esquema com comportamento momento-rotação idealizado. 
Onde:

$M_{f}$ é o momento referente ao início das fissuras na laje,

$M_{e}$ é o momento referente ao final do trecho elástico;

$M_{u}$ é o momento último da ligação;

$\phi_{f}$ é rotação da ligação em cada patamar de momento.

O EUROCODE 4 (2004), com base no EUROCODE 3 (2005), propõe uma curva $M-\phi$ não-linear a qual não é limitada pela capacidade rotacional. No entanto, o documento apresenta algumas disposições construtivas para que a ligação mista tenha capacidade rotacional suficiente para a análise global plástica.

Nesta relação, o primeiro trecho é linear até $2 / 3$ do momento resistente $(\mathrm{Mj}, \mathrm{Rd})$ com inclinação relativa à rigidez inicial (Sj,ini). Entre $2 / 3$ do momento resistente e o momento resistente, a curva é não-linear e, após o momento resistente ser atingido, a relação é uma reta horizontal. Esta relação $M-\phi$ é apresentada na Figura 2.4.

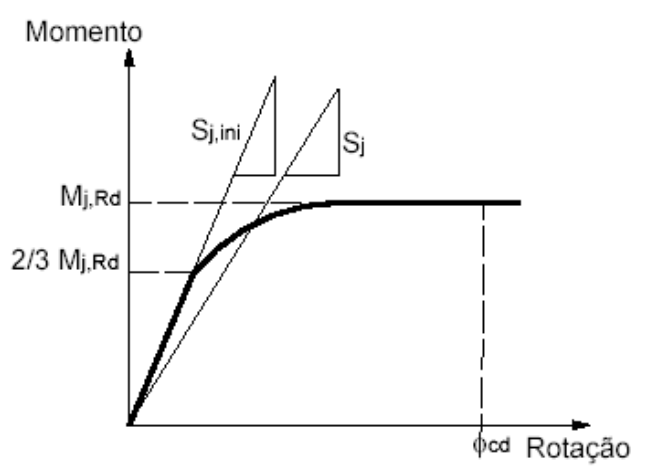

Figura 2.4: Relação momento-rotação não-linear do EUROCODE 3 (2005).

A forma da curva não-linear é obtida pela equação (1), e envolvem parâmetros como rigidez inicial, momento resistente da ligação e o momento solicitante da ligação $\left(\mathrm{M}_{\mathrm{Sd}}\right)$.

$$
S_{j}=\frac{S_{j, \text { ini }}}{\left(\frac{1,5 \cdot M_{S d}}{M_{R d}}\right)^{\psi}}
$$


Onde:

$\psi=2,7$ para ligações com chapa de topo e $\psi=3,1$ para ligações com cantoneiras.

Ahmed \& Nethercot (1997) apresentou uma relação M- $\phi$ para as ligações vigas mistas-pilar, a qual foi calibrada para o detalhe de ligação com chapa de topo não estendida, submetida a momento fletor negativo. A vantagem da relação fornecida pelas equações (2) e (4), comparada ao EUROCODE 4 (2004), é que foi idealizada considerando o comportamento da ligação mista.

O método considera um primeiro trecho linear até $45 \%$ do momento resistente $\left(M_{j, R d}\right)$ com inclinação relativa à rigidez inicial, ilustrada na Figura 2.5. Entre $45 \%$ do momento resistente e o momento resistente a curva é não-linear sendo representada por uma elipse e, após atingir o momento resistente a relação é uma reta horizontal.

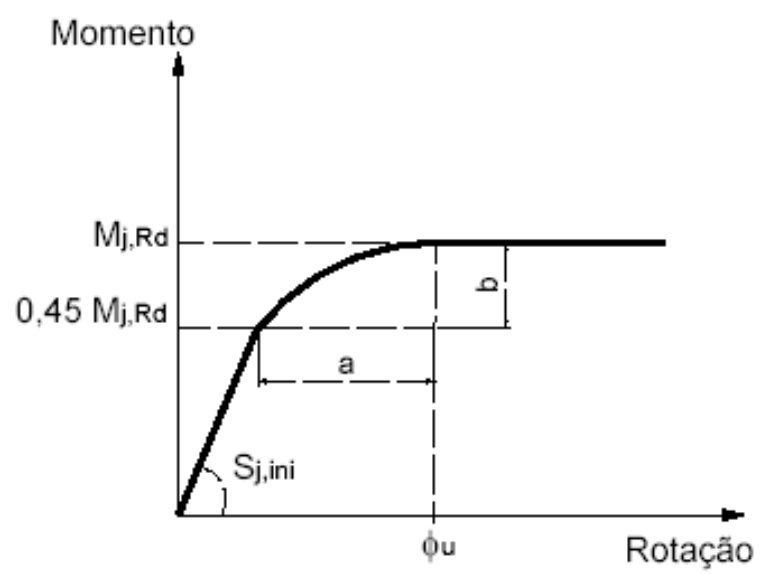

Figura 2.5: Comportamento M- $\phi$ proposto por Ahmed \& Nethercot (1997).

$$
\begin{aligned}
& M=S_{j, \text { ini }} \rightarrow 0 \leq \phi \leq \frac{0,45 \cdot M_{j, R d}}{S_{j, \text { ini }}} \\
& M=0,45 \cdot M_{j, R d}+b \cdot \sqrt{1-\left[\frac{\phi_{u}-\phi}{a}\right]^{2}} \rightarrow \frac{0,45 \cdot M_{j, R d}}{S_{j, i n i}} \leq \phi \leq \phi_{u} \\
& M=M_{j, R d} \rightarrow \phi \geq \phi_{u}
\end{aligned}
$$


Onde:

$$
\begin{aligned}
& a=\phi_{u}-\frac{0,45 \cdot M_{j, R d}}{S_{j, i n i}} \\
& b=0,55 \cdot M_{j, R d}
\end{aligned}
$$

Kishi \& Chen (1990) também propôs um modelo para representar a relação $M-\phi$ com base na rigidez inicial, momento resistente e parâmetro de forma $(\eta)$, denominado de modelo dos três parâmetros. O comportamento da ligação é apresentado na equação (5).

$$
M=\frac{S_{j, 1} \cdot \phi}{\left[1+\left(\frac{\phi}{\phi_{o}}\right)^{n}\right]^{\sqrt{n}}}+S_{j, k p} \cdot \phi
$$

Onde:

$S_{j, k p}$ é a rigidez plástica da ligação;

$S_{j, 1}=S \mathrm{j}, \mathrm{ini}-\mathrm{Sj}, \mathrm{kp}$ é a rotação plástica de referência;

$\phi_{o}=\frac{M_{j, R d}}{S_{j, \text { ini }}}$ é uma rotação plástica de referência;

$\eta$ é o parâmetro de forma;

$\mathrm{Na}$ relação $M-\phi$ pode-se considerar que a curva é abatida perto do momento resistente da ligação e, portanto, o $S_{j, k p}$ é igual a zero. Nesse caso, a equação (5) é simplificada para a equação (6), que pode ser visualizada pela Figura 2.6.

$$
M=\frac{S_{j, 1} \cdot \phi}{\left[1+\left(\frac{\phi}{\phi_{o}}\right)^{n}\right]^{\sqrt{n}}}
$$




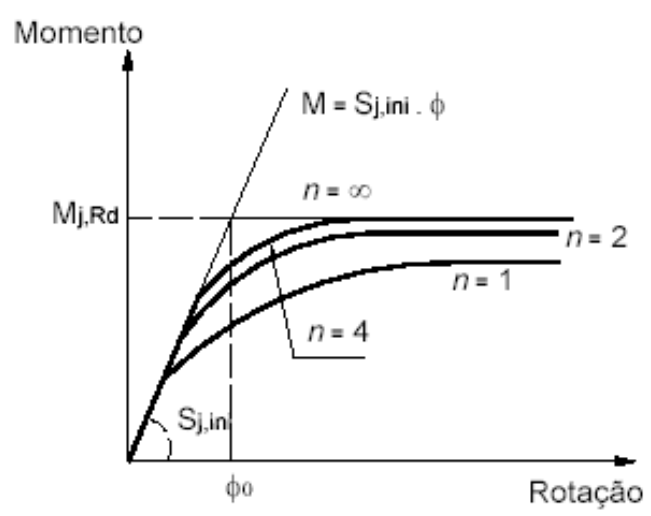

Figura 2.6: Relação $M-\phi$ proposto por kishi \& Chen (1990).

O parâmetro de forma $\eta$ foi calibrado por relações entre o quadrado da diferença entre o momento resistente estimado e momento obtido em ensaios experimentais. Segundo Kim \& Chen (1998), o valor de $\eta$ pode ser obtido pela equação (7).

$$
\begin{aligned}
& \eta=1,398 \cdot \log \left(\phi_{o}\right)+4,631 \rightarrow \log \left(\phi_{o}\right)>-2,721 \\
& \eta=0,827 \rightarrow \log \left(\phi_{o}\right) \leq-2,721
\end{aligned}
$$

Quanto maior o valor de $\eta$ mais íngrime é a curva, ou seja, se $\eta$ é igual a infinito se a relação $M-\phi$ é elasto-plástico perfeito, tal como apresentado pela Figura 2.6.

Das três relações apresentadas apenas a curva proposta por Ahmed \& Nethercot (1997) foi obtida de estudos de ligações mistas. As demais relações $M-\phi$ tiveram origem do comportamento de ligações em aço.

\subsection{4 - Resistência e rigidez das ligações}

Com o objetivo de avaliar se a ligação tem influência ou não na distribuição das solicitações na estrutura, segundo os estados limites de serviço e último, os principais sistemas de classificação para as ligações tem como base o seu comportamento momento-rotação.

O momento que é efetivamente transmitido para uma ligação, se tomarmos como base a análise elástica, é representado pela equação (8), mostrando que o momento efetivamente transmitido pela ligação é influenciado 
pela rigidez da ligação, da viga e do pilar.

$$
M_{1}=M_{0} \cdot\left[\frac{\alpha}{2+\alpha+\left(2 \cdot \alpha \cdot E \cdot I_{b} / S_{j} \cdot L_{b}\right)}\right]
$$

Onde:

$M_{1}$ é o momento real transferido pela ligação;

$M_{0}$ é o momento negativo de engastamento total;

$I_{b}$ é o momento de inércia da seção transversal da viga em momento negativo;

$L_{b}$ é o comprimento da viga;

$S_{j}$ é a rigidez da ligação;

$\alpha$ é a relação de rigidez rotacional entre o pilar e a viga expressa por $\left(\frac{K_{c} \cdot L_{b}}{E \cdot I_{b}}\right)$;

$K_{c}$ é a soma da rigidez rotacional de todos os elementos conectados à ligação exceto a viga considerada, obtida de acordo com a tabela 2.2. $I_{c}$ é o momento de inércia da seção transversal do pilar; $L_{c}$ é a altura do pilar.

Tabela 2.2: Determinação do $K_{c}$ para cada tipo de nó da ligação.

\begin{tabular}{c|c|c|c}
\hline $\begin{array}{c}\text { Tipo de } \\
\text { nó }\end{array}$ & & & \\
\hline$K_{c}$ & $\infty$ & $\frac{4 \cdot E \cdot I_{c 1}}{L_{c 1}}+\frac{4 \cdot E \cdot I_{c}}{L_{c 2}}$ & $\frac{4 \cdot E \cdot I_{c}}{L_{c}}$ \\
\hline
\end{tabular}

Quando a rigidez da ligação é muito maior se comparada com a da viga, a extremidade da viga pode ser considerada como totalmente engastada, no entanto, quando a rigidez da ligação é muito pequena comparada com a rigidez 
da viga, sua extremidade comporta-se como rotulada.

Os critérios de classificação das ligações mais empregados na análise estrutural são:

- AISC/LFRD: obtida a partir do método dos estados limites de ligações pré-qualificadas, utilizando-se de resultados experimentais;

- EUROCODE 3 (2005): classificação quanto a rigidez e resistência da ligação, de acordo com o tipo de análise global da estrutura;

- NETHERCOT (1998): considera as características de rigidez e resistência simultaneamente para os estados limites últimos e de serviço.

Apresenta-se, a seguir, apenas uma discussão particular do critério de classificação do EUROCODE 3 (2005), uma vez que se trata da referência normativa adotada pela pesquisa. Maiores detalhes a respeito dos outros dois critérios de classificação pode ser encontrado em Tristão (2006).

O EUROCODE 3 (2005) - parte 1.8 propõe que a ligação deve ser classificada segundo três tipos: simples, contínua e semi-contínua:

I) Simples: a ligação não transmite momento fletor e pode ser considerada na análise estrutural como uma rótula.

II) Contínua: a ligação é totalmente engastada;

III) Semi-contínua: o comportamento da ligação necessita ser considerado na determinação das solicitações dos elementos internos da estrutura.

Quanto à resistência, a ligação pode ser classificada como de resistência total, parcial ou rotulada por meio da comparação do seu momento resistente com o momento resistente da viga mista, de acordo com a Figura 2.7.

I. Total: o momento resistente da ligação é maior ou igual ao momento resistente da viga.

II. Rotulada: o momento resistente da ligação não é maior que $25 \%$ do momento resistente da viga. No entanto, deve ser capaz de transmitir os esforços internos e suficiente capacidade rotacional.

III. Parcial: ligações que não se encontram no critério para ligação rotulada ou total. 


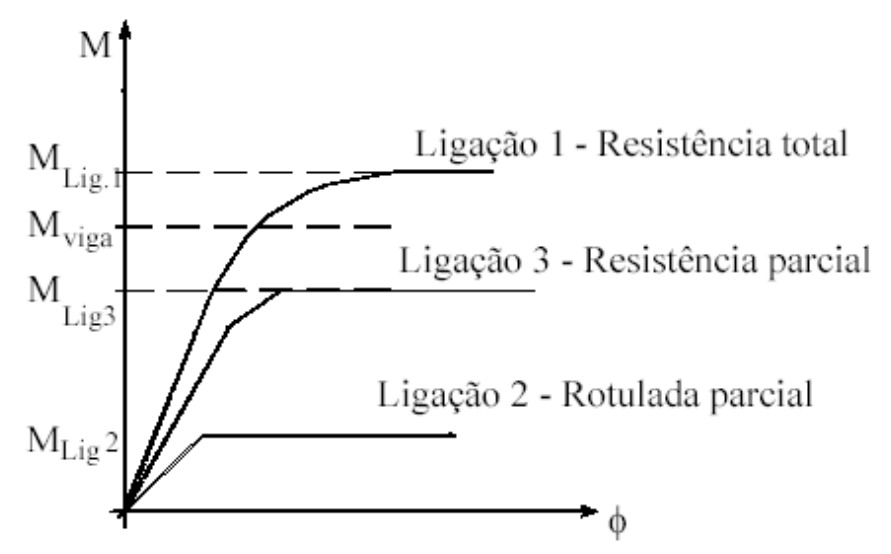

Figura 2.7: Classificação da ligação quanto à resistência.

De acordo com o tipo de análise global da estrutura, para que a ligação seja do tipo I, II ou III é necessário enquadrar-se nas classificações quanto à rigidez e resistência da Tabela 2.3, e do método de análise global para os esforços internos.

$\mathrm{Na}$ classificação quanto à rigidez rotacional, quando comparado com a rigidez do elemento conectado, é utilizado o comprimento real da viga para definir os limites de rigidez, sendo dependente do tipo de estrutura (contraventada ou não), uma vez que os efeitos da semi-rigidez das ligações diferem conforme o tipo da estrutura.

Rígidas: quando é garantida a continuidade da estrutura, não tendo nenhuma influência significativa na distribuição de forças internas e de momento na estrutura.

Flexível: ligações que devem ser capazes de transmitir as forças internas (normal e cortante) sem transmitir momentos significativos. Essas ligações possuem grande capacidade rotacional.

Semi-rígidas: permite certo grau de interação entre os elementos conectados, capazes de transmitir forças internas e momento fletor.

As equações (9) e (10) fornecem o limite de classificação para as ligações rígidas e flexíveis.

$$
\text { Rígida: } \quad S_{j, \text { ini }} \geq \frac{K_{b} \cdot I_{b} \cdot E}{L_{b}}
$$




$$
\text { Rotulada: } \quad S_{j, \text { ini }} \leq \frac{0,5 \cdot I_{b} \cdot E}{L_{b}}
$$

Tabela 2.3: Tipos de ligação segundo o EUROCODE 3 (2005).

\begin{tabular}{c|c|c|c}
\hline $\begin{array}{c}\text { Análise } \\
\text { global }\end{array}$ & \multicolumn{2}{|c}{ Classificação da ligação } \\
\hline Elástica & Flexível & Rígida & Semi-rígida \\
\hline $\begin{array}{c}\text { Rígido- } \\
\text { plástica }\end{array}$ & Flexível & $\begin{array}{c}\text { Resistência } \\
\text { total }\end{array}$ & Resistência parcial \\
\hline $\begin{array}{c}\text { Elasto- } \\
\text { plástica }\end{array}$ & Flexível & $\begin{array}{c}\text { Resígida e } \\
\text { total }\end{array}$ & $\begin{array}{c}\text { Semi-rígida e Resistência parcial } \\
\text { Semi-rígida e Resistência total } \\
\text { Rígida e Semi-rígida e Resistência } \\
\text { parcial }\end{array}$ \\
\hline $\begin{array}{c}\text { Tipo de } \\
\text { ligação }\end{array}$ & Simples & Contínua & Semi-contínua \\
\hline
\end{tabular}

O parâmetro $K_{b}$ relaciona a rigidez da viga com a rigidez da ligação, sendo apresentada na equação (11). Os valores de $K_{b}$, para que uma ligação seja considerada rígida, foram obtidos a partir da relação com o parâmetro $\rho$ que relaciona a rigidez entre a viga e o pilar dado pela equação (12). A relação entre $K_{b}$ e $\rho$ é apresentada na Figura 2.8.

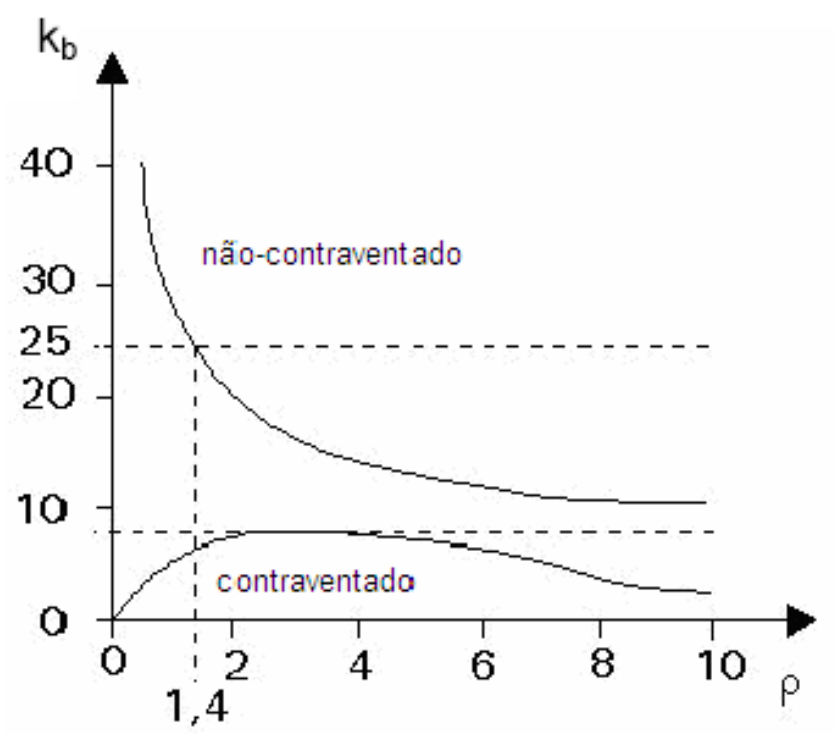

Figura 2.8: Relação entre $K_{b}$ e $\rho$ para pórtico contraventado e não contraventado. 


$$
\begin{aligned}
& K_{b}=\frac{S j \cdot L_{b}}{E \cdot I_{b}} \\
& \rho=\frac{E \cdot I_{b} \cdot L_{c}}{E \cdot I_{c} \cdot L_{b}}
\end{aligned}
$$

De acordo com a Figura 2.8, o valor de $K_{b}$ igual a 8 atende todos os casos de pórticos contraventados. Para os pórticos não contraventados, apesar do valor de $K_{b}$ igual a 25 atender apenas as situações onde $\rho \geq 1,4$, estudos confirmam que com $K_{b}$ igual a 25 para $\rho<1,4$, a ligação também pode ser considerada como rígida.

A Figura 2.9 exibe os limites parametrizados para caracterizar uma ligação como rígida, semi-rígida ou flexível. O contorno tri-linear deve-se ao efeito de degradação da rigidez da seção da viga quando esta excede o momento elástico, e os limites para a classificação são apresentados a seguir:

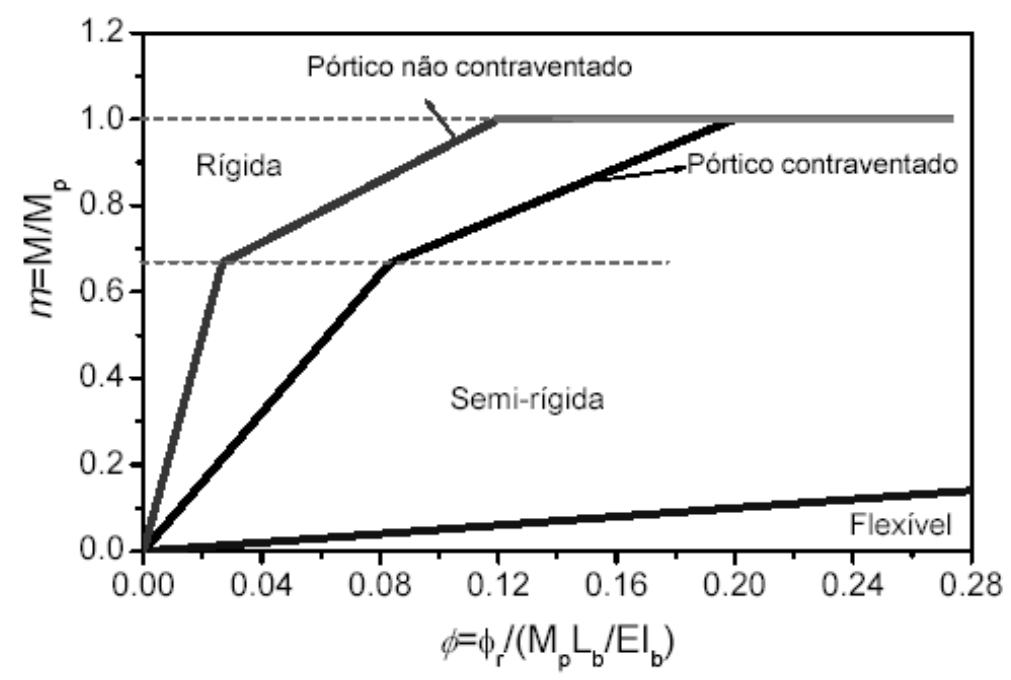

Figura 2.9: Classificação da ligação segundo a rigidez - EUROCODE 3 (2005) parte 1.8.

\section{- Estruturas contraventadas:}

Para $m<2 / 3 \rightarrow m=8 \phi$

Para $2 / 3 \leq m \leq 1 \rightarrow m=\frac{20 \cdot \phi+3}{7}$ 


\section{- Estruturas não contraventadas:}

Para $m<2 / 3 \rightarrow m=25 \phi$

Para $2 / 3 \leq m \leq 1 \rightarrow m=\frac{25 \cdot \phi+4}{7}$

Onde:

$M$ é o momento na ligação mista;

$M_{p}$ é o momento resistente negativo da viga mista;

$E$ é o módulo de elasticidade do aço;

$\phi_{r}$ é a rotação na ligação para o momento M.

Para o cálculo do momento de inércia da viga mista $\left(I_{b}\right)$, na região de momento negativo, a laje pode ser considerada não fissurada para se obter os esforços internos. No caso de se utilizar o método fissurado, a laje de concreto deve ser desprezada, considerando apenas a armadura para a obtenção dos esforços internos da estrutura.

\section{2 - Conceitos Gerais}

A segunda parte do capítulo refere-se aos conceitos gerais relativos ao comportamento não-linear dos materiais e das vigas mistas. Esses conceitos serviram de subsídio para a revisão bibliográfica do trabalho e definição dos principais parâmetros das análises experimental e numérica.

\subsection{1 - Consideração da não-linearidade dos materiais}

No estado limite último, as solicitações na estrutura podem ser obtidos por meio da análise elástica linear ou plástica. Já as verificações no estado limite de serviço, somente pode ser utilizada a análise elástica linear.

Segundo o EUROCODE 3 (2005), na análise plástica são considerados os efeitos da não-linearidade do material para a determinação das solicitações internas na estrutura, e pode ser utilizada somente quando a estrutura tem capacidade rotacional suficiente nos elementos ou nas ligações. Os elementos e as ligações devem ser calculados considerando sua resistência plástica.

Neste caso, as seções dos elementos devem ser duplamente simétricas 
ou com plano de simetria no mesmo plano de rotação do elemento, além de serem de classe 1 ou 2. Quando a rótula plástica ocorre na ligação, esta deverá ter resistência ou capacidade rotacional suficiente para garantir a formação das rótulas plásticas no elemento a ele conectado (viga).

A análise plástica pode ser considerada pelos seguintes métodos: análise rígido-plástica e análise elasto-plástica, só podendo ser empregada quando assegurada à estabilidade dos elementos onde se formam as rótulas.

$\mathrm{Na}$ análise elástica, no que diz respeito às ligações semi-rígidas, faz-se necessário a consideração da rigidez rotacional da ligação. Por outro lado, para determinação das solicitações internas, é necessário também considerar o momento resistente da ligação adicionalmente a sua rigidez inicial.

Se a resistência da ligação é maior que a da viga, as rotações estão concentradas principalmente na sua extremidade. No caso inverso, as rotações se concentram na ligação. Dessa forma, para ligações de resistência total ou totalmente conectadas, não há necessidade de verificar a capacidade rotacional da ligação.

\subsubsection{1 - Análise elástico linear para estado limite último}

A análise elástica linear no estado limite último, na qual não se considera nenhuma restrição quanto às classes da seção transversal, é o tipo de análise mais empregado nos projetos em estruturas mistas para o cálculo das solicitações internas.

Mesmo assumindo o comportamento elástico da estrutura, e consequentemente também do material, a análise elástico linear pode ser empregada também no estado limite último considerando a resistência plástica da seção transversal.

Efeitos tal como a fissuração, fluência, retração do concreto e seqüência de construção devem ser considerados na concepção estrutural de sistemas mistos. Desde que os elementos sejam de classe 1 ou 2, e não exista restrição quanto à flambagem lateral com distorção, o feito da fluência do concreto pode ser desprezado na análise para verificação do estado limite último. Caso contrário, o efeito é considerado por meio da redução do módulo de 
elasticidade do concreto.

O EUROCODE 4 (2004), como uma primeira alternativa de análise, determina que toda a seção da viga mista possa ser considerada não-fissurada (momento de inércia da seção mista em todo o vão é obtido pela homogeneização da seção mista assumindo que o concreto tracionado não esteja fissurado) conforme ilustra a Figura 2.10.

Após a análise, nas regiões onde a tensão de tração do concreto é duas vezes superior a resistência à tração média do concreto (fctm), a rigidez deverá ser reduzida para uma rigidez a flexão Eal2 (apresentada na Figura 2.11), considerando apenas a seção de aço e a armadura longitudinal. Com a nova rigidez a flexão, é realizada uma outra análise, denominada fissurada.

Pode ser adotado também, além do procedimento descrito acima, um método simplificado para vigas mistas contínuas e semi-contínuas (Figura 2.11), desde que a relação entre tramos adjacentes não seja maior que 0,6. 0 efeito da fissuração pode ser considerado ao utilizar à rigidez a flexão Eal2, na região de momento negativo, num comprimento equivalente a $15 \%$ do vão por tramo, assim evitando a determinação "exata" do ponto de inflexão do diagrama de momento.

Na região de momento positivo, a rigidez a flexão da seção mista (Eal1) é determinado da mesma forma para a análise não-fissurada.

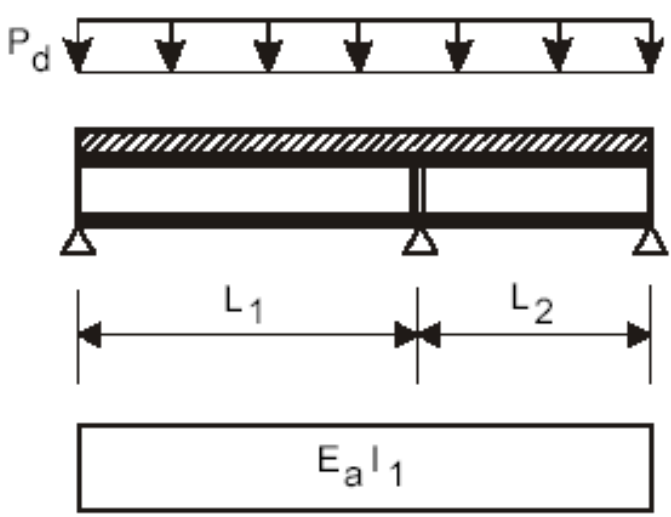

Figura 2.10: Análise elástica-linear não fissurada.

O EUROCODE 4 (2004) também permite uma análise elástica linear com 
redistribuição de momentos para o estado limite último, exceto fadiga, em vigas mistas contínua ou semi-contínua, desde que não considere no sistema estrutural o efeito global de segunda ordem.

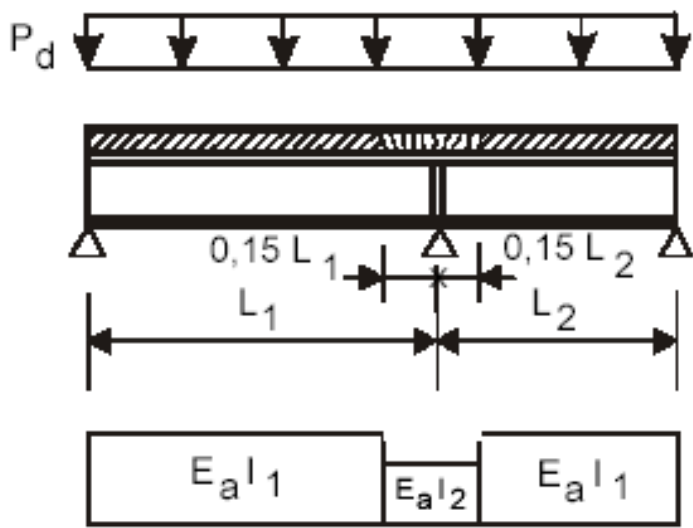

Figura 2.11: Análise elástico-linear fissurada.

Essa redistribuição tem que satisfazer o equilíbrio da estrutura e considera, de maneira simplificada, o comportamento não-linear do material e todos os tipos de flambagem, podendo ser realizada para vigas mistas com conexão total ou parcial. A redistribuição de momentos na viga contínua consiste em diminuir os momentos negativos e aumentar ao mesmo tempo os momentos positivos.

O EUROCODE 4 (2004) apresenta as porcentagens máximas do valor inicial do momento fletor negativo para a redistribuição (Tabela 2.4) de acordo com o tipo de análise adotada e a classe da seção transversal. No caso de a viga possuir todas as seções de classe 1 ou 2, o momento negativo pode ainda se diminuído em até 10\% na análise não-fissurada e $20 \%$ na análise fissurada.

A redistribuição deve apenas ser aplicada para vigas com aço estrutural de resistência maior que $355 \mathrm{MPa}$ (S355), quando todas as seções são de classe 1 ou 2 . A redistribuição não deve superar $30 \%$ na análise não-fissurada e $15 \%$ na análise fissurada.

$\mathrm{Na}$ análise elástica linear, caso o momento solicitante de cálculo $\left(M_{j, S d}\right)$ seja menor ou igual a $2 / 3 \cdot M_{j, R d}$ a rigidez secante pode ser considerada igual a rigidez inicial da ligação como apresentado pela Figura 2.12. 
Tabela 2.4: Limites para redistribuição de momentos negativos (\%).

\begin{tabular}{c|c|c}
\hline $\begin{array}{c}\text { Classe da seção } \\
\text { transversal na região } \\
\text { de momento negativo }\end{array}$ & $\begin{array}{c}\text { Análise não- } \\
\text { fissurada }\end{array}$ & $\begin{array}{c}\text { Análise } \\
\text { fissurada }\end{array}$ \\
\hline 1 & 40 & 25 \\
\hline 2 & 30 & 15 \\
\hline 3 & 20 & 10 \\
\hline 4 & 10 & 0 \\
\hline
\end{tabular}

Por outro lado, para valores de $\left(M_{j, S d}\right)$ superior a $2 / 3 \cdot M_{j, R d}$, a rigidez secante é tomada como a rigidez inicial dividida pelo parâmetro $\eta$, que para ligações viga-pilar com chapa de topo ou com cantoneiras é igual a 2.

Para se evitar o conhecimento inicial do momento resistente da ligação $\left(M_{j, R d}\right)$, como simplificação, pode-se considerar para todos os casos a rigidez secante calculada pelo segundo procedimento.
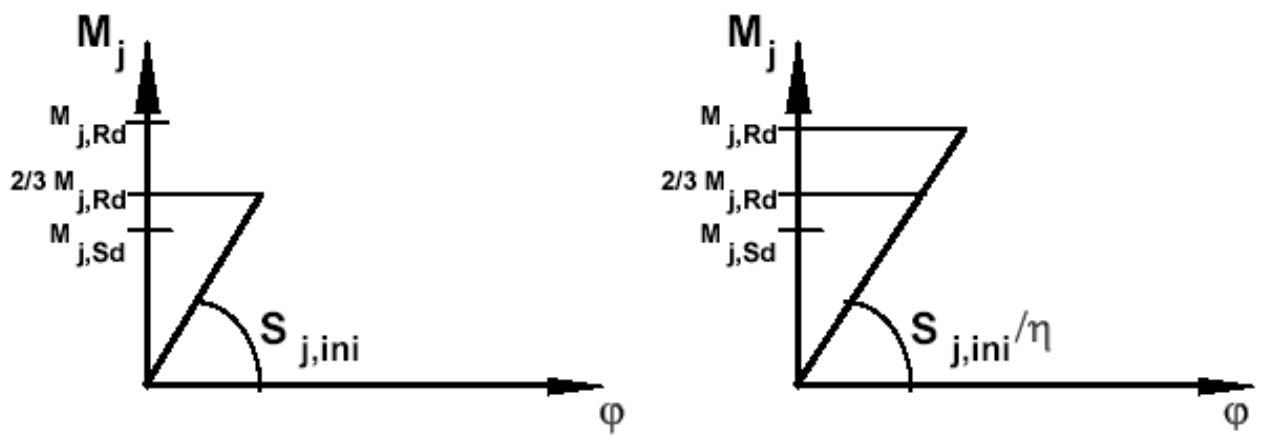

Figura 2.12: Ilustração da rigidez secante para a análise global.

\subsubsection{2 - Análise elástica linear para estado limite de serviço}

No estado limite de serviço, deve-se considerar a fissuração, retração e fluência do concreto para a determinação dos deslocamentos e solicitações internas.

Os deslocamentos da estrutura, para o estado limite de serviço, são obtidos de maneira análoga para o estado limite último. O efeito da fissuração do concreto na região de momento negativo pode ser considerado de modo semelhante ao comentado no item anterior 
Quando a conexão é completa pode-se desprezar o efeito da interação parcial. No caso de conexão parcial, o EUROCODE 4 (2004) estabelece que a interação parcial pode ser desprezada caso as exigências abaixo sejam respeitadas:

- os conectores de cisalhamento devem estar rigorosamente projetados de acordo com o especificado pela normalização;

- ou no mínimo metade do número de conectores para conexão completa devem ser utilizados;

- no caso de laje com forma incorporada com nervuras perpendiculares a viga, a altura da nervura deve ser menor que $80 \mathrm{~mm}$.

\subsubsection{3 - Análise rígido-plástica}

Segundo a análise global rígido plástica, as deformações elásticas dos elementos e das ligações são desprezadas e as deformações plásticas são assumidas concentradas nas regiões de rótulas plásticas, sendo as ligações classificadas apenas quanto à resistência para essa análise.

De acordo com o EUROCODE 4 (2004), a seção transversal onde ocorre a formação de rótulas plásticas deve ser de classe 1 , sendo todas as outras de classe 1 ou 2.

O emprego dessa análise está condicionado às limitações a seguir, na qual considera que a resistência do pórtico é governada pelo colapso da viga:

- $\quad$ pode ser aplicado somente quando não necessita ser considerado no sistema estrutural o efeito de segunda ordem;

- o momento resistente da viga mista não pode ser reduzido pela flambagem lateral com distorção da viga mista junto a ligação,

- deve ser comprovado que a capacidade de rotação das ligações mistas seja igual ou superior à capacidade de rotação das vigas;

- o elemento deve ter contenção lateral nos pontos de formação de rótula plástica, na qual essa contenção deve estar posicionada a uma distância, em relação ao ponto de formação da rótula, não superior a metade da altura da seção de aço;

- vigas com aço estrutural de resistência ao escoamento menor que 
$355 \mathrm{MPa}$ (S355);

- cada ligação viga-pilar deve ter capacidade rotacional suficiente ou ter resistência maior ou igual a 1,2 vezes a resistência plástica da viga conectada;

- caso mais da metade da ação de cálculo esteja concentrada em um comprimento não superior a um quinto do vão, no ponto de formação da rótula plástica com a laje de concreto em compressão, não podem existir tensões de compressão em mais de $15 \%$ da altura total da seção mista, sendo que essa limitação não se aplica caso a referida rótula plástica seja a última a se formar;

- para que, na análise rígido-plástica os vários tramos possam ser analisados independentemente um do outro, um vão qualquer não pode ter comprimento $50 \%$ maior que o comprimento de um vão adjacente e um vão de extremidade não pode ter comprimento $15 \%$ maior que o comprimento do vão adjacente (Figura 2.13).

$\mathrm{L}_{2}-\mathrm{L}_{1} \leq 0,50 \mathrm{~L}_{1}$

-

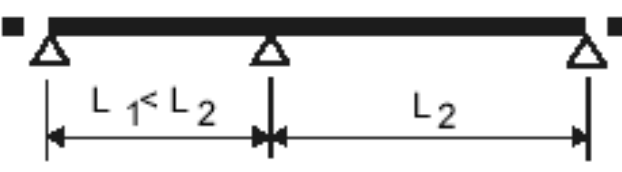

$\mathrm{L}_{1} \leq 1,15 \mathrm{~L}_{2}$

Figura 2.13: Condição de comprimento entre tramos para análise rígidoplástica.

Assim, obedecidas as exigências mencionadas, o momento fletor solicitante de cálculo (MSd), em uma seção qualquer de abscissa z é apresentado pela equação (13). Além disso, as forças cortantes solicitantes de cálculo são obtidas pela equação (14).

$$
M_{S d}=M_{S d, q}-M_{R d, e s q}^{-} \cdot \frac{(L-z)}{L}-M_{R d, d i r}^{-} \cdot\left(\frac{z}{L}\right)
$$

Onde:

$M_{S d, q}$ é o momento fletor solicitante de cálculo na viga biapoiada, em 
função da abscissa z.

$M_{R d, e s q}^{-}, M_{R d, d i r}^{-}$são os momentos fletores resistentes de cálculo nas extremidades esquerda e direita, respectivamente, em módulo, das vigas mistas sujeitas a momento negativo no caso de vigas contínuas, ou das ligações mistas, no caso de vigas semi-contínuas;

z é a abscissa da seção, a partir do apoio esquerdo;

L é o vão da viga;

$V_{S d}=V_{S d, q}+\frac{\left(M_{R d, e s q}^{-}-M_{R d, d i r}^{-}\right)}{L}$

Onde:

$V_{S d}$ é a força cortante solicitante de cálculo, em função de z;

$V_{S d, q}$ é a força cortante solicitante de cálculo na viga biapoiada, em função da abscissa z.

Para ligações com momento resistente igual ou maior que $20 \%$ do momento resistente da viga mista (ligação de resistência total), na qual foi adotada a análise global rígido-plástica, não é necessário ter a capacidade rotacional verificada, pois já está considerado que a ligação tem capacidade suficiente para que a rótula plástica se forme na viga.

\subsubsection{4 - Análise elasto-plástica}

Segundo a análise elasto-plástica, deve-se considerar as regiões fissuradas e não-fissuradas da viga mista (contínuas ou semi-contínuas), o deslizamento da conexão de cisalhamento e eventual separação da laje (efeito denominado "uplift") e a rotação devido à flambagem local nos apoios intermediários. Esse tipo de análise normalmente não é aplicado no dimensionamento de estruturas mistas.

$\mathrm{Na}$ análise elasto-plástica a seção transversal da viga onde ocorre a formação das rótulas plásticas deve ser de classe 1 , sendo todas as outras seções de classe 1 ou 2.

É necessário levar em consideração o comportamento não-linear dos materiais quando se considera a análise global elasto-plástica de pórticos, que 
simplificadamente pode ser adotada bi-linear conforme ilustra a Figura 2.14. A consideração do comportamento do material perfeitamente plástico faz com que se forme uma rótula plástica na seção da viga quando toda a seção atinge a tensão de escoamento.

Logo que se forma a rótula plástica, a estrutura redistribui os momentos formando outras rótulas. O colapso da estrutura ocorre após o surgimento de sucessivas rótulas plásticas, transformado a estrutura estática ou hiperestática em hipostática.

Dessa forma, para que se forme todo o mecanismo descrito acima, é necessário as seguintes condições:

- o aço tenha ductibilidade suficiente para que seja desenvolvida a resistência plástica da seção;

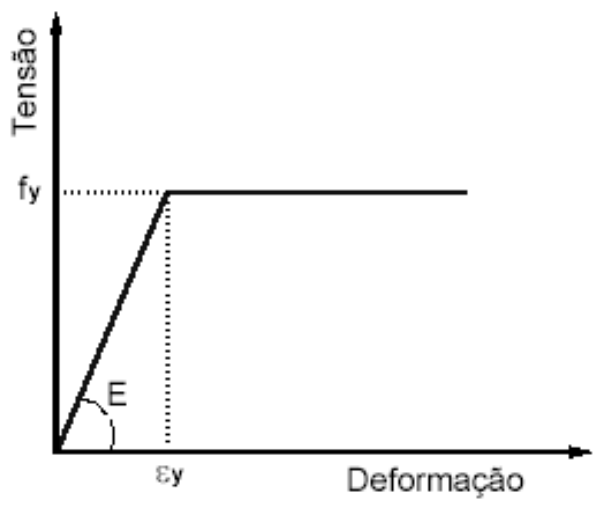

Figura 2.14: Comportamento bi-linear do material.

- a seção com rótula plástica deve ter capacidade rotacional suficiente sem a ocorrência da flambagem local (seções de classe 1 ou 2) ou lateral, permitindo a formação do mecanismo de colapso e, consequentemente a redistribuição das solicitações;

- para garantir que não ocorra a flambagem lateral no elemento sujeito a formação da rótula plástica, devem existir um contraventamento lateral apropriado na região da rótula.

Nas ligações contínuas, o comportamento $M-\phi$ deve se considerado na 
análise, podendo adotar uma simplificação bi-linear ou tri-linear conforme a Figura 2.15. A rigidez secante para a relação bi-linear é tomada como a rigidez dividida pelo parâmetro $\eta$, que nas ligações viga-pilar com chapa de topo ou cantoneiras é igual a dois.
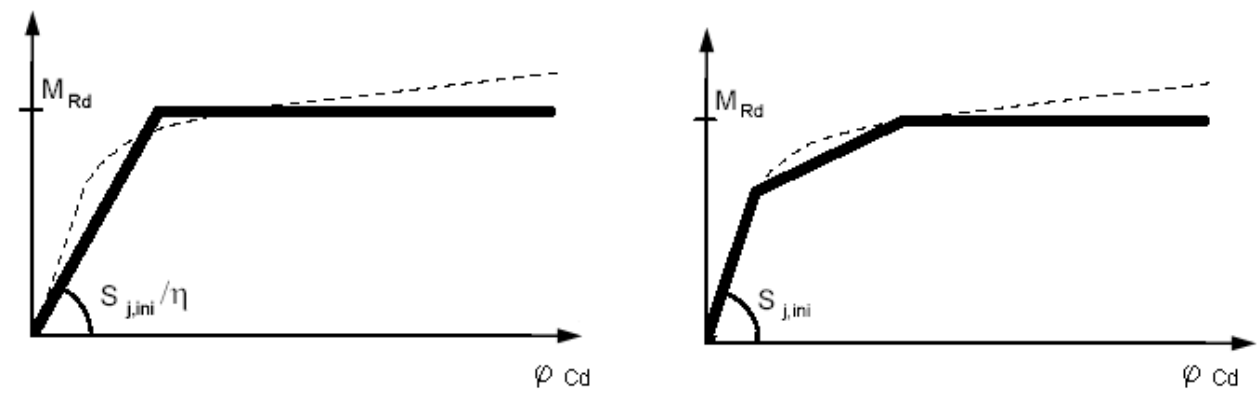

Figura 2.15: Comportamento bi-linear e tri-linear das ligações - EUROCODE 4 (2004).

\subsection{2 - Vigas mistas aço concreto}

As vigas mistas aço concreto são elementos estruturais que consistem da associação de um perfil de aço (soldado, laminado ou chapa dobrada) com uma laje de concreto, podendo ser maciça ou com forma de aço incorporada. A interação entre o perfil e a laje de concreto é estabelecida por meio de conectores de cisalhamento, com a função de garantir que ambos os elementos trabalhem em conjunto na flexão segundo o eixo perpendicular ao plano médio da alma da viga.

A influência da laje de concreto no comportamento da ligação pode ser visualizada na Figura 2.16, de dois modelos cruciformes na qual Aribert \& Lanchal aput COST1 (1996) comparou o comportamento $M-\phi$ da ligação com chapa de topo com e sem a laje de concreto. 


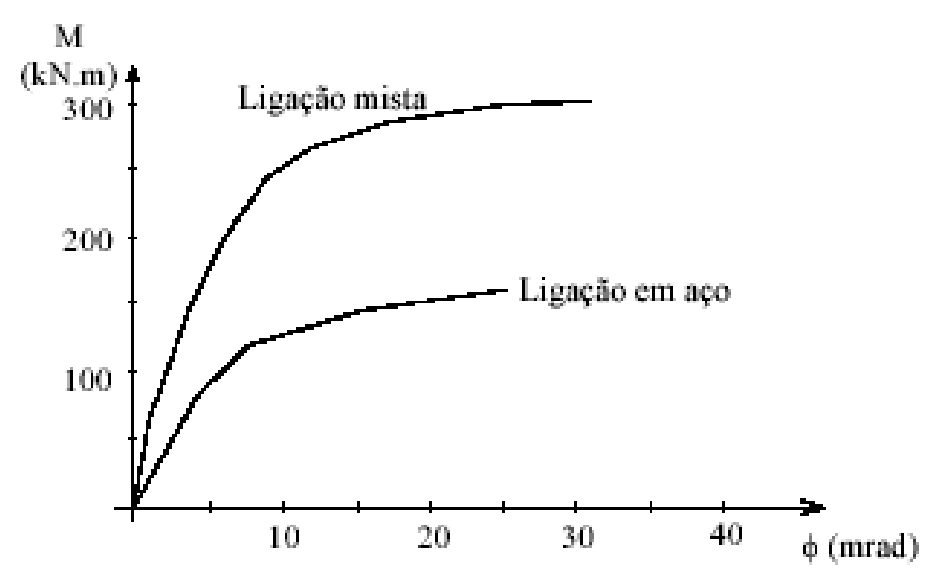

Figura 2.16: Comparação do comportamento $M-\phi$ da ligação com chapa de topo com e sem laje de concreto segundo Aribert \& Lanchal aput COST1 (1996).

O tipo de interação entre o perfil de aço e a laje de concreto está diretamente relacionado ao desempenho da viga mista. $\mathrm{Na}$ interação completa é assumido não haver deslocamento relativo entre a viga e a laje, com apenas uma linha neutra na seção. Na interação parcial há deslocamento relativo, havendo duas linhas neutras, porém, não independentes entre si, em função do grau de interação dos dois elementos. O esquema de interação entre a laje de concreto e a viga está ilustrado na Figura 2.17.

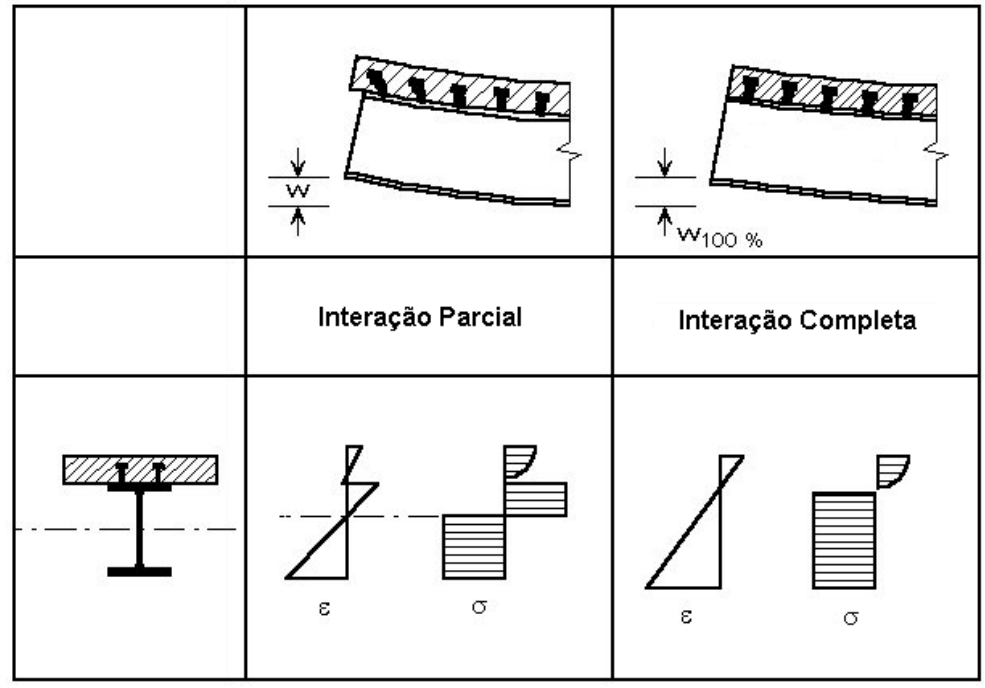

Figura 2.17: Esquema de interação entre a viga de aço e a laje de concreto.

Seguindo a mesma filosofia, no que diz respeito à resistência dos 
elementos, a resistência da viga mista na conexão completa não depende dos conectores, enquanto que na conexão parcial, a resistência dos conectores é menor que a resistência da viga de aço e da laje de concreto. Neste ponto, vale ressaltar que o grau de conexão de uma viga mista refere-se à resistência ao cisalhamento, enquanto que o grau de interação baseia-se no deslocamento relativo entre a viga e a laje de concreto.

\subsubsection{1 - Largura efetiva}

O sistema de piso com vigas mistas consiste de várias vigas "T" paralelas, sendo a mesa larga e de pequena espessura. A presença de deformações de cisalhamento no plano da laje de concreto faz com que as seções não mais permaneçam planas, provocando uma variação das tensões normais ao logo da largura da mesa ("shear lag"), que é maior sobre a viga e vai diminuindo à medida que se distancia do plano médio da seção.

Temos então que, para continuar utilizando expressões da teoria geral da flexão, é necessário recorrer à hipótese de considerar vigas equivalentes com mesa de largura efetiva, uniformizando assim a tensões.

O EUROCODE 4 (2004) prevê larguras efetivas diferentes para regiões de momento positivo e negativo, em função do vão da viga e da posição entre o centro dos conectores, conforme mostra a tabela 2.5 .

No caso de apoio externo (ligação viga-pilar de extremidade), o EUROCODE 4 (2004) define que a largura efetiva total da laje pode ser obtida pela equação (15).

$$
\beta_{\text {eff }}=b_{0}+2 \cdot \beta_{i} \cdot b_{e i}
$$

Onde:

$$
\beta_{i}=0,55+0,025 \cdot\left(\frac{L_{e}}{b_{e i}}\right) \leq 1,0
$$

$b_{e i}$ é a largura efetiva do vão externo $\left(\frac{0,85 \cdot L_{1}}{8}\right)$

$L_{e}$ é o comprimento equivalente do vão externo $\left(0,85 . L_{1}\right)$ 
Tabela 2.5: Cálculo da largura efetiva segundo o EUROCODE 4 (2004).

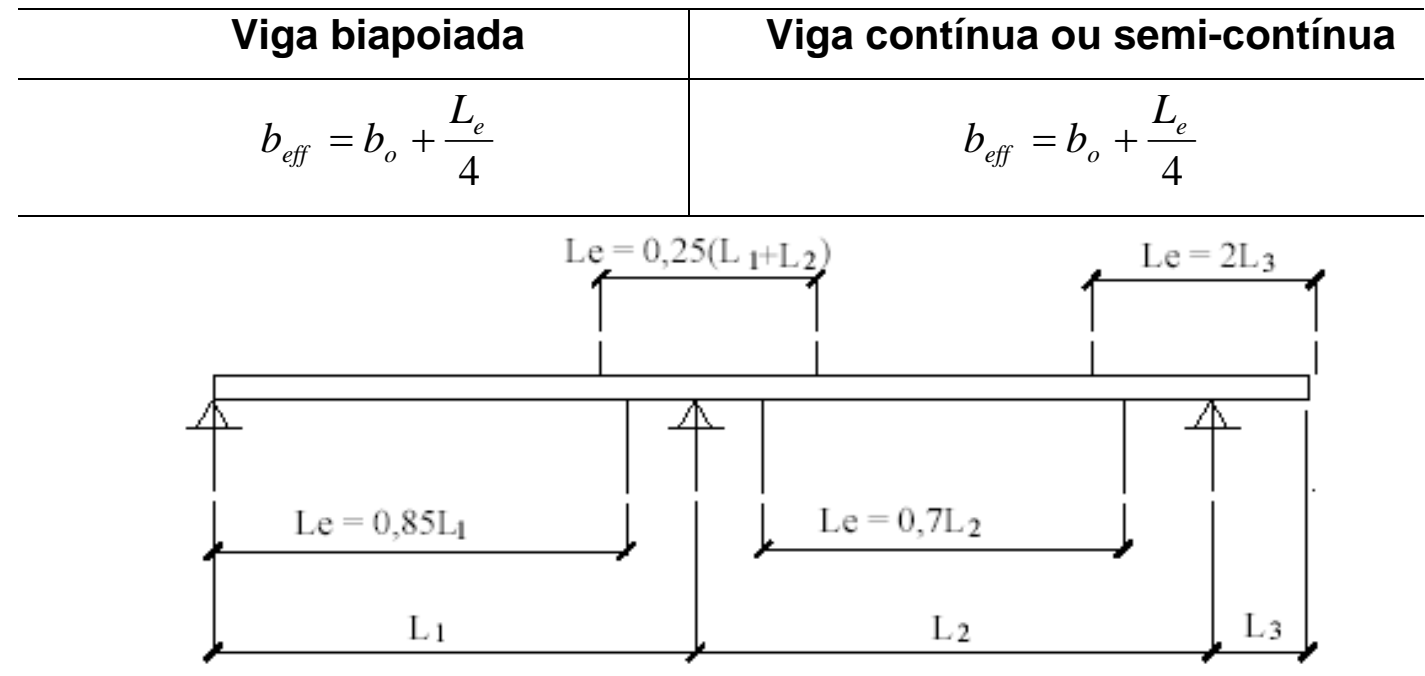

$b_{o}=$ é a distância entre centros de conectores, podendo adotar o valor de zero para estruturas de edifícios;

$L_{e}=$ é o comprimento da viga.

A largura efetiva da mesa de concreto, de cada lado da linha de centro da viga, deve ser tomada como o menor dos seguintes valores:

1) $1 / 8$ do vão da viga mista considerando entre linhas de centro dos apoios;

2) metade da distância entre a linha de centro da viga analisada e a linha de centro da viga adjacente;

3) distância da linha de centro da viga à borda de uma laje em balanço.
A largura efetiva pode ser obtida a partir de vigas biapoiadas, tomando-se em lugar dos vãos da viga as distâncias entre pontos de momento nulo:

1) nas regiões de momento positivo

- 0,85 da distância entre apoios, para vãos externos;

- 0,70 da distância entre apoios, para vãos internos;

2) nas regiões de momento negativo

- 0,25 da soma dos vãos adjacentes.

\subsubsection{2 - Comportamento em estado limite último}

O EUROCODE 4 (2004) determina que a resistência da viga mista no estado limite último é função do tipo de seção de viga de aço (1, 2, 3 ou 4), do grau de cisalhamento (completa ou parcial), do sistema de construção (escorada ou não-escorada) e do tipo de concreto. Assim, as vigas mistas 
devem ser verificadas para os seguintes estados limites últimos:

i) resistência da seção mista à flexão e da seção do aço ao cisalhamento;

ii) resistência à flambagem lateral com distorção;

iii) resistência ao cisalhamento longitudinal.

Para as regiões de momento positivo em vigas mistas, quando a seção for compacta conforme o AISC/LFRD (1999), ou quando for de classe 1 e 2 segundo o EUROCODE 4 (2004), a resistência última à flexão da viga mista pode ser calculada considerando a distribuição de tensões plásticas tanto na laje quanto na seção de aço, uma vez que na mesa superior da viga não ocorrerá flambagem local, tal como a flambagem lateral com torção, devido a presença da laje de concreto.

Para situação de momento positivo em vigas mistas contínuas ou semicontínuas, deve-se considerar um coeficiente $\beta$ que leva em conta a impossibilidade da viga no interior dos tramos de atingir a plastificação total. Esse coeficiente, de acordo com o EUROCODE 4 (2004), é determinado em função da distância entre a linha neutra plástica à face externa da laje de concreto na compressão $\left(X_{p l}\right)$, sendo que $X_{p l}$ é maior que $15 \%$ da altura da viga mista. A Figura 2.18 mostra o diagrama para obtenção do fator de redução. Para valores $X_{p l} / h$ maiores que 0,4 realiza-se a análise elástica.
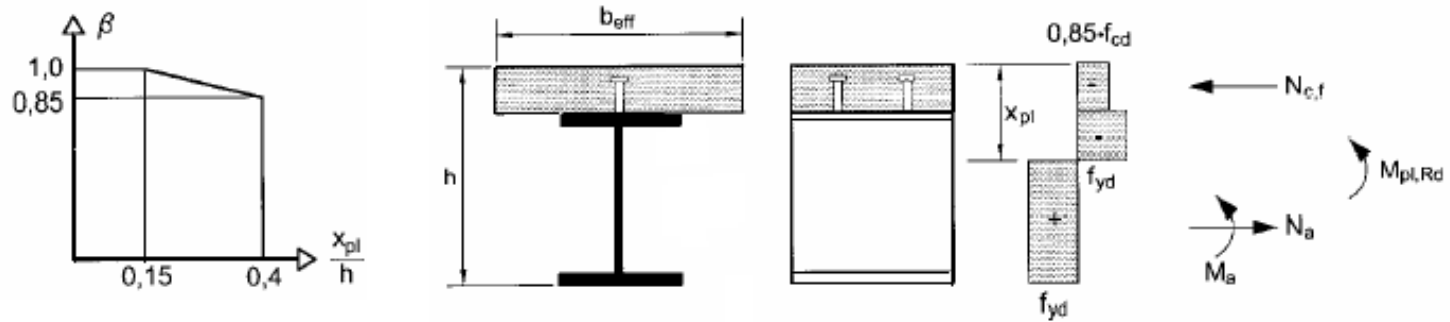

Figura 2.18: Fator de redução $\beta$ segundo o EUROCODE 4 (2004).

Para as seções não-compactas do AISC/LFRD (1999), ou seções de classe 3 segundo o EUROCODE 4 (2004), a resistência da viga é a primeira plastificação na seção, calculada segunda a teoria elástica. Para este caso, quando o sistema for não-escorado, as tensões na seção de aço devido a ações permanentes, aplicadas antes do endurecimento do concreto, precisam 
ser superpostas após o endurecimento do concreto. Para sistema escorado deve-se desconsiderar a primeira parcela.

A seção transformada é obtida pela divisão da largura efetiva do concreto por $n_{L}$, que relaciona os módulos de elasticidade do aço e do concreto, sendo que módulo de elasticidade do concreto $\left(E_{c m}\right)$ deve ser reduzido devido à consideração da fluência. O EUROCODE 4 (2004) apresenta uma expressão em função do tipo de carregamento.

O valor para a redução do módulo de elasticidade do concreto, para efeito de simplificação, pode ser tomado igual a dois para carregamento de curta e longa duração, desde que as solicitações internas causadas por deformações devido à análise global em $2^{a}$ ordem não superem os da análise em $1^{a}$ ordem em $10 \%$.

Caso a viga não seja escorada, ainda considerando região de momento positivo, deve-se verificar a viga de aço para ações aplicadas antes do concreto atingir o nível de $75 \%$ de sua resistência à compressão. O EUROCODE 4 (2004) permite que quando a seção for de classe 3 devido à alma da viga (mesas de classe 1 ou 2), a parte da alma comprimida apresentada na Figura 2.19 poderá ser desprezada, alterando a alma da viga para classe 2, permitindo assim adotar a teoria rígido-plástica.

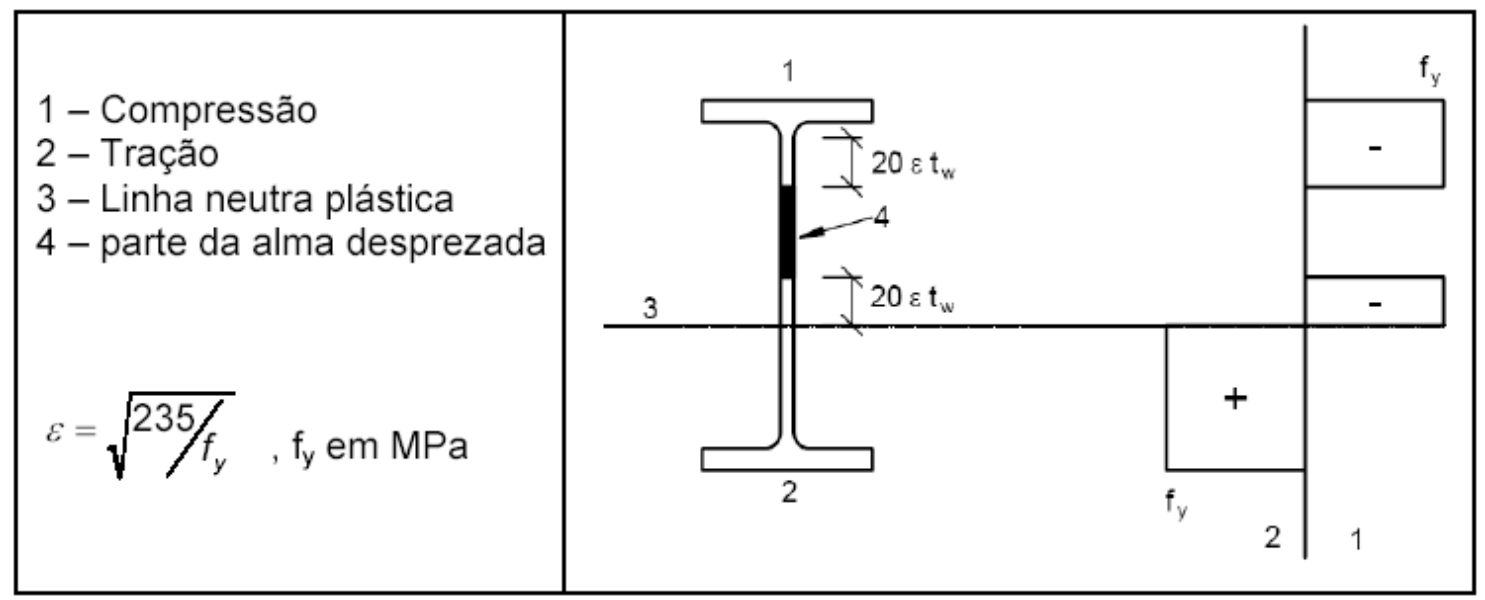

Figura 2.19: Modificação da classe de alma 3 para 2 segundo o EUROCODE 4 (2004)

Para as seções de classe 4, é adotada a teoria elástica pelo EUROCODE 
4 (2004). A avaliação de sua resistência é tomada a partir de uma seção transversal efetiva, deduzindo a área das partes suscetíveis de instabilidade local, o que resulta numa alteração da posição do centro de gravidade. $O$ EUROCODE 3 (2005) - parte 1.5 - fornece o procedimento de cálculo o módulo elástico efetivo $\left(W_{\text {eff }}\right)$ dessas seções utilizadas em vigas mistas.

No caso de não atendidas as exigências para adotar a teoria plástica, permite-se a consideração da teoria elástica desde que se utilizem as propriedades elásticas dos materiais. Dessa forma, seguem as mesmas recomendações para vigas na região de momento positivo, exceto que não são consideradas a fluência do concreto e a homogeneização da seção mista.

As vigas mistas podem estar suscetíveis ao modo de instabilidade conhecida como flambagem lateral com distorção da seção transversal, na região de momento negativo. Esse fenômeno é ilustrado na Figura 2.20, e deve-se à mesa comprimida receber apenas a restrição da alma, que é um elemento flexível, e a laje restringir a viga à torção, o que leva ao deslocamento lateral da mesa comprimida caso a alma deforme por flexão.

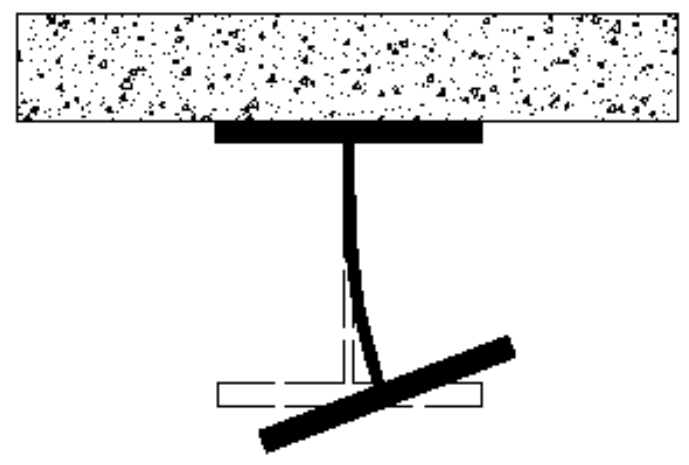

Figura 2.20: llustração da flambagem lateral com distorção.

O EUROCODE 4 (2004) considera que as vigas contínuas ou semicontínuas, de classe 1, 2 ou 3 , podem ser projetadas sem restrições à flambagem lateral com torção, caso sejam respeitadas as seguintes condições:

- o carregamento em cada vão é uniformemente distribuído e as ações permanentes excedem $40 \%$ da ação total do projeto;

- vãos adjacentes não diferem no comprimento em mais de $20 \%$, ou em $15 \%$ quando envolve vão em balanço; 
- a laje que compõem a viga mista analisada é também suportada por outra viga paralela a viga considerada;

- a viga de aço nos apoios tem sua mesa comprimida restringida lateralmente e sua alma enrijecida;

- a altura de seção de aço não excede o limite máximo apresentado na tabela 2.6.

Tabela 2.6: Altura máxima da seção de aço para evitar a verificação por flambagem lateral com distorção $(\mathrm{mm})$.

\begin{tabular}{c|c|c|c|c}
\hline $\begin{array}{c}\text { Tipo de } \\
\text { seção } \\
\text { transversal }\end{array}$ & Aço S235 & Aço S275 & Aço S355 & $\begin{array}{c}\text { Aço S420 } \\
\text { ou S460 }\end{array}$ \\
\hline IPE & 600 & 550 & 400 & 270 \\
\hline HE & 800 & 700 & 650 & 500 \\
\hline
\end{tabular}

\subsubsection{3 - Comportamento em estado limite de serviço}

As verificações a serem tomadas nas vigas mistas para o estado limite de serviço são:

- deslocamento vertical da viga (flecha);

- $\quad$ vibração da viga, especialmente em vigas de grandes vãos;

- $\quad$ fissuração do concreto.

Nas vigas mistas, para verificação do estado limite de serviço, admite-se que as seções permanecem planas após as ações de flexão, considerando interação total, tanto nas regiões de momento positivo quanto de momento negativo. Na região de momento positivo, assume-se a distribuição de tensão resultante do comportamento elástico linear, da relação tensão-deformação para o concreto e o perfil de aço.

Na região de momento negativo, a distribuição de tensão resultante é proporcionada pelo comportamento elástico linear da armadura e do perfil de aço. Para interação parcial, a viga mista sofrerá um escorregamento relativo na interface laje-viga de aço, proporcionando uma descontinuidade no diagrama 
de deformações.

O EUROCODE 4 (2004) considera que esse efeito pode ser desprezado, desde que sejam cumpridas algumas regras estabelecidas pela própria norma e, caso o fenômeno seja considerado, deve-se haver uma redução do momento de inércia da seção mista. Outro aspecto relevante é a consideração da fluência do concreto.

Esse efeito está diretamente correlacionado com a redução do módulo de elasticidade do concreto com o tempo. A influência da retração do concreto, no deslocamento vertical das vigas mistas de edifícios somente é considerada em vigas biapoiadas com relação vão x altura total da seção maior que 20.

O controle da fissuração do concreto depende do nível de solicitação na região do momento negativo. A largura da fissura pode ser estimada segundo o EUROCODE 2 (2003), onde deve ser considerado o efeito "tension stiffening" no cálculo da tensão solicitante na armadura $\left(\sigma_{s}\right)$.

Obedecendo ao limite imposto pelo EUROCODE 2 (2003), o valor limite da abertura da fissura pode ser encontrado por meio de uma armadura mínima, juntamente com limite de espaçamento ou diâmetro da barra fornecido pelo EUROCODE 4 (2004). Considera-se que metade dessa armadura mínima deve estar disposta próxima à face da laje com maior tensão de tração.

Para os casos de viga biapoiada, uma armadura longitudinal mínima também deve ser disposta dentro da largura efetiva da laje, seguindo as seguintes recomendações:

- $\quad 0,4 \%$ da área de concreto em sistema escorado;

- $\quad 0,2 \%$ da área de concreto em sistema não-escorado.

Essa armadura mínima em viga biapoiada deve estender 0,25L em cada lado do apoio, sendo o espaçamento máximo fornecido pelo EUROCODE 2 (2003).

\subsubsection{4 - Grau de conexão de cisalhamento}

Admite-se que o grau de conexão ao cisalhamento pode ser completo ou parcial. Nas regiões de momento positivo, a conexão completa é estabelecida quando a resistência da conexão é maior ou igual à resistência da laje de 
concreto ou do perfil de aço. Nas regiões de momento negativo, a conexão completa é alcançada quando a resistência da conexão é maior ou igual à resistência da armadura longitudinal.

Ao se adotar a teoria rígido-plástica para a determinação da resistência da viga mista (seção de classe 1 ou 2), o grau de conexão de cisalhamento interfere na distribuição de tensões plásticas da seção mista. Para se adotar a conexão parcial e utilizando a teoria rígido-plástica, faz-se necessário que os conectores sejam flexíveis, sendo que um limite para o grau de conexão é estabelecido pelo EUROCODE 4 (2004), aplicável aos conectores tipo pino com cabeça de acordo com a classificação abaixo:

I) quando as seções de aço componentes da viga mista têm mesas de áreas iguais;

$L_{e} \leq 25 m \quad \eta \geq 1-\left(\frac{355}{f_{y}}\right) \cdot\left(0,75-0,03 \cdot L_{e}\right) \quad \eta \geq 0,4$

$L_{e}>25 m \quad \eta \geq 1$

II) quando as seções de aço componentes da viga mista têm a área da mesa inferior igual a três vezes a área da mesa superior;

$L_{e} \leq 20 m \quad \eta \geq 1-\left(\frac{355}{f_{y}}\right) \cdot\left(0,30-0,015 \cdot L_{e}\right) \quad \eta \geq 0,4$

$L_{e}>20 m \quad \eta \geq 1$

Onde:

$\eta=$ é a relação entre o número de conectores no vão considerado e o número de conectores para a conexão completa;

$f_{y}=$ é a resistência ao escoamento do aço do perfil em MPa;

$L_{e}=$ é o comprimento do trecho de momento positivo (distância entre pontos de momento nulo), podendo ser tomado para vigas contínuas e semi-contínuas valores iguais ao considerado para determinação da largura efetiva; 
Para as seções de aço que tem a área da mesa inferior a três vezes a área da mesa superior, pode-se adotar uma interpolação das duas situações acima no cálculo do $\eta$. Na teoria elástica, a conexão parcial é considerada no cálculo do módulo de resistência elástico da seção mista, sendo que neste caso possível adotar conectores rígidos.

Os conectores devem ser dispostos entre o apoio da viga e o primeiro ponto de inflexão. Para que não haja necessidade da obtenção exata do ponto de inflexão, o EUROCODE 4 (2004) permite uma quantidade total de conectores flexíveis seja colocada uniformemente entre o apoio da viga e o ponto de momento máximo, desde que:

- a seção da viga no apoio e no ponto de momento máximo seja de classe 1 ou 2;

- $\quad$ o grau de conexão $(\eta)$ satisfaz o mencionado acima;

- o momento resistente plástico da seção mista não exceda a 2,5 vezes o momento resistente plástico da seção de aço.

A quantidade obtida é o total de conectores necessários na região de momento negativo somado ao número de conectores necessários na região de momento positivo.

\subsubsection{5 - Armaduras transversais na laje}

As armaduras transversais ao comprimento da viga, adicionadas à armadura longitudinal na laje de concreto, devem ser utilizadas com o objetivo de reduzir o efeito da fissuração na laje, em regiões onde se localizam as linhas de conectores de cisalhamento. Essas armaduras adicionais são projetadas para o estado limite último de cisalhamento longitudinal na viga e para a fissuração longitudinal.

A armadura adicional deve ser disposta ao longo do comprimento entre as seções de momento máximo positivo e nulo, e entre regiões de momento máximo negativo e nulo. 
A ruptura da laje por cisalhamento longitudinal ocorre por meio das superfícies de ruptura, conforme mostra a Figura 2.21, na qual para cada superfície é demonstrada a localização das armaduras para uma laje maciça.

Deve-se determinar a tensão de cisalhamento longitudinal atuante para cada tipo de ruptura no dimensionamento destas armaduras. Posteriormente, para o cálculo da área da armadura pode-se utilizar o modelo de bielas e tirantes proposto pelo EUROCODE 2 (2003) e apresentado na equação (16) para as lajes maciças:

$$
\left(\frac{A_{S f} \cdot f_{y d}}{S_{f}}\right)>\frac{v_{E d} \cdot h_{f}}{\cot \left(\theta_{f}\right)}
$$

Onde:

$A_{S f} / S_{f}$ é a área de armadura transversal por unidade de comprimento;

$f_{y d}$ é a tensão de escoamento de cálculo da armadura;

$V_{E d}$ é a tensão de cisalhamento longitudinal atuante, calculada pela equação (17);
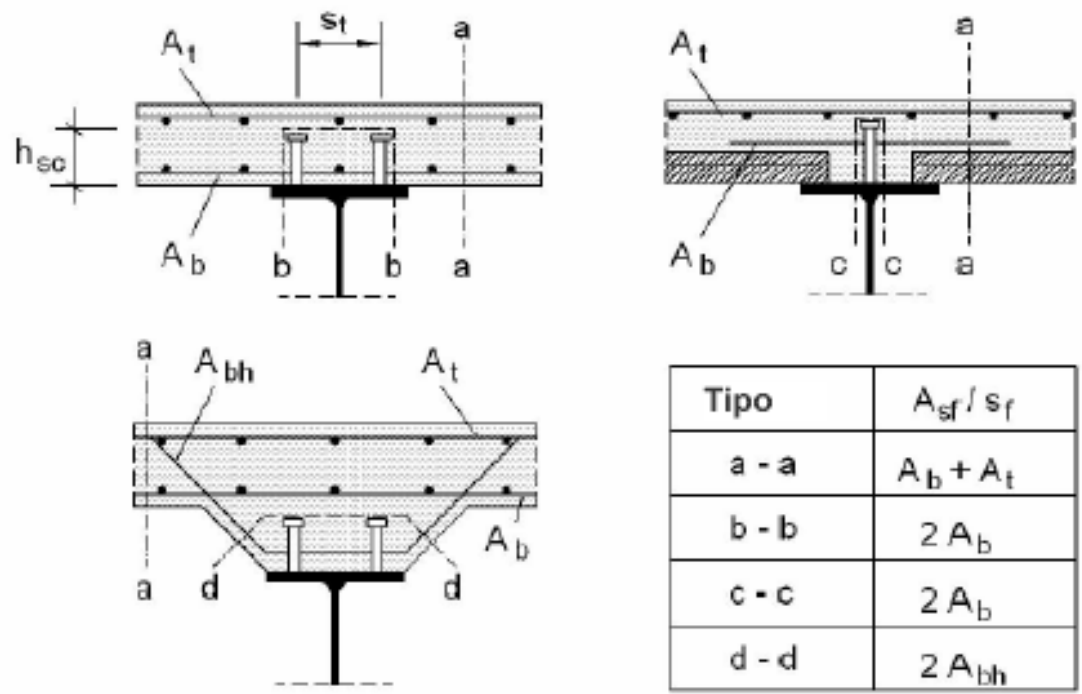

\begin{tabular}{|c|c|}
\hline Tipo & $A_{s f} / s_{f}$ \\
\hline$a-a$ & $A_{b}+A_{t}$ \\
\hline$b-b$ & $2 A_{b}$ \\
\hline$c-c$ & $2 A_{b}$ \\
\hline$d-d$ & $2 A_{b h}$ \\
\hline
\end{tabular}

Figura 2.21: Superfícies típicas de ruptura por cisalhamento longitudinal EUROCODE 4 (2004).

$h_{f}$ é o perímetro da superfície de cálculo, dado pelo EUROCODE 4 (2004);

$\theta_{f}$ é a inclinação das bielas em relação ao eixo da viga, podendo ser:

para banzos comprimidos: $45^{\circ} \geq \theta f \geq 26,5^{\circ}$ 
para banzos tracionados: $45^{\circ} \geq \theta f \geq 38,6^{\circ}$

$$
v_{E d}=\frac{P_{R d}}{s \cdot h_{f}}
$$

Onde:

$P_{R d}$ é a resistência de cálculo de um conector;

$s$ é o espaçamento entre conectores.

Nas lajes mistas com nervuras perpendiculares à viga de aço, a área da seção transversal da forma metálica pode ser somada ao primeiro termo da equação (16). É recomendável, na prática, que a área da armadura adicional não seja inferior a $0,2 \%$ da área da seção mista de cisalhamento do concreto, para cada tipo de ruptura.

Sempre que o momento fletor atuante à esquerda e à direita do pilar for diferente, devem-se utilizar armaduras transversais do lado do pilar com menor momento atuante para que a força na armadura longitudinal possa ser desenvolvida.

O guia de projeto série 8 do AISC (2001) recomenda que deve ser disposta, em cada lado do pilar, uma área de armadura transversal semelhante à área de armadura longitudinal.

O EUROCODE 4 (2004) também recomenda uma área de armadura transversal mínima disposta no lado do pilar com o menor momento atuante que pode ser obtida pela equação (18).

$$
A_{t} \geq 0,5 \cdot \beta \cdot A_{s} / \operatorname{tg} \delta
$$

Onde:

$A_{s}$ é a área da armadura longitudinal;

$\beta$ é o parâmetro que considera a condição de carregamento do pilar (pilar interno com momentos balanceados ou desbalanceados e pilar de extremidade);

$\operatorname{tg} \delta=1,35 \cdot\left(e_{T} / e_{L}-0,2\right)$, no qual:

$e_{T}$ é a distância entre eixo da alma do pilar e o centro de gravidade da 
armadura longitudinal localizada apenas de um lado do pilar;

$e_{L}$ é a distância entre a face da seção do pilar e o centro de gravidade da armadura transversal localizada apenas de um lado do pilar.

\subsubsection{6 - Armaduras longitudinais}

A maior resistência das vigas mistas na região de momento negativo é devido à colocação de armaduras longitudinais próximo a face superior da laje de concreto

O guia de projeto série 8 do AISC (2001) recomenda que devem ser adotadas armaduras entre 12,5 e $19 \mathrm{~mm}$.

Pelo projeto de revisão NBR 6118 (2003), as barras devem ter espaçamento máximo entre o menor valor de duas vezes à espessura da laje ou $20 \mathrm{~cm}$ e, a área máxima de armadura não deve superar a $8 \%$ da área de concreto.

As armaduras longitudinais devem estar dentro de uma largura equivalente a sete vezes a largura da mesa do pilar, além disso, o guia de projeto série 8 do AISC (2001) recomenda que cada lado da viga deve existir no mínimo três barras.

O comprimento da barra deve ser no mínimo $25 \%$ do vão da viga ou também segundo o guia de projeto série 8 do AISC (2001) pode-se adotar um valor correspondente ao comprimento do trecho negativo mais $305 \mathrm{~mm}$ após o ponto de momento nulo. É importante destacar que a armadura longitudinal faz parte da ligação e, dessa forma sua localização, espaçamento e quantidade de barras devem ser criteriosamente monitorados durante a construção.

\section{3 - Considerações Finais}

Neste capítulo foram reunidas as principais considerações sobre os trabalhos mais relevantes a respeito do comportamento monotônico de ligações mistas aço-concreto. O embasamento teórico apresentado neste capítulo fundamentou a definição e elaboração do programa experimental.

Adicionalmente, o estudo dos conceitos gerais relativos às vigas mistas constituiu parte essencial da fundamentação teórica do trabalho e definição dos 
principais parâmetros para a análise experimental.

No Capítulo 3 será discutido o modelo analítico de cálculo proposto pelo EUROCODE 3 (2005) - 1.8 e adotado como referência para este trabalho, para a determinação do momento resistente e rigidez inicial das ligações. Esta análise será voltada para ligações com cantoneira de alma e assento, além de uma breve abordagem do modelo proposto pelo AISC para ligações mistas. 


\section{DIMENSIONAMENTO DAS LIGAÇÕES MISTAS COM CANTONEIRAS DE ALMA E ASSENTO}

\section{1 - Introdução}

As formulações analíticas existentes, para a determinação da rigidez inicial e momento resistente das ligações mistas, têm sido desenvolvidas a partir da contribuição de vários estudos realizados nas últimas décadas.

Dentre os principais trabalhos para a determinação da rigidez inicial e momento resistente de ligações mistas, submetidas a carregamento monotônico, podemos citar Ahmed, Nethercot \& Li (1995) e Li, Nethercot \& Choo (1996b).

Estes procedimentos analíticos foram obtidos a partir de modelos previamente estabelecidos para ligações metálicas, adicionando-se a contribuição da laje de concreto e de sua armadura.

Neste capítulo é discutido o procedimento analítico de cálculo proposto pelo EUROCODE 3 (2005) - parte 1.8 para a determinação do momento resistente e rigidez inicial, com enfoque para as ligações com cantoneiras de alma e assento, que será o tipo de ligação abordada neste trabalho, além de uma breve abordagem do modelo proposto pelo AISC.

As ligações são analisadas no plano bidimensional, tendo em vista que a laje de concreto possibilita uma elevada rigidez à torção e estabilidade lateral.

$\mathrm{Na}$ apresentação do modelo analítico não será considerada a verificação do cisalhamento vertical proveniente do esforço cortante na viga, uma vez que o objetivo principal deste trabalho é analisar o comportamento da ligação devido ao momento fletor. 


\section{2 - Modelo Analítico Proposto pelo EUROCODE 3 (2005)}

\subsection{1 - Considerações iniciais}

O método proposto pelos EUROCODE 3 (2005) e EUROCODE 4 (2004), ligações em aço e mistas, respectivamente, para avaliação da rigidez inicial e momento resistente, denominado de Método das Componentes, considera que o comportamento global de uma ligação é baseado na união dos comportamentos individuais de cada componente relevante na ligação.

Este método se baseia essencialmente na distribuição plástica das forças de tração nas linhas de parafusos, assim a força em cada linha de parafuso é determinada por sua resistência potencial, e não somente pelo seu braço de alavanca em relação ao centro de rotação, característica da tradicional distribuição triangular.

Dessa forma, para ligações com chapa de topo em aço, por exemplo, as linhas de parafusos em regiões mais próximas às mesas da viga ou enrijecedores, resistem a parcelas maiores de força.

O método pode ser aplicado a várias configurações de ligações mistas ou de aço, tipo de carregamento e tipo de perfil do elemento (soldado ou laminado).

A Figura 3.1 ilustra os principais termos relativos às ligações mistas e que serão utilizados para a apresentação do método ao longo de todo o trabalho. A descrição destes termos segue abaixo:

Nó - ponto de interseção dos eixos da viga e do pilar;

Ponto nodal - inclui o nó e as extremidades dos elementos conectados;

Elementos da ligação - são os elementos que efetivamente realizam a ligação, tal como soldas, parafusos, chapas, cantoneiras, etc.

Painel da alma do pilar - região da alma do pilar onde atuam as forças de cisalhamento;

Ligação - região que abrange o painel da alma, elementos da ligação e zona nodal.

O método é aplicado de acordo com as seguintes etapas: 
1. Determinação das componentes individuais de compressão, tração e cisalhamento que influenciam no comportamento da ligação;

2. Avaliação da resistência de cada componente individual;

3. Somatório das componentes individuais para determinação das características da ligação (principalmente momento resistente e rigidez inicial).

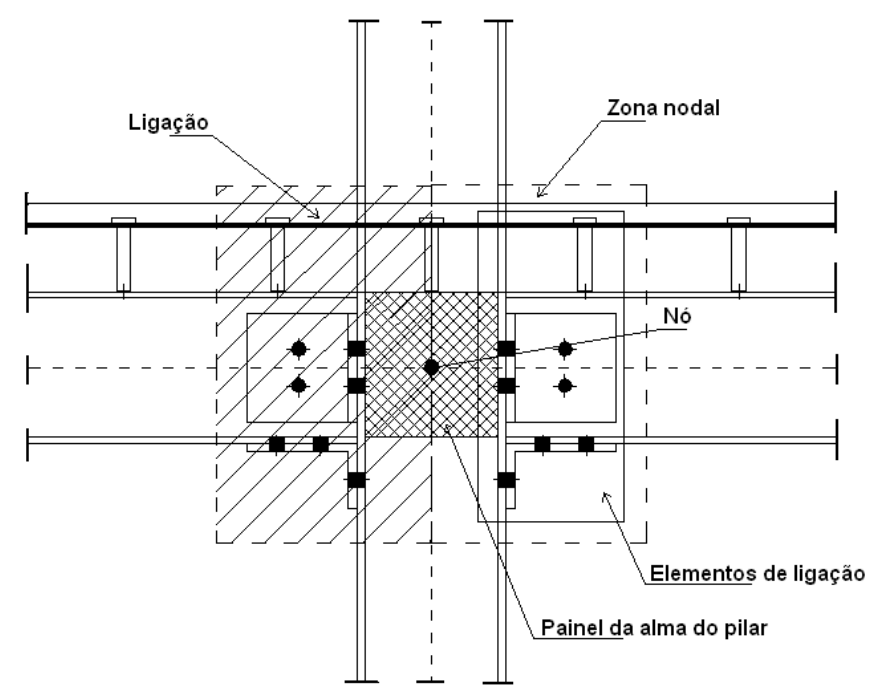

Figura 3.1: Designação dos termos da ligação.

Numa ligação submetida a momento fletor negativo, as componentes se localizam em três zonas: zonas de tração, compressão e cisalhamento horizontal, como mostra a Figura 3.2.

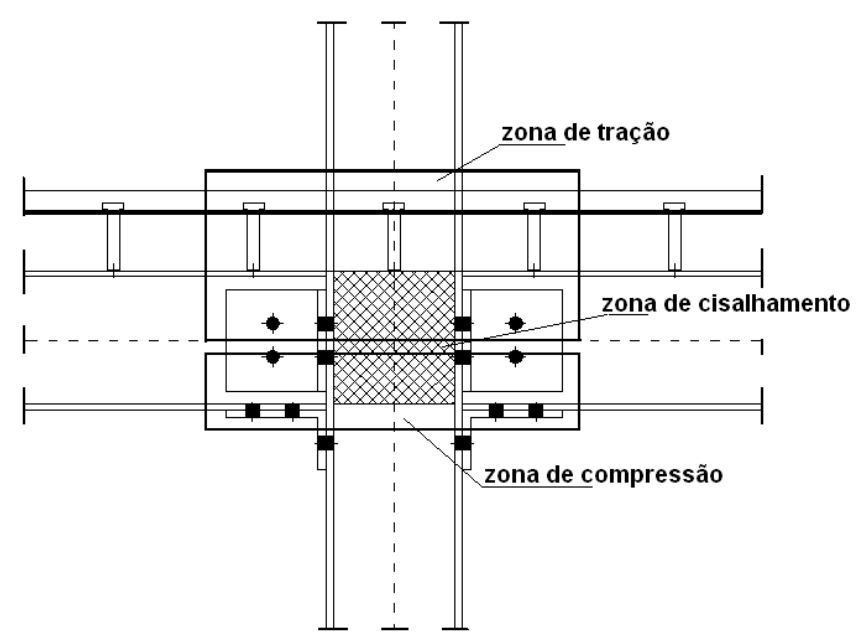

Figura 3.2: Zonas de tensões de uma ligação. 
A tabela 3.1 apresenta as componentes individuais divididas em zona de tração, compressão, cisalhamento vertical e cisalhamento horizontal, que devem ser considerados nas ligações abaixo ilustradas para a determinação do momento resistente e rigidez inicial.

I - chapa de topo estendida;

II - chapa de topo;

III - cantoneira de alma e assento.

Tabela 3.1: Componentes individuais das ligações I, II e III.

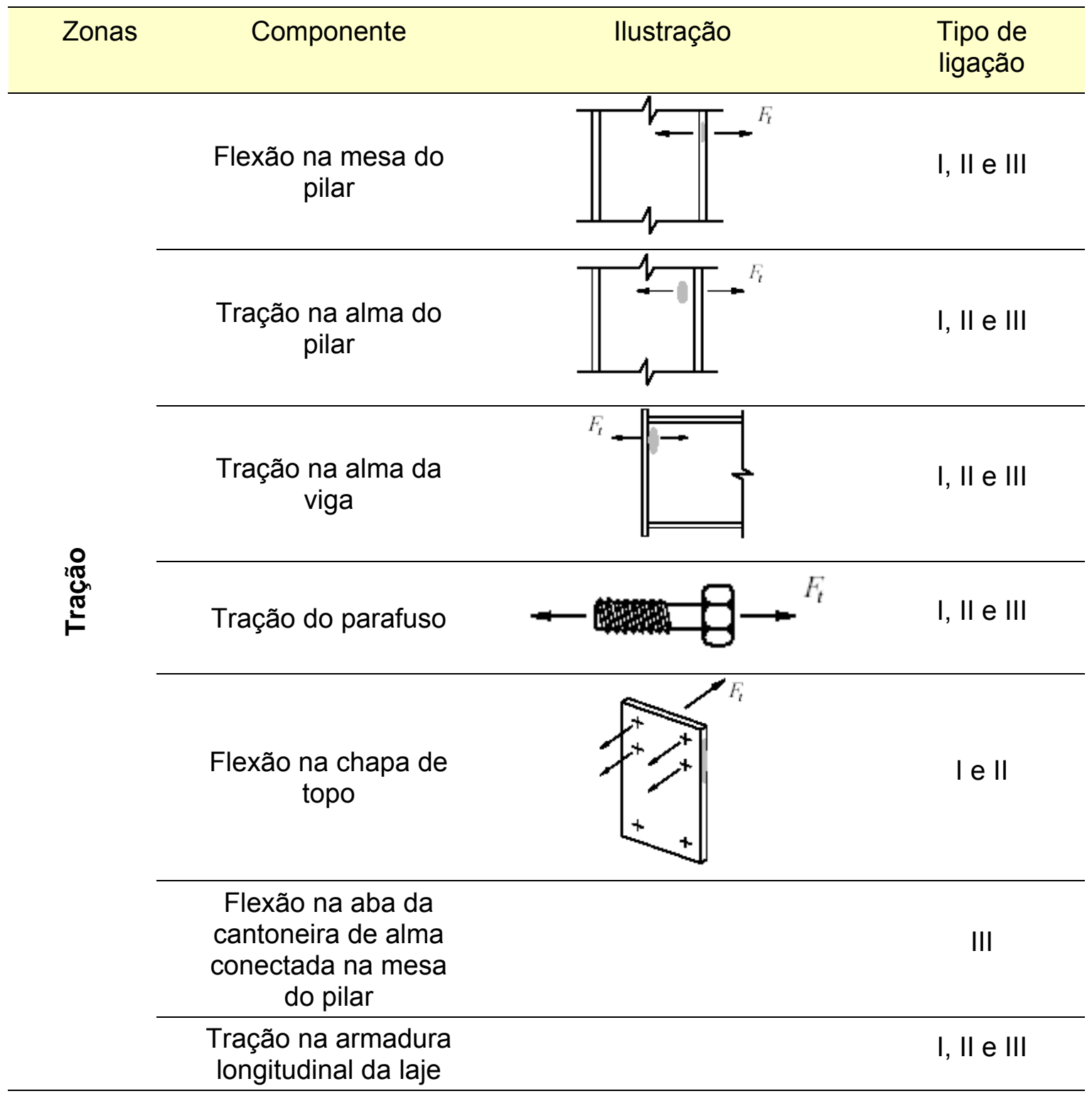




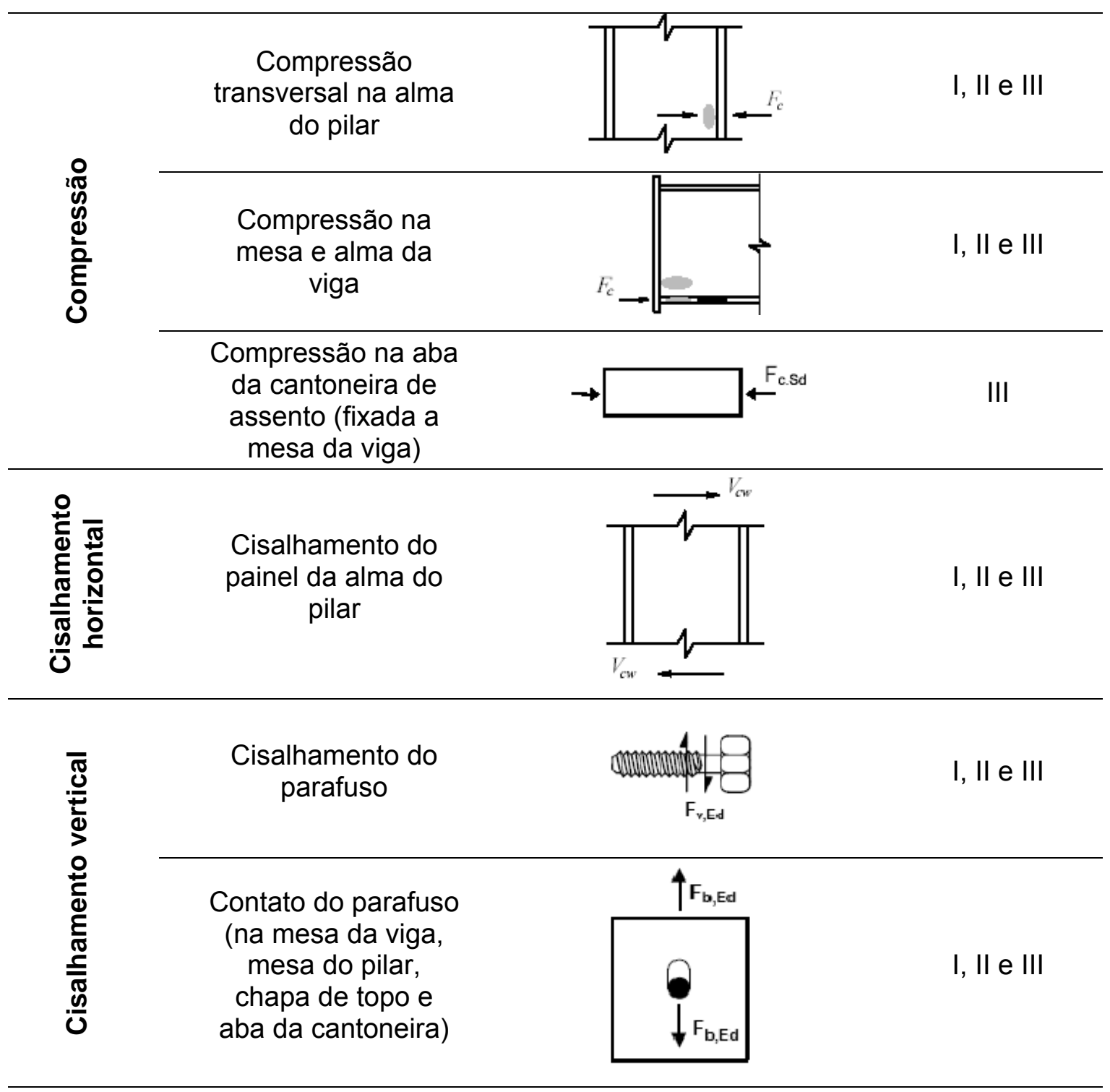

\subsection{2 - Solicitações atuantes na ligação}

As solicitações atuantes numa ligação são o momento fletor, força normal e de cisalhamento vertical provenientes das vigas conectadas, conforme ilustra a Figura 3.3, devendo a ligação ser concebida para resistir a tais solicitações.

No entanto, as solicitações provenientes do pilar (momento fletor, solicitação de cisalhamento e axial) também exercem influência no comportamento da ligação, uma vez que condicionam a resistência das componentes, como será visto adiante. 


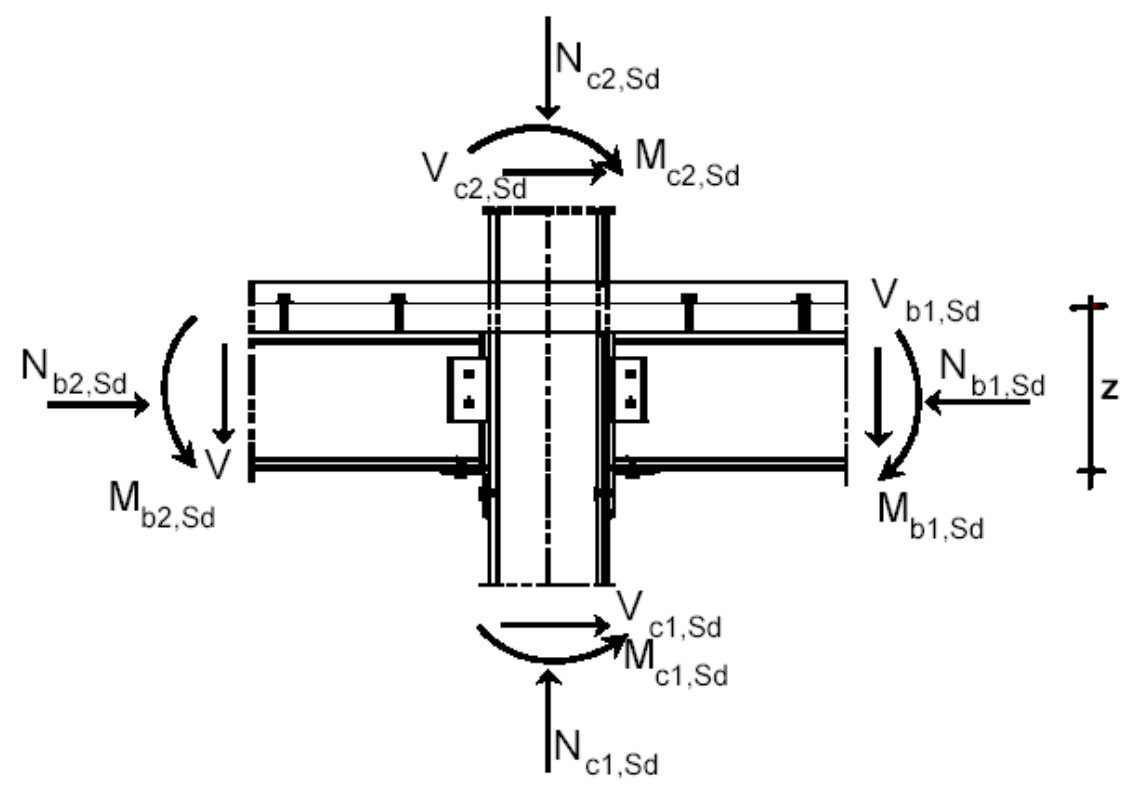

Figura 3.3: Solicitações atuantes na ligação mista.

Os momentos fletores provenientes das vigas introduzem ainda outro tipo de solicitação no painel da alma do pilar, denominado de cisalhamento horizontal. Tal solicitação também é dependente do carregamento proveniente do pilar, conforme ilustra a equação (19).

$$
V_{w p, S d}=\left(M_{b 1, S D}-M_{b 2, S d}\right) / z-\left(V_{c 1, S d}-V_{c 2, S d}\right) / 2
$$

Nas ligações com pilar de extremidade, o efeito do cisalhamento horizontal no painel de alma do pilar é bastante significativo, uma vez que todo o momento fletor proveniente da viga é transferido para o pilar e introduzido no painel. No caso de ligações com pilar interno, o efeito é aumentado proporcionalmente ao maior desbalanceamento dos momentos fletores das vigas.

O EUROCODE 3 (2005) introduz o efeito do cisalhamento horizontal no painel da alma do pilar por meio do parâmetro $\beta$, que leva em conta a magnitude de carregamento em ambos os lados do pilar (pilar interno) e a posição do pilar (interno ou de extremidade). Este parâmetro será detalhado no item 3.2.6. 
Conforme as solicitações que atuam na ligação (Figura 3.3), pode-se discriminar dois tipos de rotações numa ligação:

- Rotações provenientes das deformações dos elementos da ligação (mesa do pilar, chapa de topo, cantoneiras, parafusos, armadura, etc.) e da deformação por compressão na alma do pilar;

- Rotações (distorções) no painel da alma do pilar provocadas pela solicitação de cisalhamento horizontal.

Para ligações de nó interno com momentos balanceados, a distorção no painel de alma do pilar não vai ocorrer e, portanto, a rotação da ligação é exclusivamente devida às deformações dos elementos da ligação e à compressão na alma do pilar.

Num pórtico, essa rotação é considerada por meio de uma mola rotacional posicionada na extremidade da viga, representando a curva momento-rotação de toda ligação. O EUROCODE 3 (2005) permite como simplificação, considerar no caso de pilar de extremidade apenas uma mola rotacional por meio da soma das rotações devido aos elementos de ligação e do painel de alma do pilar.

No caso de pilar interno com momentos desbalanceados, cada extremidade de viga deve ser modelada com uma mola rotacional levando em consideração as rotações da sua respectiva ligação e do painel da alma do pilar. A Figura 3.4 ilustra ambos os casos.

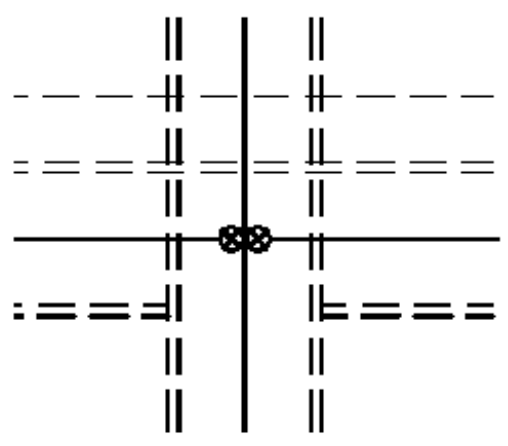

Nó interno

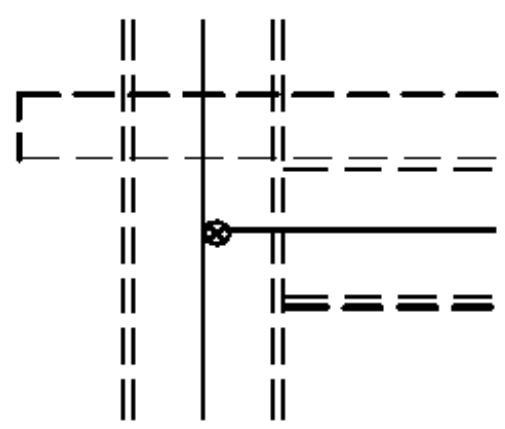

Nó de extremidade

Figura 3.4: Mola rotacional no nó interno e de extremidade. 
Dessa forma, a deformação na alma do pilar é considerada duas vezes, porém o parâmetro $\beta$ é introduzido para considerar a relação entre o carregamento no painel de alma do pilar e de cada ligação. As molas rotacionais para o nó interno e de extremidade introduzidas na interseção entre o eixo da viga com do pilar.

\subsection{3 - "T-Stub" equivalente}

A resistência e rigidez à flexão da mesa do pilar e da chapa de topo são determinadas pelo EUROCODE 3 (2005) a partir de um perfil "T" equivalente, em substituição da configuração de charneiras plásticas que se formam na redondeza dos parafusos tracionados.

O objetivo das pesquisas desses perfis "T-stub" foi estudar O comportamento das ligações que utilizavam o perfil "T" para conectar as mesas da viga com a mesa do pilar. Zoetemeijer \& Deback (1972) ensaiaram diversas configurações de perfil "T" e concluiu a existência de três diferentes modos de colapso, apresentados na Figura 3.5.

A capacidade resistente do perfil "T" para cada modo de colapso é apresentada na equação (20) e equação (22), assumindo que existe o desenvolvimento de força de alavanca $\mathrm{Q}$.

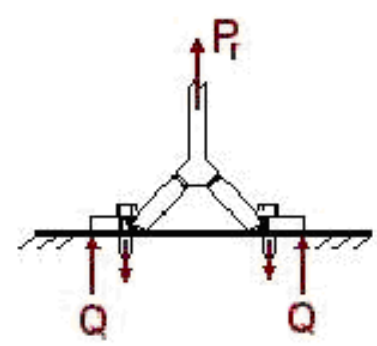

Modo 1

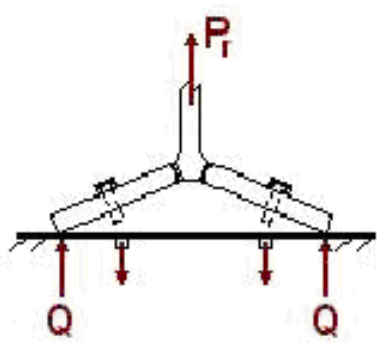

Modo 2

Ruptura do parafuso com escoamento da mesa

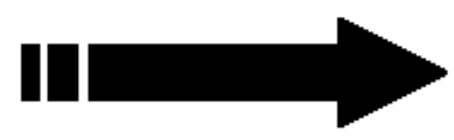

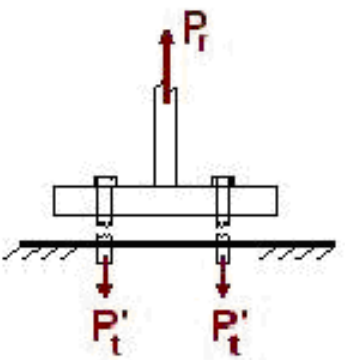

Modo 3

Ruptura dos parafusos

Chapa espessa

Parafuso com pequeno diâmetro

Figura 3.5: Modos de colapso do perfil "T-stub" - Maggi (2004). 
a) Modo 1: escoamento total da mesa do pilar ou da chapa de topo. A força de alavanca atinge seu fator máximo.

$$
F_{t, 1, R d}=\frac{4 \cdot M_{p l, 1, R d}}{m}
$$

b) Modo 2: ruptura do parafuso com escoamento do pilar ou da chapa de topo.

$$
F_{t, 2, R d}=\frac{2 \cdot M_{p l, 2, R d}+n \cdot \sum F_{t, R d}}{m+n}
$$

c) Modo 3: escoamento e ruptura isolada do parafuso, sem o desenvolvimento das forças de alavanca.

$$
F_{t, 3, R d}=\sum F_{t, R d}
$$

Onde:

m é a distância do centro do parafuso à da alma do pilar ou da viga, menos $80 \%$ do raio do perfil ou da dimensão da solda ( $a \sqrt{2}$ ), ilustrada na Figura 3.6. Para a linha de parafuso na extensão da chapa de topo, $m$ deve ser tomado como $\mathrm{m}_{\mathrm{x}}$.

$n$ é igual a $e_{\min }$ (Figura 3.6) e, no máximo igual a $1,25 \mathrm{~m}$. No caso de extensão da chapa de topo, $e_{\min }=e_{x}$.

$\sum F_{t, R d}$ é o somatório da resistência à tração do parafuso de uma linha ou de um grupo, apresentado na equação (23).

$$
F_{t, R d}=\frac{0,75 \cdot A_{b} \cdot f_{u}}{1,35}
$$

Onde:

$A_{b}$ é a área bruta do fuste do parafuso;

$f_{\mathrm{u}}$ é a resistência última a tração do aço do parafuso. 

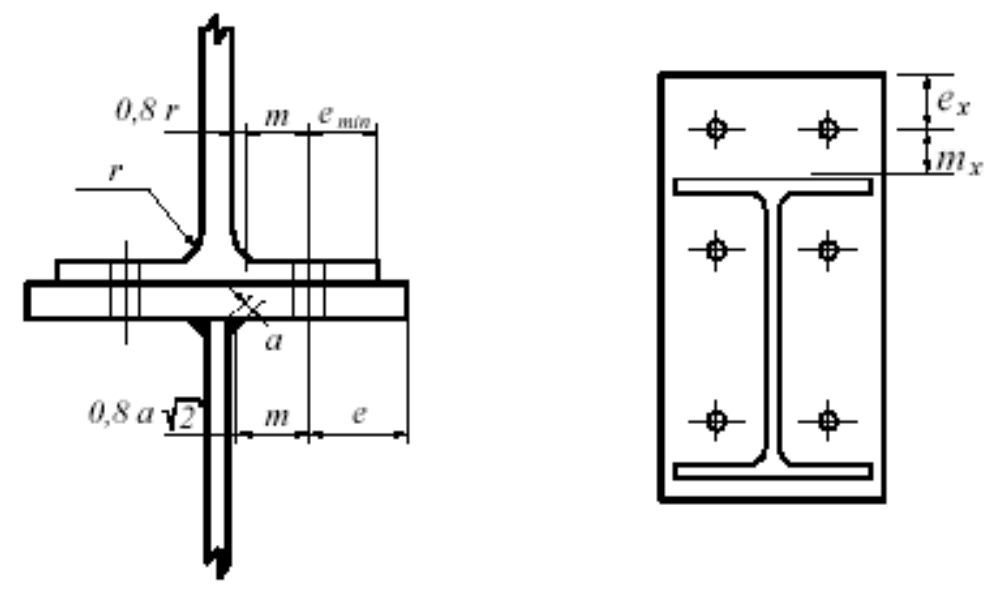

Figura 3.6: Parâmetros $m$ e e.

$M_{p l}$ é o momento de plastificação total do perfil " $T$ " equivalente, representando a mesa do pilar ou a chapa de topo, dado pela equação (24).

$$
M_{p l, 1}=\frac{\sum l_{e f f, 1} \cdot t^{2} \cdot \frac{f_{y}}{1,1}}{4} \text { e } M_{p l, 2}=\frac{\sum l_{e f f, 2} \cdot t^{2} \cdot \frac{f_{y}}{1,1}}{4}
$$

Onde:

t é a espessura da mesa do pilar ou da chapa de topo;

$f_{y}$ é a tensão de escoamento da mesa do pilar ou da chapa de topo;

$F_{t}$ é a capacidade resistente da linha ou grupo de linhas de parafusos;

$\sum l_{e f f, 1}$ e $\sum l_{e f f, 2}$ são o comprimento efetivo da linha de plastificação do perfil "T" equivalente (Figura 3.7), apresentado em forma de tabelas, de acordo com posição das linhas ou grupos de linhas de parafusos e da presença ou não de enrijecedores de alma do pilar ou da mesa da viga. Considerando uma linha de parafuso isoladamente, $\sum l_{\text {eff }, 1}=l_{\text {eff }, 1}$ e $\sum l_{\text {eff }, 2}=l_{e f f, 2}$, para os modos 1 e 2, respectivamente.

O EUROCODE 3 (2005) refere que o desenvolvimento das forças de alavanca acontecerá quando $L_{b} \leq L_{b}^{*}$ sendo $L_{b}$ a espessura da chapa de topo mais a espessura da mesa do pilar somada à metade da altura da cabeça e altura da porca, de acordo com equação (25). 


$$
L_{b}^{*}=\frac{8,8 \cdot m^{3} \cdot 0,75 \cdot A_{b}}{t_{f}^{3} \cdot \sum l_{\text {eff }, 1}}
$$

Onde

$\sum l_{\text {eff }, 1}$ é o valor do comprimento efetivo para o modo 1.

Caso não ocorra o desenvolvimento do efeito alavanca, as forças resistentes do perfil "T"são dadas pelas equações (26) e (27).

$$
\begin{aligned}
& F_{t, 12, R d}=\frac{2 \cdot M_{p l, 1, R d}}{m} \\
& F_{t, 3, R d}=\sum F_{t, R d}
\end{aligned}
$$
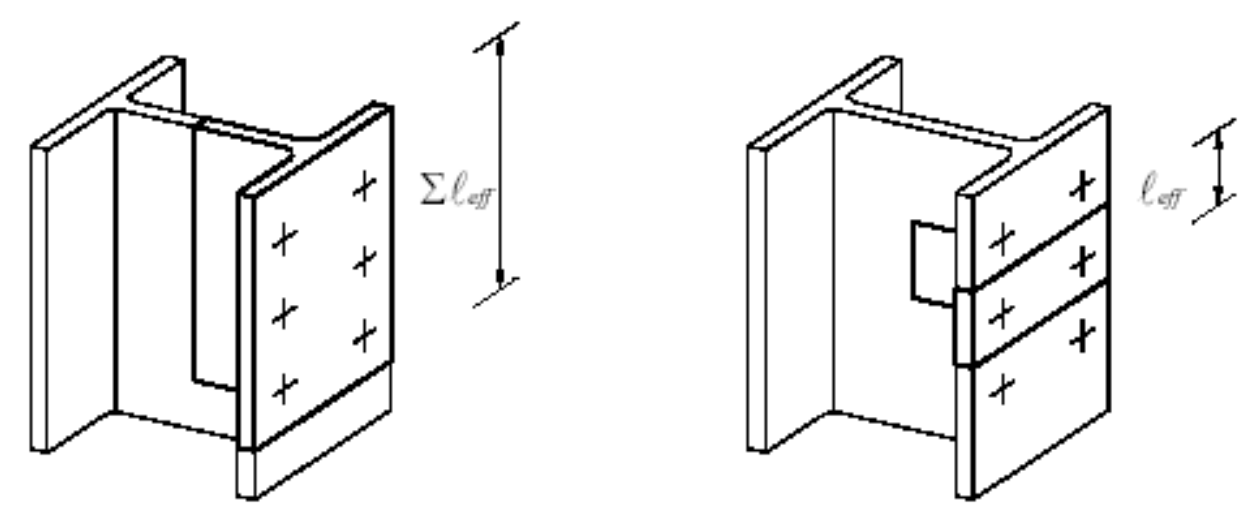

Figura 3.7: Comprimento efetivo de um perfil "T" equivalente para a análise de uma linha de parafuso isolada ou de grupo de linhas - COST-C1 (1996).

Zoetemeijer aput Romano (2001) estabeleceu os comprimentos efetivos equivalentes para que se pudesse utilizar a análise realizada no perfil "T" no cálculo da resistência da mesa do pilar ou da chapa de topo. O comprimento efetivo equivalente é dado pelo comprimento da mesa do perfil "T", sem enrijecimento, que transmite a mesma solicitação pela mesa do pilar ou chapa de topo, a partir das configurações de charneiras plásticas.

A linha de parafuso tracionado deve ser analisada isoladamente e também como parte de um grupo com as linhas anteriormente analisadas. 
$\mathrm{Na}$ análise da linha de parafuso atuando em grupo, a resistência será dada pelo menor valor obtido entre a resistência da linha de parafuso atuando isoladamente e a resistência das linhas anteriores antes da distribuição interna das forças calculadas para a ação isolada.

A Figura 3.8 ilustra o processo para determinar a capacidade das linhas de parafusos, considerando apenas a tração nos parafusos.

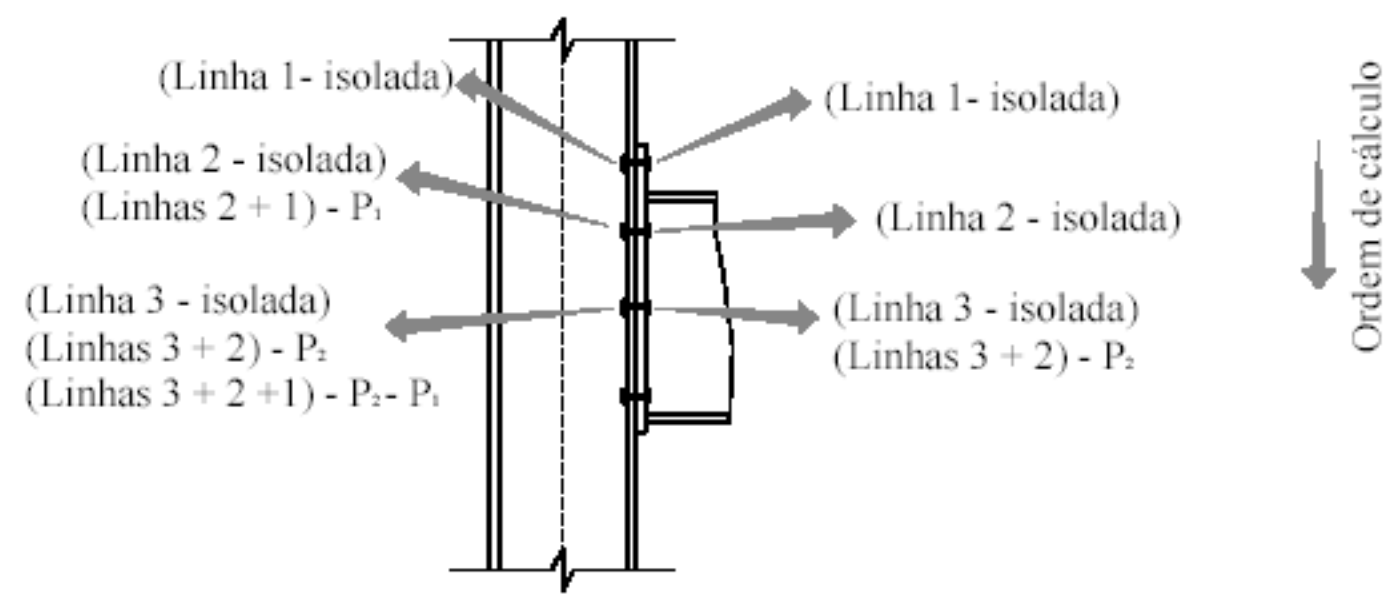

Flexão da mesa do pilar $\longrightarrow$ Flexão da chapa de topo

Figura 3.8: Ordem de verificação da capacidade resistente nas linhas de parafusos - Maggi (2004).

O enrijecedor de alma do pilar e a mesa da viga atuam como um divisor entre as linhas de parafusos para, respectivamente, os lados do pilar e da chapa de topo. A linha abaixo desses elementos não deverá ser considerada em combinação com qualquer outra linha situada acima deles. Maiores detalhes sobre as considerações do modelo "T-stub", bem como o desenvolvimento das equações referentes ao modo de colapso e desenvolvimento das forças de alavanca pode ser encontrado em Maggi (2004).

\subsection{4 - Componentes básicos tracionados}

\subsubsection{1 - Flexão na mesa do pilar}

A determinação do comprimento efetivo do perfil "T-stub" para a mesa do pilar não enrijecida é apresentada na Tabela 3.2 e Tabela 3.3, na qual 
aparecem os termos configuração circular e não circular que se referem às formas de charneiras plásticas que podem ocorrer na mesa do pilar ou na chapa de topo. Essas formas estão apresentadas na Figura 3.9.

Tabela 3.2: Comprimento efetivo para a mesa do pilar não enrijecida.

\begin{tabular}{|c|c|c|c|c|}
\hline \multirow[t]{2}{*}{$\begin{array}{l}\text { Linha de } \\
\text { parafuso }\end{array}$} & \multicolumn{2}{|c|}{$\begin{array}{l}\text { Linha de parafuso considerada } \\
\text { individualmente }\end{array}$} & \multicolumn{2}{|c|}{$\begin{array}{c}\text { Linha de parafuso considerada em } \\
\text { grupo }\end{array}$} \\
\hline & $\begin{array}{l}\text { Configuração } \\
\text { circular } l_{\text {eff }, c}\end{array}$ & $\begin{array}{c}\text { Configuração não-circular } \\
l_{e f f, n c}\end{array}$ & $\begin{array}{l}\text { Configuração } \\
\text { circular } l_{\text {eff }, c}\end{array}$ & $\begin{array}{l}\text { Configuração não- } \\
\text { circular } l_{e f f, n c}\end{array}$ \\
\hline Interna & $2 \pi m$ & $4 m+1,25 e$ & $2 p$ & $p$ \\
\hline Externa & $\begin{array}{c}\text { Mínimo } \\
\left(2 \pi m ; \pi m+2 \cdot e_{1}\right)\end{array}$ & $\begin{array}{c}\text { Mínimo } \\
\left(4 m+1,25 \cdot e ; 2 m+0,625 e+e_{1}\right)\end{array}$ & $\begin{array}{c}\text { Mínimo } \\
\left(\pi m ; 2 e_{1}+p\right)\end{array}$ & $\begin{array}{c}\text { Mínimo } \\
\left(2 m+0,625 \cdot e+p ; e_{1}+0,5 p\right)\end{array}$ \\
\hline Modo1 & \multicolumn{2}{|c|}{$l_{e f f, 1}=\operatorname{minimo}\left(l_{e f f, c} ; l_{e f f, n c}\right)$} & \multicolumn{2}{|c|}{$\sum l_{e f f, 1}=\operatorname{minimo}\left(\sum l_{e f f, c} ; \sum l_{e f f, n}\right)$} \\
\hline Modo2 & \multicolumn{2}{|r|}{$l_{e f f, 2}=l_{e f f, n c}$} & \multicolumn{2}{|c|}{$\sum l_{e f f, 2}=\sum l_{e f f, n c}$} \\
\hline
\end{tabular}

Tabela 3.3: Comprimento efetivo para a mesa do pilar enrijecida.

\begin{tabular}{|c|c|c|c|c|}
\hline \multirow[t]{2}{*}{$\begin{array}{l}\text { Linha de } \\
\text { parafuso }\end{array}$} & \multicolumn{2}{|c|}{$\begin{array}{l}\text { Linha de parafuso considerada } \\
\text { individualmente }\end{array}$} & \multicolumn{2}{|c|}{$\begin{array}{l}\text { Linha de parafuso considerada em } \\
\text { grupo }\end{array}$} \\
\hline & $\begin{array}{l}\text { Configuração } \\
\text { circular } l_{e f f, c}\end{array}$ & $\begin{array}{l}\text { Configuração não- } \\
\text { circular } l_{e f f, n c}\end{array}$ & $\begin{array}{l}\text { Configuração } \\
\text { circular } l_{\text {eff,c }}\end{array}$ & $\begin{array}{l}\text { Configuração não- } \\
\text { circular } l_{e f f, n c}\end{array}$ \\
\hline $\begin{array}{c}\text { Interna e } \\
\text { adjacente ao } \\
\text { enrijecedor }\end{array}$ & $2 \pi m$ & $\alpha m$ & $\pi m+p$ & $0,5 p+\alpha m-2 m-0,625 e$ \\
\hline $\begin{array}{l}\text { Interna e não } \\
\text { adjacente ao } \\
\text { enrijecedor }\end{array}$ & $2 \pi m$ & $2 m+1,25 e$ & $2 p$ & $p$ \\
\hline $\begin{array}{c}\text { Externa e } \\
\text { adjacente ao } \\
\text { enrijecedor }\end{array}$ & $\begin{array}{c}\text { Mínimo } \\
\left(2 \pi m ; \pi m+2 \cdot e_{1}\right)\end{array}$ & $e_{1}+\alpha m-(2 m+0,625 e)$ & $\begin{array}{l}\text { Não } \\
\text { considerar }\end{array}$ & Não considerar \\
\hline Modo1 & \multicolumn{2}{|c|}{$l_{\text {eff }, 1}=\operatorname{minimo}\left(l_{\text {eff }, c} ; l_{\text {eff }, n c}\right)$} & \multicolumn{2}{|c|}{$\sum l_{\text {eff }, 1}=\operatorname{minimo}\left(\sum l_{\text {eff }, c} ; \sum l_{\text {eff }, n c}\right)$} \\
\hline Modo2 & \multicolumn{2}{|c|}{$l_{e f f, 2}=l_{e f f, n c}$} & \multicolumn{2}{|c|}{$\sum l_{\text {eff }, 2}=\sum l_{\text {eff }, n c}$} \\
\hline & e duas linh & le parafusos & & \\
\hline
\end{tabular}

Os parâmetros para o cálculo do comprimento efetivo da ligação com chapa de topo é mostrado na Figura 3.10, para perfil laminado e soldado. 


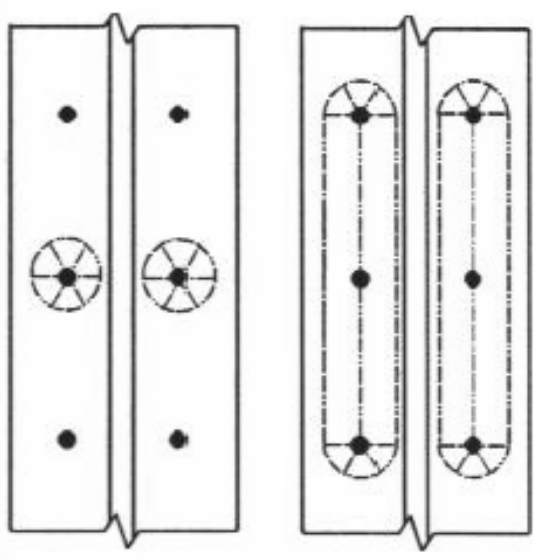

(a)
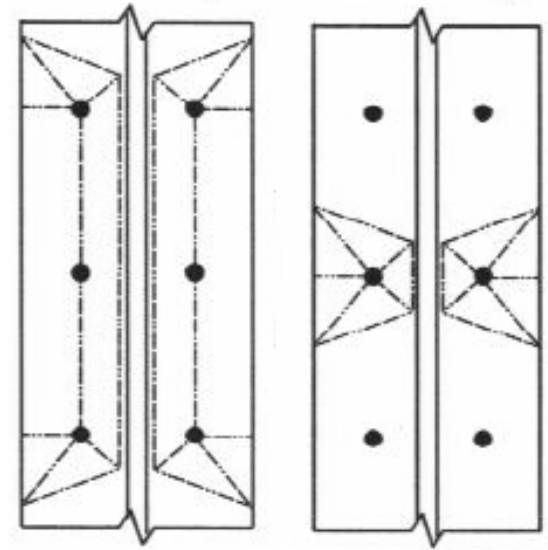

(b)

Figura 3.9: Configurações circulares (a) e não-circulares (b) de charneiras plásticas - Figueiredo (2004).

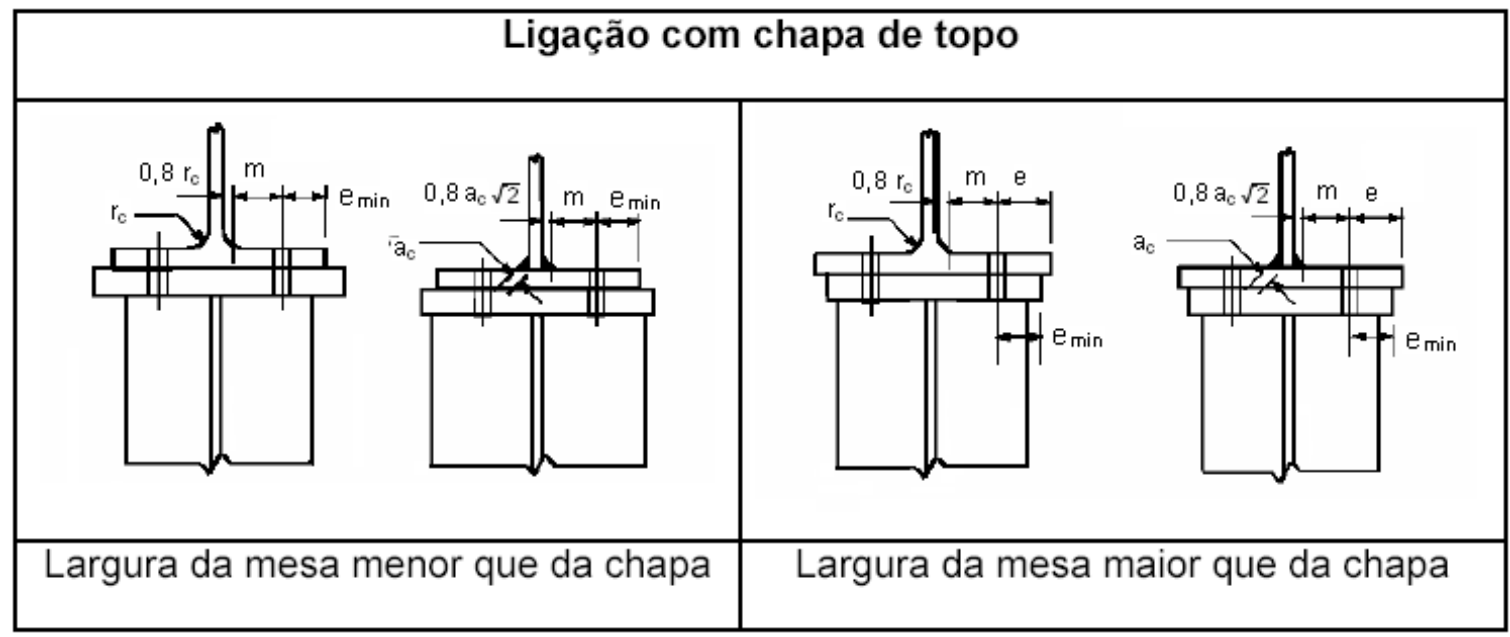

Figura 3.10: Parâmetros $e, e_{\min }$ e $m$.

Os valores de $\alpha$ na Tabela 3.2 e Tabela 3.3 são dados pelo ábaco Figura 3.11, a partir do cálculo de $\lambda_{1}$ e $\lambda_{2}$, onde:

$m_{1}$ é igual a $m ;$

$m_{2}$ é distância vertical do centro do parafuso à face do enrijecedor de alma do pilar, menos $80 \%$ da dimensão da solda entre a mesa do pilar e o enrijecedor. 


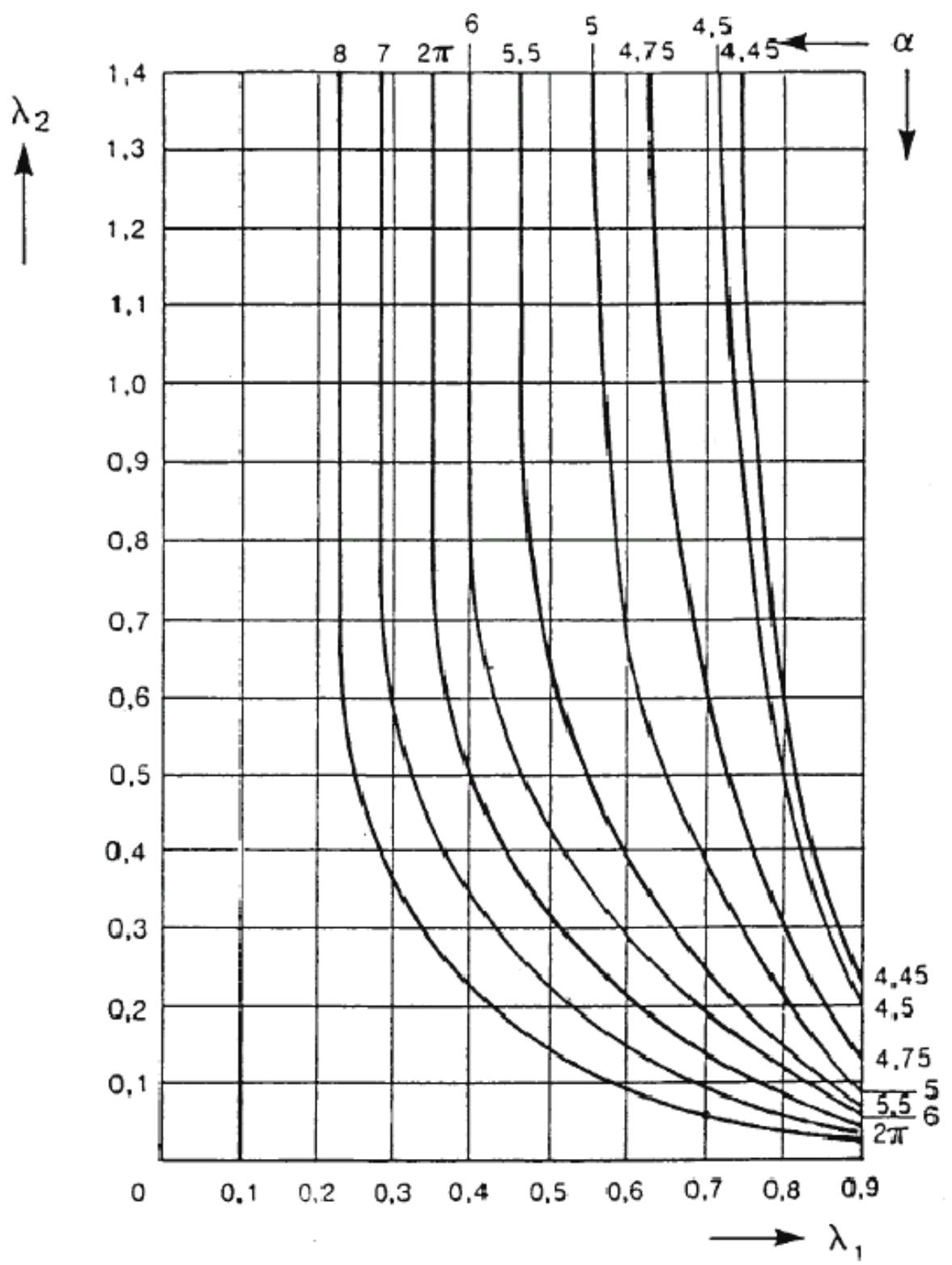

$$
\begin{aligned}
& \lambda_{1}=\frac{m_{1}}{m_{1}+e} \\
& \lambda_{2}=\frac{m_{2}}{m_{1}-e}
\end{aligned}
$$

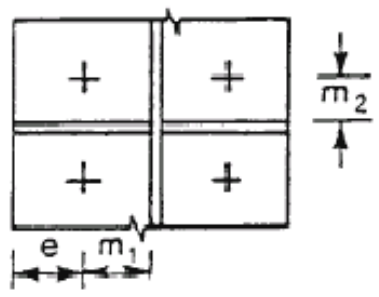

Figura 3.11: Valores $\alpha$ para mesa do pilar enrijecida e chapa de topo EUROCODE 3 (2005) - parte 1.8.

\subsubsection{2 - Tração na alma do pilar}

A resistência da alma do pilar não enrijecida submetida à tração é dada pela equação (28). 


$$
F_{t, w c, R d}=\omega \cdot b_{e f f, t, w c} \cdot t_{w c} \cdot \frac{f_{y, m c}}{1,1}
$$

Onde:

$\omega$ é o fator de redução devido a possíveis efeitos de interação com cisalhamento na alma, sendo calculado por meio da Tabela 3.4.

$b_{\text {eff,t,wc }}$ é comprimento efetivo do "T"-stub equivalente que se refere à flexão na mesa do pilar para ligações parafusadas.

Tabela 3.4: Parâmetro $\omega$.

\begin{tabular}{cc}
\hline Parâmetro $\beta$ & Fator de redução $\omega$ \\
\hline $0 \leq \beta<0,5$ & $\omega=1$ \\
\hline $0,5 \leq \beta<1,0$ & $\omega=\omega_{1}+2 \cdot(1-\beta) \cdot\left(1-\omega_{1}\right)$ \\
\hline$\beta=1,0$ & $\omega=\omega_{1}+2 \cdot(\beta-1) \cdot\left(\omega_{2}-\omega_{1}\right)$ \\
\hline $1,0<\beta<2,0$ & $\omega=\omega_{2}$ \\
\hline$\omega_{1}=\frac{1}{\sqrt{1+1,3 \cdot\left(\frac{b_{\text {eff,c,wc }} \cdot t_{w c}}{A_{v c}}\right)^{2}}}$ & $\omega_{2}=\frac{1}{\sqrt{1+5,2 \cdot\left(\frac{b_{\text {eff }, c, w c} \cdot t_{w c}}{A_{v c}}\right)^{2}}}$ \\
\hline
\end{tabular}

Onde:

$A_{v c}$ é a área da alma do pilar sob cisalhamento, equações (29) e (30).

$\beta$ é o parâmetro que considera o efeito do cisalhamento horizontal na alma do pilar (item 3.2.6).

$$
\begin{aligned}
& A_{v c}=A_{c}-2 \cdot b_{f c} \cdot t_{f c}+\left(t_{w c}+2 \cdot r_{c}\right) / t_{f c} \quad \text { (perfis laminados) } \\
& A_{v c}=h_{w c} \cdot t_{w c} \quad \text { (perfis soldados) }
\end{aligned}
$$

\subsubsection{3 - Tração na alma da viga}

A resistência à tração da alma da viga é obtida pela equação (31).

$$
F_{t, w b, R d}=b_{e f f, t, w b} \cdot t_{w b} \cdot \frac{f_{y, w b}}{1,1}
$$


Onde:

$b_{\text {eff,t,wb }}$ é o comprimento efetivo do "T-stub" equivalente que se refere à flexão da chapa de topo, obtido para linha de parafuso individual ou em grupo.

\subsubsection{4 - Flexão na chapa de topo}

Embora o presente trabalho se restrinja apenas as ligações com cantoneira de alma e assento, a verificação da flexão da chapa de topo se faz necessária, uma vez que para a determinação da resistência da componente flexão na aba da cantoneira de alma, considera-se a resistência do "T"-stub tomando comprimentos equivalentes $\left(l_{\text {eff }}\right)$.

A resistência de cada linha tracionada para a flexão da chapa de topo é semelhante ao procedimento para flexão na mesa do pilar.

A Tabela 3.5 apresenta os procedimentos para a determinação do comprimento equivalente para flexão da chapa de topo, adotando as seguintes considerações:

- o parâmetro $e_{\min }$ da Figura 3.10 deverá ser usado para a parte da chapa compreendida entre as mesas da viga. Para extensão da chapa o $\theta_{\min }$ é igual a $\theta x$ (Figura 3.12);

- na extensão da chapa os valores de $(e)$ e $(m)$ devem ser substituídos por $\left(e_{x}\right)$ e $\left(m_{x}\right)$.
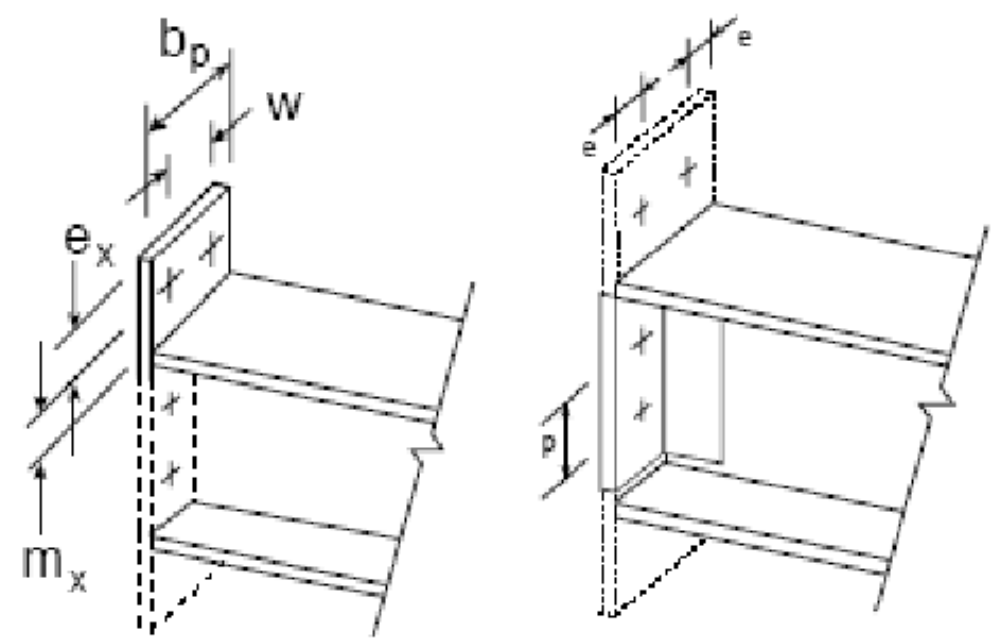

Figura 3.12: Parâmetros para flexão da chapa de topo - Tristão (2006). 
Tabela 3.5: Comprimento efetivo para flexão da chapa de topo.

\begin{tabular}{|c|c|c|c|c|}
\hline \multirow[t]{2}{*}{$\begin{array}{l}\text { Linha de } \\
\text { parafuso }\end{array}$} & \multicolumn{2}{|c|}{$\begin{array}{l}\text { Linha de parafuso considerada } \\
\text { individualmente }\end{array}$} & \multicolumn{2}{|c|}{$\begin{array}{c}\text { Linha de parafuso considerada } \\
\text { em grupo }\end{array}$} \\
\hline & $\begin{array}{l}\text { Configuração } \\
\text { circular } l_{e f f, c}\end{array}$ & $\begin{array}{l}\text { Configuração não-circular } \\
\qquad l_{e f f, n c}\end{array}$ & $\begin{array}{l}\text { Configuração } \\
\text { circular } l_{e f f, c}\end{array}$ & $\begin{array}{l}\text { Configuração não- } \\
\text { circular } l_{e f f, n c}\end{array}$ \\
\hline $\begin{array}{l}\text { Acima da } \\
\text { mesa } \\
\text { tracionada } \\
\text { da viga }\end{array}$ & $\begin{array}{c}\text { Mínimo } \\
2 \pi m_{x} \\
\pi m_{x}+w \\
\pi m_{x}+2 \cdot e\end{array}$ & $\begin{array}{c}\text { Mínimo } \\
4 \cdot m_{x}+1,25 \cdot e_{x} \\
e+2 \cdot m_{x}+0,625 \cdot e_{x} \\
0,5 \cdot b_{p} \\
0,5 \cdot w+2 \cdot m_{x}+0,625 \cdot e_{x}\end{array}$ & $\begin{array}{l}\text { não } \\
\text { considerar }\end{array}$ & não considerar \\
\hline $\begin{array}{c}1^{\mathrm{a}} \text { linha } \\
\text { abaixo da } \\
\text { mesa } \\
\text { tracionada } \\
\text { da viga }\end{array}$ & $2 \pi m$ & $\alpha \cdot m$ & $\pi m+p$ & $0,5 p+\alpha m-2 m-0,625 e$ \\
\hline $\begin{array}{l}\text { Interna e } \\
\text { não } \\
\text { adjacente } \\
\text { à mesa } \\
\text { tracionada }\end{array}$ & $2 \pi m$ & $4 \cdot m+1,25 \cdot p$ & $2 \cdot p$ & $p$ \\
\hline Modo1 & $l_{\text {eff }, 1}=$ & $\operatorname{minimo}\left(l_{e f f, c} ; l_{\text {eff,nc }}\right)$ & $\sum l_{e f f, 1}=\operatorname{mir}$ & $\operatorname{no}\left(\sum l_{e f f, c} ; \sum l_{e f f, n c}\right)$ \\
\hline Modo2 & & $l_{\text {eff }, 2}=l_{\text {eff }, n c}$ & & ${ }_{, 2}=\sum l_{e f f, n c}$ \\
\hline$\alpha$ éo & ura 3.11 & & & \\
\hline
\end{tabular}

\subsubsection{5 - Tração na armadura longitudinal da laje}

A área efetiva a ser considerada na resistência a tração da armadura longitudinal é aquela que está na região da área efetiva da laje de concreto.

A resistência da armadura nas ligações com pilares de extremidade ou pilares internos com momentos balanceados, considerando que a viga mista tem interação completa na região de momento negativo, é dada pela equação (32).

$$
F_{r, R d}=A_{s, r} \cdot \frac{f_{y, r}}{1,15}
$$


Onde:

$A_{s, r}$ é a área efetiva de armadura;

$f_{y, r}$ é a tensão de plastificação do aço da armadura.

Para pilares internos com momentos desbalanceados, onde haverá diferenças de forças nas armaduras em cada lado do pilar, a força na armadura será mantida em equilíbrio na ligação se a laje de concreto no lado de menor momento estiver necessariamente em contato com a mesa do pilar.

Nethercot (1996b) afirma que a força de contato entre a laje de concreto e a mesa do pilar é igual à diferença entre as forças nas armaduras de cada lado da ligação. Dessa forma, pode-se determinar a resistência da armadura por meio da equação (33).

$$
F_{r, R d}=F_{r 2}+F_{c o n}
$$

Onde:

$F_{r 2}$ é a força na armadura do lado oposto à ligação em análise;

$F_{c o n}$ é a resistência ao esmagamento da laje de concreto devido ao contato com a mesa do pilar.

A parcela $F_{r 2}$ sempre se refere ao lado da ligação com menor momento atuante e, também se admite que o momento resistente desse lado seja obtido considerando somente a resistência da armadura $\left(F_{r 2}\right)$ e da mesa comprimida da viga. Dessa forma, $F_{r 2}$ é obtido em função do momento atuante e do braço de alavanca.

A equação (34) fornece o valor de $F_{r, R d}$ desenvolvido por Yogi aput Nethercot (1996b) a partir da equação (32). Assim, a resistência na armadura deve ser a menor dada por essas duas equações.

$$
F_{r, R d}=\frac{M_{c 2}}{L_{r}}+0,67 \cdot \beta \cdot b_{f c} \cdot h_{c l} \cdot \frac{f_{c}}{\gamma_{c}}
$$


Onde:

$M_{c 2}$ é o momento atuante no lado de menor momento da ligação;

$L_{r}$ é a distância da armadura ao centro de compressão da ligação;

$\beta$ é o fator de resistência à compressão local do concreto, podendo ser tomado de forma conservadora igual a 2;

$b_{f c}$ é a largura da mesa do pilar;

$h_{c l}$ é a altura da laje de concreto, sendo que somente a capa de concreto deve ser considerada em laje mista;

$f_{c}$ é a resistência a compressão do concreto;

$\gamma_{c}$ é o coeficiente de segurança do concreto.

\subsection{5 - Componentes individuais de compressão}

\subsubsection{1 - Compressão transversal na alma do pilar}

A resistência à compressão transversal da alma do pilar é dada pela equação (35).

$$
F_{c, w c, R d}=\omega \cdot k_{w c} \cdot \rho \cdot b_{e f f, c, w c} \cdot t_{w c} \cdot \frac{f_{y, w c}}{\gamma_{c}}
$$

Onde:

$\omega$ é o fator de redução devido a possíveis efeitos de iteração com cisalhamento na alma, sendo obtido segundo a Tabela 3.4;

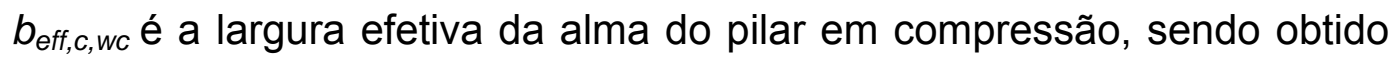
segundo a equação (36), para ligações com cantoneira de assento;

$b_{e f f, c, w c}=2 \cdot t_{a}+0,6 \cdot r_{a}+5 \cdot\left(t_{f c}+s\right)$

$a_{c}$ é a solda de composição do pilar;

$s=r_{c}$ para pilares de seção laminada;

$s=\sqrt{2 \cdot a_{c}}$;

$t_{f b}$ é a espessura da mesa comprimida da viga;

$t_{f C}$ é a espessura da mesa do pilar;

$t_{a}$ é a espessura da cantoneira de assento;

$r_{a}$ é o raio de curvatura da cantoneira de assento; 
$\rho$ é o fator de redução devido à flambagem da chapa, tomado igual a 1 para ligações com cantoneira.

$k_{w c}$ é o parâmetro que considera o efeito da tensão longitudinal na alma do pilar ( $\sigma_{\text {comp,Ed }}$ ) devido a força axial e o momento fletor do pilar, conforme mostra a equação (37) representado na Figura 3.13.

$$
\begin{gathered}
1,7-\frac{\sigma_{\text {comp }, E d}}{f_{y, w c}} \rightarrow \sigma_{c o m p, E d}>0,7 \cdot f_{y, w c} \\
1,7-\frac{\sigma_{c o m p, E d}}{f_{y, w c}} \rightarrow \sigma_{c o m p, E d}>0,7 \cdot f_{y, w c}
\end{gathered}
$$
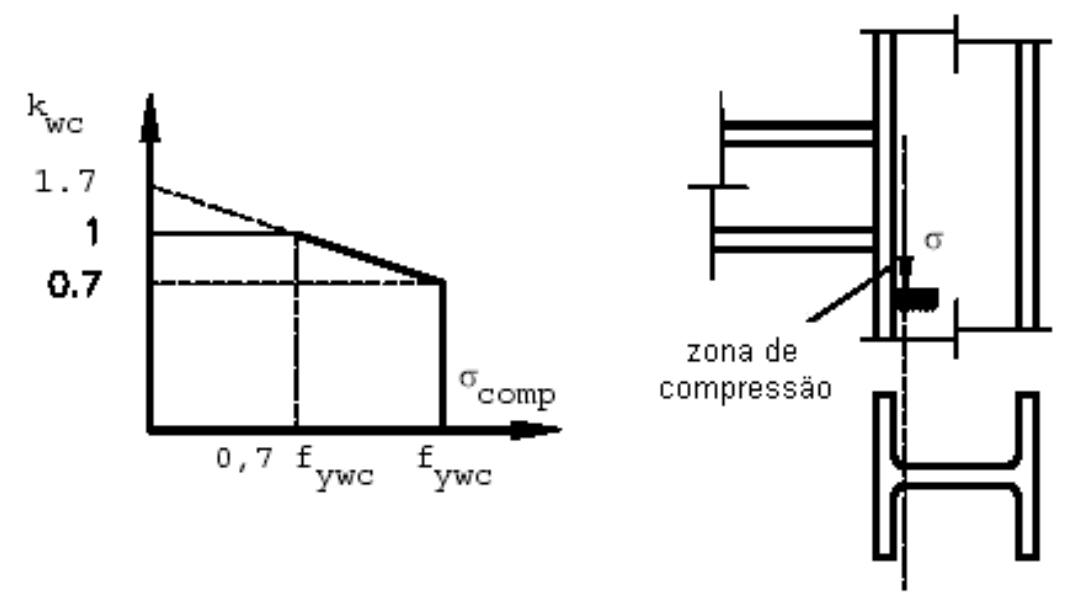

Figura 3.13: Gráfico para os valores de $k_{w c}$.

O fator $k_{w c}$ varia de 0,7 a 1 , portanto, na primeira análise da estrutura deve-se adotar o valor de 1 e depois verificar se a tensão de compressão longitudinal no pilar é maior que $70 \%$ da tensão de escoamento da alma do pilar $\left(f_{y, w c}\right)$.

Os parâmetros para o cálculo da largura efetiva da alma do pilar de seção laminada e soldada para ligações com cantoneira de assento são mostrados na Figura 3.14. 


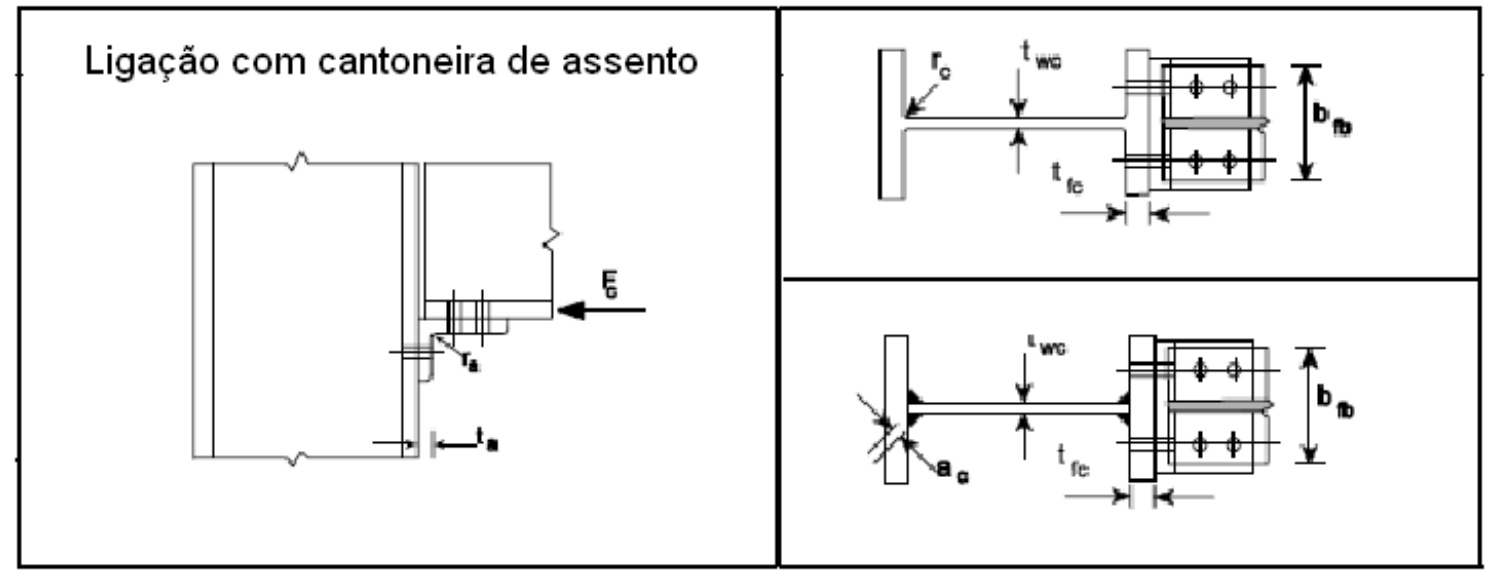

Figura 3.14: Parâmetros para o cálculo da largura efetiva da alma do pilar a compressão.

\subsubsection{2 - Compressão na mesa e alma da viga}

A equação (38) apresenta a resistência à compressão da mesa da viga e da parte da alma comprimida. Essa força atua no centro de compressão da ligação.

$$
F_{t, f n, R d}=\frac{M_{c, R d}}{\left(h-t_{f b}\right)}
$$

Onde:

$h$ é altura da viga conectada;

$M_{c, R d}$ é o momento resistente da seção transversal da viga isolada;

$t_{f b}$ é a espessura da mesa comprimida da viga.

\subsubsection{3 - Compressão na aba da cantoneira de assento}

A resistência à compressão da aba da cantoneira de assento conectada a mesa da viga é dada pela equação (39).

$F_{c, B A, R d}=b_{L} \cdot t_{L} \cdot \frac{f_{y}}{1,1}$

Onde:

$b_{L}$ é o comprimento da aba da cantoneira conectada a viga;

$f_{L}$ é a espessura da aba da cantoneira conectada a viga. 


\subsection{6 - Componente individual em cisalhamento horizontal}

A deformação da alma do pilar ocorre devido às solicitações de cisalhamento, resultado da combinação da força de cisalhamento horizontal, proveniente do binário de forças, que surgem nas mesas da viga e das forças de cisalhamento no pilar acima e abaixo da ligação, provenientes da análise global da estrutura.

Como simplificação, pode-se determinar a força de cisalhamento horizontal que atua no painel da alma $\left(V_{w p}\right)$ como o produto da força $F$ pelo parâmetro $\beta$, como apresentado na Figura 3.15 para situação de pilar interno e externo.

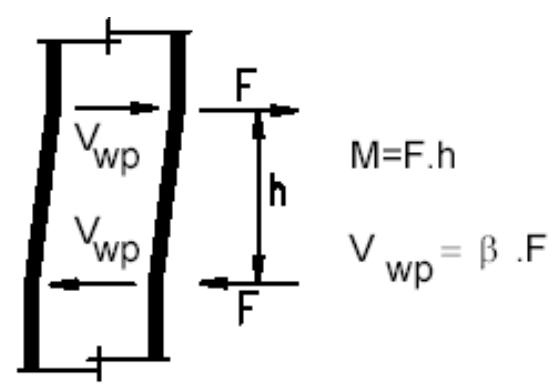

(a) pilar de extremidade

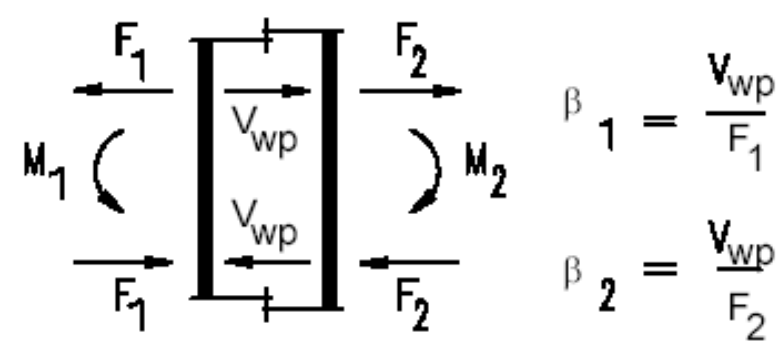

(b) Pilar interno

Figura 3.15: Força de cisalhamento no painel da alma do pilar.

O parâmetro $\beta$ pode ser obtido por meio das equações (40) e (41) para cada lado do pilar, porém sua utilização em projetos demanda iterações, uma vez que seria necessário conhecer os momentos fletores atuando em cada lado do pilar. Para evitar este processo, a Tabela 3.6 apresenta os valores de $\beta$ que poderiam ser utilizados para os casos correntes em projeto.

$$
\begin{aligned}
& \beta_{1}=\left|1-\frac{M_{2}}{M_{1}}\right| \leq 2 \\
& \beta_{2}=\left|1-\frac{M_{1}}{M_{2}}\right| \leq 2
\end{aligned}
$$


Onde:

$M_{1}$ é o momento de interseção da viga com o pilar pelo lado esquerdo;

$M_{2}$ é o momento de interseção da viga com o pilar pelo lado direito;

Tabela 3.6: Valor simplificado de $\beta$ para três casos típicos

\begin{tabular}{c}
$\begin{array}{c}\text { Configuração da ligação e } \\
\text { carregamento }\end{array}$ \\
\hline \\
\hline
\end{tabular}

Para o caso de pilar de extremidade, a força de cisalhamento horizontal proveniente do momento fletor da viga é significativa, devendo ser considerado. No caso de pilar interno com momentos desbalanceados, a magnitude da força de cisalhamento horizontal depende da diferença entre momentos fletores.

A resistência ao cisalhamento da alma do pilar não enrijecida, para ligações com pilar de extremidade ou pilar interno que tenham vigas conectadas de mesma altura, é fornecida pela equação (42). Esse procedimento só é válido quando $\frac{d}{t_{w}} \leq 0,9 \cdot \sqrt{\frac{235}{f_{y w}}}$, sendo $f_{y w}$ em MPa, na qual o fator de redução 0,9 considera a tensão longitudinal de compressão no pilar. 


$$
V_{w p, R d}=\frac{0,69 \cdot A_{v c} \cdot \frac{f_{y, w c}}{1,1}}{\sqrt{3}}
$$

Onde:

$$
\begin{aligned}
& A_{v c}=A_{c}-2 \cdot b_{f c} \cdot t_{f c}+\left(t_{w c}+2 \cdot r_{c}\right) \cdot t_{f c} \text { para perfis laminados; } \\
& A_{v c}=t_{w c} \cdot h_{w c} \text { para perfis soldados. }
\end{aligned}
$$

Essa resistência pode ser aumentada através da utilização de enrijecedores transversais nas zonas de tração e compressão. A equação (43) apresenta a determinação dessa resistência adicional quando se utiliza enrijecedores.

$$
V_{w p, a d d, R d} \leq\left\{\begin{array}{l}
\frac{4 \cdot M_{p l, f c, R d}}{d_{s}} \\
\frac{2 \cdot M_{p l, f c, R d}+2 \cdot M_{p l, s t, R d}}{d_{s}}
\end{array}\right.
$$

Onde:

$d_{s}$ é a distância entre as linhas de centro de enrijecedores;

$M_{p l, f c, R d}$ é o momento resistente plástico da mesa do pilar em relação ao menor eixo de inércia $(Z$.fy);

$M_{p l, s t, R d}$ é o momento resistente plástico do enrijecedor em relação ao maior eixo de inércia $\left(Z_{\text {.fy }}\right)$.

\subsection{7 - Determinação do momento resistente}

O procedimento, apresentado neste trabalho, para o cálculo do momento resistente da ligação considera que a viga está submetida a momento fletor e força cortante, não abrangendo, dessa forma, as situações onde a força axial na viga excede $5 \%$ da resistência plástica da seção transversal (0,9.A. $\left.f_{y}\right)$.

No caso de ligações com chapa de topo, a solda entre a chapa de topo e a viga não limita o momento resistente da ligação, sendo portando calculada a parte. 
O momento resistente da ligação é calculado com base na distribuição das forças internas na ligação, obtidas através da resistência potencial de cada componente individual. As forças internas de compressão estão localizadas no centro de compressão da ligação, enquanto que as forças internas de tração estão nas linhas de armadura e dos parafusos tracionados mais distantes do centro de compressão.

A distribuição das forças internas de tração plástica é adotada ao invés da distribuição elástica triangular, em relação ao centro de compressão da ligação. Assim, as linhas em regiões mais enrijecidas assumem maior parcela de força. Os tipos de distribuição das forças internas de tração estão ilustrados na Figura 3.16.

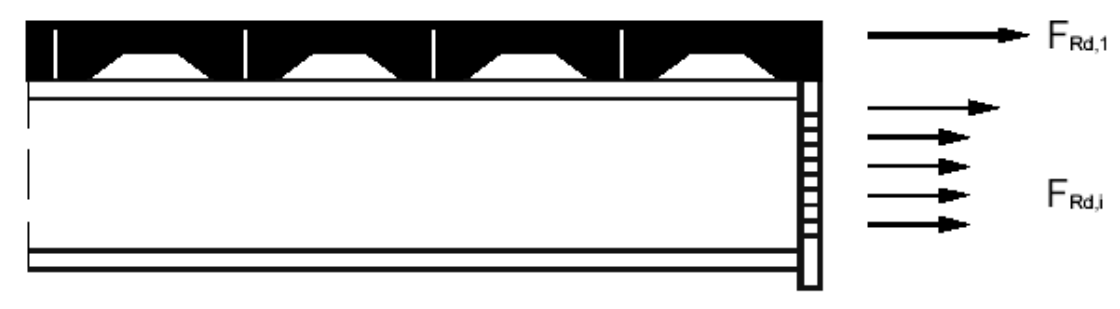

Distribuição plástica das forças internas de tração

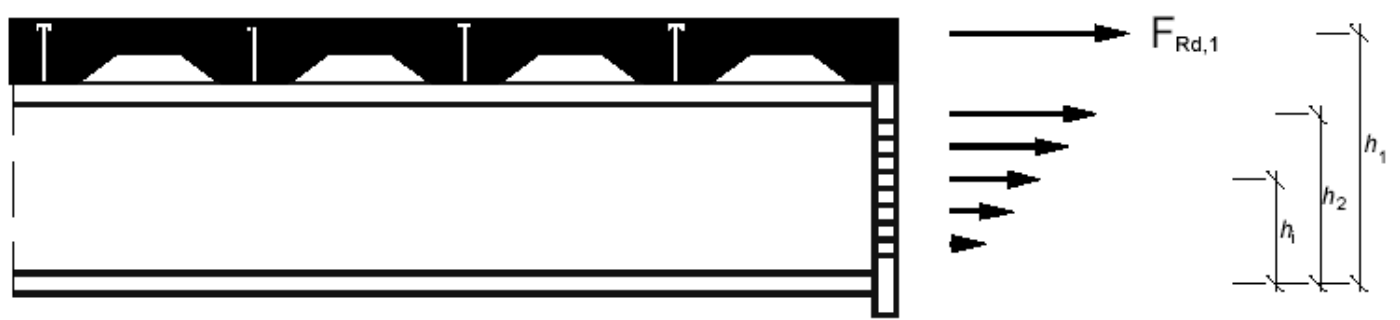

Distribuição elástica das forças internas de tração

Figura 3.16: Forma de distribuição das forças internas de tração.

Para o cálculo do momento resistente plástico de uma ligação mista, considerando a redistribuição plástica das forças internas de tração, são adotados os seguintes critérios:

- As forças internas estão em equilíbrio com as forças aplicadas na ligação;

- A resistência e capacidade de deformação de cada componente não são excedidas; 
- A compatibilidade de deslocamentos é desprezada.

A força na armadura longitudinal é considerada como mais uma linha tracionada, podendo assim adotar o procedimento do EUROCODE 3 (2005). Portanto, para ligações onde existem duas ou mais linhas tracionadas (considerando a armadura), o momento resistente da ligação é dado pela equação (44).

$$
M_{j, R d}=F_{r, R d} \cdot L_{r}+\sum F_{t r, R d} \cdot h_{r}
$$

Onde:

$F_{r, R d}$ é a resistência da linha da armadura;

$L_{r}$ é a distância da linha da armadura ao centro de compressão que está situado na linha de centro da mesa comprimida;

$F_{t r, R d}$ é a resistência efetiva da linha de parafuso $r$;

$h_{r}$ é a distância da linha de parafuso $r$ ao centro de compressão;

r é o número de uma linha tracionada específica.

Para as ligações viga mista-pilar com cantoneiras de alma e assento, além da armadura é também considerada a contribuição das linhas de parafusos na cantoneira de alma. A Figura 3.17 ilustra essa consideração.

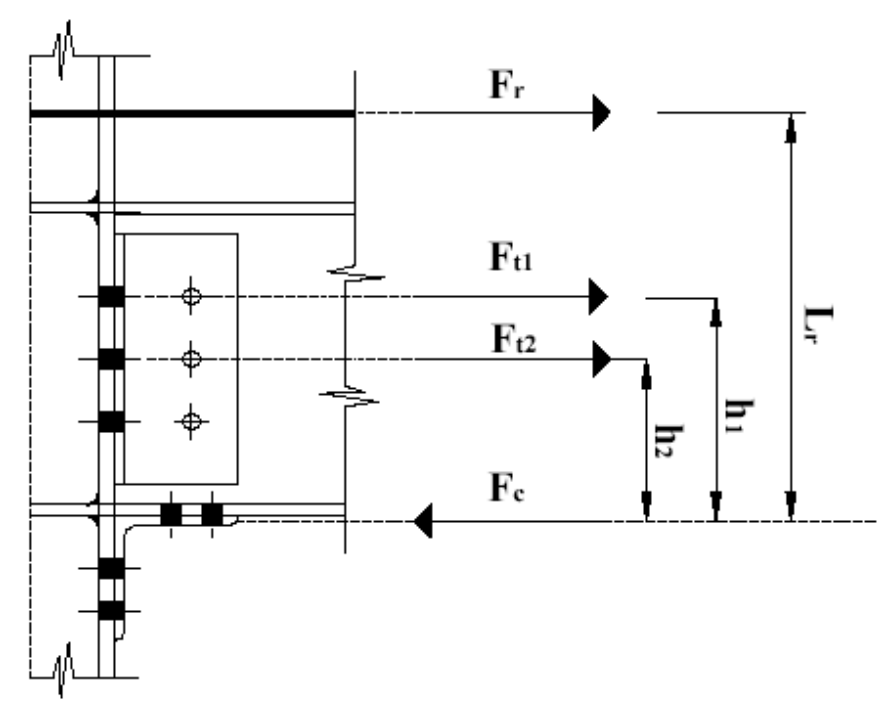

Figura 3.17: Distribuição da forças internas das ligações com cantoneiras. 
A resistência potencial à tração de uma linha de parafuso $\left(F_{t r, R d}\right)$ na cantoneira de alma é a menor resistência das componentes individuais abaixo:

- flexão na mesa do pilar;

- tração na alma do pilar;

- tração na alma da viga;

- flexão na aba de cantoneira de alma (cantoneira fixada à mesa do pilar).

No cálculo da resistência da componente flexão na aba da cantoneira de alma considera-se a resistência do "T"-stub tomando comprimentos equivalentes $\left(l_{\text {eff }}\right)$, da mesma forma como é feito para a flexão na chapa de topo. O EUROCODE 3 (2005) não faz nenhuma menção a componente referente à flexão da aba da cantoneira de alma.

A resistência potencial da linha tracionada deve ser reduzida caso a somatória das linhas tracionadas, incluindo a armadura, seja maior que a resistência da alma do pilar ao cisalhamento ou maior que a resistência da componente comprimida. Nesse caso, é considerado que a distribuição plástica das forças internas é interrompida devido à resistência à compressão.

A redução da resistência potencial da linha deve iniciar-se de baixo para cima, ou seja, da linha r para a linha de armadura. Tal procedimento é tomado para garantir o equilíbrio das forças internas na ligação, devendo satisfazer a equação (45).

$$
F_{r, R d}+\sum F_{t r, R d} \leq F_{c, R d}
$$

Onde:

$F_{C, R d}$ é o menor valor entre a resistência da alma do pilar em compressão $\left(F_{c, w c, R d}\right)$, a resistência à compressão da mesa e alma da viga $\left(F_{c, f n, R d}\right)$, resistência à compressão da aba da cantoneira fixada na mesa da viga e a resistência ao cisalhamento do painel da alma do pilar $\left(\frac{V_{w p, R d}}{\beta}\right)$. 
Nas ligações com cantoneiras de alma e assento, a resistência ao cisalhamento dos parafusos que conectam a cantoneira de assento com a mesa da viga deve ser maior que a força de compressão $F_{c, R d}$.

Caso não seja atendida a equação (45), o procedimento de cálculo descrito abaixo deve ser adotado para a redução da resistência potencial das linhas tracionadas. Esse procedimento é o mesmo considerado para o caso de ligações com chapa de topo com três linhas tracionadas (Figura 3.18).

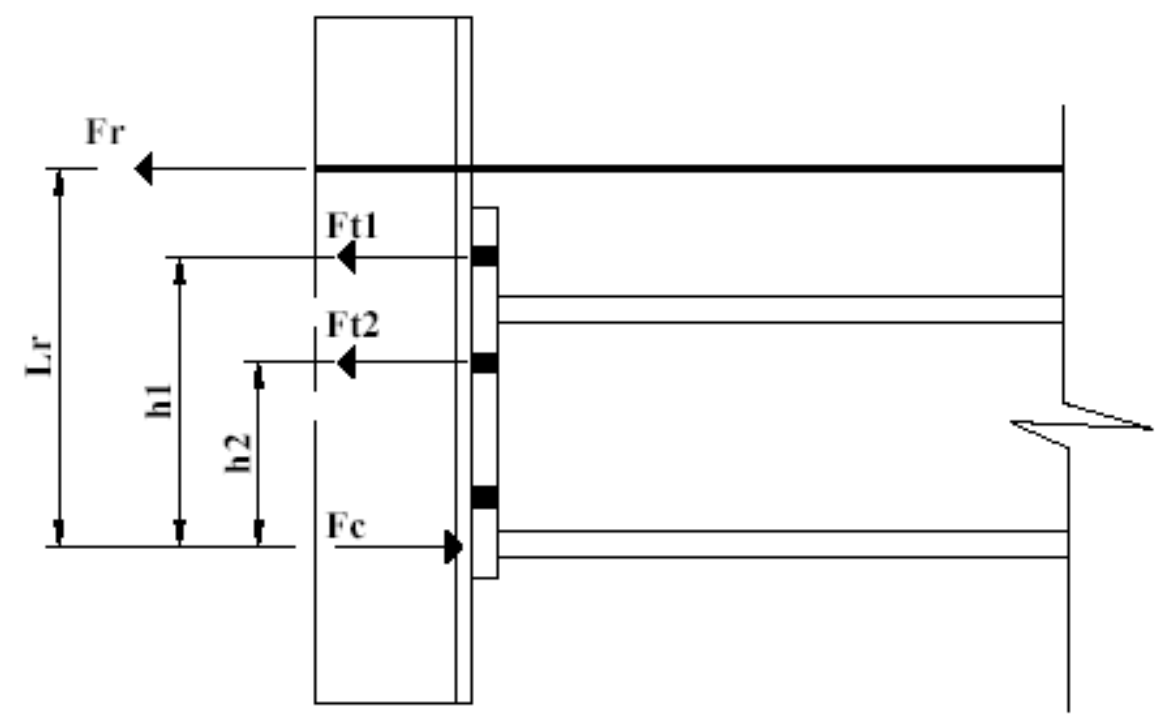

Figura 3.18: Distribuição das forças internas para ligações com chapa de topo estendida (3 linhas tracionadas).

Se $F_{r, R d}+F_{t 1, R d}+F_{t 2, R d}>F_{c, R d}$ :

$d F=F_{r, R d}+F_{t 1, R d}+F_{t 2, R d}-F_{c, R d}$

Então:

Se $d F \leq F_{t 2, R d} \Rightarrow\left\{\begin{array}{l}F_{r, R d} *=F_{r, R d} \\ F_{t 1, R d} *=F_{t 1, R d} \\ F_{t 2, R d} * F_{t 2, R d}-d F\end{array}\right.$

Se $F_{t 1, R d}+F_{t 2, R d} \leq d F>F_{t 2, R d} \Rightarrow\left\{\begin{array}{l}F_{r, R d} *=F_{r, R d} \\ F_{t 1, R d} *=F_{t 1, R d}-\left(d F-F_{t 2, R d}\right) \\ F_{t 2, R d} *=0\end{array}\right.$ 
Se $d F>F_{t 1, R d}+F_{t 2, R d} \Rightarrow\left\{\begin{array}{l}F_{r, R d} *=F_{c, R d} \\ F_{t 1, R d} * 0 \\ F_{t 2, R d} * 0\end{array}\right.$

Portanto: $M_{j, R d}=F_{r, R d} \cdot L_{r}+F_{t 1, R d} \cdot h_{1}+F_{t 2, R d} \cdot h_{2}$

Onde:

$F_{r, R d}{ }^{*}$ é a força na linha de armadura após a redução;

$F_{t 1, R d}{ }^{*}$ é a força na linha de parafuso 1 após a redução;

$F_{t 2, R d}{ }^{*}$ é a força na linha de parafuso 2 após a redução.

\subsection{8 - Determinação da rigidez inicial da ligação}

A rigidez inicial da ligação é obtida a partir da rigidez elástica das componentes individuais. O comportamento de cada componente é representado por uma mola e a relação força-deslocamento é definida pela equação (46). As componentes individuais com coeficientes de rigidez $\left(k_{i}\right)$, iguais ao infinito, não devem ser consideradas para o cálculo da rigidez inicial, uma vez que não contribuem para a deformabilidade da ligação.

$$
F_{i}=k_{i} \cdot E \cdot \Delta_{i}
$$

Onde:

$F_{i}$ é a força na mola $i$;

$K_{i}$ é o coeficiente de rigidez do componente $i$;

$E$ é o módulo de elasticidade do aço;

$\Delta i$ é o deslocamento da mola $i$.

O método considera que tanto as deformações de compressão da mesa e alma da viga como de tração da alma da viga, já estão incluídas quando a viga deforma-se por flexão, não considerando esses componentes para a determinação da rigidez da ligação. Além disso, algumas hipóteses relacionadas abaixo são adotadas: 
- as forças internas estão em equilíbrio com o momento fletor aplicado;

- a compatibilidade dos deslocamentos é considerada mediante uma rigidez infinita da seção transversal da viga.

A rigidez inicial é calculada admitindo que a força em ambas as linhas de tração e compressão é igual a $F$ e que o momento $(M)$ que atua na ligação é o produto entre $F$ e a distância entre o centro de compressão da ligação e a linha tracionada ( $z$ ). Portanto, através da equação (47) determina-se a rigidez global de uma ligação.

$$
S_{j, \text { ini }}=\frac{M}{\theta}=\frac{F \cdot z}{\frac{E \cdot \Delta_{i}}{Z}}=\frac{F \cdot z^{2}}{\frac{F}{E} \sum_{i} \frac{1}{k_{i}}}=\frac{E \cdot z^{2}}{\sum_{i} \frac{1}{k_{i}}}
$$

Onde:

z é o braço de alavanca;

Para o caso de mais de uma linha tracionada, é assumido que as deformações das linhas tracionadas são proporcionais à distância ao centro de compressão, porém as forças elásticas em cada linha tracionada são dependentes da rigidez das componentes.

Neste caso, existe a necessidade de determinar um braço de alavanca equivalente $\left(z_{e q}\right)$ para um coeficiente de rigidez equivalente que representa todas as linhas tracionadas $\left(k_{e q}\right)$. O cálculo da rigidez inicial para mais de uma linha tracionada é apresentada na equação (48).

$$
S_{j, i n i}=\frac{E \cdot z_{e q}{ }^{2}}{\frac{1}{k_{e q}}+\sum_{i} \frac{1}{k_{i}}}
$$

Onde:

$$
\begin{aligned}
& z_{e q}=\frac{\sum_{r} k_{e f f, r} \cdot h_{r}^{2}}{\sum_{r} k_{e f f, r} \cdot h_{r}} \\
& k_{e f f, f}=\frac{1}{\sum_{r} k_{i, r}}
\end{aligned}
$$


$k_{e q}=\frac{\sum_{r} k_{e f f, r} \cdot h_{r}}{Z_{e q}}$

$h_{r}$ é a distância da linha tracionada $r$ ao centro de compressão;

$k_{i, r}$ considera as componentes individuais na linha de tração $r$;

$k_{i}$ considera as componentes individuais na linha de compressão.

O coeficiente $k_{\text {eff,r }}$ é obtido pela associação em série das componentes individuais na linha $r$, enquanto que $k_{e q}$ é determinado pela associação em paralelo dos coeficientes $k_{\text {eff,r }}$.

Os modelos de molas, com os coeficientes de rigidez que devem ser considerados para determinação da rigidez inicial da ligação mista com cantoneira de alma e assento são ilustrados na Figura 3.19.
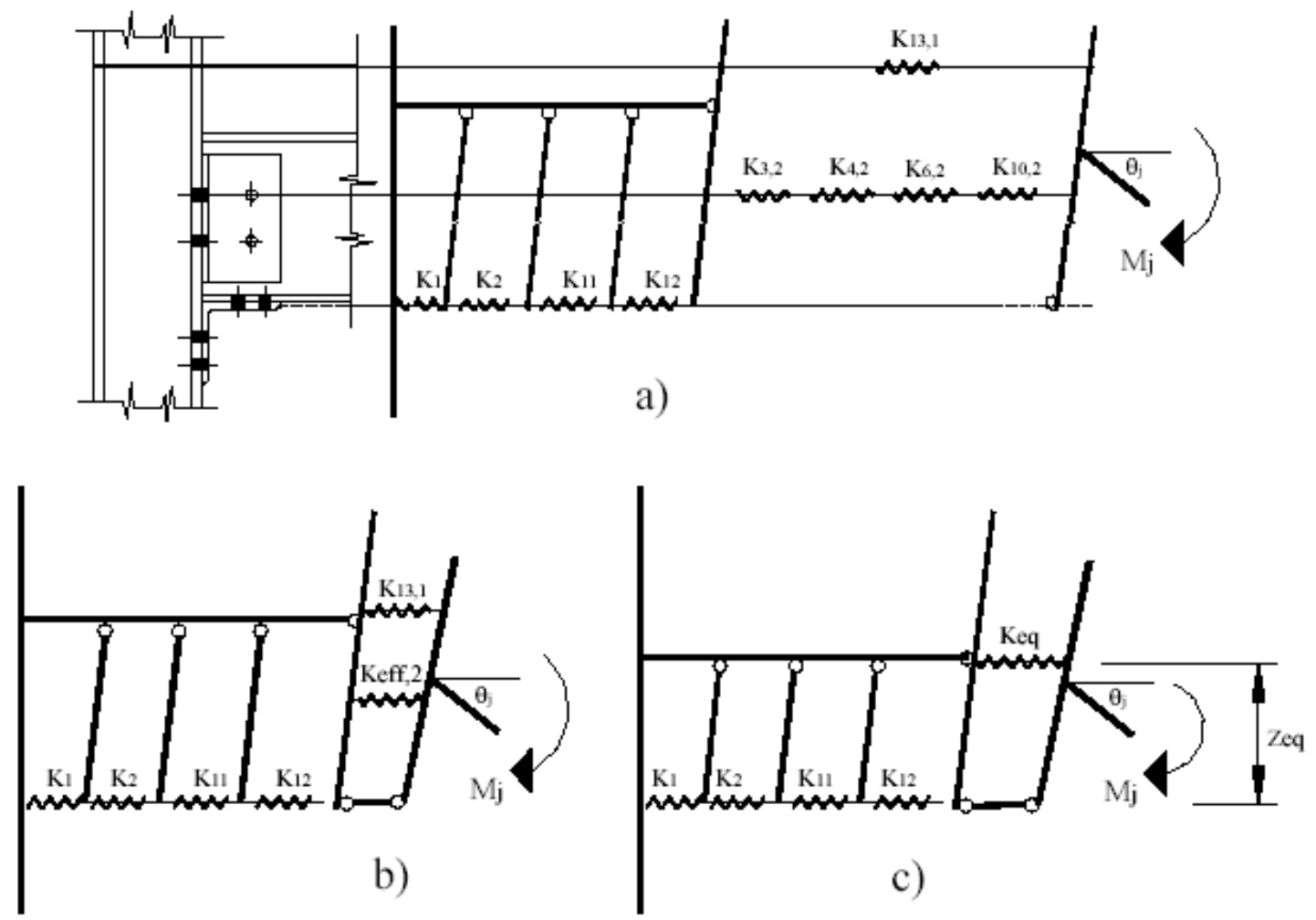

Figura 3.19: modelo de mola para ligação mista com cantoneira de alma e assento.

Quando a alma do pilar tem enrijecedor na região de compressão, não há necessidade de considerar a compressão na alma do pilar $\left(k_{2}\right)$. Além disso, o cisalhamento no painel da alma do pilar $\left(k_{1}\right)$, para ambas as situações de pilar 
de extremidade e pilar interno, com momentos desbalanceados, é apenas considerado para alma de pilar não enrijecida nas regiões de tração e compressão.

Nas ligações com cantoneiras as componentes $k_{11}$ e $k_{12}$ não são consideradas quando os parafusos são protendidos de acordo com as normalizações.

Os coeficientes de rigidez das componentes são apresentados na Tabela 3.7, na qual os parâmetros das equações encontram-se descritos nos itens 3.2.4, 3.2.5 e 3.2.6.

Para considerar a deformação da conexão de cisalhamento na rigidez da armadura deve-se multiplicar o $k_{13}$ por $k_{\text {slip }}$ dado pela equação (49).

$$
k_{\text {slip }}=\frac{1}{1+\frac{E_{r} \cdot k_{10}}{k_{s c}}}
$$

Onde:

$E_{r}$ é o módulo de elasticidade do aço da armadura;

$$
\begin{aligned}
& k_{s c}=\frac{N \cdot k_{s c}}{v-\left(\frac{v-1}{1+\xi}\right) \cdot \frac{h_{s}}{d_{s}}} \\
& v=\sqrt{\frac{(1+\xi) \cdot N \cdot k_{s c} \cdot \ell \cdot d_{s}^{2}}{E_{a} \cdot I_{a}}} ; \xi=\frac{E_{a} \cdot I_{a}}{d_{s}^{2} \cdot E_{r} \cdot A_{s}} .
\end{aligned}
$$

Onde:

$h_{s}$ é a distância entre a linha de armadura e o centro de compressão;

$d_{s}$ é a distância entre a linha de armadura e o centro de gravidade da seção da viga de aço;

$I_{a}$ é o momento de inércia da seção da viga de aço;

$\ell$ é o comprimento da viga em momento negativo, podendo ser tomado em pórticos contraventados o valor de $15 \%$ do vão da viga.

$N$ é o número de conectores de cisalhamento no comprimento $\ell$, considerando-se apenas o número necessário para interação completa; 
$K_{s c}$ é a rigidez de um conector de cisalhamento, podendo ser tomado o valor de $100 \mathrm{kN} / \mathrm{mm}$ para conector "stud bolt"com 19mm de diâmetro em ambas as lajes maciça e mista.

Tabela 3.7: Coeficientes de rigidez das componentes individuais.

\begin{tabular}{|c|c|}
\hline Componente individual & Coeficiente de rigidez (unidade de comprimento) \\
\hline \multirow[b]{2}{*}{$\begin{array}{l}\text { Cisalhamento no painel } \\
\text { da alma do pilar }\end{array}$} & Enrijecida (tração e compressão) \\
\hline & $k_{1}=\frac{0,38 \cdot A_{c c}}{\beta \cdot z_{e q}}$ \\
\hline \multirow[b]{2}{*}{$\begin{array}{l}\text { Compressão na alma do } \\
\text { pilar }\end{array}$} & Não enrijecida \\
\hline & $k_{2}=\frac{0,7 \cdot b_{e f f, c, w c} \cdot t_{w c}}{d_{c}}$ \\
\hline Tração na alma do pilar & $k_{3}=\frac{0,7 \cdot b_{e f f, t, w c} \cdot t_{w c}}{d_{w c}}$ \\
\hline Flexão na mesa do pilar & $k_{4}=\frac{0,9 \cdot \ell_{e f f} \cdot t_{f c}^{3}}{m^{3}}$ \\
\hline Flexão na chapa de topo & $k_{5}=\frac{0,9 \cdot \ell_{e f f} \cdot t_{p}^{3}}{m^{3}}$ \\
\hline $\begin{array}{l}\text { Flexão na aba da } \\
\text { cantoneira de alma }\end{array}$ & $k_{6}=\frac{0,9 \cdot \ell_{e f f} \cdot t_{w a}{ }^{3}}{m_{w a}{ }^{3}}$ \\
\hline Tração no parafuso & $\begin{array}{l}\qquad k_{10}=1,6 \cdot \frac{A_{s}}{L_{b}} \\
\text { Lb é a espessura da chapa de topo mais a espessura da } \\
\text { mesa do pilar somada à metade da soma entre a altura da } \\
\text { cabeça e altura da porca. }\end{array}$ \\
\hline Cisalhamento no parafuso & $\mathrm{K}_{11}$ (ver Tabela 3.7) \\
\hline $\begin{array}{c}\text { Contato do parafuso com } \\
\text { a chapa }\end{array}$ & $\mathrm{K}_{12}$ (ver Tabela 3.7) \\
\hline Tração na armadura & $\mathrm{K}_{13}($ ver Tabela 3.8) \\
\hline
\end{tabular}


Tabela 3.8: Coeficientes $\mathrm{k}_{11}$ e $\mathrm{k}_{12}$ para as ligações com cantoneiras de alma e assento.

\begin{tabular}{|c|c|c|}
\hline Componente & \multicolumn{2}{|c|}{ Coeficiente de rigidez } \\
\hline \multirow{3}{*}{$\begin{array}{l}\text { Cisalhamento no } \\
\text { parafuso }\end{array}$} & Sem protensão & Com protensão \\
\hline & $k_{11}=\frac{16 \cdot n_{b} \cdot d^{2} \cdot f_{u b}}{E \cdot d_{M 16}}$ & $k_{11}=\infty$ \\
\hline & $\begin{array}{l}d_{M 16} \text { é o diâmetro do parafuso d } \\
n_{b} \text { é o número de linhas de para }\end{array}$ & $\begin{array}{l}\text { em; } \\
\text { em cisalhamento, }\end{array}$ \\
\hline \multirow{6}{*}{$\begin{array}{l}\text { Compressão na alma } \\
\text { do pilar }\end{array}$} & Sem protensão & Com protensão \\
\hline & $k_{12}=\frac{24 \cdot n_{b} \cdot k_{b} \cdot k_{t} \cdot d \cdot f_{u}}{E}$ & $k_{12}=\infty$ \\
\hline & $\left(0,25 \cdot e_{b} / d+0,5\right.$ & $\begin{array}{l}e_{b} \text { é a distância da linha de } \\
\text { parafuso à face livre da } \\
\text { chapa na direção da força; }\end{array}$ \\
\hline & $k_{b 1} \leq\left\{\begin{array}{l}0,25 \cdot p_{s} / d+0,375 \\
1,25\end{array}\right.$ & $\begin{array}{l}f_{u} \text { é a resistência última do } \\
\text { aço que está em contato } \\
\text { com o parafuso; }\end{array}$ \\
\hline & $k_{t} \leq\left\{\begin{array}{l}1,5 \cdot t_{j} / d_{M 16} \\
2,5\end{array}\right.$ & $\begin{array}{l}p_{s} \text { é o espaçamento entre } \\
\text { as linhas de parafusos na } \\
\text { direção da força; }\end{array}$ \\
\hline & & $t_{j}$ é a espessura da chapa. \\
\hline
\end{tabular}

Tabela 3.9: Coeficientes de rigidez da armadura longitudinal.

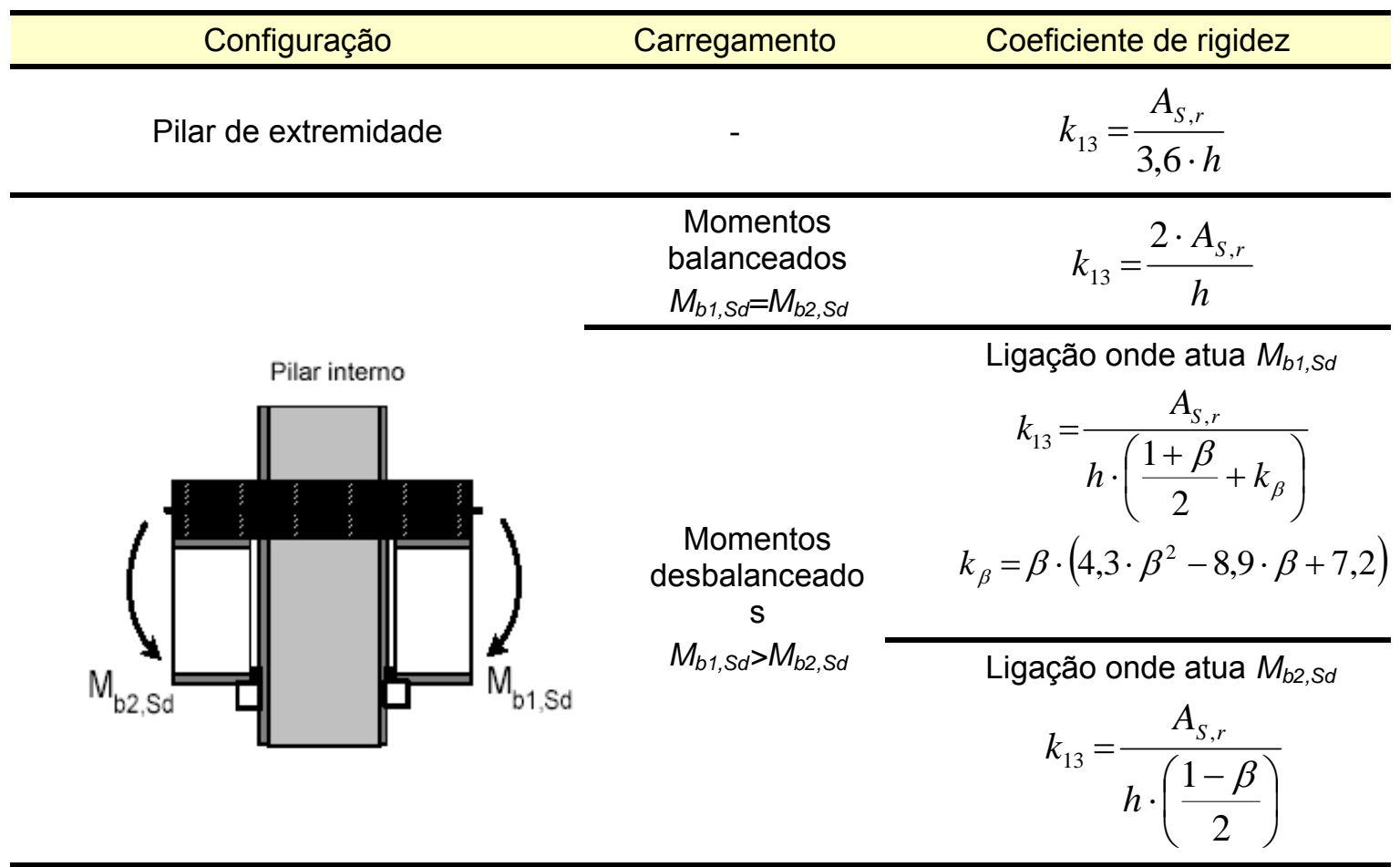

$A_{s r}$ é área da armadura longitudinal dentro da área efetiva da laje na linha tracionada $r$;

$M_{S d}$ é o momento solicitante de cálculo atuando na ligação;

$h$ é a altura da seção do pilar, 


\section{3 - Capacidade Rotacional}

O EUROCODE 4 (2004) não apresenta nenhum modelo de cálculo específico para estimativa da capacidade rotacional, referindo-se apenas que a influência das fissuras do concreto, o efeito "tension stiffening" e a deformação dos conectores sejam considerados.

Dentre os trabalhos desenvolvidos, destacam-se os trabalhos do SCI/BCSA (1995), AHMED \& NETHERCORT (1996) e do COST-C1 (1996), sendo que somente o último considera todos os parâmetros do EUROCODE 4 (2004), sendo então adotado neste trabalho.

O método considera que a determinação da deformação da armadura é baseada no comprimento e ductibilidade da armadura, como também o efeito "tension stiffening" do concreto entre as fissuras. Essa deformação é tomada com $\left(\varepsilon_{\min }\right)$, podendo ser obtida pela equação $(50)$. O comportamento da armadura envolvida pelo concreto é apresentada pela Figura 3.20.

$$
\varepsilon_{\text {sтu }}=\varepsilon_{s y}-\beta \cdot \Delta \varepsilon_{s r}+\delta_{0} \cdot\left(1-\frac{\sigma_{s r \ell}}{f_{y s}}\right) \cdot\left(\varepsilon_{s u}-\varepsilon_{s y}\right)
$$

Onde:

$\varepsilon_{s y}=\frac{f_{y, r}}{E_{s}}$

$\varepsilon_{s u}$ é a deformação correspondente ao limite de resistência da armadura isolada;

$\beta_{t}$ é igual a 0,4 para ações de curta duração;

$$
\Delta \varepsilon_{s r}=\frac{\sigma_{s r \ell}}{E_{s}}-\frac{f_{c t m}}{E_{c}}
$$

$\delta_{o}$ é igual a 0,8 para barras de alta ductibilidade com saliências ou mossas;

$$
\sigma_{\text {srt }}=\frac{f_{c t m}}{\rho_{s, e f f}} \cdot\left(1+\frac{E_{s}}{E_{c}} \cdot \rho_{s, e f f}\right)
$$


Onde:

$\rho_{s, \text { eff }}=\frac{2 \cdot A_{s}}{A_{c}} ;$

$A_{s}$ é a área de armadura dentro da largura efetiva;

$A_{c}$ é a área da capa de concreto, descontando-se a área da armadura longitudinal;

$$
\begin{aligned}
& f_{c t m}=0,3 \cdot\left(f_{c k}\right)^{2 / 3} \cdot \xi,\left(f_{c t m} \text { e } f_{c k} \text { em MPa }\right) \\
& \xi=0,3+0,7 \cdot\left(\frac{\gamma_{c}}{24}\right) \\
& \gamma_{c}=24 \mathrm{kN} / \mathrm{m}^{3}
\end{aligned}
$$

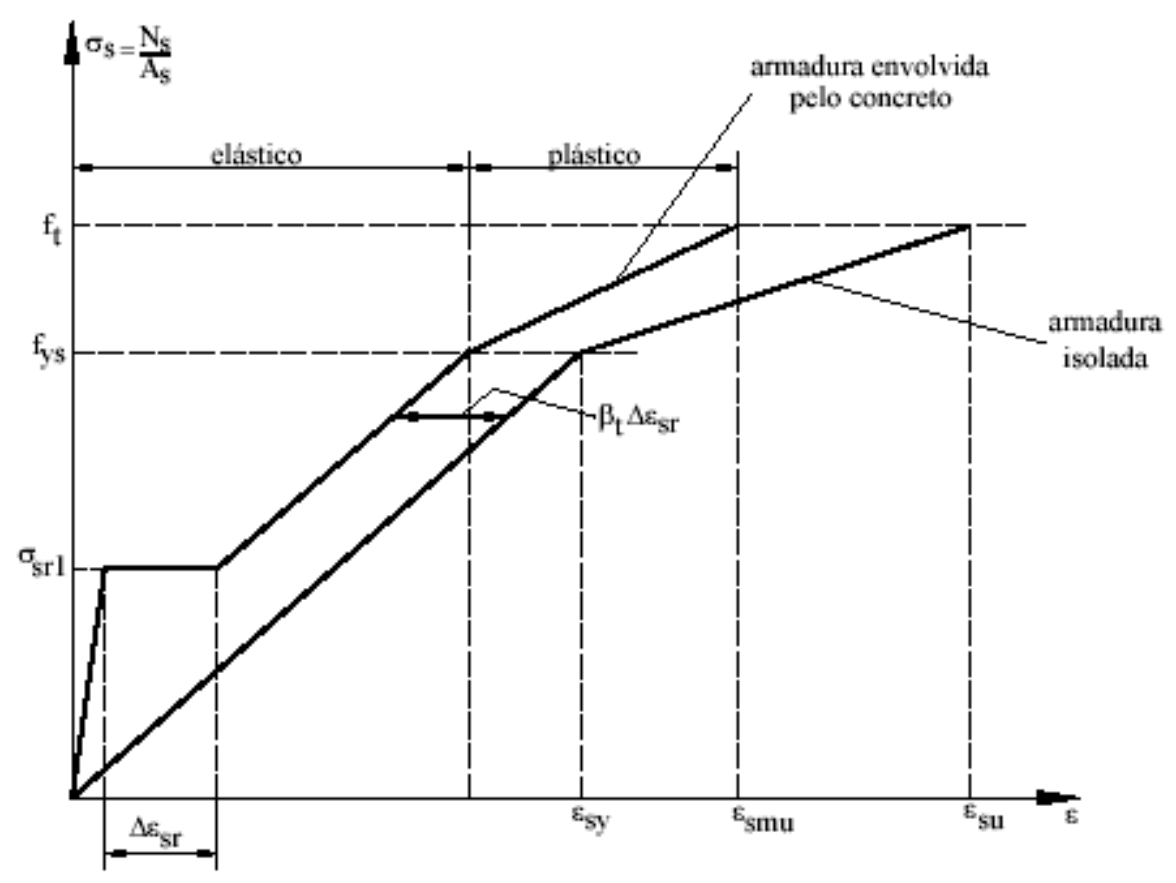

Figura 3.20: Diagrama dos comportamentos tensão-deformação da armadura isolada e da armadura envolvida pelo concreto.

Outro parâmetro que também influencia na capacidade rotacional é a deformação dos conectores. Para explicar o comportamento dos conectores dúcteis, a Figura 3.21 apresenta uma curva momento-rotação de uma ligação mista que é aproximada por um diagrama tri-linear (OABC). $O$ deslizamento no ponto A é dado pela equação (51). 


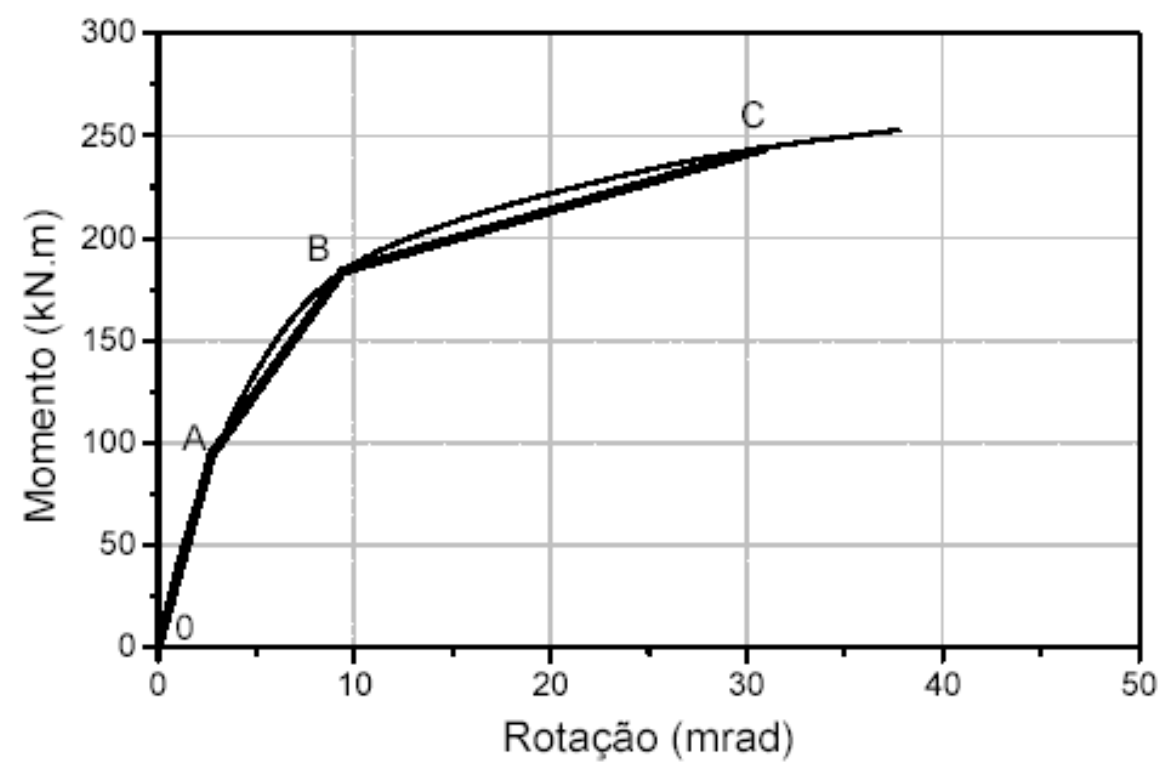

Figura 3.21: Aproximação trilinear OABC.

$$
S^{(A)}=\frac{F_{S}^{(A)}}{K_{S C}}
$$

Onde:

$F_{s}^{(A)}$ é a força na armadura para o momento na ligação no ponto $A$, podendo ser adotado o valor de 0,7.qrk.

$q_{r k}$ é a resistência característica de apenas um conector;

$K_{s c}$ é a rigidez da conexão de cisalhamento, dado pela eq (49).

O ponto $\mathrm{B}$ corresponde ao desenvolvimento da força de interação máxima entre armadura e a viga de aço. Portanto, para conexão completa o deslizamento em B é dado pela equação (52).

$$
s^{(B)}=2 \cdot s^{(A)} \cdot \frac{F_{s}^{(B)}}{F_{S}^{(A)}}
$$

Onde:

$$
F_{s}^{(B)}=A_{s} \cdot f_{y, r}
$$

Temos então que a capacidade rotacional obtida pela equação (53): 


$$
\phi_{c}=\frac{\Delta_{u s}+\Delta_{u i}+s^{(B)}}{L_{r}}
$$

Onde:

$\Delta_{u s}=L \cdot \varepsilon_{\text {smu }}$;

$L=0,5 \cdot h_{c}+p_{1} \leq 250 \mathrm{~mm}$;

$h_{c}$ é a altura da seção do pilar;

$p_{1}$ é a distância da face do pilar ao primeiro conector;

$\Delta_{u i}$ é a capacidade de deformação da ligação em aço, podendo ser tomado igual à $4 \mathrm{~mm}$ para ligação com chapa de topo e cantoneira de alma e assento;

$L_{r}$ é a distância da linha da armadura à linha de centro da mesa comprimida.

Este procedimento de cálculo despreza qualquer deformação inelástica da seção da viga de aço na região nodal, região que é afetada pela ligação da viga com o pilar.

Caso a conexão de cisalhamento seja completa, não é esperado que a capacidade rotacional seja limitada pelo colapso da conexão de cisalhamento. Por outro lado, em conexão parcial com conectores perfil "U" formado a frio pode ocorrer à ruptura dos conectores.

\section{4 - Modelo Proposto pelo AISC}

No guia de projeto em aço série 8 denominado de "Partially Restrained Composite Connections" é apresentado um procedimento de cálculo para pórticos contraventados e não-contraventados, de edifícios de andares múltiplos com até 10 pavimentos, considerando a semi-rigidez na ligação mista.

A ligação mista semi-rígida, apresentada no guia, é com cantoneira de alma e assento ou com apenas a cantoneira de assento (Figura 3.22). A utilização de ligação com apenas a cantoneira de assento é recomendada para o eixo de menor inércia em pórticos contraventados. 

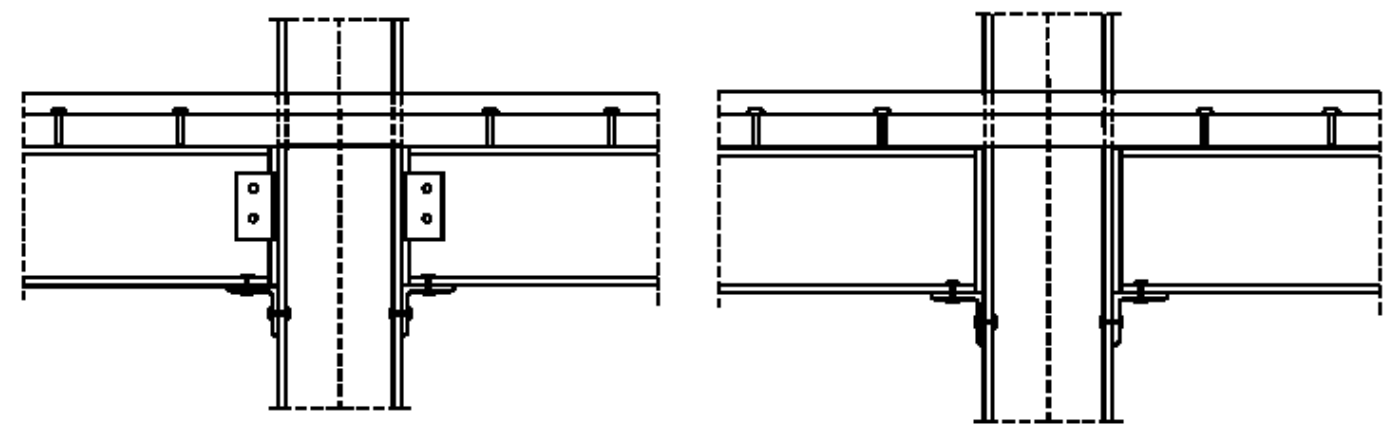

Figura 3.22: Ligação com cantoneira de alma e assento e ligação com apenas a cantoneira de assento.

As ligações mistas da figura acima são denominadas de PR-CC e tem resistência menor que a da viga mista (resistência parcial). A relação momentorotação desse tipo de ligação submetida a momento fletor negativo é apresentada na equação (54) e foi obtida de vários testes e estudos paramétricos.

$$
M_{n}=C 1 \cdot\left(1-e^{-C 2 \cdot \theta}\right)+C 3 \cdot \theta
$$

Onde:

$C 1=0,18 \cdot\left(4 \cdot A_{s} \cdot f_{y b r}+0,857 \cdot A_{l} \cdot f_{y}\right) \cdot(d+Y 3) ;$

$C 2=0,775$

$C 3=0,007 \cdot\left(A_{l}+A_{w f}\right) \cdot f_{y} \cdot(d+Y 3) ;$

M é o momento atuante na ligação (kip.in);

$\theta$ é a rotação na extremidade da viga (radianos);

$d$ é a altura da viga de aço (in);

Y3 é a distância da face superior da mesa da viga de aço à linha de centro da armadura, em in.

$A_{s}$ é a área de aço da armadura, em in ${ }^{2}$;

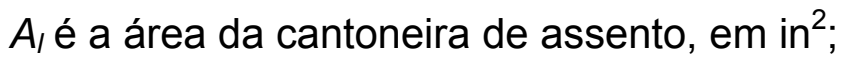

$A_{w f}$ é a área bruta das duas cantoneiras de alma para cálculo do cisalhamento, em in ${ }^{2}$;

$f_{y r b}$ é a tensão de plastificação do aço da armadura, em ksi; 
$f_{y}$ é a tensão de plastificação do aço das cantoneiras, em ksi.

O manual apresenta também tabelas com informações para o projeto de ligações mistas pré-qualificadas que foram analisadas para um grande número de mecanismo de colapso e condição de carregamento. Nessas tabelas, por meio da configuração geométrica da ligação, o tipo de aço e tipo de pórtico (contraventado ou não) pode-se obter o momento na ligação na rotação de 2,5 $\operatorname{mrad}\left(M_{2}\right)$ e o momento último na ligação de $20 \mathrm{mrad}\left(M_{1}\right)$. As rotações de 2,0 e $20 \mathrm{mrad}$ as denominadas rotações de serviço e última, respectivamente, podendo assim construir uma relação bi-linear.

A determinação do momento resistente de cálculo das ligações submetida a momento fletor negativo é obtida por meio da equação (55), para cantoneiras de alma e assento, e equação (56) para ligações com somente cantoneira de assento. Cabe ressaltar ainda que o momento resistente foi avaliado para uma rotação de $10 \mathrm{mrad}$.

$$
\begin{aligned}
& M_{n}=\phi \cdot\left[0,245 \cdot\left(4 \cdot A_{s} \cdot f_{y r b}+A_{w f} \cdot f_{y}\right) \cdot(d+Y 3)\right] \\
& M_{n}=\phi \cdot\left[A_{s} \cdot f_{y r b} \cdot(d+Y 3)\right]
\end{aligned}
$$

Onde:

$\phi$ é o coeficiente de minoração da resistência, igual a 0,85.

\section{5 - Considerações Finais sobre os Métodos de Cálculo}

O método analítico apresentado pelo EUROCODE 3 (2005) para o cálculo do momento resistente e rigidez inicial é bastante complexo, incorporando diferentes tipos de detalhes de ligações e configuração de carregamento. Diante desta característica e para praticidade nos cálculos, torna-se necessário a programação em função da quantidade de verificações.

Por outro lado, o método possibilita ao projetista o cálculo mais preciso das ligações e, consequentemente, mais eficiente e econômico, uma vez que conhecendo a resistência e rigidez das componentes individuais é possível 
realizar várias combinações. Além disso, o método também considera a deformabilidade do painel da alma e o efeito da força de compressão no pilar na ligação.

A determinação do momento resistente e da rigidez inicial pelo procedimento do guia de projeto em aço série 8 , do AISC, é bem mais simples, uma vez que é expressa por equações que foram geradas por meio de várias análises experimentais e estudos paramétricos. Todavia, abrange apenas ligações com cantoneiras de alma e assento ou somente cantoneira de assento.

O Capítulo 4 a seguir apresenta e descreve os ensaios experimentais, com os respectivos procedimentos, considerações, instrumentação, carregamento e caracterização dos materiais para os modelos isolados e o pavimento tipo. 


\section{4}

\section{ENSAIOS EXPERIMENTAIS DOS PROTÓTIPOS ISOLADOS E PAVIMENTO TIPO}

\section{1 - Considerações Iniciais}

O planejamento do programa experimental teve como ponto de partida o objetivo de analisar o comportamento das ligações viga mista-pilar com cantoneiras de alma e assento em sistemas isolados e contínuos (pavimento tipo), de modo a permitir uma melhor avaliação do comportamento das ligações mistas considerando várias condições de carregamento, em particular a deterioração da rigidez em função da fissuração da laje. Para a realização dos ensaios foi solicitado e aprovado junto à FAPESP um Projeto de Auxílio à Pesquisa que englobasse todos os ensaios previstos.

Os ensaios foram realizados no Laboratório de Estruturas da Escola de Engenharia de São Carlos (SET-EESC), composto de protótipos de ligações isoladas e de um pavimento tipo, constituído de duas vigas principais com um trecho em balanço, vigas secundárias e contraventamento no topo dos pilares.

O programa experimental teve os seguintes objetivos:

- Investigar o comportamento da ligação mista em estado limite de serviço e último, considerando protótipos isolados e pertencentes a um pavimento tipo;

- Avaliar a deterioração da rigidez da ligação em função da fissuração da laje para os vários estágios de carregamento;

- Verificar a eficiência do procedimento adotado para ancoragem das barras da armadura longitudinal da viga mista e acréscimo da taxa de armadura transversal, com o objetivo de restringir a fissuração na laje. 
A configuração e geometria adotada para a ligação (dimensões das cantoneiras, chapas e perfis da viga e pilar) foi padronizada para todos os protótipos experimentais, bem como o tipo de laje pré-moldada e a taxa de armadura longitudinal da viga mista.

\section{2 - Modelos isolados: pilar de borda e centro}

\subsection{1 - Geometria dos modelos}

Ao todo foram ensaiados protótipos que representam quatro modelos de ligações isoladas (dois modelos cruciformes e dois com a configuração denominada de "T", representando um pilar de borda), de acordo com a descrição resumida da Tabela 4.1.

Tabela 4.1: Descrição resumida dos modelos isolados.

\begin{tabular}{c|c|c|c}
\hline Protótipo & Tipo de ligação & $\begin{array}{c}\text { Taxa de armadura } \\
\text { longitudinal }\end{array}$ & $\begin{array}{c}\text { Taxa de armadura } \\
\text { transversal }\end{array}$ \\
\hline TNRSS $^{2}$ & Pilar de borda (“T”) & $1 \%$ & $0,2 \%$ \\
\hline TRSS $^{3}$ & Pilar de borda (“T”) & $1 \%$ & $1 \%$ \\
\hline CNRSS $^{4}$ & Pilar central (cruciforme) & $1 \%$ & $0,2 \%$ \\
\hline CRSS $^{5}$ & Pilar central (cruciforme) & $1 \%$ & $1 \%$ \\
\hline
\end{tabular}

Os modelos foram constituídos de vigas mistas com perfis laminados $W$ $200 \times 26,6 \mathrm{Kg} / \mathrm{m}$ para a viga principal (conectadas na mesa do pilar) e W $150 \times$ $13 \mathrm{Kg} / \mathrm{m}$ para a viga secundária (conectadas na alma) e conectores de cisalhamento do tipo $U$, conforme ilustram as Figura 4.1 e 4.2, respectivamente.

No ponto de aplicação do carregamento foram posicionados enrijecedores e alma da viga e, além disso, considerou-se conexão parcial entre a viga de

\footnotetext{
${ }^{2}$ TNRSS - T No Reinforced Secundary Steel

${ }^{3}$ TRSS - T Reinforced Secundary Steel

${ }^{4}$ CNRSS - Cruciforme No Reinforced Secundary Steel

${ }^{5}$ CRSS - Cruciforme Reinforced Secundary Steel
} 
aço e a laje de concreto.

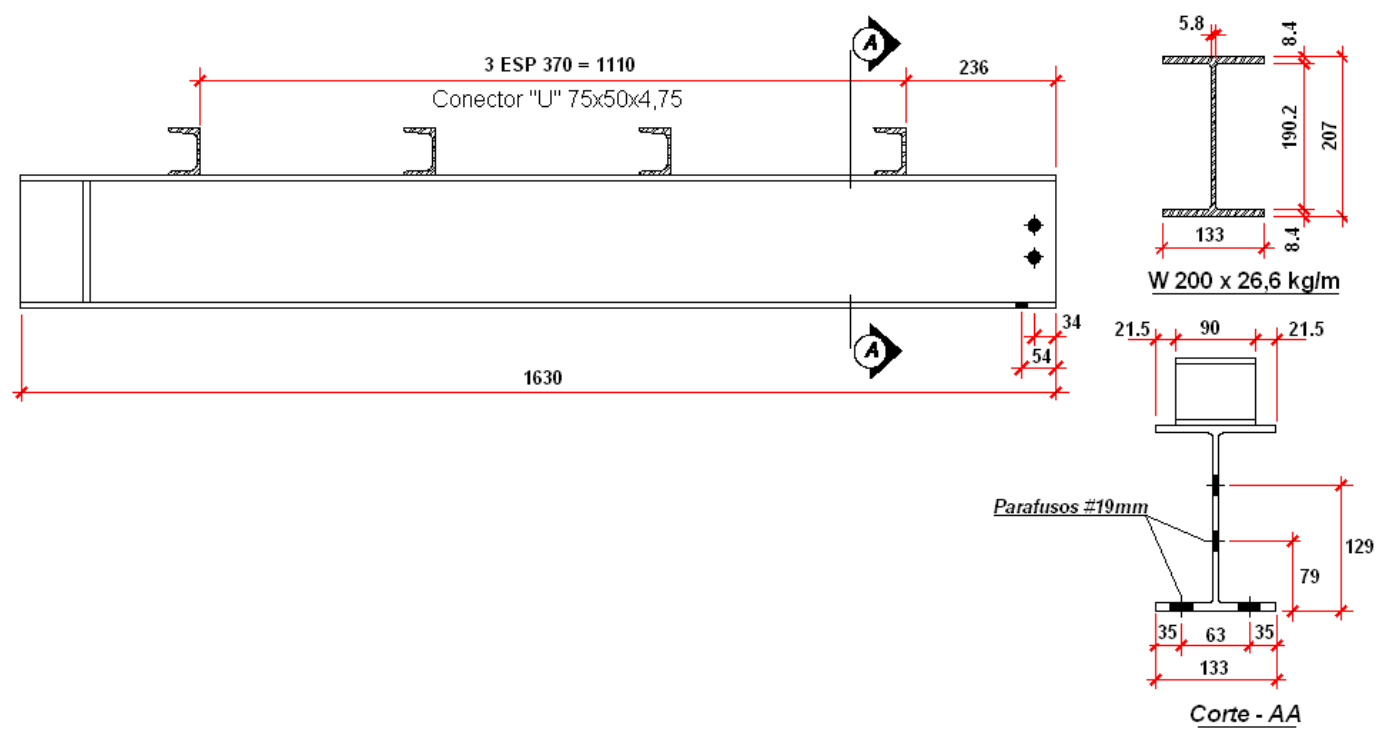

Figura 4.1: Geometria da viga principal $(\mathrm{mm})$.
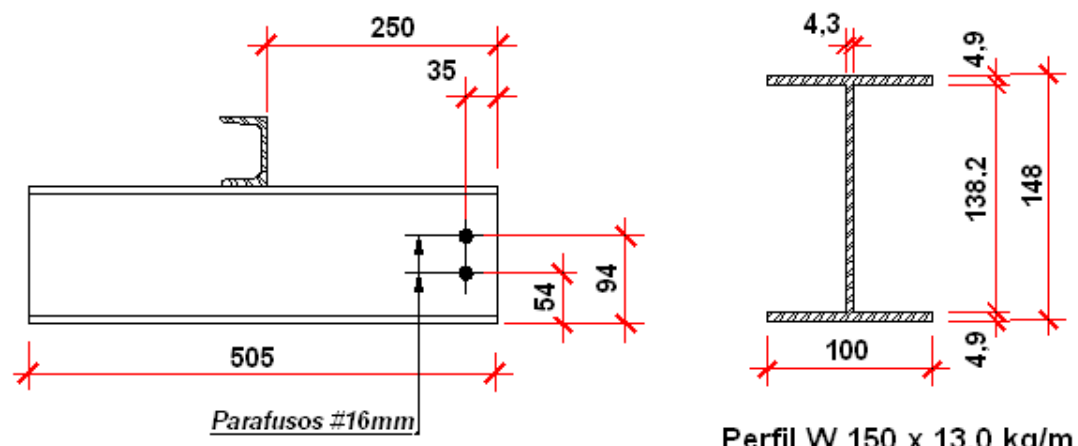

Perfil W $150 \times 13,0 \mathrm{~kg} / \mathrm{m}$

Figura 4.2: Geometria da viga secundária ( $\mathrm{mm})$.

Para os pilares foi adotado o perfil laminado HP $200 \times 53 \mathrm{Kg} / \mathrm{m}$, conforme apresenta a Figura 4.3. A viga principal foi conectada no pilar através de cantoneiras de alma e assento, enquanto que a viga secundária foi conectada por uma chapa de alma soldada a outra chapa que tem a função de enrijecer as mesas do pilar, constituindo-se então numa ligação rotulada.

A ligação da viga principal no pilar foi feita por parafusos ASTM A325 com diâmetro de 19 mm, enquanto que as ligações secundárias, por parafusos de $16 \mathrm{~mm}$. As dimensões e furos das cantoneiras de assento (L4"x4"x5/16") e alma (L3"x3"x1/2") são ilustrados na Figura 4.4. 

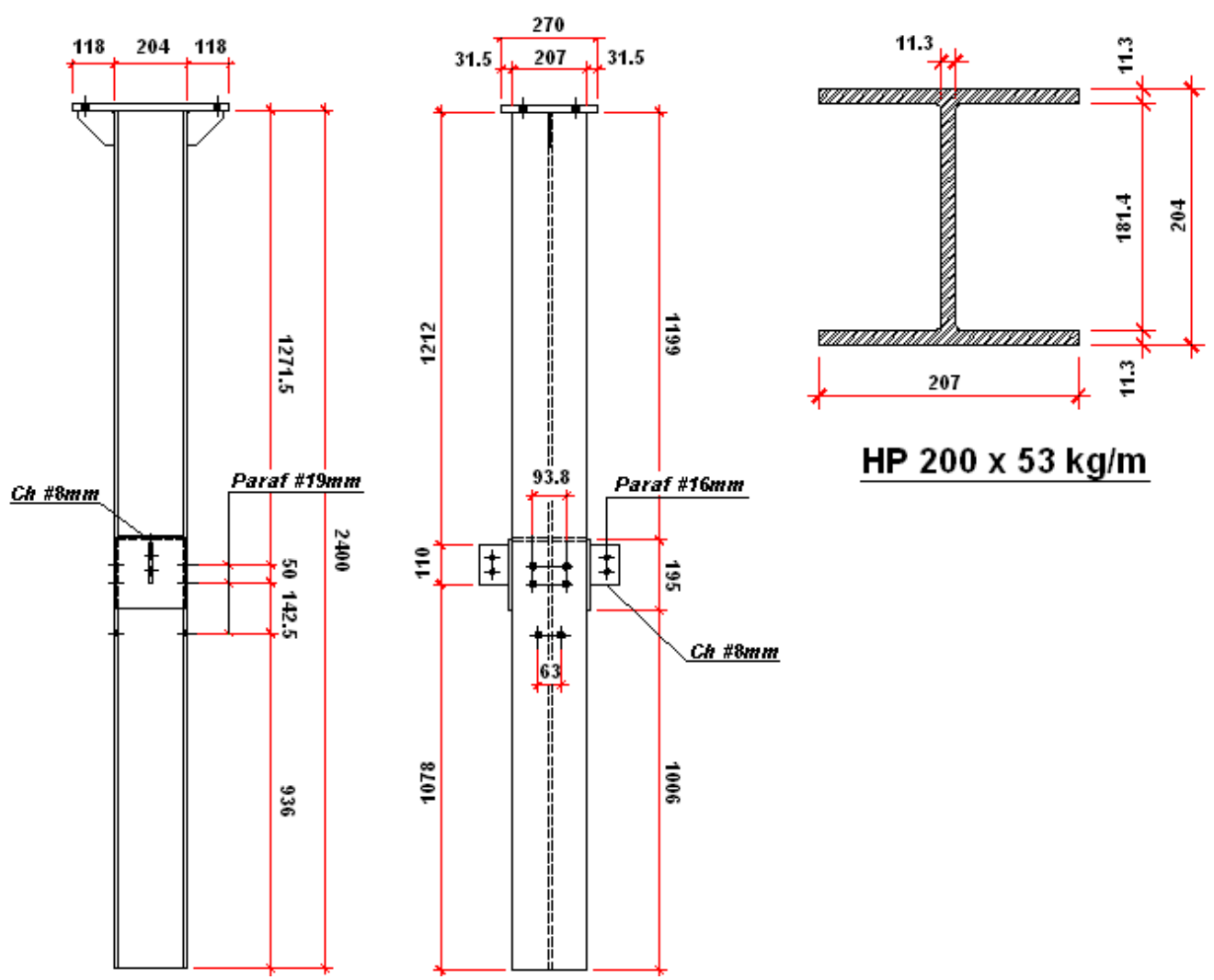

$\underline{\mathrm{HP}} 200 \times 53 \mathrm{~kg} / \mathrm{m}$

Figura 4.3: Geometria do pilar para protótipo de ligação cruciforme (mm).
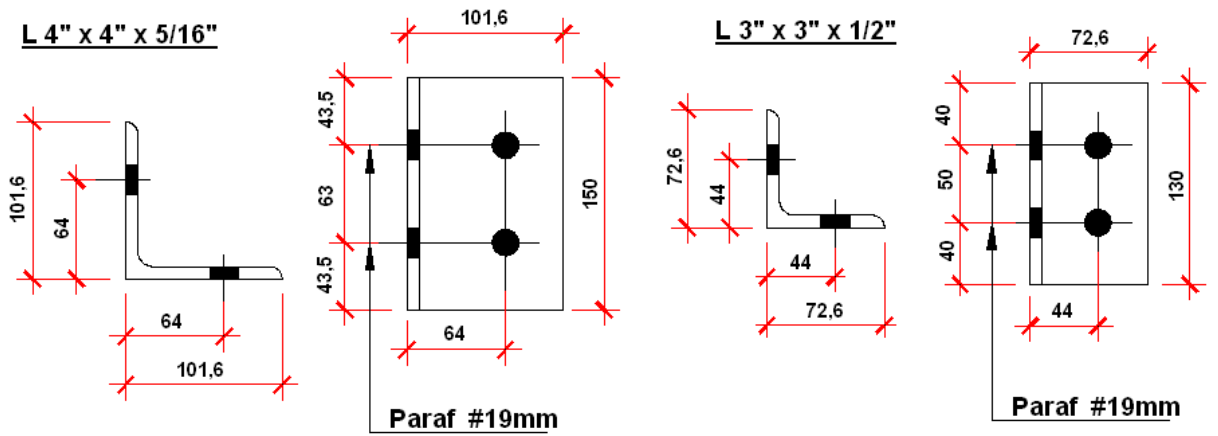

Figura 4.4: Dimensões e gabaritos de furação das cantoneiras (mm).

\subsection{2 - Armaduras e montagem dos modelos}

A laje de concreto armado foi constituída de vigotas pré-moldadas e lajotas cerâmicas, técnica construtiva de laje pré-moldada amplamente empregada no Brasil, com a espessura de $12 \mathrm{~cm}$ e largura efetiva de $126 \mathrm{~cm}$. A largura efetiva da laje foi definida de acordo com as recomendações do EUROCODE 4 (2004), bem como o diâmetro e espaçamento das barras 
transversais.

A armadura longitudinal da viga mista representa uma taxa de aproximadamente $1 \%$, constituído por oito barras de $10 \mathrm{~mm}$ e armadura secundária por barras de $6 \mathrm{~mm}$. O acréscimo na taxa de armadura secundária foi obtido com a colocação de barras $10 \mathrm{~mm}$ na direção transversal e $8 \mathrm{~mm}$ na direção longitudinal.

O detalhe adotado para a ancoragem das armaduras longitudinais dispensa a armadura de contorno do pilar, conforme ilustra a Figura 4.5 para o protótipo TNRSS e Figura 4.6 para o protótipo TRSS. O Apêndice A deste trabalho apresenta a descrição completa de todo o detalhamento das armaduras negativas e positivas dos protótipos isolados e do pavimento tipo.

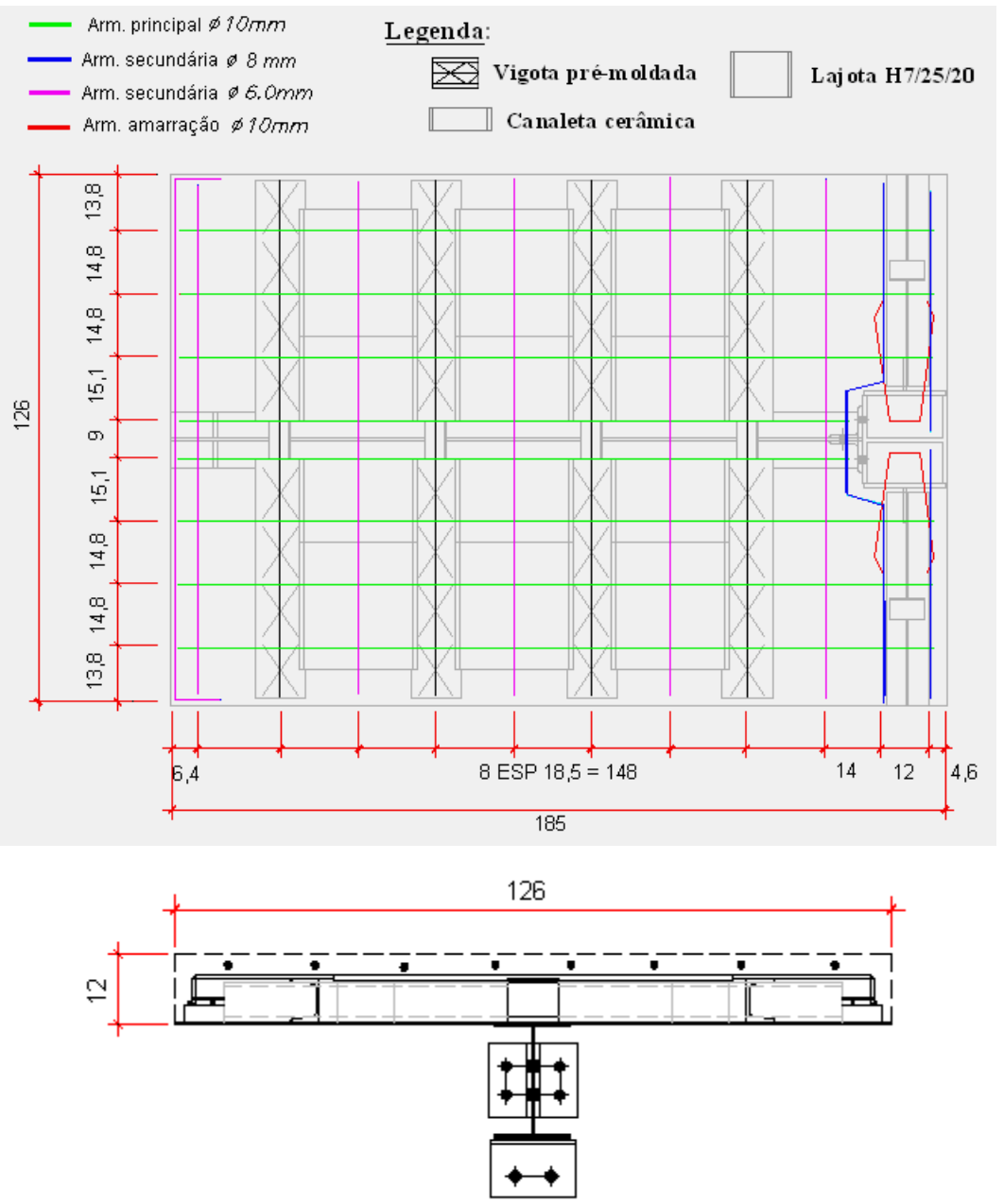

Figura 4.5: Detalhamento das armaduras para o protótipo CNRSS de pilar de canto e seção transversal da viga mista $(\mathrm{cm})$. 


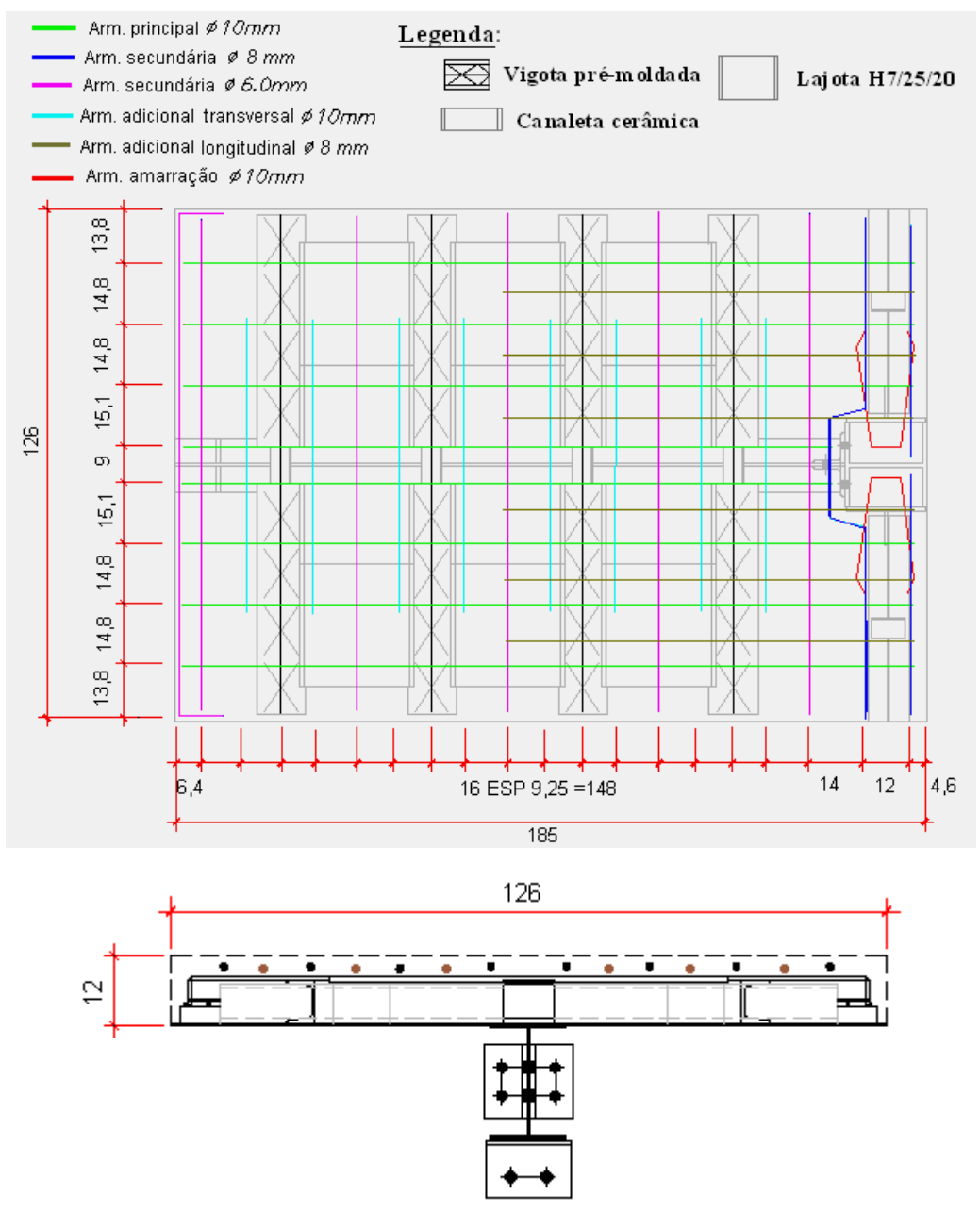

Figura 4.6: Detalhamento das armaduras para o protótipo CRSS de pilar de canto e seção transversal da viga mista $(\mathrm{cm})$.

A disposição das armaduras principais e secundárias, assim como todo o dispositivo de ancoragem adotado foi padronizada para todos os modelos isolados e também para o pavimento tipo.

A Figura 4.7 apresenta uma visão geral da ligação metálica do modelo isolado cruciforme CNRSS, com detalhe das ligações da viga principal e secundária. A Figura 4.8 ilustra a montagem das formas, disposição dos apoios e a região para colocação das vigotas e lajotas pré-moldadas. 

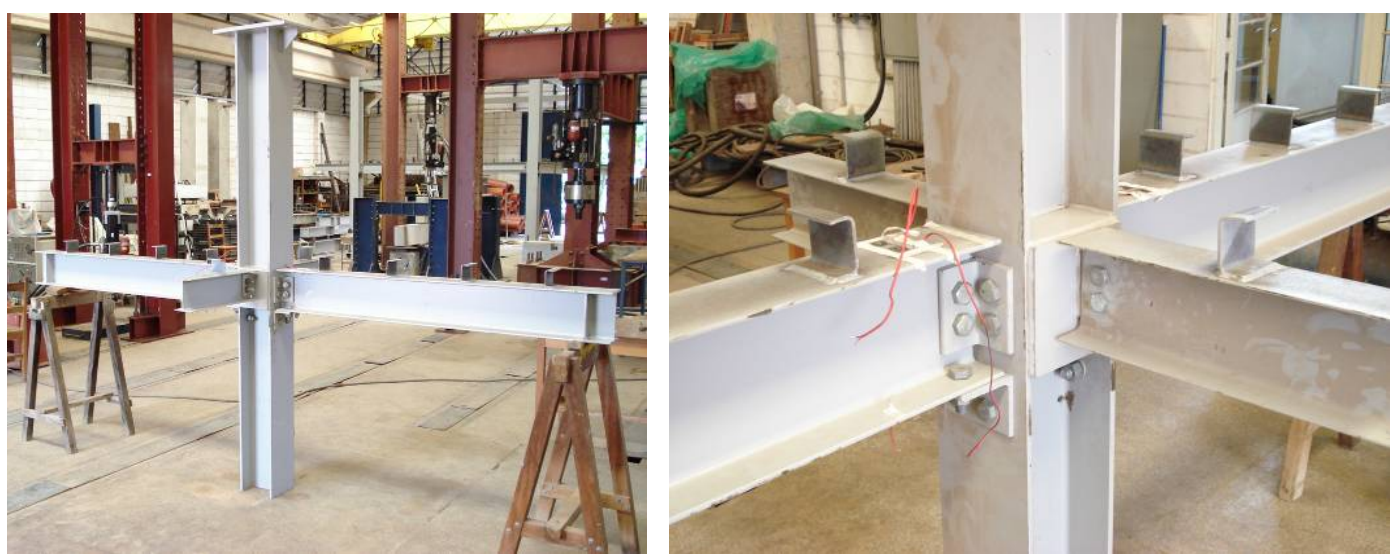

Figura 4.8: Visão geral e detalhe da ligação metálica no modelo cruciforme.
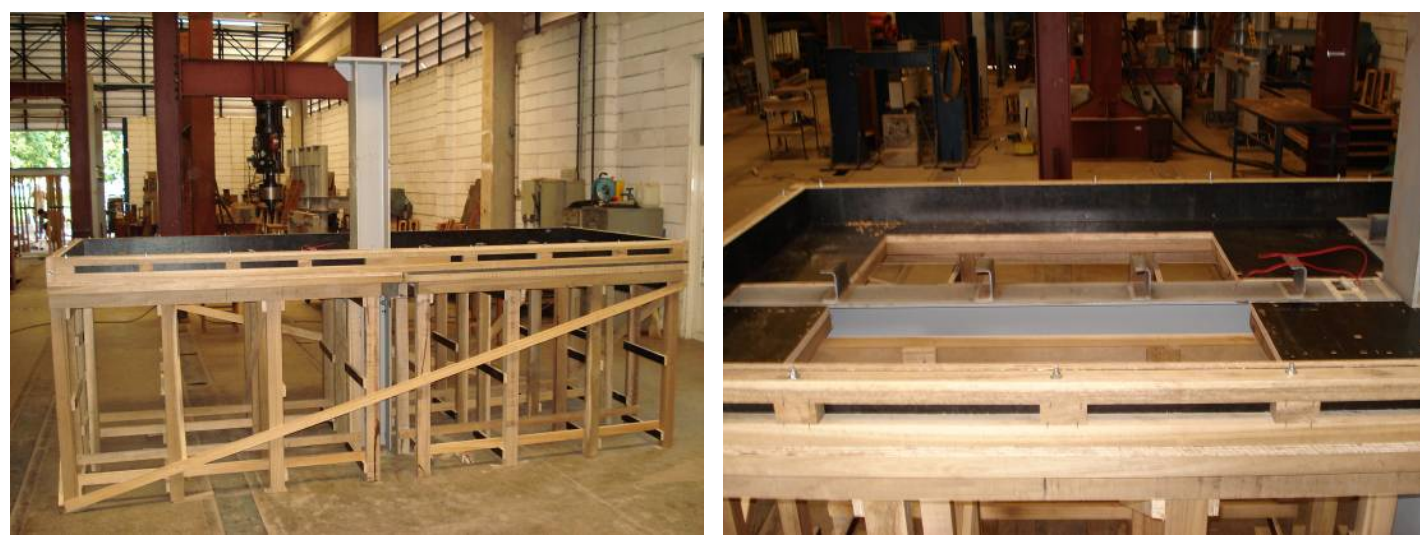

Figura 4.8: Montagem das formas no modelo cruciforme.

$\mathrm{Na}$ Figura 4.9 tem-se o modelo isolado CNRSS antes da concretagem, após a colocação das vigotas, lajotas e armaduras, com o detalhe da continuidade da armadura superior e inferior da vigota treliçada.
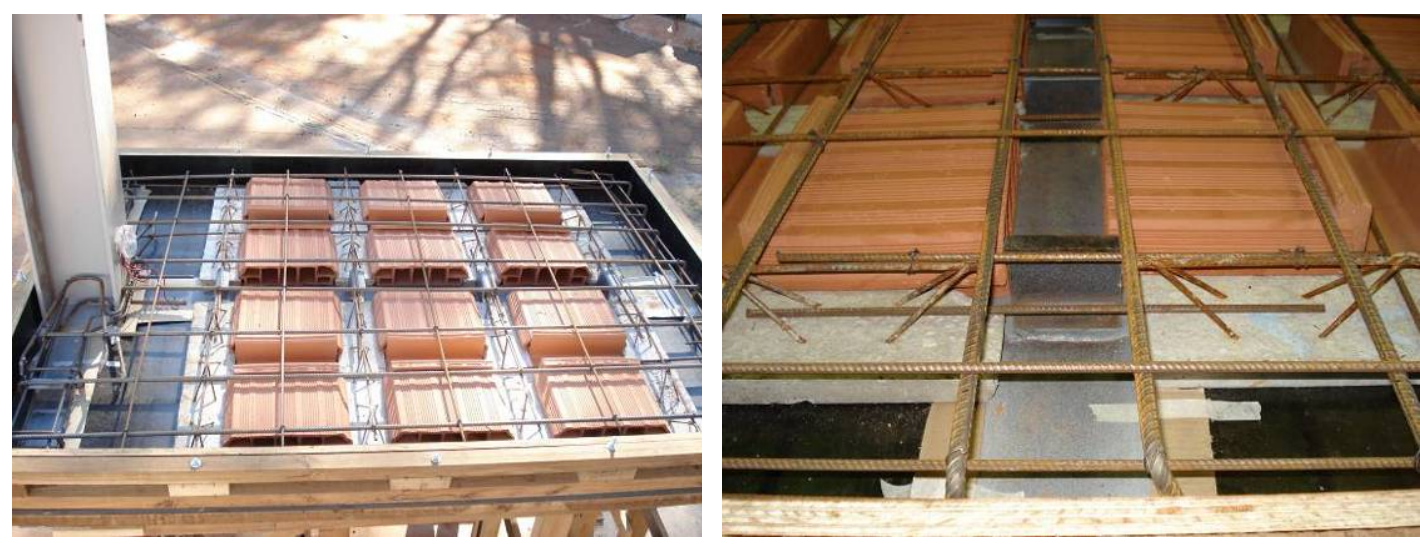

Figura 4.9: Disposição das armaduras do protótipo TNRSS antes da concretagem e detalhe da continuidade da armadura das vigotas. 


\subsection{3 - Sistemas de aplicação dos carregamentos}

Os sistemas de aplicação dos carregamentos das ligações isoladas seguiram as mesmas técnicas e procedimentos empregados em trabalhos anteriores do Departamento de Engenharia de Estruturas da Escola de Engenharia de São Carlos.

Para o sistema cruciforme, o esquema de ensaio adotado considerou as extremidades das vigas principais fixas e o carregamento aplicado no pilar, com o objetivo de provocar uma reação nas extremidades das vigas, conforme ilustra o esquema da Figura 4.10.

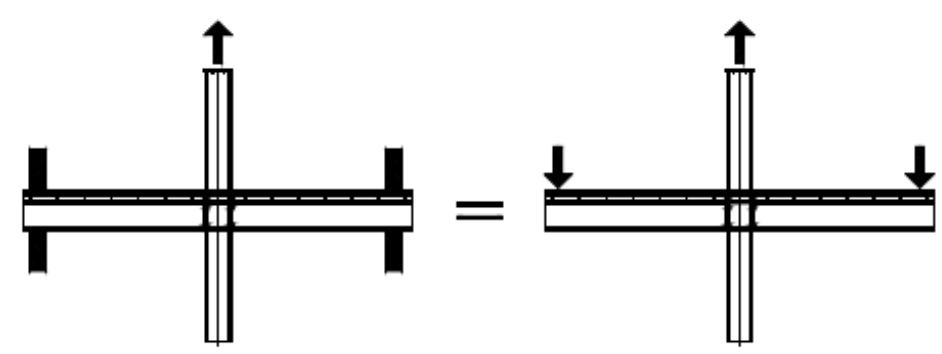

Figura 4.10: Esquema de carregamento do modelo cruciforme.

O esquema de ensaio do protótipo demandou de três pórticos de reação, o atuador servo-controlado com capacidade de $500 \mathrm{kN}$ posicionado no pórtico central e o travamento nas extremidades realizado pela viga dos outros dois pórticos. A Figura 4.11 apresenta a geometria do protótipo isolado cruciforme em elevação e em planta.

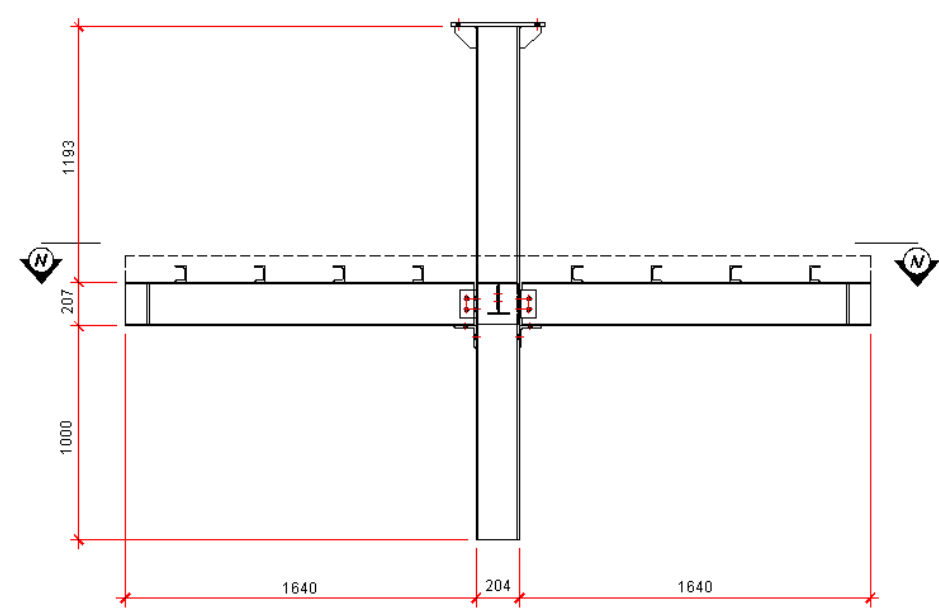

Elevação

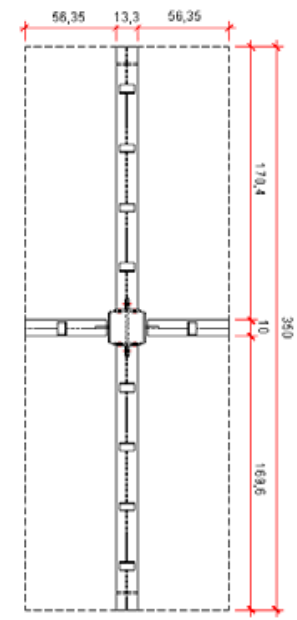

Planta: Corte - NN

Figura 4.11: Modelo isolado de ligação viga mista-pilar de centro. 
A Figura 4.12 ilustra o protótipo isolado cruciforme após a montagem, com todos os dispositivos de ensaio conectados.
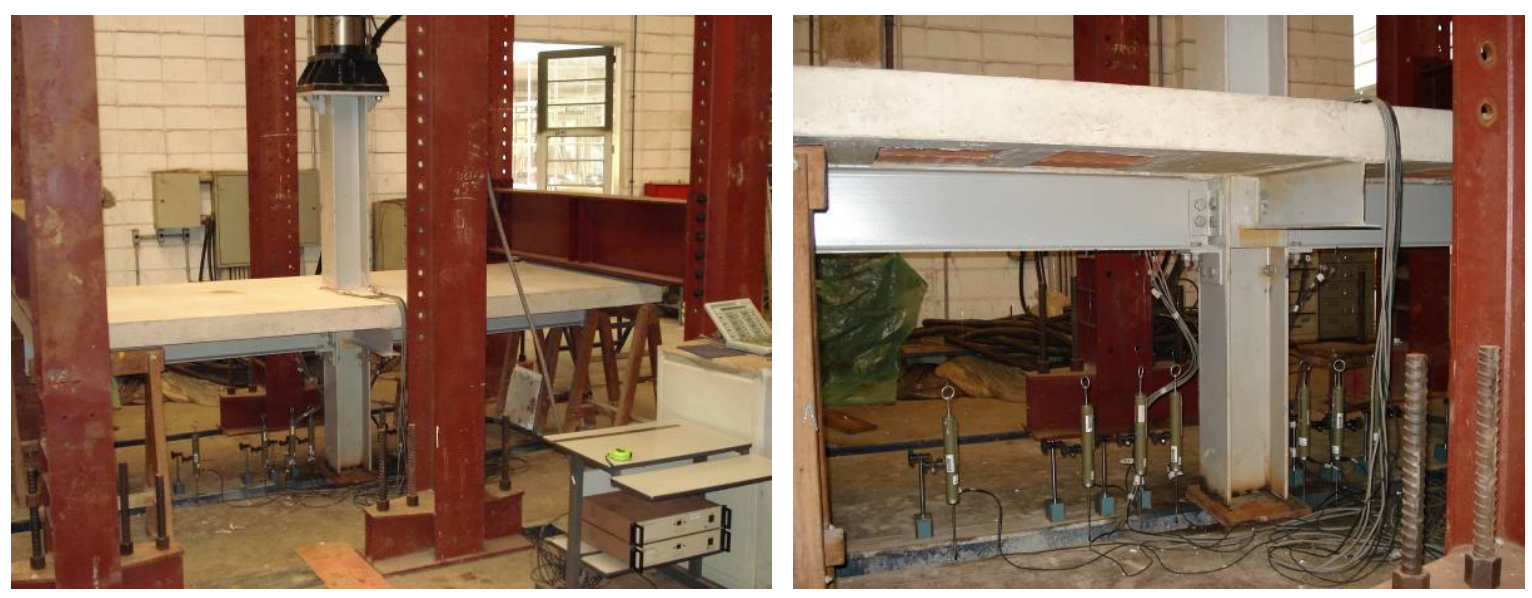

Figura 4.12 - Visão geral do protótipo isolado de pilar de centro.

Nos modelos isolados em "T", o carregamento foi aplicado na extremidade da viga principal por um atuador hidráulico, com capacidade de carga de $300 \mathrm{kN}$, posicionado em um pórtico de reação. No topo do pilar foi projetada uma trave diagonal, ligando o topo do pilar a uma viga base, com o objetivo de restringir os deslocamentos horizontais na extremidade superior do pilar, sem a consideração do carregamento de compressão, de acordo com o esquema da Figura 4.13.

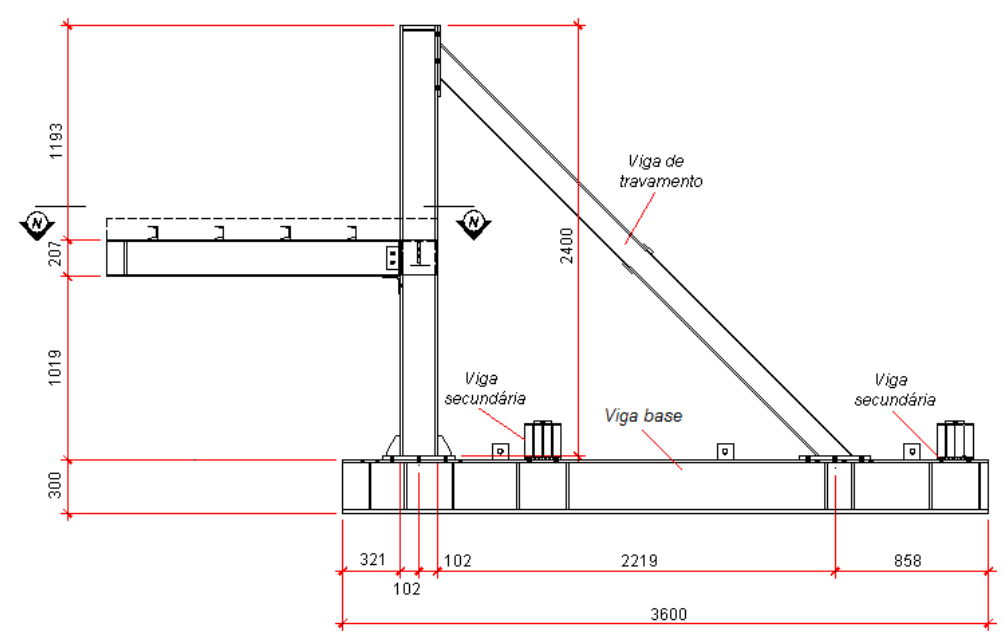

Elevação

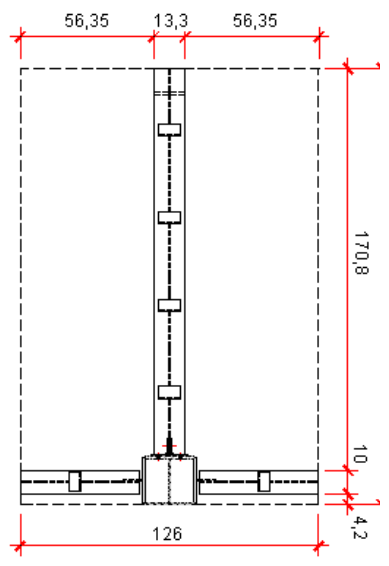

Planta: Corte - NN

Figura 4.13 - Modelos isolados de ligação viga mista-pilar de borda.

A base do pilar foi conectada diretamente na viga base, adicionalmente 
um sistema constituído de vigas de contenção (denominadas de vigas secundárias), perpendiculares à viga base, foi concebido para a ligação da viga base às canaletas da laje de reação.

A seção da viga secundária foi constituída por dois perfis I soldados pelas mesas, o conjunto foi parafusado na viga base e conectado na laje de reação por chumbadores. Uma visão geral do modelo isolado "T" com todos os dispositivos de ensaio montados, as vigas base e de contenção estão ilustrados na Figura 4.14.
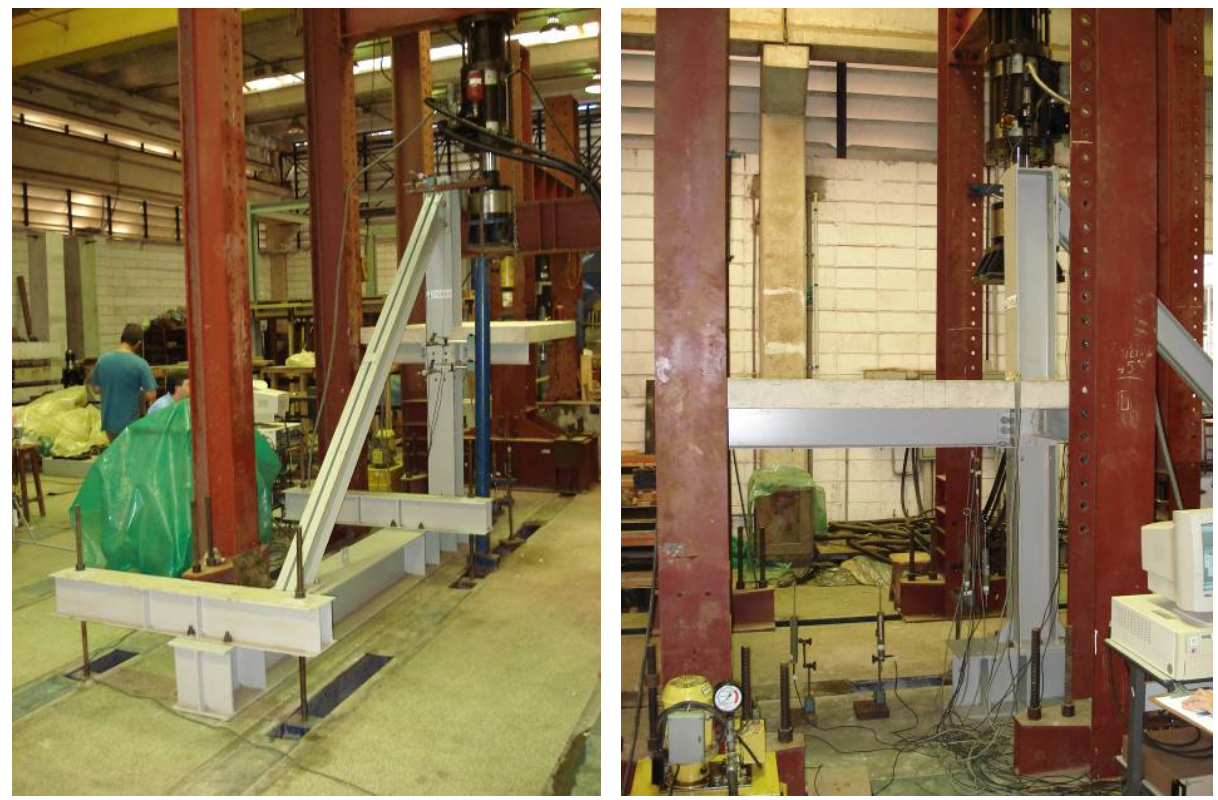

Figura 4.14 - Visão geral do protótipo isolado de pilar de borda.

\subsection{4 - Instrumentação}

Os modelos isolados foram instrumentados com o objetivo de avaliar o comportamento momento-rotação da ligação, deformações e deslocamentos em alguns elementos da ligação.

A Figura 4.15 a seguir apresenta as posições e numeração dos extensômetros utilizados na viga principal. Além destes, também foram utilizados extensômetros na armadura longitudinal da viga mista e armadura de contorno do pilar, esta última com a função de ancoragem da armadura da viga mista, conforme ilustra a Figura 4.16. 


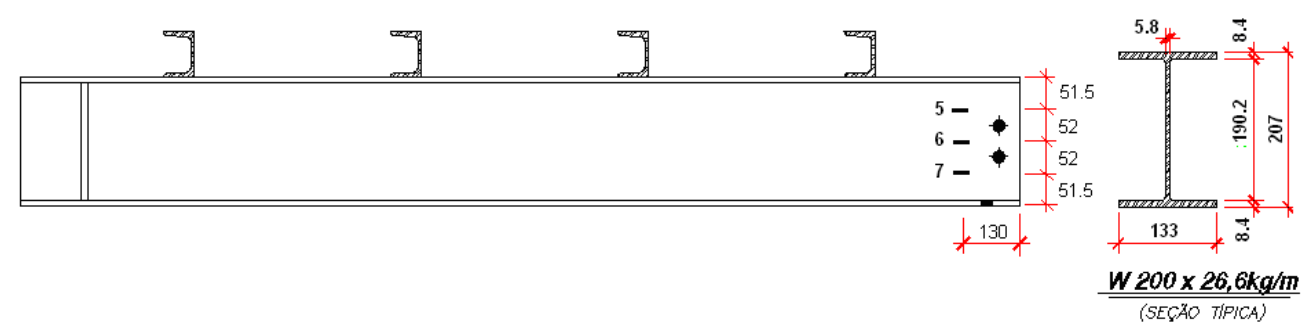

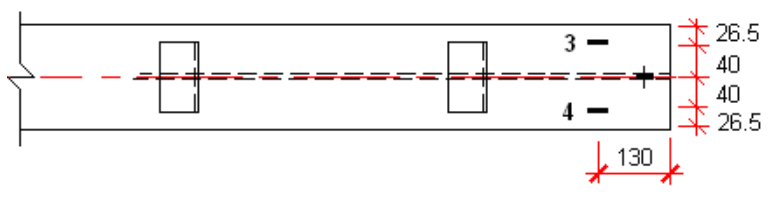

Mesa superior

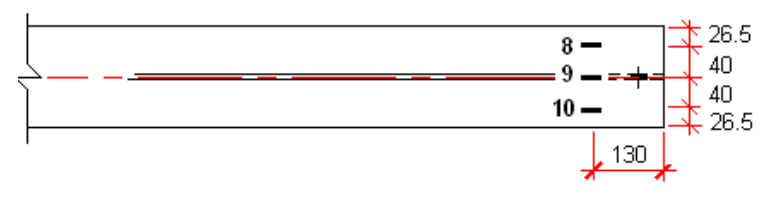

Mesa inferior

Figura 4.15: Posição e numeração dos extensômetros na viga principal.
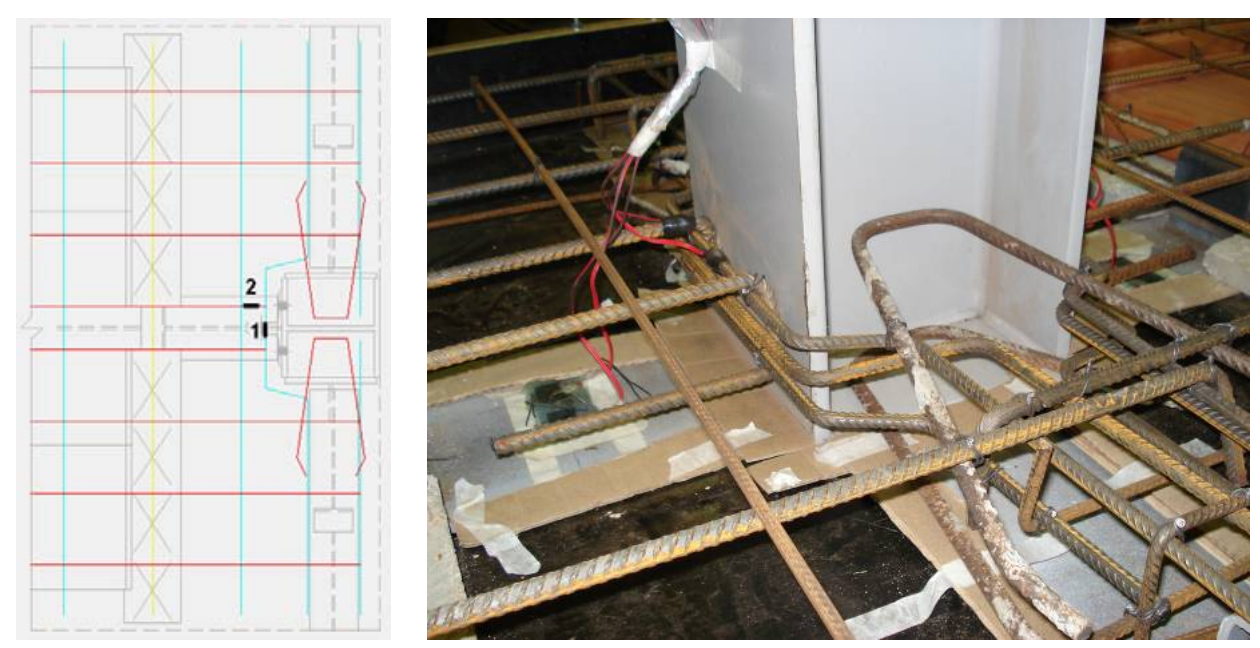

Figura 4.16: Posição dos extensômetros nas armaduras.

Além da extensometria apresentada, também foram utilizados transdutores com curso de $100 \mathrm{~mm}$ na mesa inferior da viga principal. No modelo isolado " $\mathrm{T}$ " também foi medido os deslocamentos em três pontos do pilar. As posições e numeração dos transdutores para os modelos isolados de pilar de borda e centro estão ilustrados na Fig. 4.17. 

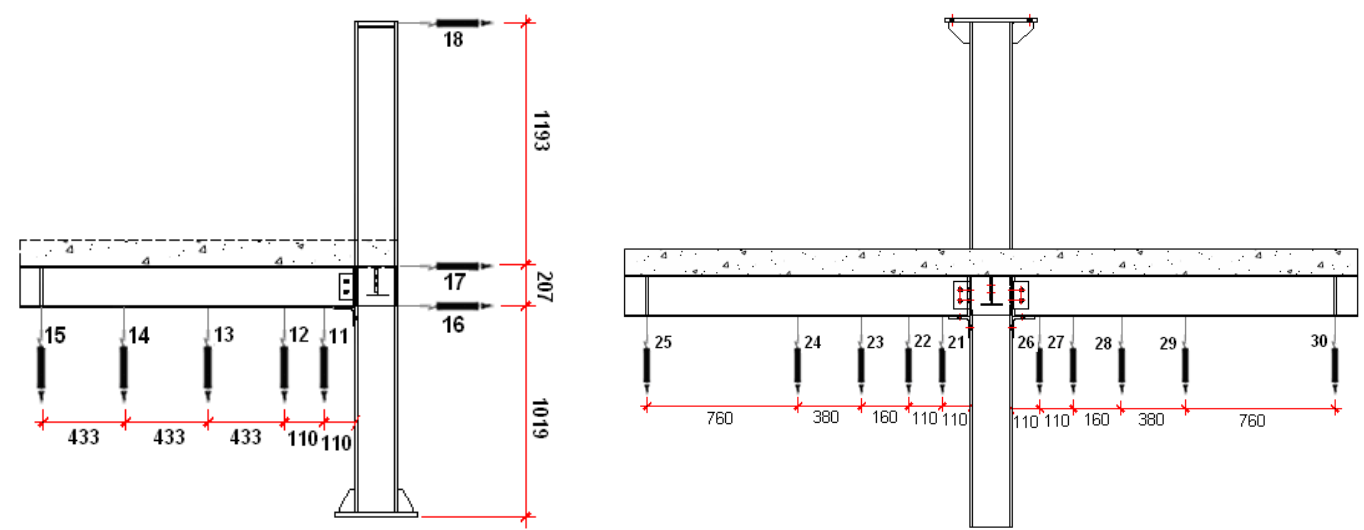

Figura 4.17: Posição e numeração dos transdutores nos modelos isolados.

\section{3 - Pavimento Tipo}

\subsection{1 - Geometria do protótipo}

O pavimento tipo ensaiado foi projetado com aproximadamente $33 \mathrm{~m}^{2}$ de área da laje, com o objetivo de reproduzir a geometria dos três tipos de ligações: pilar de canto, borda e de centro.

O modelo foi composto de dois pórticos interligados por uma laje prémoldada com vigotas e lajotas cerâmicas, com um dos pórticos constituído por pilares de canto e de borda, e o outro, um pórtico interno da estrutura, com a consideração da largura efetiva.

A Figura 4.18 apresenta o pavimento tipo ensaiado, em planta, com a respectiva numeração das ligações, que a partir deste momento será utilizada como referência na identificação de cada ligação do pavimento tipo. Da mesma forma que os modelos isolados TRSS e CRSS, a taxa de armadura longitudinal e transversal de todas as ligações do pavimento tipo foi de $1 \%$. Os perfis da viga principal, secundária, cantoneiras e o pilar, bem com o detalhe da ligação das vigas principais nos pilares foram os mesmo dos modelos isolados.

Os pilares do pavimento tipo foram contraventados no topo, através de vigas U 6" x 12,2 Kg/m conectadas por chapas de topo. As Figuras 4.19 e 4.20 ilustram as elevações lateral e frontal do pavimento tipo segundo os cortes AA e BB da Figura 4.18. 


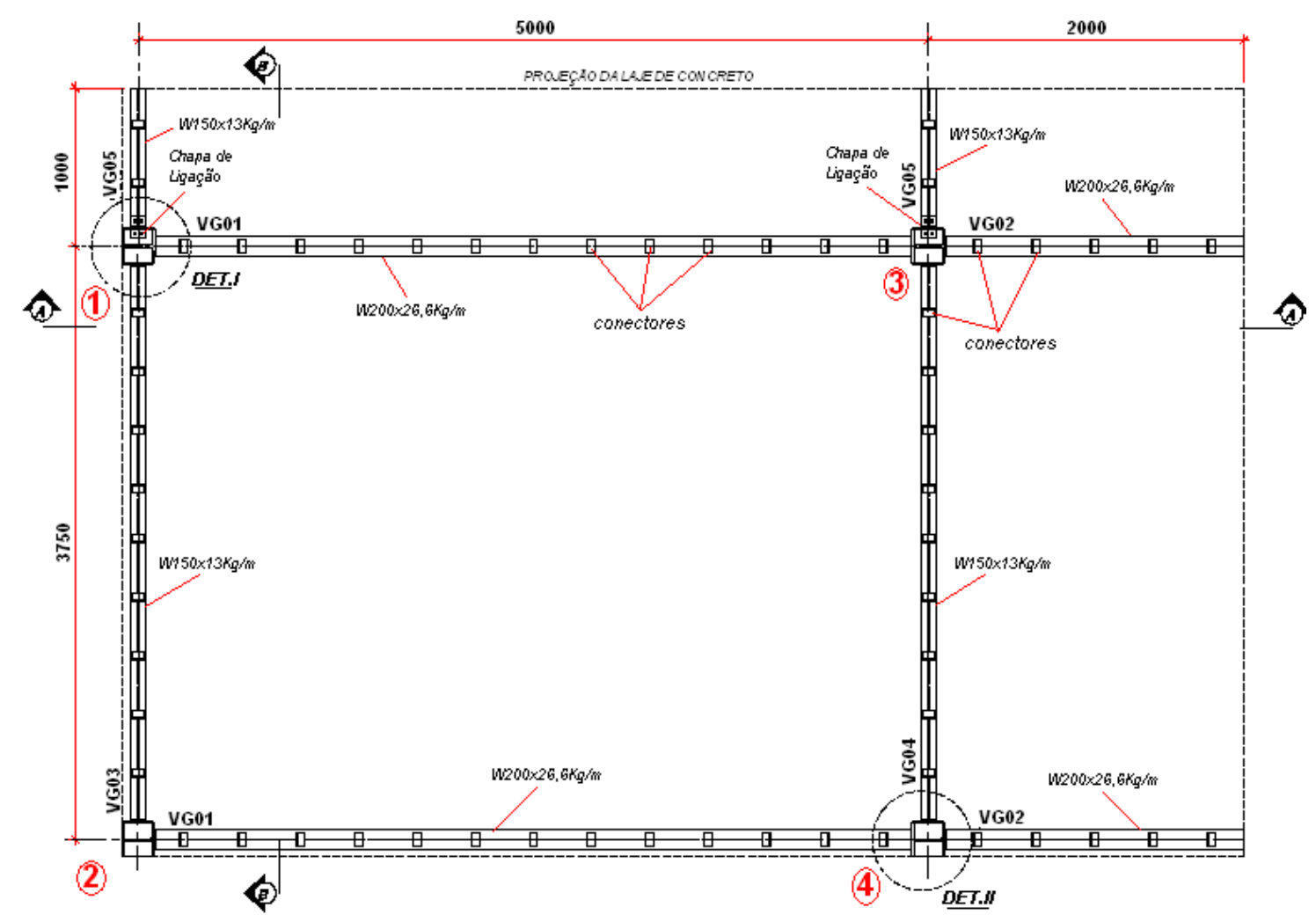

Figura 4.18: Esquema do pavimento tipo ensaiado - Planta (mm).

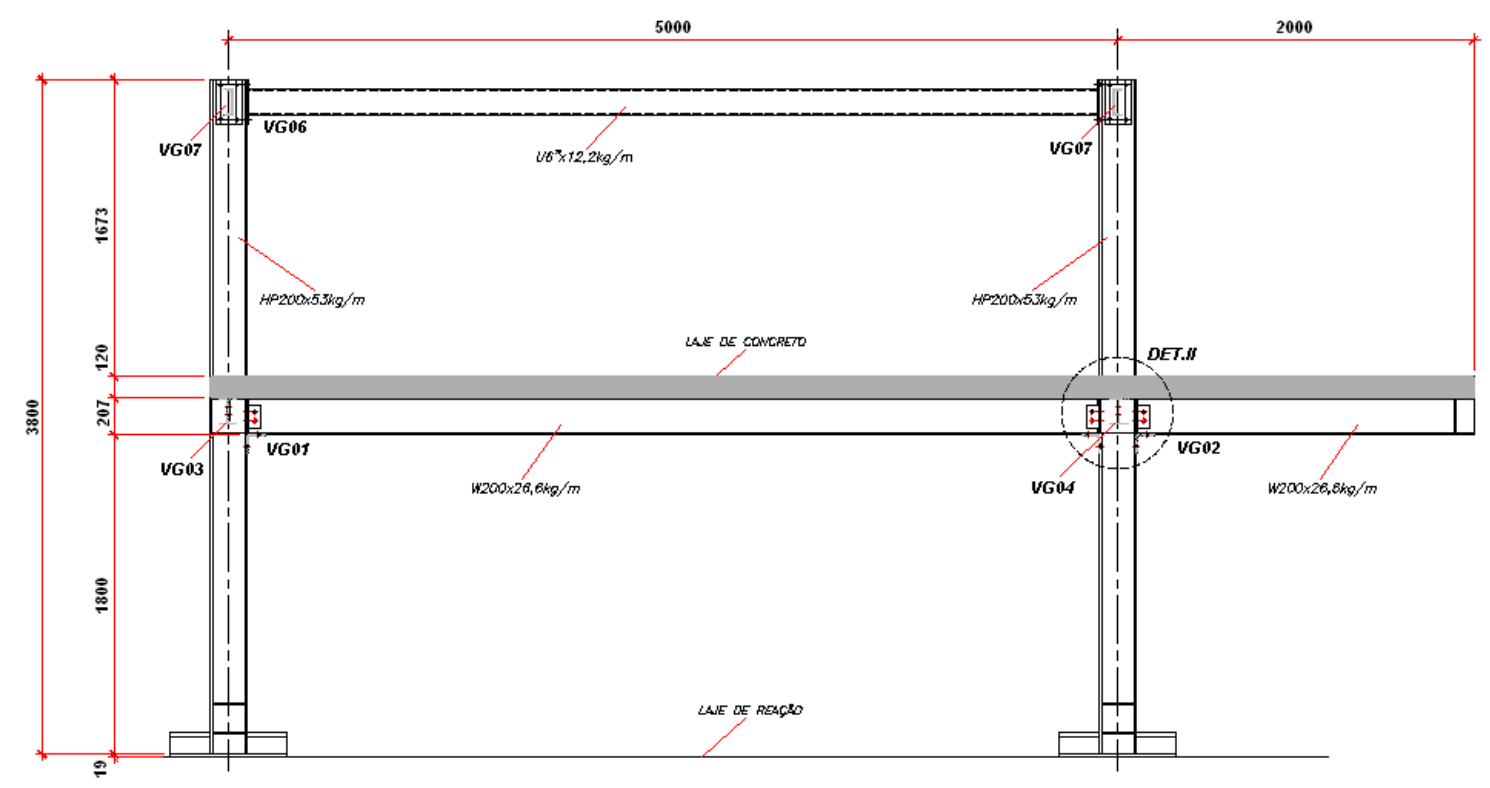

Figura 4.19: Elevação lateral do pavimento tipo - Corte AA (mm).

O pavimento tipo foi projetado com a viga secundária VG05 conectada nos pilares através de uma chapa de ligação parafusada na mesa superior da 
viga e no enrijecedor de alma do pilar, conforme ilustra o DET.I da Figura 4.21. As vigas secundárias VG03 e VG04 são apoiadas nos pilares (DET.Il da Figura 4.22), reproduzindo o mesmo tipo de ligação das vigas secundárias dos modelos isolados.

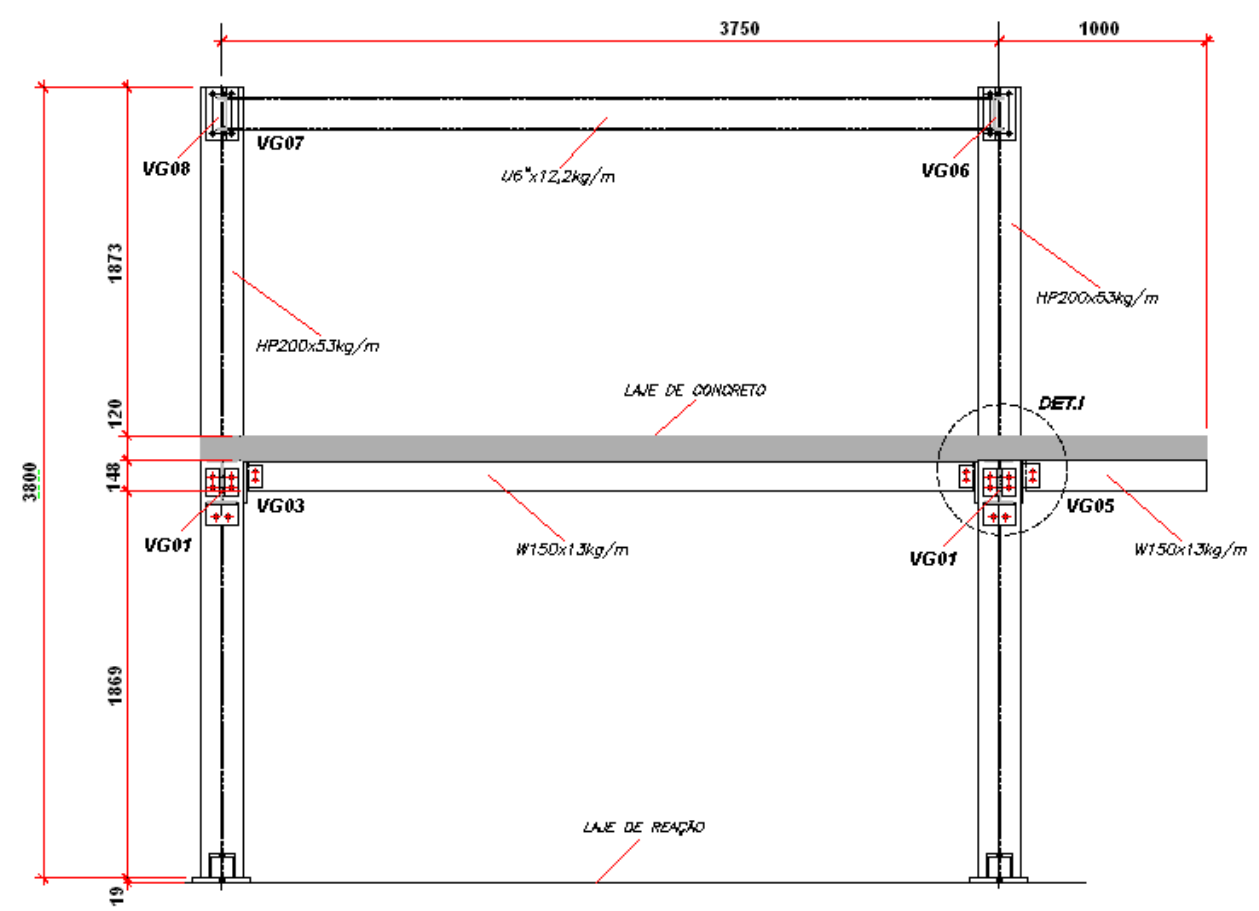

Figura 4.20: Elevação frontal do pavimento tipo - Corte BB (mm).

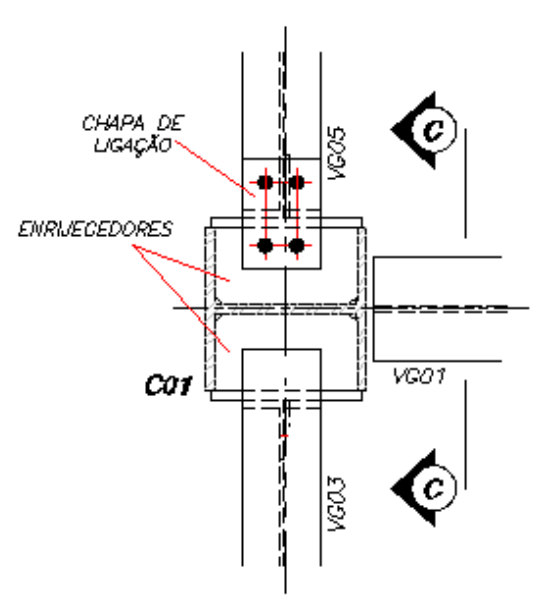

$\underline{\text { PLANTA }}$

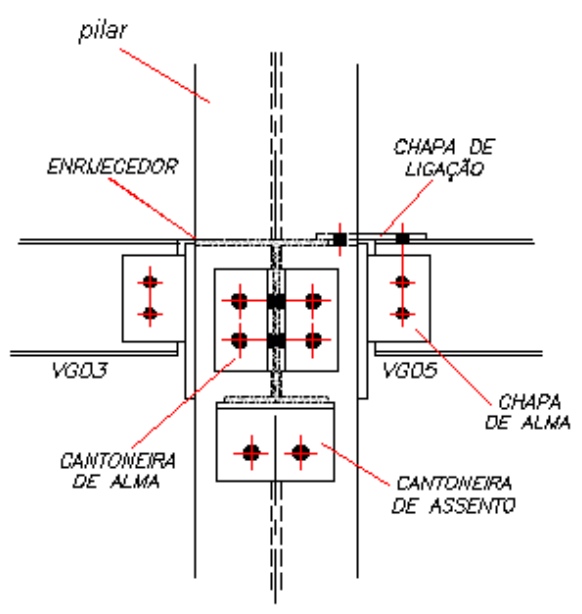

$\underline{\text { CORTE-CQ }}$

Figura 4.21: Detalhe I. 


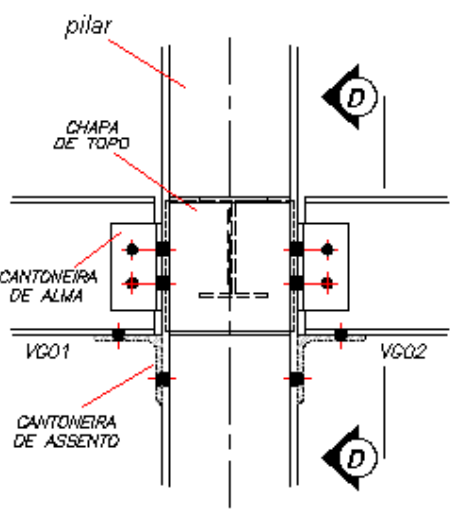

$\underline{\text { VSTA }}$

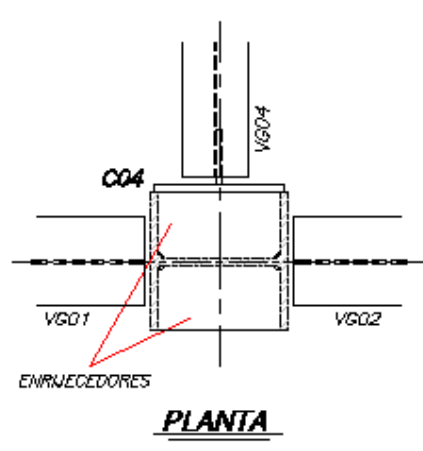

$\underline{\text { PLANTA }}$

Figura 4.22: Detalhe II.

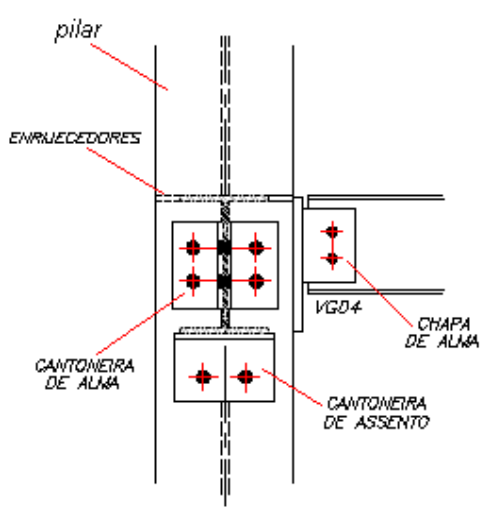

COATE-DD

\subsection{2 - Montagem do pavimento tipo}

Neste item será descrito todo o procedimento de montagem do pavimento tipo, com o posicionamento das vigotas pré-moldadas e lajotas, montagem das formas e procedimentos de concretagem.

O procedimento de montagem do pavimento tipo iniciou-se com a marcação e posicionamento dos pilares na laje de reação e, em seguida, foram montados as vigas de contraventamento dos pilares, seguido pelas vigas principais e secundárias, e por último, as vigas em balanço.

A Figura 4.23 a seguir ilustra a base do pilar, com os chumbadores conectados na laje de reação, e o detalhe da ligação das vigas de contraventamento no topo do pilar. Na Figura 4.24 têm-se uma visão geral após a montagem da estrutura metálica.
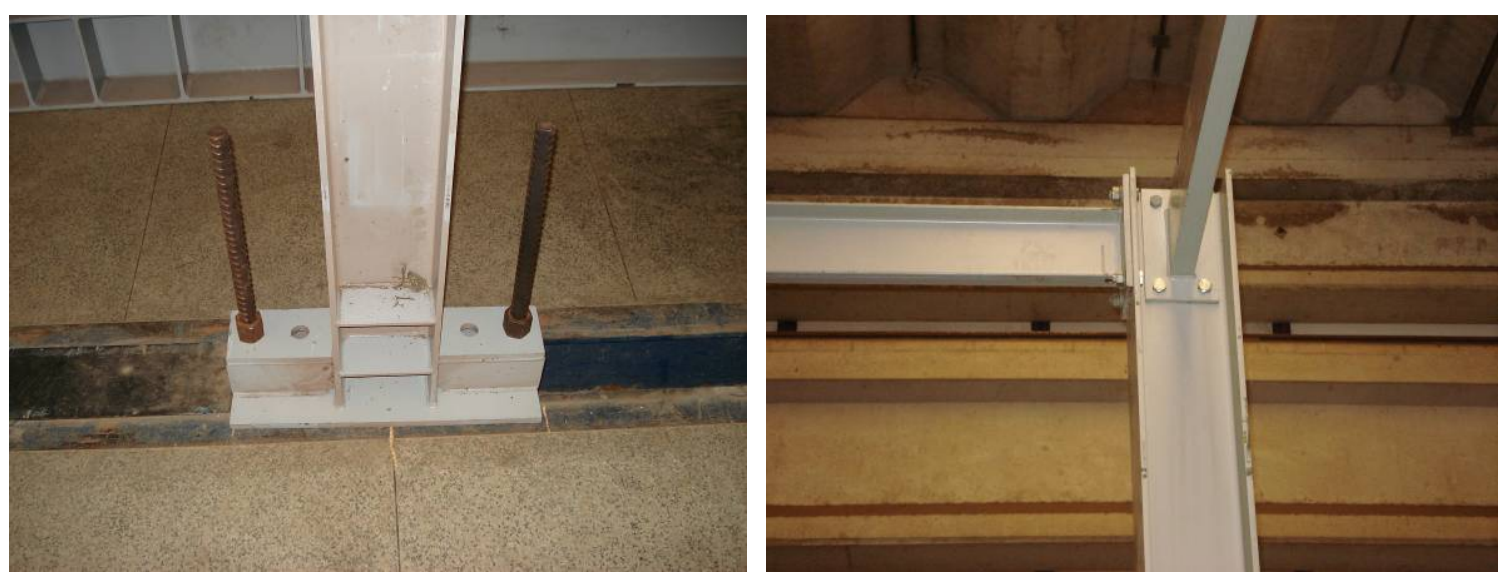

Figura 4.23: Detalhe da base do pilar e das vigas de contraventamento. 


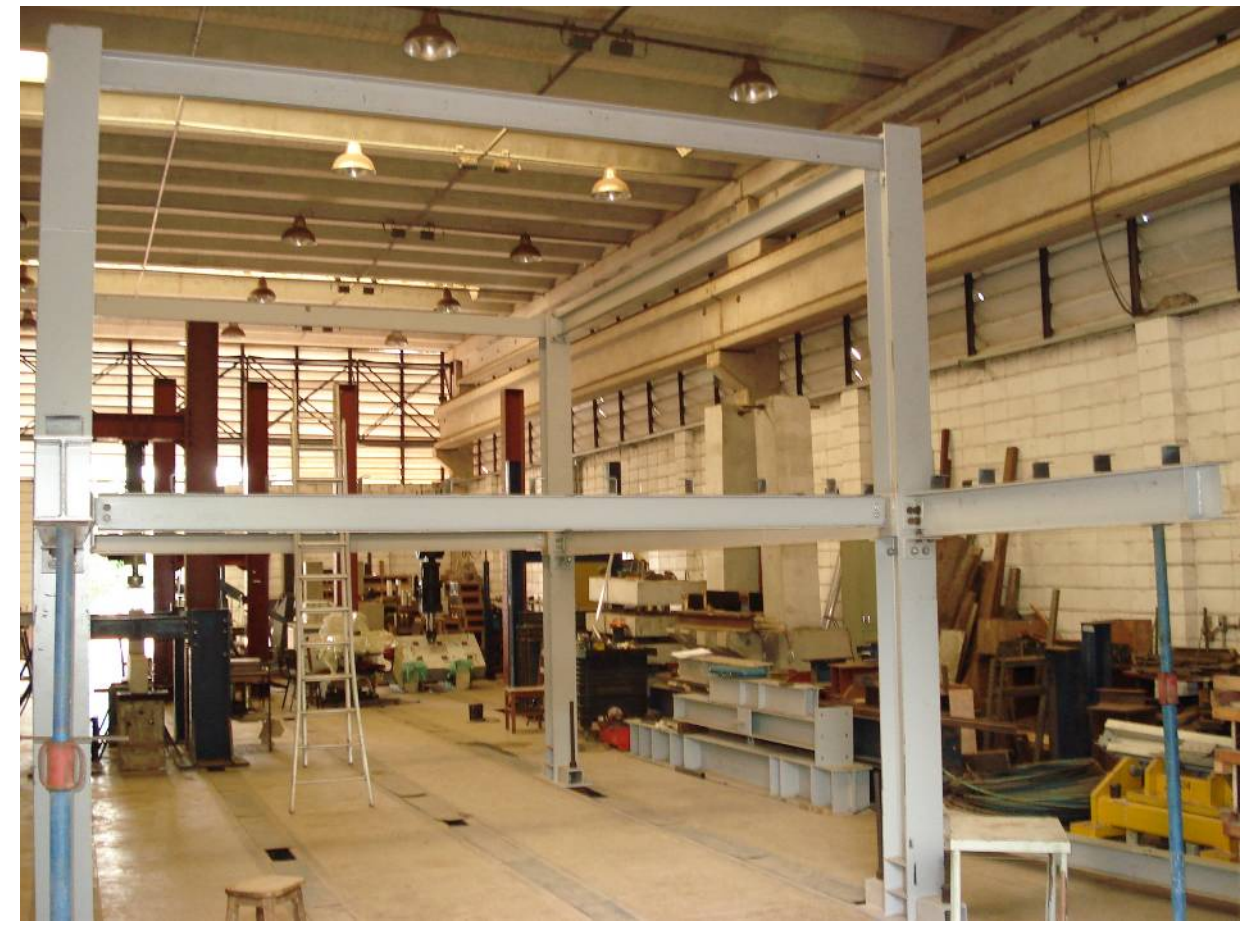

Figura 4.24: Visão geral da estrutura metálica do pavimento tipo.

A Figura 4.25 ilustra cada ligação do pavimento tipo, de acordo com numeração apresentada na Figura 4.17. Após a montagem de todas as vigas, foi realizado o primeiro procedimento de aperto dos parafusos para posterior colocação das fôrmas e sistemas de apoio.

As formas foram posicionadas nas regiões próximas das vigas secundárias, onde não foi preenchido com lajotas ou vigotas pré-moldadas. Apesar da utilização de vigotas em uma direção, a laje foi armada nas duas direções com a utilização de canaletas cerâmicas, posicionadas na direção perpendicular das vigotas. Todo esquema de posicionamento das vigotas, lajotas, canaletas e das armaduras do pavimento tipo estão detalhados no Apêndice $A$.

A Figura 4.26 ilustra o pavimento tipo após a montagem das formas, posicionadas apenas na região sem o preenchimento das vigotas prémoldadas e lajotas. Na Figura 4.27 têm-se uma visão geral do pavimento tipo antes da concretagem. 
Capítulo 4: Ensaios experimentais dos protótipos isolados e pavimento tipo

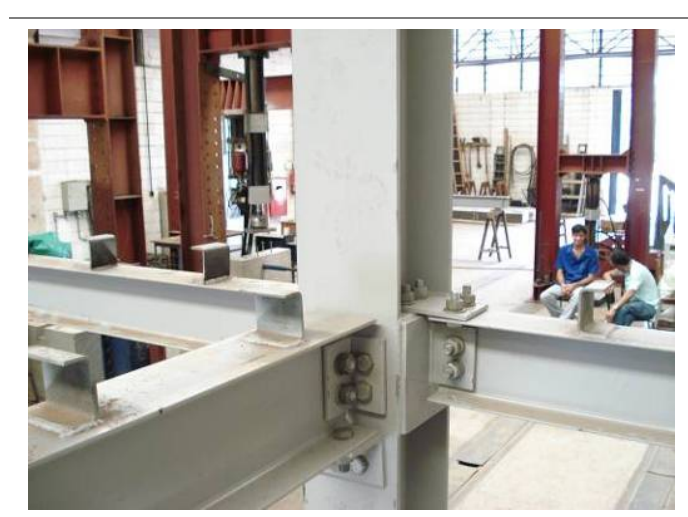

Ligação 1

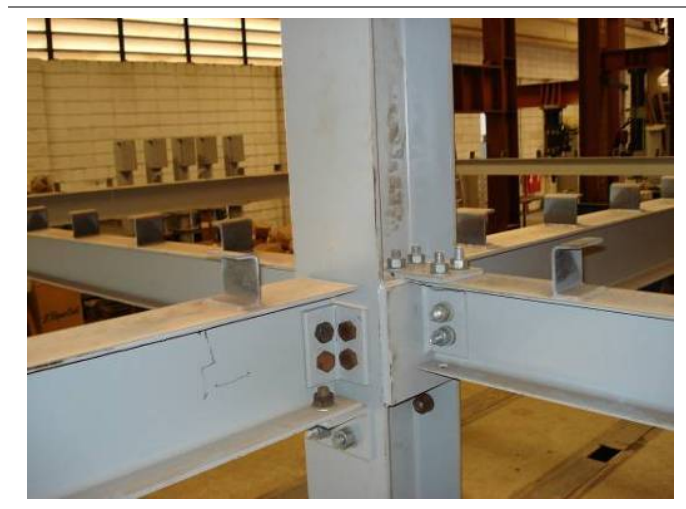

Ligação 3

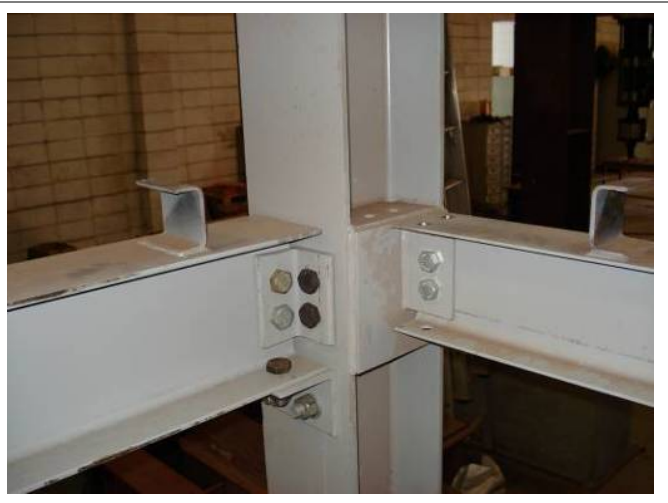

Ligação 2

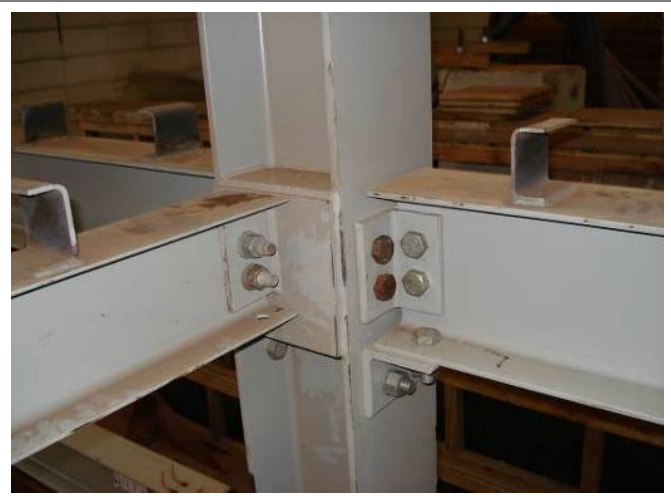

Ligação 4

Figura 4.25: Nós do pavimento tipo.

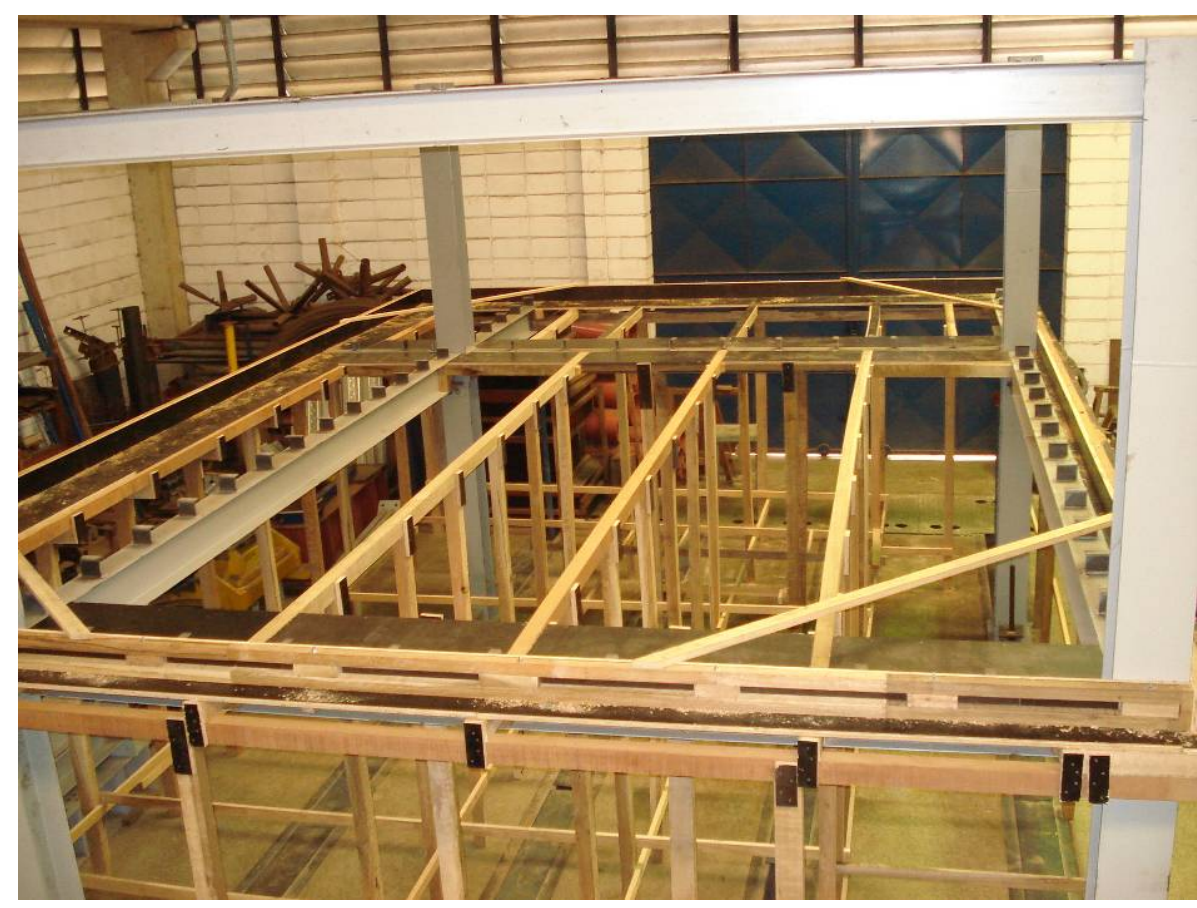

Figura 4.26: Visão geral do pavimento tipo após a montagem das formas. 


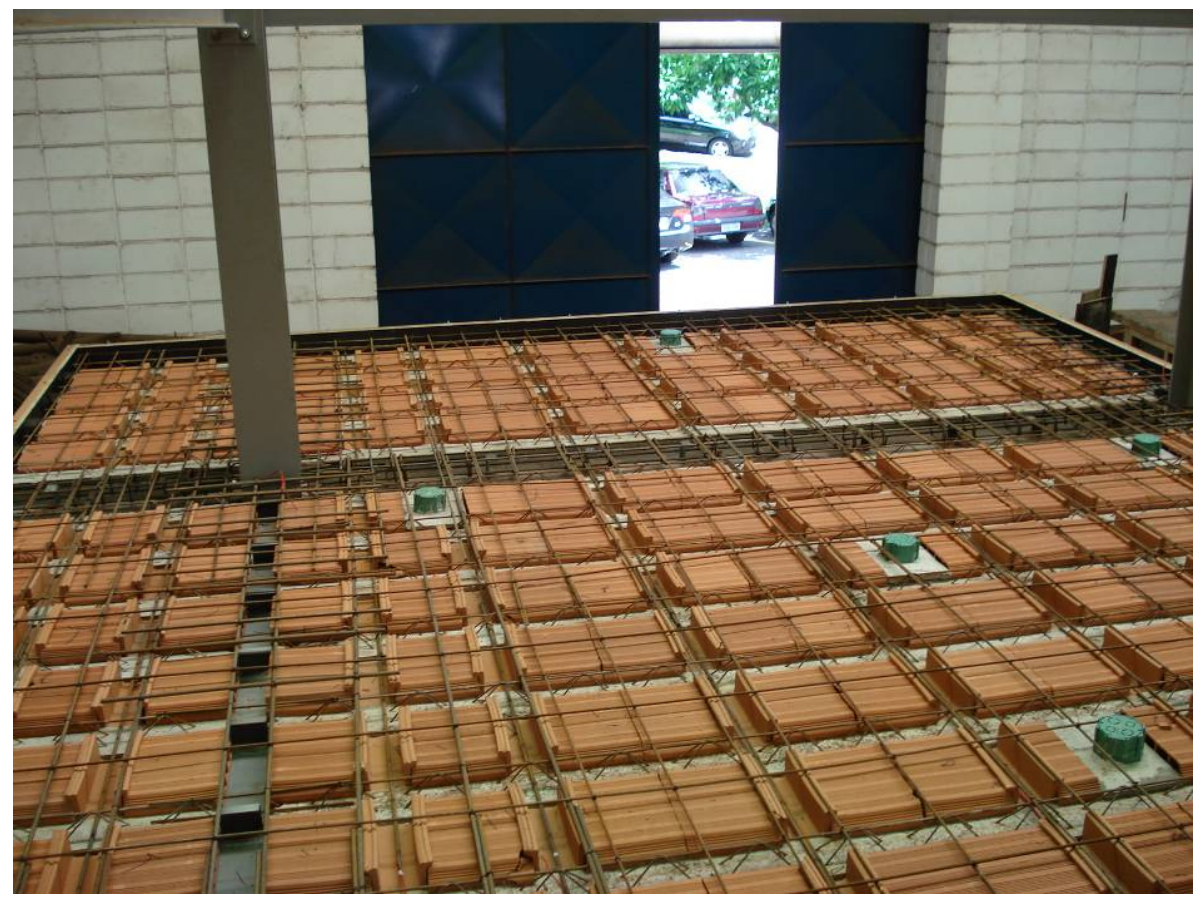

Figura 4.27: Visão geral do pavimento tipo antes da concretagem.

A concretagem do pavimento tipo demandou de aproximadamente $4 \mathrm{~m}^{3}$ de concreto usinado, toda a operação de concretagem durou aproximadamente 3 horas e contou com o auxílio de um caminhão munck, além da ponte rolante do galpão do laboratório, para alcançar todos os pontos do pavimento. A Figura 4.28 abaixo ilustra a sequência de concretagem do pavimento tipo.
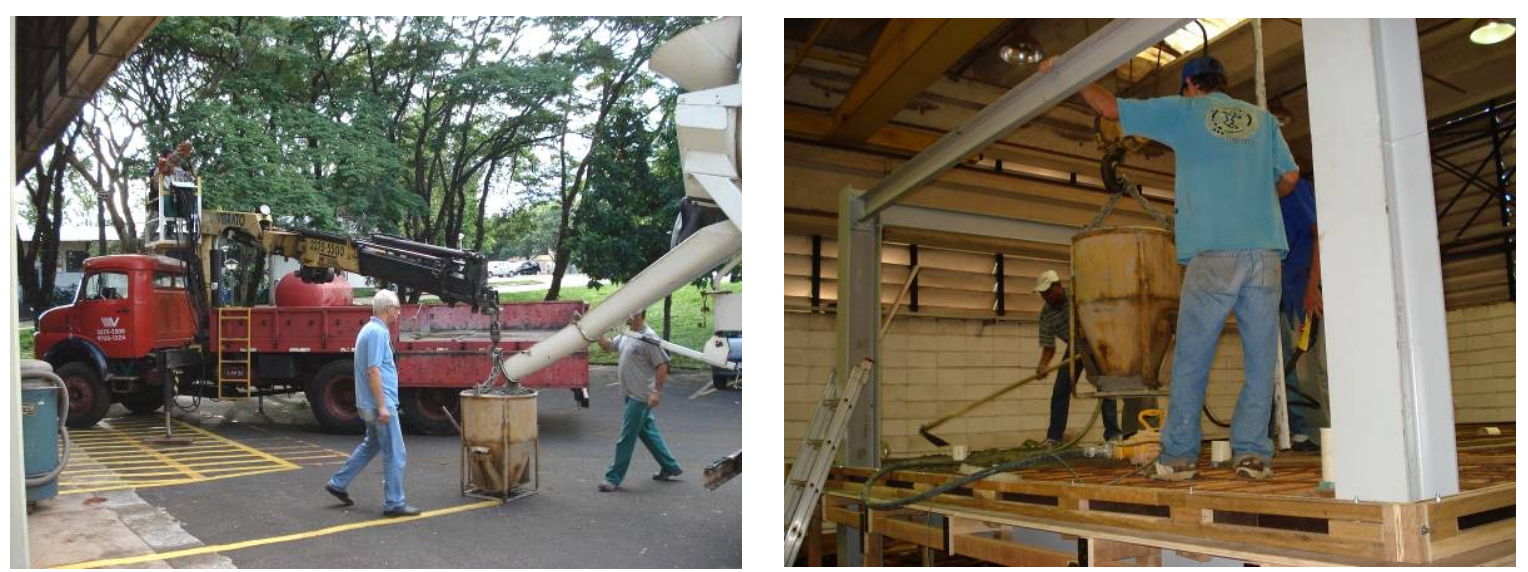

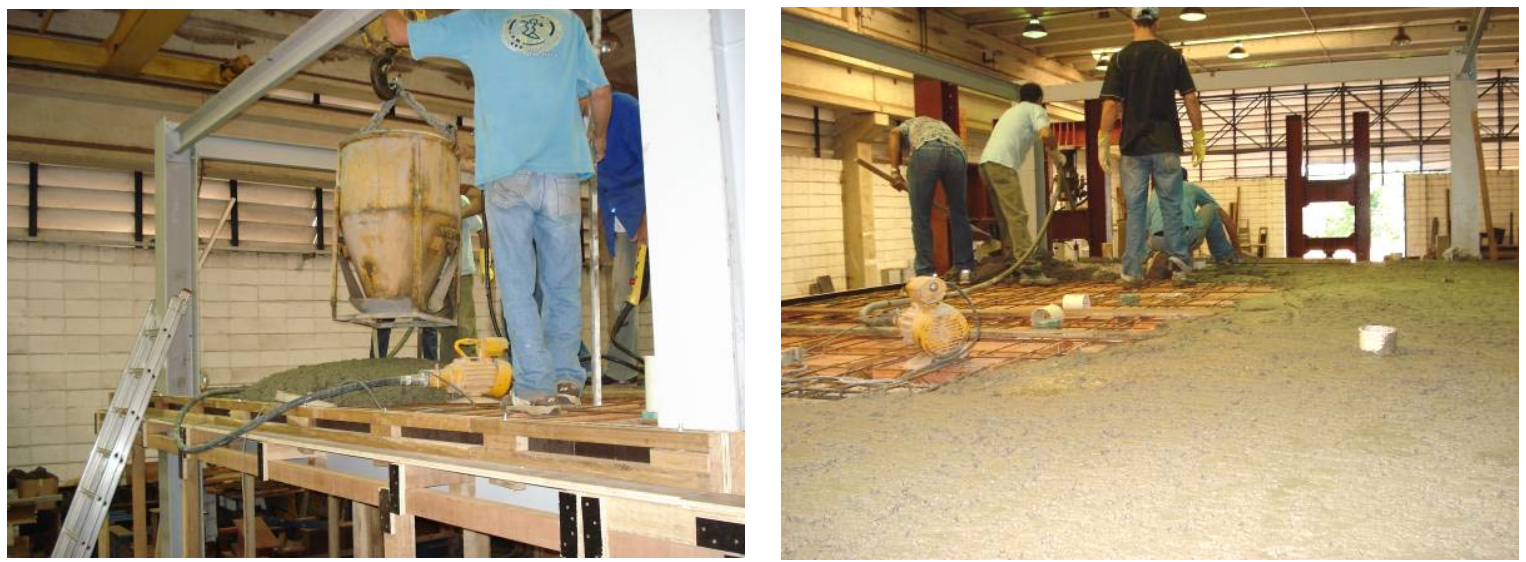

Figura 4.28: Sequência de concretagem do pavimento tipo.

\subsection{3 - Etapas de aplicação do carregamento}

O carregamento no pavimento tipo foi constituído de duas etapas, obedecendo a seguinte ordem:

1) Carregamento distribuído na laje, constituído de oito fases em estado limite de serviço;

2) Carregamento concentrado, aplicado em nove fases distintas na laje e sobre as vigas principais do pavimento tipo.

A primeira etapa de carregamento no pavimento tipo simulou um carregamento uniformemente distribuído, com o objetivo de solicitar a laje e observar a formação de fissuras durante o estado limite de serviço, principalmente nas regiões próximas das ligações. Para tal solicitação, utilizaram-se placas pré-moldadas de concreto e outras peças pré-moldadas disponíveis no Laboratório de Estruturas, posicionadas no vão central da laje e nos balanços.

As placas pré-moldadas possuíam dimensões iguais a $240 \times 50 \mathrm{~cm} \mathrm{e}$ espessuras de 8 e $10 \mathrm{~cm}$. Foram utilizadas 10 placas de $8 \mathrm{~cm}$ de espessura com peso igual a $240 \mathrm{kgf}$ cada peça e 5 placas com espessura de $10 \mathrm{~cm}$ e peso igual a $300 \mathrm{kgf}$ cada.

Adicionalmente, foram utilizadas 5 peças de concreto de base com dimensões iguais a $40 \times 40 \mathrm{~cm}$ e peso igual a $160 \mathrm{kgf}$ cada, 3 placas de concreto de dimensões iguais a $150 \times 80 \mathrm{~cm}$, espessura de $20 \mathrm{~cm}$ e peso igual a $600 \mathrm{kgf}$ cada e 2 placas de concreto de dimensões iguais a $150 \times 80 \mathrm{~cm}$, 
espessura de $25 \mathrm{~cm}$ e peso igual a $750 \mathrm{kgf}$ cada. A Figura 4.29 ilustra essas peças pré-moldadas.
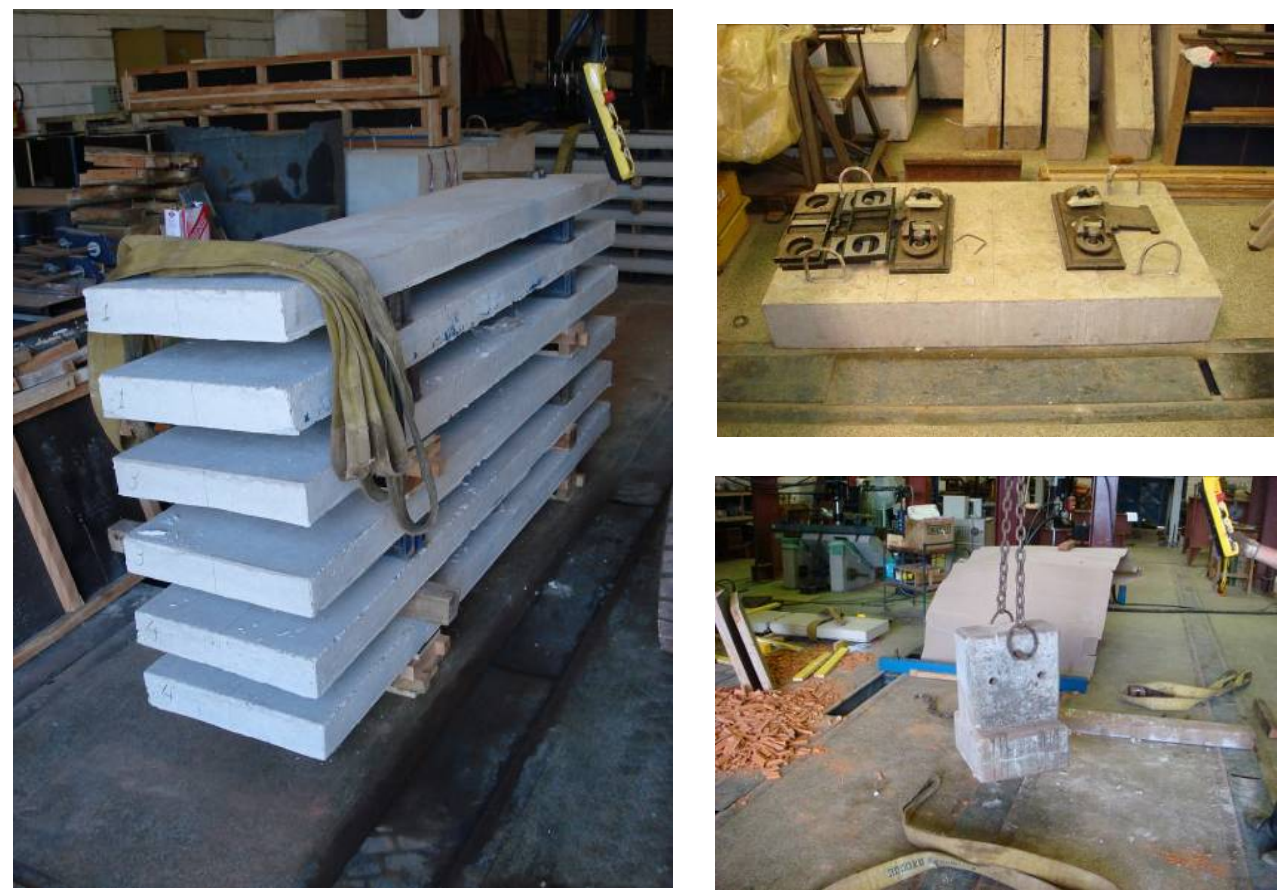

Figura 4.29: Visão geral das peças pré-moldadas utilizadas na etapa de carregamento distribuído do pavimento tipo.

A Tabela 4.2 apresenta uma descrição resumida das oito fases da etapa de carregamento distribuído na laje do pavimento tipo, com o respectivo esquema de carregamento em planta e a sobrecarga em cada área indicada na figura de acordo com a respectiva fase.

Tabela 4.2: Esquema de ensaio e descrição resumida das oito fases da etapa de carregamento distribuído.

\begin{tabular}{|c|c|c|c|}
\hline \multirow{6}{*}{1} & $\mathrm{H}_{1}$ & \multirow{5}{*}{3} & \multirow{5}{*}{$\begin{array}{l}\text { Carregamento com } 10 \text { placas } \\
(240 \times 50 \mathrm{~cm}) \text { de } 8 \mathrm{~cm} \text { de espessura } \\
(240 \mathrm{Kgf} \text { cada): } \\
\text { Área }(1)=128 \mathrm{Kgf} / \mathrm{m}^{2} ; \\
\text { Área }(2)=0 ; \\
\text { Área }(3)=0 .\end{array}$} \\
\hline & & & \\
\hline & & & \\
\hline & & & \\
\hline & & & \\
\hline & $H$ & 4 & \\
\hline
\end{tabular}




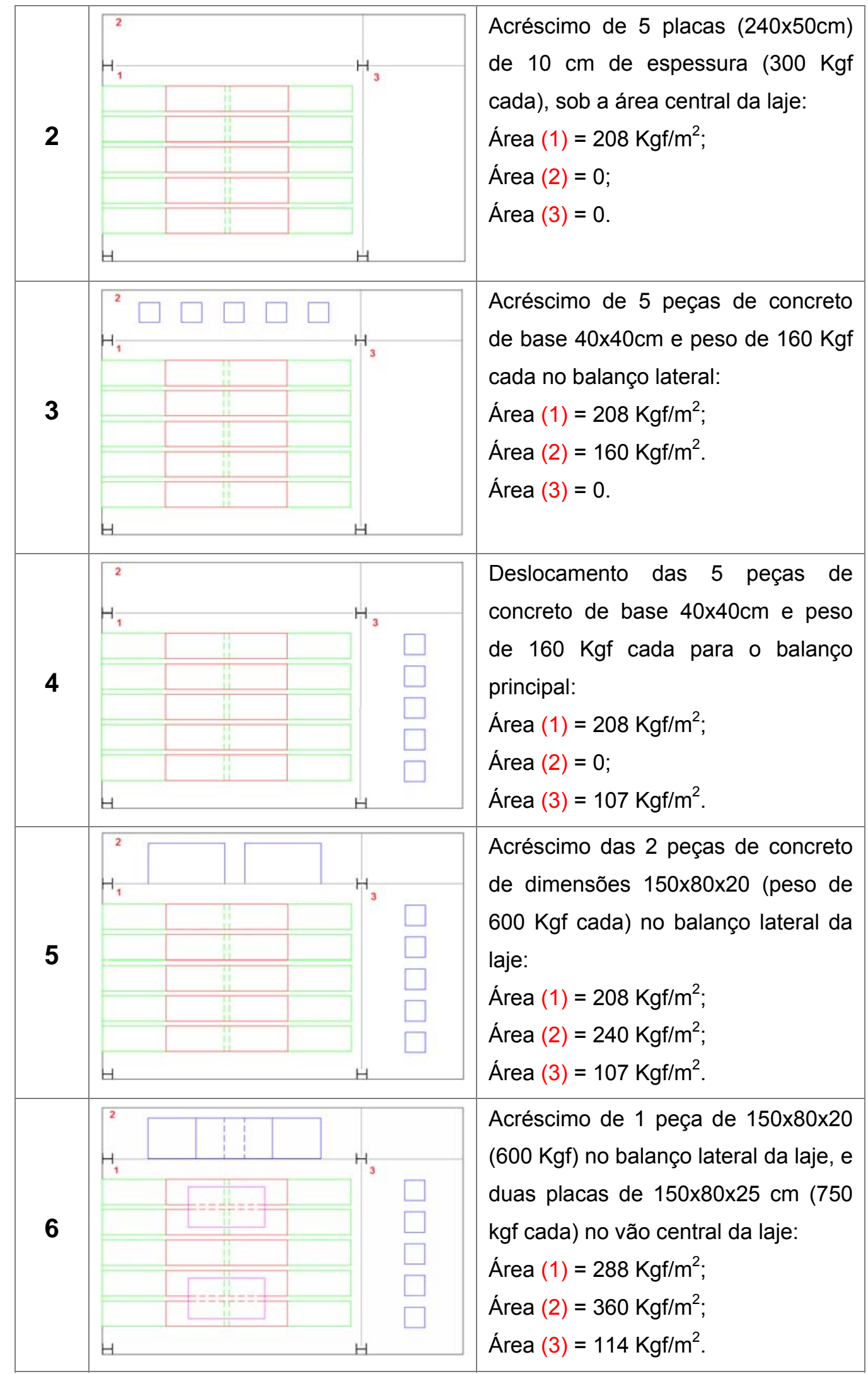




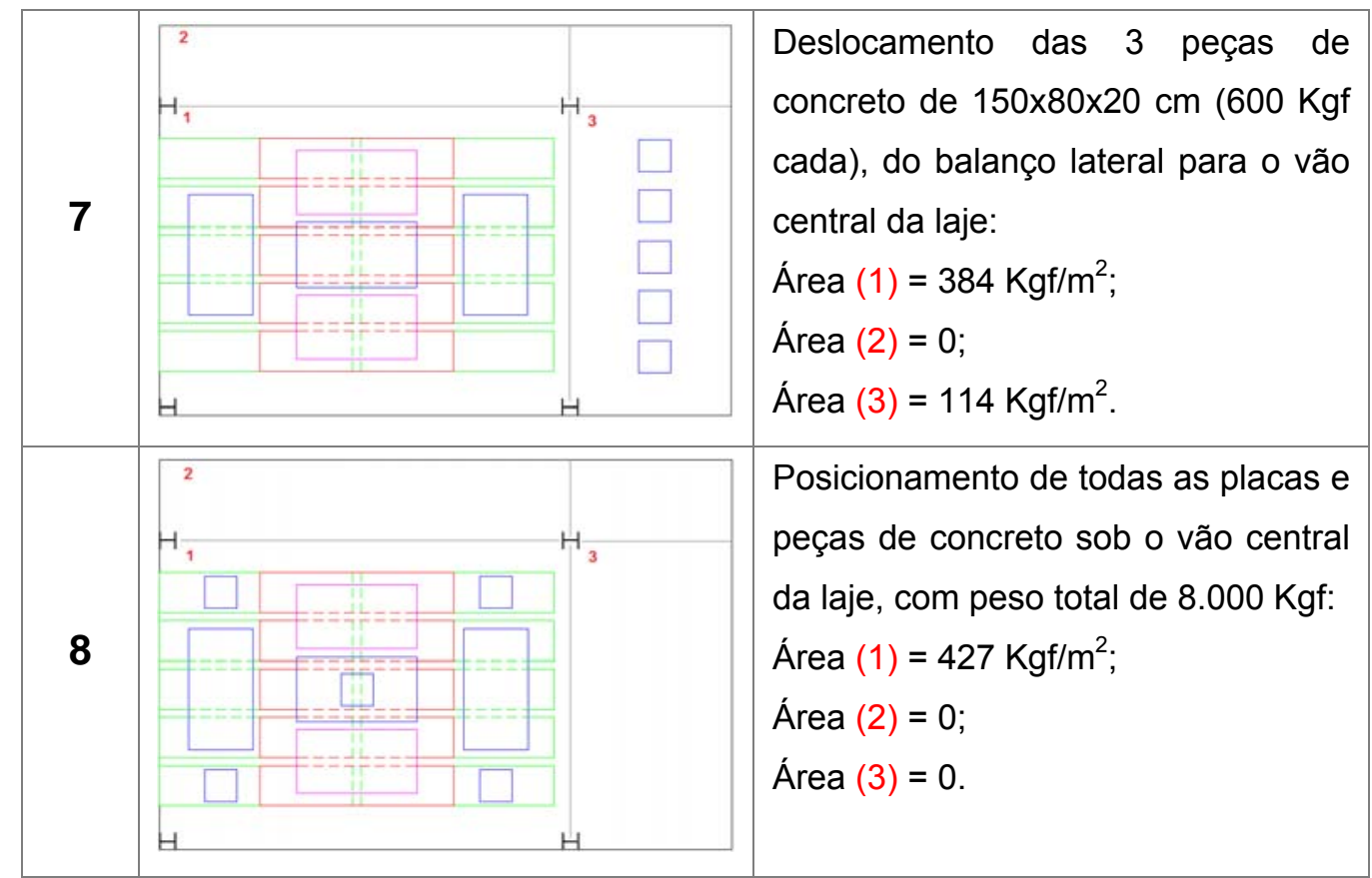

A Figura 4.30 ilustra a visão geral da última fase da etapa de carregamento distribuído na laje do pavimento tipo.
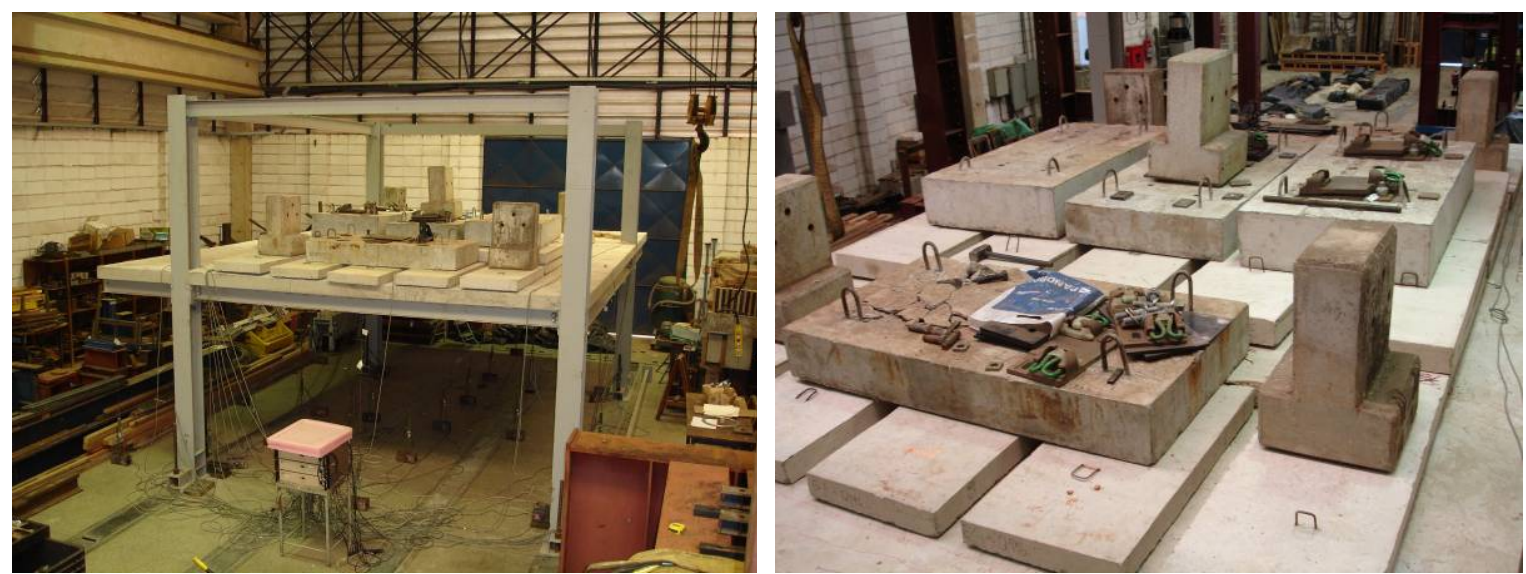

Figura 4.30: Visão geral da última fase da etapa do carregamento distribuído.

Para o carregamento concentrado, foi utilizado um sistema de reação especial, montado sob o pavimento tipo. Esse sistema, que consistiu de um pórtico de aproximadamente $1 \mathrm{~m}$ de altura conectada na laje de reação, permitiu a fixação da célula de carga (atuador hidráulico) com capacidade da carga de $300 \mathrm{kN}$.

O carregamento concentrado foi aplicado sobre a laje utilizando-se perfis metálicos de elevada rigidez. Estes perfis foram ligados por cordoalhas aos 
pórticos de reação posicionados abaixo da laje, através de alguns pontos prédefinidos na laje que não foram concretados.

A Figura 4.31 ilustra os pontos de passagem das cordoalhas para a aplicação do carregamento, e a Figura 4.32 apresenta o pórtico de reação montado sob a laje do pavimento tipo, com a célula de carga e os perfis de elevada rigidez para aplicação do carregamento concentrado.

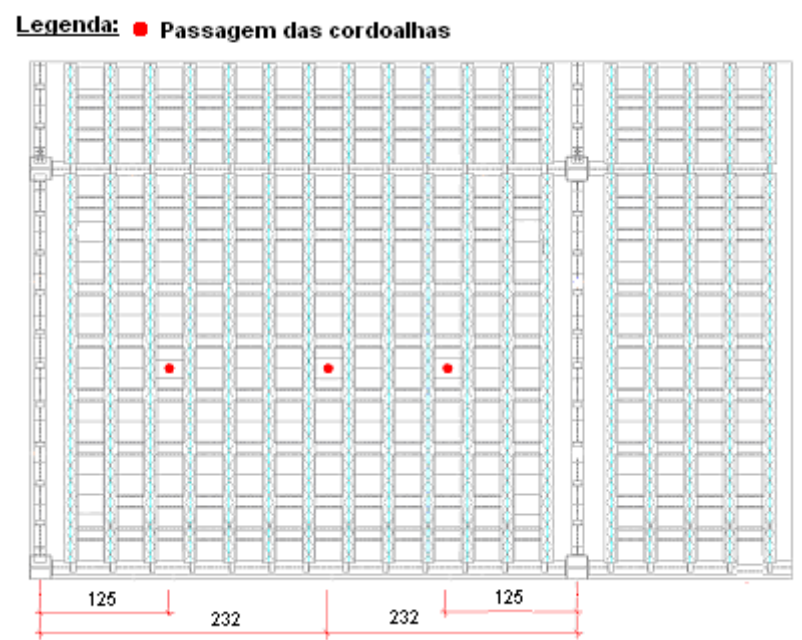

Figura 4.31: Pontos de passagem das cordoalhas para o carregamento concentrado na laje e na viga principal.
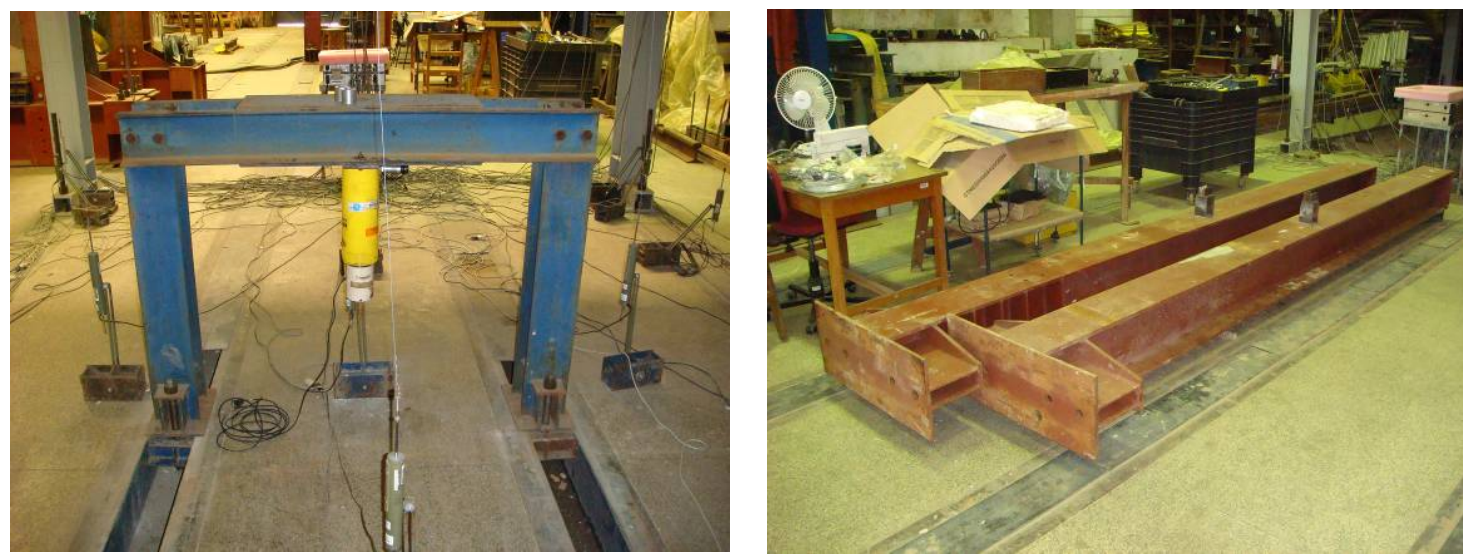

Figura 4.32: Pórtico de reação sob a laje do pavimento tipo e perfis de elevada rigidez para aplicação do carregamento concentrado.

Estes perfis de elevada rigidez utilizados para o carregamento concentrado foram pilares pertencentes a um pórtico de reação do Laboratório de Estruturas, com a soldagem de mecanismos auxiliares de ancoragem e 
apoio, devidamente dimensionados para resistirem a solicitação prevista em cada fase da etapa de carregamento concentrado.

Os esquemas de carregamento com a respectiva descrição resumida de cada fase da etapa de carregamento concentrado estão apresentados na Tabela 4.3 abaixo.

Tabela 4.3: Esquema de ensaio e descrição resumida das nove fases da etapa de carregamento concentrado no pavimento tipo.

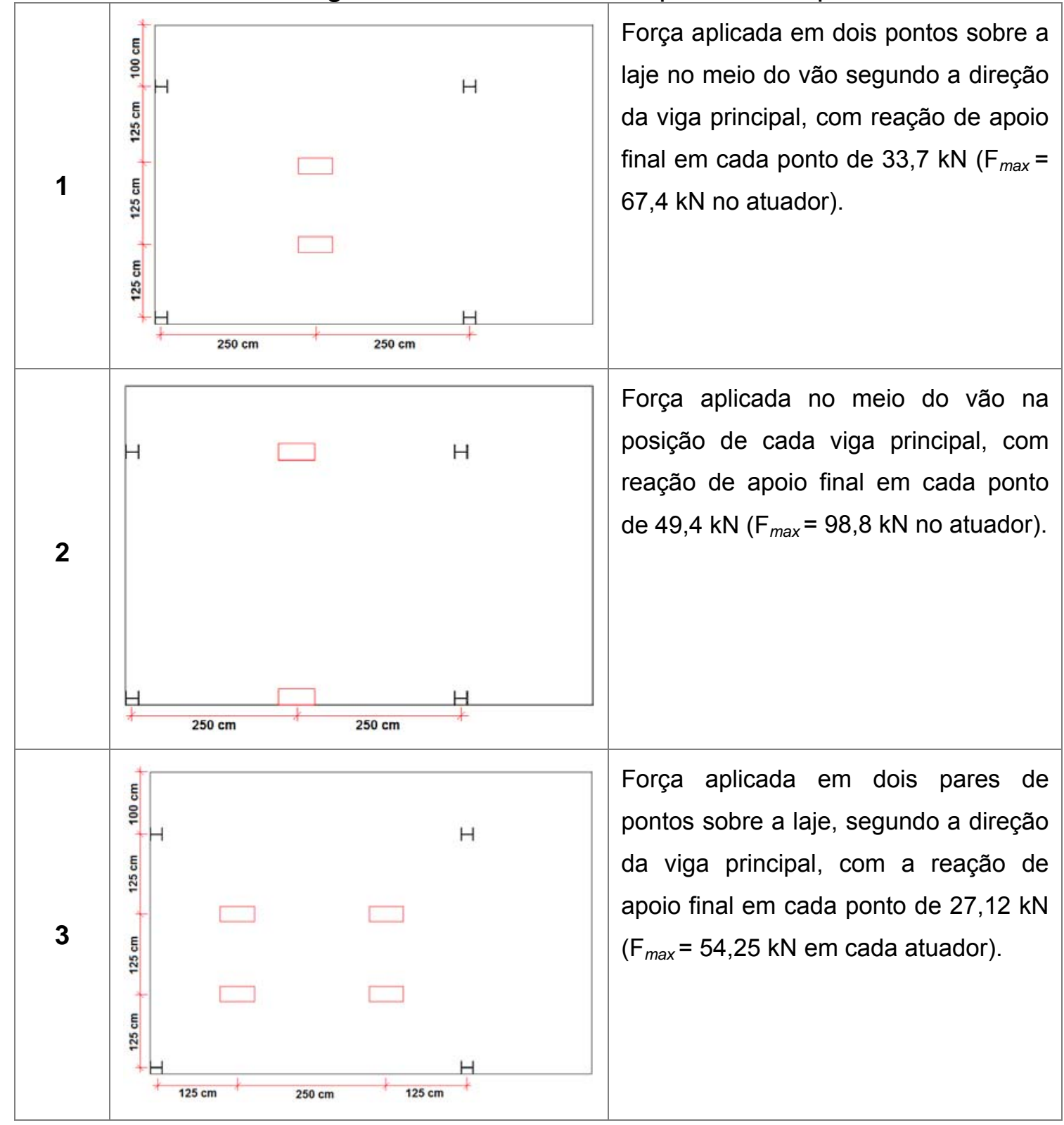


Capítulo 4: Ensaios experimentais dos protótipos isolados e pavimento tipo

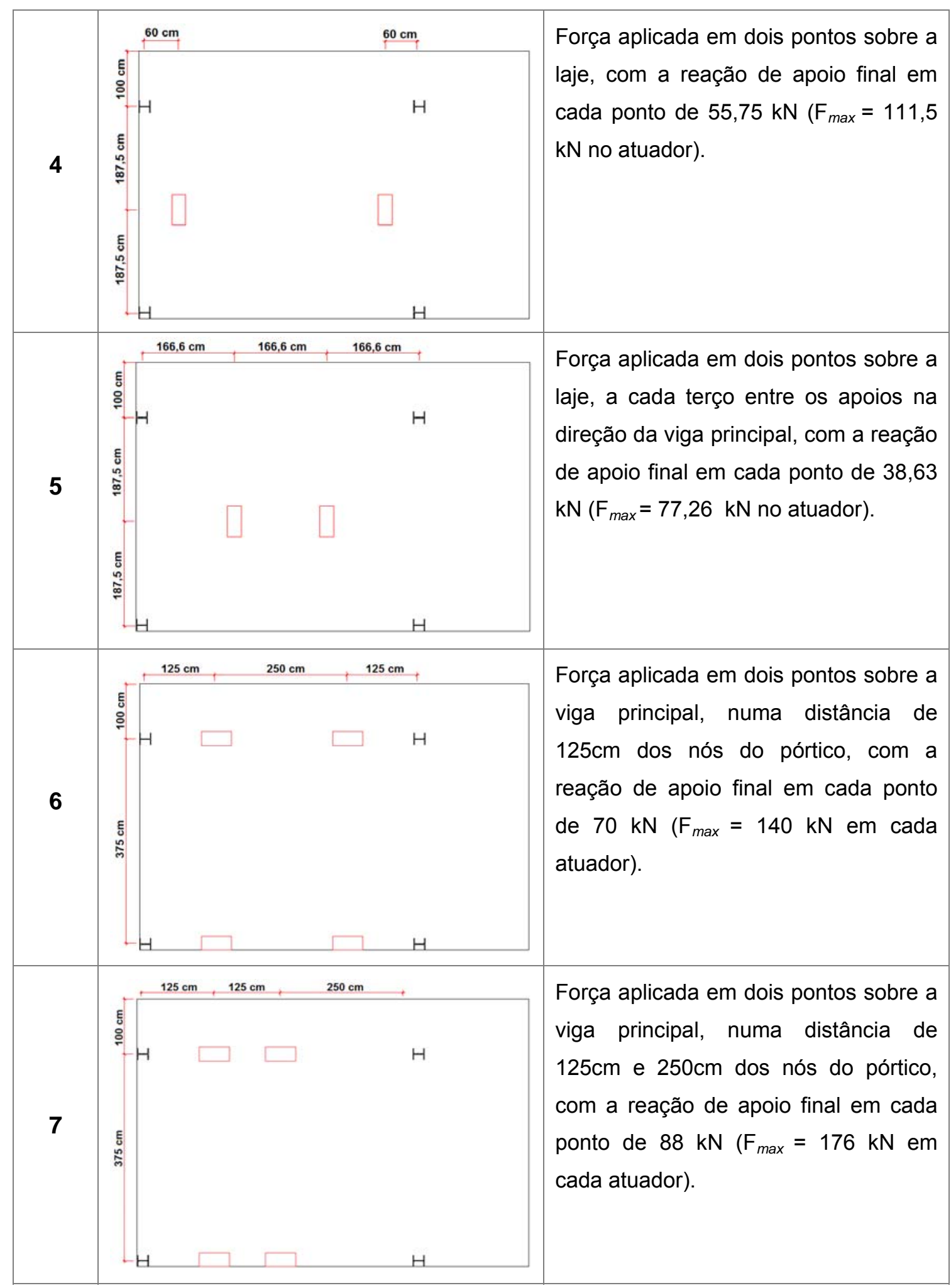




\begin{tabular}{|c|c|c|c|c|}
\hline 8 & $\begin{array}{l}E \\
\stackrel{\Xi}{-} \\
-H\end{array}$ & $\square \square$ & $\mathrm{H}$ & $\begin{array}{l}\text { Força aplicada em dois pontos sobre a } \\
\text { viga principal, numa distância de } \\
195 \mathrm{~cm} \text { e } 230 \mathrm{~cm} \text { dos nós do pórtico, } \\
\text { com a reação de apoio final em cada } \\
\text { ponto de } 110 \mathrm{kN} \text { ( } F_{\max }=220 \mathrm{kN} \text { em } \\
\text { cada atuador). } \\
\text { Nesta fase ocorreu o colapso da } \\
\text { ligação } 1 \text { devido à abertura excessiva } \\
\text { de fissuras na laje de concreto. }\end{array}$ \\
\hline 9 & 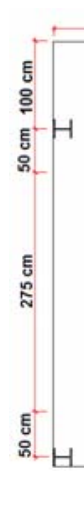 & $\square \square$ & $\mathrm{H}$ & $\begin{array}{l}\text { Força aplicada em dois pontos sobre a } \\
\text { laje, na mesma distância de } 195 \mathrm{~cm} \text { e } \\
230 \mathrm{~cm} \text { dos nós do pórtico da fase } 8 \text {, } \\
\text { com a reação de apoio final em cada } \\
\text { ponto de } 55 \mathrm{kN} \text { ( } F_{\text {max }}=110 \mathrm{kN} \text { em } \\
\text { cada atuador). } \\
\text { Esta última fase foi concebida para } \\
\text { atingir o colapso da laje do pavimento } \\
\text { tipo. }\end{array}$ \\
\hline
\end{tabular}

A Figura 4.33 ilustra as fases 1 e 8 do carregamento concentrado no pavimento tipo, com todo o esquema de montagem do ensaio, aplicação do carregamento e leitura de dados.

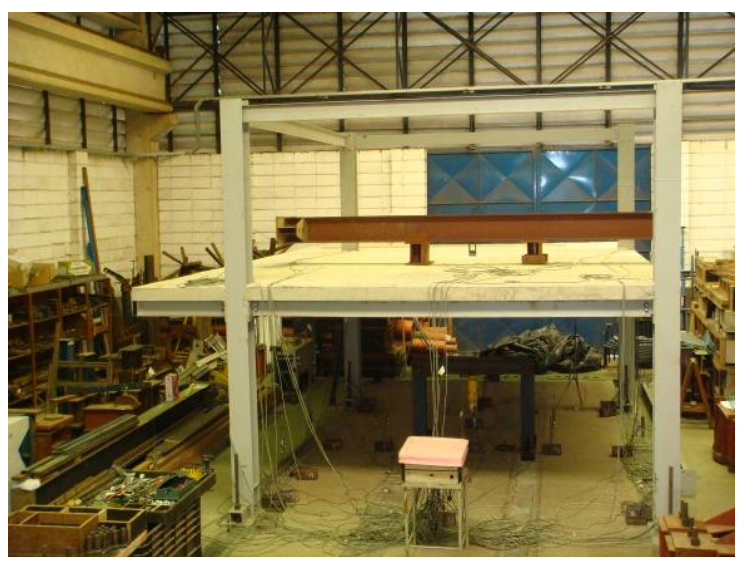

Carregamento concentrado: Fase 1

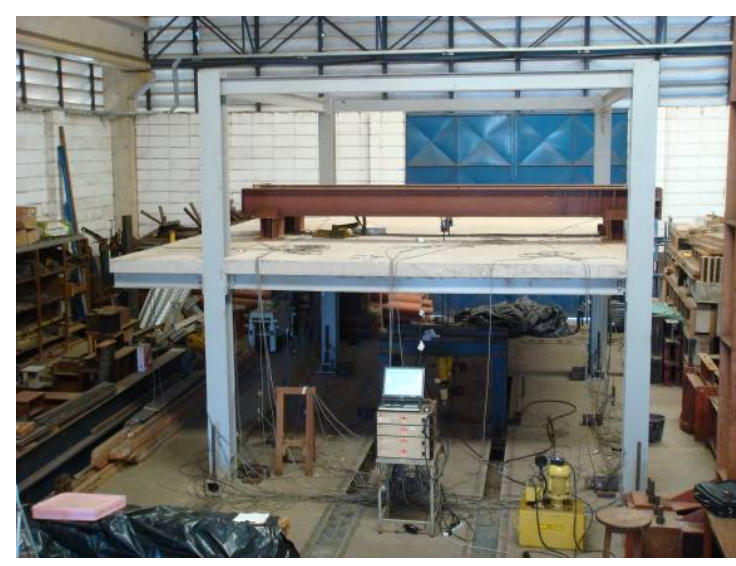

Carregamento concentrado: Fase 8

Figura 4.33: Fases 1 e 8 da etapa de carregamento concentrado na laje do pavimento tipo. 


\subsection{4 - Instrumentação}

A instrumentação do pavimento tipo seguiu os mesmos critérios dos modelos isolados, tendo como objetivo medir deformações localizadas e o deslocamento vertical nas vigas, próximo das ligações e no vão central, e em alguns pontos pré-definidos da laje. Para tal, foram utilizados extensômetros uniaxiais e transdutores de deslocamento.

Os extensômetros foram posicionados próximos às ligações e no meio do vão nas vigas principais do pavimento tipo. Os extensômetros da mesa superior foram posicionados na face inferior da mesa por terem sido colados após a concretagem do pavimento tipo. As Figuras 4.34, 4.35 e 4.36 ilustram as posições dos extensômetros na viga principal entre apoios do pavimento tipo

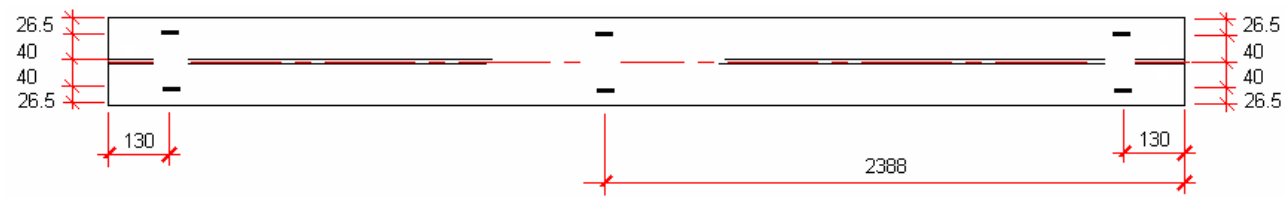

Figura 4.34: Posição dos extensômetros nas mesas superior e inferior da viga principal entre apoios.

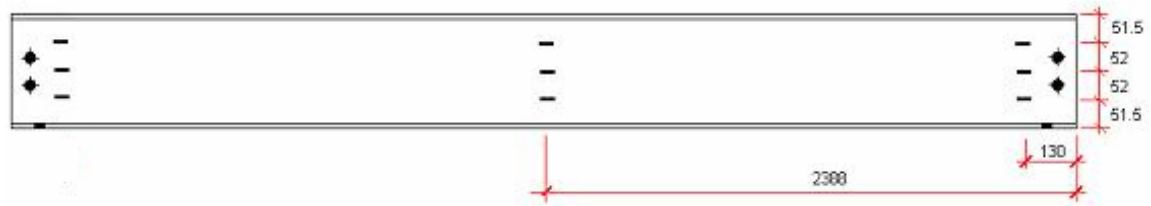

Figura 4.35: Posição dos extensômetros na alma da viga principal entre apoios.
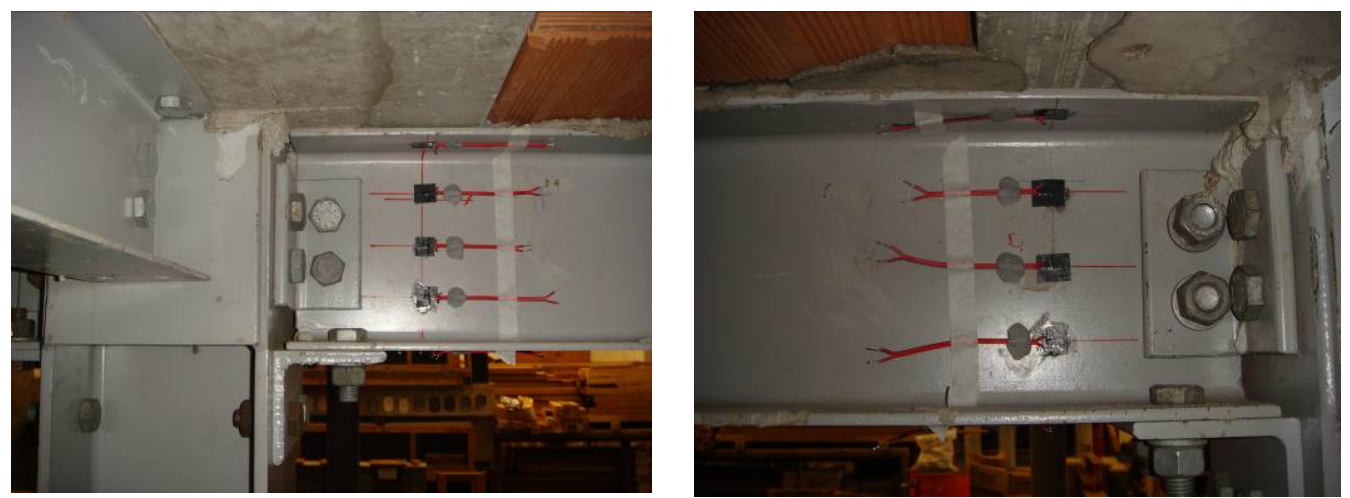

Figura 4.36: Extensômetros da viga principal do pavimento tipo.

Além da viga principal, também foram posicionados extensômetros nas armaduras de contorno e longitudinal negativa junto aos pilares do pavimento 
tipo, seguindo mesmo critério adotado para os protótipos isolados, conforme ilustram as Figuras 4.37 e 4.38.

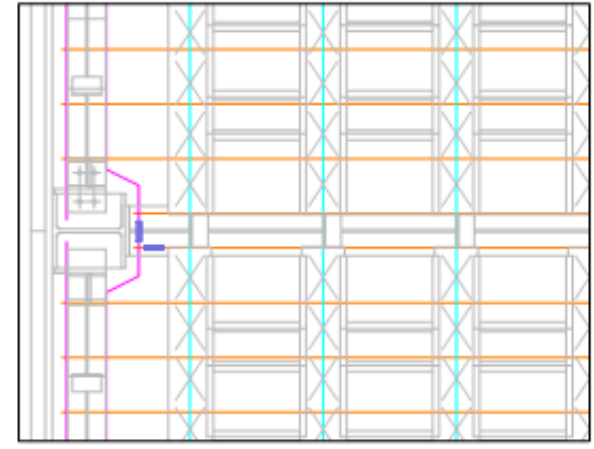

Ligação 1

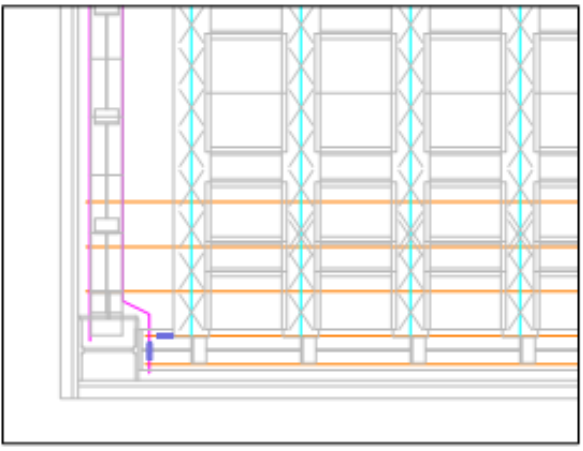

Ligação 2

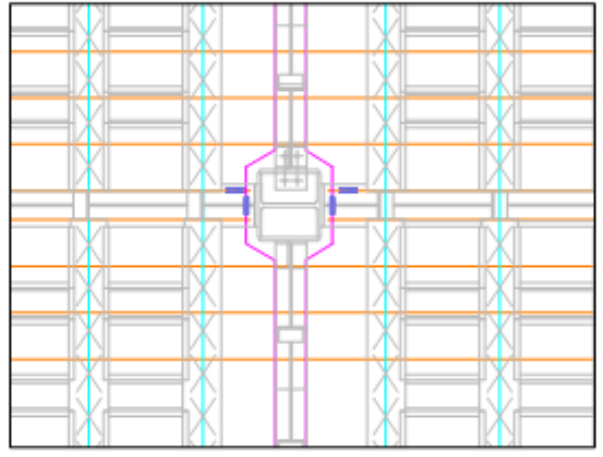

Ligação 3

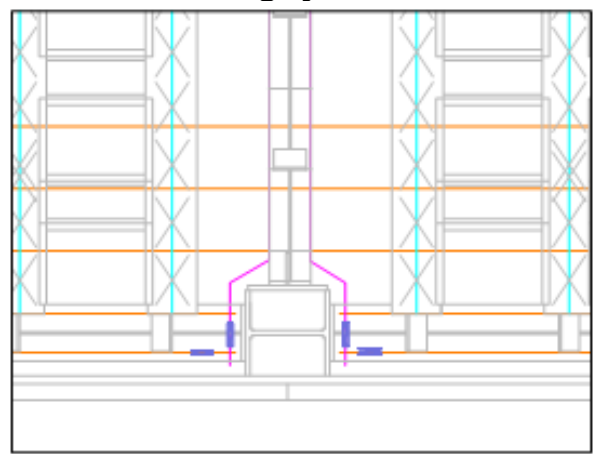

Ligação 4

Figura 4.37: Posição dos extensômetros na armadura de contorno e longitudinal negativa nas ligações do pavimento tipo.
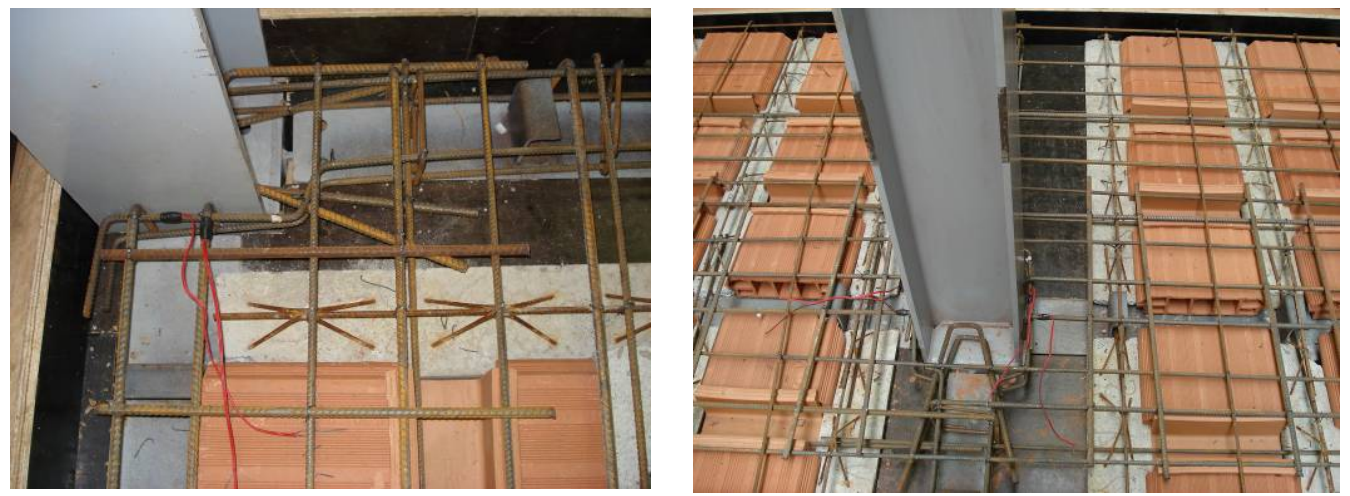

Figura 4.38: Extensômetros das armaduras da laje do pavimento tipo.

Os transdutores de deslocamento foram posicionados junto a viga principal, próximo das ligações (com o objetivo de se obter as rotações), além do meio do vão e balanço. Também foram escolhidos pontos pré-determinados na laje e na viga secundária para a aferição dos deslocamentos, conforme ilustra a Figura 4.39. 


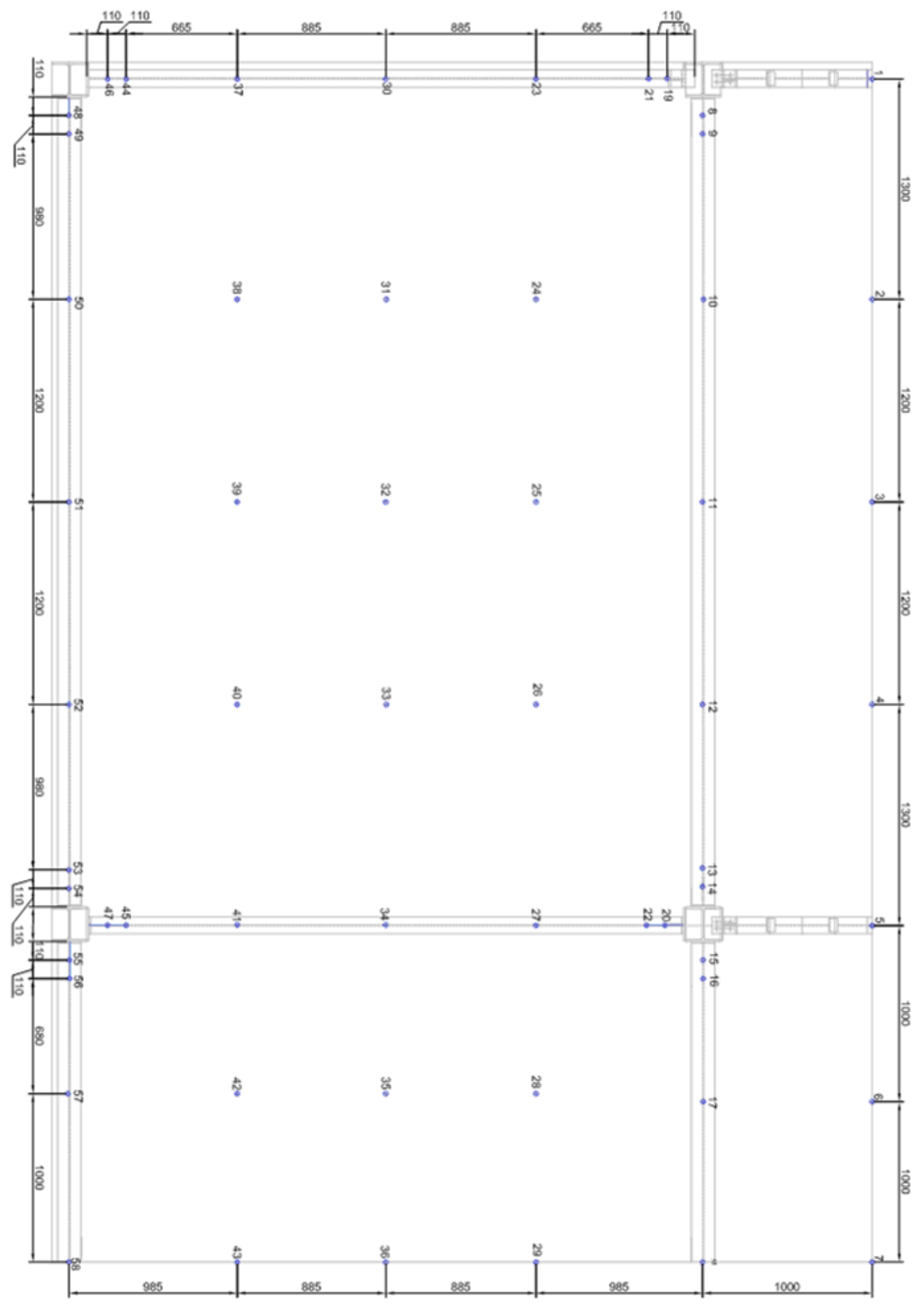

Figura 4.39: Posicionamento dos transdutores de deslocamento na viga principal e laje do pavimento tipo. 
No total, foram definidos 58 pontos de medição de deslocamentos, englobando a laje e as vigas (principais e secundárias) do pavimento tipo, que foram selecionados de acordo com o resultado a ser obtido em cada fase das etapas de carregamento.

$\mathrm{Na}$ Figura 4.40 tem-se os transdutores de deslocamento sob a laje do pavimento tipo, antes do início da primeira fase da etapa de carregamento distribuído na laje.

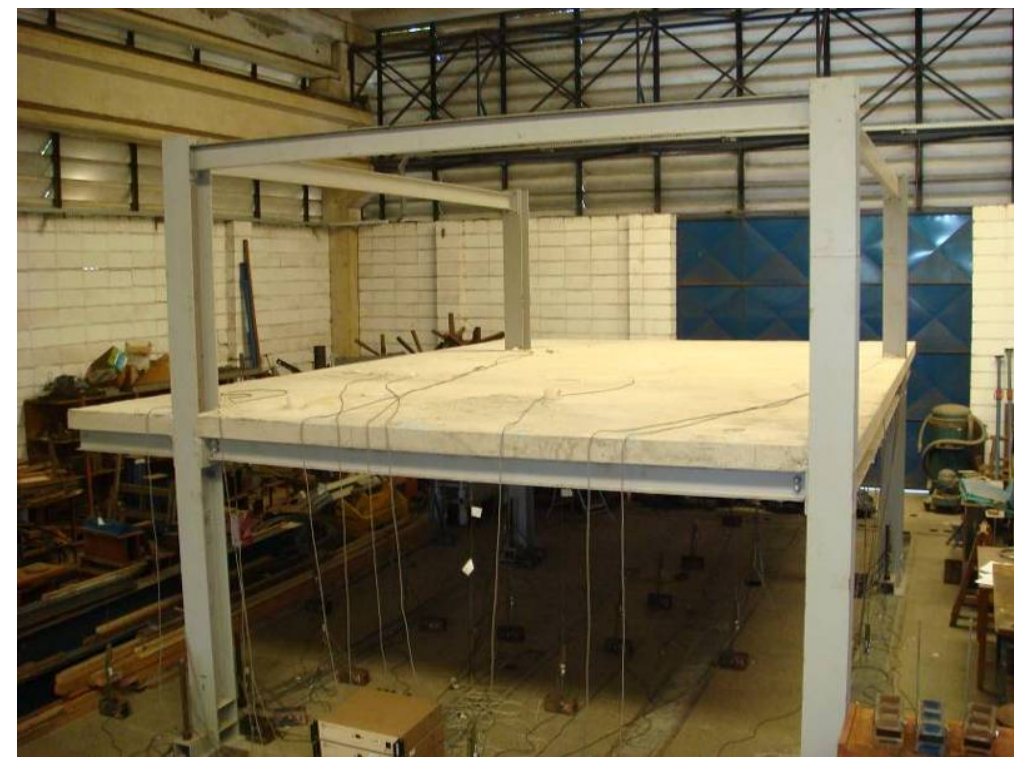

Figura 4.40: Transdutores posicionados sob a laje o pavimento tipo antes da primeira etapa de carregamento distribuído.

\section{4 - Caracterização dos Materiais}

Os ensaios de caracterização dos materiais foram realizados no Departamento de Engenharia de Materiais e no Departamento de Engenharia de Estruturas da Escola de Engenharia de São Carlos.

Para a caracterização do concreto, foram utilizados corpos de prova cilíndricos de $15 \mathrm{~cm}$ de diâmetro e $176,71 \mathrm{~cm}^{2}$ de área de contato. O ensaio de compressão simples foi realizado pela máquina ELE AUTOTEST 2000 (Figura 4.41) com velocidade de carregamento de $5,30 \mathrm{kN} / \mathrm{s}$.

A Tabela 4.4 apresenta a resistência à compressão média para os corpos de prova dos modelos isolados e do pavimento tipo, com a respectiva idade de ruptura e a especificação do concreto para cada modelo. 


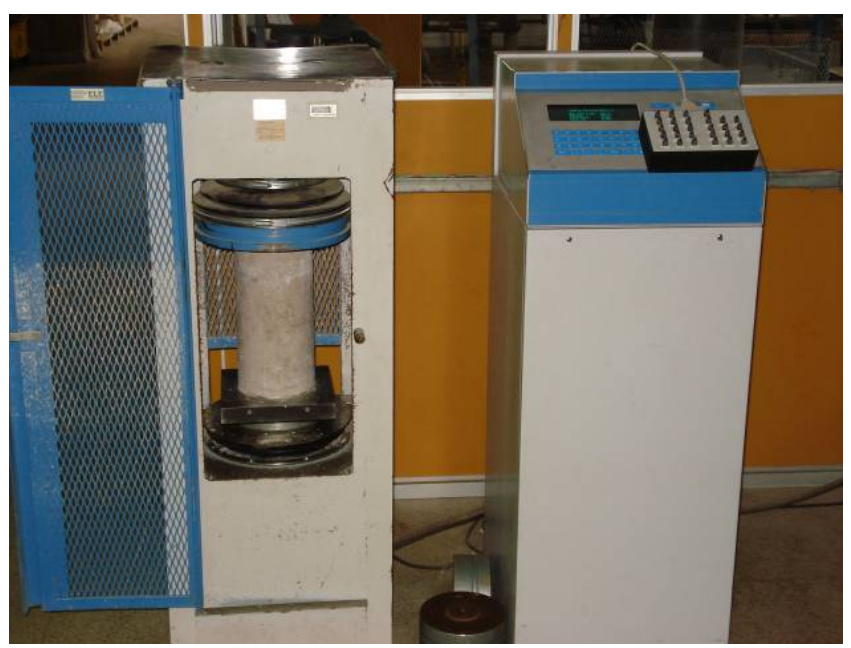

Figura 4.41: Ensaio de caracterização dos corpos de prova de concreto.

Tabela 4.4: Resistência à compressão média do concreto.

\begin{tabular}{|c|c|c|}
\hline Corpo de prova & Resistência (MPa) & Especificação (MPa) \\
\hline TNRSS e CNRSS & $39,2(28$ dias $)$ & $30-(28$ dias $)$ \\
\hline CRSS e TRSS & $18,91(22$ dias $)$ & $20-(28$ dias $)$ \\
\hline Pavimento tipo & $26,14(64$ dias $)$ & $20-(28$ dias $)$ \\
\hline
\end{tabular}

Os aços das armaduras e perfis foram ensaiados em máquina de ensaio universal INSTRON, conforme ilustra a Figura 4.42 a seguir. Nas armaduras longitudinais foi utilizado aço CA-50, com ensaios para os diâmetros de 8 e 10 $\mathrm{mm}$, de acordo com as recomendações da NBR 6152(1992) e NBR 7480(1996).

Para cada diâmetro, foram utilizadas duas barras de aproximadamente $1 \mathrm{~m}$ de comprimento, porém perdeu-se uma das peças para a barra de $8 \mathrm{~mm}$ durante o ensaio. A Figura 4.43 apresenta a relação tensão-deformação do aço das armaduras. 

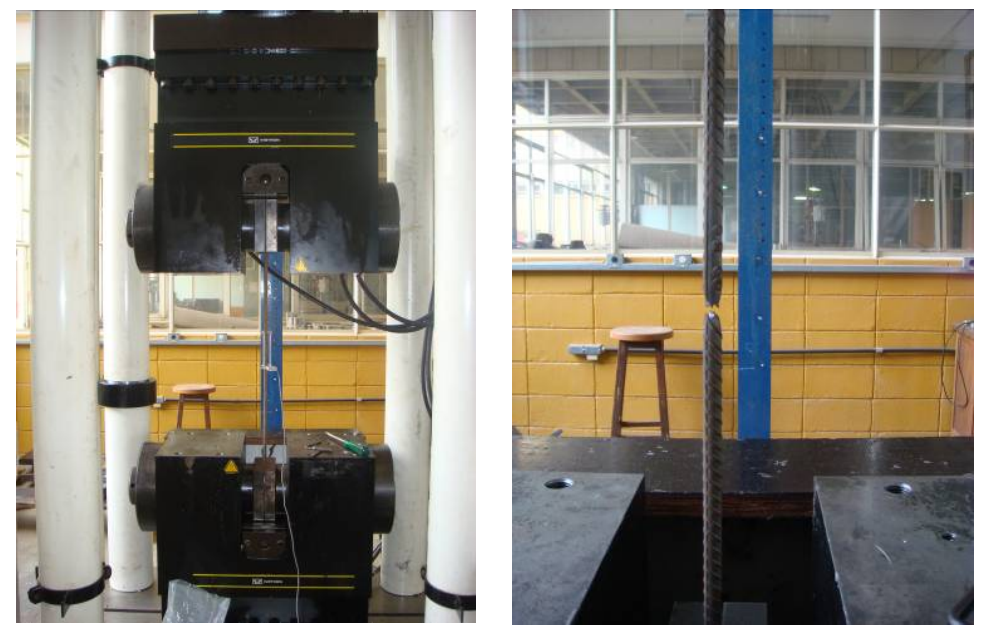

Figura 4.42: Ensaio de caracterização do aço das armaduras.
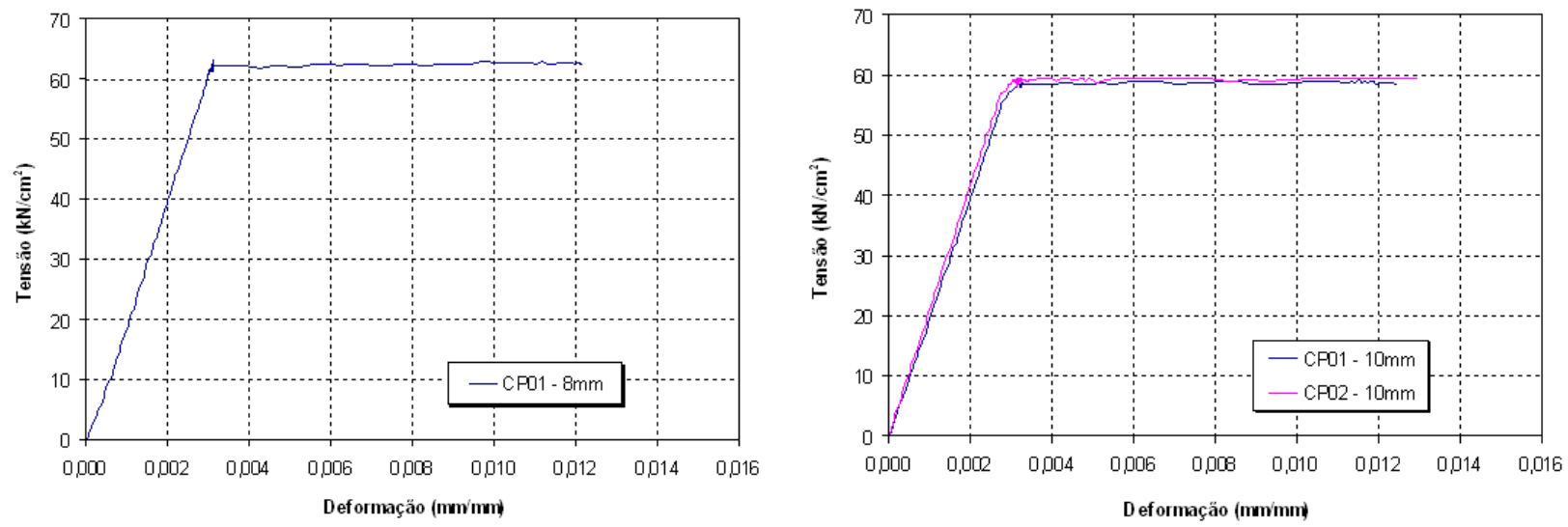

Figura 4.43: Relação tensão-deformação do aço das armaduras.

Em relação ao aço dos perfis metálicos, foram ensaiados três corpos de prova obtidos a partir da alma dos perfis da viga principal, secundária, pilar e cantoneiras. A Figura 4.44 ilustra os corpos de provas antes e depois dos ensaios e a Figura 4.45 as curvas tensão-deformação para o aço dos perfis.
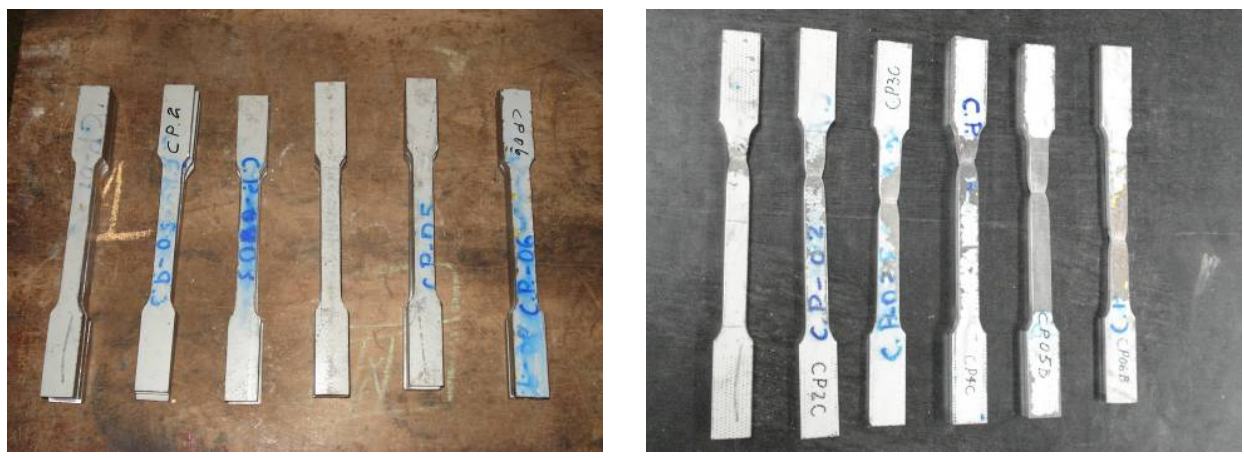

Figura 4.44: Corpos de prova antes e depois dos ensaios de caracterização. 

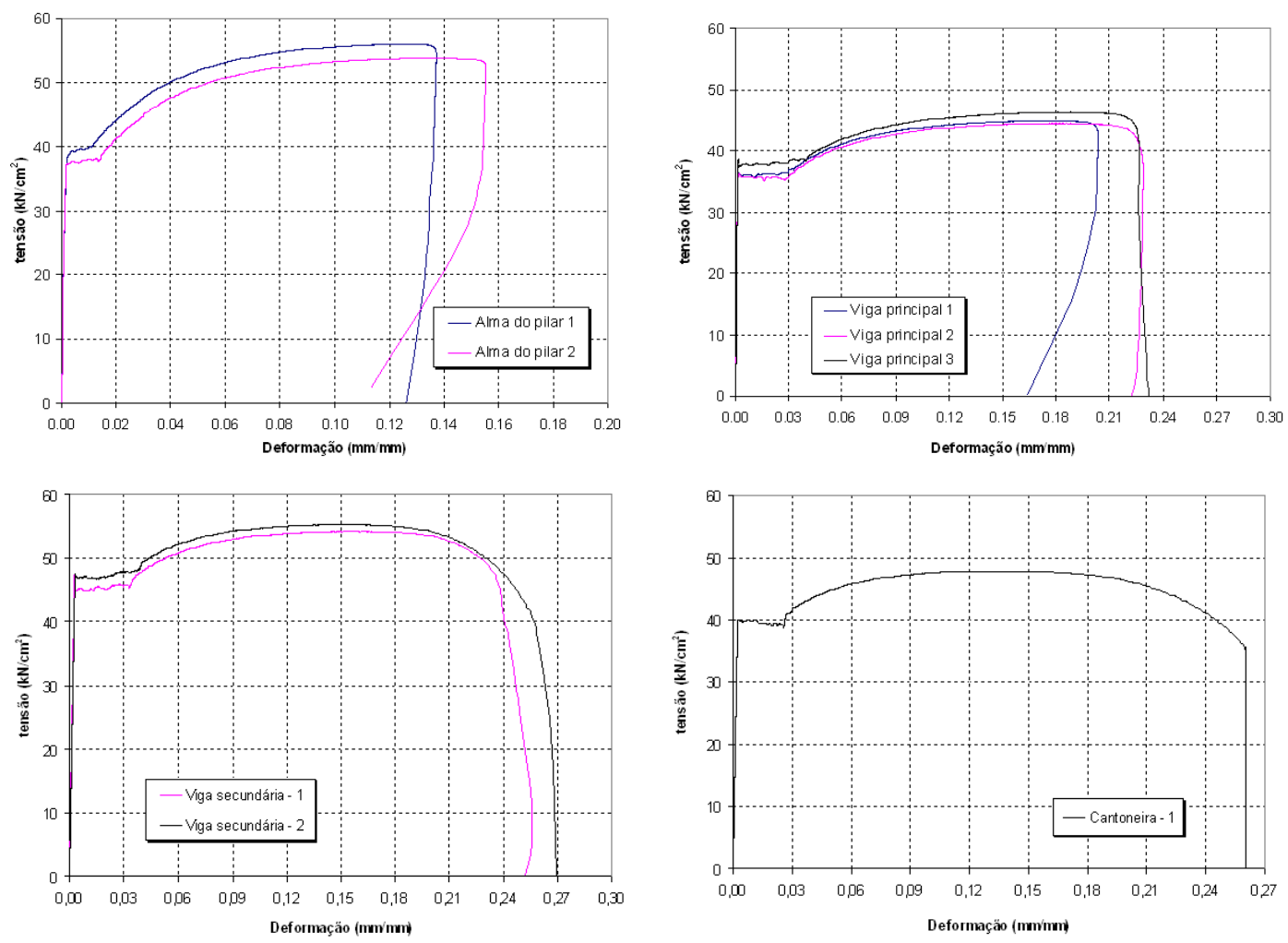

Figura 4.45: Relação tensão-deformação do aço dos perfis.

A Tabela 4.5 abaixo apresenta o resumo dos resultados médios dos aços ensaiados para os perfis e armaduras.

Tabela 4.5: Resumo das características dos aços ensaiados.

\begin{tabular}{c|c|c|c|c}
\hline Corpo de prova & $\mathbf{f}_{\mathrm{y}}\left(\mathbf{k N} / \mathbf{c m}^{2}\right)$ & $\mathbf{f}_{\max }\left(\mathbf{k N} / \mathbf{c m}^{2}\right)$ & $\mathbf{f}_{\mathrm{r}}\left(\mathbf{k N} / \mathbf{c m}^{2}\right)$ & $\varepsilon_{\mathrm{r}}(\%)$ \\
\hline Alma do pilar & 37,36 & 56,00 & 52,3 & 14,6 \\
\hline Alma da viga principal & 36,41 & 45,12 & 40,40 & 21,6 \\
\hline Alma da viga secundária & 45,45 & 54,65 & 40,00 & 25,3 \\
\hline Cantoneira & 39,7 & 47,8 & 35,22 & 26,0 \\
\hline Armadura 8 mm & 59,33 & 62,52 & 61,37 & 1,22 \\
\hline Armadura 10 mm & 55,43 & 59,48 & 58,6 & 1,16 \\
\hline $\mathrm{f}_{\mathrm{y}}=$ tensão de escoamento & & & \\
\hline $\mathrm{f}_{\mathrm{max}}=$ tensão máxima & & & \\
\hline $\mathrm{f}_{\mathrm{r}}=$ tensão na ruptura \\
\hline$\varepsilon_{\mathrm{r}}=$ deformação na ruptura
\end{tabular}




\section{5 - Considerações Finais}

Em conformidade com a metodologia experimental adotada, os modelos isolados tiveram como objetivo reproduzir as ligações de pilar de centro e de borda do pavimento tipo, de acordo com a proposta do trabalho no que diz respeito à taxa de armadura secundária, sua influência na fissuração e, consequentemente, na rigidez da ligação.

Os pontos de instrumentação apresentados anteriormente (principalmente o que se refere à extensometria) foram tomados para comparação com os resultados numéricos.

Adicionalmente, os resultados obtidos na caracterização dos materiais (aços dos perfis, armaduras e concreto) foram utilizados para a constituição dos modelos constitutivos da modelagem numérica.

Em relação ao pavimento tipo, sua geometria e as etapas de carregamento (constituído de suas respectivas fases) foram definidas com o objetivo de avaliar comportamento das ligações mistas, em particular, a deterioração da rigidez em função da fissuração da laje para as várias fases de carregamento.

No Capítulo 5 têm-se os principais resultados dos modelos isolados e para as ligações do pavimento tipo, com ênfase para comportamento força $x$ deslocamento e momento $x$ rotação para cada ligação, além dos deslocamentos e deformações dos respectivos elementos. 


\section{RESULTADOS EXPERIMENTAIS}

\section{1 - Considerações Iniciais}

Este capítulo apresenta os resultados experimentais dos modelos isolados e do pavimento tipo. Os resultados descritos referem-se ao comportamento força $x$ deslocamento $(F x D)$, momento $x$ rotação $(M-\phi)$ global das ligações, além das deformações nas vigas e nas armaduras longitudinais e de contorno do pilar.

\section{2 - Modelos Isolados}

\subsection{1 - Modelo TNRSS}

A ligação do protótipo TNRSS apresentou comportamento semi-rígido, com o carregamento último no atuador igual a $33,5 \mathrm{kN}$ e deslocamento máximo na extremidade da viga de $8,14 \mathrm{~cm}$. A Figura 5.1 ilustra a curva FxD no ponto de aplicação do carregamento e a foto com os deslocamentos finais do protótipo. Para este modelo, a taxa de armadura secundária foi de $0,2 \%$.
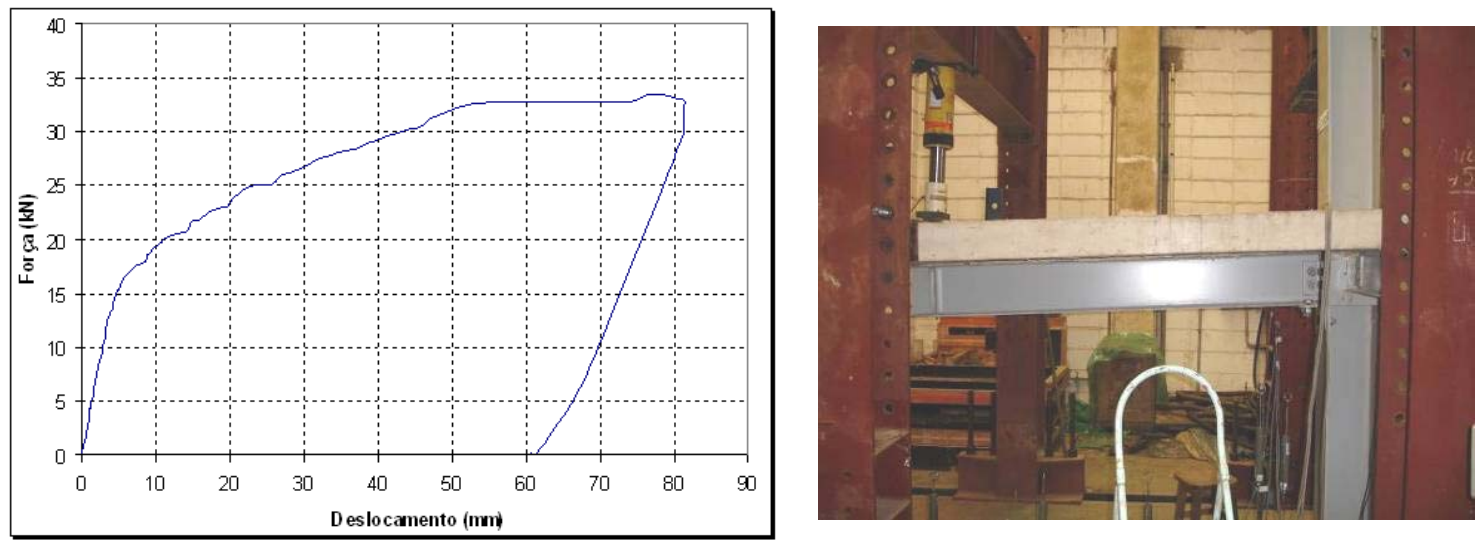

Figura 5.1: Força x deslocamento no ponto de aplicação do carregamento. 
O modo de colapso observado foi devido à abertura excessiva de fissuras na laje (acima de $0,3 \mathrm{~mm}$ para ambientes urbanos), com grande concentração de fissuras na região próxima do pilar. A Figura 5.2 apresenta o comportamento $M-\phi$ total da ligação e os deslocamentos finais do protótipo. Em todos os modelos isolados, o momento fletor considera a distância do ponto de aplicação do carregamento até o centro geométrico da ligação.
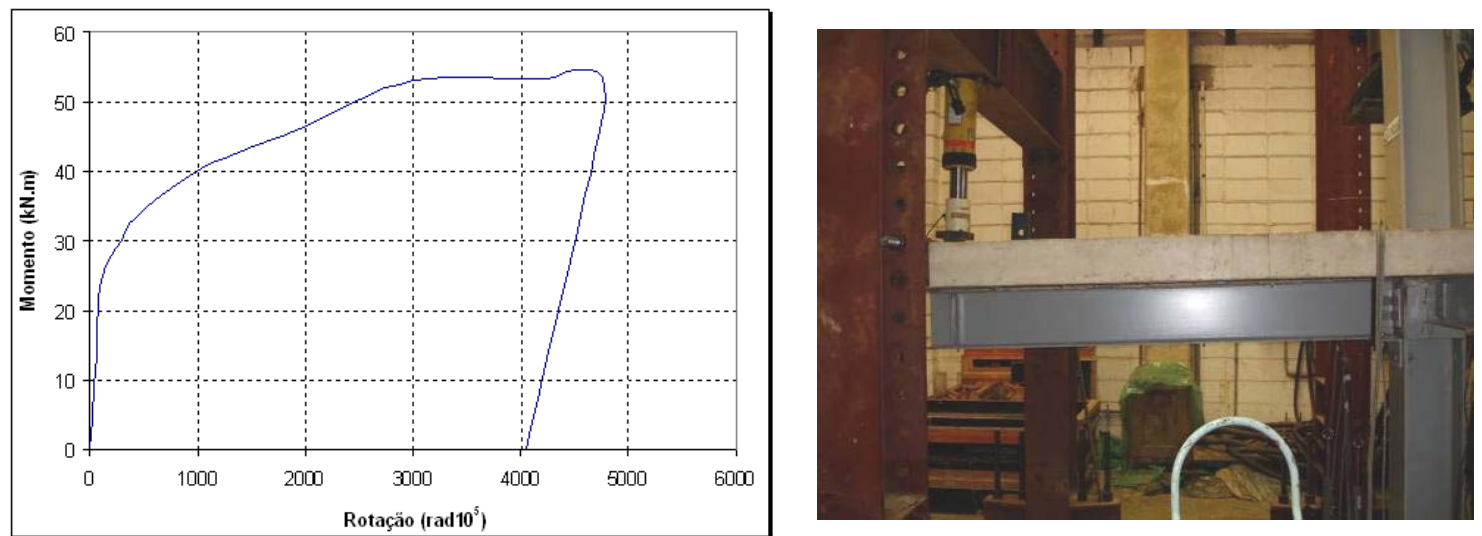

Figura 5.2: Comportamento $M-\phi$ total da ligação TNRSS.

As deformações na armadura longitudinal e de contorno (ancoragem das armaduras longitudinais) estão representadas na Figura 5.3, nos respectivos pontos indicados. As deformações não atingiram o limite de proporcionalidade, sendo superiores na armadura de contorno.
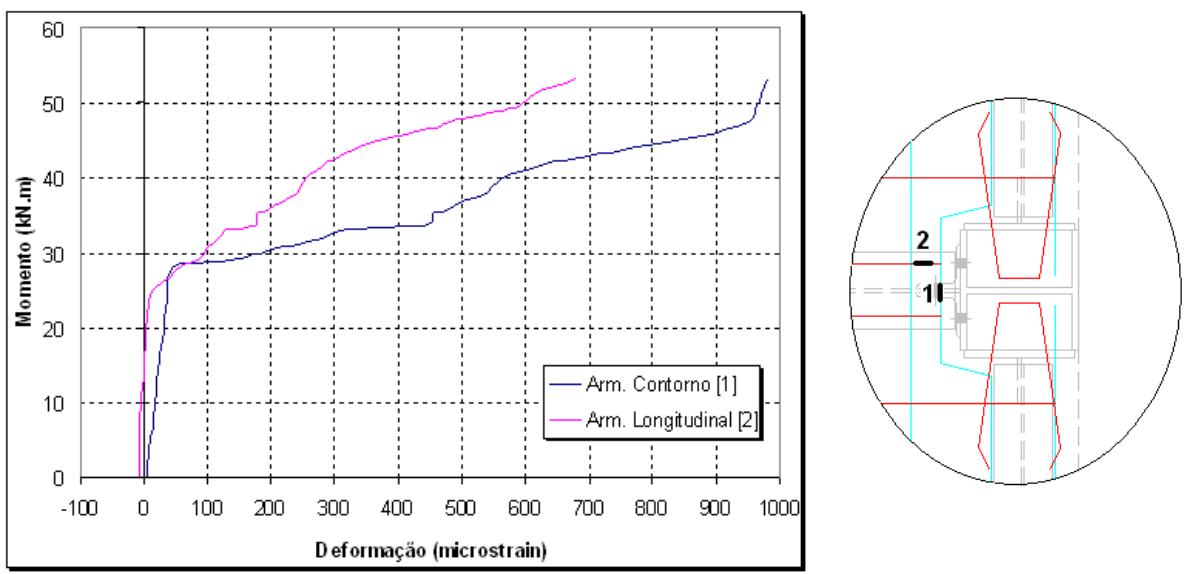

Figura 5.3: Deformações nas armaduras de contorno e longitudinal.

Embora a armadura longitudinal, posicionada acima da viga, não tenha atingido deformações plásticas, as armaduras adjacentes apresentaram níveis 
de deformações bem superiores, de acordo com os resultados obtidos da análise numérica que será apresentada e discutida no Capítulo 6.

$\mathrm{Na}$ Figura 5.4 tem-se as deformações na viga, para uma seção localizada a $130 \mathrm{~mm}$ de sua extremidade nas posições ao lado indicadas. Em todos os modelos, as deformações da mesa superior e inferior foram obtidas a partir da média dos extensômetros nestas posições.
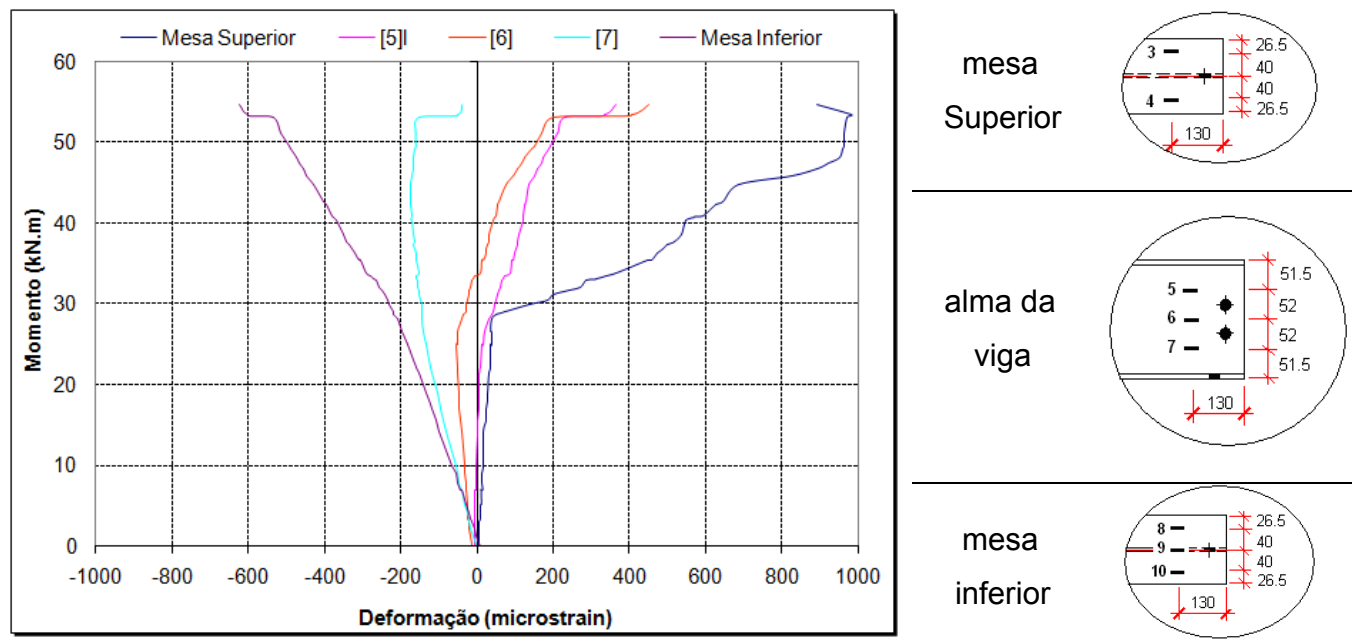

Figura 5.4: Deformações na seção da viga.

$\mathrm{Na}$ figura anterior, observa-se que a partir do instante que o momento na ligação atinge aproximadamente $30 \mathrm{kNm}$, as deformações de tração na mesa superior começam a aumentar e, os pontos 5 e 6 apresentam deformações de tração. Tal resultado indica que a $L N$ na viga não se deslocou para a mesa superior, conforme o esperado para os níveis superiores de carregamento. A Figura 5.5 ilustra a fissuração da laje, com a abertura de uma grande fissura diagonal a mesa do pilar (aproximadamente $45^{\circ}$ ).
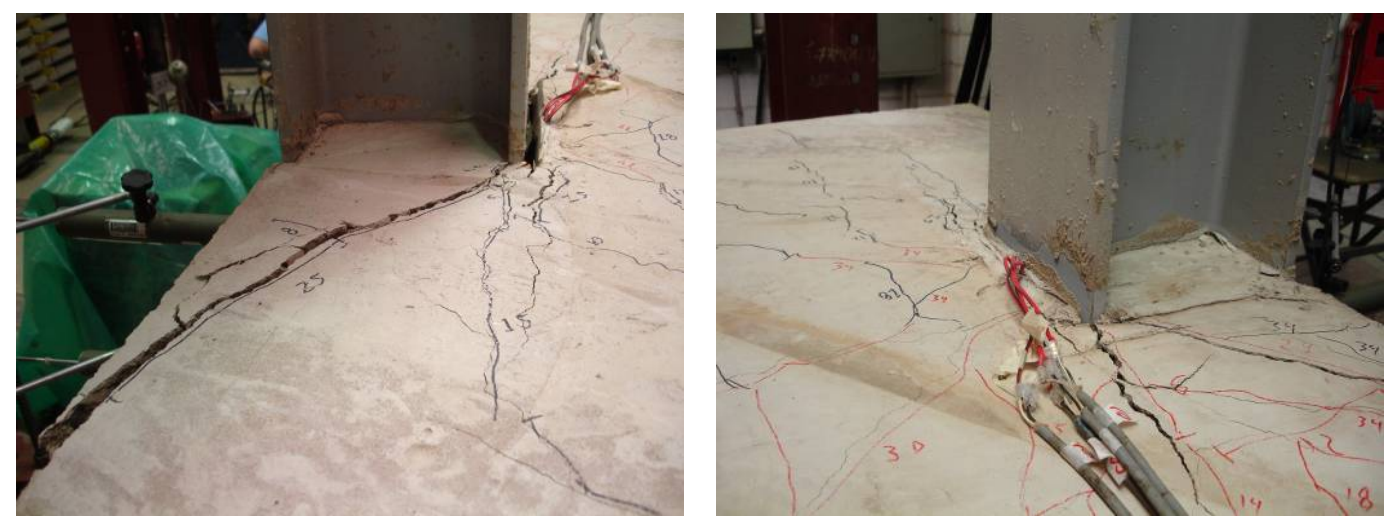

Figura 5.5: Fissuração da laje ao término do ensaio. 
Além das deformações na viga, o comportamento global da ligação e os mecanismos de colapso observados apontam que a ancoragem das armaduras não funcionou de maneira efetiva, proporcionando um nível de resistência e rigidez abaixo do esperado para a ligação.

\subsection{2 - Modelo TRSS}

O protótipo TRSS teve comportamento semelhante ao modelo anterior. A Figura 5.6 ilustra o comportamento força x deslocamento (FxD) da ligação e o deslocamento final do modelo, com o carregamento máximo no atuador de $27,9 \mathrm{kN}$, para o deslocamento na extremidade da viga de $2,9 \mathrm{~cm}$.
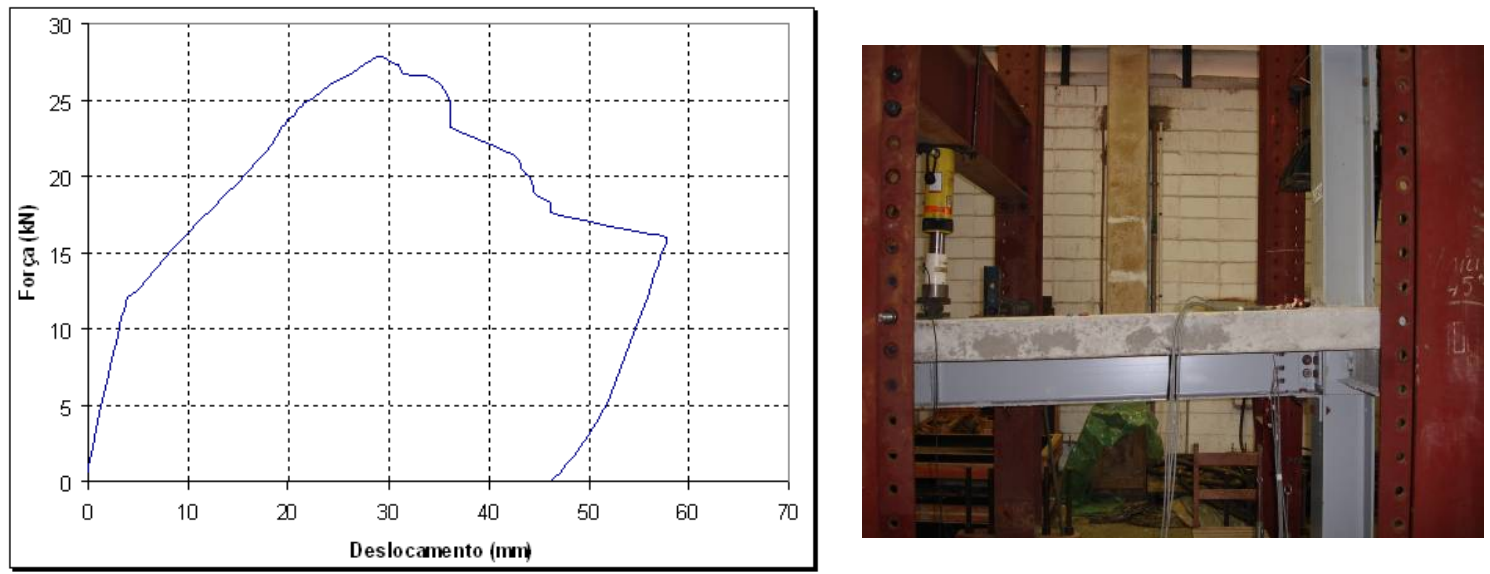

Figura 5.6: Força x deslocamento no ponto de aplicação do carregamento.

O modo de colapso observado também foi devido à abertura excessiva de fissuras laje, com a concentração de fissuras na região próxima do pilar. A Figura 5.7 a seguir ilustra a curva momento x rotação $(M-\phi)$ total da ligação e o deslocamento final do modelo quando na aplicação da máxima solicitação. 

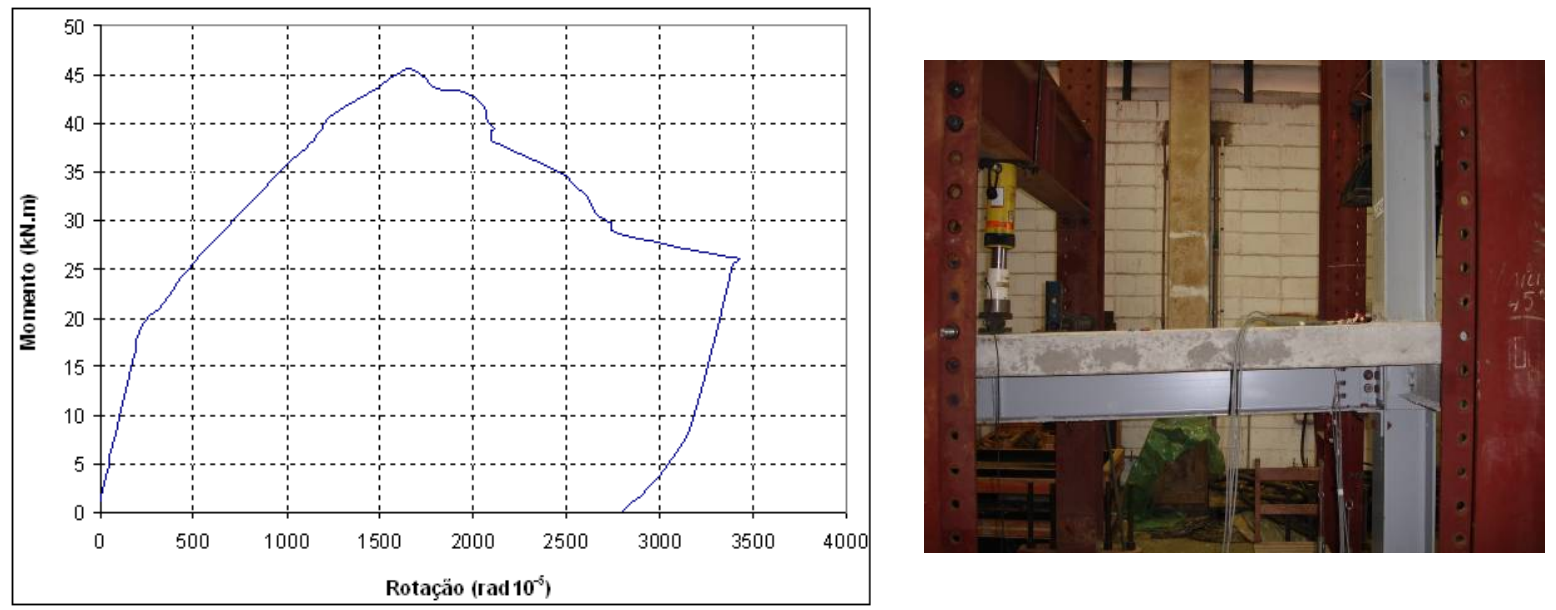

Figura 5.7: Comportamento $M-\phi$ total do modelo TRSS.

A Figura 5.8 apresenta as deformações na armadura longitudinal e de contorno (ancoragem das armaduras longitudinais) nos pontos indicados. As deformações na armadura longitudinal apresentaram valores inferiores quando comparados com a armadura de contorno e, da mesma forma que no protótipo TNRSS, também não atingiram o limite da tensão de proporcionalidade.
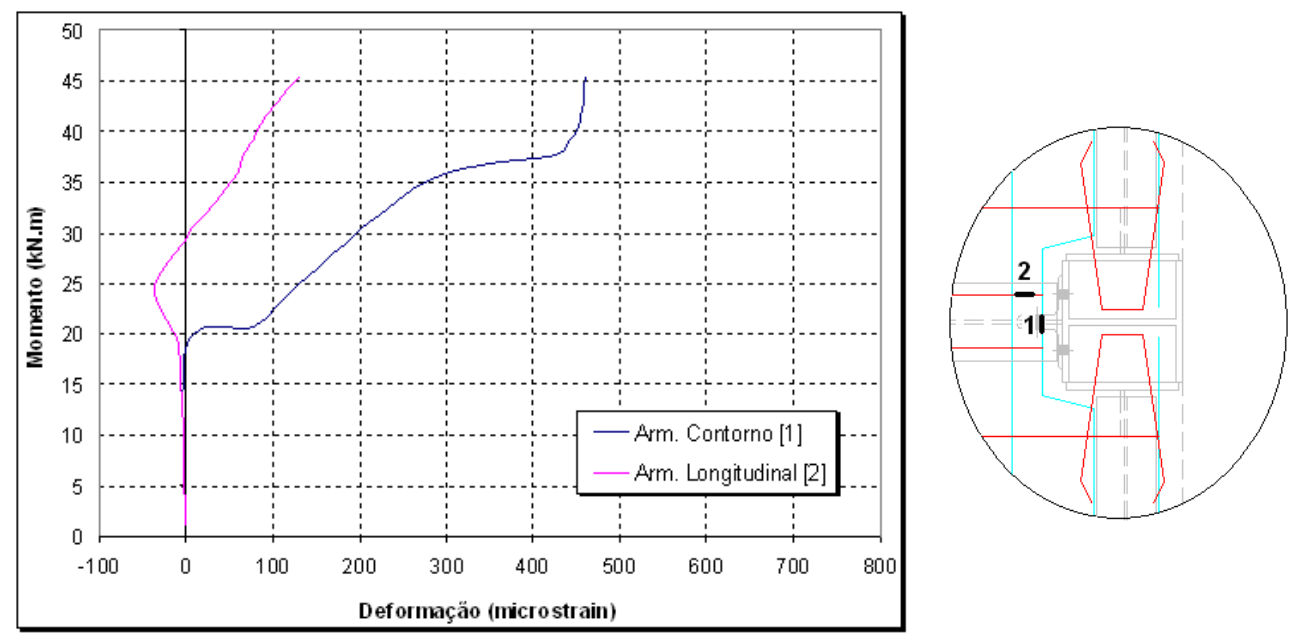

Figura 5.8: Deformação nas armaduras longitudinal e de contorno.

$\mathrm{Na}$ Figura 5.9 tem-se as deformações na viga nos respectivos pontos indicados. As deformações de tração na mesa superior e nos pontos 5 e 6 começam a aumentar partir do instante que o momento na ligação atinge aproximadamente de $25 \mathrm{kNm}$. Para o carregamento final de $45 \mathrm{kNm}$, a linha neutra ficou posicionada entre os pontos 5 e 6 na alma da viga. 

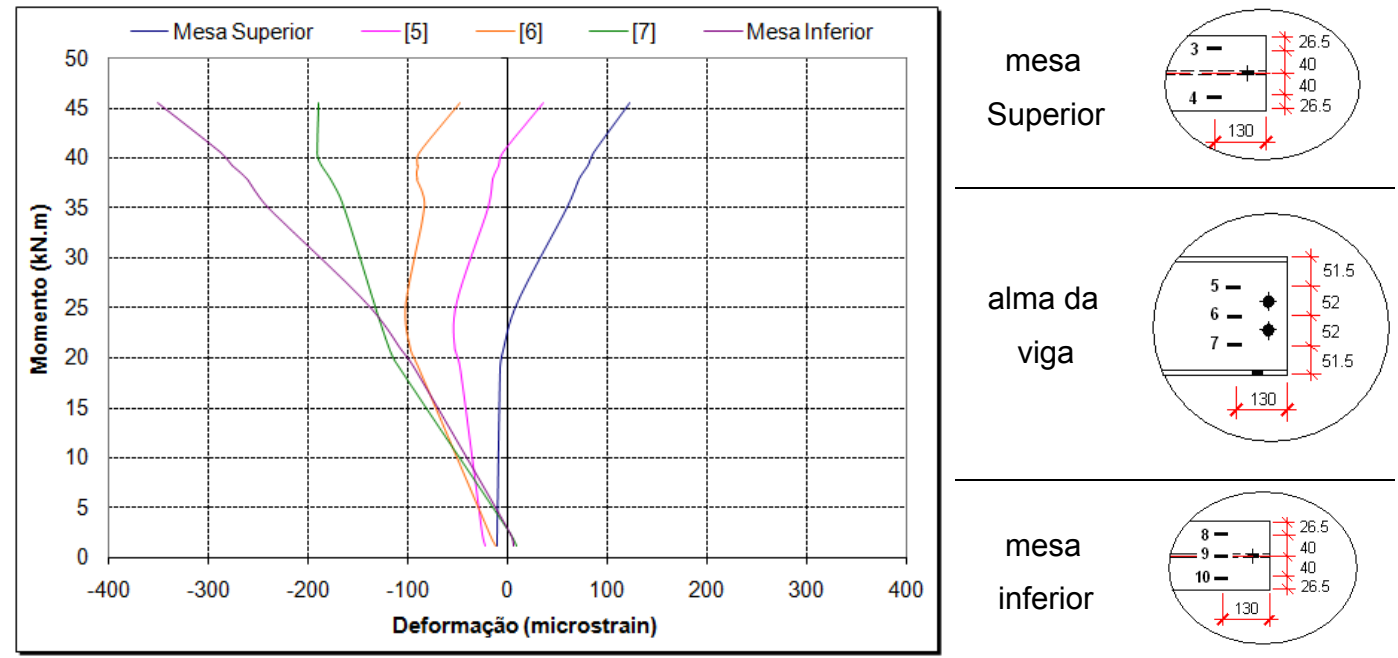

Figura 5.9: Deformação na seção da viga mista do modelo TRSS.

Embora este modelo tenha sido concebido com o acrécimo da taxa de armadura secundária (de $0,2 \%$ para 1,0\%), o mecanismo de fissuração da laje foi o mesmo observado para o protótipo TNRSS. A Figura 5.10 ilustra a fissuração da laje, na região próxima ao pilar, com a presença das mesmas fissuras diagonais do modelo anterior, porém com a abertura de fissuras inferior ao observado no protótipo TNRSS. Este acréscimo das armaduras secundárias foi adotado com o objetivo de restringir a abertura de fissuras na laje.

A repetição do comportamento global e do modo fissuração da laje reforça a análise de que a ancoragem das armaduras longitudinais não funcionou efetivamente para os modelos de pilar de canto, proporcionando que a ligação tivesse sua rigidez e resistência abaixo do esperado.
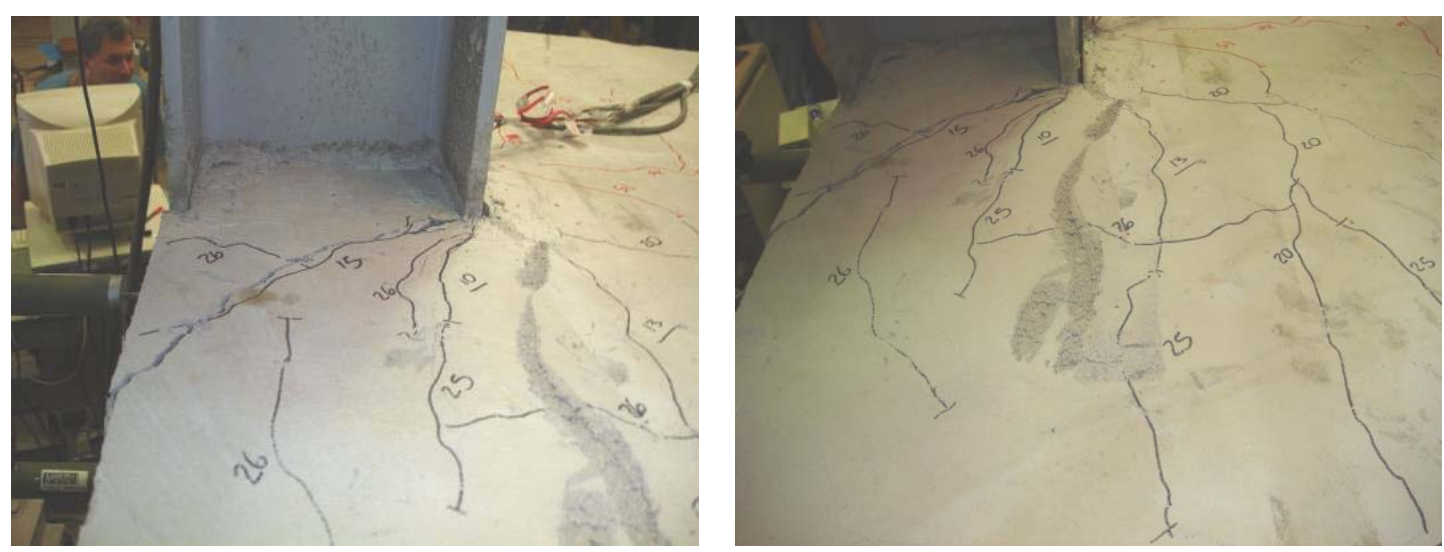

Figura 5.10: Fissuração da laje ao final do ensaio. 


\subsection{3 - Modelo CNRSS}

Para o modelo cruciforme CNRSS foi adotado taxa de armadura secundária de $0,2 \%$. A Figura 5.11 apresenta a curva FxD com o deslocamento máximo na posição do atuador de $4,8 \mathrm{~cm}$, equivalente à reação máxima na extremidade da viga de $57 \mathrm{kN}$.
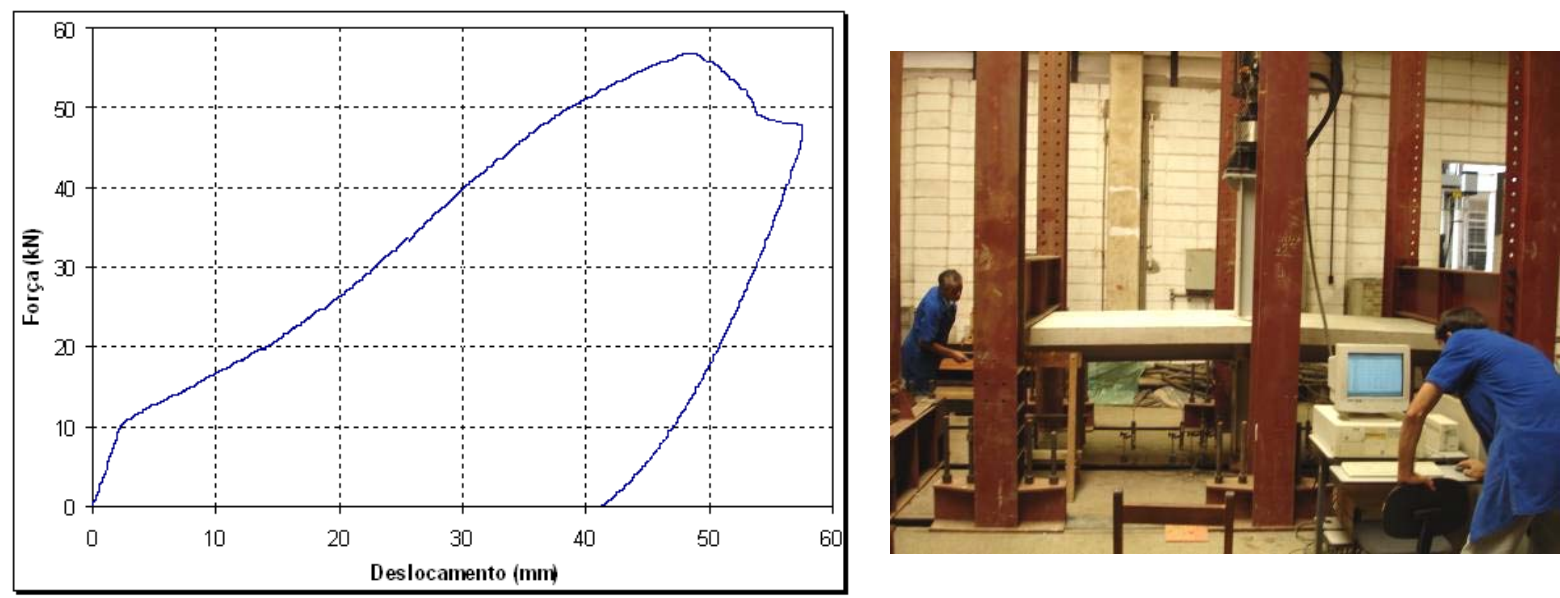

Figura 5.11: Curva força $x$ deslocamento na posição do atuador.

Além dos deslocamentos na posição do atuador, foram medidos os deslocamentos em cinco pontos para cada viga dos modelos cruciformes, com o objetivo de avaliar a simetria do ensaio e obter as rotações da ligação. As Figuras 5.12 e 5.13 apresentam os deslocamentos nos transdutores nos pares de transdutores T21-T26, T22-T27 e T23-T28 (conforme esquema indicado).
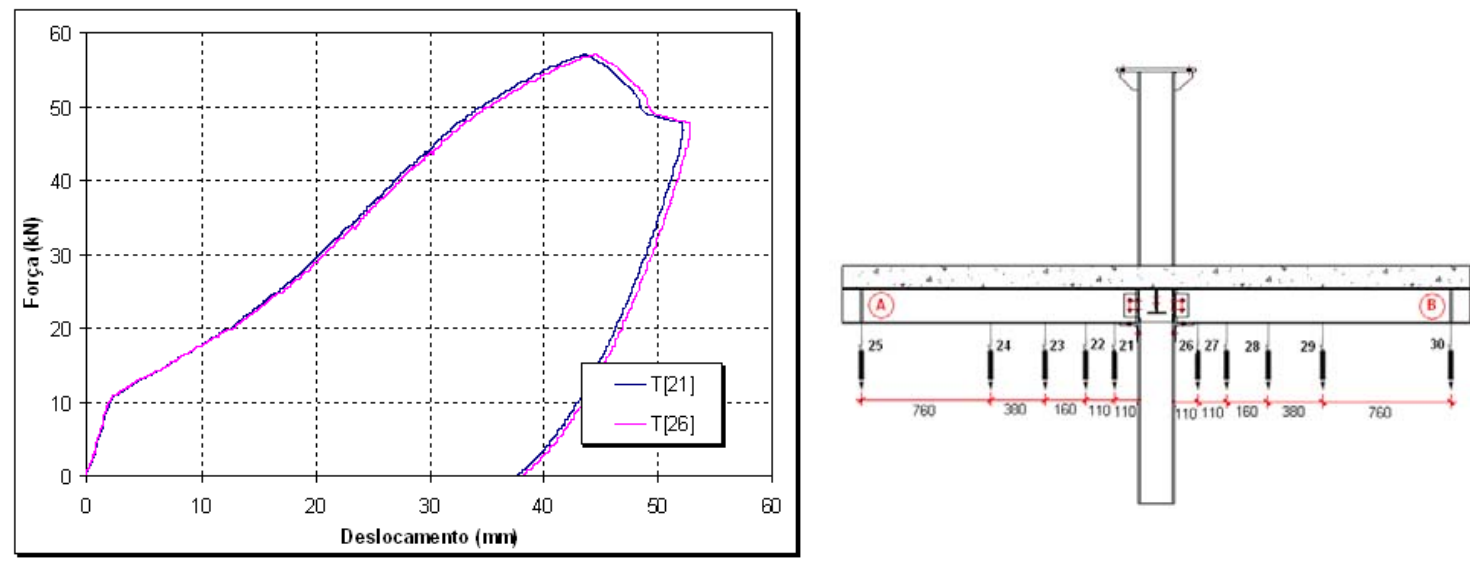

Figura 5.12: Força $x$ deslocamento nos transdutores T21-T26.

Durante a fase de carregamento as curvas dos pares de transdutores praticamente se sobrepõem, com uma pequena diferença na fase de 
descarregamento após o colapso em cada ligação do modelo. Estes resultados confirmam a validade da concepção de duas ligações simétricas do modelo.
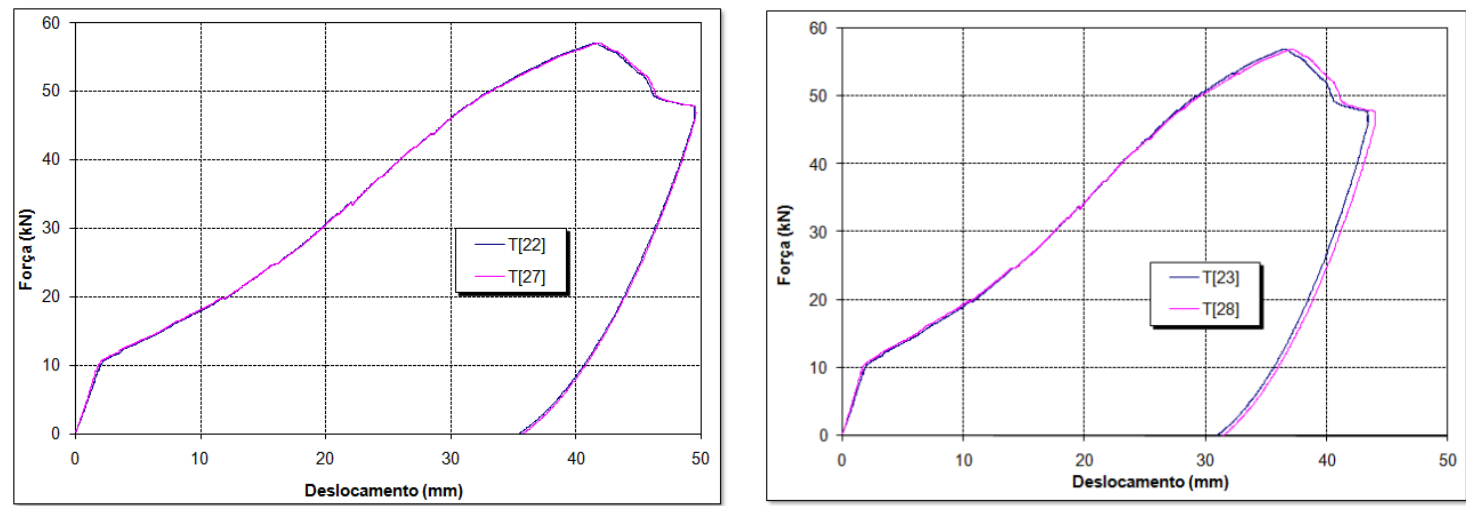

Figura 5.13: Força $x$ deslocamento nos transdutores T22-T27 e T23-T28.

A Figura 5.14 ilustra o comportamento momento $x$ rotação $(M-\phi)$ total da ligação A (esquema da Figura 5.12). O momento máximo para cada ligação atingiu aproximadamente $92 \mathrm{kN} . \mathrm{m}$, patamar bem superior quando comparado com o modelo TNRSS que atingiu o máximo de $54,6 \mathrm{kN}$.m, evidenciando a perda de resistência e rigidez dos protótipos isolados "T" proporcionado pela ancoragem ineficiente das armadura longitudinais da viga mista.
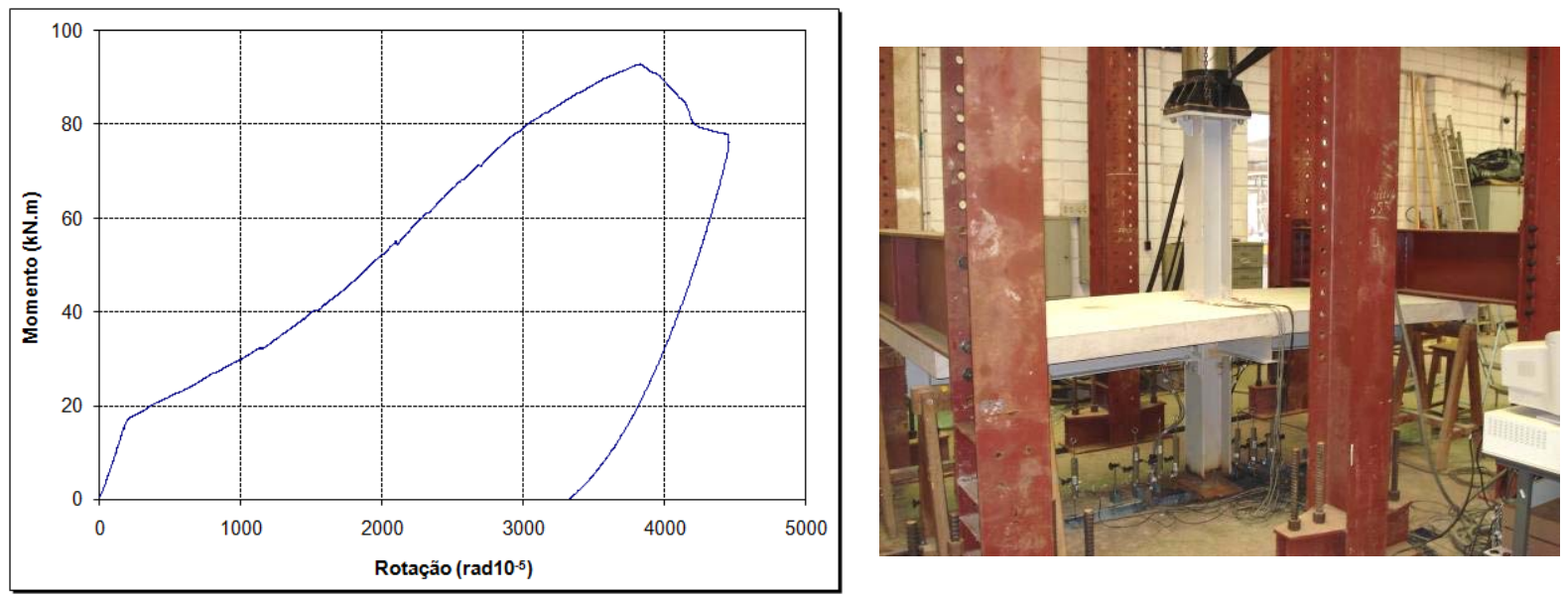

Figura 5.14: Comportamento $M-\phi$ total da ligação A.

Além disso, o comportamento $M-\phi$ evidencia a perda de rigidez da ligação, a partir do instante que o momento atinge $18,6 \mathrm{kNm}$, devido à abertura excessiva das fissuras na laje, que se concentrou na região próxima ao pilar. A Figura 5.15 apresenta as deformações na armadura longitudinal e de contorno. 

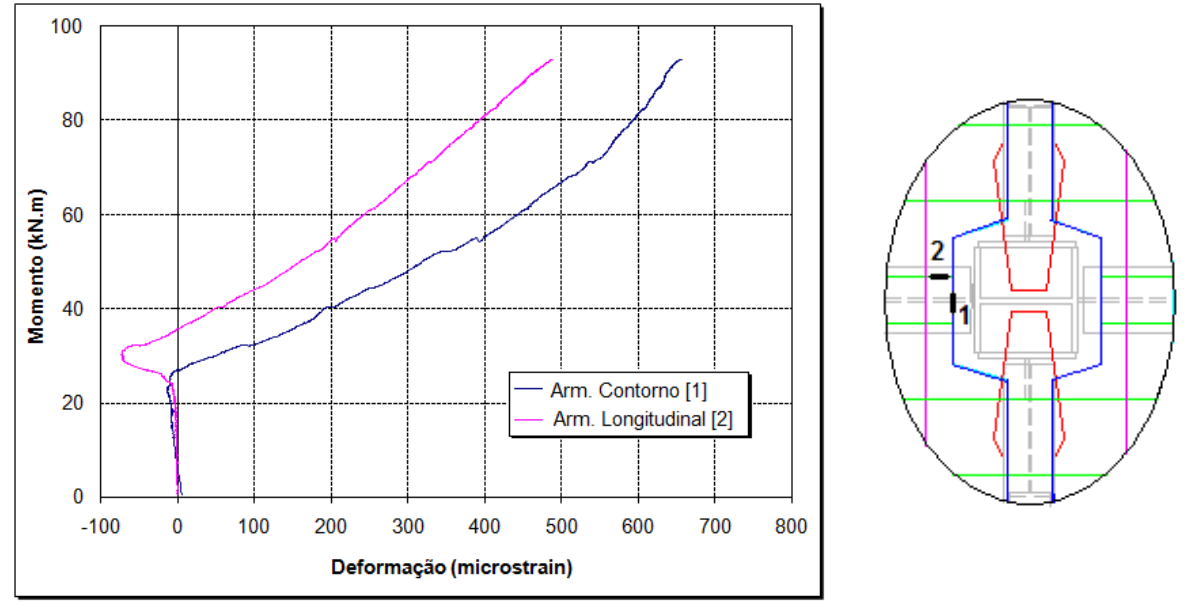

Figura 5.15: Deformação nas armaduras longitudinal e de contorno.

A Figura 5.16 apresenta as deformações na seção da viga mista, no qual se observa que a linha neutra se localiza próximo da mesa superior para o carregamento final, com maiores deformações na mesa inferior em relação à mesa superior da viga.

O resultado comentado acima aponta no sentido da presença de uma linha de tração na posição das armaduras da viga mista, o que por sua vez só foi possível pela efetiva ancoragem das armaduras longitudinais.
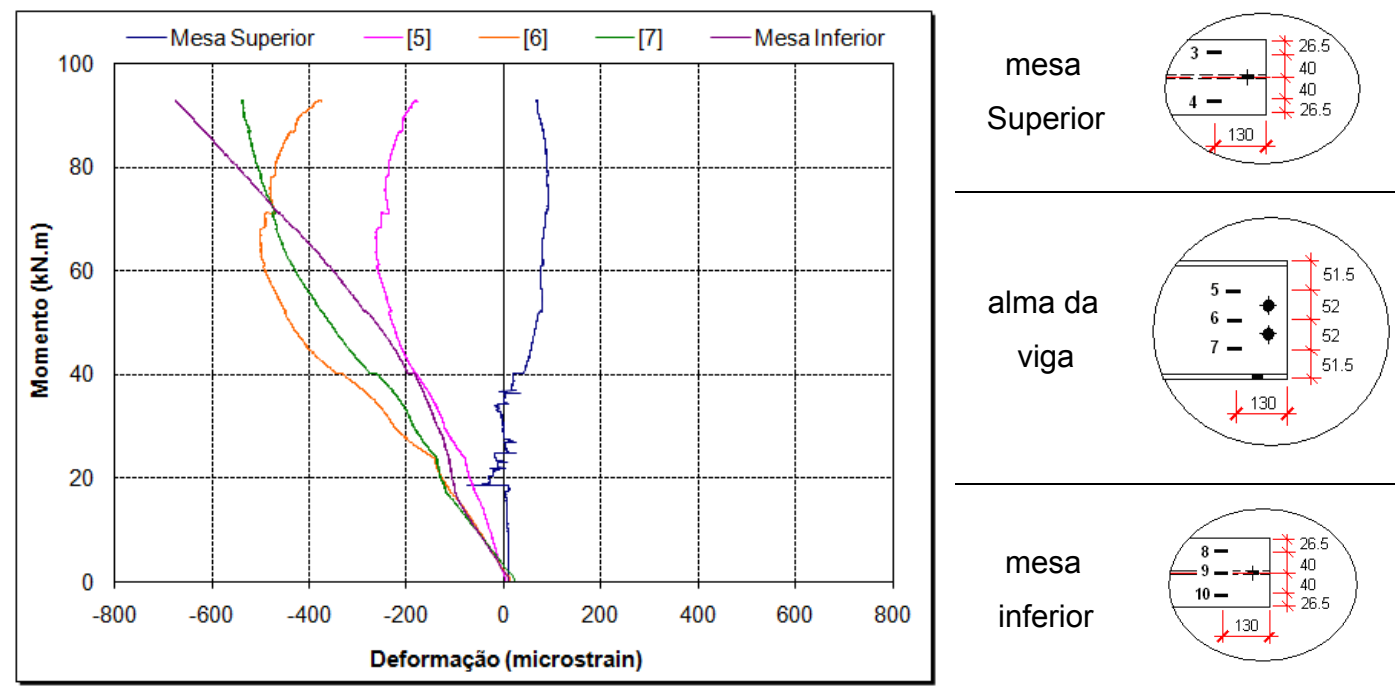

Figura 5.16: Deformações na seção da viga.

O modo de colapso observado na ligação foi devido à abertura excessiva das fissuras na laje (região próxima ao pilar), conforme ilustra a Figura 5.17 abaixo. As primeiras fissuras na laje se formaram paralelas à mesa do pilar, 
expandindo-se para região de contorno e, por último, próximo as extremidades da viga.
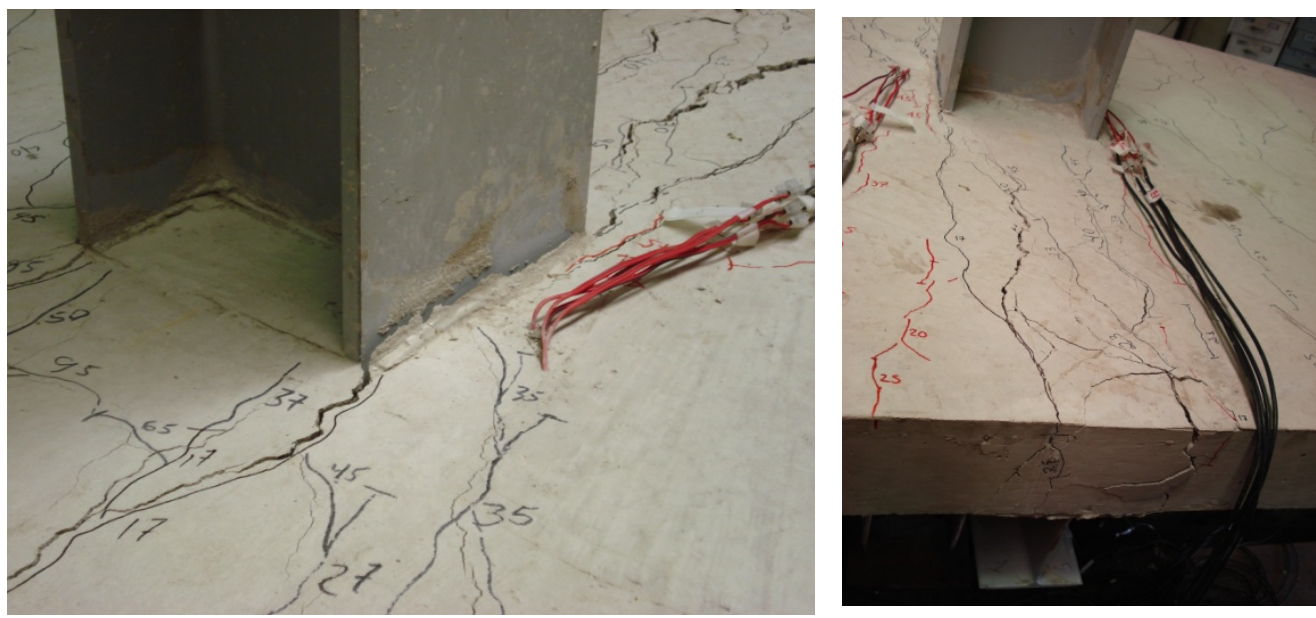

Figura 5.17: Fissuração da laje ao término do ensaio do protótipo CNRSS.

\subsection{4 - Modelo CRSS}

Para o modelo cruciforme CRSS foi adotado taxa de armadura secundária de 1\%. A Figura 5.18 apresenta a curva FxD, com o deslocamento máximo na posição do atuador de $3,6 \mathrm{~cm}$, equivalente à reação máxima na extremidade da viga de $42 \mathrm{kN}$.
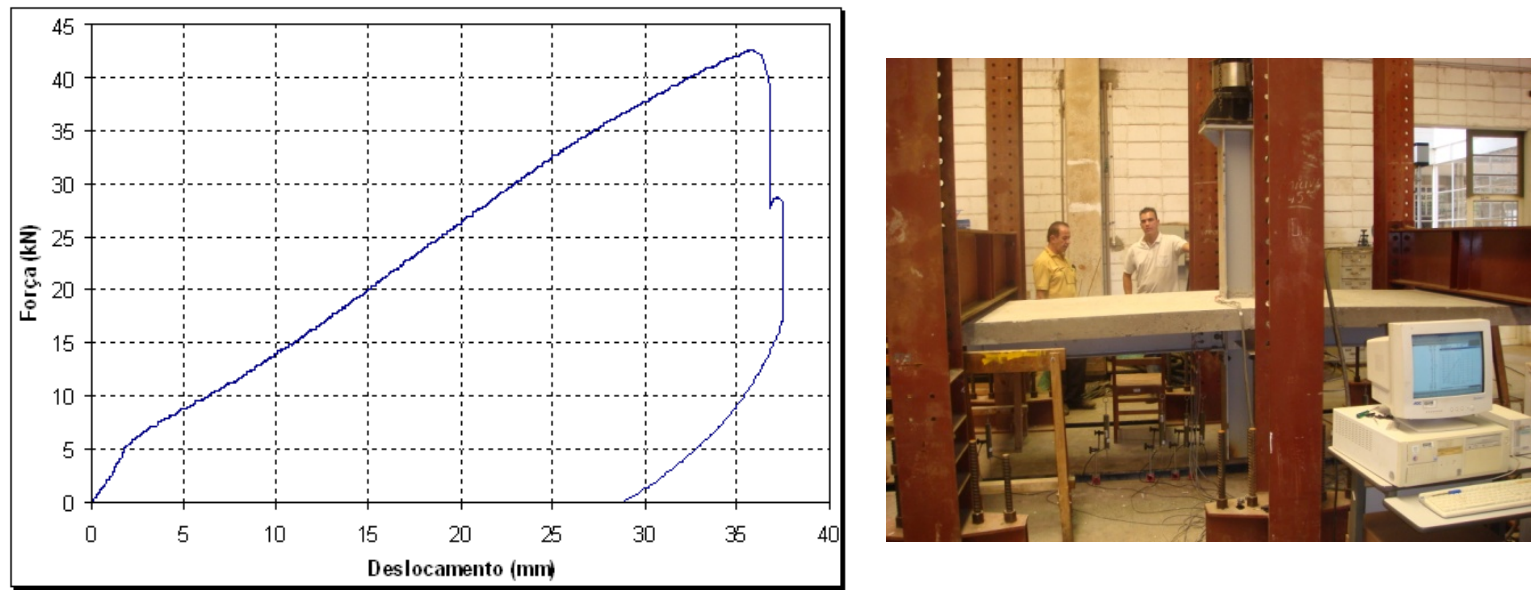

Figura 5.18: Curva força $x$ deslocamento na posição do atuador.

As Figuras 5.19 e 5.20 apresentam os deslocamentos nos pares de transdutores T21-T26, T22-T27 e T23-28 (conforme esquema indicado). Da mesma forma que no modelo CNRSS, as curvas dos pares de transdutores 
praticamente se sobrepõem na fase de carregamento, com uma diferença de deslocamentos maior no par T23-T28, essa diferença é acrescida na fase de descarregamento devido ao colapso em cada ligação do modelo.
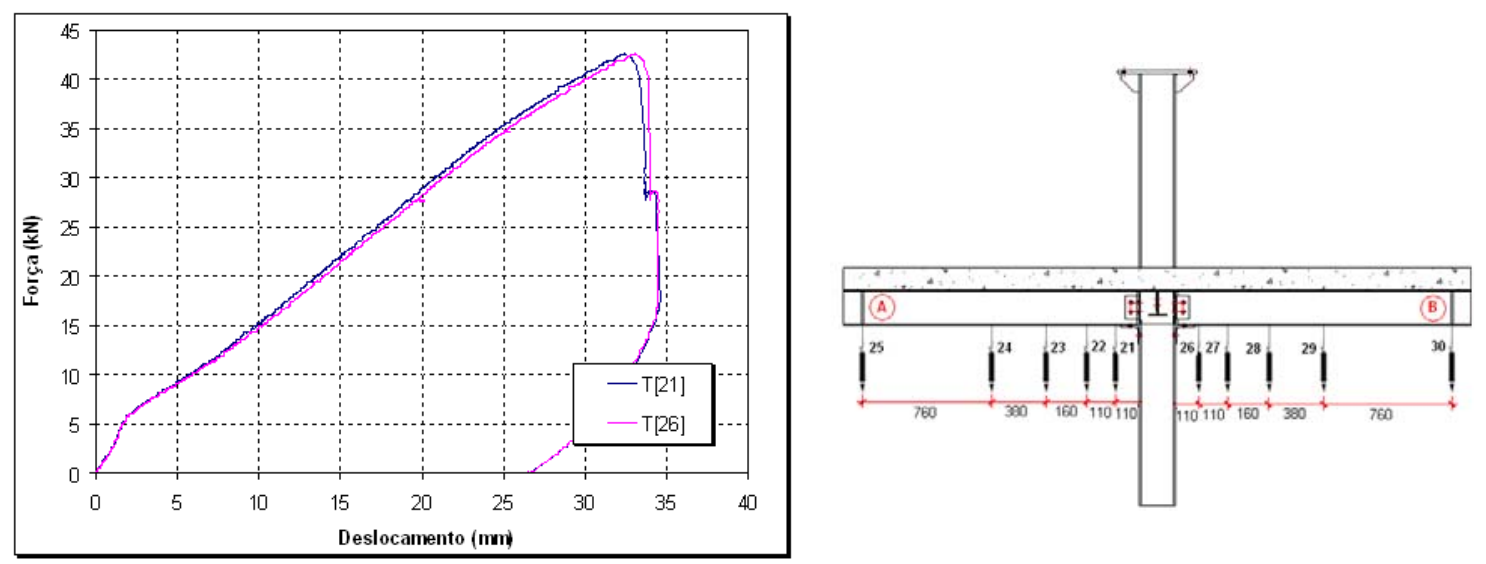

Figura 5.19: Força $\mathrm{x}$ deslocamento nos transdutores T21-T26.
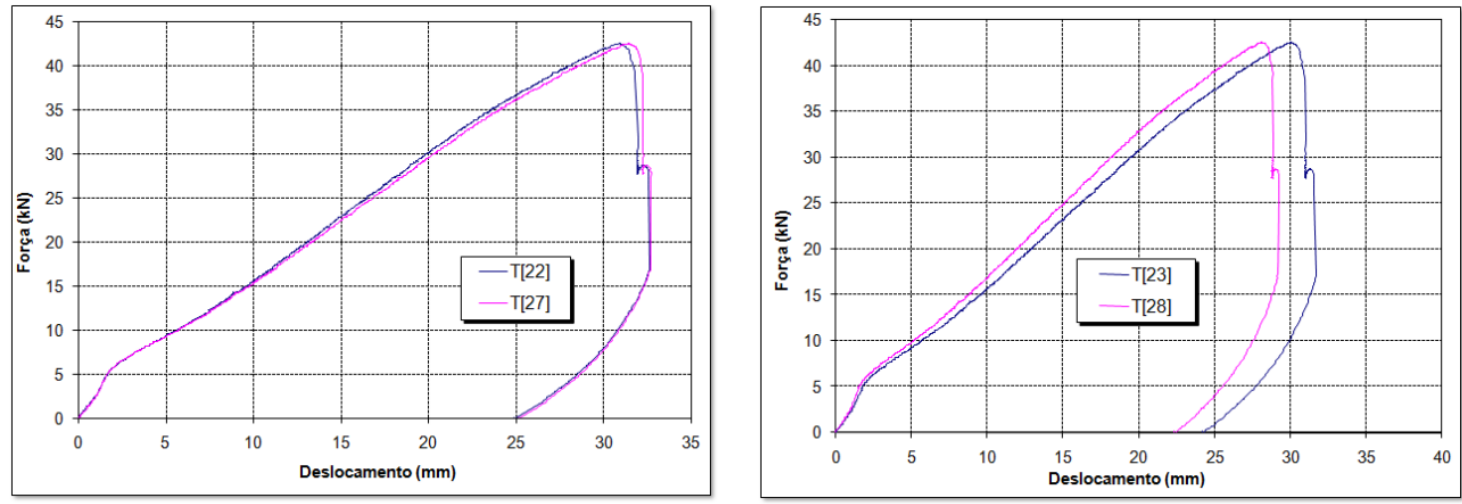

Figura 5.20: Força x deslocamento nos transdutores T22-T27 e T23-T28.

A Figura 5.21 ilustra o comportamento momento $x$ rotação $(M-\phi)$ total da ligação $A$ e o deslocamento máximo do modelo. A resistência última da ligação cruciforme do protótipo CRSS foi menor quando comparado à ligação do modelo CNRSS, com a perda de rigidez devido à fissuração da laje tendo início a partir no momento na ligação de $10 \mathrm{kN} \cdot \mathrm{m}$, aproximadamente a metade do protótipo anterior. Tal resultado vai de encontro com os resultados de caracterização do concreto, conforme apresentado no item 4.4 do capítulo anterior. 

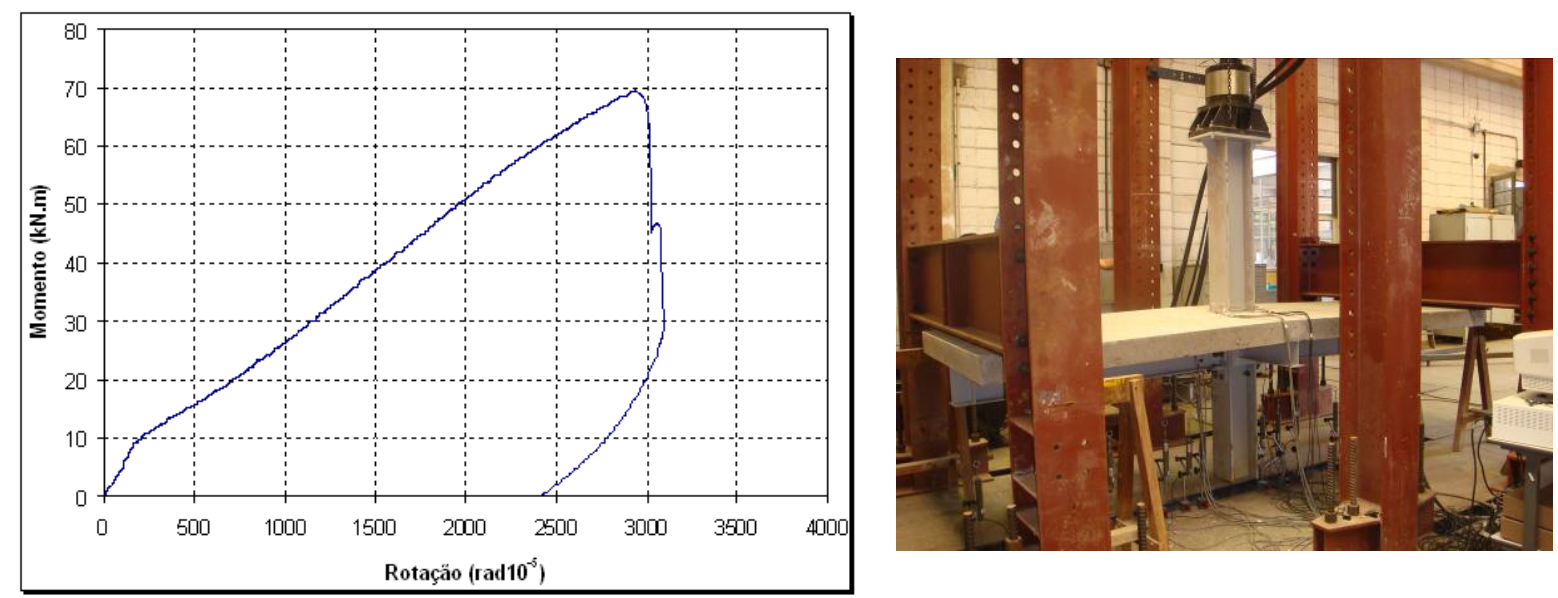

Figura 5.21: Comportamento momento x rotação $(M-\phi)$ total da ligação A.

A Figura 5.22 apresenta às deformações na armadura longitudinal e de contorno, e a Figura 5.23 as deformações na seção da viga mista. Da mesma forma que no protótipo CNRSS, a linha neutra se localiza próximo à mesa superior para o carregamento final.
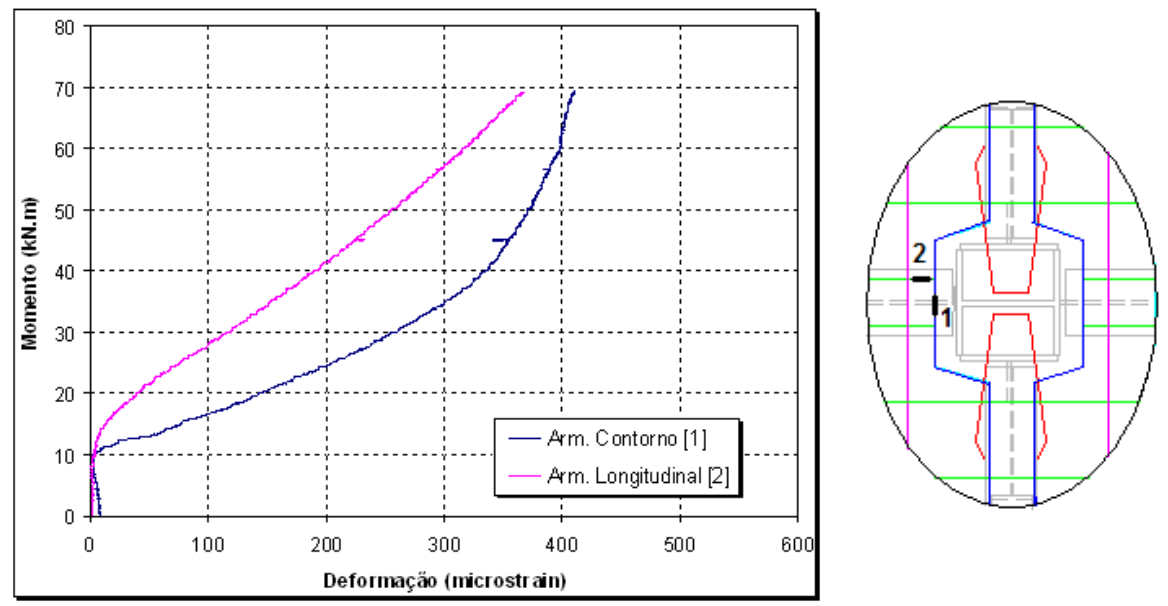

Figura 5.22: Deformação nas armaduras longitudinal e de contorno.

O acréscimo da taxa de armadura secundária funcionou no que diz respeito na restrição de abertura de fissuras na laje, conforme ilustra a Figura 5.24, quando comparado à fissuração da laje observada no protótipo CNRSS. No entanto, para os modelos isolados o mecanismo de surgimento das fissuras, sua disposição e as etapas de carregamento em que as primeiras fissuras foram observadas não foram modificados com o acréscimo na taxa de 
armadura secundária da laje.
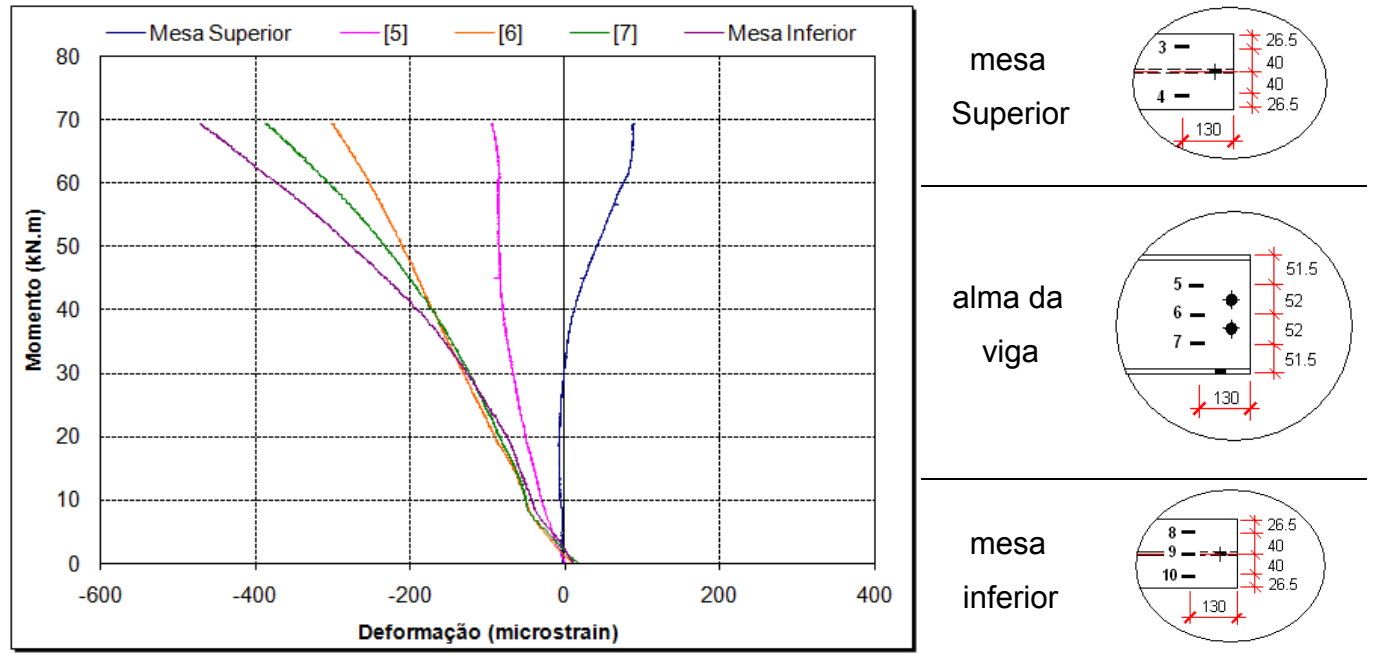

Figura 5.23: Deformações na seção da viga do modelo CRSS.
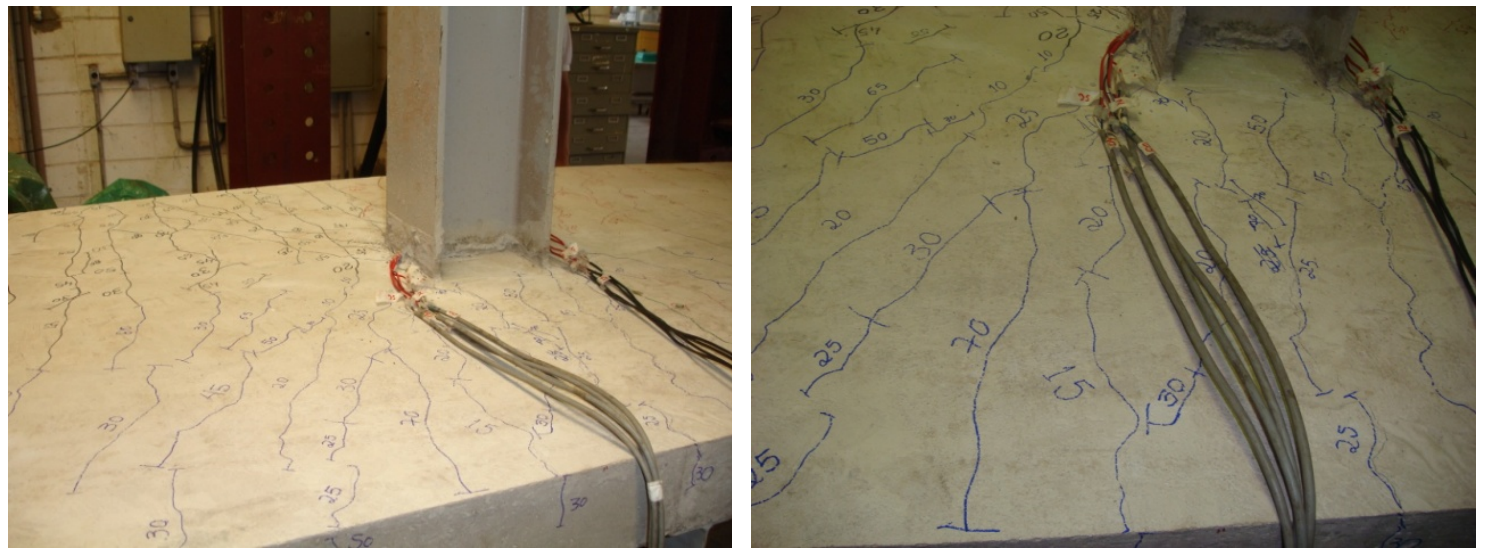

Figura 5.24: Fissuração na laje do modelo CRSS ao término do carregamento.

Diferentemente do observado nos demais modelos isolados, o modo de colapso do modelo CRSS foi devido ao cisalhamento do parafuso na cantoneira de mesa, conforme apresenta a Figura 5.25.

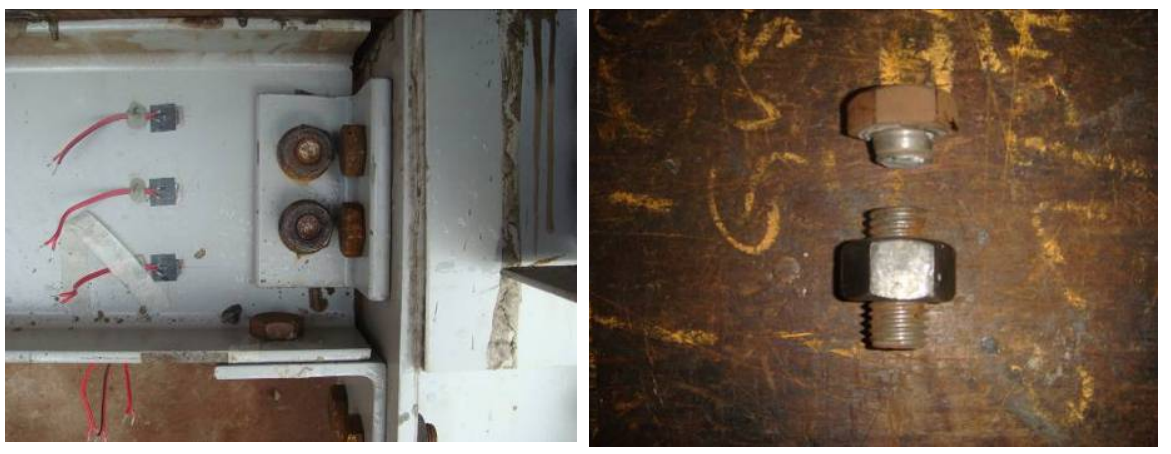

Figura 5.25: Cisalhamento do parafuso na cantoneira de mesa. 


\section{3 - Pavimento Tipo}

\subsection{1 - Resultados da etapa de carregamento distribuído}

$\mathrm{Na}$ primeira etapa de carregamento foram obtidos os deslocamentos na laje para cada fase, de acordo com o posicionamento dos transdutores dando origem as linhas 1 e 2 da Figura 5.26. A figura apresenta também a numeração adotada para as vigas principais ( 1 e 2), vigas secundárias ( 3 e 4) e das ligações do pavimento tipo.

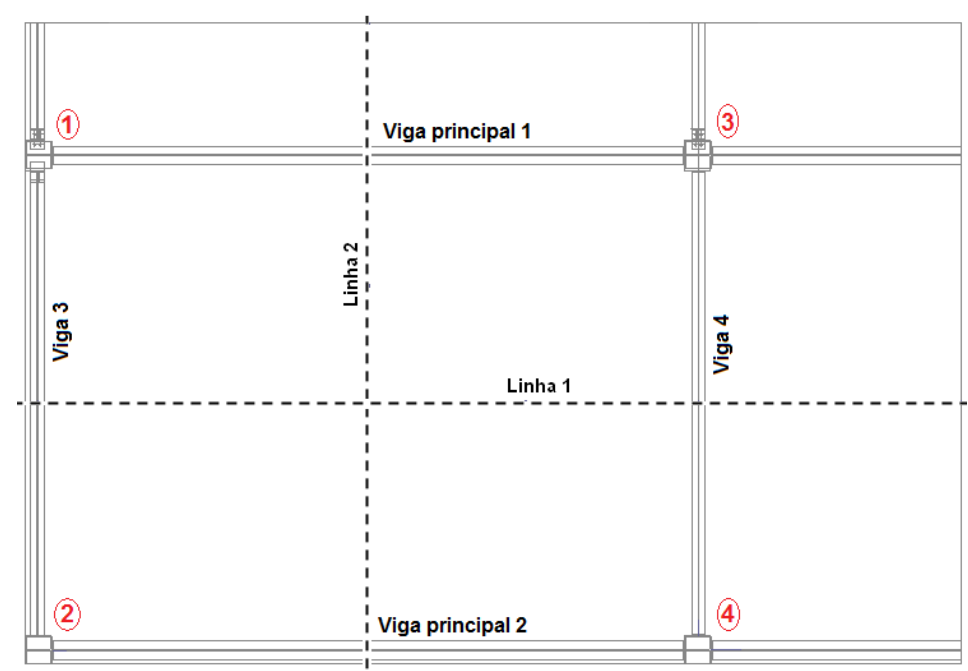

Figura 5.26: Linhas com o posicionamento dos transdutores para aferição dos deslocamentos na laje.

Os deslocamentos nas linhas de transdutores 1 e 2 para as oito fases do carregamento distribuído, de acordo com o ítem 4.3.3 do capítulo anterior, estão ilustrados nas Figura 5.27 e 5.28 , respectivamente.

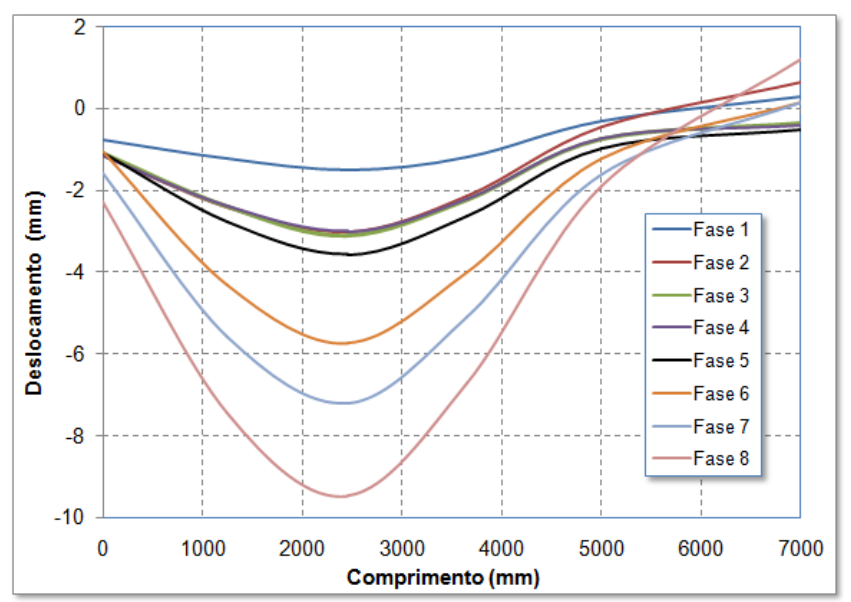

Figura 5.27: Deslocamentos na Linha 1 da laje do pavimento tipo para as oito fases da etapa de carregamento distribuído. 


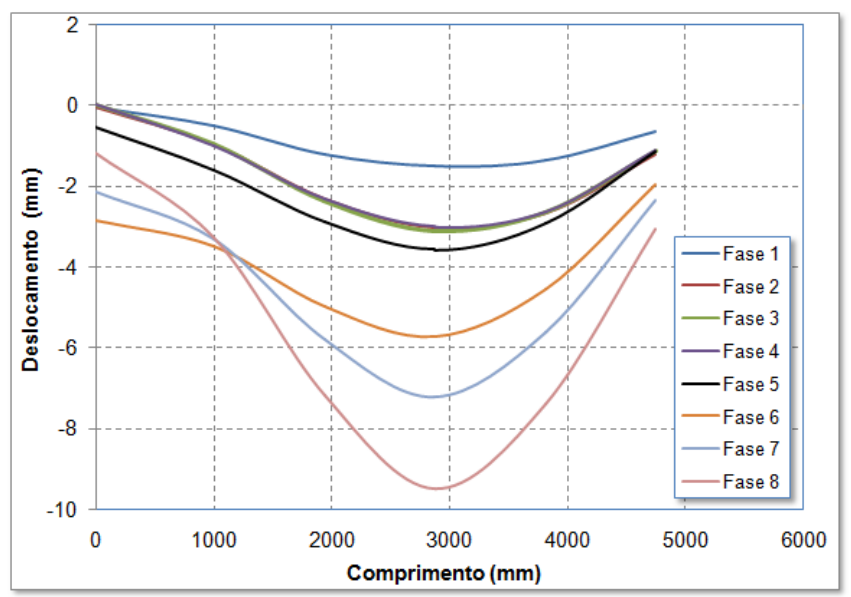

Figura 5.28: Deslocamentos na Linha 2 da laje do pavimento tipo para as oito fases da etapa de carregamento distribuído.

A fissuração da laje resultante da etapa de carregamento distribuído nas ligações do pavimento tipo está ilustrada na Figura 5.29.

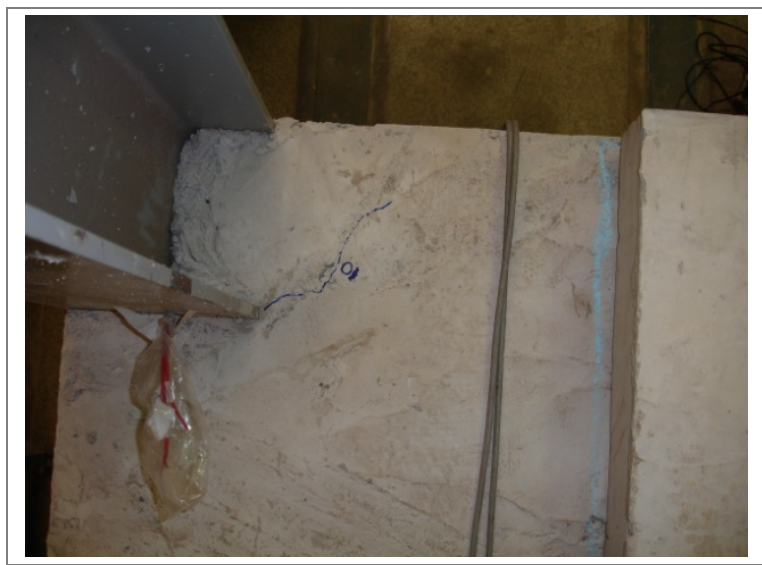

Ligação 2

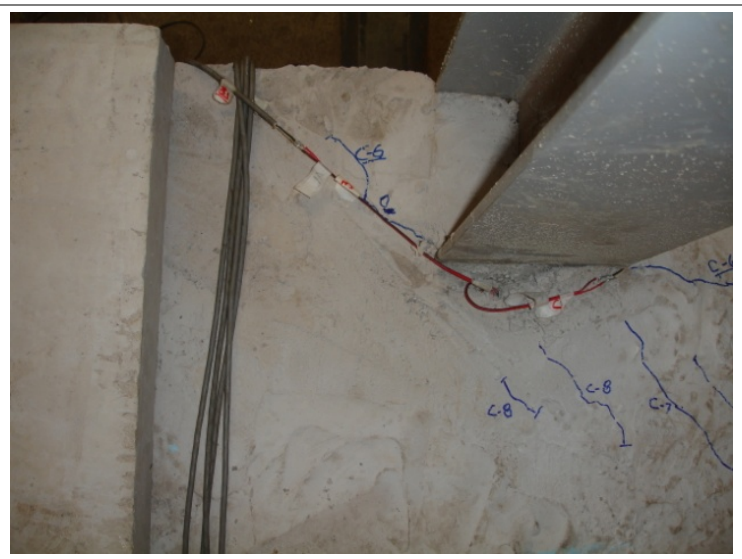

Ligação 1

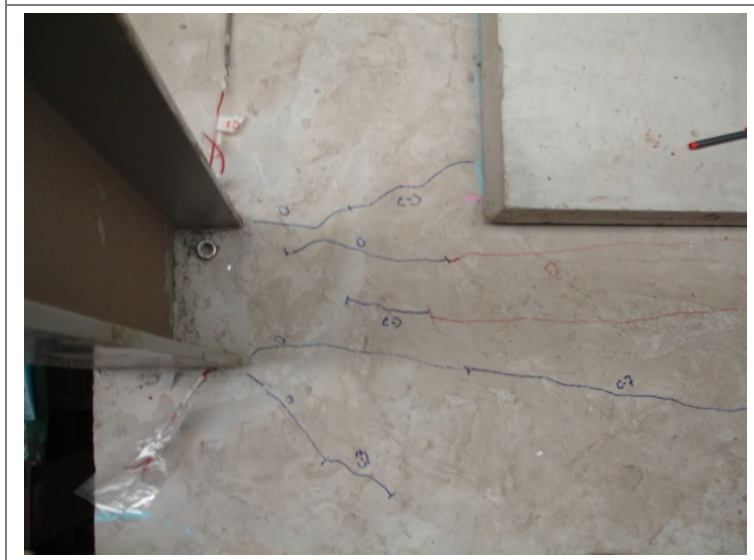

Ligação 4

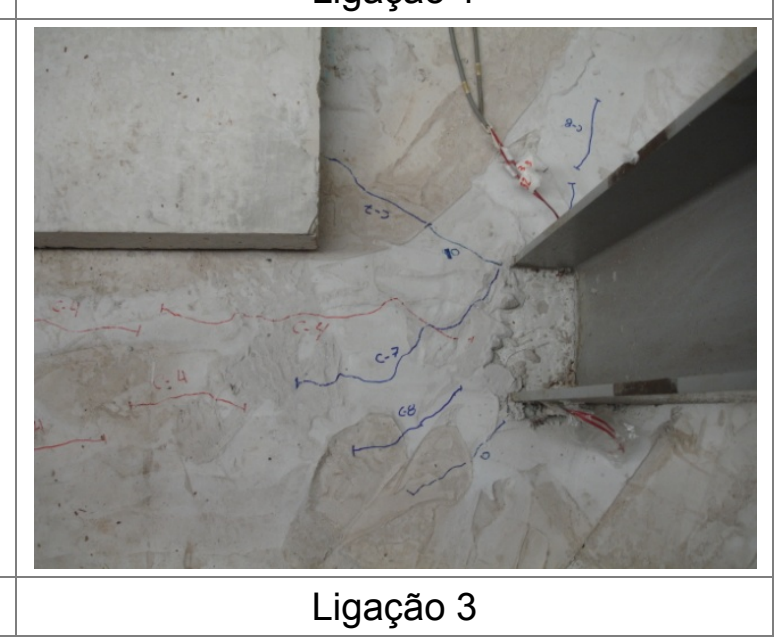

Figura 5.29: Fissuras nas ligações do pavimento tipo resultantes da etapa de carregamento distribuído na laje. 


\subsection{2 - Resultados da etapa de carregamento concentrado}

Para cada fase da etapa de carregamento concentrado, serão apresentados os resultados referentes aos deslocamentos da linha 1 de transdutores, conforme a Tabela 5.1 a seguir. Para apresentação destes resultados foi tomado como referência a força de solicitação no atuador $\left(F_{\max }\right)$ para cada fase de carregamento, de acordo com a breve descrição apresentada. Os resultados complementares referentes aos deslocamentos na linha 2, vigas principais e secundárias do pavimento tipo estão indicados no Apêndice B.

Tabela 5.1: Deslocamentos na linha 1 de transdutores para as nove fases da etapa de carregamento concentrado no pavimento tipo.

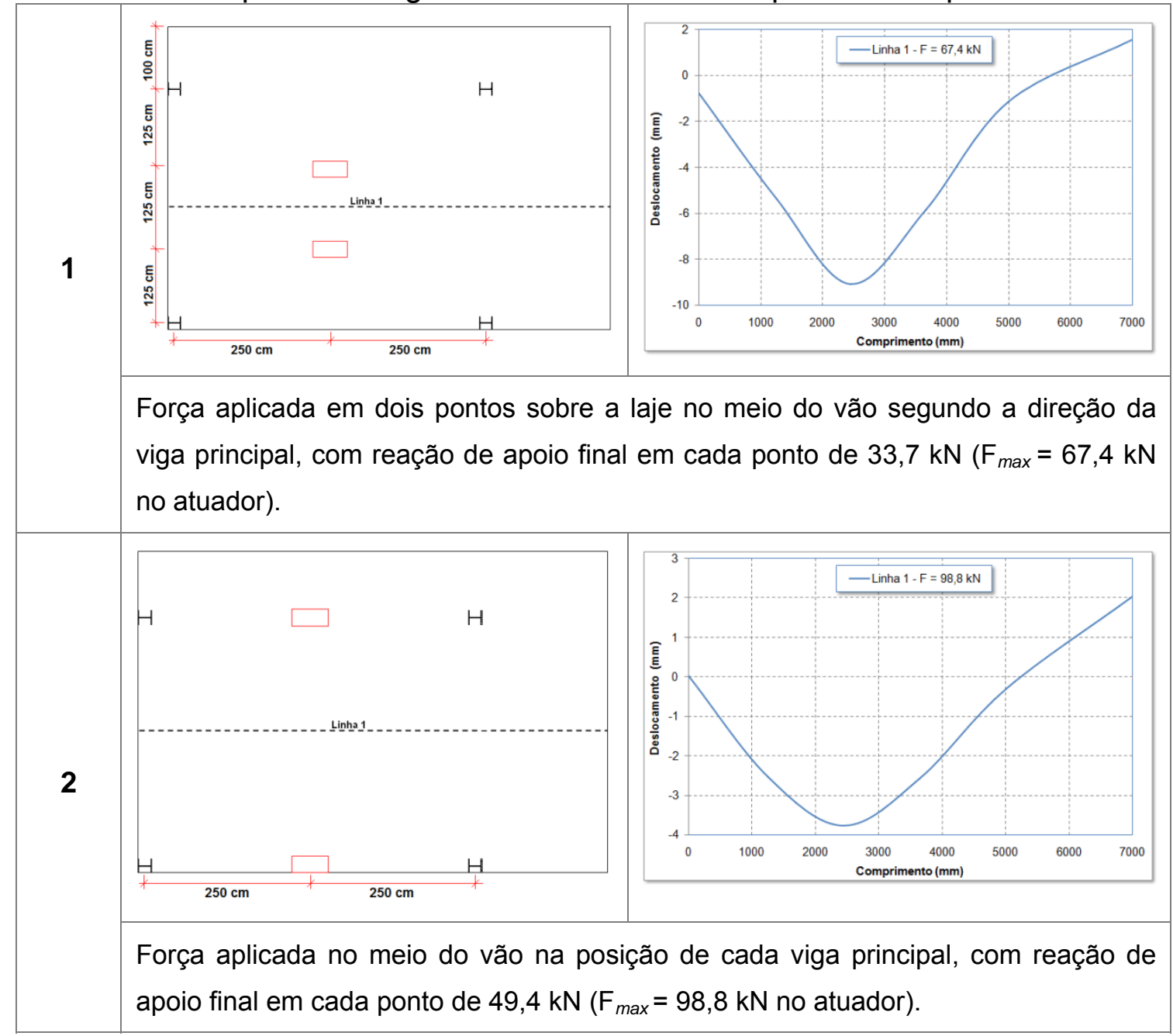




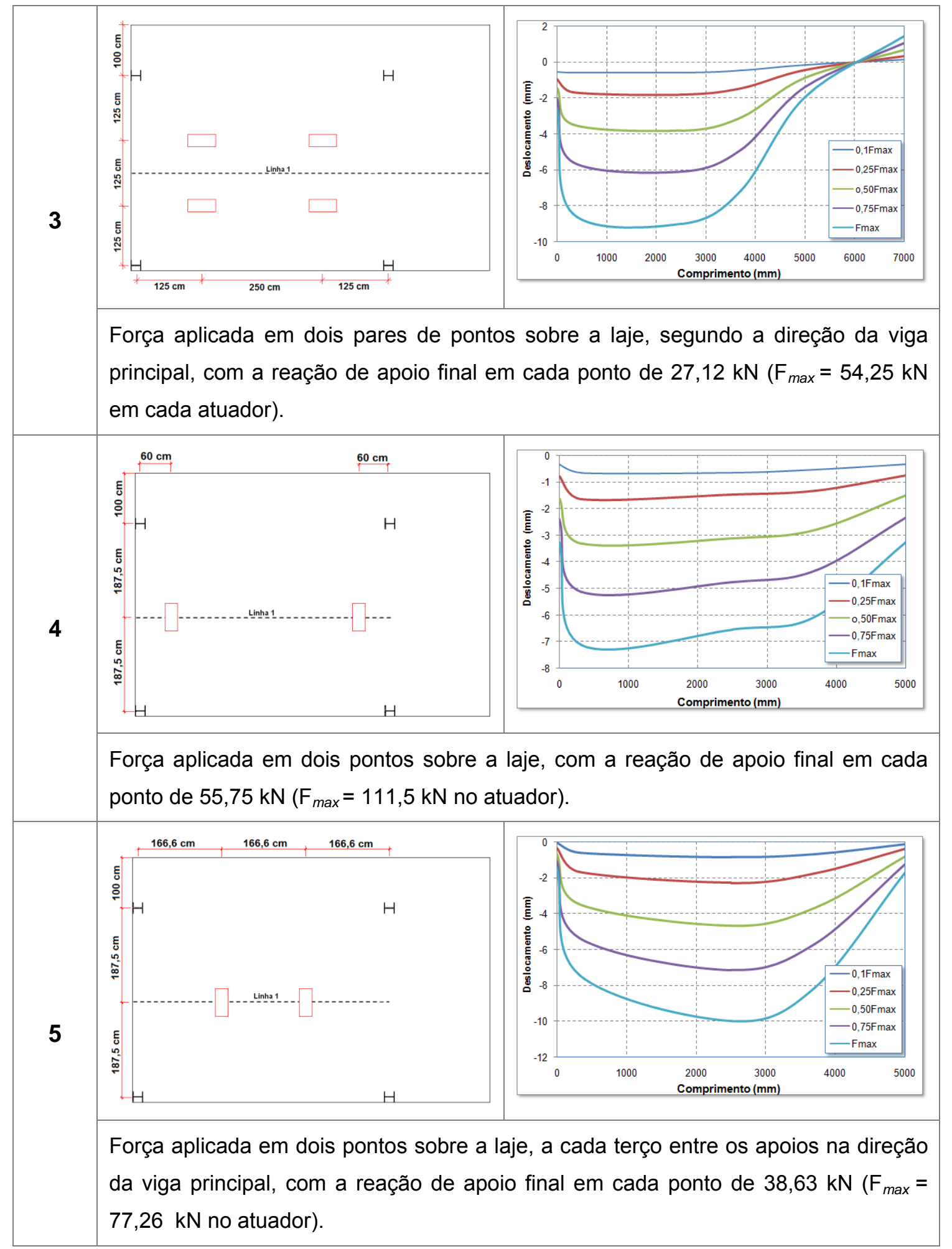




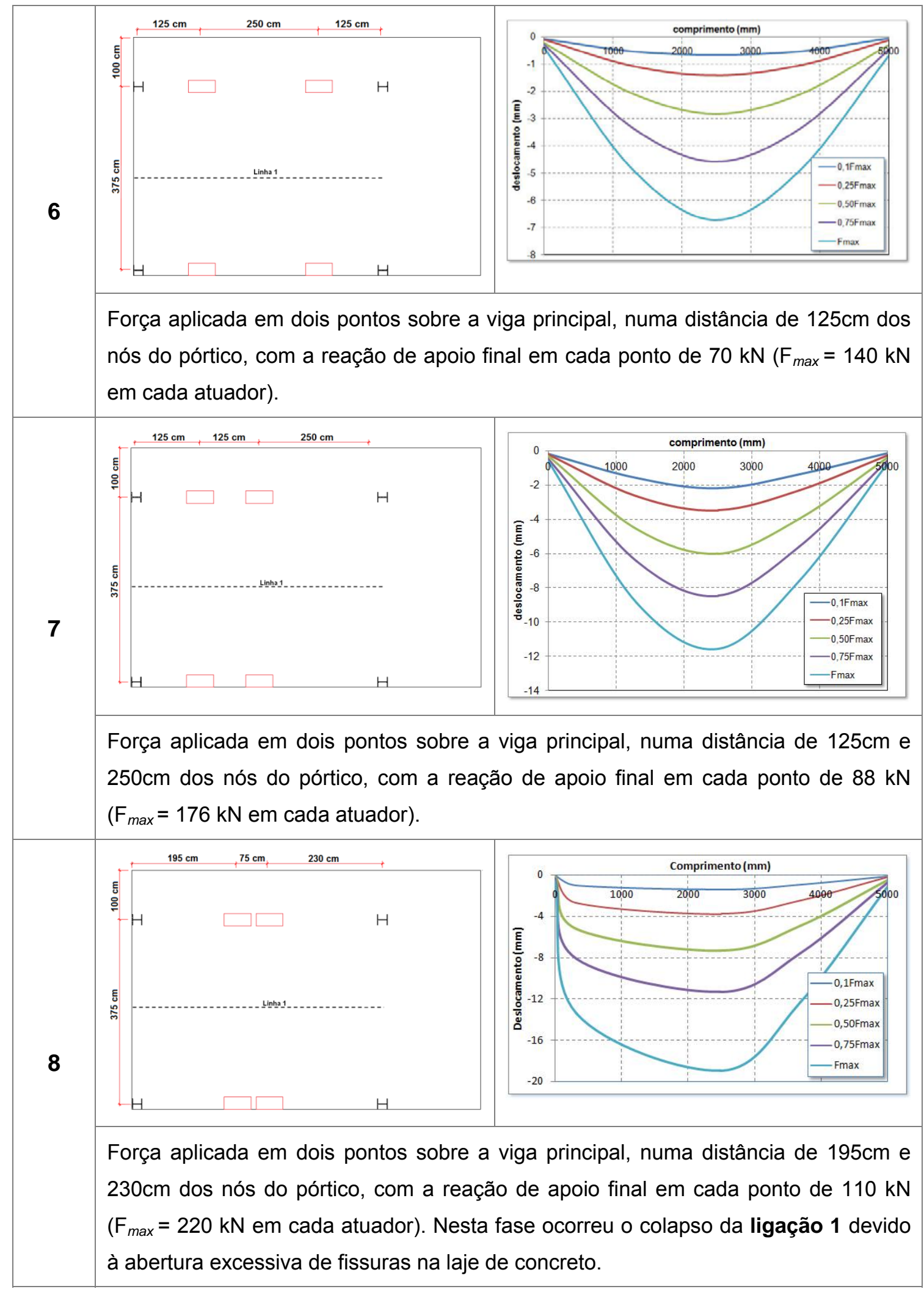




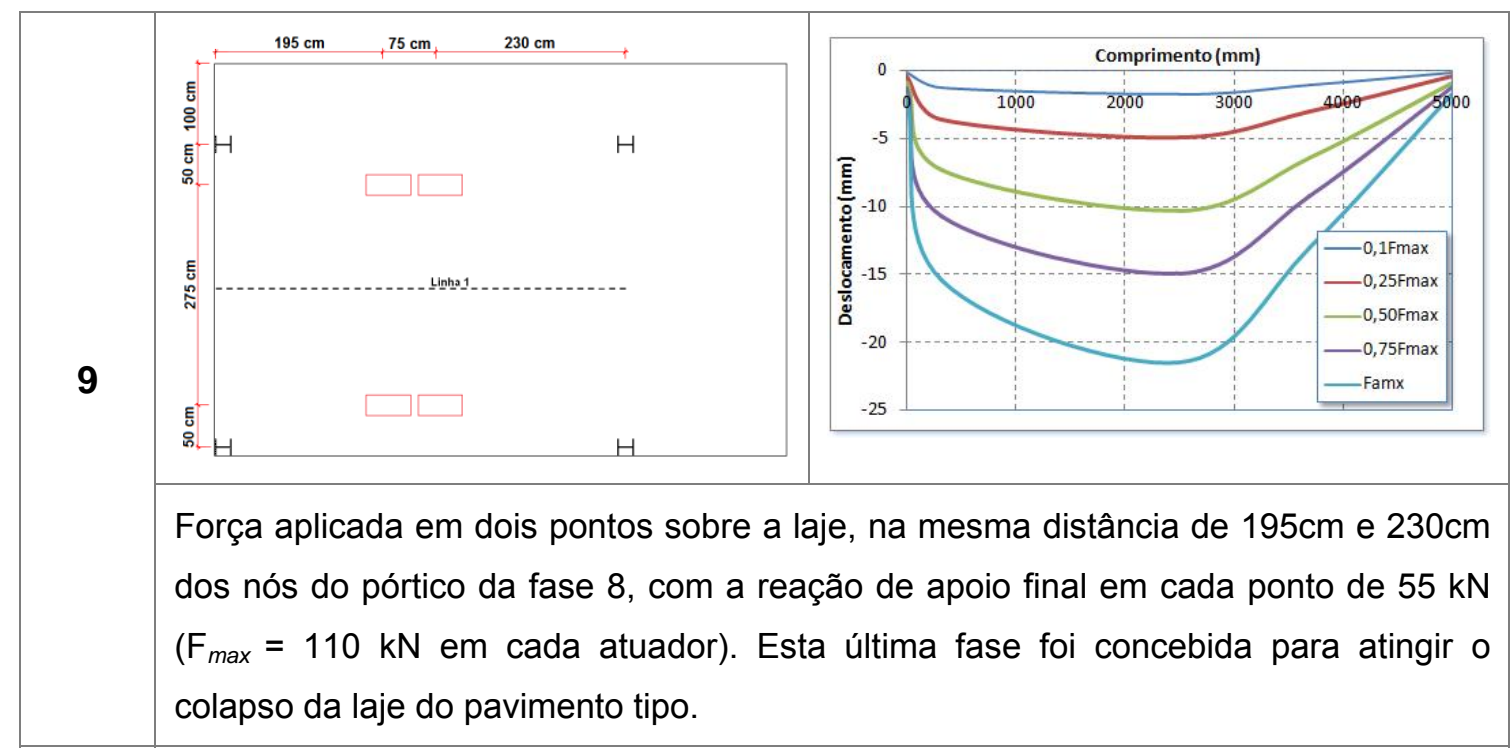

Os resultados relativos ao comportamento força $x$ deslocamento $(F x D)$, momento $\mathrm{x}$ rotação $(M-\phi)$, e deformações na viga e armaduras são apresentados separadamente para cada ligação do pavimento tipo, de acordo com a numeração indicada na Figura 5.26 para o carregamento da fase 8 , no qual foi observado o colapso da Lig. [1] devido à abertura excessiva de fissuras na laje de concreto.

Para a análise das ligações do pavimento tipo, foi adotada a força no atuador $\left(F_{\max }\right)$ como referência na relação força $x$ deslocamento de cada ligação. Para a obtenção do momento fletor foi considerado a condição teórica de momento de engastamento perfeito nas ligações de cada pórtico do pavimento tipo (formado pelas vigas principais), para o carregamento da fase 8 da etapa de carregamento concentrado (etapa 2).

\subsubsection{1 - Ligação [1]}

A Figura 5.30 apresenta o comportamento $\mathrm{FxD}$ e $M-\phi$ na ligação, tomando-se um transdutor de deslocamento posicionado numa distância de 22 $\mathrm{cm}$ da face do pilar como referência para obtenção do deslocamento e da rotação na ligação.

A Figura 5.31 ilustra as deformações longitudinais na viga, numa seção posicionada a $130 \mathrm{~cm}$ da face do pilar. Os extensômetros dispostos na 
armadura longitudinal e de contorno da Lig. [1] foram perdidos quando na concretagem do pavimento tipo.

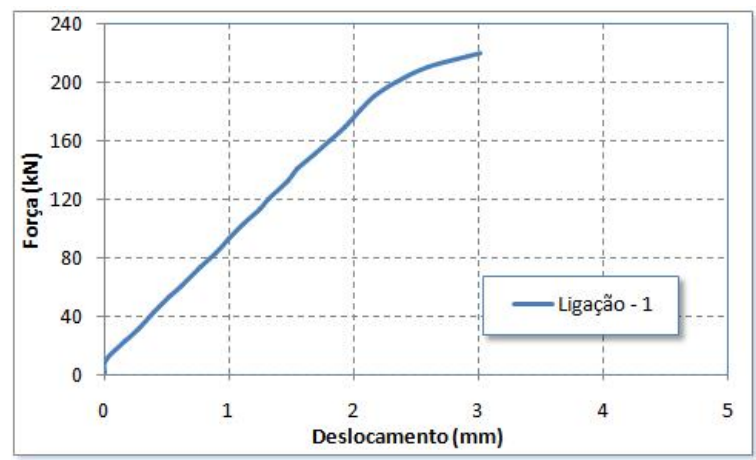

Curva FxD

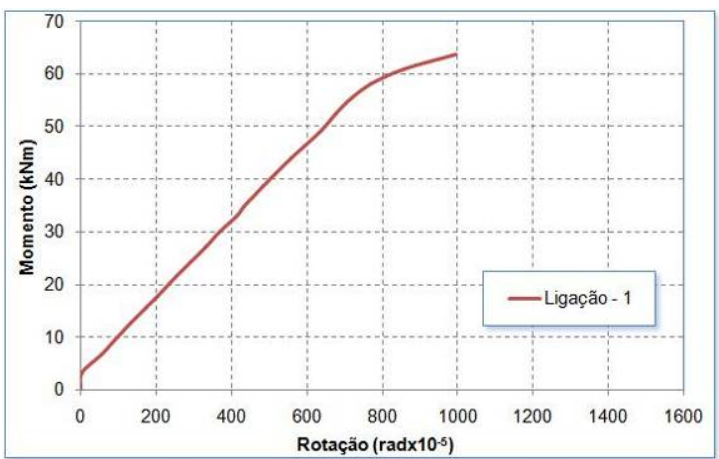

Curva $M-\phi$

Figura 5.30: Comportamento $F x D$ e $M-\phi$ para a Lig. [1] do pavimento tipo.
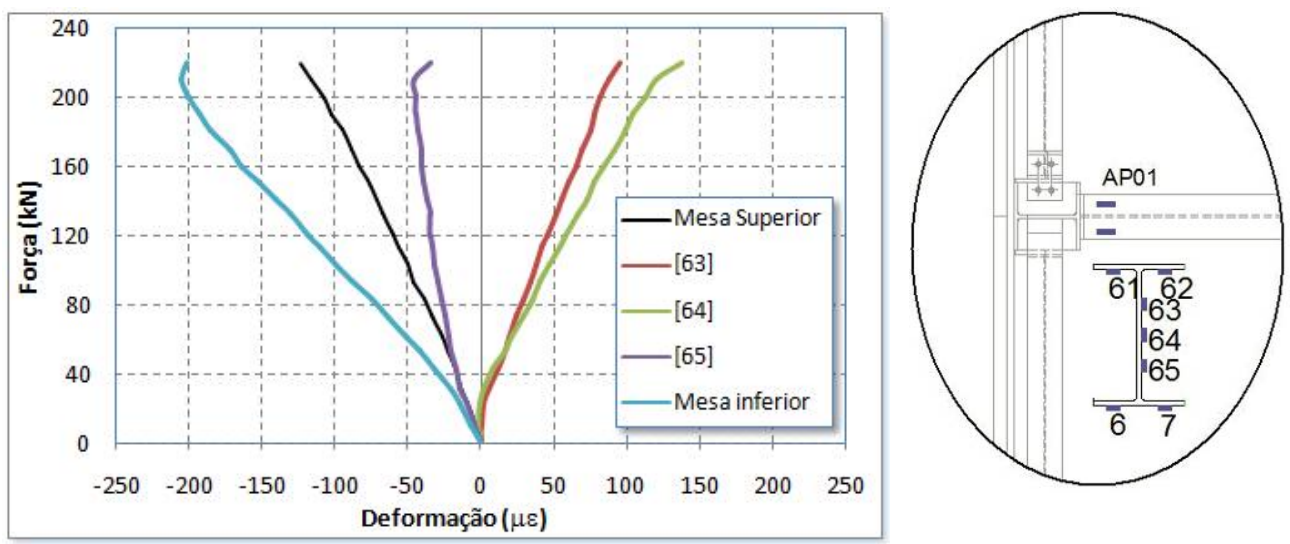

Figura 5.31: Deformações nos extensômetros da viga.

Conforme ilustra a figura anterior, os extensômetros da mesa superior da viga foram posicionados em sua face inferior, com as deformações das mesas superior e inferior obtida a partir da média dos extensômetros (61-62) e (6-7), respectivamente. A Figura 5.32 apresenta as deformações em toda altura da viga (mesma seção anterior), ao longo do incremento do carregamento na ligação, no qual observa-se que os extensômetros da mesa superior da viga apresentam deformações de compressão. 


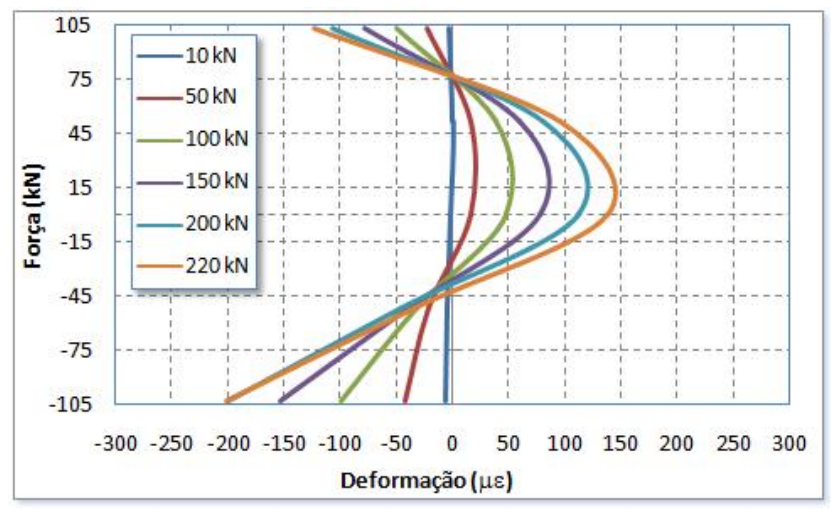

Figura 5.32: Deformações longitudinais na seção da viga ao longo do carregamento.

Esse efeito foi observado em todas as ligações do pavimento tipo e é explicado pela considerável parcela da componente de deformação longitudinal devido ao cisalhamento nesta posição (região próxima da extremidade da viga), que na face interna da mesa superior da viga é subtraída da parcela devida a deformação de flexão (tração).

A Figura 5.33 ilustra a fissuração da laje na Lig. [1] ao término do ensaio, com o detalhe para presença de fissuras inclinadas de aproximadamente $45^{\circ}$ a partir da mesa do pilar, mesma configuração de fissuração da laje observada nos modelos isolados de pilar de borda.
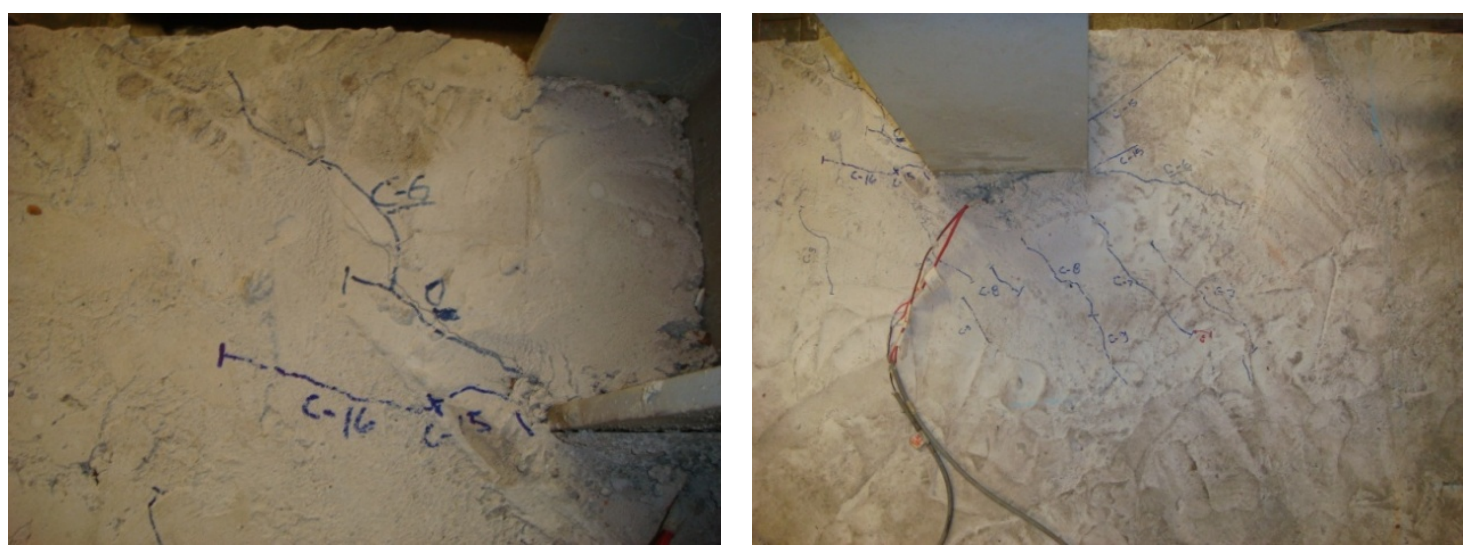

Figura 5.33: Fissuração da laje de concreto na Lig. [1] após o ensaio.

\subsubsection{2 - Ligação [2]}

A Figura 5.34 ilustra o comportamento FxD e $M-\phi$, tomando-se como referência um transdutor de deslocamento posicionado na mesma distância de $22 \mathrm{~cm}$ da face do pilar. 


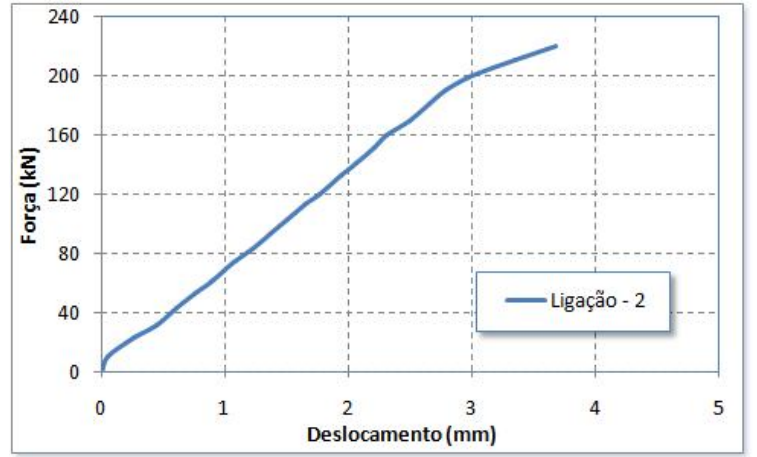

Curva FxD

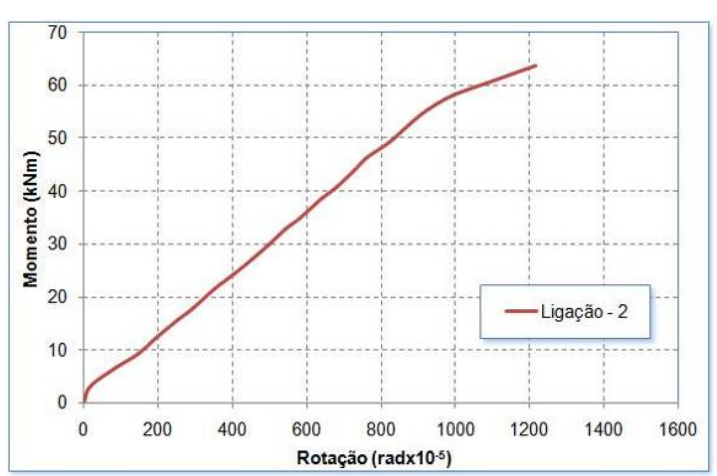

Curva $M-\phi$

Figura 5.34: Comportamento FxD e $M-\phi$ para a Lig. [2] do pavimento tipo.

A deformação da armadura longitudinal da viga mista na Lig. [2] é apresentada na Figura 5.35, uma vez que o extensômetro da armadura de contorno foi perdido quando na concretagem do modelo. A armadura longitudinal também apresentou pequenas deformações ao longo do carregamento. Para esta ligação não foram colocados extensômetros na viga para aferição das deformações.
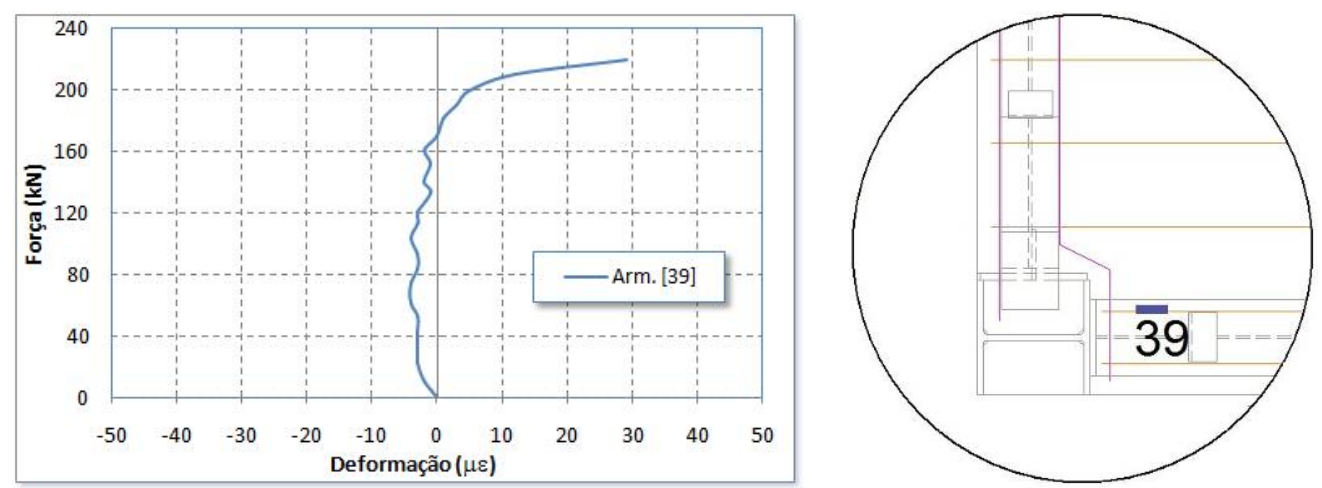

Figura 5.35: Deformação na armadura longitudinal da viga mista na Lig. [2].

A Figura 5.36 ilustra a fissuração da laje na ligação [2] ao término do ensaio, com o detalhe para a presença da mesma fissura inclinada de aproximadamente $45^{\circ}$, observada na ligação anterior e nos modelos isolados de pilar de borda. 


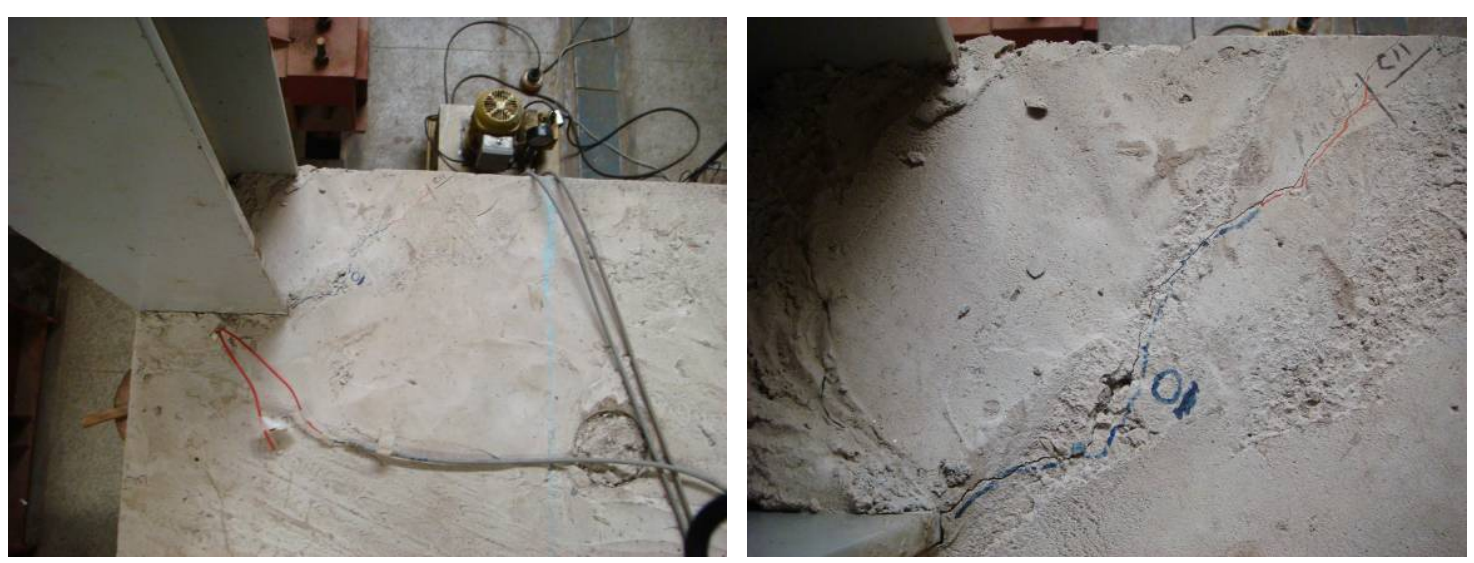

Figura 5.36: Fissuração da laje de concreto na Lig [2] após o ensaio.

\subsubsection{3 - Ligação [3]}

$\mathrm{Na}$ ligação [3] foram aferidas as deformações na viga e nas armaduras longitudinal e de contorno do pilar. A Figura 5.37 apresenta o comportamento FxD e $M-\phi$.

Seguindo o mesmo padrão adotado para as ligações anteriores, a força indicada no atuador foi utilizada como referência para obtenção das deformações na viga e nas armaduras longitudinais e de contorno. A Figura 5.38 ilustra as deformações longitudinais na viga, numa seção posicionada a $130 \mathrm{~cm}$ da face do pilar.

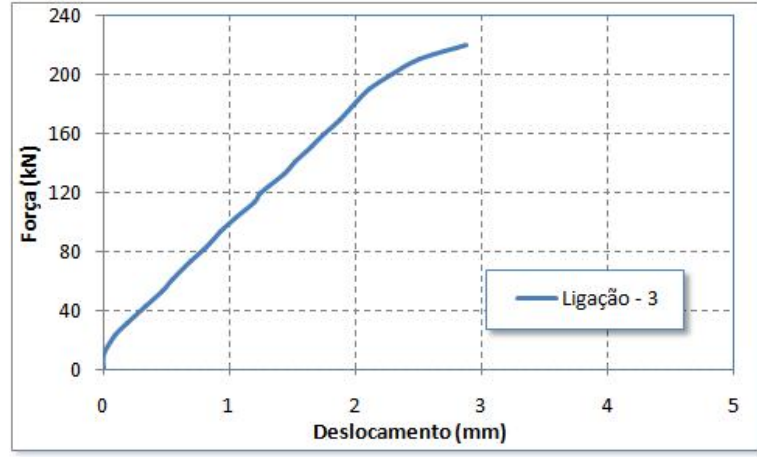

Curva FxD

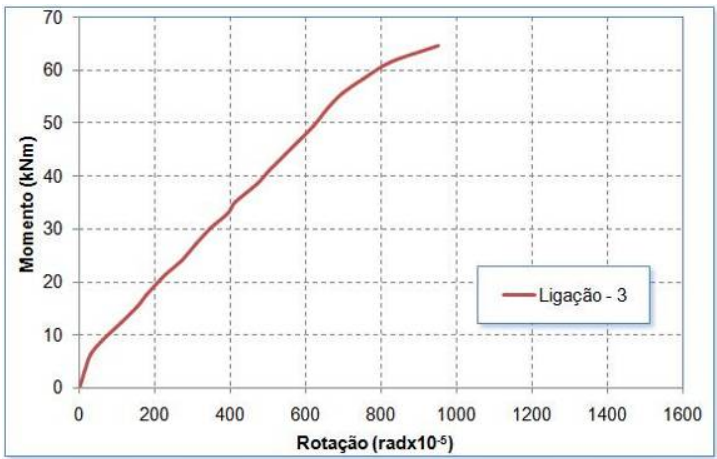

Curva $M-\phi$

Figura 5.37: Comportamento FxD e $M-\phi$ para a Lig. [3] do pavimento tipo. 

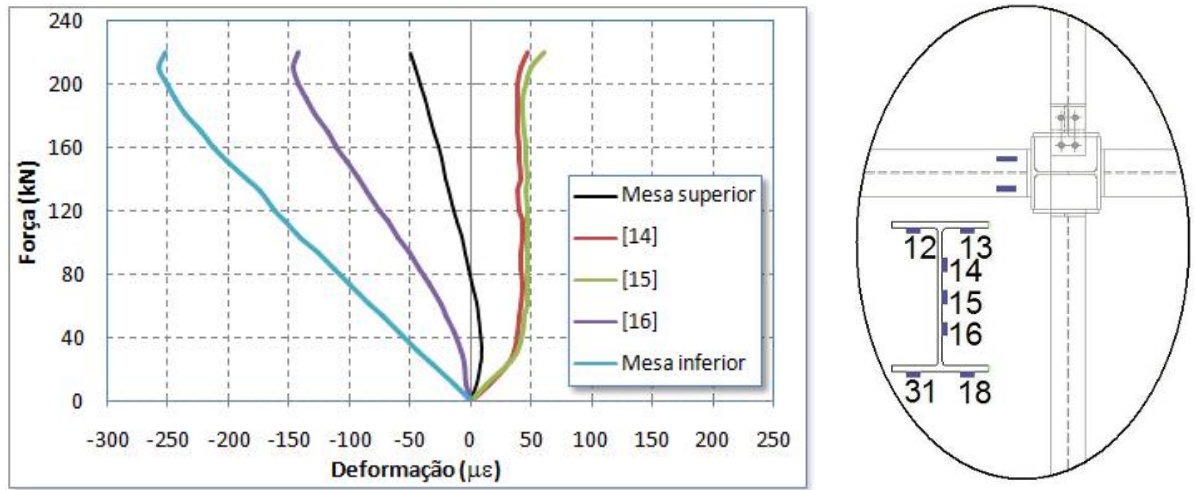

Figura 5.38: Deformações longitudinais nos extensômetros da viga.

Na Figura 5.39 abaixo se tem as deformações longitudinais em toda altura da viga (mesma seção da figura anterior), ao longo do incremento do carregamento na ligação [3].

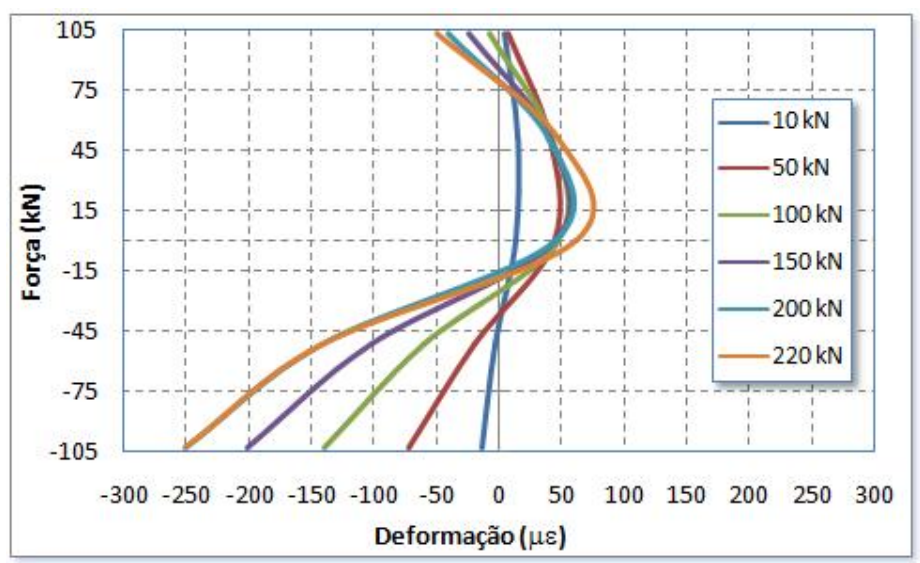

Figura 5.39: Deformações longitudinais na seção da viga ao longo do carregamento.

As deformações da armadura longitudinal e de contorno da viga mista estão apresentadas na Figura 5.40. Na ligação [3] também foi observado pequenas deformações na viga e nas armaduras longitudinais e de contorno.

A Figura 5.41 ilustra a fissuração da laje ao final da etapa de carregamento concentrado. A análise dos resultados mostrou a formação das mesmas configurações de fissuração observada nos modelos isolados de pilar de centro, porém com grande parte das fissuras tendo sua origem na etapa anterior de carregamento distribuído na laje. 

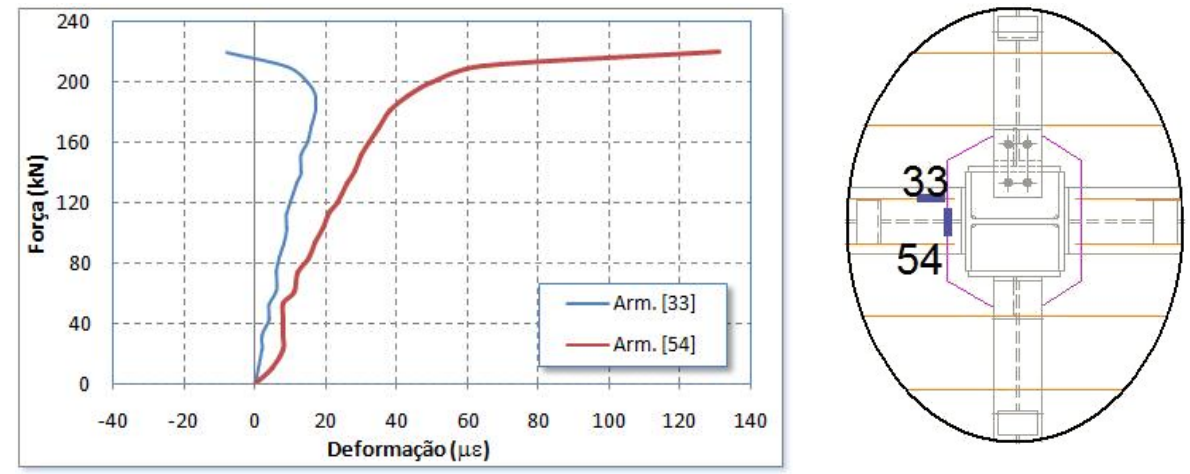

Figura 5.40: Deformação na armadura longitudinal e de contorno da viga mista na Lig. [3].
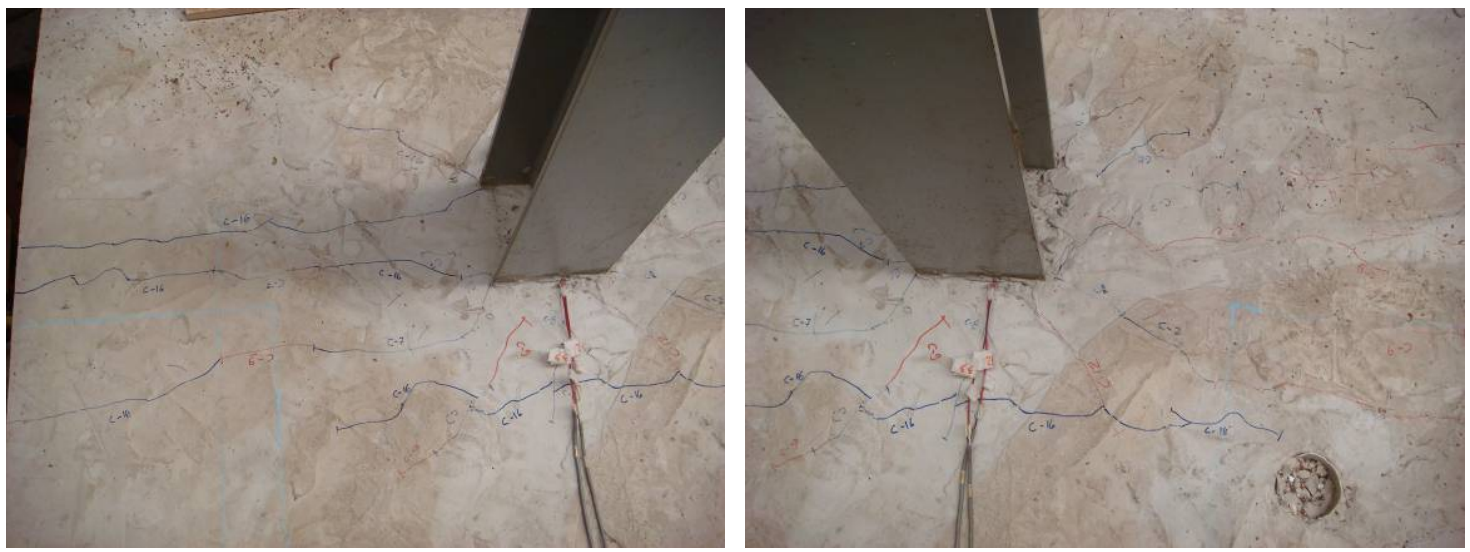

Figura 5.41: Fissuração da laje de concreto na Lig. [3] após o ensaio.

\subsubsection{4 - Ligação [4]}

A Figura 5.42 ilustra o comportamento FxD e $M-\phi$ para a Lig. [4] do pavimento tipo. Na Figura 5.43 têm-se as deformações na viga, considerando apenas o extensômetro 28 na mesa inferior da viga.

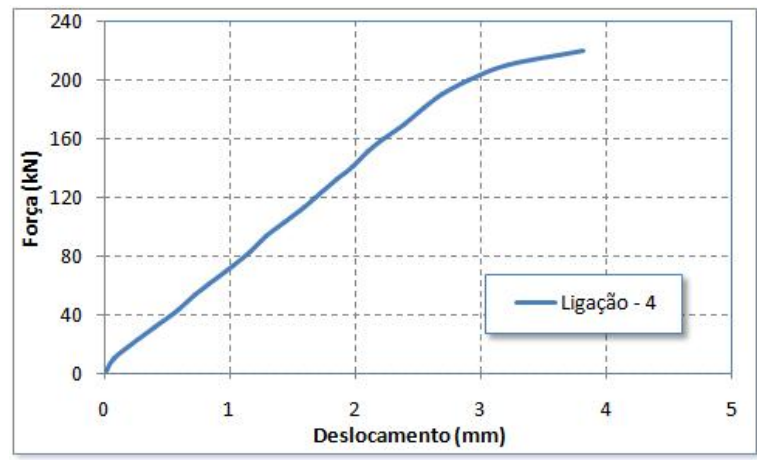

Curva FxD

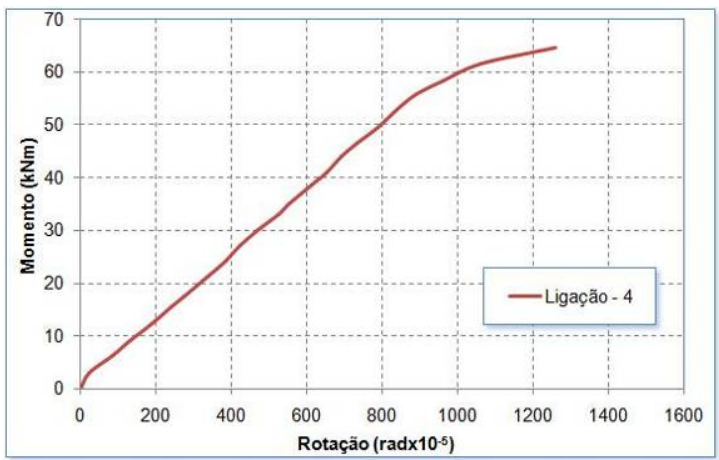

Curva $M-\phi$

Figura 5.42: Comportamento FxD e $M-\phi$ para a Lig. [4] do pavimento tipo. 

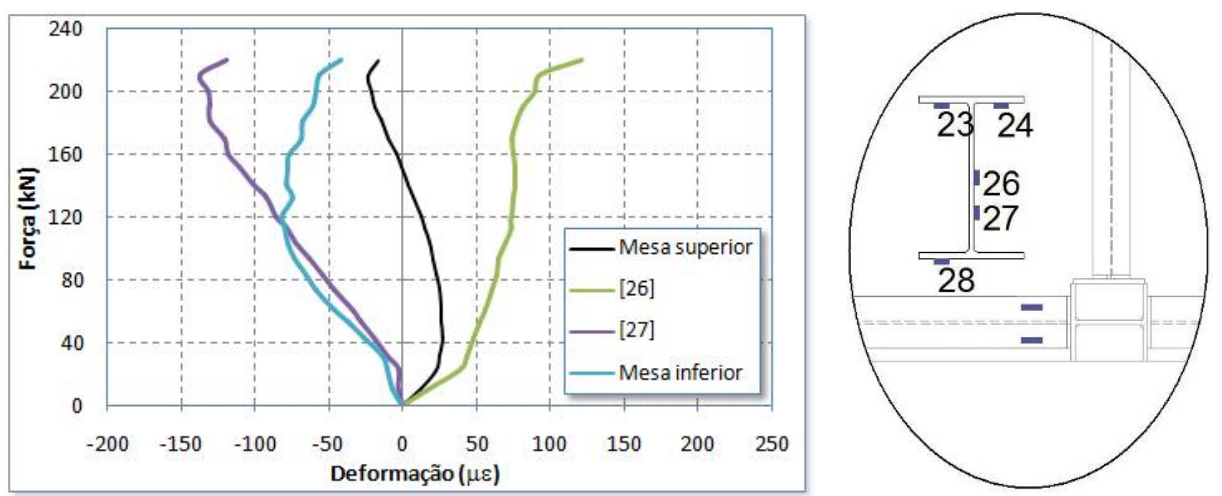

Figura 5.43: Deformações longitudinais nos extensômetros da viga.

A Figura 5.44 apresenta as deformações longitudinais em toda altura da viga, considerando a mesma seção da figura anterior, ao longo do incremento do carregamento na ligação [4].

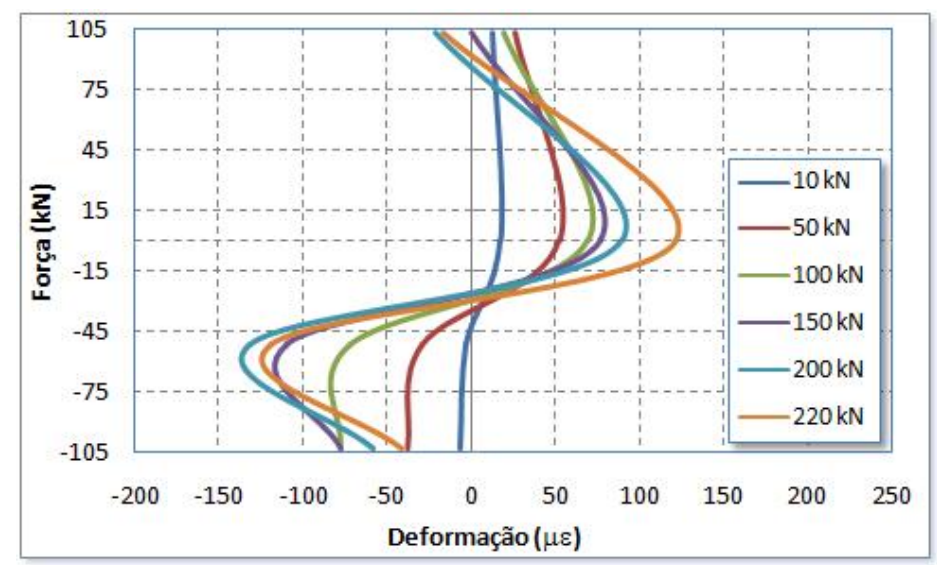

Figura 5.44: Deformações longitudinais na seção da viga ao longo do carregamento.

As deformações da armadura longitudinal e de contorno da viga mista estão ilustradas na figura 5.45. Em todas as ligações do pavimento tipo foi observado baixo valores de deformações na viga e nas armaduras, com maiores valores de deformações nas armaduras de contorno em relação as armaduras longitudinais. 

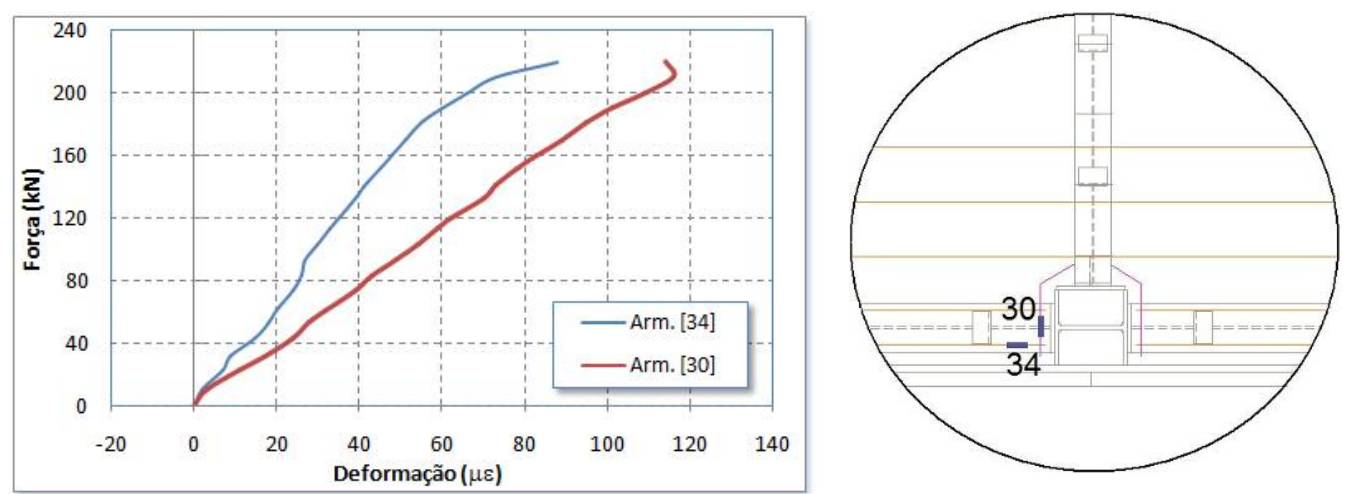

Figura 5.45: Deformação nas armaduras longitudinal e de contorno da viga mista na ligação [4].

A Figura 5.46 ilustra a fissuração da laje ao término do ensaio, com o detalhe para o surgimento de fissuras paralelas à mesa e inclinadas de aproximadamente $45^{\circ}$ a partir da mesa do pilar.
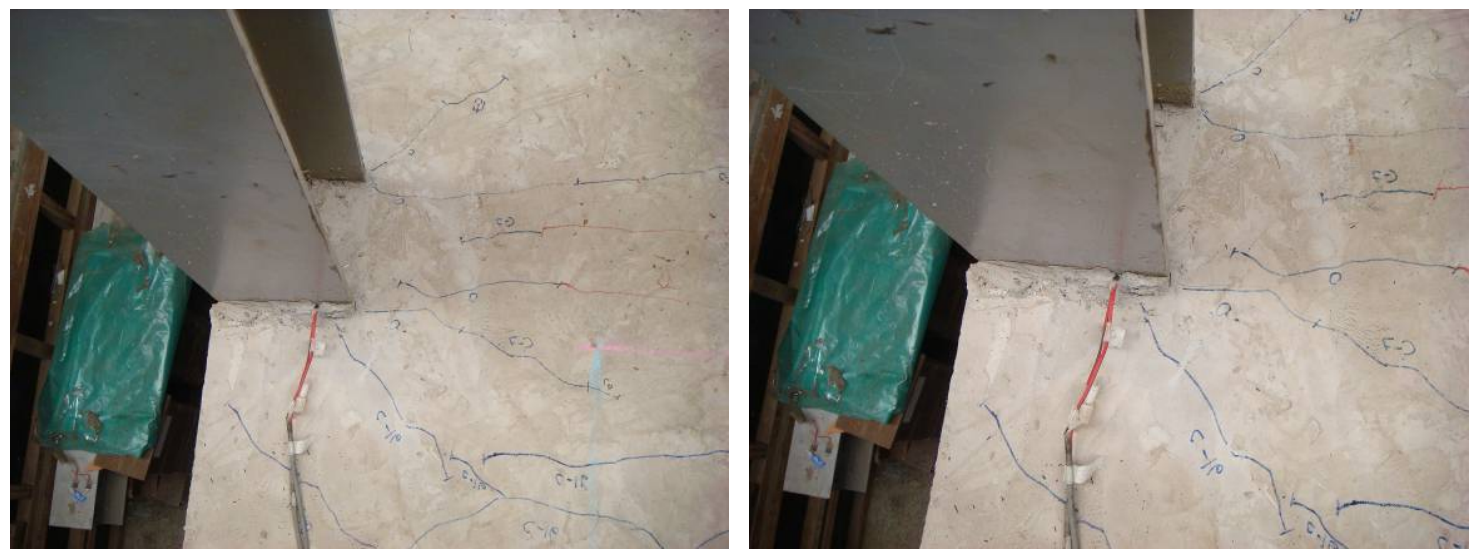

Figura 5.46: Fissuração da laje de concreto na ligação [4] após o ensaio.

\section{4 - Considerações Finais}

De maneira geral, o pavimento tipo ensaiado conseguiu reproduzir satisfatoriamente as ligações mistas em meio contínuo, ou seja, inseridas dentro da continuidade de toda a estrutura. Os resultados obtidos mostraram o mesmo mecanismo de fissuração da laje observado nos protótipos isolados de pilar de canto e de borda.

Entretanto, o surgimento e a expansão dessas fissuras no pavimento tipo deram-se em estágios de carregamento bem superiores quando comparado com os modelos isolados, devido à continuidade física do meio (vigas transversais, da laje e de suas respectivas armaduras). 
No entanto, vale ressaltar que no pavimento tipo o início da formação de fissuras deu-se na etapa de carregamento distribuído. A análise dessa formação de fissuras na região das ligações devido ao carregamento distribuído na laje, e sua influência na rigidez e resistência das mesmas serão realizadas no Capítulo 7 , que diz respeito à análise e comparação dos resultados.

O Capítulo 6 a seguir refere-se a descrição da metodologia de modelagem numérica, que tem como característica principal a consideração da laje de concreto, bem como os resultados principais em termos do comportamento momento-rotação, deformações e deslocamentos dos elementos para os protótipos isolados. 


\section{6}

\section{DESCRIÇÃO E RESULTADOS DA MODELAGEM NUMÉRICA}

\section{1 - Considerações Iniciais}

Este capítulo apresenta à descrição e resultados da modelagem numérica das ligações viga mista-pilar. Os principais aspectos abordados referem-se à definição da geometria, os tipos de elementos finitos utilizados, à representação das relações constitutivas dos materiais e as condições de contorno e carregamento. A metodologia de modelagem numérica adotada neste trabalho complementa os trabalhos Maggi (2000), Maggi (2004) e Tristão (2006).

Embora o tipo de ligação estudada neste trabalho seja de cantoneira de alma e assento, a filosofia utilizada permite que os mesmos procedimentos sejam adotados para qualquer configuração de ligação. Este trabalho tem como proposta a inclusão da laje de concreto e das armaduras longitudinais na modelagem de ligações viga mista-pilar, além da não consideração da simetria segundo o plano médio da alma da viga.

Os modelos numéricos foram desenvolvidos utilizando o software ANSYS, e adicionalmente um software específico para o pré-processamento dos modelos, denominado de TRUEGRID, que permite ganhos significativos de produtividade e precisão na fase de construção da malha de elementos finitos.

\section{2 - Critérios Adotados na Análise Numérica}

Diante da complexidade do comportamento estrutural das ligações mistas e dos resultados que se pretende obter, especificamente a rigidez e os estados 
limites a que está submetida, busca-se uma análise que represente, da melhor forma possível, o comportamento da ligação.

A representatividade da modelagem numérica depende de vários critérios, dos quais os mais importantes são a escolha dos tipos de elementos finitos e dos modelos de não-linearidade dos materiais, com as respectivas descrições da relação tensão-deformação. Os procedimentos abaixo foram rigorosamente seguidos para a modelagem numérica:

- Definição da geometria do modelo;

- Escolha do tipo de elemento finito para cada componente do modelo, como por exemplo, viga de aço, pilar, parafusos, conectores, laje de concreto e cantoneiras;

- Construção da malha de elementos finitos, através do programa TRUEGRID;

- Definição dos modelos de não-linearidade dos materiais;

- Aplicação das condições de contorno;

- Aplicação da protensão nos parafusos;

- Aplicação do carregamento na extremidade da viga;

Após a definição da geometria do modelo e a escolha do tipo de elemento finito para cada componente da ligação, o processo de simulação numérica foi iniciado por uma fase denominada de pré-processamento, na qual constitui-se a geometria dos modelos, discretização, condições de contorno e aplicação do carregamento.

Para esta etapa de pré-processamento foi utilizado o programa TRUEGRID, que juntamente com o programa ANSYS, permite uma construção rápida das malhas por meio de arquivos já parametrizados. A partir desses arquivos, o modelo é processado no ANSYS.

\subsection{1 - Não-linearidade do material}

Visando uma melhor consideração das características dos materiais envolvidos na ligação, foram adotados diagramas multilineares para a representação do comportamento tensão-deformação do aço e concreto. 
Dessa forma, adotou-se um modelo representativo do diagrama multilinear, consistente com o material utilizado, designado por Multi-linear Isotropic Hardening Plasticity (MISO) no software ANSYS. Este modelo consiste em segmentos de retas consecutivos que permitem definir o comportamento elástico, a plastificação e o comportamento pós-plastificação do material, de acordo com os valores de parâmetros fornecidos pelo usuário.

$\mathrm{Na}$ laje de concreto também foi utilizado o diagrama multi-linear MISO, de acordo com a região tracionada e comprimida da laje, definida a partir da posição teórica da linha neutra. Esta estratégia apresentou resultados satisfatórios e com uma boa convergência da solução numérica, embora não permita a simular numericamente a fissuração da laje de concreto. Os modelos constitutivos testados que possibilitam a representação da fissuração do concreto, quando tracionado, apresentaram instabilidade de convergência logo nos primeiros passos de carga, nos quais surgem as primeiras fissuras na laje.

Embora a boa representatividade da resposta numérica diante da estratégia adotada, no que diz respeito ao comportamento global e local nos componentes em aço da ligação, cabe ressaltar que a análise do comportamento da laje de concreto ficou significantemente comprometida pela não representação efetiva do comportamento do material concreto, principalmente no que diz respeito a análise de fissuração na laje.

\subsection{2 - Não-linearidade geométrica}

A concepção dos modelos numéricos, com a utilização de elementos finitos tridimensionais já indica a necessidade de levar em consideração os efeitos da não-linearidade geométrica, o que também é consistente com a etapa de realização dos ensaios experimentais.

A consideração do comportamento não-linear geométrico também se impõe devido à necessidade de se considerar a interação entre os diversos elementos componentes da ligação, com a utilização de elementos finitos especiais com os quais é possível simular o contato entre parafusos, porcas, cantoneiras, pilar, laje de concreto e viga. As características dos elementos utilizados para essa finalidade serão descritos mais adiante. 
De acordo com Maggi (2004), a inclusão da consideração de grandes deslocamentos não modifica significamente os resultados numéricos, principalmente com relação ao comportamento global das ligações.

No entanto, o autor refere que a consideração de grandes deslocamentos apresentou maior representatividade na convergência da solução numérica para a determinação dos estados limites últimos das ligações, permitindo gerar possíveis instabilidades localizadas.

\section{3 - Elementos Finitos Adotados}

A escolha dos tipos de elementos finitos a serem utilizados na modelagem numérica depende, principalmente, das características da geometria e das considerações a serem feitas na representação do modelo, além do atendimento da necessidade de precisão nos resultados e conveniência de minimização do esforço computacional na análise numérica.

Desta maneira, foram escolhidos três tipos de elementos. O primeiro tipo, volumétrico, para a representação dos componentes em aço (viga, pilar, cantoneiras e parafusos) e para a laje de concreto; um segundo, de "contato", para a representação das descontinuidades geométricas; e utilizou-se ainda elementos de barra, para a modelagem dos conectores de cisalhamento e armadura longitudinal.

\subsection{1 - Elemento SOLID45}

Este elemento volumétrico é constituído por oito nós, com três graus de liberdade referentes à translação nas direções $X, Y$ e $Z$ (Figura 6.1). Possui também características de plasticidade e ortotropia, utilizando formulações de integração total com oito pontos de integração (pontos de Gauss) e, admitindo a utilização de diagrama multi-linear para representação do comportamento tensão-deformação.

De acordo com Maggi (2004), este elemento pode apresentar uma resposta numérica desfavorável para esforços de flexão, devido a um efeito numérico denominado de "shear locking", que provoca o aumento da rigidez do elemento finito. Maggi (2004) menciona que esse efeito pode ser minimizado 
pela utilização de elementos com funções de interpolação quadráticas, o que levaria a um aumento significativo do número de nós por elemento.

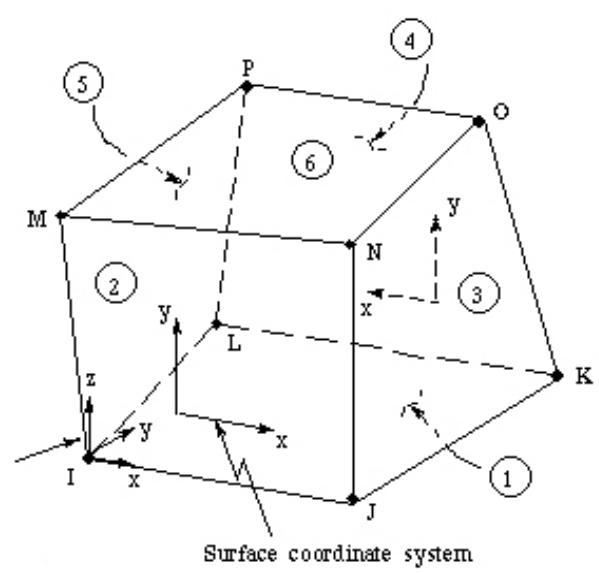

Figura 6.1 - Elemento volumétrico SOLID45.

Fonte: ANSYS Help System Release 9.0.

Maggi (2004) refere-se ainda que, para problemas de plasticidade, faz-se necessário que os elementos finitos permitam descontinuidades no campo dos deslocamentos, devido ao desenvolvimento de linhas de plastificação. Neste caso, elementos com interpolação linear apresentam melhores resultados quando comparados a elementos de ordem mais alta.

Para minimizar o efeito "shear locking" utilizando elementos finitos lineares considerou-se os modos incompatíveis de deslocamento, possibilitando graus de liberdade adicionais, e fictícios, que utilizam campos mistos de deslocamento, de maneira minimizar o aumento natural de rigidez do elemento hexaédrico. O pilar, viga, cantoneiras, chapas e parafusos foram discretizados com este elemento finito.

\subsection{2 - Elemento SOLID65}

Este elemento, também volumétrico, foi utilizado na discretização da laje de concreto, também possui oito nós, cada um com três graus de liberdade, sendo eles translação nas direções $X, Y$ e $Z$ (Figura 6.2). Permite simular o comportamento de materiais como o concreto com fissuração na tração e 
esmagamento na compressão.

As armaduras secundárias são incluídas sob a forma de taxas, orientados segundo os ângulos $\phi$ e $\theta$, e resistem apenas a esforços axiais. Tanto o elemento em si, quanto a armadura permitem a consideração da não linearidade dos materiais.

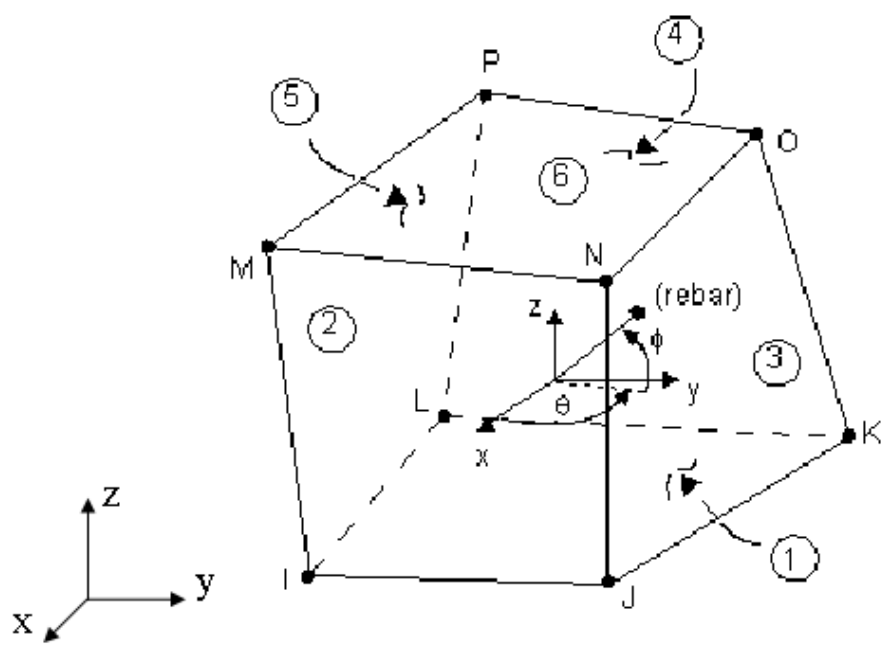

Figura 6.2 - Elemento volumétrico SOLID65.

Fonte: ANSYS Help System Release 9.0.

\subsection{3 - Elemento BEAM23}

O elemento finito BEAM 23, apresentado na Figura 6.3, foi utilizado para simular o comportamento das armaduras longitudinais. É um elemento uniaxial com capacidade de flexão, tração e compressão, sendo composto por dois nós com três graus de liberdade por nó, translações nas direções $x$ e y e rotação segundo o eixo z. Por meio deste elemento pode-se considerar a plasticidade do material, porém só é admitida sua propriedade isotrópica. 


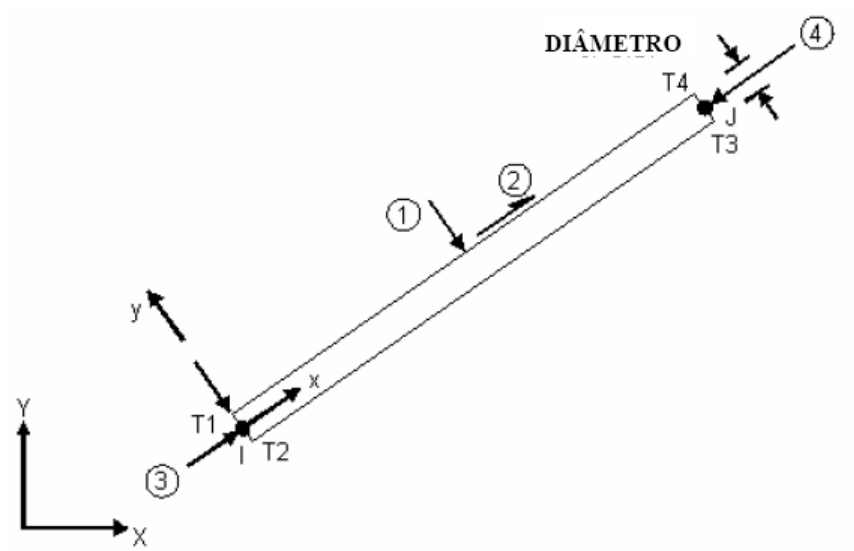

Figura 6.3 - Elemento de viga BEAM23.

Fonte: ANSYS Help System Release 9.0.

\subsection{4 - Elemento BEAM4}

O elemento BEAM4 foi utilizado para discretizar as armaduras transversais e possui capacidade de tração, compressão, torção e flexão. Este elemento é 3D uniaxial elástico, definido por dois nós, com seis graus de liberdade por nó (translações e rotações segundo os eixos $\mathrm{X}, \mathrm{Y}$ e Z) e com a consideração de grandes deslocamentos.

A escolha deste elemento deu-se pela necessidade da simulação numérica das armaduras secundárias (perpendiculares ao eixo longitudinal da viga), uma vez que o elemento é tridimensional. A Figura 6.4 representa geometricamente o elemento.

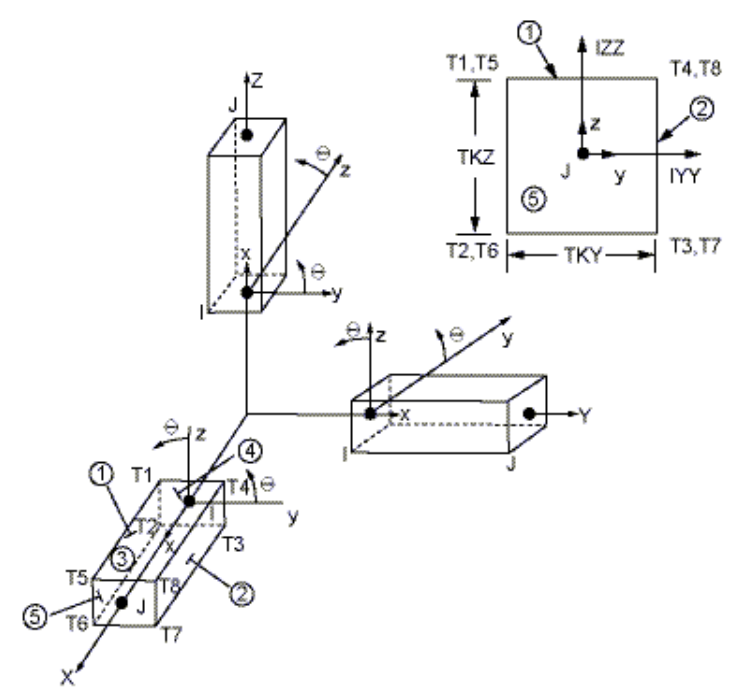

Figura 6.4 - Elemento de viga BEAM4.

Fonte: ANSYS Help System Release 9.0. 


\subsection{5 - Elemento BEAM 189}

O elemento BEAM189 (Figura 6.5) foi utilizado na modelagem dos conectores de cisalhamento. Trata-se de um elemento de viga, com três nós (l, $\mathrm{J}$ e $\mathrm{K}$ ) e seis graus de liberdade por nó, o que inclui as translações e as rotações segundo os eixos $\mathrm{X}, \mathrm{Y}$ e $\mathrm{Z}$.

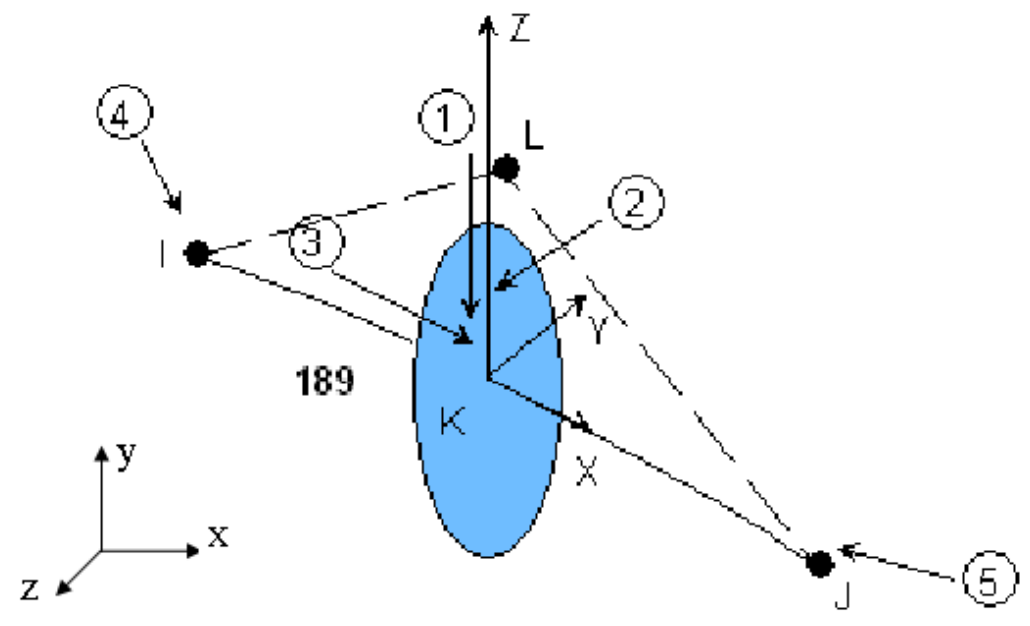

Figura 6.5 - Elemento de viga BEAM189.

Fonte: ANSYS Help System Release 9.0.

Este elemento foi escolhido por permitir uma modelagem mais simples dos conectores, sem perder a representatividade necessária. $O$ elemento responde a esforços de flexão, possibilitando a consideração da não linearidade do material, e ainda permite configurar a forma da seção transversal.

A orientação local do elemento em questão se dá com o eixo $x$ partindo do nó I em direção ao nó $J$, enquanto que os eixos $Y$ e $Z$ são definidos com o auxílio de um nó adicional (nó $L$ da Figura 6.5). Avaliações mais detalhadas realizadas por Kotinda (2006) indicaram que a orientação desses nós interfere na estabilidade numérica do processamento.

\subsection{6 - Elemento COMBIM39}

Para simulação numérica do deslizamento relativo entre a armadura de aço e a laje de concreto foi utilizado o elemento de mola COMBIN39, com apenas o grau de liberdade de deslocamento em X (direção do eixo longitudinal 
da viga).

A relação força-deslocamento utilizada no elemento COMBIN39 foi obtida a partir de ensaios de arrancamento. $O$ presente trabalho utiliza os resultados obtidos por Almeida Filho (2006) para esta relação. A Figura 6.6 ilustra uma curva típica da relação tensão-deslizamento local, obtida a partir de um ensaio de arrancamento com deformação controlada de acordo com Castro (2002).

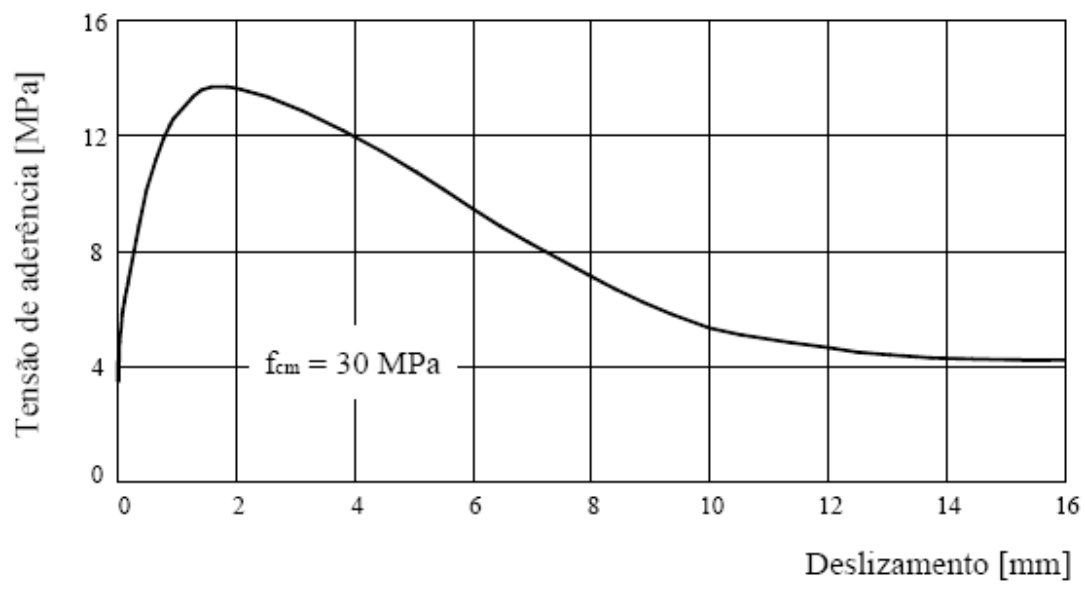

Figura 6.6 - Relação tensão-deslizamento local. Fonte: Castro (2002).

\subsection{7 - Elementos de contato TARGE 170 e CONTA 173}

O contato foi definido pelos elementos TARGE 170 e CONTA 173, os quais possuem três graus de liberdade em cada nó, conforme apresenta a Figura 6.7, com translações segundo $\mathrm{X}, \mathrm{Y}$ e Z. Ambos trabalham associados para dar origem a uma ferramenta numérica denominada par de contatos.

Os elementos representam o modelo de contato definido pelo ANSYS como superfície-superfície, possuem propriedades físicas idênticas e são utilizadas no caso tridimensional.

O elemento TARGE 170 é definido para a superfície alvo e o elemento CONTA 173 para a superfície de contato. Essas duas superfícies precisam ser estabelecidas, no qual a superfície alvo será aquela mais rígida e a superfície de contato a mais deformável, não levando em consideração, para este caso, o tipo de material. A Tabela 6.1 apresenta os pares de contato do modelo numérico para ligações com cantoneiras de alma e assento. 


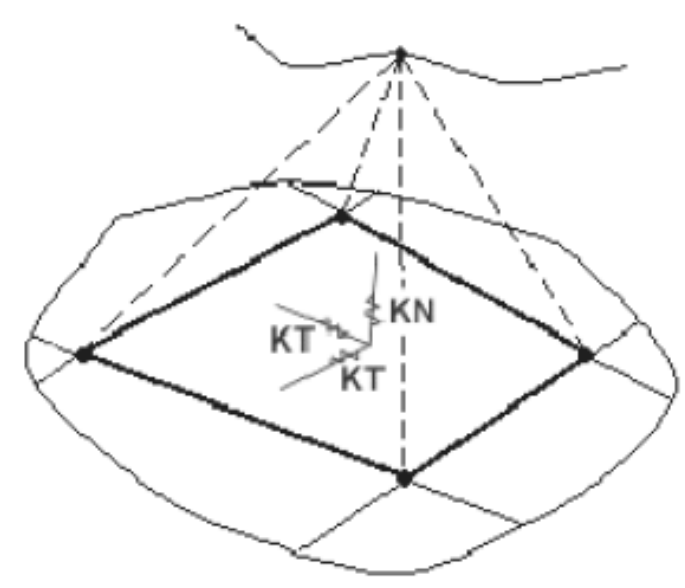

Figura 6.7 - Representação de um par de contato.

Fonte: ANSYS Help System Release 9.0.

Esse elemento de contato trabalha apenas quando a superfície de contato penetra na superfície alvo, ou seja, quando ocorre transferência de tensões de compressão no contato. Por outro lado, nenhuma força de tração é transferida quando ocorre separação entre as superfícies.

Tabela 6.1: Pares de contato de ligações com cantoneira de alma e assento.

Pares de contato

\begin{tabular}{|c|c|c|}
\hline Tipo de ligação & Superfície Target & Superfície Contact \\
\hline \multirow{8}{*}{$\begin{array}{l}\text { Cantoneiras de } \\
\text { alma e assento }\end{array}$} & Mesa do pilar & $\begin{array}{l}\text { Face da viga em } \\
\text { contato com o pilar }\end{array}$ \\
\hline & Mesa da viga & Aba da cantoneira \\
\hline & Aba da cantoneira & Cabeça do parafuso \\
\hline & $\begin{array}{l}\text { Furo da mesa da viga } \\
\text { e aba da cantoneira }\end{array}$ & Fuste do parafuso \\
\hline & Mesa do pilar & Aba da cantoneira \\
\hline & Mesa do pilar & Porca do parafuso \\
\hline & $\begin{array}{l}\text { Furos da mesa do pilar } \\
\text { e aba da cantoneira }\end{array}$ & Fuste do parafuso \\
\hline & Mesa da viga & Laje de concreto \\
\hline
\end{tabular}


A rigidez entre as superfícies alvo e contato é dada por meio da rigidez de contato normal (FKN) e da rigidez de contato tangencial (FKT), que por sua vez é proporcional a rigidez normal e ao coeficiente de atrito.

A tolerância e a rigidez normal têm grande influência no processo de convergência do modelo numérico, sendo necessário prever o seu valor. Este parâmetro pode variar dependendo do tamanho do elemento finito, ou seja, modelos com malha mais refinadas podem ter FKN diferente de modelos menos refinados.

\section{4 - Definição da Geometria e Malha}

$\mathrm{Na}$ definição da malha e geometria das ligações com cantoneira de alma e assento, da mesma forma que para as ligações com chapa de topo, são adotados os seguintes procedimentos:

- Foram compatibilizados os nós coincidentes da laje e dos conectores nas translações referentes aos eixos horizontais $X \quad e \quad Z$. Adicionalmente, o nó da posição da mesa superior do conector $U$ foi acoplado também segundo a direção vertical $\mathrm{Y}$, com o objetivo de representar a ancoragem mecânica existente nessa região. A Figura 6.8 ilustra esses acoplamentos.

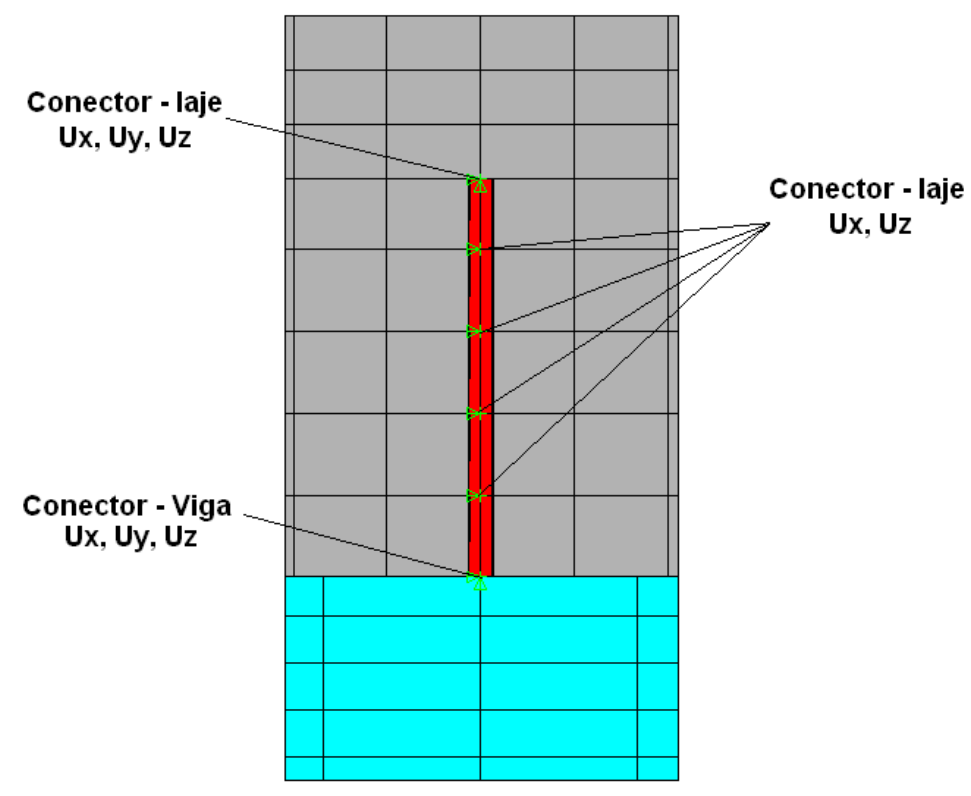

Figura 6.8: Acoplamento dos nós da laje e conectores. 
- Devido ao posicionamento dos conectores de cisalhamento, todo o comprimento da viga possui a mesma discretização refinada do trecho próximo a ligação, uma vez que nessa região podem existir problemas de plastificação e instabilidade local no trecho comprimido. A malha na região dos parafusos também foi gerada com um número maior de elementos, devido à grande concentração de tensões;

- Esse grau de refinamento na malha de elementos finitos também foi utilizado na região do painel de alma do pilar;

- Em todos os furos foram consideradas folgas entre as chapas e os parafusos;

- Na discretização do parafuso, foi considerado como pertencente a um corpo único, ou seja, os nós do fuste foram acoplados aos nós da porca e da cabeça, seguindo a metodologia de Maggi (2000), conforme apresenta a Figura 6.9. O fuste do parafuso foi modelado com o seu diâmetro nominal e comprimento igual às espessuras das chapas que estavam conectadas.

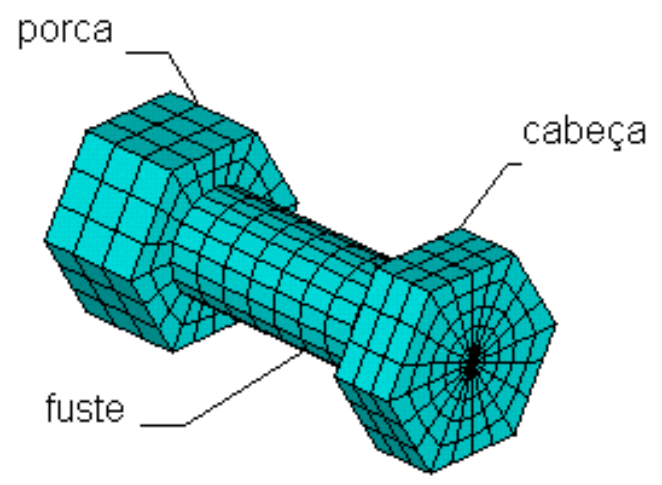

Figura 6.9: Detalhe da discretização dos parafusos.

- Essa técnica de modelagem do parafuso, juntamente com o modelo constitutivo adotado, proporciona um comportamento satisfatório quanto à capacidade resistente e deformabilidade.

A Figura 6.10 a seguir ilustra a representação numérica da ligação viga mista-pilar do protótipo isolado " $\mathrm{T}$ " ensaiado experimentalmente. Na figura foi 
representada somente uma parte da laje para uma melhor visualização das armaduras longitudinais e conectores de cisalhamento.

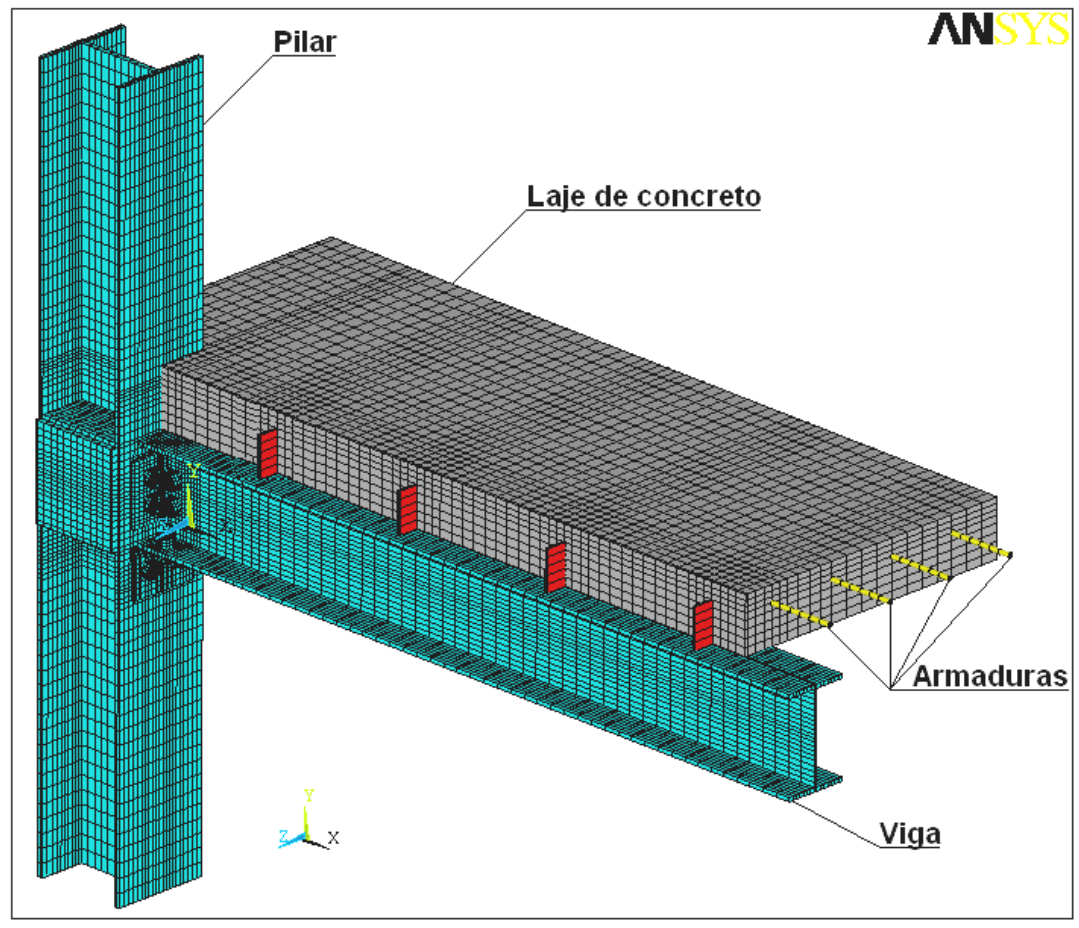

Figura 6.10: Visão geral da ligação viga mista-pilar do protótipo isolado "T" ensaiado experimentalmente.

Para o protótipo isolado cruciforme, a análise numérica contemplou duas situações:

- Consideração da simetria, segundo um plano passando pelo CG da seção do pilar perpendicular a alma, com as devidas condições de contorno;

- Modelo crucifome completo com a continuidade da laje e armaduras longitudinais.

Os resultados obtidos para a modelagem com a simetria, conforme descrita anteriormente apresentou a mesma precisão na comparação dos resultados em relação à segunda situação, de modelagem sem simetria, porém, com um tempo de processamento bem menor, por este possuir praticamente o dobro do número de elementos, nós e de graus de liberdade. 


\section{5 - Modelos Constitutivos para os Materiais}

Numa ligação mista, a rigidez inicial depende das características elásticas dos materiais, das características geométricas, da protensão dos parafusos e do tipo de carregamento. Por outro lado, o desenvolvimento das deformações plásticas e a redistribuição das tensões, assim como a caracterização do colapso, dependem dos modelos constitutivos adotados para simular a plasticidade dos materiais.

Da mesma forma que a rigidez inicial, o comportamento no estado limite de serviço e a caracterização dos estados limites últimos são os principais fatores a serem obtidos com a melhor representatividade possível. Para tal, é de fundamental importância a utilização de relações constitutivas que permitam representar adequadamente o comportamento dos materiais.

Diagramas multilineares da relação tensão-deformação foram adotados para simular as diversas etapas da plastificação do aço, incluindo patamares de escoamento, os efeitos de encruamento e os limites de deformação e de tensão para caracterização da ruptura.

Este trabalho adotou as relações das curvas tensão-deformação de Maggi (2004) para os aços das chapas (viga, pilar, cantoneiras e enrijecedores) e dos parafusos, apresentados na Figura 6.11 e Figura 6.12, respectivamente.

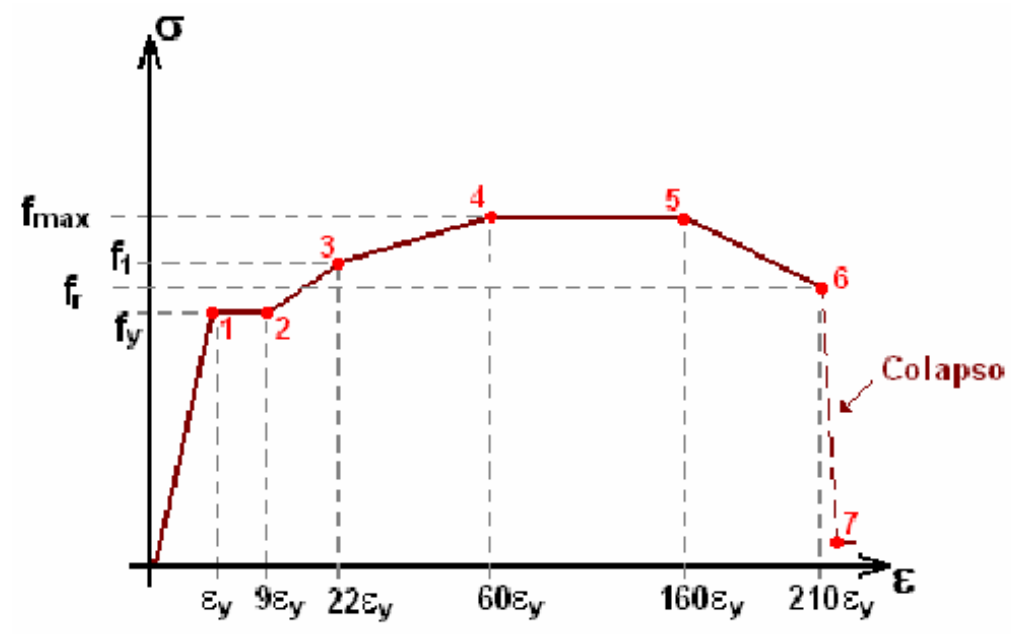

Figura 6.11: Diagrama multilinear para o aço das chapas.

O programa ANSYS permite a utilização de diversos tipos de modelos 
constitutivos multilineares, dentre os quais adotou-se um modelo com encruamento isótropo, com capacidade de reproduzir a plasticidade do aço, utilizando as tensões equivalentes de Von Mises como critério de plastificação. A Tabela 6.2 apresenta os valores dos pontos indicados de cada curva.

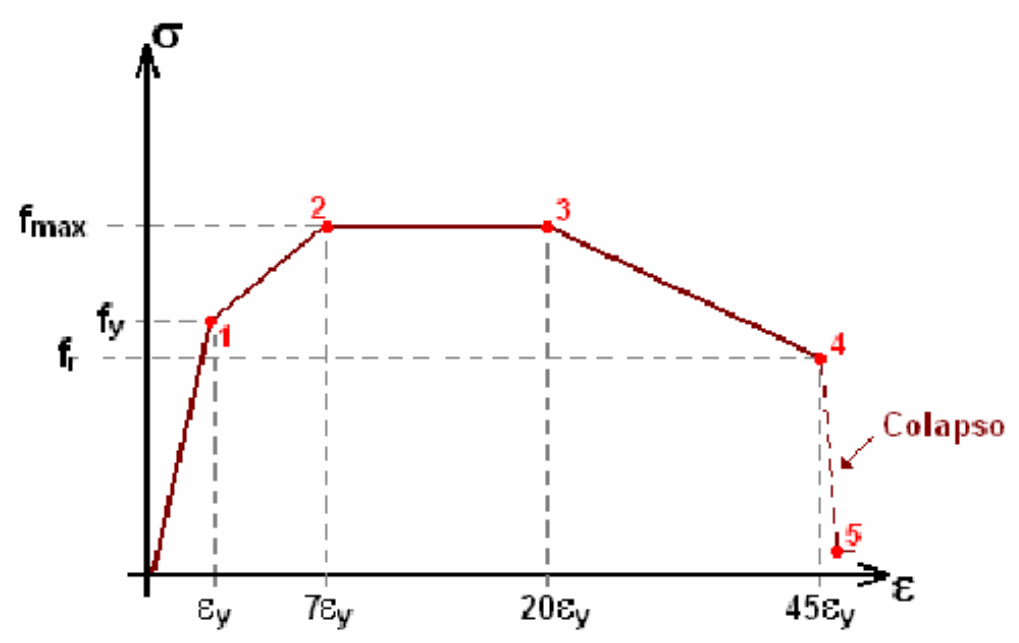

Figura 6.12: Diagrama multilinear para o aço dos parafusos.

Tabela 6.2: Definição dos pontos nos diagramas.

\begin{tabular}{cccc}
\hline \multicolumn{2}{c}{ Ponto } & Chapas & Parafusos \\
\hline \multirow{2}{*}{1} & $\sigma$ & $\mathrm{f}_{\mathrm{y}}$ & $\mathrm{f}_{\mathrm{y}}$ \\
& $\varepsilon$ & $\varepsilon_{\mathrm{y}}$ & $\varepsilon_{\mathrm{y}}$ \\
\hline \multirow{2}{*}{2} & $\sigma$ & $\mathrm{f}_{\mathrm{y}}$ & $f_{y}+0,25 \cdot\left(f_{u}+f_{y}\right)$ \\
& $\varepsilon$ & $9 \cdot \varepsilon_{y}$ & $7 \cdot \varepsilon_{y}$ \\
\hline \multirow{2}{*}{3} & $\sigma$ & $f_{y}+0,50 \cdot\left(f_{u}+f_{y}\right)$ & $f_{y}+0,25 \cdot\left(f_{u}+f_{y}\right)$ \\
& $\varepsilon$ & $22 \cdot \varepsilon_{y}$ & $20 \cdot \varepsilon_{y}$ \\
\hline \multirow{2}{*}{4} & $\sigma$ & $\mathrm{f}_{u}$ & $f_{y}-0,15 \cdot\left(f_{u}+f_{y}\right)$ \\
& $\varepsilon$ & $60 \cdot \varepsilon_{y}$ & $45 \cdot \varepsilon_{y}$ \\
\hline \multirow{2}{*}{5} & $\sigma$ & $f_{u}$ & 1,1 \\
& $\varepsilon$ & $160 \cdot \varepsilon_{y}$ & $1,01 \cdot\left(45 \cdot \varepsilon_{y}\right)$ \\
\hline \multirow{2}{*}{6} & $\sigma$ & $f_{y}+0,20 \cdot\left(f_{u}+f_{y}\right)$ & - \\
& $\varepsilon$ & $210 \cdot \varepsilon_{y}$ & - \\
\hline 7 & $\sigma$ & 0,1 & - \\
& $\varepsilon$ & $1,01 \cdot\left(210 \cdot \varepsilon_{y}\right)$ &
\end{tabular}

Em ambos os diagramas, existe um trecho descendente, após a tensão $f_{u}$ 
para os aços das chapas e dos parafusos, com o objetivo de caracterizar a ruptura do material, em que o último ponto é obtido por uma deformação igual a $1 \%$ a mais que a deformação última e tensão igual a 0,1. Esse trecho tem por objetivo provocar uma falta de convergência na solução numérica.

Maggi (2004) propõe uma correção das tensões, por meio da equação (57), para a utilização desses diagramas nos modelos. Essa correção é feita devido aos valores de tensão e deformação serem tomados com referência à área inicial, desconsiderando-se a estricção da seção transversal na região de ruptura.

$$
\begin{aligned}
& e=\ln (1+\varepsilon) \\
& s=\sigma(1+\varepsilon)
\end{aligned}
$$

Onde:

e é a deformação corrigida;

$S$ é a tensão corrigida;

$\sigma$ é a tensão convencional;

$\varepsilon$ é a deformação convencional.

Na laje de concreto, o modelo constitutivo adotado na compressão foi do tipo multilinear com encruamento isótropo, sendo que a curva tensãodeformação utilizada, conforme apresenta a Figura 6.13, foi extraída do EUROCODE 2 (2003) seguindo a relação dada pela equação (58):

$$
\sigma=f_{c m} \cdot \frac{k \cdot \eta-\eta^{2}}{1+(k-2) \cdot \eta}, \text { para } 0<\varepsilon<\varepsilon_{c 1}
$$

Onde:

$\eta=\varepsilon / \varepsilon_{c 1}$

$\varepsilon_{c 1}(\% \circ)=0,7 \cdot f_{c m}^{0,31}<2,5$;

$k=1,1 \cdot E_{c m} \cdot\left|\varepsilon_{c 1}\right| / f_{c m} ;$

$f_{c m}$ é o valor médio de resistência à compressão do concreto para o corpo de prova cilíndrico;

$\varepsilon_{c 1}$ é a deformação correspondente à tensão máxima de compressão; 
$\varepsilon_{c u 1}$ é a deformação última à compressão;

$E_{c m} / 1000$ é o módulo de elasticidade do concreto.

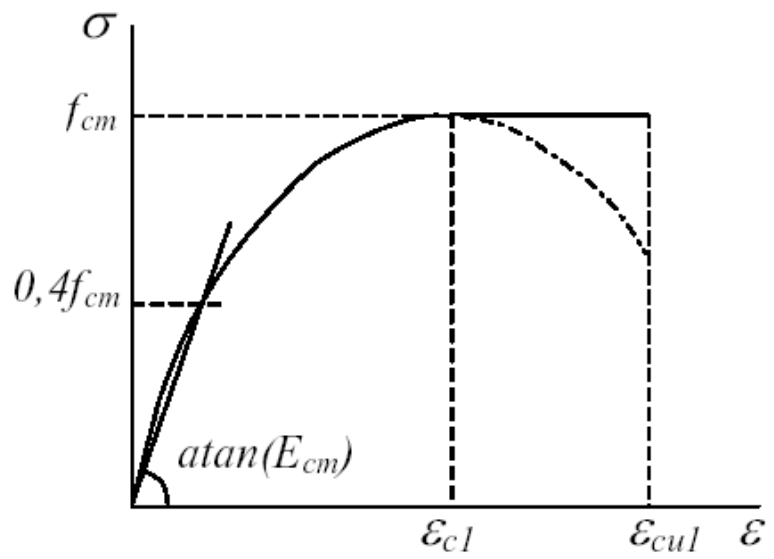

Figura 6.13: Modelo constitutivo adotado para o concreto na compressão. Fonte: EUROCODE 4 (2004).

O modelo constitutivo adotado para a região tracionada da laje foi do tipo linear, com os valores da resistência última à tração e o módulo de elasticidade obtida a partir de ensaios de caracterização.

\section{6 - Condições de Contorno e Carregamento}

As condições de contorno representam as restrições impostas aos modelos numéricos. Como o trabalho englobou duas configurações, as restrições dependeram do tipo de ligação. Os nós da face superior e inferior do pilar foram restringidos nas três direções globais, reproduzindo assim o sistema de travamento dos modelos. O carregamento foi aplicado em duas etapas:

1) Protensão inicial dos parafusos

A protensão inicial dos parafusos foi realizada por meio de variações de temperatura negativa no fuste dos parafusos. Devido à restrição imposta pelo contato, entre a cabeça e rosca do parafuso com as chapas, surgem tensões de tração que se desenvolve ao longo do fuste à medida que este se retrai. Dessa forma, pressões de contato surgem entre as chapas conectadas pelos parafusos, simulando assim os efeitos da protensão inicial.

Na modelagem, foi adotado um coeficiente de dilatação térmica fictício de 
$10^{-5}$ como característica do material dos parafusos. A NBR 8800 (1986) estabelece uma força de protensão mínima fornecida pela equação (59), cujo valor corresponde a $70 \%$ da resistência característica a tração do parafuso.

$$
T_{b}=0,49 \cdot A_{b} \cdot f_{u b}
$$

Onde:

$A_{b}$ é a área bruta do parafuso;

$f_{u b}$ é a resistência à ruptura do aço do parafuso.

\section{2) Carregamento na viga}

O carregamento que provocou o momento na ligação foi aplicado na extremidade da viga na forma de deslocamento negativo segundo a direção $\mathrm{Y}$. A opção de se aplicar deslocamento ao invés de força foi devido ao fato de a convergência durante o processamento ficar mais estável e rápida.

\section{7 - Resultados Numéricos}

Neste item serão apresentados e discutidos os principais resultados numéricos das ligações isoladas ensaiadas experimentalmente. Além dos modelos de ligação mista, também foi considerado um modelo de ligação em aço de pilar de extremidade, com a mesma geometria, o que possibilitou comparar parâmetros tais como resistência, rigidez e a plastificação dos componentes.

Primeiramente será feito uma análise do comportamento global das ligações e, em seguida, uma análise detalhada de cada configuração de ligação separadamente.

A análise numérica permite o estudo de parâmetros de difícil aferição experimental, principalmente com relação à distribuição de tensões e deformações nos principais elementos da ligação, que contribuem na caracterização da resistência e rigidez. Os modelos numéricos foram analisados considerando a relação constitutiva dos materiais obtida em laboratório, com a correção das tensões de deformações de acordo com a eq. 57. 


\subsection{1 - Comportamento global da ligação}

Os quatro protótipos isolados modelados numericamente apresentaram resultados semelhantes, com uma pequena variação devido à presença de armadura adicional e configuração da ligação (pilar de centro e borda).

Embora o modelo constitutivo do material concreto não permita o estudo da fissuração da laje, foi observado nos modelos numéricos que a presença da armadura adicional possibilitou uma melhor distribuição das forças de tração na laje.

A Figura 6.14 ilustra o comportamento força $x$ deslocamento $(F x D)$ da ligação para os modelos mistos aço concreto. Embora a mesma geometria da ligação, observa-se uma pequena diferença entre as ligações de pilar de borda e de centro, e até mesmo dentre os dois modelos com a mesma configuração geométrica, devido à influência da taxa de armadura secundária e da resistência do concreto.

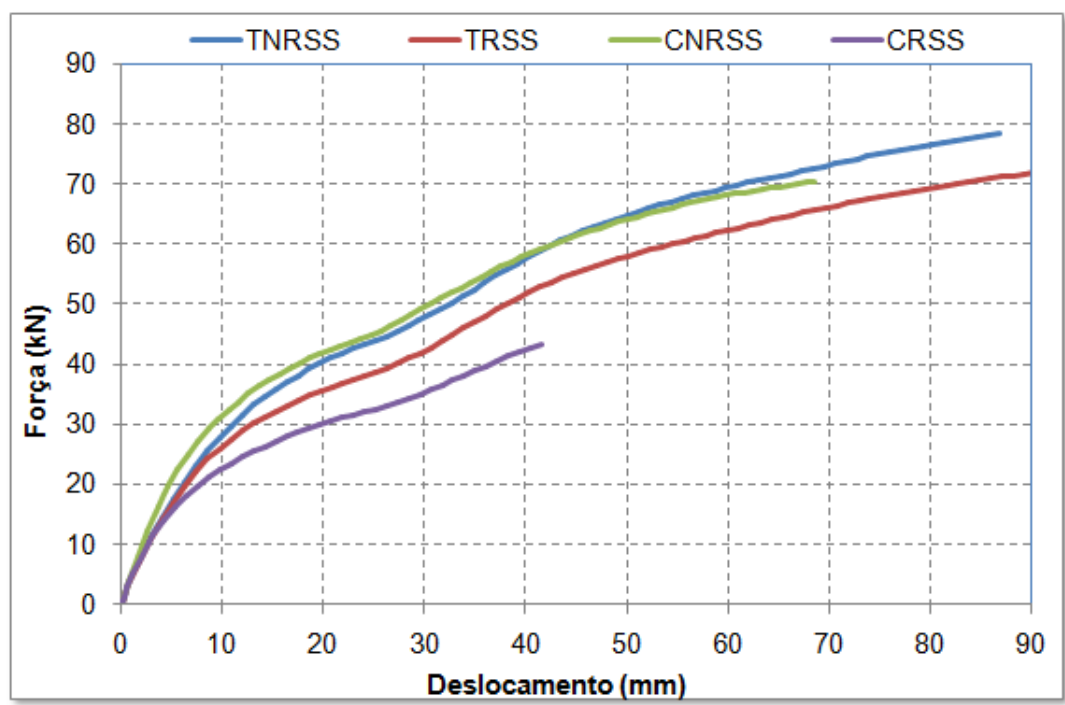

Figura 6.14: Curva F x D para os modelos numéricos isolados.

Em todos os modelos, observou-se um trecho praticamente elástico até um momento na ligação de aproximadamente $17 \mathrm{kN} . \mathrm{m}$, onde tem-se o início da perda de resistência à tração da laje de concreto (efeito de fissuração na laje). $\mathrm{Na}$ Figura 6.15 tem-se o comportamento momento $\mathrm{x}$ rotação $(M-\phi)$ dos modelos mistos e para a mesma ligação em aço, sem a laje de concreto. 


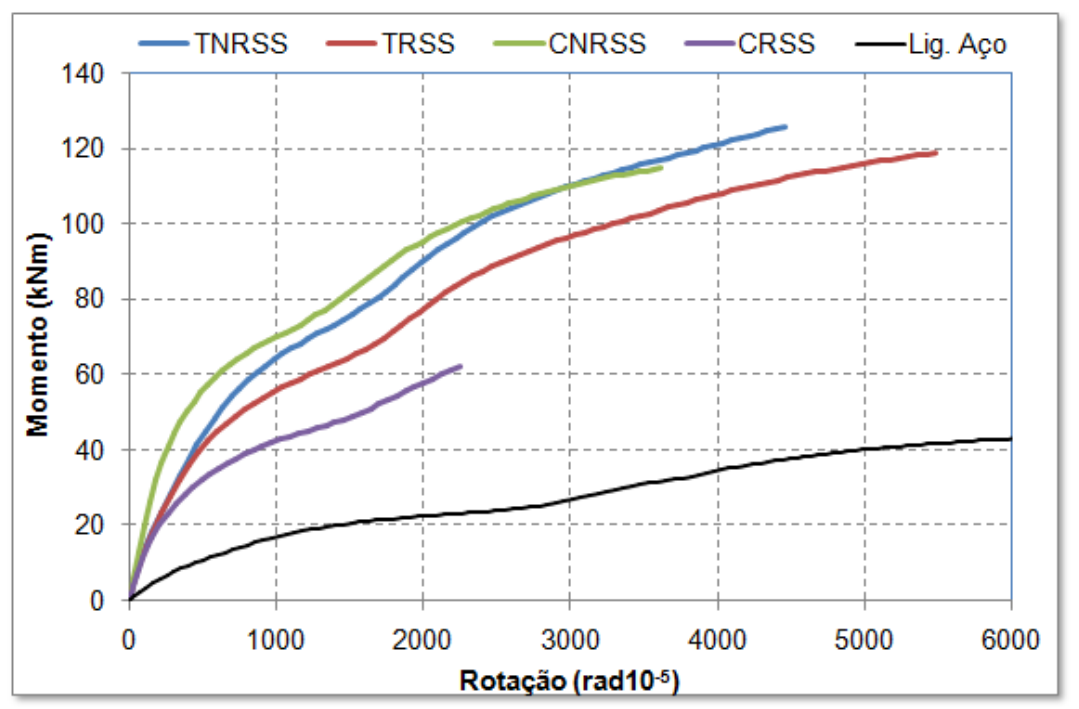

Figura 6.15: Comportamento $M-\phi$ para os modelos numéricos mistos e ligação metálica.

No gráfico da Figura 6.15, o carregamento último nos modelos mistos foi aproximadamente três vezes superior que a mesma ligação em aço, exceção ao modelo CRSS que não atingiu um patamar elevado de carregamento por problemas de convergência. Em todos os modelos numéricos observou-se a presença de instabilidade numérica devido ao elevado gradiente de tensões na laje, principalmente próximos aos conectores de cisalhamento, o que levou à interrupção do processamento em estágios avançados do carregamento.

Ainda dentro da análise do gráfico da Figura 6.15 , observa-se que o comportamento $M-\phi$ se aproxima do modelo teórico tri-linear previsto pelo EUROCODE 3 (2003), conforme ilustra a Figura 6.16. A curva tri-linear a seguir é meramente ilustrativa, a obtenção e análise dos resultados numéricos e teóricos, bem como os experimentais, serão realizadas no capítulo seguinte, que se refere à comparação dos resultados. 


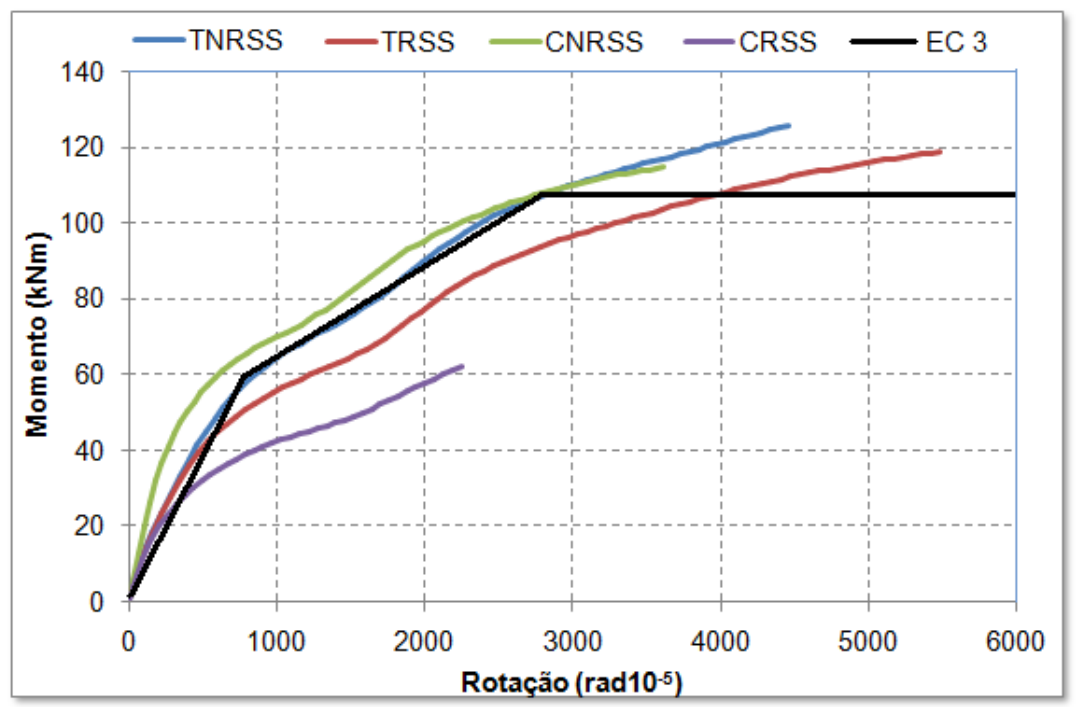

Figura 6.16: Curva $M-\phi$ para os modelos numéricos e projeção da curva trilinear do EUROCODE 3 (2003).

Alguns aspectos relacionados às tensões nos componentes da ligação, tais como as vigas, cantoneiras, pilar e armaduras, foram analisados separadamente para os modelos numéricos de pilar de borda e central.

\subsection{2 - Modelos numéricos de pilar de borda}

Nos modelos numéricos de pilar de borda, as armaduras da viga mista e das cantoneiras de alma atingiram tensões superiores ao limite de proporcionalidade, no regime pós-elástico, enquanto que as tensões e deformações medidas nos demais elementos da ligação (viga, chapas e pilar) apresentaram-se no regime elástico.

A Figura 6.17 ilustra os aspectos qualitativos das deformações no modelo numérico TRSS para quatro estágios de carregamento. 


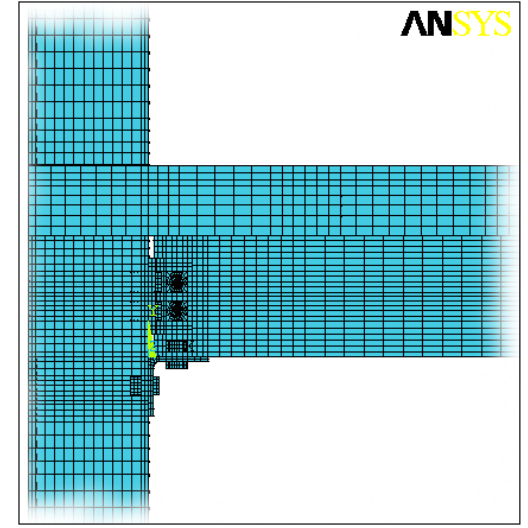

$\mathrm{M}=0 \mathrm{kN} \cdot \mathrm{m}$

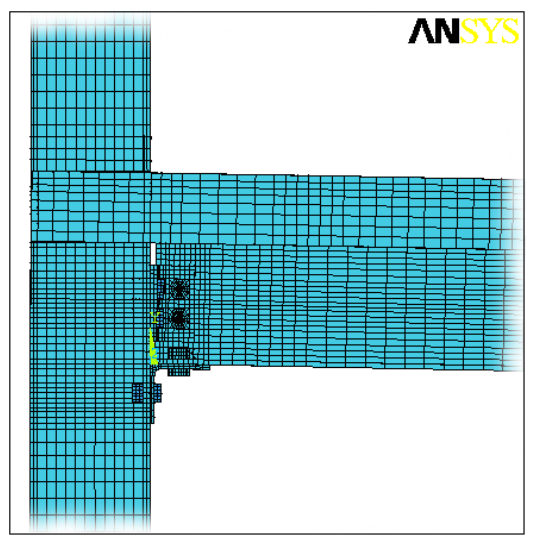

$M=80 \mathrm{kN} \cdot \mathrm{m}$

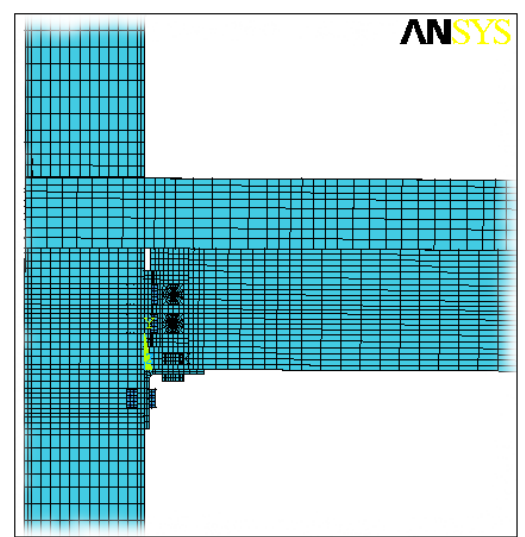

$M=40 \mathrm{kN} \cdot \mathrm{m}$

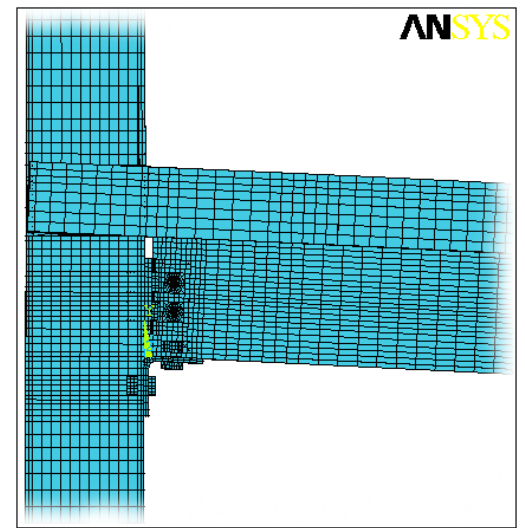

$M=118.64 \mathrm{kN} \cdot \mathrm{m}$

Figura 6.16: Deformação no modelo numérico TRSS.

No que diz respeito à plastificação da cantoneira de alma, observou-se uma ligeira flexão da aba da cantoneira em contato com a mesa do pilar. A Figura 6.18 apresenta as tensões de Von-Mises para o modelo TRSS e a Figura 6.19 às tensões de plastificação equivalente para o carregamento último de 118,64 kN.m na ligação.

Esse efeito da plastificação das cantoneiras de alma da ligação também foi observado no modelo em aço, de acordo com as tensões de plastificação equivalentes da Figura 6.20. A comparação entre as Figura 6.19 e 6.20 apontam diferentes mecanismos de plastificação das cantoneiras alma da viga para as ligações metálica e mista, com concentração de tensões de plastificação na zona comprimida das cantoneiras da ligação mista. 

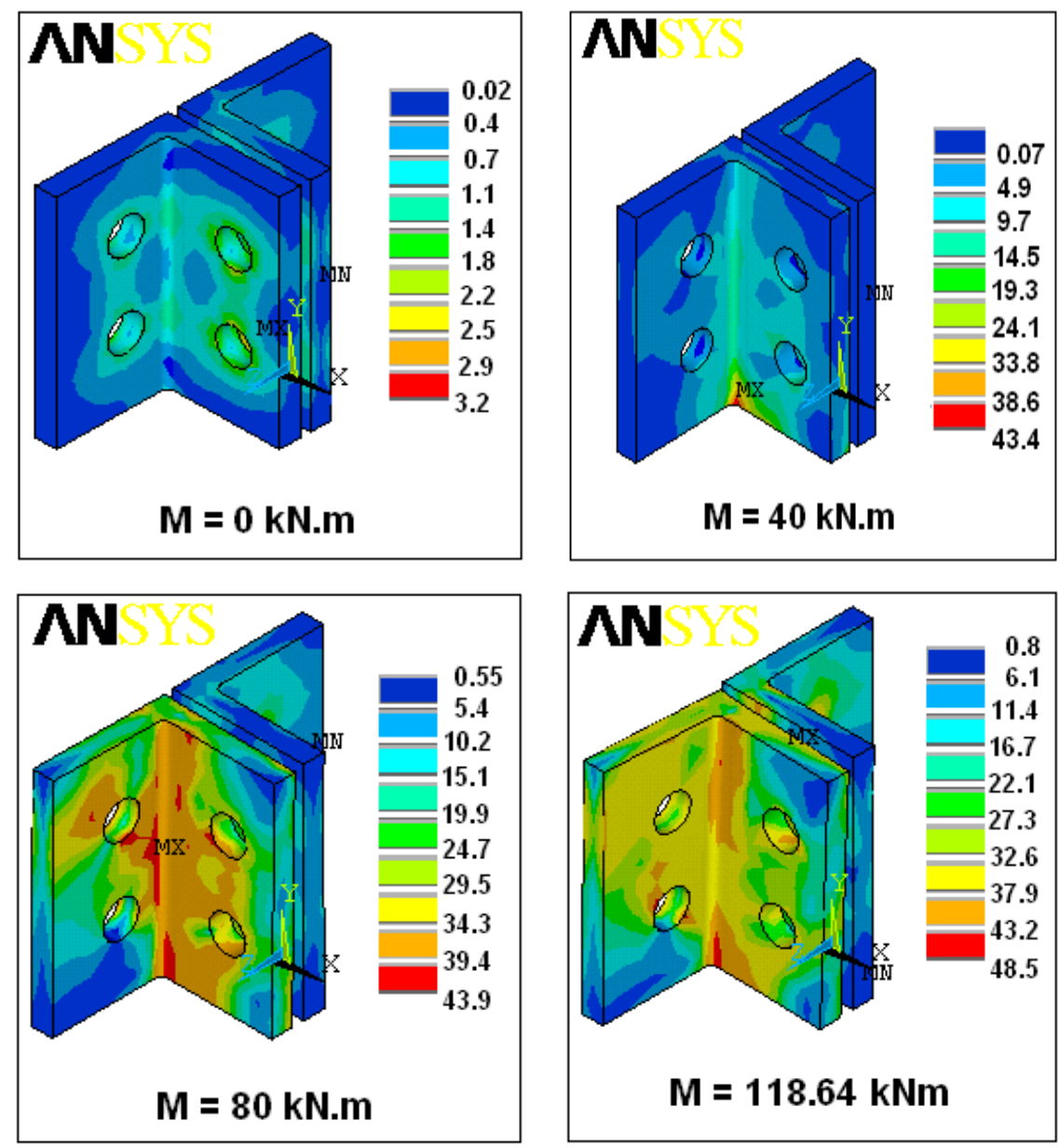

Figura 6.18: Tensões de Von-Mises nas cantoneiras de alma do modelo TRSS $\left(\mathrm{kN} / \mathrm{cm}^{2}\right)$.

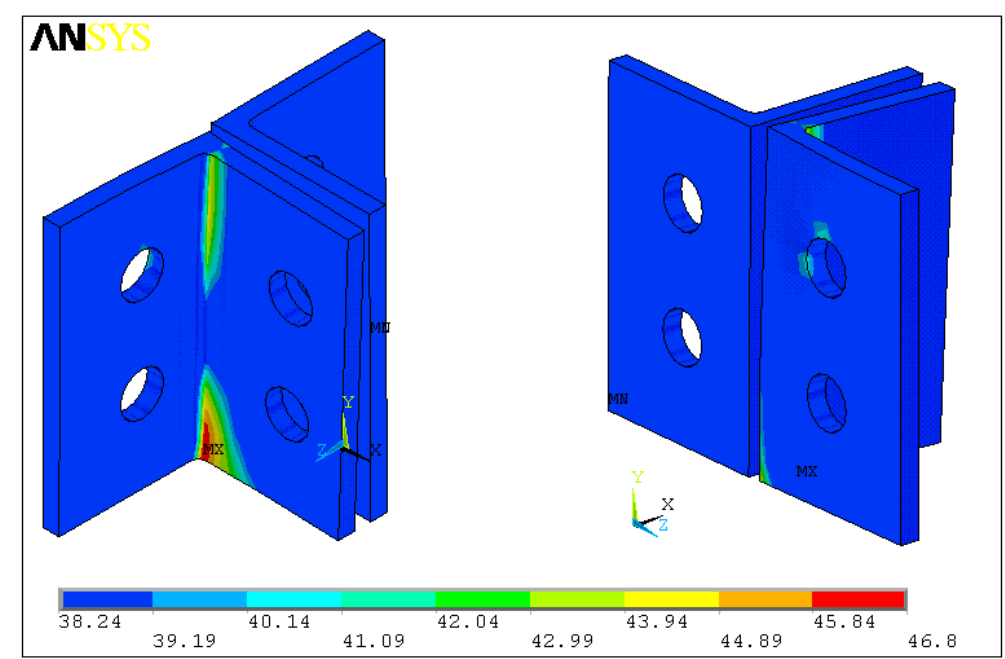

Figura 6.19: Tensões de plastificação equivalente nas cantoneiras de alma do modelo TRSS para o carregamento último $\left(\mathrm{kN} / \mathrm{cm}^{2}\right)$.

A estratégia numérica adotada, com a modelagem de todas as armaduras 
longitudinais e transversais, conseguiu representar a linha de tração que se forma na posição das armaduras da viga mista, a concentração dos esforços de tração nestas armaduras e a mudança da linha neutra na viga.

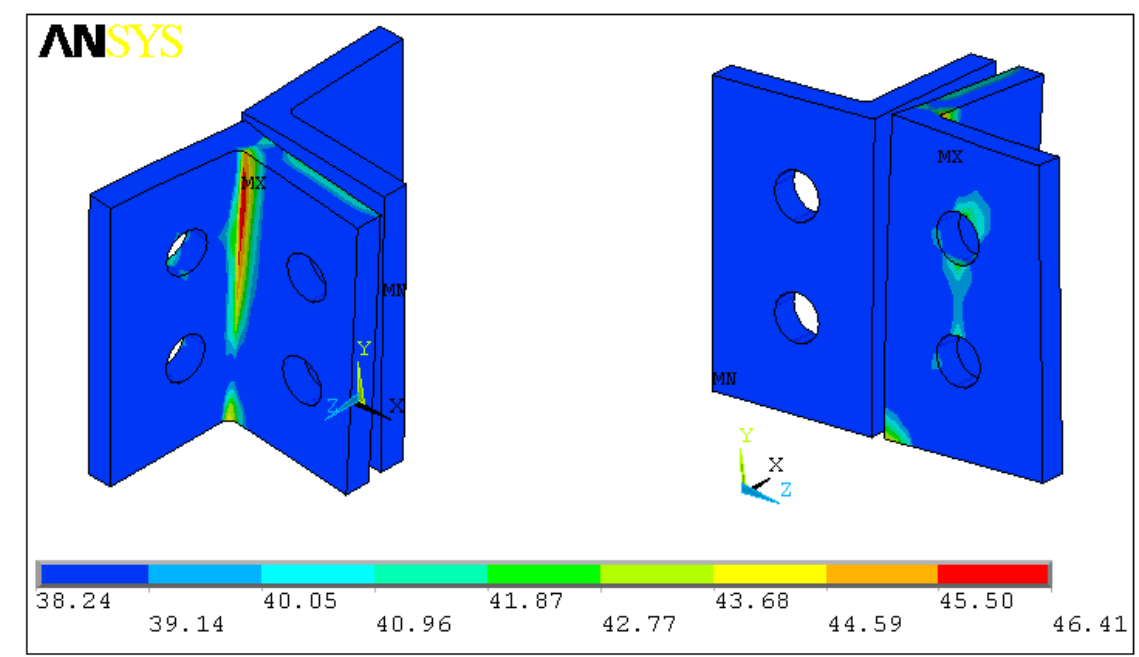

Figura 6.20: Tensões de plastificação equivalente nas cantoneiras de alma do modelo de ligação metálica $\left(\mathrm{kN} / \mathrm{cm}^{2}\right)$.

O acréscimo da taxa de armadura da laje também permitiu uma melhor capacidade de distribuição das tensões de tração nas armaduras longitudinais. Entretanto, observou-se que as amaduras posicionadas acima da mesa da viga com níveis de tensões de tração bem inferiores às demais armaduras, posicionadas lateralmente ao pilar.

A Figura 6.21 ilustra esse efeito, de acordo com a tensão longitudinal (direção X) nas armaduras dos os modelos de pilar de canto.

Outra vantagem da modelagem numérica proposta neste trabalho, foi a possibilidade da análise individual do comportamento de cada barra de armadura, ao contrário da modelagem de Tristão (2006), em que todas as armaduras longitudinais trabalhavam em conjunto, pois estavam acopladas.

A Figura 6.22 apresenta as tensões longitudinais (direção $X$ ) nas armaduras da viga mista para o modelo TRSS, no qual se observa de forma mais clara o gradiente de tensões entre as armaduras laterais da viga e as amaduras posicionadas acima da mesa, para um momento último de 118,64 kNm na ligação. 

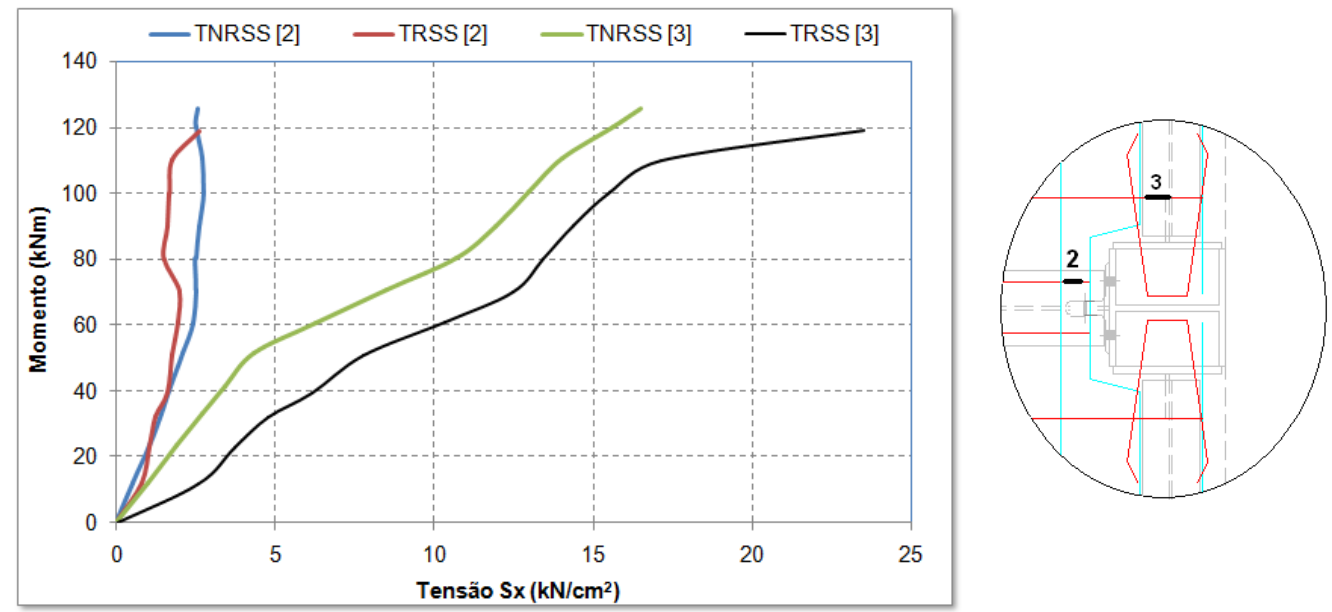

Figura 6.21: Tensões longitudinais na armadura da viga mista para ligação de pilar de borda $\left(\mathrm{kN} / \mathrm{cm}^{2}\right)$.

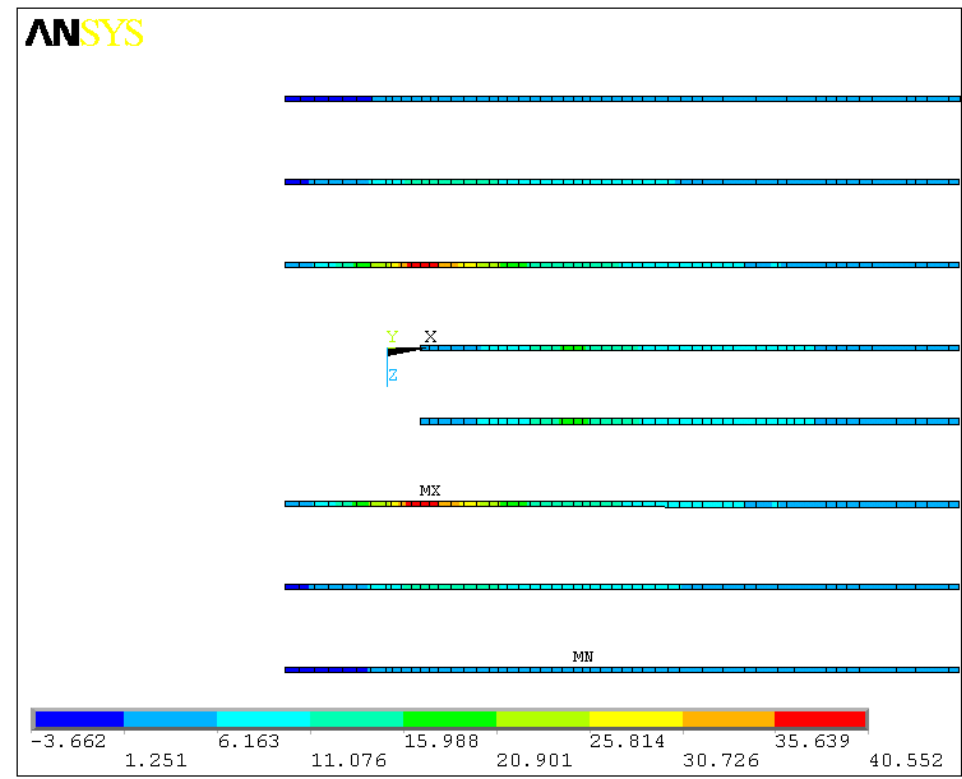

Figura 6.22: Tensões longitudinais nas armaduras da viga mista do modelo TRSS $\left(\mathrm{kN} / \mathrm{cm}^{2}\right)$.

No que diz respeito ao comportamento da viga, as deformações longitudinais (direção $\mathrm{x}$ ) foram obtidas numa seção aproximadamente $\mathrm{H}_{\text {vigal }} / 2 \mathrm{a}$ partir da ligação, conforme ilustra a Figura 6.23, sendo essa a mesma seção da instrumentação experimental.

Da mesma forma para deformações, as tensões na viga para estes mesmo pontos estão apresentadas na Figura 6.24. Em ambos os modelos, as tensões e, consequentemente, as deformações obtidas numericamente 
encontram-se no regime elástico. As tensões e deformações na mesa superior e inferior da viga foram obtidas a partir do valor médio dessas grandezas para os nós destas posições.

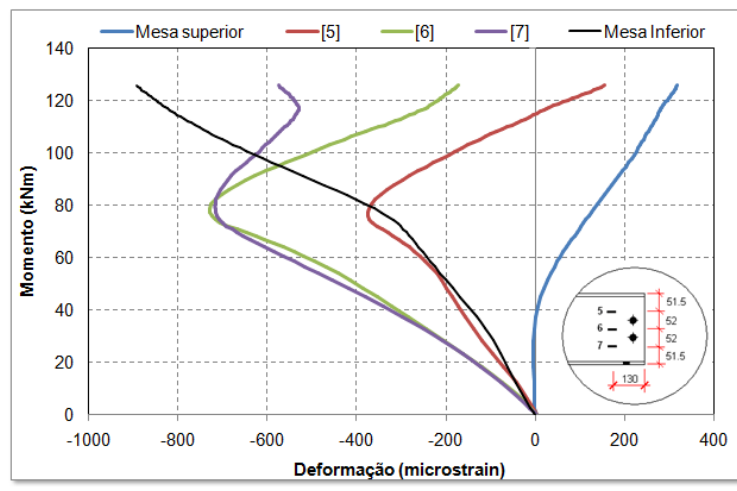

TNRSS

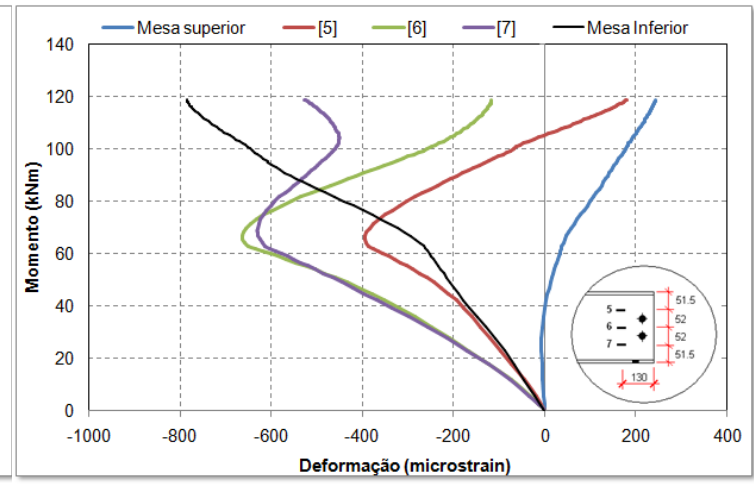

TRSS

Figura 6.23: Deformações na seção da viga para os modelos numéricos de pilar de borda.

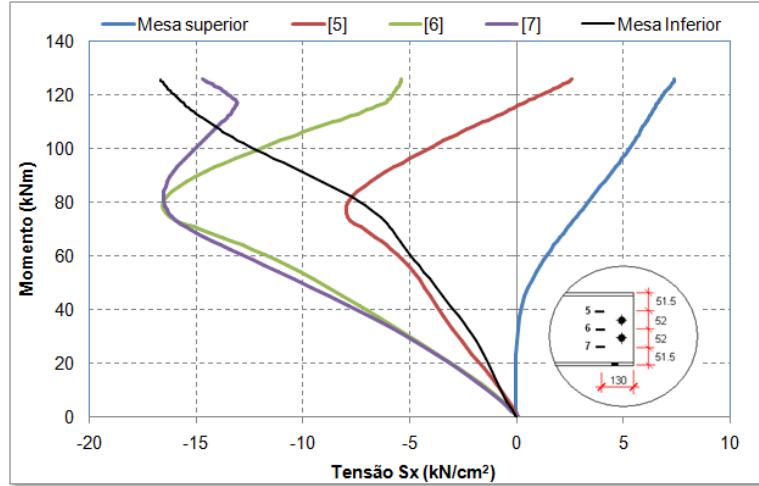

TNRSS

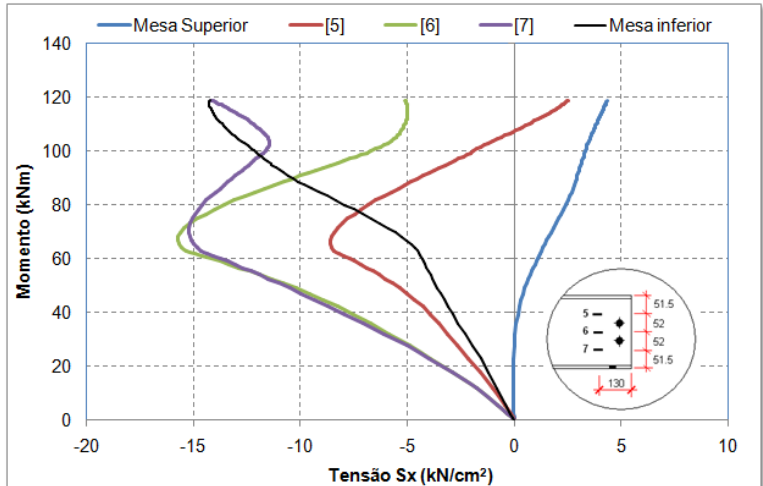

TRSS

Figura 6.24: Tensões longitudinais na seção da viga para os modelos numéricos de pilar de borda $\left(\mathrm{kN} / \mathrm{cm}^{2}\right)$.

Nos modelos numéricos, a mesa superior ficou levemente tracionada, indicando que a posição da linha neutra na viga localizou-se pouco abaixo da mesa superior. Tais resultados estão de acordo com o previsto, pois a concepção de tais modelos teve como consideração a interação parcial entre viga e laje de concreto.

Aqui cabe ressaltar que os modelos numéricos levaram em consideração a ancoragem perfeita das barras da viga mista, o que não ocorreu da forma 
ideal nos protótipos isolados de pilar de canto nos ensaios experimentais, tal como será visto no capítulo 7 , que é dedicado à comparação dos resultados. Embora a existência do comportamento descrito acima, obteve-se a mesma ordem de grandeza e distribuição das tensões na viga quando comparados com os resultados experimentais.

No que diz respeito ao pilar, foram analisadas também as tensões longitudinais (direção X) e de cisalhamento em sua alma, segunda uma linha vertical na posição do centro geométrico do perfil. A posição da mesa comprimida da viga foi tomada como o ponto de referência, considerando também as linhas de parafusos e a região da mesa tracionada, de acordo com as Figuras 6.25 e 6.26 , respectivamente.

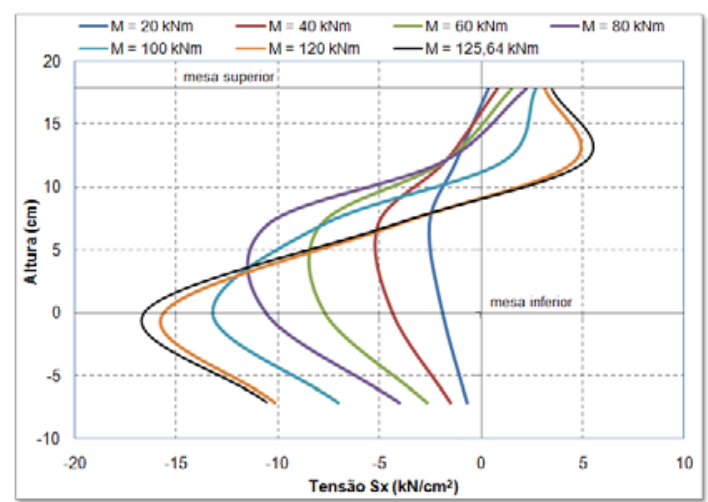

TNRSS

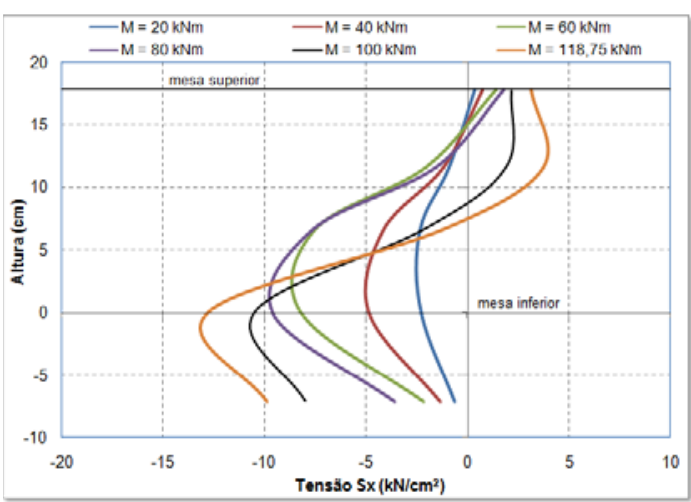

TRSS

Figura 6.25: Tensões longitudinais na alma do pilar para os modelos numéricos de pilar de borda $\left(\mathrm{kN} / \mathrm{cm}^{2}\right)$.

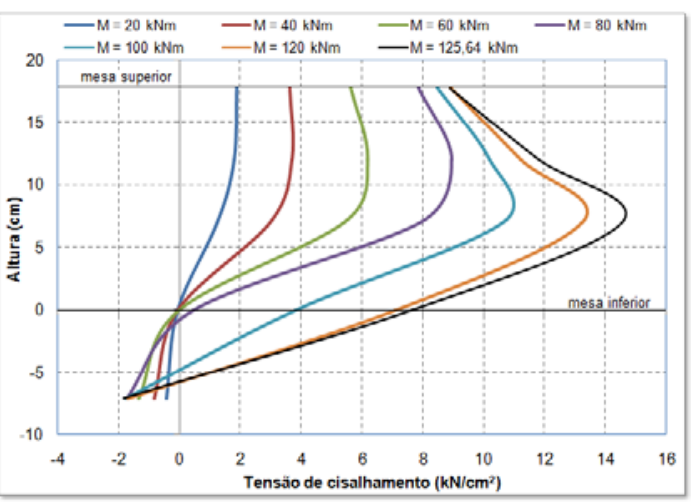

TNRSS

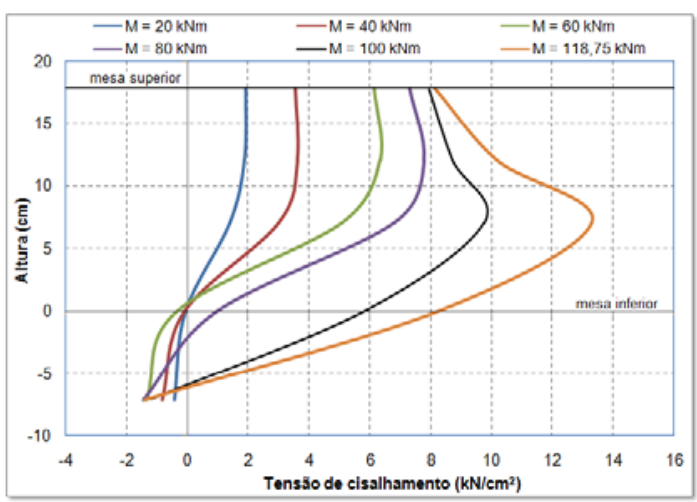

TRSS

Figura 6.26: Tensões de cisalhamento na alma do pilar para os modelos numéricos de pilar de borda $\left(\mathrm{kN} / \mathrm{cm}^{2}\right)$. 
Da mesma forma que na viga, as tensões longitudinais (direção $\mathrm{x}$ ) e de cisalhamento na alma do pilar também não atingiram o limite de proporcionalidade ao longo de todo o carregamento. As chapas soldadas entre as mesas do pilar, para a ligação das vigas secundárias (eixo de menor inércia do pilar), contribuíram para o enrijecimento da ligação, com a respectiva redução das tensões de cisalhamento na alma do pilar e, consequentemente, das deformações de toda a ligação.

Dessa forma, pode-se considerar eficiente o enrijecimento da alma do pilar por meio deste detalhe proposto para ligação no eixo de menor inércia. A Figura 6.27 a seguir ilustra as tensões de cisalhamento para o carregamento final do modelo TNRSS (momento na ligação de 125,64 kNm).

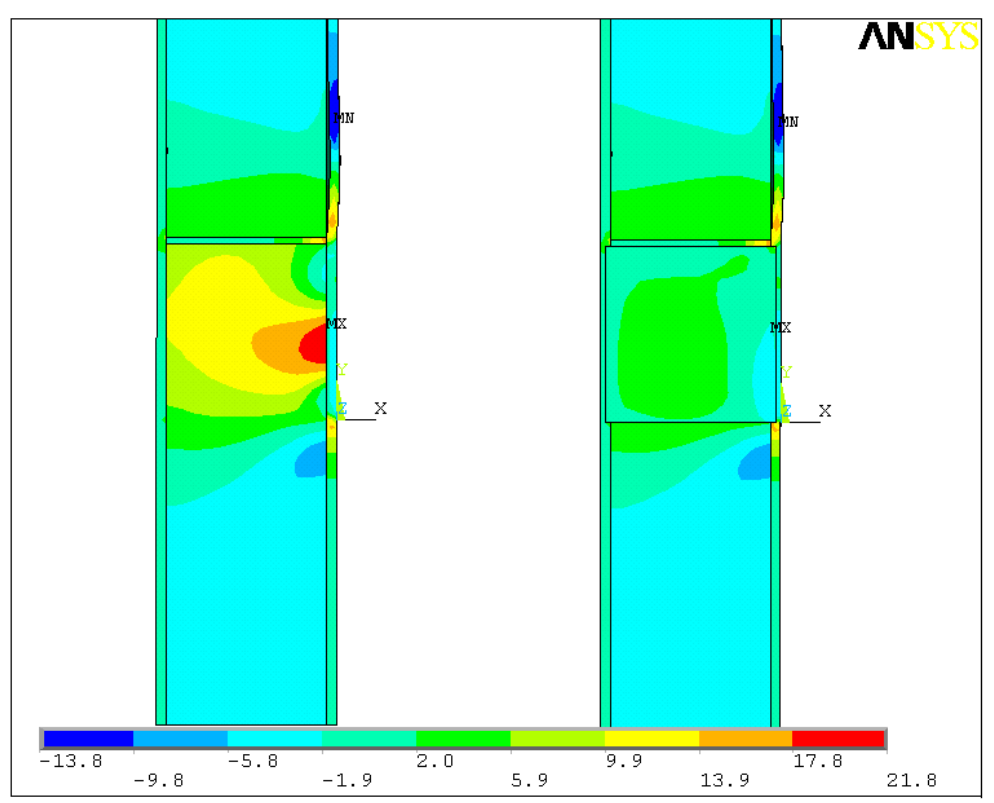

Figura 6.27: Distribuição das tensões de cisalhamento na alma do pilar para o carregamento último do modelo TNRSS $\left(\mathrm{kN} / \mathrm{cm}^{2}\right)$.

\subsection{3 - Modelos numéricos de pilar de centro}

Nos modelos numéricos de pilar central, além da plastificação das cantoneiras de alma, nos mesmos moldes ilustrados no item anterior, observou-se também elevados níveis de plastificação na cantoneira de assento, na região da linha de parafuso com a mesa da viga, apontando no sentido de um possível cisalhamento dos parafusos entre essas chapas.

Esse efeito foi observado em ambos os modelos de pilar de centro e, 
como visto no capítulo anterior, o cisalhamento do parafuso entre a cantoneira de assento e a viga foi o modo de colapso do protótipo CRSS. A Figura 6.28 ilustra as tensões de Von-Mises na cantoneira de assento para o modelo CNRSS e a Figura 6.29 às tensões de plastificação equivalente para o carregamento último de $114,82 \mathrm{kNm}$ na ligação.
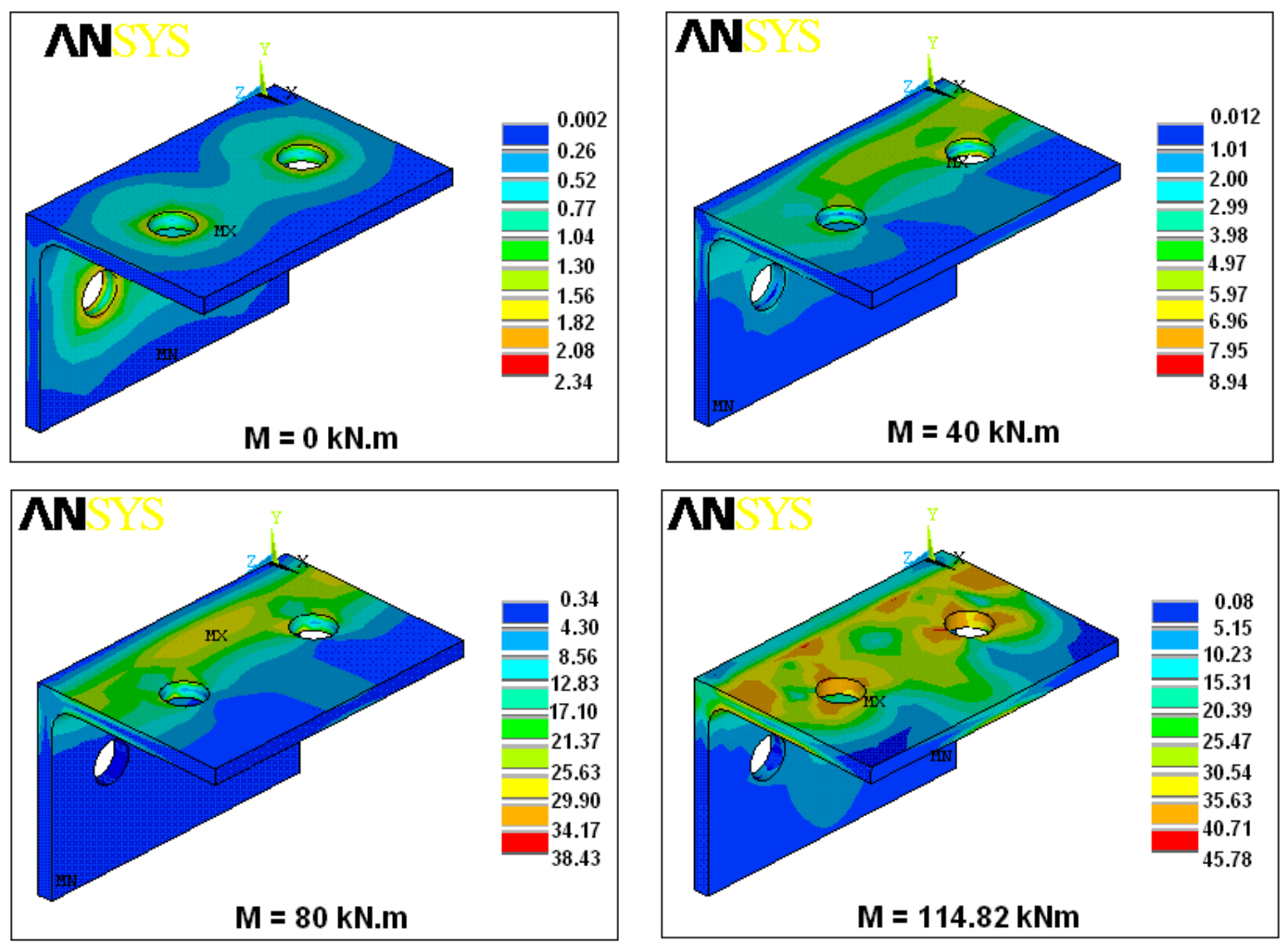

Figura 6.28: Tensões de Von-Mises nas cantoneiras de assento do modelo CNRSS $\left(\mathrm{kN} / \mathrm{cm}^{2}\right)$.

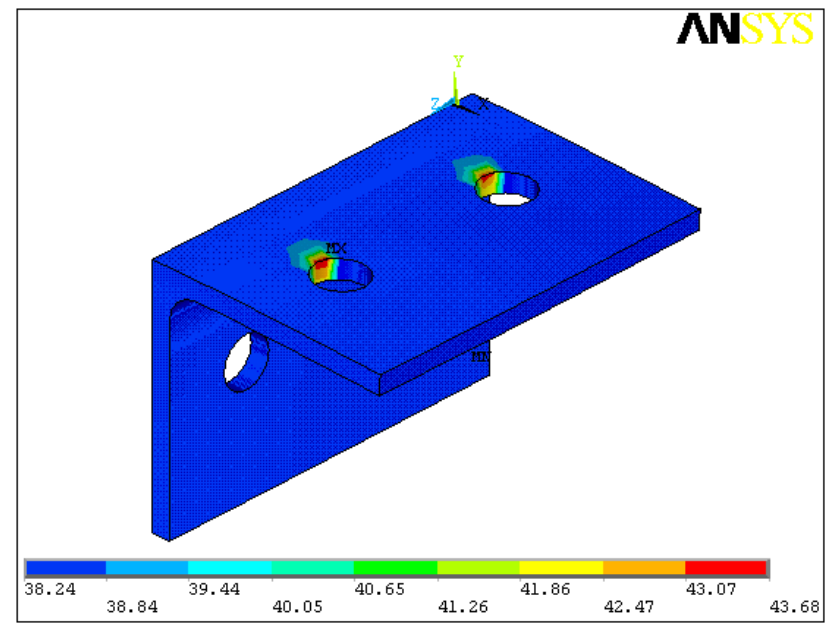

Figura 6.29: Tensões de plastificação equivalente na cantoneira de assento do modelo CNRSS para o carregamento último. $\left(\mathrm{kN} / \mathrm{cm}^{2}\right)$. 
Da mesma forma que nos modelos de pilar de canto, as amaduras posicionadas acima da mesa da viga também tiveram níveis de tensões de tração bem inferiores das demais armaduras, posicionadas lateralmente ao pilar, que por sua vez atingiram a tensão de escoamento para o aço das armaduras. A Figura 6.30 apresenta a tensão longitudinal (direção X) nas armaduras indicadas e a Figura 6.31 ilustra as tensões longitudinais em todas as armaduras da viga mista do modelo CNRSS, para o momento último de 114,82 kNm na ligação.
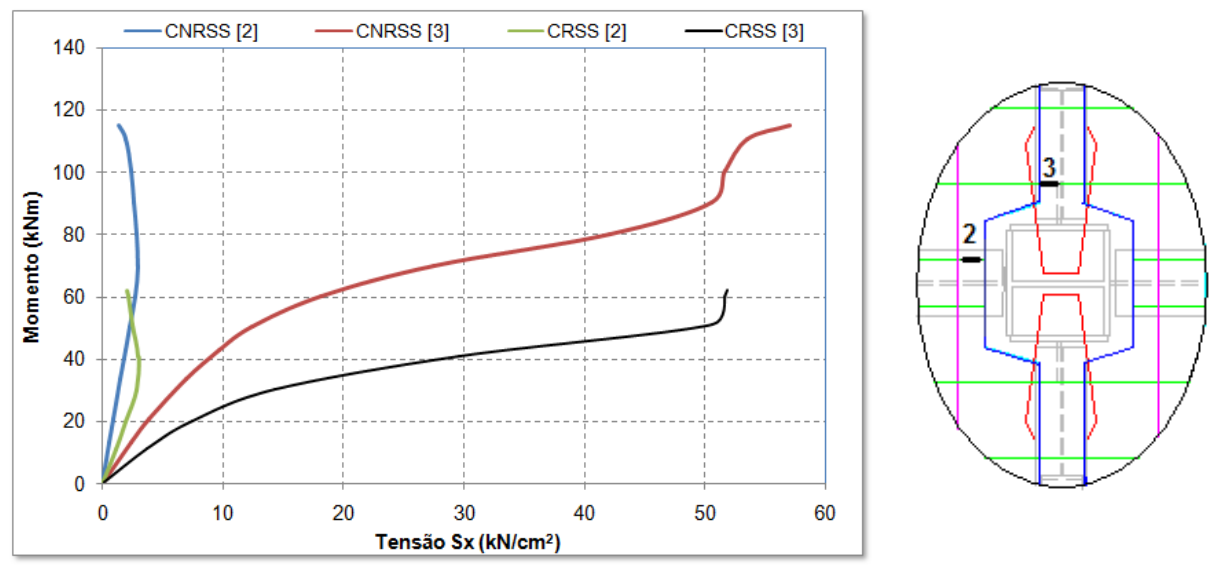

Figura 6.30: Tensões longitudinais na armadura da viga mista para ligação de pilar de centro $\left(\mathrm{kN} / \mathrm{cm}^{2}\right)$.

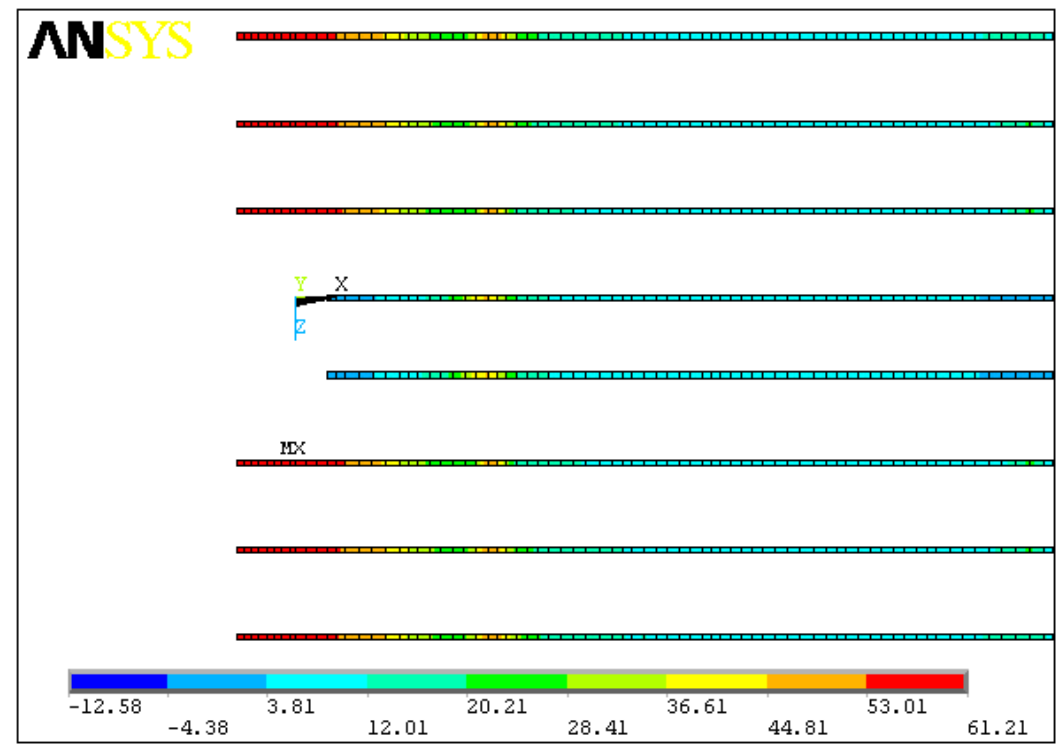

Figura 6.31: Tensões longitudinais nas armaduras da viga mista do modelo CNRSS $\left(\mathrm{kN} / \mathrm{cm}^{2}\right)$.

De maneira geral, se observou maiores níveis de tensões longitudinais 
nas armaduras dos modelos de pilar de centro, em relação aos modelos de pilar de canto, chegando a atingir ao limite de escoamento em algumas barras das armaduras longitudinais do modelo CNRSS.

As tensões e deformações longitudinais na viga (direção $\mathrm{x}$ ), também não excederam o limite de proporcionalidade das tensões, comportamento igualmente observado nas ligações de pilar de canto. A Figura 6.32 ilustra deformações longitudinais na viga, numa seção aproximadamente $\mathrm{H}_{\text {viga }} / 2$ a partir da ligação.

As tensões longitudinais estão apresentadas na Figura 6.33 para a mesma seção transversal. Seguindo o mesmo procedimento anterior, as deformações e tensões na mesa superior e inferior da viga foram obtidas a partir do valor médio dessas grandezas para os nós destas posições.

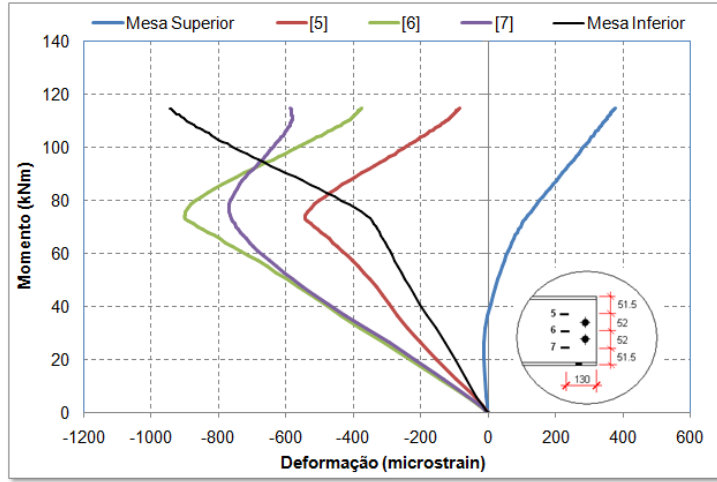

CNRSS

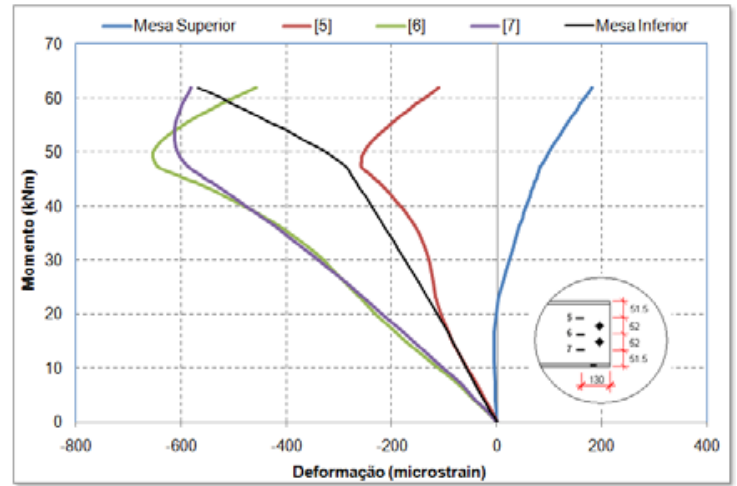

CRSS

Figura 6.32: Deformações na seção da viga para os modelos numéricos de pilar de centro.

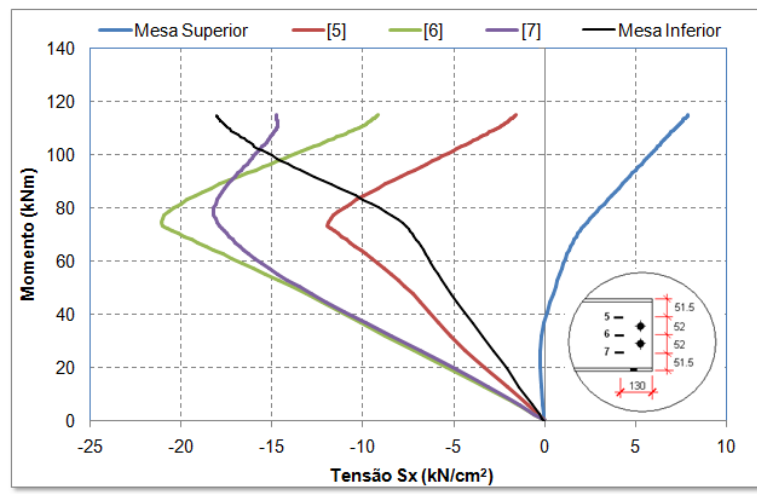

CNRSS

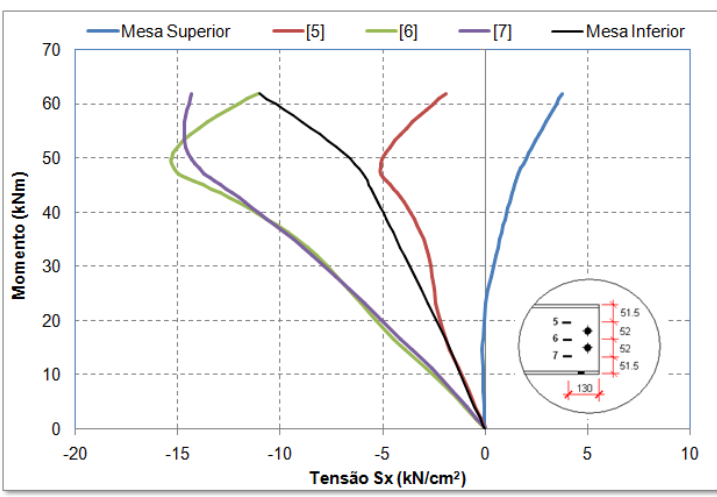

CRSS

Figura 6.33: Tensões longitudinais na seção da viga para os modelos numéricos de pilar de centro $\left(\mathrm{kN} / \mathrm{cm}^{2}\right)$. 
De acordo com os resultados das figuras anteriores, a mesa da viga encontra-se tracionada e a posição da linha neutra na viga localiza-se pouco abaixo da mesa superior. Tais resultados, também são coincidentes com as ligações de pilar de borda e acordo com o previsto, pois a concepção teve como consideração a interação parcial entre viga e laje de concreto.

No pilar, as tensões longitudinais (direção $\mathrm{x}$ ) e de cisalhamento na alma, segundo o plano de simetria, considerando também as linhas de parafusos e a região da mesa tracionada, estão lustradas nas Figuras 6.34 e 6.35, respectivamente, com a posição da mesa comprimida da viga tomado como o ponto de referência.

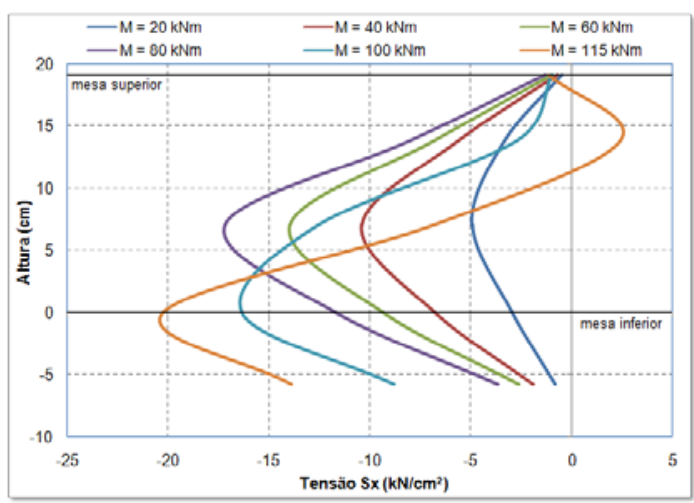

CNRSS

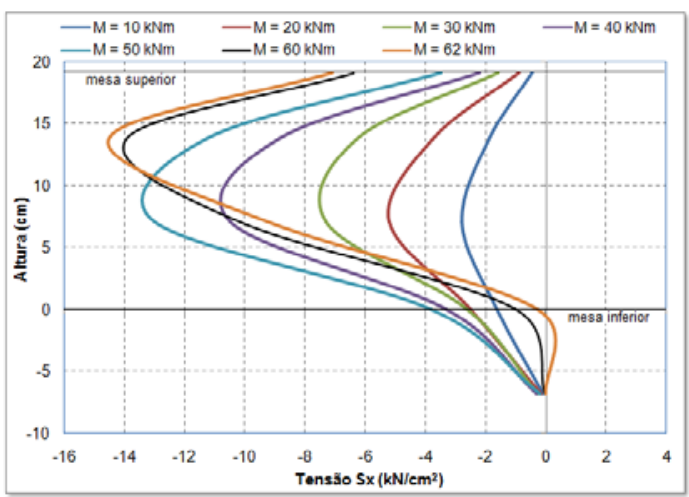

CRSS

Figura 6.34: Tensões longitudinais na alma do pilar para os modelos numéricos de pilar de borda $\left(\mathrm{kN} / \mathrm{cm}^{2}\right)$.

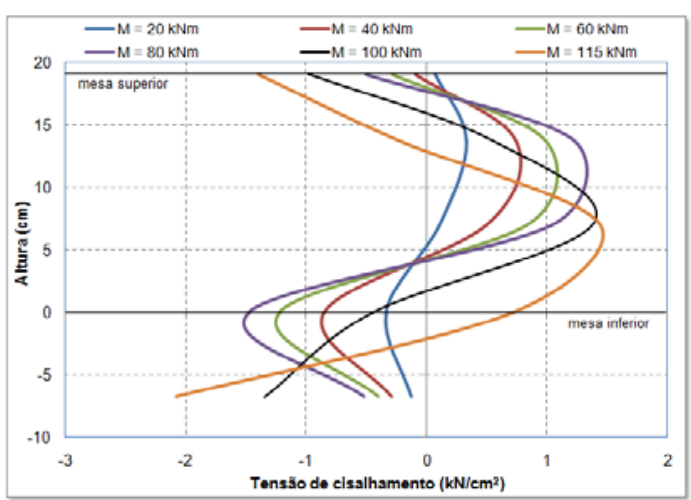

CNRSS

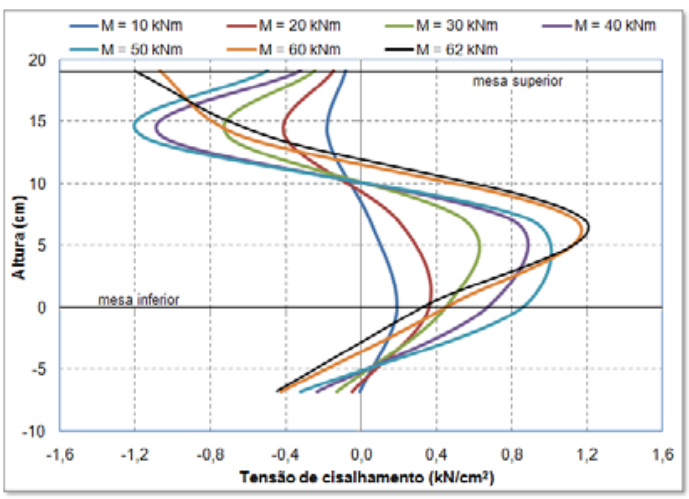

CRSS

Figura 6.35: Tensões de cisalhamento na alma do pilar para os modelos numéricos de pilar de borda $\left(\mathrm{kN} / \mathrm{cm}^{2}\right)$.

As tensões na alma do pilar também se apresentaram no regime elástico ao longo de todo o carregamento, com as tensões longitudinais em níveis 
maiores nas ligações de pilar de centro, em relação aos modelos de pilar de borda. Para as tensões de cisalhamento na alma, se observou o contrário, uma vez que não há equilíbrio nas forças externas de cisalhamento atuantes no painel de alma do pilar, nas ligações de pilar de canto. A Figura 6.36 a seguir ilustra as tensões de cisalhamento para o carregamento final do modelo CNRSS (momento de 114,82 kN.m na ligação).

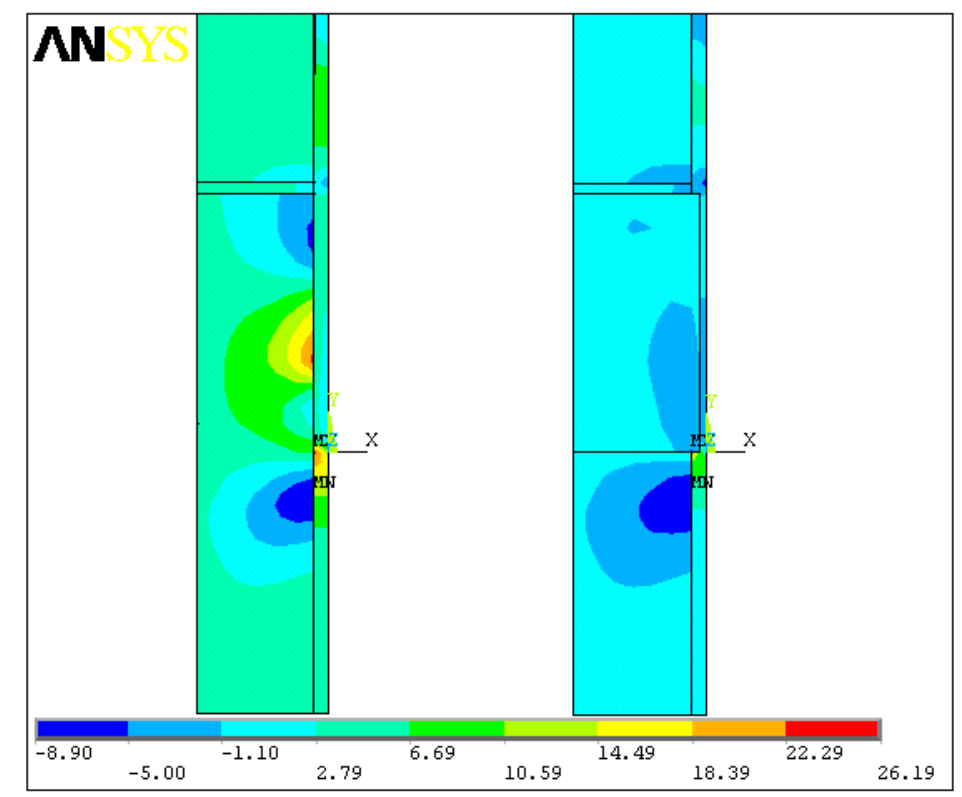

Figura 6.36: Distribuição das tensões de cisalhamento na alma do pilar para o carregamento último do modelo CNRSS $\left(\mathrm{kN} / \mathrm{cm}^{2}\right)$.

\section{8 - Comentários Finais a respeito da Modelagem Numérica}

A modelagem numérica proposta neste trabalho foi bastante complexa, exigindo várias etapas, desde a obtenção da malha de elementos finitos até a fase de pós-processamento. Por este motivo, observa-se a importância de se automatizar todas as etapas, possibilitando um ganho considerável de tempo nas alterações de geometria e malha de elementos finitos.

O procedimento de modelagem numérica descrito neste capítulo permite a análise do comportamento de grande parte dos detalhes e tipos de ligações comumente utilizados na concepção de projetos, uma vez que se necessita apenas das dimensões dos elementos conectados, das características dos materiais envolvidos e do tipo de carregamento.

Apesar do elevado número de nós e elementos finitos, necessários para 
uma boa representatividade numérica, bem como a consideração das nãolinearidades física e geométrica, o processamento dos modelos numéricos foi obtido em aproximadamente $9 \mathrm{~h}$ (processador de $2,6 \mathrm{GHz}$ ), uma vez que todos os parâmetros foram cuidadosamente estabelecidos de modo a permitir a otimização da convergência.

Com base no modelo numérico, conseguiu-se prever os principais elementos de colapso da ligação, que foram a plastificação das armaduras longitudinais, cantoneiras de alma e de mesa e cisalhamento dos parafusos. Apesar de o modelo numérico não reproduzir a fissuração da laje, a estratégia adotada conseguiu representar satisfatoriamente o comportamento da laje tracionada, com a distribuição de tensões para as armaduras desta região.

A Figura 6.37 a seguir ilustra os deslocamentos do modelo numérico TRSS e do respectivo protótipo experimental, para uma rotação na ligação de $4000 \operatorname{rad} 10^{-5}$.
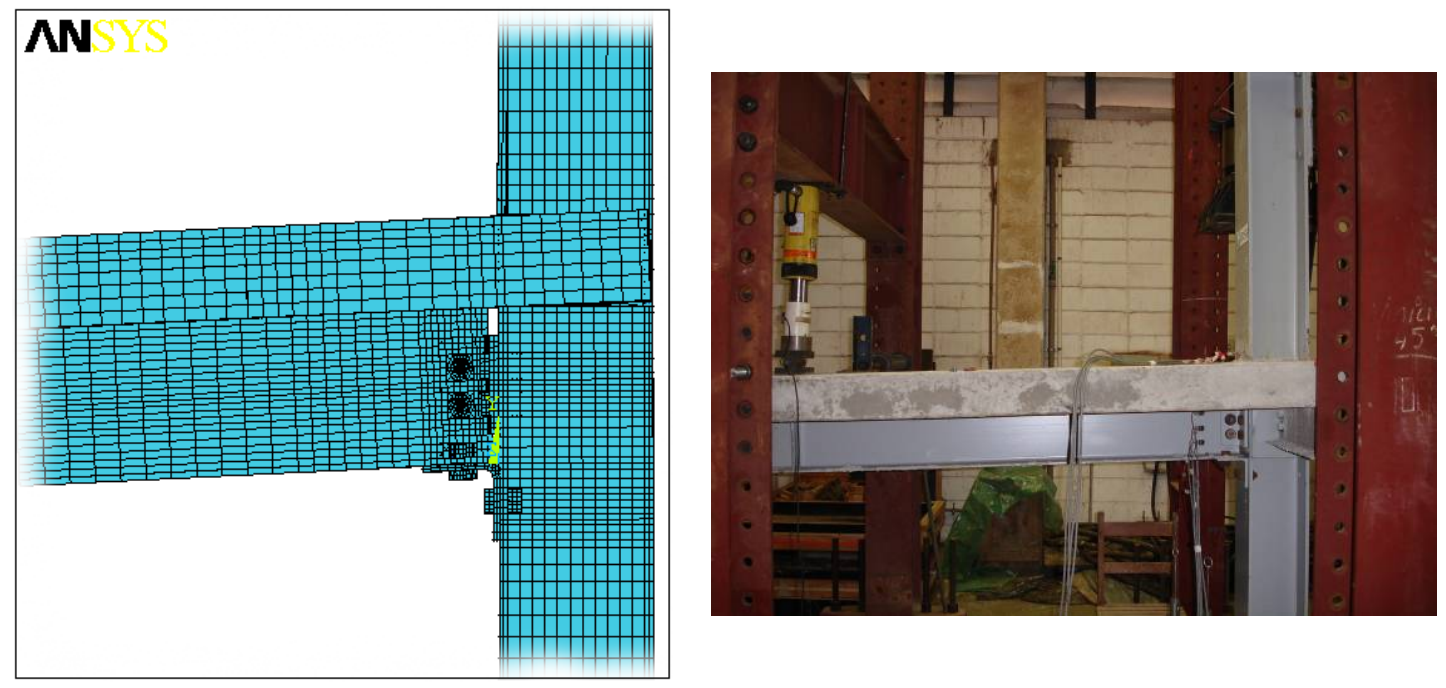

Figura 6.37: Deslocamentos na ligação para o modelo numérico e protótipo experimental TRSS para rotação de $4000{\operatorname{rad} 10^{-5}}^{\text {. }}$

A análise da distribuição de tensões nas armaduras longitudinais, alma do pilar e cantoneiras da ligação são importantes, uma vez que o método das componentes utiliza o conceito de que a resistência da ligação está diretamente relacionada com o primeiro componente a atingir a plastificação, que no caso das ligações analisadas foram as cantoneiras de alma e armaduras longitudinais. 
Além disso, o método das componentes não considera a componente flexão da aba da cantoneira de alma para este tipo de ligação, sendo então adotado, segundo o tal procedimento normativo, a componente flexão da chapa de topo para o cálculo da resistência e rigidez da ligação.

Aqui também vale ressaltar a respeito da laje de concreto, que devido ao método construtivo adotado para a laje pré-moldada, possuiu uma espessura de apenas $5 \mathrm{~cm}$ de concreto maciço (parte superior), e os demais $7 \mathrm{~cm}$ de espessura da laje sendo intercalados por lajotas cerâmicas e concreto.

Embora o modelo numérico não representasse de forma precisa 0 comportamento do concreto, principalmente quando submetido à tração, os resultados obtidos para o estado limite último foram satisfatórios. $\mathrm{O}$ capítulo 7 a seguir é dedicado a análise comparativa dos resultados analíticos, previstos pelo EUROCODE 3 (2005) e EUROCODE 4 (2004), além dos resultados experimentais e numéricos. 


\section{7}

\section{ANÁLISE E COMPARAÇÃO DOS RESULTADOS}

\section{1 - Introdução}

Este capítulo tem como objetivo a análise e comparação dos resultados experimentais, numéricos e analíticos, com o foco na discussão dos principais aspectos que influenciaram no comportamento das ligações dos protótipos experimentais isolados e do pavimento tipo.

Os resultados segundo o Método das Componentes, descrito no Capítulo 3 ,foram determinados utilizando as propriedades dos materiais resultantes da caracterização em laboratório, com o coeficiente de ponderação de resistência dos materiais igual a 1.

Os valores da rigidez inicial e momento resistente obtidos segundo as análises experimental, numérica e analítica foram apresentados e comparados, no sentido de identificar os principais fatores que influenciaram os resultados.

Por fim, uma análise mais apurada foi desenvolvida com base na comparação do comportamento global e dos elementos individuais das ligações dos protótipos isolados e do pavimento tipo, tomando como referência o Método das Componentes, com o objetivo de estabelecer o grau de influência da taxa de armadura secundária e da fissuração na laje de concreto na determinação da rigidez e resistência das ligações viga mista-pilar.

\section{2 - Análise e Comparação dos Resultados Numéricos e} Experimentais

Este item teve como proposta a comparação dos principais resultados experimentais e numéricos, com o objetivo de discutir as vantagens e desvantagens da metodologia de modelagem numérica adotada neste trabalho, 
além da eficiência da distribuição e ancoragem das armaduras dos protótipos experimentais isolados e do pavimento tipo.

\subsection{1 - Comportamento momento-rotação total da ligação}

A resposta do comportamento global das ligações dos protótipos isolados, em comparação com os respectivos modelos numéricos é apresentada nas Figuras 7.1 e 7.2, por meio das curvas momento-rotação total para as ligações de pilar de borda e centro, respectivamente. A rotação total foi obtida através da somatória da rotação dos elementos da ligação.

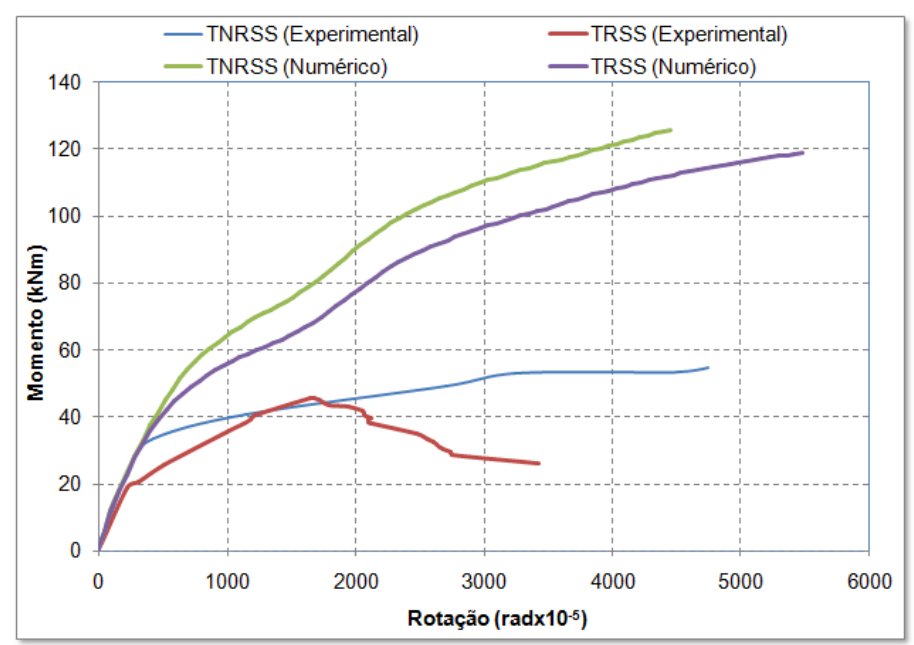

Figura 7.1: Curva momento-rotação total da ligação dos modelos numéricos e dos protótipos isolados de pilar de borda.

Para os protótipos de pilar de borda, observa-se um comportamento satisfatório comparando-se a rigidez inicial, porém, com uma grande perda de rigidez nos modelos experimentais a partir do momento na ligação de $20 \mathrm{kN}$.m para o protótipo TRSS e aproximadamente de 34kN.m para o protótipo TNRSS, atingindo uma solicitação máxima na ligação de aproximadamente $46 \mathrm{kN} . \mathrm{m}$ e $55 \mathrm{kN} . \mathrm{m}$, respectivamente. Nos modelos numéricos, o momento máximo na ligação atingiu $120 \mathrm{kN} . \mathrm{m}$ no modelo TNRSS.

Esse resultado é atribuído à falha de ancoragem das armaduras longitudinais nos protótipos isolados de pilar de borda, conforme análise descrita no capítulo 5, prejudicando assim a distribuição de tensões de tração na ligação e o consequente aumento da abertura de fissuras na laje. Por outro 
lado, os modelos numéricos foram concebidos com a ancoragem efetiva das armaduras, o que permitiu as armaduras longitudinais assumirem grande parcela das tensões de tração na ligação, de modo a atingir um valor do momento resistente da ligação bem acima do observado para os respectivos protótipos experimentais.

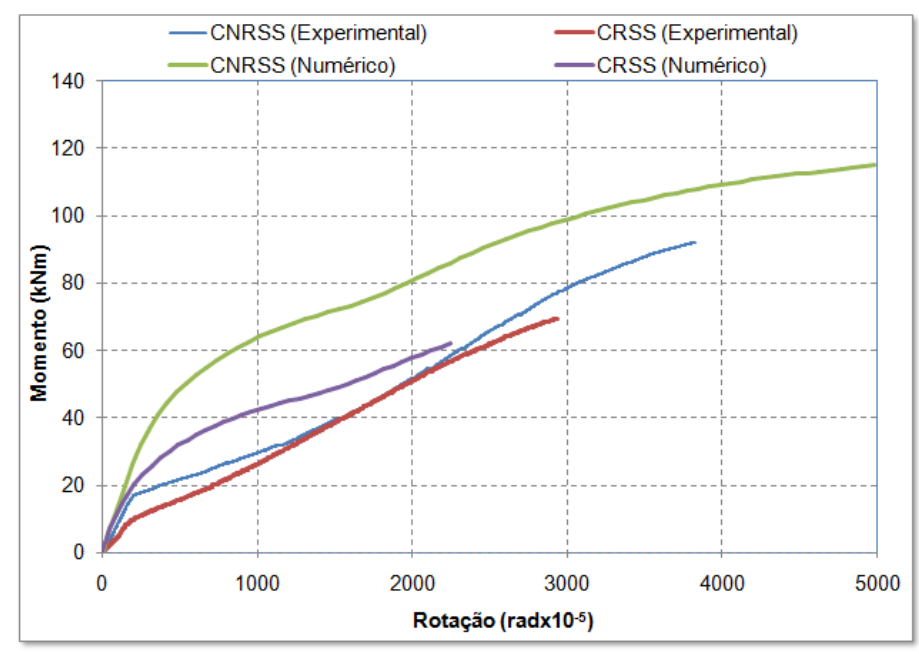

Figura 7.2: Curva momento-rotação total da ligação dos modelos numéricos e dos protótipos isolados de pilar de centro.

Para os protótipos de pilar de centro, o momento resistente e último apresentaram resultados mais próximos dos obtidos pela análise numérica, conforme ilustra a Figura 7.2. A rigidez inicial do protótipo experimental CRSS foi menor quando comparados com o protótipo CNRSS e dos respectivos modelos numéricos.

Ainda em relação ao gráfico da Figura 7.2, observa-se uma significante diferença na trajetória da curva dos modelos numéricos, em comparação aos respectivos protótipos experimentais após o início da fissuração da laje, com as curvas praticamente coincidentes ou convergentes no trecho inicial e próximo do momento último da ligação.

Esse resultado se deve à limitação do modelo numérico, no que se refere à representação do material concreto quando tracionado, conforme descrito no capítulo anterior, caracterizada na comparação do trecho não-linear do comportamento momento-rotação total da ligação.

A Figura 7.3 a seguir ilustra o comportamento momento-rotação dos 
protótipos experimentais isolados de pilar de borda e a respectiva ligação do pavimento tipo (Lig. [1]), além da ligação de pilar de canto (Lig. [2]). A rigidez inicial da Ligação [2] do pavimento tipo foi menor quando comparada às respectivas ligações dos protótipos isolados, apontando uma ligeira influência do estado de fissuração da laje e da continuidade das vigas no plano de menor inércia do pilar no comportamento da rigidez inicial da ligação.
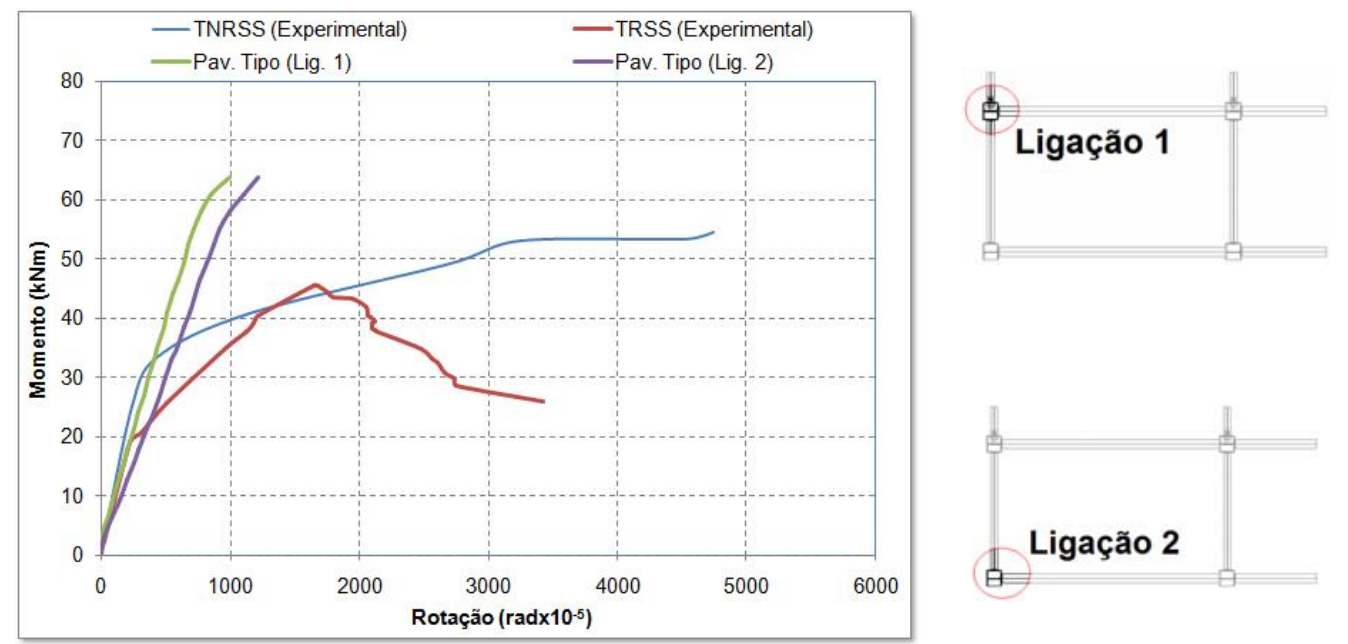

Figura 7.3: Curva momento-rotação total da ligação dos protótipos isolados de pilar de borda e as Ligações [1] e [2] do pavimento tipo.

A Figura 7.4 estabelece o mesmo paralelo de comparação para as ligações de pilar de centro.
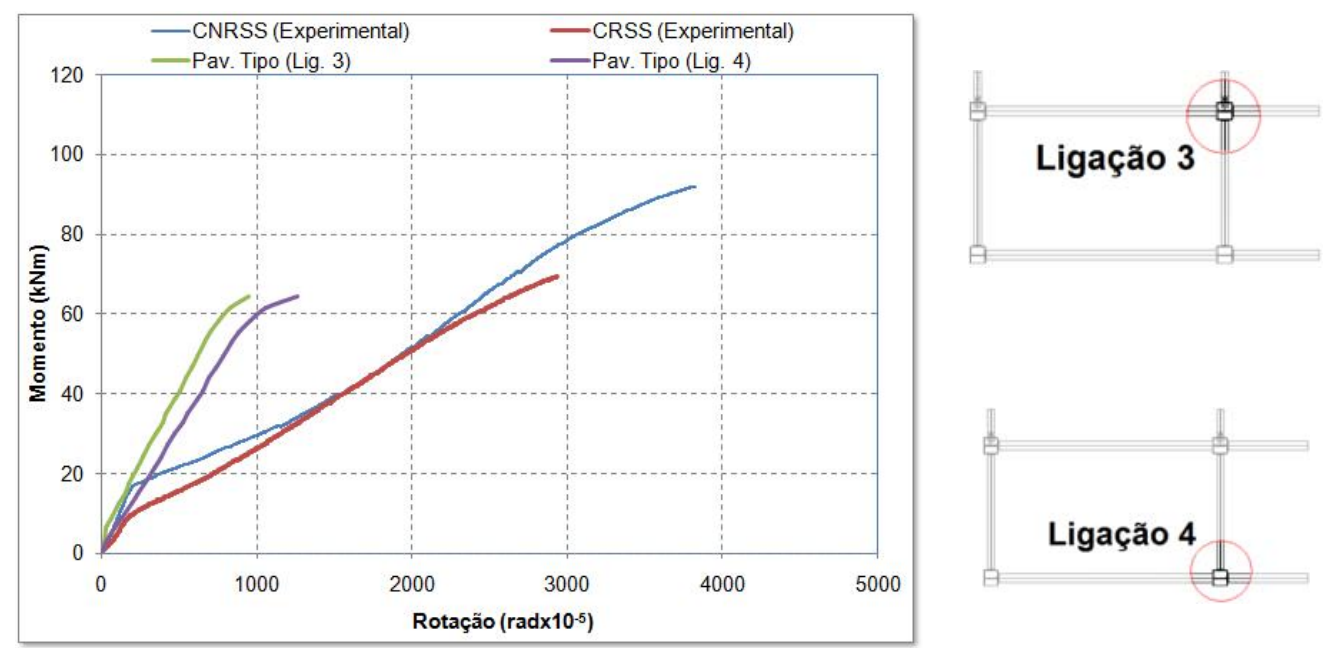

Figura 7.4: Curva momento-rotação total da ligação dos protótipos isolados de pilar de centro e as Ligações [3] e [4] do pavimento tipo. 
De acordo com o resultado da figura anterior, a rigidez inicial da Lig. [4] do pavimento tipo foi menor quando comparado ao protótipo isolado CNRSS e pela Lig. [3]. Já o protótipo CRSS apresentou o menor valor para rigidez inicial dentre todos os modelos de pilar de centro, além da antecipação do colapso da ligação, apontando para uma provável falha na ancoragem das armaduras da viga mista, além da menor resistência do concreto quando comparado aos demais modelos. Tal resultado também vai de encontro com o modo de colapso observado experimentalmente, devido ao cisalhamento do parafuso da cantoneira de mesa, conforme resultados indicados no Capítulo 5.

Aqui cabe ressaltar que foi adotado o acréscimo na taxa de armadura secundária da laje do pavimento tipo e dos protótipos isolados CRSS e TRSS, com taxa de $1 \%$, enquanto que a taxa de armadura secundária para os protótipos CNRSS e TNRSS foi de 0,2\% (taxa mínima recomendada pela revisão da NBR 8800 (2006)).

As Figuras 7.5 e 7.6 apresentam o comportamento momento-rotação total das ligações dos modelos numéricos, dos protótipos experimentais isolados e do pavimento tipo, para as ligações de pilar de borda e central, respectivamente.
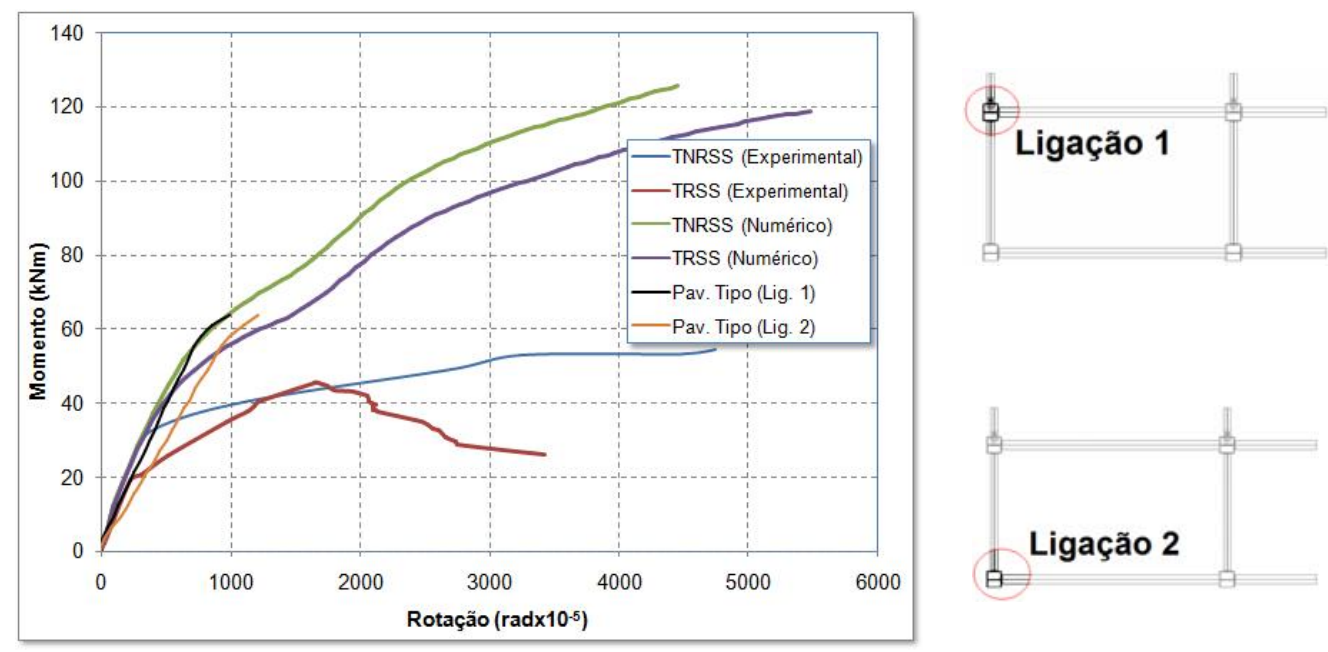

Figura 7.5: Curva momento-rotação total das ligações dos modelos numéricos, protótipos isolados de pilar de borda e das Ligações [1] e [2] do pavimento tipo.

De acordo com a análise dos resultados apresentados na Figura 7.5, o detalhe proposto para a ancoragem das armaduras longitudinais da viga mista 
funcionou de maneira mais efetiva nas ligações do pavimento tipo, quando comparada curva momento-rotação com os protótipos isolados, com o comportamento bem próximo da condição ideal de ancoragem das armaduras, representado pelos modelos numéricos.

A continuidade da viga no plano de menor inércia do pilar, da própria laje de concreto e das armaduras de contorno do pilar (onde estão ancoradas as armaduras longitudinais da viga mista) explica a melhor eficiência do detalhe proposto neste trabalho para a ancoragem das armaduras longitudinais nas ligações inseridas no pavimento tipo.
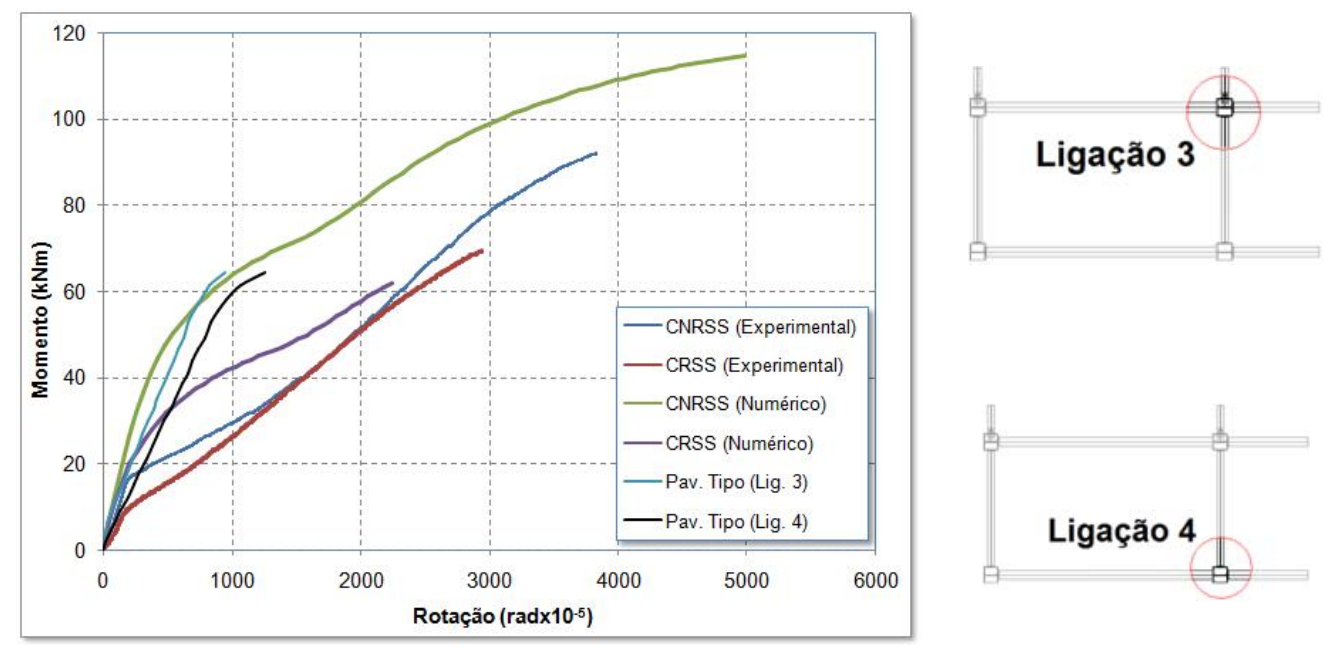

Figura 7.6: Curva momento-rotação total das ligações dos modelos numéricos, protótipos isolados de pilar de centro e das Ligações [3] e [4] pavimento tipo.

\subsection{2 - Análise dos elementos da ligação}

Diante dos aspectos apresentados e discutidos no item anterior, vê-se uma grande diferença na eficiência de ancoragem das armaduras longitudinais nas ligações do pavimento tipo, quando comparado com os protótipos isolados. Neste item serão apresentados os resultados das deformações nas armaduras, de contorno do pilar e longitudinais da viga mista.

As Figuras 7.7 e 7.8 ilustram as deformações na armadura de contorno do pilar nos protótipos isolados de pilar de borda e de centro, respectivamente. 

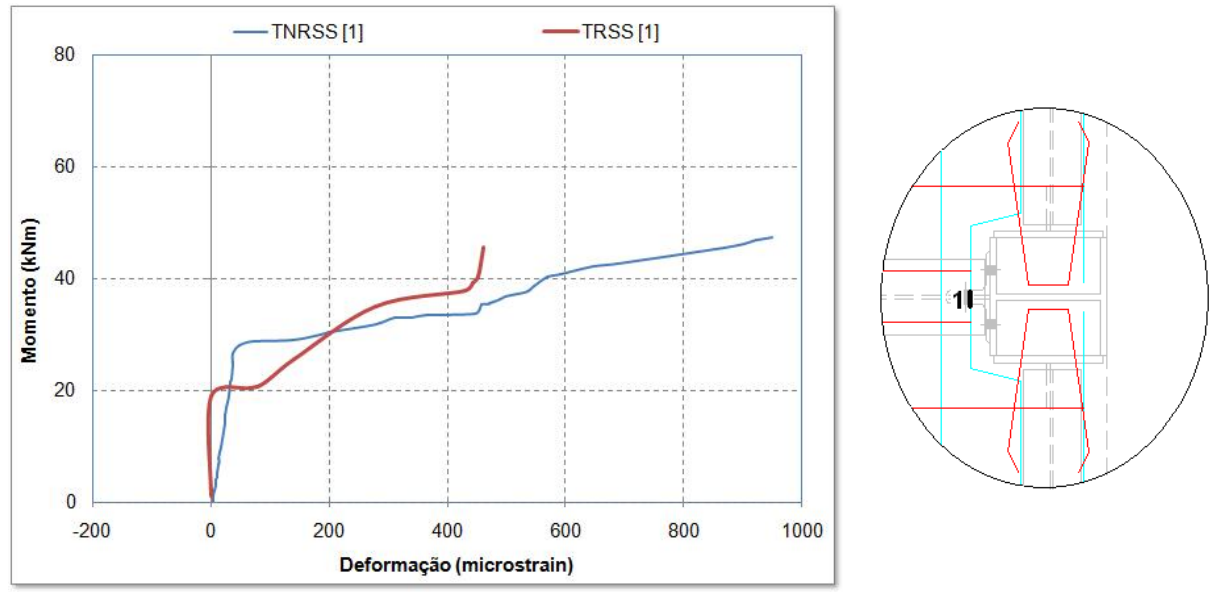

Figura 7.7: Deformações na armadura de contorno para os protótipos isolados de pilar de borda.
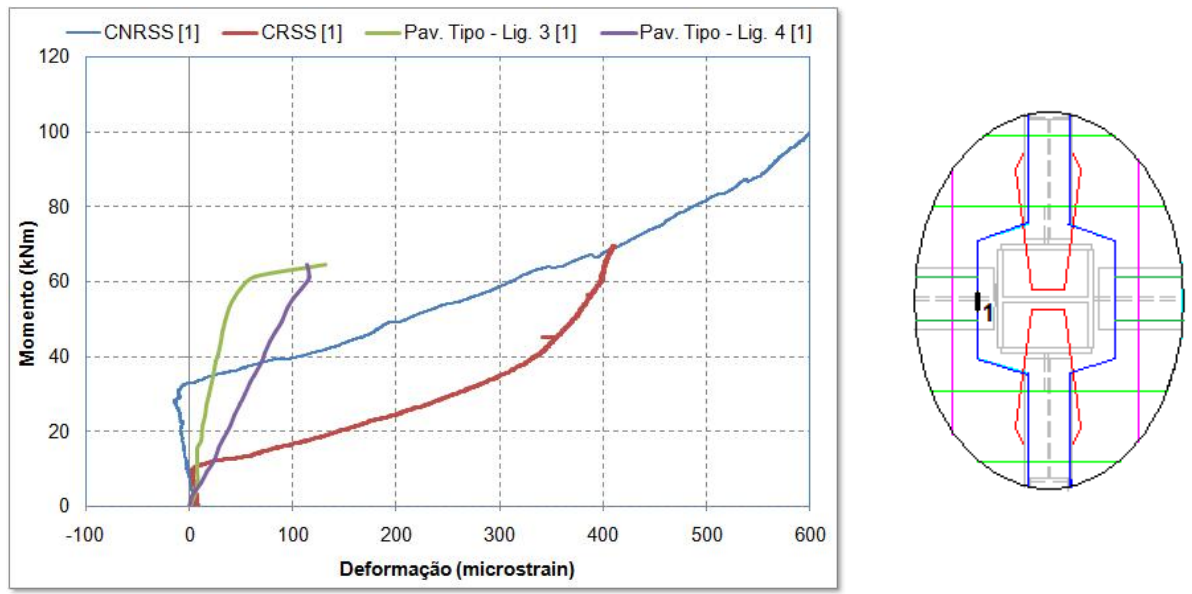

Figura 7.8: Deformações na armadura de contorno para os protótipos isolados de pilar de centro e a respectiva ligação do pavimento tipo.

Em ambas as figuras, observa-se um baixo nível de deformação nas armaduras, principalmente nas armaduras de contorno das Ligações [3] e [4] do pavimento tipo. Na Ligação [1] os extensômetros da armadura longitudinal e de contorno foram perdidos na concretagem.

A continuidade das vigas e laje na direção de menor inércia do pilar, e consequentemente das armaduras transversais e de contorno, proporcionam uma melhor distribuição das tensões de tração, redução da quantidade e da abertura de fissuras na laje para as ligações do pavimento tipo.

A Figura 7.9 ilustra a fissuração da laje no protótipo TRSS e da Ligação 
[1] do pavimento tipo, sendo que a taxa de armadura secundária foi de $1 \%$ em ambos os modelos.

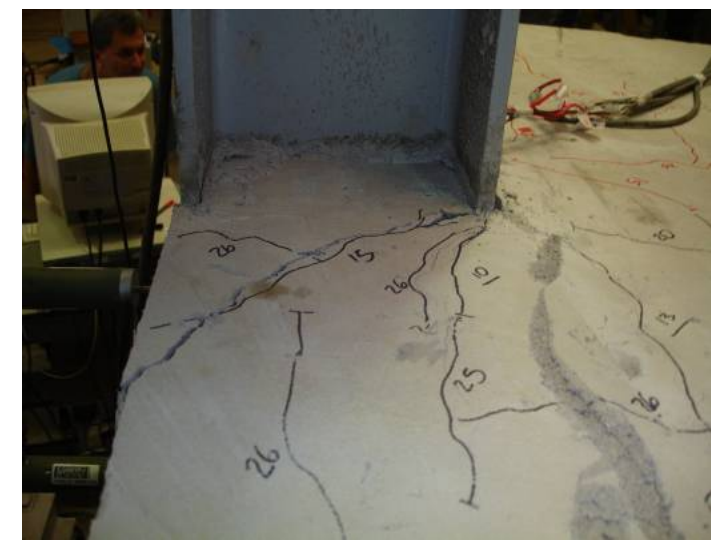

TRSS

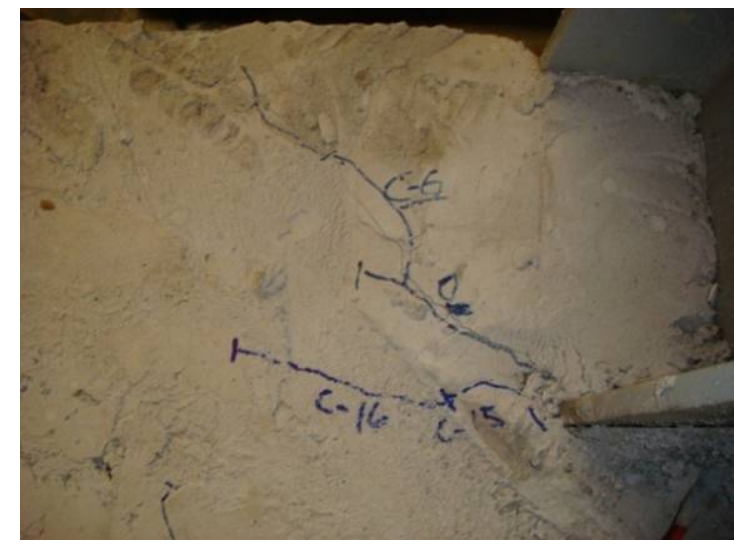

Ligação [1] - Pav. Tipo

Figura 7.9: Fissuração na laje ao término do ensaio para o protótipo isolado TRSS e da ligação [1] do pavimento tipo.

As deformações na armadura longitudinal posicionada acima da viga, nos protótipos isolados de pilar de borda e de centro, além das Ligações [3] e [4] do pavimento tipo, estão ilustradas nas Figuras 7.10 e 7.11.
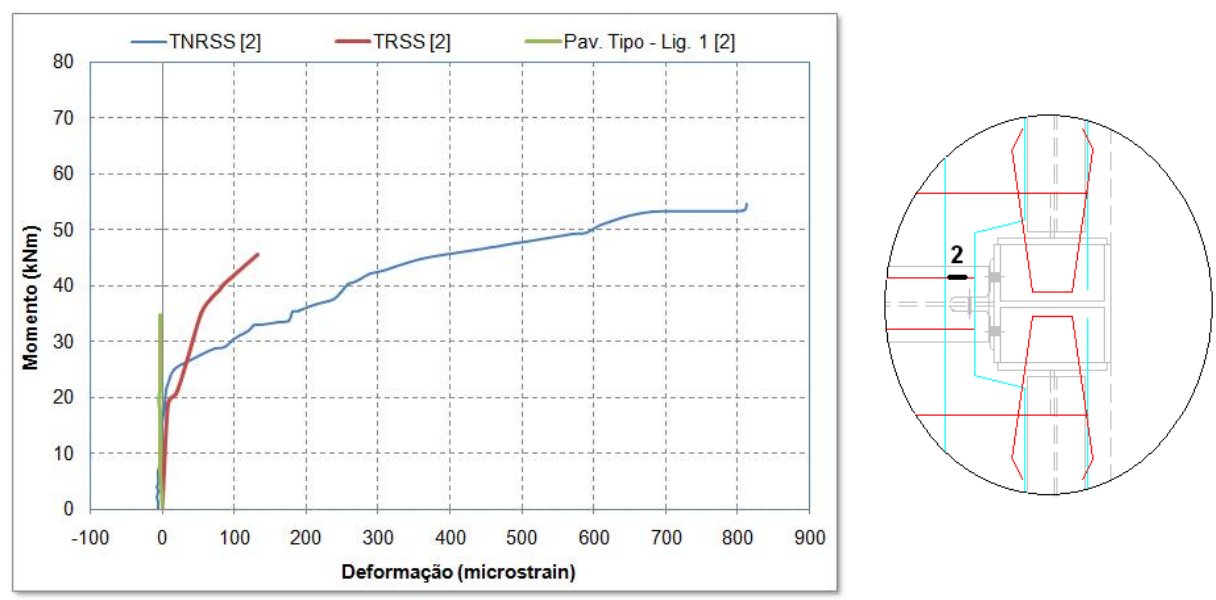

Figura 7.10: Deformações na armadura longitudinal nos protótipos isolados de pilar de borda e na ligação [2] do pavimento tipo.

Os resultados obtidos reforçam a observação da melhor distribuição das tensões de tração na laje e armaduras do pavimento tipo, com a conseqüente redução das deformações, considerando um mesmo nível de solicitação.

Ainda com relação às deformações nas armaduras longitudinais, os 
resultados da análise numérica descritos no capítulo anterior, indicam maiores níveis de deformações longitudinais nas armaduras dos modelos de pilar de centro, em relação aos modelos de pilar de borda, além de deformações maiores nas armaduras posicionadas lateralmente à viga.
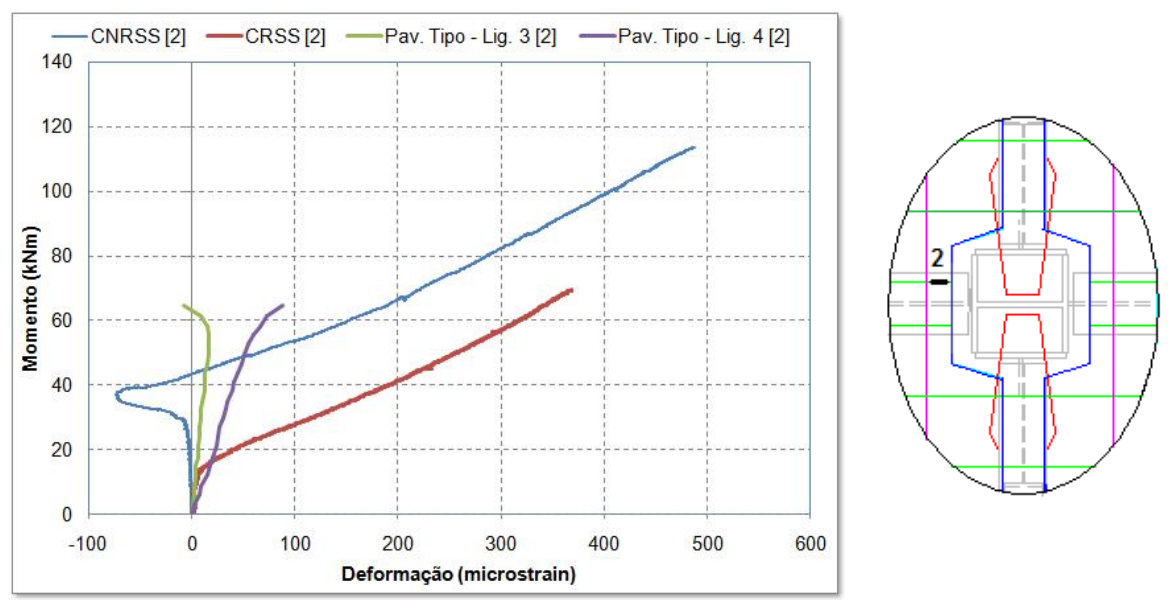

Figura 7.11: Deformações na armadura longitudinal nos protótipos isolados de pilar de centro nas Ligações [3] e [4] do pavimento tipo.

Na Figura 7.12 tem-se a fissuração da laje no protótipo CRSS e na Ligação [3] do pavimento tipo após o término dos ensaios.

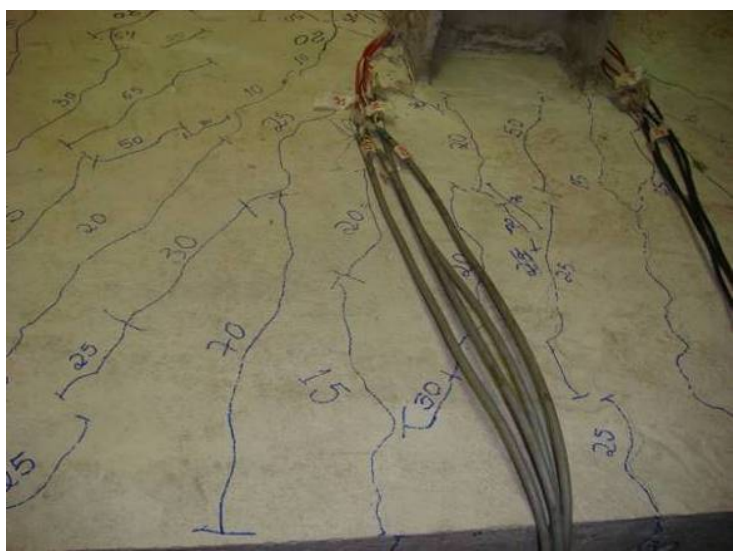

CRSS

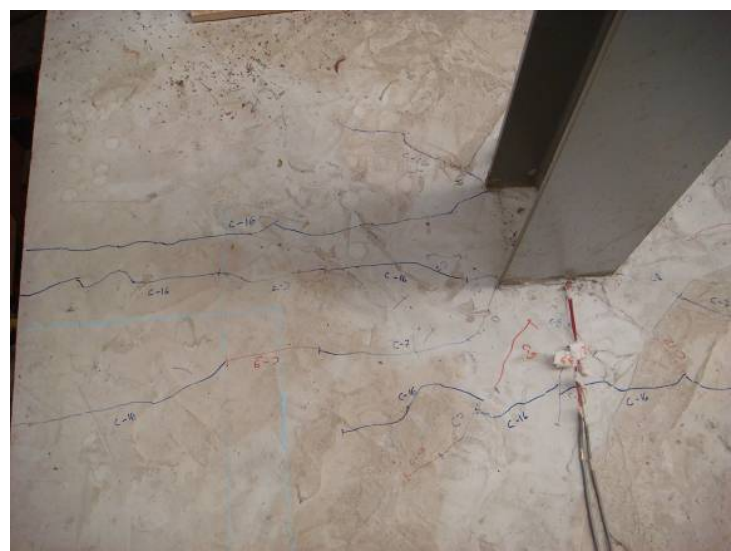

Ligação [3] - Pav. Tipo

Figura 7.12: Fissuração na laje ao término do ensaio para o protótipo isolado CRSS e na Ligação [3] do pavimento tipo.

Com base nos resultados das deformações longitudinais nas armaduras indicados acima e na análise numérica descrita no capítulo anterior, conclui-se que as tensões de tração foram concentradas nas armaduras longitudinais 
adjacentes (laterais da viga). Este resultado também foi observado nos ensaios experimentais realizados em Tristão (2006) para ligações de pilar de borda.

Dessa forma, ressalta-se a importância da continuidade das vigas na direção do eixo de menor inércia do pilar, bem como da laje e armaduras de contorno e longitudinais no pavimento tipo. Estas características possibilitaram uma melhor distribuição de tensões de tração e a consequente redução da fissuração, além de uma menor perda na solicitação do momento fletor transmitido da viga para o pilar após a fissuração da laje, considerando o mesmo valor da rotação relativa entre viga e pilar das ligações dos modelos isolados.

\section{3 - Análise pelo Método das Componentes}

O método analítico proposto pelos EUROCODE 3 (2005) e EUROCODE 4 (2004) foi utilizado como referência normativa, com o propósito de avaliar os resultados das rigidez inicial e momento resistente das ligações viga mista-pilar com cantoneiras de alma e assento, considerando as ligações dos protótipos isolados e inseridas no pavimento tipo.

O EUROCODE 3 (2005) não considera nenhuma abordagem a respeito da contribuição da cantoneira de alma no comportamento da ligação. Dessa forma, de acordo com a metodologia de dimensionamento apresentada no Capítulo 3, foram adotadas as equações relativas à componente flexão da chapa de topo para o cálculo da rigidez e resistência da componente flexão da aba da cantoneira de alma conectada a mesa do pilar.

A identificação de todas as componentes que influenciam na rigidez inicial e no momento resistente, de acordo com o tipo de ligação adotado neste trabalho, foi apresentada no Capítulo $3 \mathrm{com}$ a respectiva metodologia de cálculo.

A Tabela 7.1 resume as equações utilizadas para obtenção da rigidez e da força resistente potencial das componentes que atuam nas ligações dos protótipos ensaiados, ressaltando que devido às diferenças da posição das ligações (pilar de borda e de centro), algumas componentes apresentaram resultados desiguais, embora a geometria da ligação adotada para todos os 
protótipos foi idêntica.

Tabela 7.1: Equações para determinação da resistência e rigidez de cada componente.

\begin{tabular}{ccc}
\hline Componente & Resistência $\left(\mathbf{F}_{\text {rd }}\right)$ & Rigidez (k) \\
\hline Flexão na mesa do pilar & Teoria "T stub” & $k_{3}=\frac{0,9 \cdot l_{\text {eff }} \cdot t_{f c}^{3}}{m^{3}}$ \\
\hline Tração na alma do pilar & $F_{t, w c, R d}=\omega \cdot b_{\text {eff } t, w c} \cdot t_{w c} \cdot \frac{f_{y, w c}}{1,1}$ & $k_{4}=\frac{0,7 \cdot b_{\text {eff } t, w c} \cdot t_{w c}}{d_{w c}}$
\end{tabular}

Tração na alma da viga

$$
F_{t, w b, R d}=b_{e f f t, t w b} \cdot t_{w b} \cdot \frac{f_{y, w b}}{1,1} \quad \infty
$$

Tração no parafuso

$$
F_{t, R d}=2 \cdot\left(0,68 \cdot A_{b} \cdot f_{u}\right) \quad k_{7}=1,6 \cdot \frac{A_{s}}{L_{b}}
$$

Flexão na aba da cantoneira de assento

$$
\text { Teoria "T stub" } \quad k_{6}=\frac{0,9 \cdot l_{\text {eff }} \cdot t_{w a}^{3}}{m_{w a}^{3}}
$$

Tração na armadura longitudinal

$$
F_{r, R d}=A_{s, r} \cdot \frac{f_{y, r}}{1,15} \quad k_{10}=\left(\frac{A_{s, r}}{3,6 \cdot h}\right) \cdot K_{\text {slip }}
$$

Compressão transversal na alma do pilar

$$
F_{c, w c, R d}=\omega \cdot k_{w c} \cdot \rho \cdot b_{e f f, c, w c} \cdot t_{w c} \cdot \frac{f_{y, w c}}{1,1}
$$

Compressão na mesa e alma da viga

$$
F_{c, f n, R d}=\frac{M_{c, R d}}{\left(h-t_{f b}\right)}
$$

\section{Compressão na aba da \\ cantoneira de assento \\ Cisalhamento do painel da alma do pilar}

$$
F_{c, B A, R d}=b_{L} \cdot t_{L} \cdot f_{y, B A}
$$

$$
F_{w p, R d}=\frac{0,9 \cdot A_{v c} \cdot f_{y, w c}}{\beta \cdot \sqrt{3}}
$$

No cálculo da rigidez inicial das ligações, as contribuições do cisalhamento dos parafusos e da pressão de contato nas chapas não foram consideradas, uma vez que foi realizado a protensão inicial dos parafusos.

A componente de rigidez de cisalhamento no painel de alma do pilar foi considerada infinita devido ao enrijecimento da alma, proporcionado pela chapa de ligação das vigas secundárias, soldadas junto às mesas do pilar. A simbologia das formulações da Tabela 7.1 estão descritas a seguir. 


\section{Símbolos:}

$l_{\text {eff }}$ é o comprimento efetivo do perfil "T-stub" referente à flexão da mesa do pilar ou aba da cantoneira de alma;

$L_{b}$ é a espessura da chapa de topo mais a espessura da mesa do pilar somada à metade da soma entre a altura da cabeça e a altura da porca;

$\rho$ é fator de redução devido à flambagem da chapa;

$\omega$ é fator de redução devido a possíveis efeitos de interação com cisalhamento da alma;

$\beta$ é o parâmetro que considera o efeito de cisalhamento horizontal no painel de alma do pilar;

$A_{b}$ é a área bruta do fuste do parafuso;

$A_{s}$ é a área efetiva do fuste do parafuso;

$A_{s, r}$ é a área efetiva da armadura;

$b_{e f f, c, w c}$ é a largura efetiva da alma do pilar em compressão;

$b_{e f f, t, w b}$ é o comprimento efetivo do "T-stub" equivalente referente á flexão da chapa de topo;

$b_{e f f, t, w c}$ é o comprimento efetivo do "T-stub" equivalente referente á flexão da mesa do pilar;

$b_{L}$ é o comprimento da aba da cantoneira conectada a viga;

$d_{w c}$ é a largura da mesa do pilar descontando os raios de curvatura da seção;

$A_{v c}$ é a área da alma do pilar sob cisalhamento;

$k_{w c}$ é o parâmetro que considera o efeito da tensão longitudinal na alma do pilar $\left(\sigma_{c o m, E d}\right)$ devido à força axial e o momento fletor no pilar;

$f_{u}$ é a resistência última à tração do aço do parafuso;

$f_{y, B A}$ é a tensão de escoamento da cantoneira de assento;

$f_{y, w c}$ é a tensão de escoamento da alma do pilar;

$f_{y, w c}$ é a tensão de escoamento da alma do pilar;

$f_{y r}$ é a tensão de plastificação do aço da armadura;

$h$ é a altura da viga conectada;

$k_{\text {slip }}$ é parâmetro que considera a deformação da conexão de cisalhamento;

$m$ é a distância do centro do parafuso á face da alma do pilar ou da viga, menos $80 \%$ do raio do perfil

$M_{c, R d}$ é o momento resistente da seção transversal da viga isolada;

$m_{w a}$ é a distância do centro do parafuso, conectado a mesa do pela, a face da aba da cantoneira conectada a alma da viga, menos $80 \%$ do raio da cantoneira;

$t_{f b}$ é a espessura da mesa comprimida da viga;

$t_{f c}$ é a espessura da mesa do pilar;

$t_{L}$ é a espessura da aba da cantoneira conectado a viga;

$t_{w a}$ é a espessura da aba da cantoneira conectada a mesa do pilar;

$t_{w b}$ é a espessura da alma da viga;

$t_{w c}$ é a espessura da alma do pilar;

$Z_{\text {eq }}$ é o braço de alavanca equivalente das linhas tracionadas; 
As tabelas 7.2 e 7.3 apresentam a força resistente potencial $\left(F_{r d}\right)$, a rigidez de cada componente $(k)$, o momento resistente $\left(M_{r d}\right)$ e a rigidez inicial $\left(S_{j, i n i}\right)$ das ligações de pilar de borda e centro, respectivamente.

Tabela 7.2: Caracterização das componentes, resistência e rigidez inicial das ligações de pilar de borda.

\begin{tabular}{|c|c|c|c|c|}
\hline Componente & $\begin{array}{c}F_{r d} \\
(k N)\end{array}$ & $\begin{array}{c}\mathrm{K} \\
(\mathrm{mm})\end{array}$ & $\begin{array}{c}M_{\mathrm{rd}} \\
(\mathrm{kNm})\end{array}$ & $\begin{array}{c}S_{j, \text { ini }} \\
(\mathrm{kNm} / \mathrm{rad})\end{array}$ \\
\hline Flexão na mesa do pilar (modo 2) - Linha 1 & 193,0 & 4,1 & \multirow{10}{*}{65,07} & \multirow{10}{*}{$12.832,44$} \\
\hline Tração na alma do pilar - Linha 1 & 653,6 & 7,5 & & \\
\hline Tração na alma da viga - Linha 1 & 192,4 & $\infty$ & & \\
\hline Tração no parafuso - Linha 1 & 312,3 & 11,0 & & \\
\hline $\begin{array}{l}\text { Flexão na aba da cantoneira de alma (modo } \\
\qquad 1 \text { ) - Linha } 1\end{array}$ & 70,9 & 0,50 & & \\
\hline Tração na armadura longitudinal & 310,3 & 0,81 & & \\
\hline Compressão transversal na alma do pilar & 355,0 & $\infty$ & & \\
\hline Compressão da mesa e alma da viga & 474,6 & $\infty$ & & \\
\hline $\begin{array}{c}\text { Compressão na aba da cantoneira de } \\
\text { assento }\end{array}$ & 213,4 & $\infty$ & & \\
\hline Cisalhamento no painel da alma do pilar & 430,6 & $\infty$ & & \\
\hline
\end{tabular}

Tabela 7.3: Caracterização das componentes, resistência e rigidez inicial das ligações de pilar de centro.

\begin{tabular}{|c|c|c|c|c|}
\hline Componente & $\begin{array}{l}F_{r d} \\
(k N)\end{array}$ & $\begin{array}{c}\mathrm{K} \\
(\mathrm{mm})\end{array}$ & $\begin{array}{c}M_{r d} \\
(k N m)\end{array}$ & $\begin{array}{c}S_{\mathrm{j}, \mathrm{ini}} \\
(\mathrm{kNm} / \mathrm{rad})\end{array}$ \\
\hline Flexão na mesa do pilar (modo 2) - Linha 1 & 193,0 & 4,1 & \multirow{10}{*}{65,07} & \multirow{10}{*}{$15.295,05$} \\
\hline Tração na alma do pilar - Linha 1 & 687,96 & 7,5 & & \\
\hline Tração na alma da viga - Linha 1 & 192,4 & $\infty$ & & \\
\hline Tração no parafuso - Linha 1 & 312,3 & 11,0 & & \\
\hline $\begin{array}{l}\text { Flexão na aba da cantoneira de alma } \\
\qquad \text { (modo 1) - Linha } 1\end{array}$ & 70,9 & 0,50 & & \\
\hline Tração na armadura longitudinal & 310,3 & 6,17 & & \\
\hline Compressão transversal na alma do pilar & 373,6 & $\infty$ & & \\
\hline Compressão da mesa e alma da viga & 474,6 & $\infty$ & & \\
\hline $\begin{array}{c}\text { Compressão na aba da cantoneira de } \\
\text { assento }\end{array}$ & 213,4 & $\infty$ & & \\
\hline Cisalhamento no painel da alma do pilar & 0 & $\infty$ & & \\
\hline
\end{tabular}

Em ambos os casos, pilar de borda e centro, a menor força resistente 
potencial na zona de compressão foi a componente compressão na aba da cantoneira de assento. Por outro lado, na linha de parafusos abaixo da mesa superior da viga (Linha 1), a menor força potencial foi da componente flexão na aba de cantoneira de alma, com o valor bem inferior aos demais componentes, além de apresentar o modo 1 de colapso do perfil "T", que equivale ao escoamento total da cantoneira.

O EUROCODE 3 (2005) não considera o aumento da resistência da componente compressão transversal de alma do pilar quando existe a presença de enrijecedor, ou de qualquer outra forma de enrijecimento de alma do pilar. No caso de pilar de centro, a força resistente potencial da componente cisalhamento do painel de alma do pilar é nula, devido ao equilíbrio das forças de tração e compressão atuantes na ligação.

Com base na consideração de interação parcial entre a viga e a laje (com a consideração de duas linhas neutras), a Linha 1 de parafusos (abaixo da mesa superior da viga) localiza-se na zona de compressão, ou seja, a linha neutra em estado limite último está acima desta linha de parafusos. Este fato deve-se a área de armadura longitudinal na laje de concreto.

Como a força resistente potencial de tração nas armaduras longitudinais foi superior a componente compressão na aba da cantoneira de assento, houve uma redução da força de tração nas armaduras e, portanto, o momento resistente foi calculado para todas as ligações a partir do binário de forças igual a 213,4 kN, conforme ilustra a Figura 7.13.

Para que a $1^{\text {a }}$ linha de parafusos estivesse na zona de tração, com redistribuição plástica dos esforços de tração ao longo das linhas, a área de armadura longitudinal deveria ser reduzida e a resistência da componente compressão na aba da cantoneira de assento aumentada. 


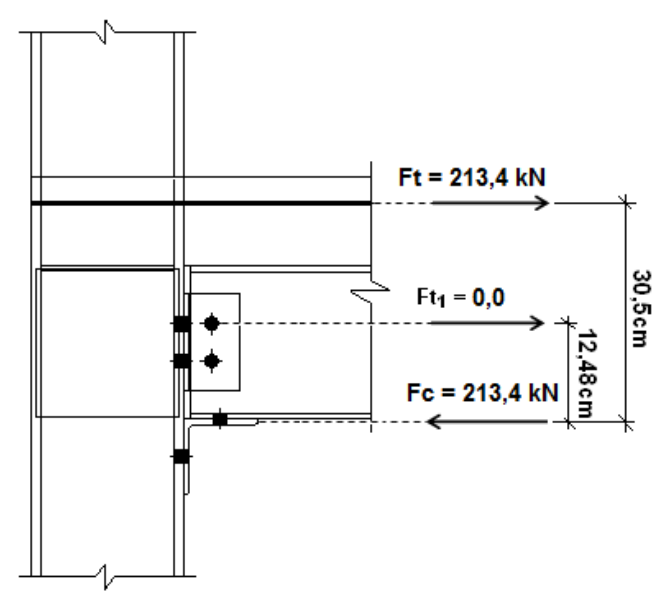

Figura 7.13: Cálculo do momento resistente para os protótipos experimentais.

\section{4 - Discussão dos Resultados de Acordo com as Três}

\section{Análises}

Neste trabalho a análise numérica teve caráter de complementação dos resultados experimentais e analíticos, para o comportamento semi-rígido das ligações viga mista-pilar com cantoneiras de alma e assento.

Para os resultados analíticos foram adotadas curvas momento-rotação bilinear e tri-linear, conforme as especificações do EUROCODE 3 (2005). As Figuras 7.14 e 7.15 apresentam as curvas momento-rotação total de acordo com as três análises, para os modelos numéricos e protótipos isolados de pilar de borda, com taxa de armadura secundária da laje de 0,2\% e 1,0\%, respectivamente.

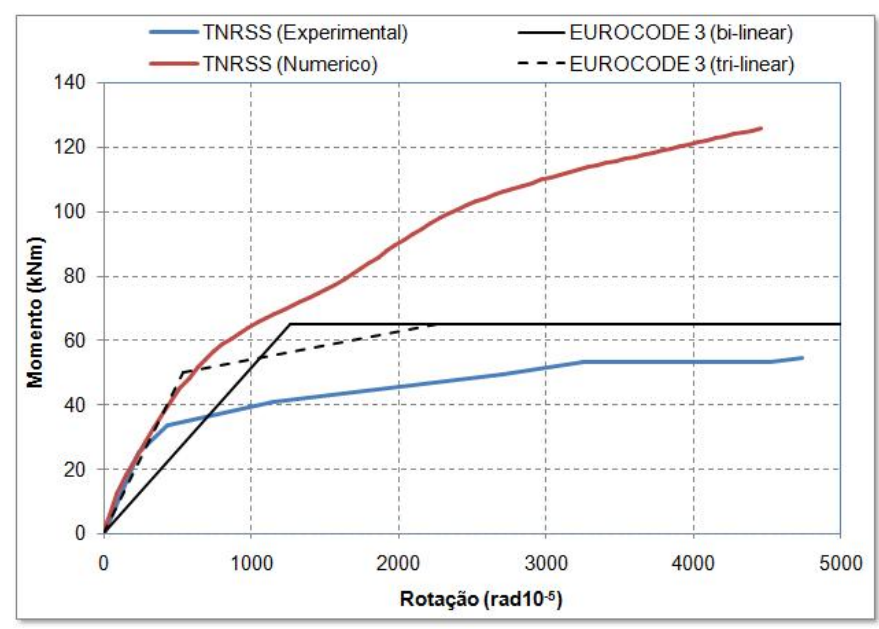

Figura 7.14: Relação momento-rotação total para as ligações de pilar de borda com taxa de armadura secundária da laje de $0,2 \%$. 


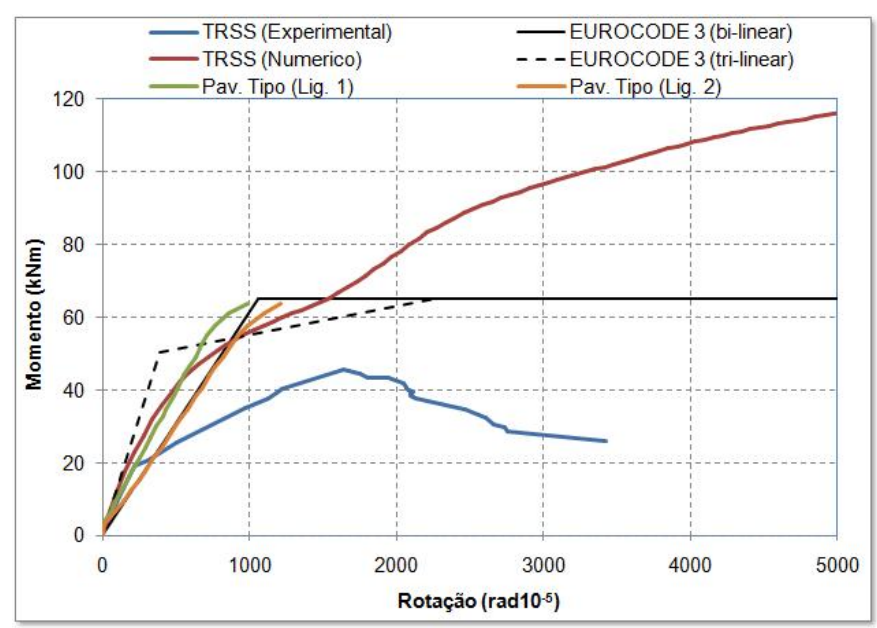

\section{Ligação 1}

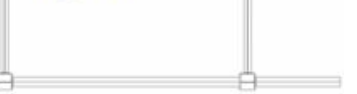

Ligação 2

Figura 7.15: Relação momento-rotação total para as ligações de pilar de borda com taxa de armadura secundária da laje de 1,0\%.

Todas as equações para determinação das curvas analíticas estão indicadas no item 2.1.3 do Capítulo 2. A rigidez inicial dos modelos numéricos e dos protótipos experimentais apresentaram resultados praticamente coincidentes com a curva tri-linear do EUROCODE 3 (2005), exceção feita a Ligação [2] do pavimento tipo, cujo valor da rigidez inicial ficou mais próxima da curva bi-linear.

As Figuras 7.16 e 7.17 ilustram as curvas momento-rotação total, de acordo com as três análises, para as ligações de pilar de centro com taxa de armadura secundária da laje de $0,2 \%$ e 1,0\%, respectivamente.

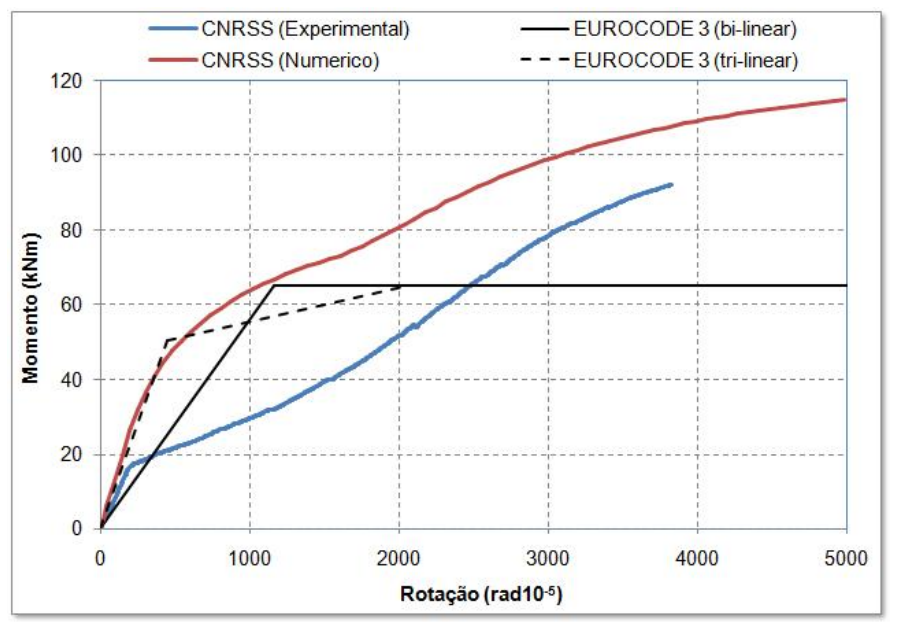

Figura 7.16: Relação momento-rotação total para as ligações de pilar de centro com taxa de armadura secundária da laje de $0,2 \%$. 

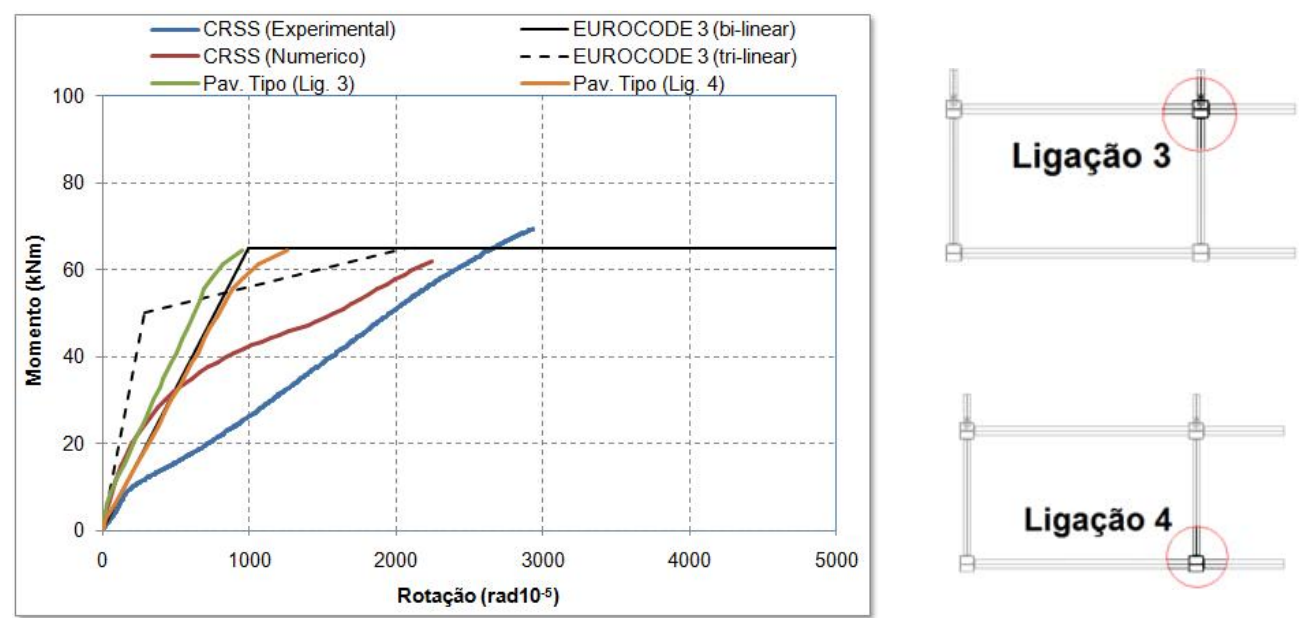

Ligação 4

Figura 7.17: Relação momento-rotação total para as ligações de pilar de centro com taxa de armadura secundária da laje de 1,0\%.

Nas ligações de pilar de centro, o protótipo CRSS e a Ligação [4] do pavimento tipo apresentaram valores da rigidez inicial mais próxima do modelo bi-linear. A Figura 7.17 também deixa claro que a rigidez inicial da ligação do protótipo isolado CRSS ficou abaixo das ligações do pavimento tipo, evidenciando alguma falha quando na montagem ou ancoragem das armaduras longitudinais do protótipo.

Embora o EUROCODE 3 (2005) permita a utilização das curvas bi-linear e tri-linear de forma corrente em projeto, os resultados acima indicam que, no estado limite último, a resposta da ligação pode ser alterada, conforme mostraram os resultados das ligações do pavimento tipo, cuja continuidade da viga na direção do eixo de menor inércia do pilar proporcionou um maior momento transmitido da viga mista para o pilar após o colapso devido à abertura excessiva de fissuras na laje, quando comparado aos protótipos isolados.

A síntese dos parâmetros de rigidez inicial e momento resistente das ligações por meio dos estudos experimentais, numéricos e analíticos são apresentados nas Tabelas 7.4 e 7.5, para as ligações de pilar de borda e de centro, respectivamente, considerando para o momento resistente o valor do momento máximo na ligação ou o momento equivalente a rotação de 2260

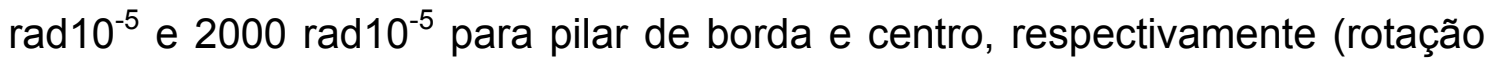
equivalente ao momento resistente do modelo tri-linear do EUROCODE 3 
(2005)).

Tabela 7.4: Momento resistente e rigidez inicial para as ligações de pilar de borda.

\begin{tabular}{ccccccc}
\hline \multirow{2}{*}{ Ligação } & Parâmetro & $\begin{array}{c}\text { Experimental } \\
\mathbf{( 1 )}\end{array}$ & $\begin{array}{c}\text { Numérico } \\
\mathbf{( 2 )}\end{array}$ & $\begin{array}{c}\text { Analítico } \\
\mathbf{( 3 )}\end{array}$ & $\mathbf{( 1 ) / ( 2 )}$ & $\mathbf{( 1 ) / ( 3 )}$ \\
\hline \multirow{2}{*}{ TNRSS } & $M_{r d}(\mathrm{kNm})$ & 46,83 & 94,62 & 65,07 & 0,49 & 0,72 \\
\cline { 2 - 7 } & $S_{j, \text { ini }}(\mathrm{kNm} / \mathrm{rad})$ & $10.397,6$ & $12.143,83$ & $12.832,4$ & 0,86 & 0,81 \\
\hline \multirow{2}{*}{ TRSS } & $M_{r d}(\mathrm{kNm})$ & 45,57 & 80,68 & 65,07 & 0,57 & 0,70 \\
\cline { 2 - 7 } & $S_{j, \text { ini }}(\mathrm{kNm} / \mathrm{rad})$ & $8.723,2$ & $13.686,79$ & $12.832,4$ & 0,64 & 0,68 \\
\hline \multirow{2}{*}{$\begin{array}{c}\text { Pav. Tipo } \\
\text { [1] }\end{array}$} & $M_{r d}(\mathrm{kNm})$ & 63,93 & - & 65,07 & - & 0,98 \\
\hline \multirow{2}{*}{$\begin{array}{c}\text { Pav. Tipo } \\
\text { [2] }\end{array}$} & $S_{j, \text { ini }}(\mathrm{kNm} / \mathrm{rad})$ & $11.921,62$ & - & $12.832,4$ & - & 0,93 \\
\cline { 2 - 7 } & $M_{r d}(\mathrm{kNm})$ & 63,93 & - & 65,07 & - & 0,98 \\
\hline
\end{tabular}

A rigidez inicial das Ligações [1] e [2] do pavimento tipo foram inferiores quando comparado ao valor analítico fornecido pelo EUROCODE 3 (2005). A Ligação [1] apresentou rigidez inicial aproximadamente igual ao modelo isolado TNRSS, mesmo com a fissuração da laje resultante das fases anteriores de carregamento no pavimento tipo. Por fim, a rigidez inicial da Ligação [2] ficou abaixo da rigidez inicial da Ligação [1] em aproximadamente $36 \%$, efeito este causado pela continuidade de apenas uma viga na direção do eixo de menor inércia do pilar.

Tabela 7.5: Momento resistente e rigidez inicial para as ligações de pilar de centro.

\begin{tabular}{ccccccc}
\hline \multirow{2}{*}{ Ligação } & Parâmetro & $\begin{array}{c}\text { Experimental } \\
\mathbf{( 1 )}\end{array}$ & $\begin{array}{c}\text { Numérico } \\
\mathbf{( 2 )}\end{array}$ & $\begin{array}{c}\text { Analítico } \\
\mathbf{( 3 )}\end{array}$ & $\mathbf{( 1 ) / ( 2 )}$ & $\mathbf{( 1 ) / ( 3 )}$ \\
\hline \multirow{2}{*}{ CNRSS } & $M_{r d}(\mathrm{kNm})$ & 51,8 & 80,04 & 65,07 & 0,65 & 0,80 \\
\cline { 2 - 7 } & $S_{j, \text { ini }}(\mathrm{kNm} / \mathrm{rad})$ & $12.835,2$ & $14.792,1$ & $15.295,1$ & 0,87 & 0,84 \\
\hline \multirow{2}{*}{ CRSS } & $M_{r d}(\mathrm{kNm})$ & 50,93 & 59,17 & 65,07 & 0,86 & 0,78 \\
\cline { 2 - 7 } & $S_{j, \text { ini }}(\mathrm{kNm} / \mathrm{rad})$ & $5.456,5$ & $13.237,3$ & $15.295,1$ & 0,41 & 0,37 \\
\hline \multirow{2}{*}{$\begin{array}{c}\text { Pav. Tipo } \\
\text { [3] }\end{array}$} & $M_{r d}(\mathrm{kNm})$ & 64,62 & - & 65,07 & - & 0,99 \\
\hline \multirow{2}{*}{$\begin{array}{c}\text { Pav. Tipo } \\
\text { [4] }\end{array}$} & $S_{j, \text { ini }}(\mathrm{kNm} / \mathrm{rad})$ & $15.500,2$ & - & $15.295,1$ & - & 1,01 \\
\cline { 2 - 7 } & $M_{r d}(\mathrm{kNm})$ & 64,62 & - & 65,07 & - & 0,99 \\
\hline
\end{tabular}


Nas ligações de pilar de centro, a rigidez inicial da Ligação [3] do pavimento tipo foi superior aos respectivos protótipos isolados e praticamente coincidentes quando comparado ao valor analítico fornecido pelo EUROCODE 3 (2005).

A rigidez inicial da Ligação [4] do pavimento tipo também foi aproximadamente de $36 \%$ inferior em relação a Ligação [3], seguindo a mesma diferença obtida na comparação da rigidez inicial das Ligações [1] e [2].

Este resultado aponta na direção de uma relação pouco variável entre a continuidade das vigas (assim como da laje de concreto e armaduras) na direção do eixo de menor inércia do pilar e a rigidez inicial das ligações na direção do eixo de maior inércia, considerando estas inseridas num pavimento tipo.

A Figura 7.18 ilustra a fissuração da laje na Ligação [1] após a etapa de carregamento concentrado do pavimento tipo e a laje do modelo isolado TRSS ao término do ensaio.

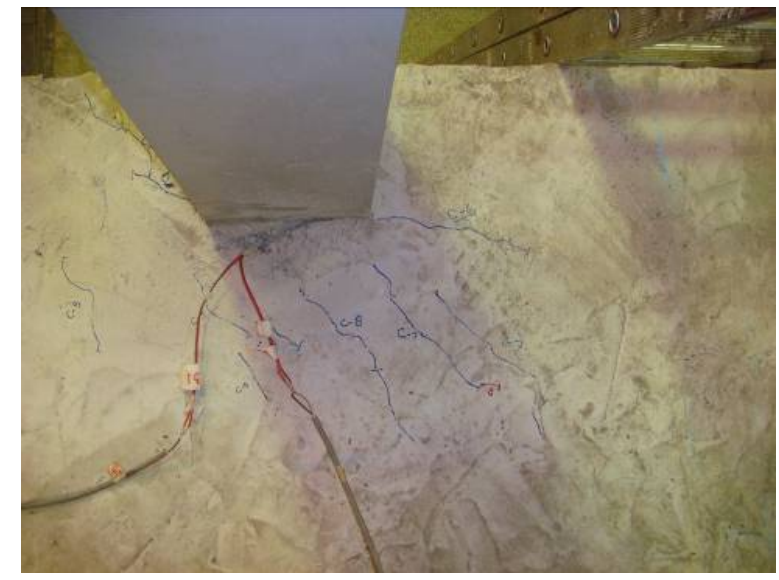

Pav. Tipo - Lig. [1]

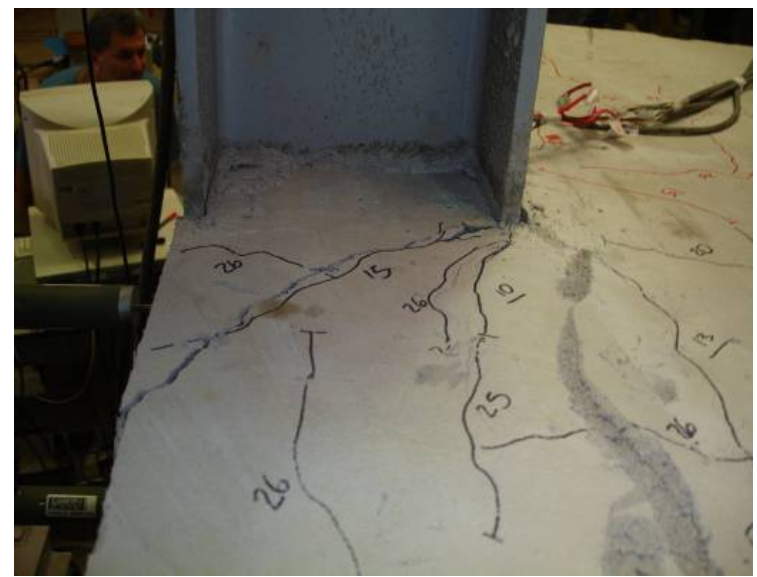

TRSS

Figura 7.18: Fissuração da laje na Ligação [1] do pavimento tipo após a etapa de carregamento concentrado e da laje no modelo isolado TRSS.

De modo geral, a ancoragem das armaduras longitudinais dos protótipos isolados de pilar de borda não funcionou de forma efetiva, prejudicando assim a proposta deste trabalho de analisar a influência da taxa de armadura secundária na rigidez e resistência das ligações mistas, para as ligações vigamista pilar de borda. 
A Tabela 7.6 estabelece uma comparação dos resultados experimentais obtidos para a rigidez inicial e momento resistente das ligações dos protótipos isolados TNRSS e TRSS, além da Ligação [1] do pavimento tipo.

Tabela 7.6: Comparação dos resultados experimentais dos protótipos isolados de pilar de borda e a respectiva ligação do pavimento tipo.

\begin{tabular}{cccccc}
\hline Parâmetro & $\begin{array}{c}\text { Pav. Tipo [1] } \\
\text { (1) }\end{array}$ & $\begin{array}{c}\text { TNRSS } \\
\text { (2) }\end{array}$ & $\begin{array}{c}\text { TRSS } \\
\text { (3) }\end{array}$ & (1)/(2) & (1)/(3) \\
\hline$M_{R d}(\mathrm{kNm})$ & 64,62 & 46,83 & 45,57 & 1,38 & 1,42 \\
\hline$S_{j, \text { ini }}(\mathrm{kNm} / \mathrm{rad})$ & $15.500,2$ & $10.397,6$ & $8.723,2$ & 1,49 & 1,76 \\
\hline
\end{tabular}

Ainda com relação à ancoragem das armaduras longitudinais nos protótipos de pilar de borda, a Figura 7.19 ilustra que o protótipo TRSS apresentou antecipação do colapso devido à abertura excessiva das fissuras na laje de concreto, quando comparado como o protótipo TNRSS, além de menor valor para a rigidez inicial.

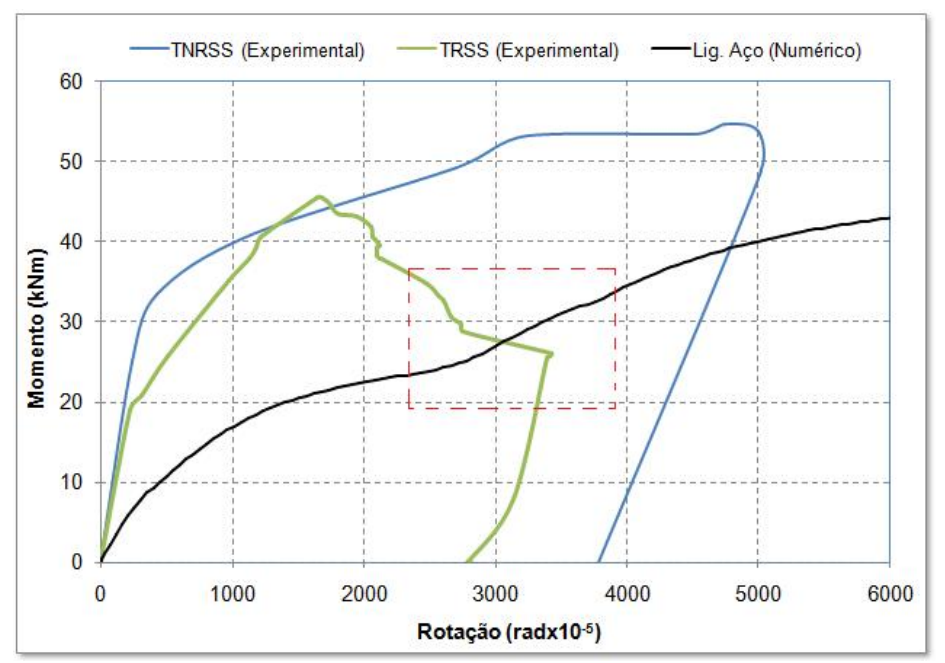

Figura 7.19: Comportamento momento-rotação dos protótipos TNRSS, TRSS e da respectiva ligação metálica.

Após o colapso do protótipo TRSS devido à abertura excessiva de fissuras na laje, a resistência da ligação passa a ser comandada pela ligação em aço (cantoneiras e parafusos). Este fenômeno também pode ser visualizado pela Figura 7.19, através do comportamento momento-rotação total dos modelos experimentais TNRSS e TRSS e da respectiva ligação metálica, 
obtida por meio da modelagem numérica.

O comportamento descrito acima, embora não represente nenhuma utilidade do ponto de vista de projeto, é extremamente importante na consideração numa condição de sismo, onde a ligação passa a ter comportamento dúctil após o colapso da laje de concreto, conforme observado em Tristão (2006).

A Figura 7.20 apresenta a fissuração da laje de concreto na Ligação [3] do pavimento tipo após a etapa de carregamento concentrado e do modelo isolado CRSS. Nesta mesma figura, observa-se que a configuração de formação das fissuras na laje foi a mesma para os dois modelos, com predominância para as fissuras paralelas as mesas do pilar.

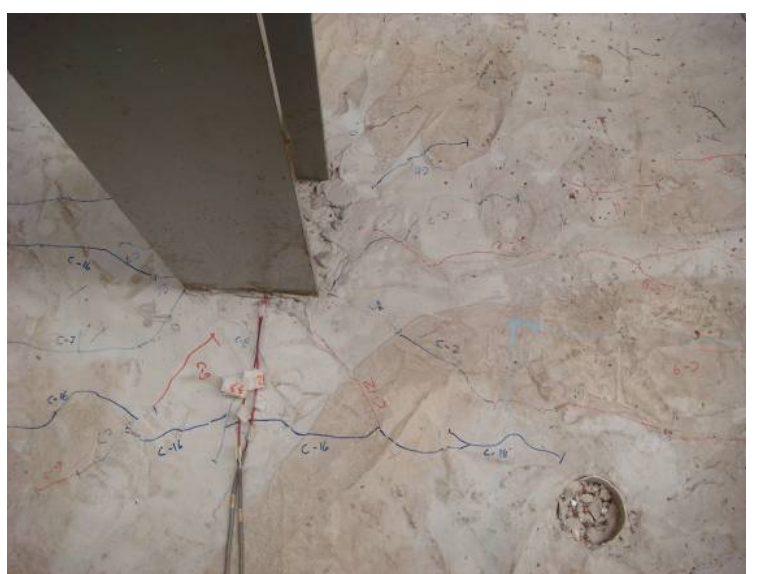

Pav. Tipo - Lig. [3]

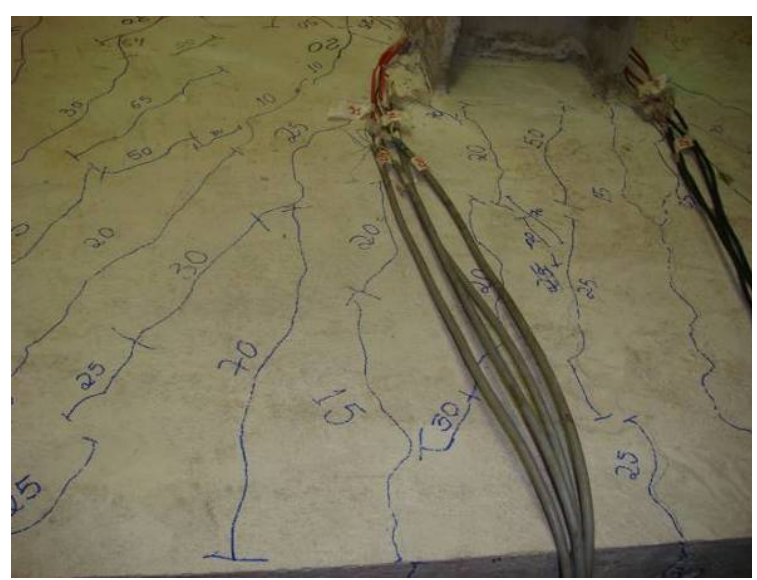

CRSS

Figura 7.20: Fissuração na laje da Ligação [3] do pavimento tipo após a etapa de carregamento concentrado e na laje do protótipo isolado CRSS.

A Tabela 7.7 estabelece a comparação dos resultados experimentais obtidos para a rigidez inicial e momento resistente das ligações dos protótipos isolados CNRSS e CRSS, além da Ligação [3] do pavimento tipo.

Tabela 7.7: Comparação dos resultados experimentais dos protótipos isolados de pilar de centro e a Ligação [3] do pavimento tipo.

\begin{tabular}{cccccc}
\hline Parâmetro & $\begin{array}{c}\text { Pav. Tipo [3] } \\
\text { (1) }\end{array}$ & $\begin{array}{c}\text { CNRSS } \\
\text { (2) }\end{array}$ & $\begin{array}{c}\text { CRSS } \\
\text { (3) }\end{array}$ & (1)/(2) & (1)/(3) \\
\hline$M_{R d}(\mathrm{kNm})$ & 64,62 & 51,8 & 50,93 & 1,25 & 1,27 \\
\hline$S_{j, \text { ini }}(\mathrm{kNm} / \mathrm{rad})$ & $15.500,2$ & $12.835,2$ & $5.456,5$ & 1,21 & 2,84 \\
\hline
\end{tabular}


No que diz respeito à ancoragem das armaduras longitudinais, foi observado o funcionamento de forma efetiva do detalhe proposto para as ligações do pavimento tipo, com resultados satisfatórios no que se refere à rigidez inicial e momento resistente da ligação, comparando-se com protótipos isolados e com os modelos numéricos. Este resultado deve-se principalmente a continuidade da viga na direção do eixo de menor inércia do pilar.

A influência do acréscimo da taxa de armadura secundária, para restringir a fissuração da laje, também foi observada pelos resultados experimentais. A Figura 7.21 ilustra a fissuração da laje dos protótipos isolados CNRSS e CRSS após o término do ensaio.

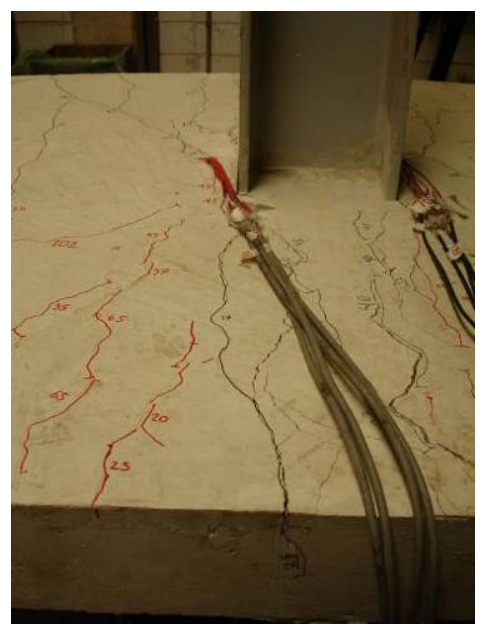

CNRSS

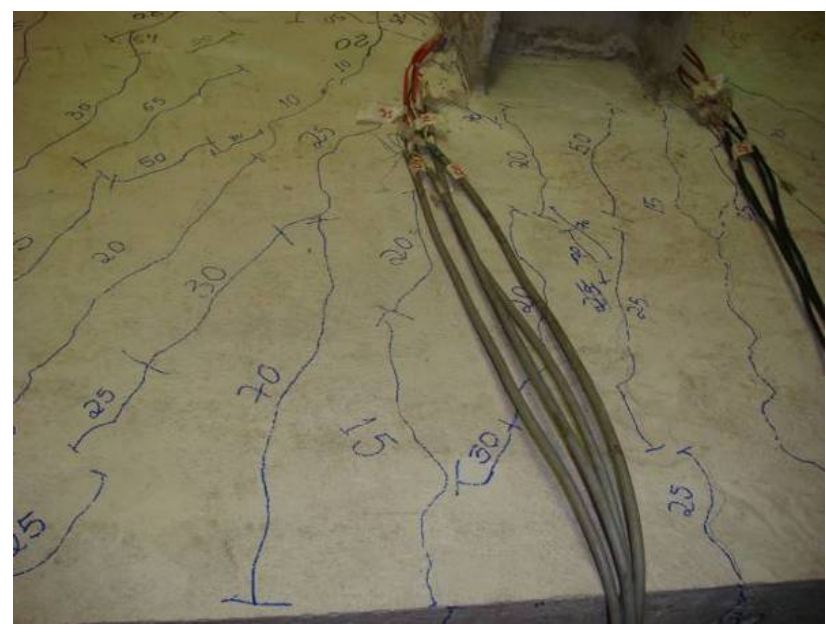

CRSS

Figura 7.21: Fissuração na laje ao final do ensaio dos protótipos CNRSS e CRSS.

De maneira geral, o acréscimo da taxa de armadura secundária da laje mostrou-se eficiente na restrição e abertura de fissuras na laje, embora o mecanismo e disposição das fissuras não tenha se alterado em função da taxa de armadura secundária da laje.

Ainda no que diz respeito à influência da taxa de armadura secundária na laje, é importante ressaltar que a modelagem numérica dos protótipos isolados considerou todas as armaduras secundárias e longitudinais. Embora tal consideração permitisse uma melhor distribuição das tensões de tração na laje, não foi possível observar um ganho considerável no comportamento da ligação, principalmente na rigidez inicial e momento resistente. Este resultado 
deve-se a não consideração da fissuração na representação do modelo constitutivo do material concreto na modelagem numérica.

Por fim, no que diz respeito à classificação das ligações, de acordo com o EUROCODE 3 (2005), todas ligações ensaiadas podem ser consideradas semi-rígidas e de resistência parcial, conforme apresentam as Figuras $7.22 \mathrm{e}$ 7.23, para ligações de pilar de borda e centro, respectivamente, considerando vão da viga de $5 \mathrm{~m}$ (pavimento tipo) e sistema contraventado.
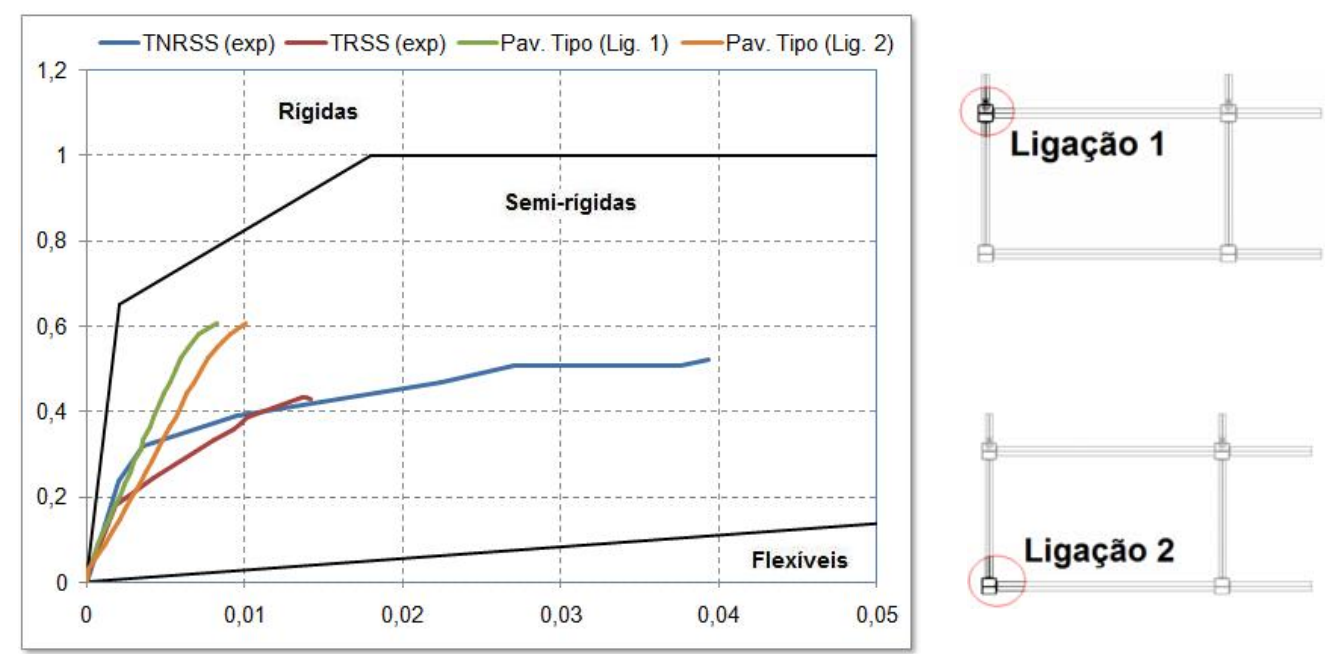

Figura 7.22: Classificação de acordo com o EUROCODE 3 (2005) para as Ligações[1] e [2] do pavimento tipo e protótipos de pilar de borda.
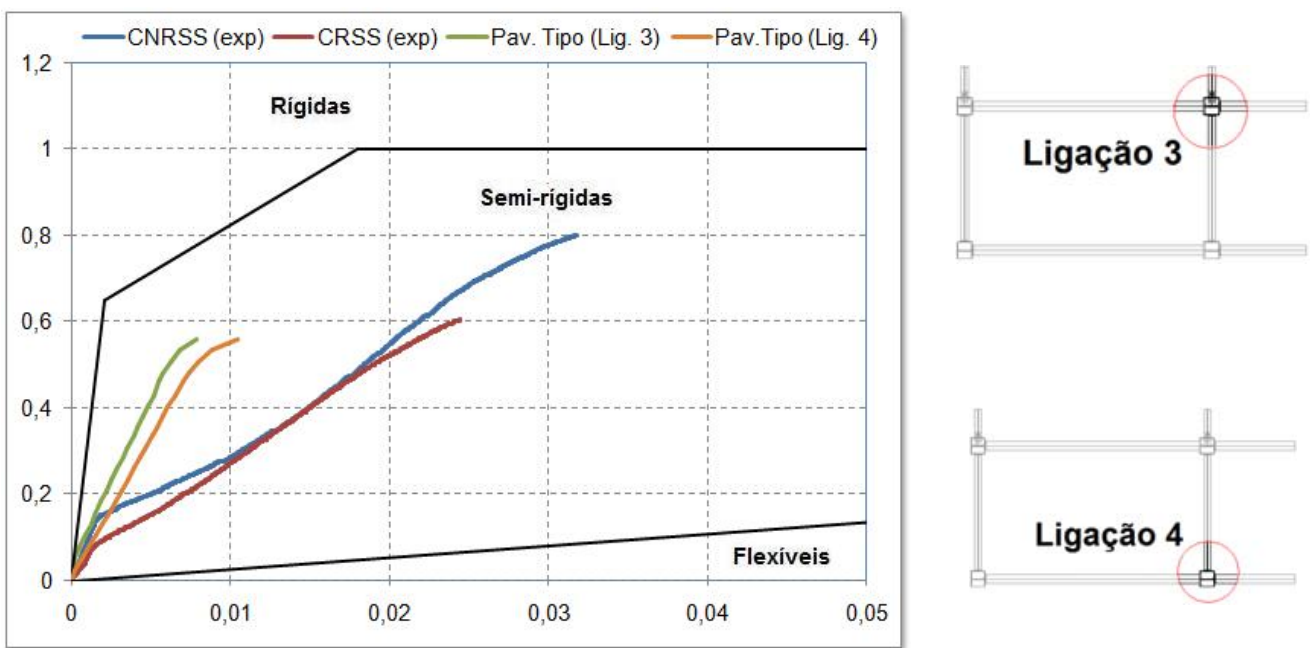

Figura 7.23: Classificação de acordo com o EUROCODE 3 (2005) para as Ligações [3] e [4] do pavimento tipo e protótipos de pilar de centro.

As ligações da modelagem numérica dos protótipos isolados também 
podem ser classificadas como semi-rígida e de resistência parcial, da mesma forma que os modelos experimentais.

\section{5 - Fissuração na Laje do Pavimento Tipo}

Nas ligações do pavimento tipo, o mecanismo de fissuração da laje teve seu início durante a etapa de carregamento distribuído e, durante cada fase da etapa de carregamento concentrado, foi observado à formação de novas fissuras além da ampliação da abertura das fissuras já existentes. A Figura 7.24 ilustra as fissuras em cada ligação do pavimento tipo após as etapas de carregamento distribuído (etapa 1) e concentrado (etapa 2).

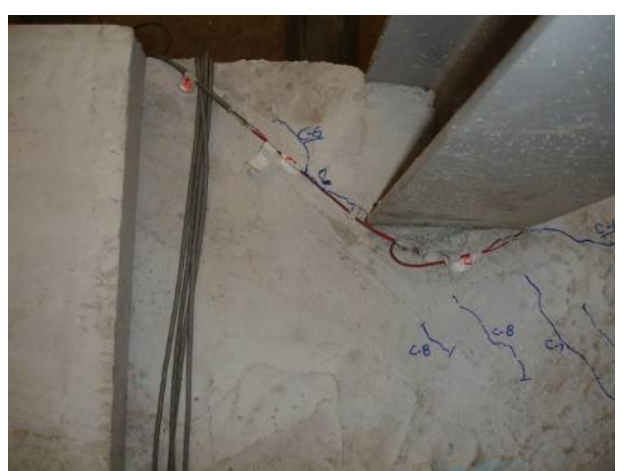

Ligação 1: Distribuído

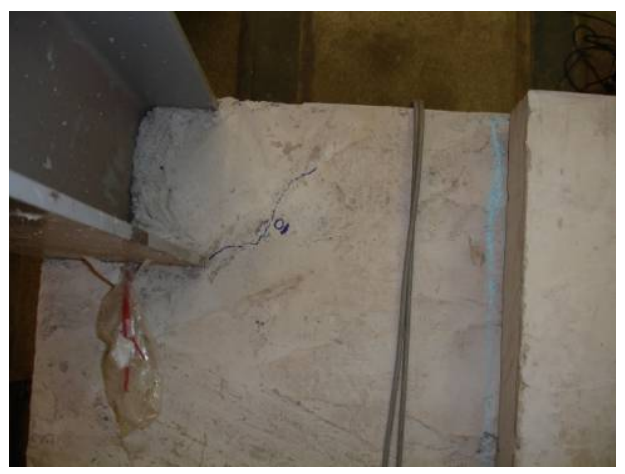

Ligação 2: Distribuído

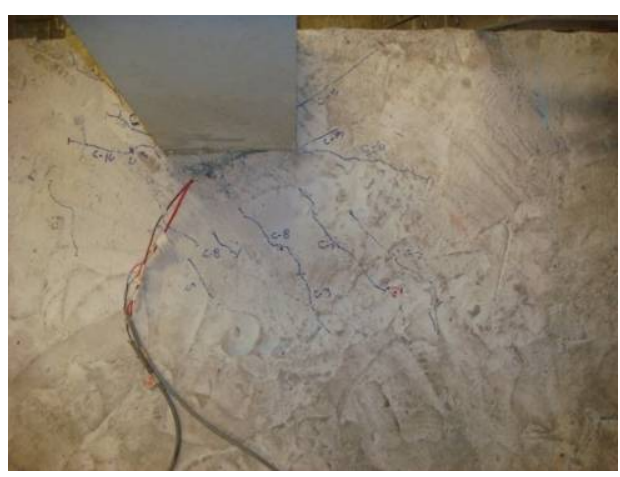

Ligação 1: Concentrado

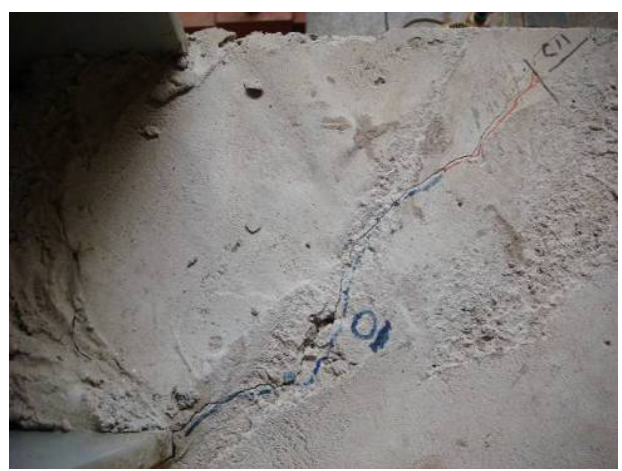

Ligação 2: Concentrado 


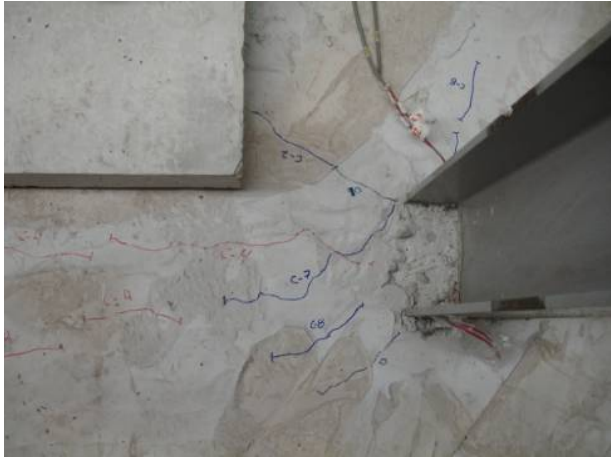

Ligação 3: Distribuído

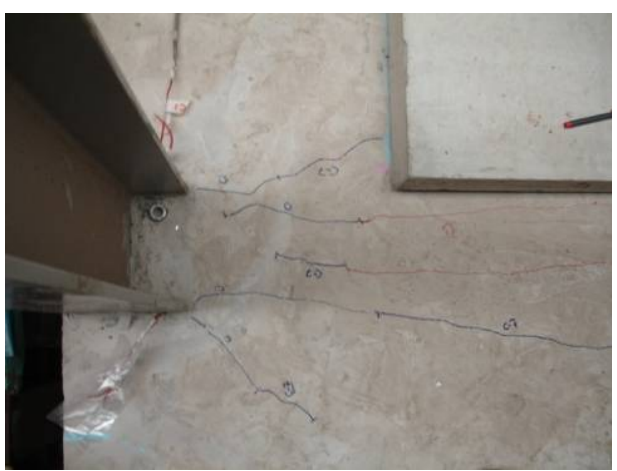

Ligação 4: Distribuído

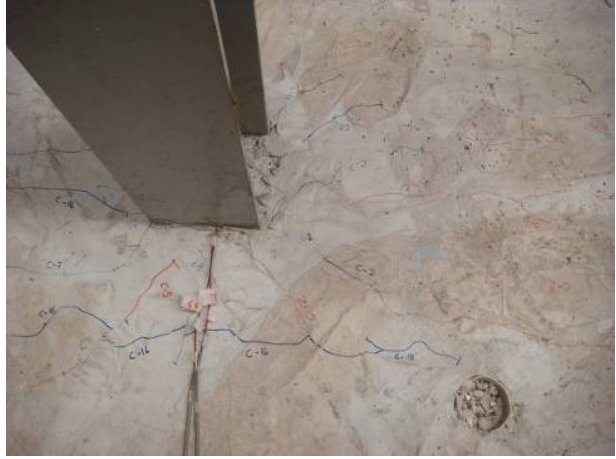

Ligação 3: Concentrado

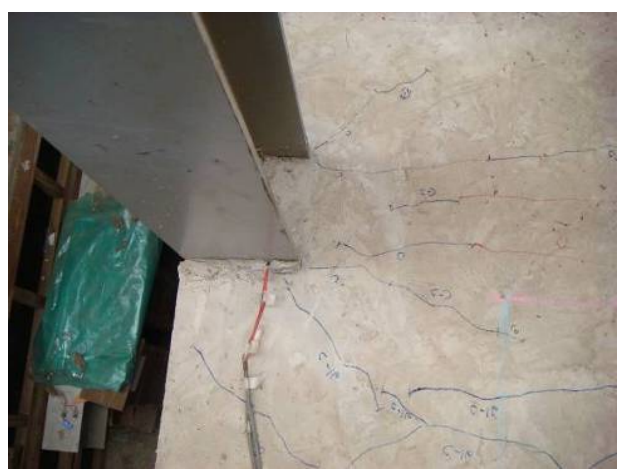

Ligação 4: Concentrado

Figura 7.24: Fissuração da laje nas ligações do pavimento tipo ao término das etapas de carregamento distribuído e concentrado.

$\mathrm{Na}$ ligação de pilar de centro (Ligação [3]), as fissuras na laje resultantes da etapa de carregamento concentrado foram predominantemente fissuras paralelas à mesa do pilar, enquanto que para as ligações de pilar de borda e de canto, as novas fissuras foram predominantemente inclinadas em aproximadamente $45^{\circ}$ a partir da mesa do pilar. O mecanismo de fissuração das ligações do pavimento tipo coincidiu com o observado em Wang\&Li (2006), para pórticos de dois vãos.

A partir da análise comparativa apresentada na Tabela 7.8, observa-se que a condição prévia de fissuração na laje, resultante da etapa de carregamento distribuído, foi mais significativa na determinação da rigidez inicial das Ligações [2] e [4] do pavimento tipo, em relação as Ligações [1] e [3], tomando como referência os resultados obtidos de acordo com a metodologia do EUROCODE 3 (2005). 
Tabela 7.8: Comparação da rigidez inicial das ligações do Pav. Tipo e segundo o Método das Componentes do EUROCODE 3 (2005).

\begin{tabular}{|c|c|c|c|c|}
\hline Ligação & $\begin{array}{c}\text { Pav. Tipo } \\
\text { [1] }\end{array}$ & $\begin{array}{c}\text { Pav. Tipo } \\
\text { [2] }\end{array}$ & $\begin{array}{c}\text { Pav. Tipo } \\
\text { [3] }\end{array}$ & $\begin{array}{c}\text { Pav. Tipo } \\
\text { [4] }\end{array}$ \\
\hline$S_{j, \text { ini }}(k N m / r a d)$ & $11.921,7$ & $8.103,7$ & $15.500,2$ & $9.717,7$ \\
\hline $\begin{array}{c}S_{j, \text { ini }}(\mathrm{kNm} / \mathrm{rad}) \\
\text { EUROCODE } 3 \\
(2005)\end{array}$ & $12.832,4$ & $12.832,4$ & $15.295,1$ & $15.295,1$ \\
\hline$S_{j, \text { ini }} / S_{j, \text { ini }}(E C 3)$ & 0,93 & 0,63 & 1,01 & 0,64 \\
\hline
\end{tabular}

Outro aspecto importante que diz respeito ao comportamento das ligações inseridas no pavimento tipo, está relacionado a perda de rigidez e da resistência da ligação após o colapso devido à abertura excessiva das fissuras na laje, que foi bem menor nas ligações do pavimento tipo, quando comparado aos respectivos protótipos isolados, conforme apresentam as Tabelas $7.9 \mathrm{e}$ 7.10 abaixo para as ligações de pilar de borda e de centro, respectivamente.

Tabela 7.9: Perda da rigidez devido à fissuração da laje nas ligações dos protótipos isolados de pilar borda e a respectivas ligações do Pav. Tipo.

\begin{tabular}{ccccc}
\hline Ligação & Pav. Tipo [1] & Pav. Tipo [2] & TNRSS & TRSS \\
\hline$S_{j, \text { ini }}(\mathrm{kNm} / \mathrm{rad})$ & $11.921,7$ & $8.103,7$ & $10.397,6$ & $8.723,2$ \\
\hline$S_{j}(\mathrm{kNm} / \mathrm{rad})$ & $4.999,0$ & $3.943,1$ & $1.365,2$ & $1.185,5$ \\
\hline $\boldsymbol{S}_{j, \text { ini }} / \boldsymbol{S}_{\mathbf{j}}$ & $\mathbf{2 , 3 8}$ & $\mathbf{2 , 0 6}$ & $\mathbf{7 , 6 2}$ & $\mathbf{7 , 3 6}$ \\
\hline
\end{tabular}

Tabela 7.10: Perda da rigidez devido à fissuração da laje nas ligações dos protótipos isolados de pilar centro e a respectivas ligações do Pav. Tipo.

\begin{tabular}{ccccc}
\hline Ligação & Pav. Tipo [3] & Pav. Tipo [4] & CNRSS & CRSS \\
\hline$S_{j, \text { ini }}(\mathrm{kNm} / \mathrm{rad})$ & $15.500,2$ & $9.717,7$ & $12.835,2$ & $5.456,5$ \\
\hline$S_{j}(\mathrm{kNm} / \mathrm{rad})$ & $4.855,0$ & $3.994,1$ & $1.961,1$ & 880,4 \\
\hline $\boldsymbol{S}_{j, \text { ini }} / \boldsymbol{S}_{\boldsymbol{j}}$ & $\mathbf{3 , 1 9}$ & $\mathbf{2 , 4 3}$ & $\mathbf{6 , 5 4}$ & $\mathbf{6 , 2 0}$ \\
\hline
\end{tabular}

Os resultados acima apontam que a perda de resistência e rigidez após o colapso devido à abertura excessiva das fissuras na laje foi praticamente 
uniforme para todas as ligações do pavimento tipo. Na comparação com as ligações dos protótipos isolados, a perda de rigidez da ligação após o colapso devido à abertura excessiva das fissuras na laje foi em média de duas a quatro vezes maiores que as mesmas ligações inseridas no pavimento tipo.

\section{6 - Comentários Finais}

Os resultados apresentados neste capítulo mostraram que 0 procedimento analítico para as ligações mistas com cantoneira de alma e assento pode apresentar resultados não satisfatórios, quando se utiliza a componente flexão da chapa de topo para caracterizar a componente flexão da aba da cantoneira de alma, com valores excessivamente a favor da segurança, o que pode ocasionar, em determinadas situações, o desenvolvimento de mecanismos de colapso não previstos pelo modelo analítico.

Os resultados obtidos pela modelagem numérica foram satisfatórios, quando comparados com os protótipos experimentais no que diz respeito à previsão da rigidez inicial e o estado limite último da ligação. A modelagem das armaduras longitudinais da viga mista, com a consideração da aderência entre armadura e laje de concreto por meio de elementos de mola permitiu a representação da linha de tração formada por estes elementos.

A metodologia adotada para a modelagem numérica, sem a consideração da simetria segundo o plano médio da alma da viga, possibilitou o desenvolvimento dos mecanismos de colapso da ligação de forma mais representativa e precisa.

No pavimento tipo, a fissuração da laje resultante da etapa de carregamento distribuído não resultou em considerável perda de rigidez inicial das ligações, embora o mecanismo de fissuração observado tenha sido o mesmo quando comparado aos modelos isolados.

Este resultado é atribuído à continuidade da viga na direção do eixo de menor inércia do pilar, que possibilitou uma melhor redistribuição das tensões de tração nas armaduras da laje, mesmo com o estado de fissuração resultante de carregamentos anteriores.

A fissuração da laje nos modelos isolados de pilar de borda e centro, 
mesmo em estágios iniciais dentro do estado limite de serviço, ocasiona em significativa perda da rigidez inicial da ligação.

O acréscimo da taxa de armadura secundária na laje, principalmente na região de contorno do pilar, mostrou-se eficiente na redução da fissuração, principalmente quando observado a abertura de fissuras nos ensaios dos protótipos isolados CNRSS e CRSS.

Finalmente, no Capítulo 8 a seguir são apresentadas as conclusões finais do trabalho e sugestões para a continuidade da linha de pesquisa. 


\section{8 \\ CONCLUSÕES FINAIS}

A proposta inicial deste trabalho teve como principal objetivo a análise do comportamento das ligações viga mista-pilar com cantoneiras de alma e assento, em estado limite último e de serviço, considerando as ligações inseridas em um pavimento tipo e em protótipos isolados.

No pavimento tipo, várias situações de carregamento foram avaliadas com o objetivo de estudar o comportamento das ligações mistas, em particular, a deterioração da rigidez em função da fissuração da laje.

A comparação com a metodologia de dimensionamento proposta pelo EUROCODE 3 (2005) e EUROCODE 4 (2004) tiveram como base a rigidez inicial e o momento resistente da ligação, em função de cada um dos componentes da ligação.

Especificamente ao Método das Componentes proposto pelo EUROCODE 3 (2005), a componente flexão da aba da cantoneira de alma foi observado como a componente crítica dentre todas no que se refere a linha de parafusos da ligação. Os pilares utilizados nos ensaios experimentais, por suas características geométricas e devido ao enrijecimento entre as suas mesas, não representou um elemento crítico para essas ligações.

A metodologia adotada neste trabalho utilizou também, além do programa experimental, a modelagem numérica como ferramenta para a análise e comparação dos resultados.

Conforme comentado ao longo deste trabalho, os modelos numéricos possibilitam análises mais detalhadas com relação a diversos dados que não podem ou são de difícil medição experimental.

Dessa forma, o desenvolvimento dos modelos numéricos teve parte 
importante como um dos objetivos deste trabalho, uma vez que possibilitou contribuir no aprimoramento de uma metodologia de modelagem numérica, iniciado em Maggi (2000), com a introdução da laje de concreto na modelagem das ligações mistas, com cada uma das armaduras longitudinais trabalhando de forma independente, além da consideração do modelo sem a simetria ao longo do plano médio da alma da viga.

Ademais, a metodologia de modelagem numérica para ligações viga mista-pilar, com cantoneiras de alma e assento, pode ser estendida para outras tipologias de ligações parafusadas, como por exemplo, ligações com chapa de topo estendida, não-estendida, ligações com perfis $\mathrm{T}$, além de ligações soldadas.

Entretanto, cabe ressaltar que dentro das limitações da modelagem, os resultados numéricos devem ser utilizados com critério, uma vez que geralmente reproduzem modelos idealizados de ligações reais, ou seja, sem considerar imperfeições geométricas. Além disso, utilizam relações uniaxiais tensão-deformação para simular os materiais, notadamente uma simplificação, embora determinadas simplificações possam ser utilizadas uma vez determinados os objetivos da modelagem.

Diante de todos estes aspectos, com relação à modelagem numérica podem-se fazer as seguintes conclusões:

- A modelagem numérica com a introdução da laje de concreto e armaduras, além da não consideração da simetria ao longo do plano médio da alma da viga, mostrou-se uma ferramenta precisa para o estudo de comportamentos que são tridimensionais, uma vez que o tempo computacional de processamento já não é um fator limitante na grande maioria dos casos;

- A consideração da aderência das armaduras longitudinais na laje de concreto, por meio de elementos de mola na modelagem numérica, possibilitou a análise das tensões e deformações em cada armadura separadamente, com o conjunto de armaduras formando uma linha de tração na ligação; 
- A ancoragem das armaduras nos modelos numéricos possibilitou a redistribuição dos esforços de tração na linha de parafusos, o deslocamento da linha neutra da viga no sentido da mesa superior, nas seções da viga próximas da ligação, e o desenvolvimento da plastificação nos componentes da ligação no estado limite último;

- A adoção da modelagem numérica sem a consideração da simetria ao longo do plano médio da alma da viga mostrou-se adequada, uma vez que permitiu a redistribuição dos esforços em toda largura da laje, além de precisão nos resultados, sem um acréscimo significativo no esforço computacional de processamento dos modelos;

Com base na aplicação da modelagem no Capítulo 6 e na comparação dos resultados apresentados no Capítulo 7, conclui-se que os modelos numéricos são capazes de representar, satisfatoriamente, os mecanismos de transferência de esforços entre viga, pilar e laje de concreto, os mecanismos de colapso de cada componente e os estados limites últimos.

Os resultados numéricos foram utilizados, juntamente com os resultados experimentais, para a discussão do comportamento das ligações viga mistapilar com cantoneiras de alma e assento. A comparação desses resultados foi realizada com o objetivo de avaliar o desempenho de cada uma das componentes, a rigidez e a capacidade resistente de cada ligação, além de traçar uma analogia para avaliar a metodologia proposta pelo EUROCODE 3 (2005) e EUROCODE 4 (2004) para ligações mistas com cantoneira de alma e assento.

Dessa forma, com base nos resultados numéricos e experimentais conclui-se que:

- A rigidez inicial e momento resistente dos modelos numéricos apresentaram resultados satisfatórios quando comparados com os protótipos experimentais e os resultados analíticos do EUROCODE 3 (2005);

- A representação do material concreto na modelagem da laje da 
ligação mista, com a consideração de dois modelos constitutivos diferentes (um para o trecho comprimido da laje o outro para a parte tracionada), a partir da posição teórica da linha neutra e sem a consideração da fissuração do concreto, quando tracionado, não possibilitou uma análise mais apurada deste elemento e sua interação com a ligação, em estado limite de serviço;

- Por outro lado, a simplificação acima descrita na representação do comportamento da laje de concreto, possibilitou o desenvolvimento pós-elástico da ligação, com resultados bastante satisfatórios no que diz respeito ao estado limite último, quando comparados com os respectivos protótipos isolados e principalmente com as respectivas ligações do pavimento tipo;

Por sua vez, o programa experimental que teve como principais objetivos investigar o comportamento das ligações mistas em estado limite último e de serviço, avaliar a deterioração da rigidez da ligação em função da fissuração da laje, verificar a eficiência da ancoragem das barras da armadura longitudinal da viga mista e o acréscimo na taxa de armadura transversal, considerando protótipos isolados e pertencentes a um pavimento tipo.

As principais conclusões decorrentes da comparação do programa experimental, com os resultados analíticos e numéricos são descritos a seguir:

- No pavimento tipo, a fissuração da laje na etapa de carregamento distribuído não resultou numa considerável perda da rigidez inicial das ligações, embora o mecanismo de fissuração observado tenha sido o mesmo quando comparado aos modelos isolados. Este resultado é atribuído à continuidade da viga na direção do eixo de menor inércia do pilar, que possibilitou uma melhor redistribuição das tensões de tração nas armaduras da laje, mesmo com a condição de fissuração anterior.

- A componente flexão da aba da cantoneira de alma, de acordo com o procedimento analítico do Método das Componentes do EUROCODE 
3 (2005), apresentou resistência potencial bem abaixo dos demais componentes da linha de parafusos da ligação viga mista-pilar com cantoneiras de alma e assento;

- A resistência potencial à compressão foi atingida no modelo experimental isolado CRSS, além dos resultados da análise numérica, com o alargamento dos furos (concentração de tensões) na aba da cantoneira de assento e na mesa inferior da viga (análise numérica), além do cisalhamento do parafuso da mesa inferior com a cantoneira de apoio (protótipo CRSS);

- A consideração da componente flexão da chapa de topo para o cálculo da resistência potencial da componente flexão da aba da cantoneira de alma pode, em alguns casos, levar a obtenção de resultados excessivamente conservadores para esta componente, 0 que de acordo com o Método das Componentes que pode ocultar uma redistribuição plástica das forças para outras componentes da ligação, sem que tal efeito seja devidamente previsto em projeto. Dessa forma, a componente flexão da aba da cantoneira de alma deve ser caracterizada analiticamente de forma precisa, para a obtenção de sua correta resistência potencial de acordo com a metodologia do Método das Componentes;

- No que diz respeito aos protótipos experimentais, atenção especial deve ser dada para garantir a ancoragem das armaduras longitudinais, quando não se tem a continuidade das armaduras, especialmente na análise de protótipos isolados que não possuem a continuidade geométrica das vigas na direção do eixo de menor inércia do pilar;

- O acréscimo da taxa de armadura secundária da viga mista (de 0,2\% para 1\%) mostrou-se eficiente na restrição da abertura de fissuras da laje na região próxima da ligação, principalmente nos protótipos experimentais em que a ancoragem das armaduras longitudinais funcionou de maneira efetiva (protótipos isolados de pilar de centro e 
as ligações do pavimento tipo);

- A curva momento-rotação tri-linear, indicada no EUROCODE 3 (2005) para o comportamento das ligações, apresentou resultados mais próximos para a rigidez inicial das ligações viga mista-pilar do pavimento tipo.

A comparação dos resultados experimentais, numéricos e analíticos mostrou que, apesar de os protótipos experimentais terem sido concebidos geometricamente para ter como mecanismo de colapso a componente compressão na aba da cantoneira de assento, de acordo com o Método das Componentes, na maioria dos modelos o modo de colapso observado foi devido à abertura excessiva de fissuras na laje, exceção feita ao protótipo CRSS no qual ocorreu o cisalhamento do parafuso entre a mesa inferior da viga e a cantoneira de assento.

Além disso, a análise numérica identificou mecanismos de plastificação diferentes nas cantoneiras de alma da viga das ligações mistas, em relação ao mecanismo de plastificação das cantoneiras de alma, considerando a mesma ligação metálica.

Diante das conclusões comentadas acima, destacam-se novamente que:

I. A fissuração da laje mostrou-se menos relevante que a continuidade das vigas na direção do eixo de menor inércia do pilar, no que se refere à determinação da rigidez inicial das ligações mista inseridas num pavimento tipo;

II. A perda de rigidez e da resistência após o colapso devido à abertura excessiva das fissuras na laje de concreto foi bem menos significativa nas ligações do pavimento tipo, quando comparado aos respectivos protótipos isolados, devido a esta característica de continuidade das vigas na direção do eixo de menor inércia do pilar, possibilitando uma melhor redistribuição dos esforços de tração nas armaduras e laje;

III. Especial atenção deve ser dada na concepção de modelos isolados de ligações viga mista-pilar de modo a garantir a efetiva ancoragem das armaduras longitudinais, uma vez que neste caso não haverá a 
parcela de contribuição das vigas secundárias (direção do eixo de menor inércia do pilar) e elementos a estes associados.

IV. A componente flexão da aba da cantoneira de alma necessita de caracterização do seu comportamento, de acordo com a metodologia do Método das Componentes, uma vez que esta componente possui geometria e comportamento distintos da componente flexão da chapa de topo. Para tal, a utilização da modelagem numérica constitui numa ferramenta poderosa, uma vez que permite identificar com grande precisão os mecanismos de plastificação e colapso, para posterior desenvolvimento da caracterização da resistência potencial da componente;

V. A metodologia de modelagem numérica adotada e desenvolvida neste trabalho foi capaz de representar de forma satisfatória os mecanismos plásticos e os estados limites últimos da ligação.

Diante das conclusões apresentadas acima, destaca-se a necessidade de quantificar os mecanismos de plastificação da componente flexão da aba da cantoneira de alma, uma vez que este elemento desenvolve mecanismos próprios e, com base nestes, podem ser determinados resistência potencial da componente.

A análise dessas configurações pode ser realizada com a utilização de modelos numéricos, uma vez que apresentam correlações satisfatórias com o comportamento das ligações e, representam uma ferramenta eficiente para o desenvolvimento de análises paramétricas mais abrangentes, que certamente conduziriam ao desenvolvimento e aprimoramento dos modelos analíticos existentes.

Considerando as limitações da análise proposta neste trabalho e a necessidade de um maior aprofundamento, os seguintes tópicos são sugeridos a fim de dar continuidade a esta linha de pesquisa:

- Ampliação das observações experimentais no que diz respeito aos efeitos da fissuração da laje na rigidez inicial das ligações, através de ensaios com outras geometrias tais como chapa de topo, cantoneiras 
de alma ou cantoneiras de apoio e ligações soldadas;

- O desenvolvimento de um modelo constitutivo eficiente, no que se refere à convergência numérica e qualidade dos resultados, que represente o material concreto com sua capacidade de resistência a compressão e tração num único modelo constitutivo, com a imprescindível característica de fissuração do material, extremamente necessária para a análise das ligações em estado limite de serviço e último;

- A realização de análises paramétricas para a observação dos mecanismos de plastificação das cantoneiras de alma, quando submetidas à flexão, com a inclusão da variação de geometria deste elemento, bem como dos perfis do pilar, viga e diâmetro dos parafusos, além de outros detalhes de ancoragem e disposição das armaduras longitudinais e transversais;

- A determinação, com base na análise paramétrica acima descrita, de modelos analíticos complexos ou simplificados que representem diretamente a capacidade resistente das cantoneiras de alma da viga;

- A incorporação deste modelo na determinação da rigidez das ligações, seguindo a filosofia do Método das Componentes.

Finalmente ressalta-se que, dentre as metodologias existentes para 0 dimensionamento das ligações, o Método das Componentes pode ser considerado um dos mais racionais e conceitualmente modernos. Por outro lado, ao dividir a ligação em componentes, surgem comportamentos complexos que não podem ser tratados isoladamente, o que leva a adoção de simplificações durante o processo.

Dessa forma, justificam-se pesquisas cujo objetivo seja a análise mais detalhada de cada componente e a influência destes no comportamento das ligações. Uma vez bem caracterizada este comportamento e suas variações, torna-se possível a representação cada vez mais realística das ligações na análise estrutural e na concepção de projetos. 


\section{REFERÊNCIAS BIBLIOGRÁFICAS}

AHMED, B. and NETHERCOT, D. A. (1995). Numerical modeling of composite flush end-plate connections. Journal of Singapore Structural Steel Society, 6 (1), p. 87-102.

AHMED, B. and NETHERCOT, D. A. (1996). Effect of High Shear on the Moment Capacity of Composite Cruciform Endplate Connections. Journal of Constructional Steel Research, v. 40, p. 129-163.

AHMED, B. and NETHERCOT, D. A. (1997). Design of composite finplate and angle cleated connections. Journal of Constructional Steel Research, v. 41, n. 1, p. $1-29$.

AHMED, B. and NETHERCOT, D. A. (1997). Prediction of initial stiffness and available rotation capacity of major axis composite endplate connections. Journal of Constructional Steel Research, v. 41, n. 1, p. 31-60.

AHMED, B. and NETHERCOT, D. A. (1998). Effect of column axial: load and composite connection behaviour. Engineering Structures, v. 20, n. 1-2, p. 113-128.

AHMED, B.; LI, T.Q. and NETHERCOT, D. A. (1995). Modeling composite connection response. Connections in steel structures III: Proceedings of the Third International Workshop, Trento. p. 259-268.

ALMEIDA FILHO, F. M. (2006). Contribuição ao estudo da aderência entre barras de aço e concretos auto-adensáveis. Tese de Doutorado, Escola de Engenharia de São Carlos, USP, 291p.

ALTMMAN, R.; MAQUOI, R. and JASPART, J-P. (1991). Experimental study of non-linear behaviour of beam-to-column composite joints. Journal of Constructional Steel Research, v. 18, p. 45-54.

ALVES, V. C. G. (2000). Ligações Mistas Aço Concreto, Viga-Pilar e Viga-Viga, com Resistência Parcial. Belo Horizonte. Tese (Mestrado). Universidade Federal de Minas Gerais.

AMERICAN INSTITUTE OF STEEL CONSTRUCTION (1999). Load and Resistence Factor Design Specification for Structural Steel Buildings, Chicago, USA. 
AMERICAN INSTITUTE OF STEEL CONSTRUCTION (2005). Load and Resistence Factor Design Specification for Structural Steel Buildings, Chicago, USA ("Draft" da versão de 1999).

AMMERMAN, D.J. and LEON, R. (1987). Behaviour of semi-rigid composite connections. Engeneering Journal/AISC, p. 53-61.

ARIBERT \& LANCHAL (1992). Experimental investigation of composite in global interpretation. Proceedings of COST C1 Conference on semi-rigid joints, Strasburg, France, p. 158-169.

ARIBERT, J-M. (1995). Influence of slip of shear connection on composite joint behaviour. Connections in steel Structures III: Proceedings of the Third International Workshop, Trento, p. 11-22.

BENUSSI, F.; BERNUZZI, C.; NOĖ, S. and ZANDONINI, R. (1996). Experimental analysis of semi-rigid composite frames. In: Proceedings of the IABSE Colloquium: Semi-rigid structural connections, Istambul, p. 105-114.

BENUSSI, F., NETHERCOT, D.A., ZANDONINI, R. (1995). Experimental behaviour of semi-rigid connections in frames. Connections in steel structures III: Proceedings of the Third International Workshop, Trento, p. 57-66.

BESSA, W. (2004). Análise Numérica Tridimensional de Ligações Viga-Coluna com Chapa de Topo na Direção do Eixo de Menor Inércia do Pilar. Dissertação de Mestrado, Universidade Federal de Ouro Preto, UFOP, $163 p$.

BESSA, W; RIBEIRO, L. F. L; NEVES, L. F. C; GOMES, F. C. T. (2005). A 3D Numerical Analysis of Minor-Axis Steel Beam-to-Column End Plate Connections. Eurosteel Conference on Steel and Composite Structures, Maastricht, Netherlands.

BESSA, W; GONÇALVES, R. M; RIBEIRO, L. F. L. (2006). Estudo Numérico de Ligações Parafusadas com Chapa de Topo em Aço. III Congresso Internacional da Construção Metálica (III CICOM), Ouro Preto, Brazil.

BESSA, W; GONÇALVES, R. M; MUNAIAR NETO, J; RIBEIRO, L. F. L. (2008) Metodologia para Modelagem Numérica de Ligações Viga Mista-Pilar com a Laje Maciça de Concreto. XXXIII Jornadas Sudamericanas de Ingenieria Estructural. Santiago, 26-30 Mayo. 
BESSA, W.; GONÇALVES, R. M.; CALADO, L. and CASTIGLIONI, C. A. (2008). Advanced Numerical Modelling of Composite Steel Concrete Joints. 5th EUROSTEEL - European Conference on Steel and Composite Structures. Graz, 03-05 September.

BOUAZAOUI, L.; PERRENOT, G.; DELMAS, Y.; LI, A. (2007). Experimental Study of Bolted Steel Concrete Composite Structures. Journal of Constructional Steel Research, v. 63, p. 1268-78.

BROWN, N. D. and ANDERSON, D. (2001). Structural Properties of Composite Major Axis End Plate Connections. Journal of Constructional Steel Research, v. 57, p. 327-349.

CALADO, L.; CASTIGLIONI, C. A. (1996). Steel Beam-to-Column Connections Under Low-Cycle Fatigue Experimental and Numerical Research. Proceedings of XI World Conference on Earthquake Engineering, Acapulco, Mexico.

CALADO, L.; MELE, L. (2000). Experimental Behaviour of Steel Beam-toColumn Joints: Fully Welded vs Bolted Connections. In Proceedings of the 12th World Conference on Earthquake Engineering, Auckland, New Zeland, Paper n 2570/6/A.

CALADO, L.; CASTIGLIONI, C. A; CARYDIS, P. (2000). Shaking Table Tests for Seismic Performance Evaluation of Steel Frames. In Proceedings of the 12th European Conference on Earthquake Engineering, London, UK, Paper $\mathrm{n} 685$.

CALADO, L.; BRITO, A. (2002). Stress-Strain Relationship for Steel Under Uniaxial Cyclic Loadings. Advances in Structural Engineering, n. 5, p. 143-151.

CALADO, L. (2003). Non-Linear Cyclic Model of Top and Seat with Web Angle for Steel Beam-to-Column Connections. Engineering Structures, n 25, p. 1189-1197, March.

CASTRO C.M. (2002). O Concreto de alto desempenho: estudo da aderência com a armadura sob ações repetidas. Dissertação (Mestrado), Escola de Engenharia de São Carlos USP, 194p.

COST C1 (1996). Composite steel-concrete joints braced frames for buildings. Brussels, Luxemburg. 
DAVID, D. L. (2007). Análise Teórica e Experimental de Conectores de Cisalhamento e Vigas Mistas Constituídas por Perfis de Aço Formados a Frio e Laje de Vigotas Pré-Moldadas. Tese de Doutorado, Escola de Engenharia de São Carlos, USP, 256p.

DE NARDIN, S. (1999). Estudo teórico-experimental de pilares mistos compostos de aço preenchidos com concreto de alta resistência. Dissertação de Mestrado, Escola de Engenharia de São Carlos, USP, $163 p$.

EUROCODE 2 (2003). prEN 1992-1-1. Design of concrete structures: Part 1-1: General rules and rules for buildings.

EUROCODE 3 (2005). Design of steel joints, Part 1.1: General Rules and Rules for Building. European Committee for Standardization, Brussels, Belgium.

EUROCODE 3 (2005). Design of steel joints, Part 1.8: Design of Joints. European Committee for Standardization, Brussels, Belgium.

EUROCODE 4 (2004). prEN 1994-1-1 Design of Composite Steel and Concrete Structures - Part1-1: General Rules and Rules for Buildings. European Commitee for Standartization, Bruxelas (final Draft).

FAELLA, C.; PILUSO, V. and RIZZANO G. (2000). Structural Steel Semi-Rigid Connections: Theory, Design and Software. Boca Raton FL: CRC Press LLC.

FIGUEIREDO, L. M. B. (2004). Ligações mistas aço concreto - Análise teórica e experimental. Tese de Doutorado, Escola de Engenharia de São Carlos, USP, 215p.

FIGUEIREDO, L. M. B.; TRISTÃO, G. A.; GONÇALVES, R. M.; MAGGI, Y. I. (2004). Modelo Analítico para Cálculo do Momento Resistente de Ligações Viga-Pilar com Chapa de Topo Estendida. In: Jornadas SudAmericanas de Ingeniería Estructural, Mendoza.

GOMES, F. (2002). The EC3 classification of joints and alternative proposals. Eurosteel 2002, p. 987-996.

HENSMAN, J. S; NETHERCOT, D. A. (2001). Numerical study of unbraced composite frames: generation of data to validate use of the wind moment method of design. Journal of Constructional Steel Research, n 57, p. 791-809. 
JEONG, Y.J. (2007). Simplified Model to Predict Partial-Interactive Structural Performance of Steel-Concrete Composite Slabs. Journal of Constructional Steel Research, (in press).

KATTNER, M. and CRISINEL, M. (2000). Finite Element Modelling of SemiRigid Composite Joints. Computers \& Structures, v. 78, p. 341-353.

KIM, Y. and CHEN, W. F. (1998). Practical analysis for partially restrained frame design. Journal of Structural Engineering. v. 124, n. 7, p. 736-748.

KISHI, N. and CHEN, W. F. (1990). Moment-rotation relation of semi-rigid connections with angles. Journal of Structural Engineering. v. 116, n. 7, p. 1813-1834.

KOTINDA, T. I. (2006). Modelagem numérica de vigas mistas aço-concreto simplesmente apoiada: ênfase ao estudo da interface laje-viga. Dissertação de Mestrado, Escola de Engenharia de São Carlos, USP, $116 p$.

LEON, R. (1990). Semi-rigid of composite construction. Journal of Constructional Steel Research, v. 39, n. 3, p. 167-191.

LI, T. Q; CHOO, B. S and NETHERCOT, D. A. (1995). Connection Element Method for the Analysis of Semi-Rigid Frames. Journal of Constructional Steel Research, v.32, p. 143-171.

LI, T. Q; MOORE, D. B; NETHERCOT, D. A. and CHOO, B. S. (1996a). The Experimental Behaviour of a Full-Scale Semi-Rigidly Connected Composite Frame: Detailed Appraisal. Journal of Constructional Steel Research, v.39, p. 193-220.

LI, T. Q; MOORE, D. B; NETHERCOT, D. A. and CHOO, B. S. (1996b). The Experimental Behaviour of a Full-Scale, Semi-Rigidly Connected Composite Frame: Overall Considerations. Journal of Constructional Steel Research, v.39, p. 167-191.

MAGGI, Y. I. (2000). Análise Numérica, via MEF do Comportamento de Ligações Parafusadas Viga-Coluna com Chapa de Topo. Dissertação de Mestrado, Escola de Engenharia de São Carlos, USP, 255p.

MAGGI, Y. I. (2004). Análise do Comportamento Estrutural de Ligações Parafusadas Viga-Pilar com Chapa de Topo Estendida. Tese de Doutorado, Escola de Engenharia de São Carlos, USP, 264p. 
MAGGI, Y.I., GONÇALVES, R. M., LEON, R. T., RIBEIRO, L. F. L. (2005). Parametric Analysis of Steel Bolted End Plate Connections Using Finite Element Modelling. Journal of Constructional Steel Research, Vol. 61, p. 689-708.

NEVES, L. F. C. (1996). Nós Semi-Rígidos em Estruturas Metálicas: Avaliação da Rigidez em Configurações de Eixo Fraco. Dissertação de Mestrado, Universidade de Coimbra, Coimbra, Portugal.

NEVES, L. F. C. (2004). Comportamento monotônico e cíclico de ligações de eixo fraco e tubulares em estruturas metálicas e mistas aço-betão. Tese de Doutorado, 558p, Universidade de Coimbra, Coimbra, Portugal.

NETHERCOT, D. A.; LI, T. Q. and CHOO, B. S (1995). Required Rotations and Moment Redistribution for Composite Frames and Continuous Beams. Journal of Constructional Research, v. 35, p. 121-163.

NETHERCOT, D. A.; LI, T. Q. and AHMED, B. (1998). Unified Classification System for Beam-to-Column Connections. Journal of Constructional Steel Research, v.45, n.1, p. 39-65.

NETHERCOT, D. A. (2000). Frame Structures: Global Performance, Static and Stability Behaviour. General Report. Journal of Constructional Steel Research, v. 55, p. 109-124.

NBR 8800. (2006). Projeto e Execução de Estruturas de Aço e de Estruturas Mistas Aço-Concreto em Edifícios. Projeto de revisão da NBR 8800, Draft.

PRELORENTZOU P. A. (1992). Um Estudo sobre Ligações Viga-Coluna em Estruturas de Aço. Dissertação de Mestrado, Escola de Engenharia de São Carlos, USP, 221p.

QUEIROZ, F.D.; VELLASCO, P.C.G.S.; NETHERCOT, D.A. (2007). Finite Element of Composite Beams with Full and Partial Shear Connection. Journal of Constructional Steel Research, v. 63, p. 505-21.

QUEIROZ, G. \& ALVES V.C.G. (1999). Utilização de Ligações Mistas em Estruturas de Edifícios. II Seminário Internacional "O Uso de Estruturas Metálicas na Construção Civil”, 9-12 de Novembro.

QUEIROZ, G.; PIMENTA, R. J.; MATA, L. A. (2001). Elementos das Estruturas Mistas Aço-Concreto. Belo Horizonte, Editora o Lutador. 336p. 
RIBEIRO, L. F. L. (1998). Estudo do Comportamento Estrutural de Ligações Parafusadas Viga-Coluna com Chapa de Topo: Análise TeóricoExperimental. Tese de Doutorado, Escola de Engenharia de São Carlos, USP, 560p.

ROMANO, V. P. (2001). Dimensionamento de ligações viga-coluna com chapa de topo: modelo do EUROCODE 3. Dissertação de Mestrado, Universidade Federal de Ouro Preto, UFOP.

SHERBOURNE, A. N. and BAHAARI, M. R. (1994). 3D Simulation of End Plate Bolted Connections. Journal of Structural Engineering, v.120, n. 11, p.3122-3136.

SHERBOURNE A. N. and BAHAARI, M. R. (1996a). 3D Simulation of Bolted Connections Unstiffened Columns-I T-stub Connections. Journal of Constructional Steel Research, v. 40, n. 3, p. 169-187.

SHERBOURNE, A. N. and BAHAARI, M. R. (1996b). 3D Simulation of Bolted Connections Unstiffened Columns-II Extended End Plate Connections. Journal of Constructional Steel Research, v. 40, n. 3, pp. 189-223.

SHERBOURNE, A. N. and BAHAARI, M. R. (1997a). Finite Element Prediction of End Plate Bolted Connection Behavior. 1: Parametric study. Journal of Structural Engineering, v.123, n. 2, p.157-164.

SHERBOURNE, A. N. and BAHAARI, M. R. (1997b). Finite Element Prediction of End Plate Bolted Connection Behavior. 2: Analytic Formulation. Journal of Structural Engineering, v.123, n. 2, p.165-175.

TRISTÃO, G. A.; CALADO, L.; GONÇALVES, R. M. (2005). Comparação entre Procedimento Europeu e Americano tendo por base a Análise Experimental e a Modelação Numérica: Aplicação ao caso de Ligações Viga-Pilar com Cantoneiras. V Congresso de Construção Metálica e Mista. Lisboa, Portugal, 24-25 Novembro.

TRISTÃO, G. A.; GONÇALVES, R. M.; MUNAIAR NETO, J.; MAGGI, Y. I. (2005). Bean-to-Column Connections Numerical Modelling. Eurosteel Conference on Steel and Composite Structures. Netherlands, 08-10 June. 
TRISTÃO, G. A. (2006). Análise Teórica e Experimental de Ligações Mista Viga-Pilar de Extremidade com Cantoneiras de Alma e Assento. Tese de Doutorado, Escola de Engenharia de São Carlos, USP, 282p.

VASDRAVELLIS, G.; VALENTE, M. and CASTIGLIONI, C. A. (2008). Behavior of exterior partial-strength composite beam-to-column connections: Experimental study and numerical simulations. Journal of Constructional Steel Research. In Press, corrected proof, January.

XIAO, Y.; CHOO, B. S. and NETHERCOT, D. A. (1994). Composite Connections in Steel and Concrete I. Experimental Behavior of Composite Beam-Column connections. Journal of Constructional Steel Research, v. 31, n. 1, p. 3-30.

XIAO, Y.; CHOO, B. S. and NETHERCOT, D. A. (1996). Composite Connections in Steel and Concrete. Part II. Moment Capacity of End Plate Beam to Column Connections. Journal of Constructional Steel Research, v. 37, n. 1, p. 63-90.

WANG, J. F. and LI, G. Q. (2006). Testing of Semi-Rigid Steel-Concrete Composite Frames Subjected to Vertical Loads. Engineering Structures. In press, corrected proof, November. 


\section{APÊndice}

\section{DETALHAMENTO DOS PROTÓTIPOS EXPERIMENTAIS}

Neste apêndice são apresentados os detalhamentos de armaduras positivas e negativas, posição das vigotas, lajotas e canaletas para os protótipos isolados e o pavimento tipo.

\section{A.1 - Protótipo Isolado CNRSS}

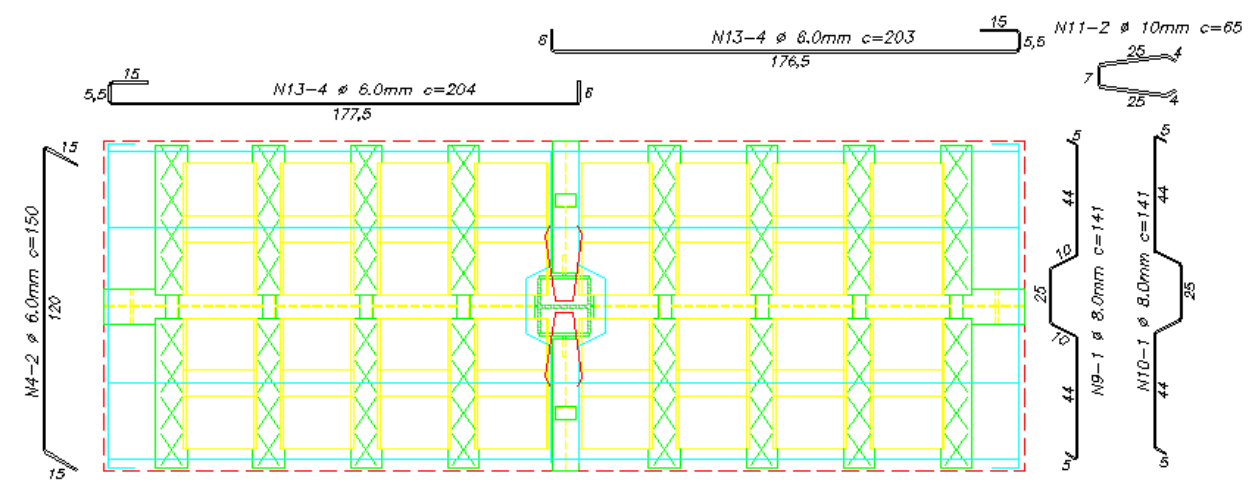

Figura A.1: Armadura positiva do protótipo CNRSS.

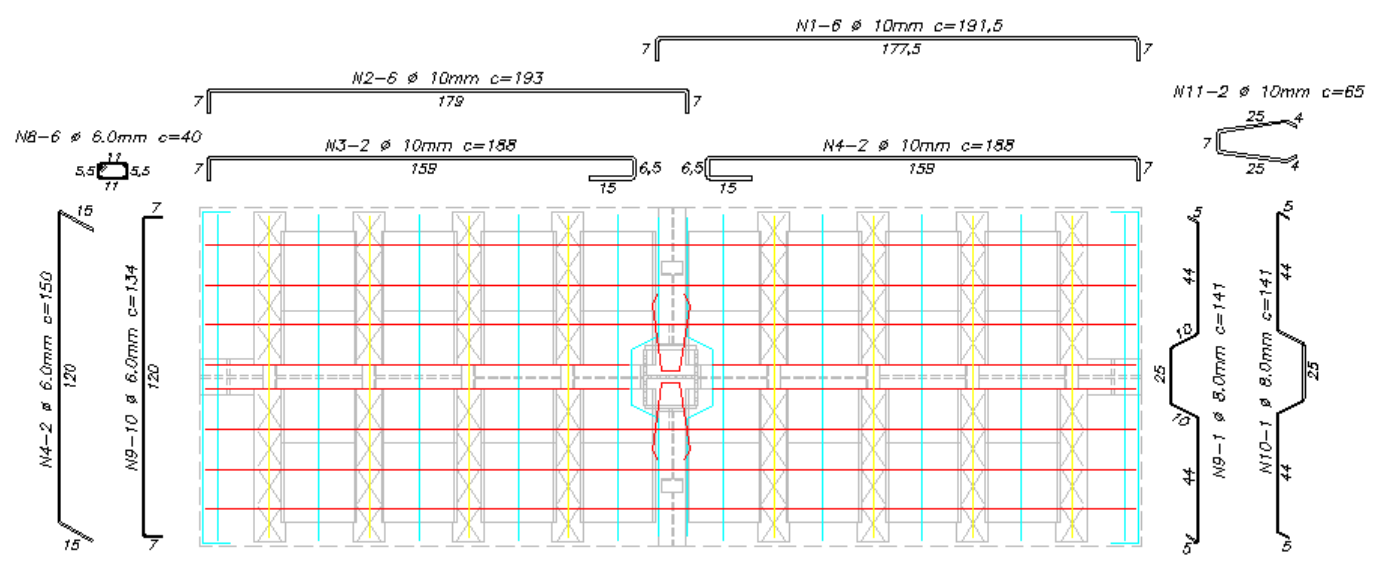

Figura A.2: Armadura negativa do protótipo CNRSS. 

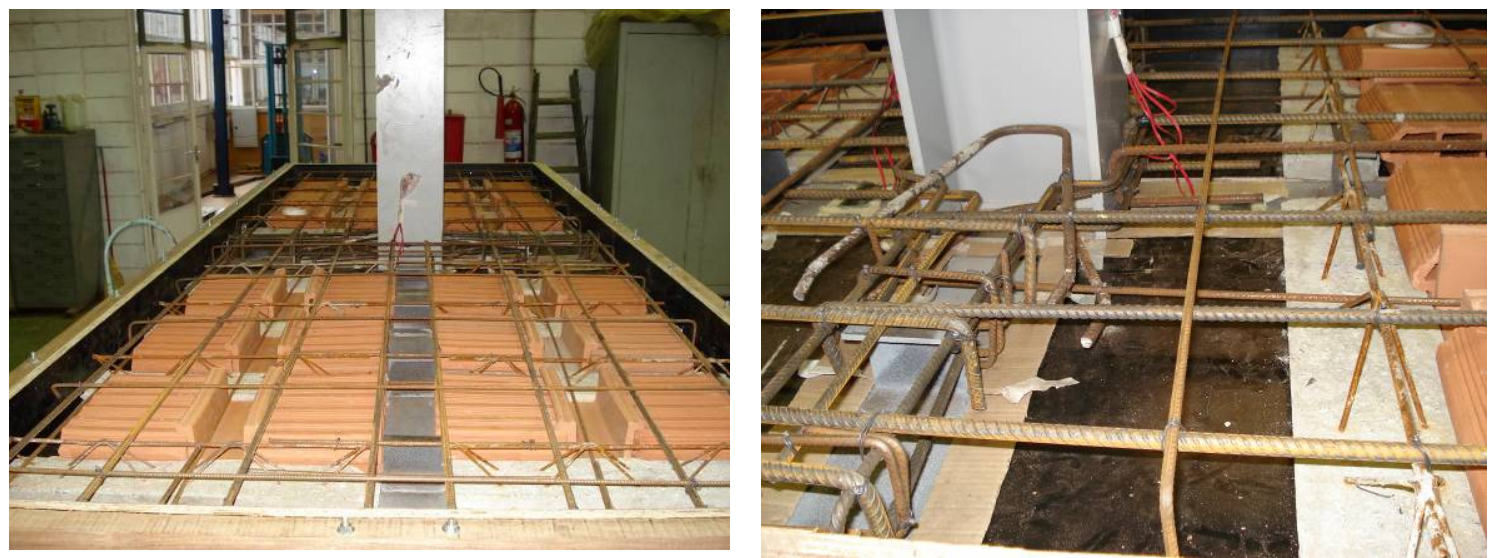

Figura A.3: Montagem da laje do protótipo CNRSS antes da concretagem.

\section{A.2 - Protótipo Isolado CRSS}

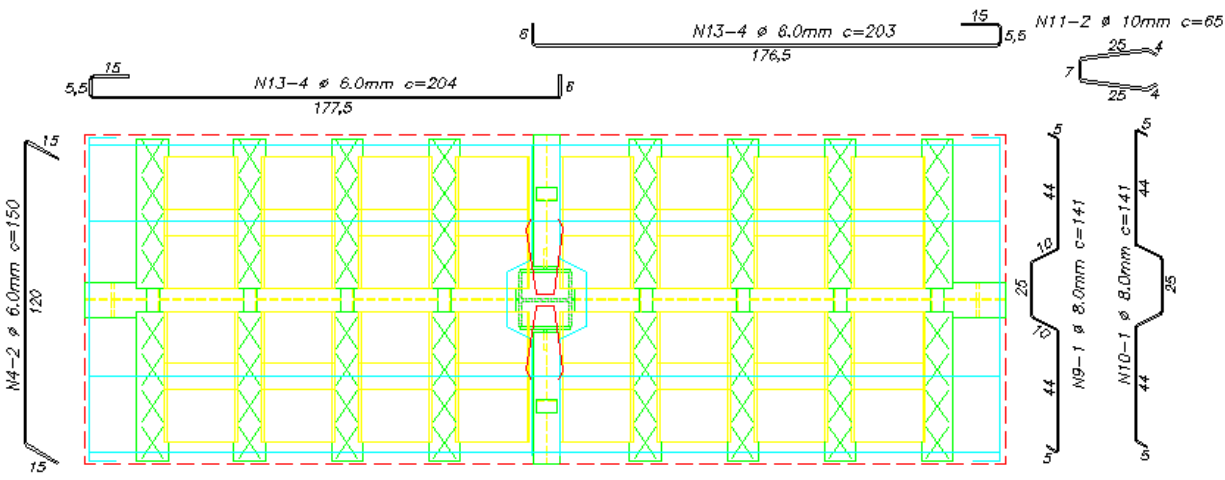

Figura A.4: Armadura positiva do protótipo CRSS.

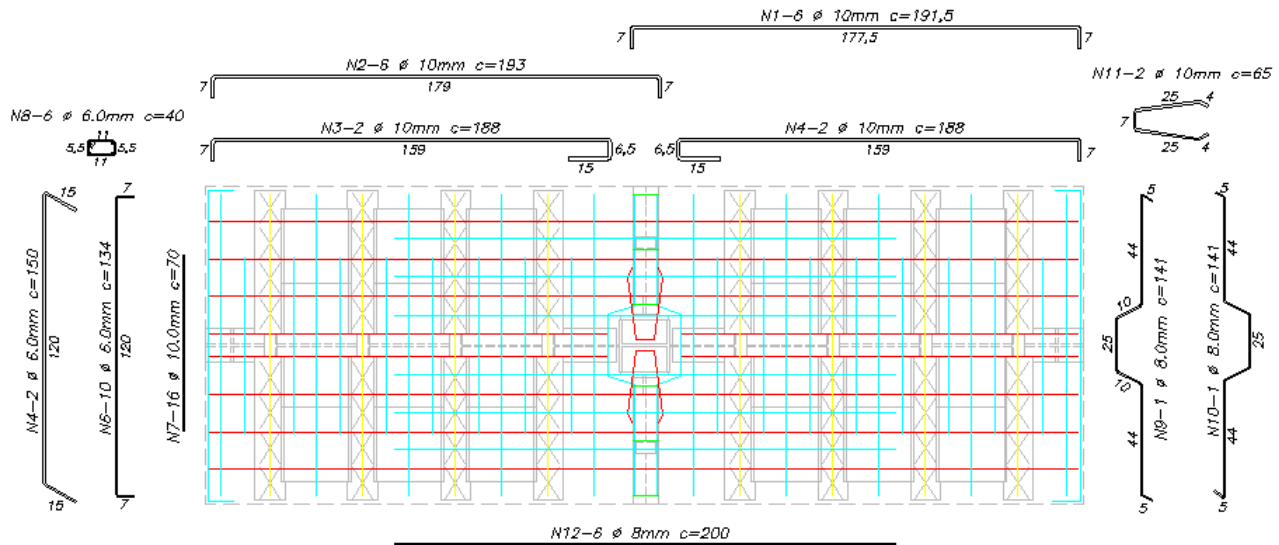

Figura A.5: Armadura negativa do protótipo CNRSS. 

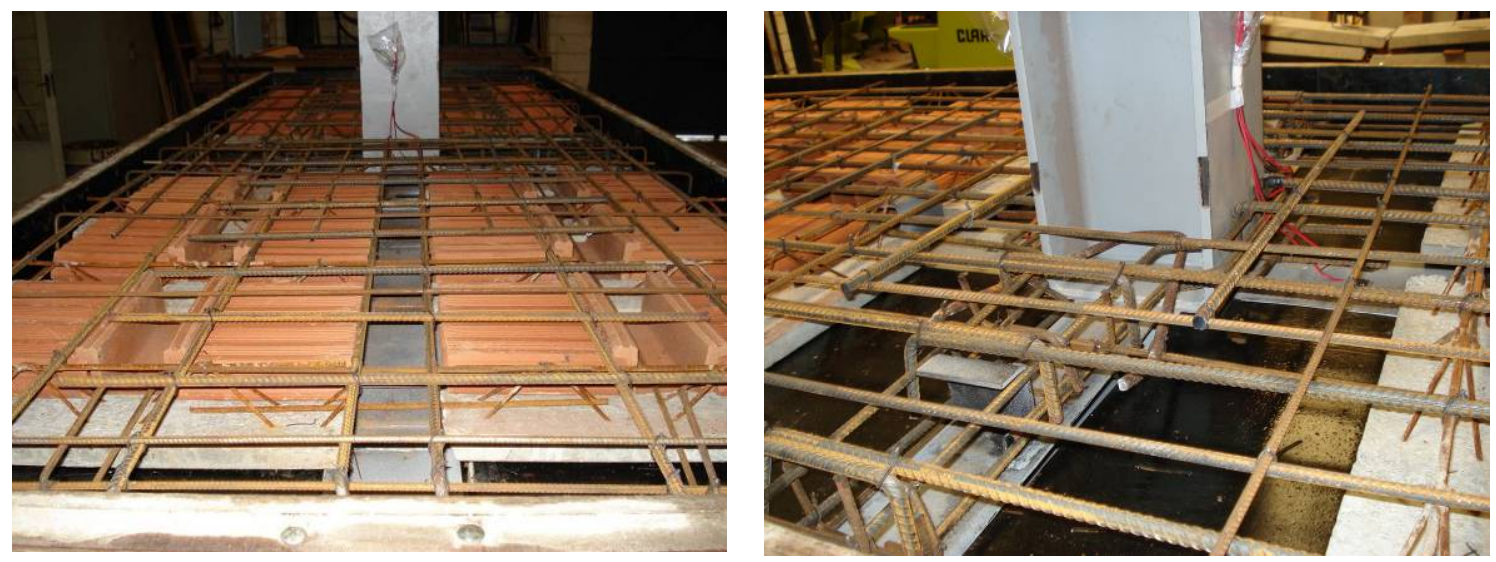

Figura A.6: Montagem da laje do protótipo CRSS antes da concretagem.

\section{A.3 - Protótipo Isolado TNRSS}

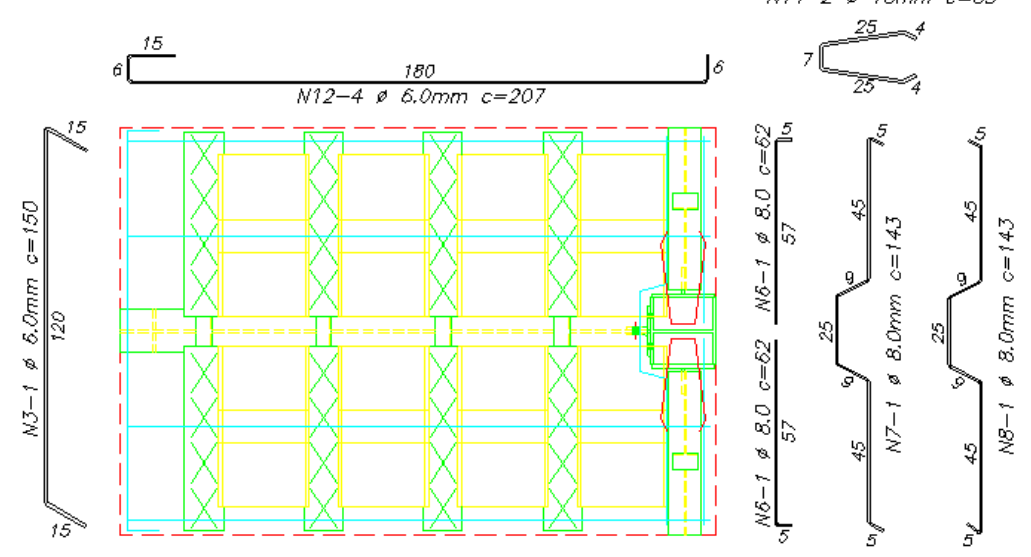

Figura A.7: Armadura positiva do protótipo TNRSS.

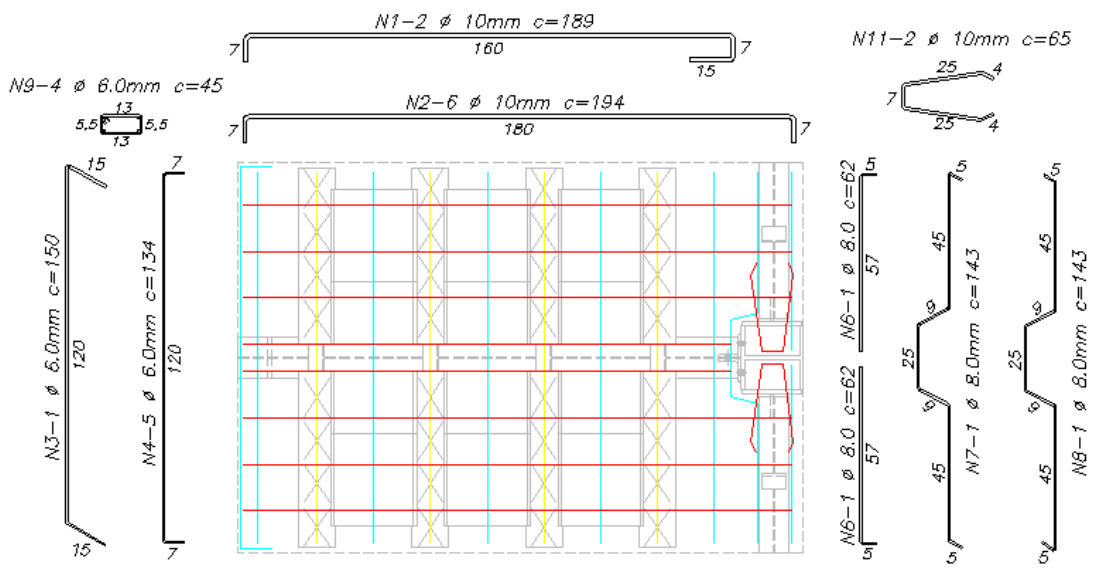

Figura A.8: Armadura negativa do protótipo TNRSS. 

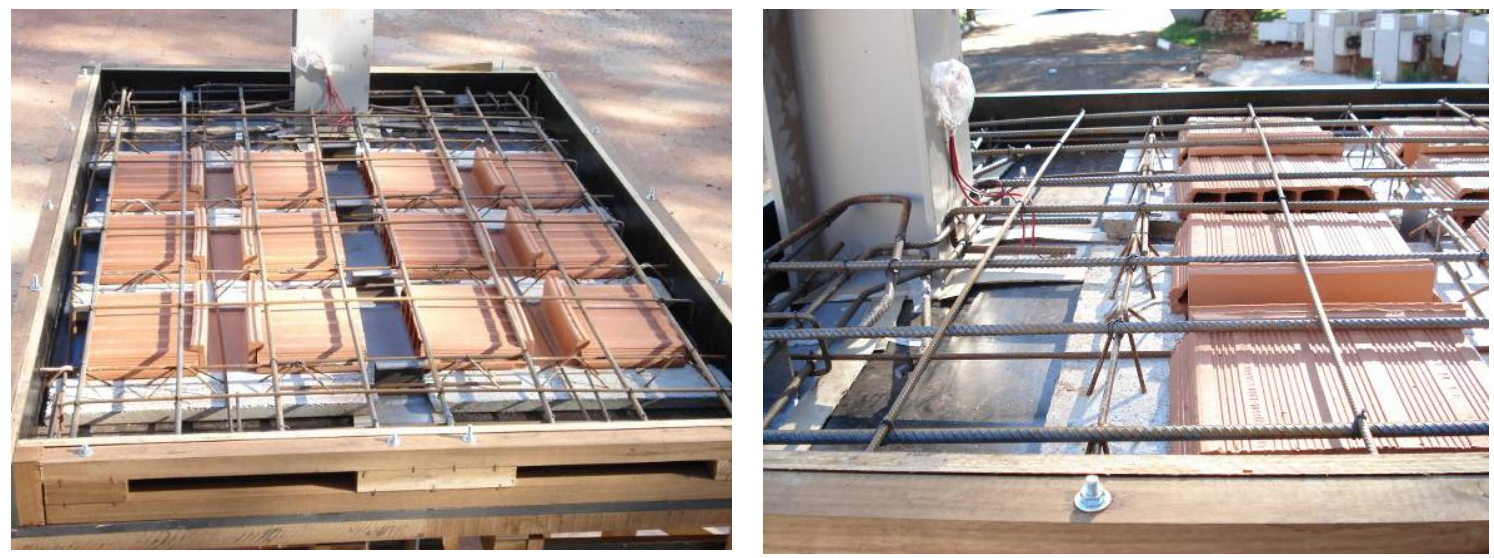

Figura A.9: Montagem da laje do protótipo TNRSS antes da concretagem.

\section{A.4 - Protótipo Isolado TRSS}
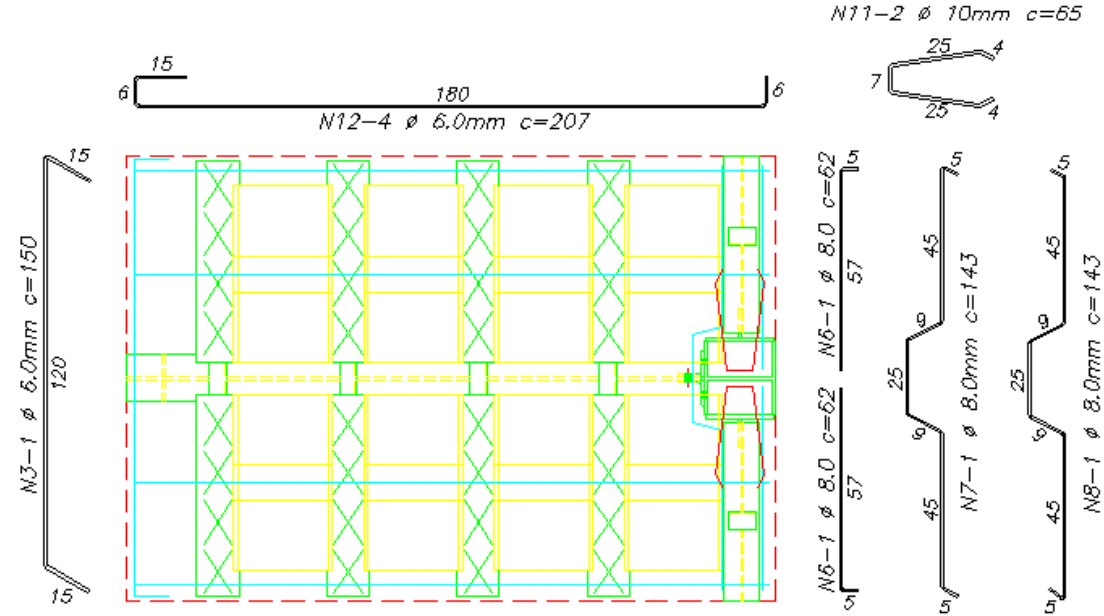

Figura A.10: Armadura positiva do protótipo TRSS.
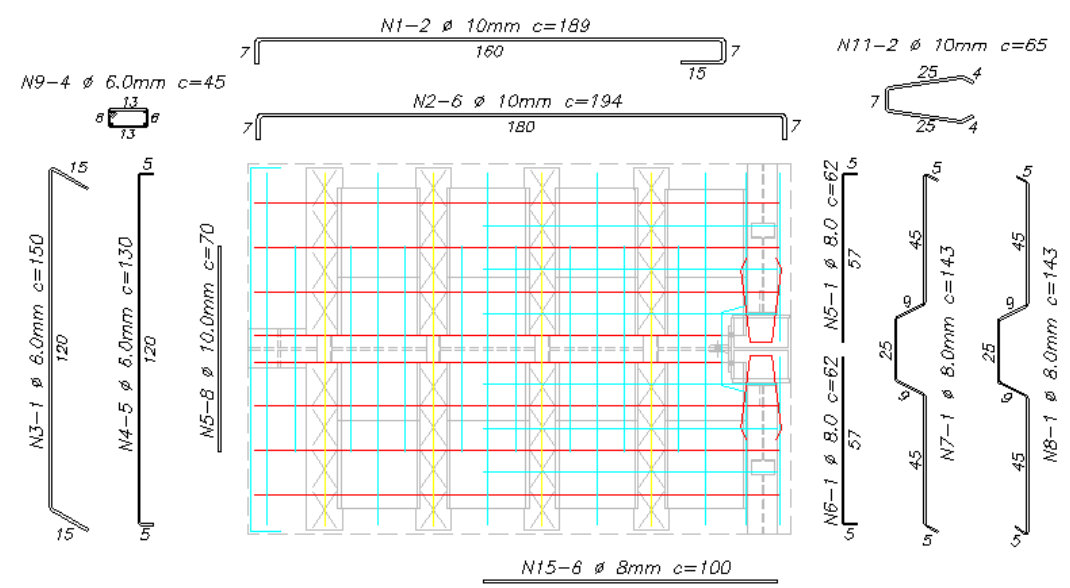

Figura A.11: Armadura negativa do protótipo TRSS. 
Apêndice A: Detalhamento dos protótipos experimentais
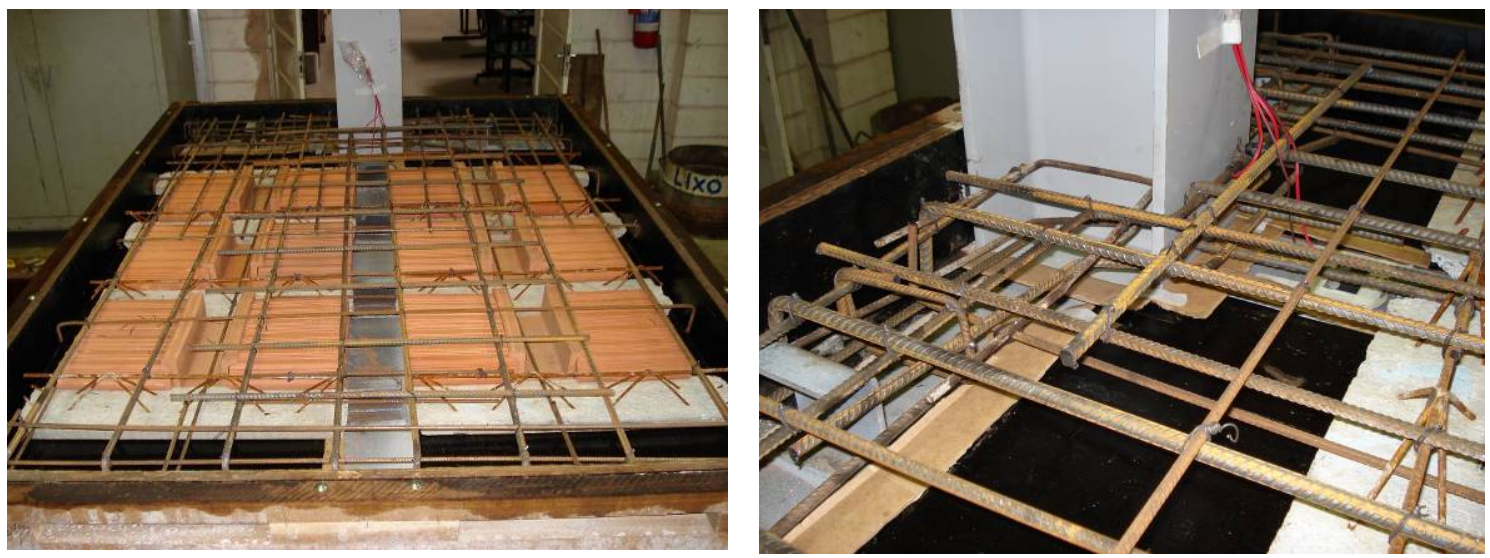

Figura A.12: Montagem da laje do protótipo TRSS antes da concretagem. 


\section{A.5 - Pavimento Tipo}

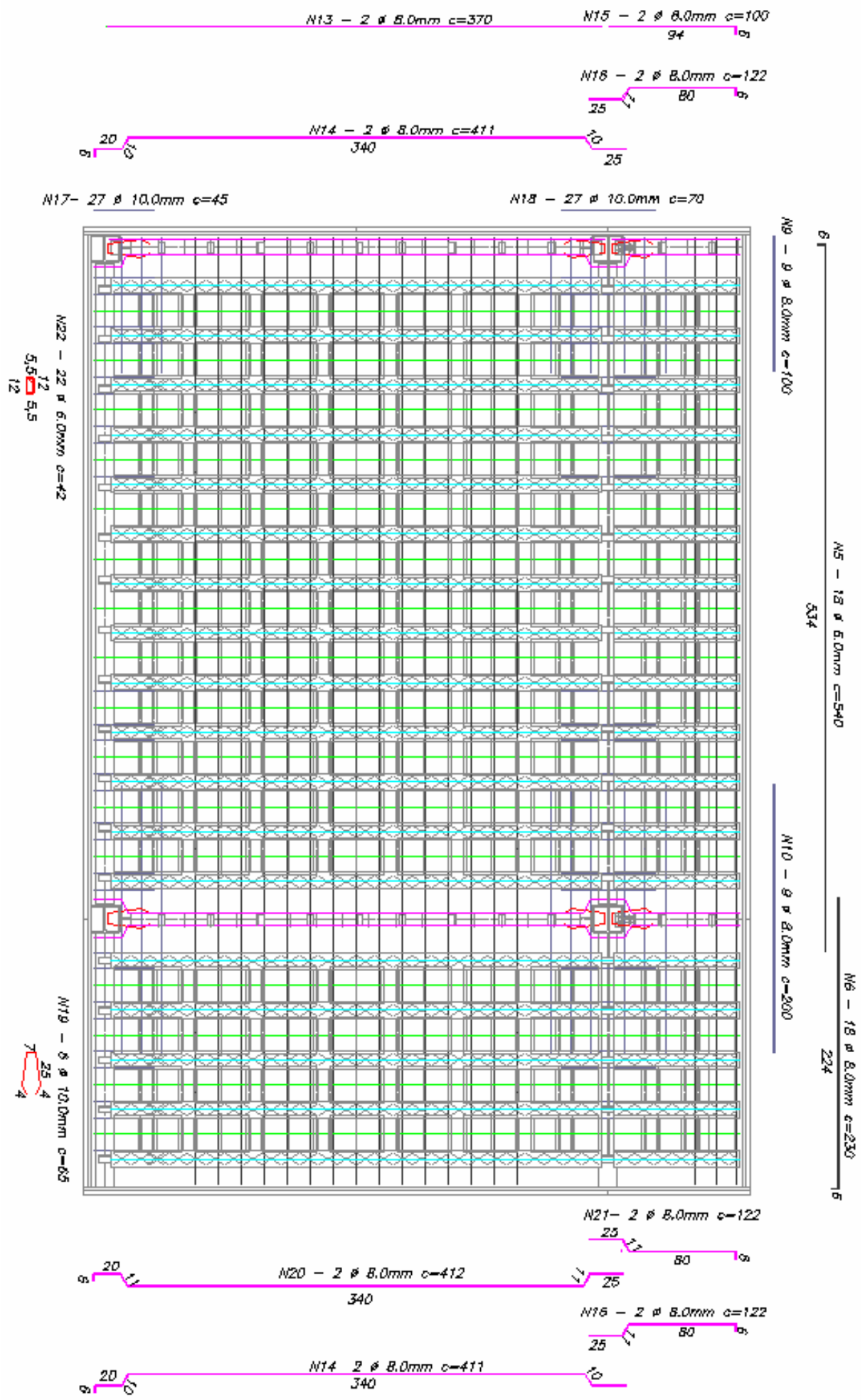

Figura A.12: Armadura negativa do pavimento tipo. 


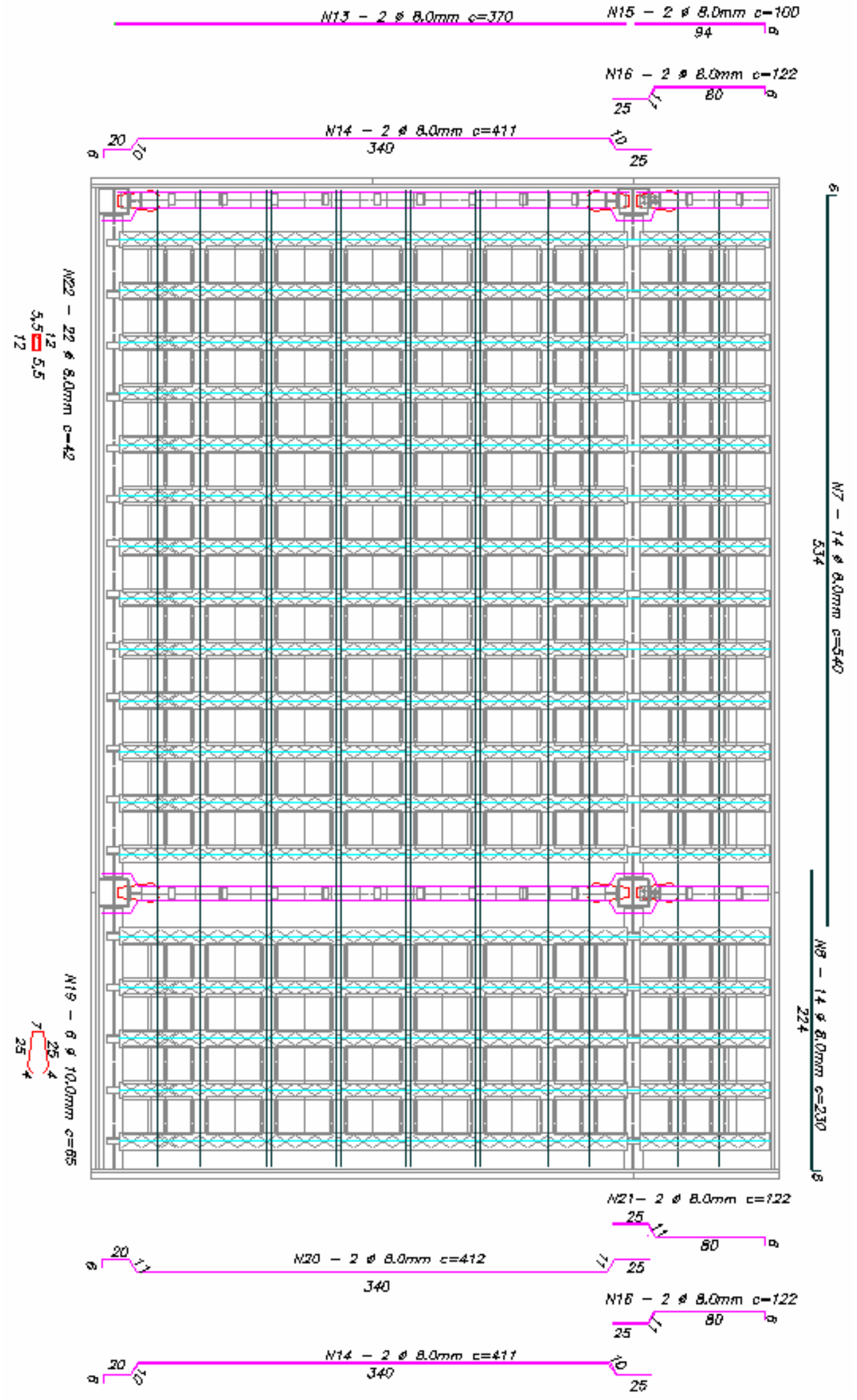

Figura A.13: Armadura positiva do pavimento tipo. 


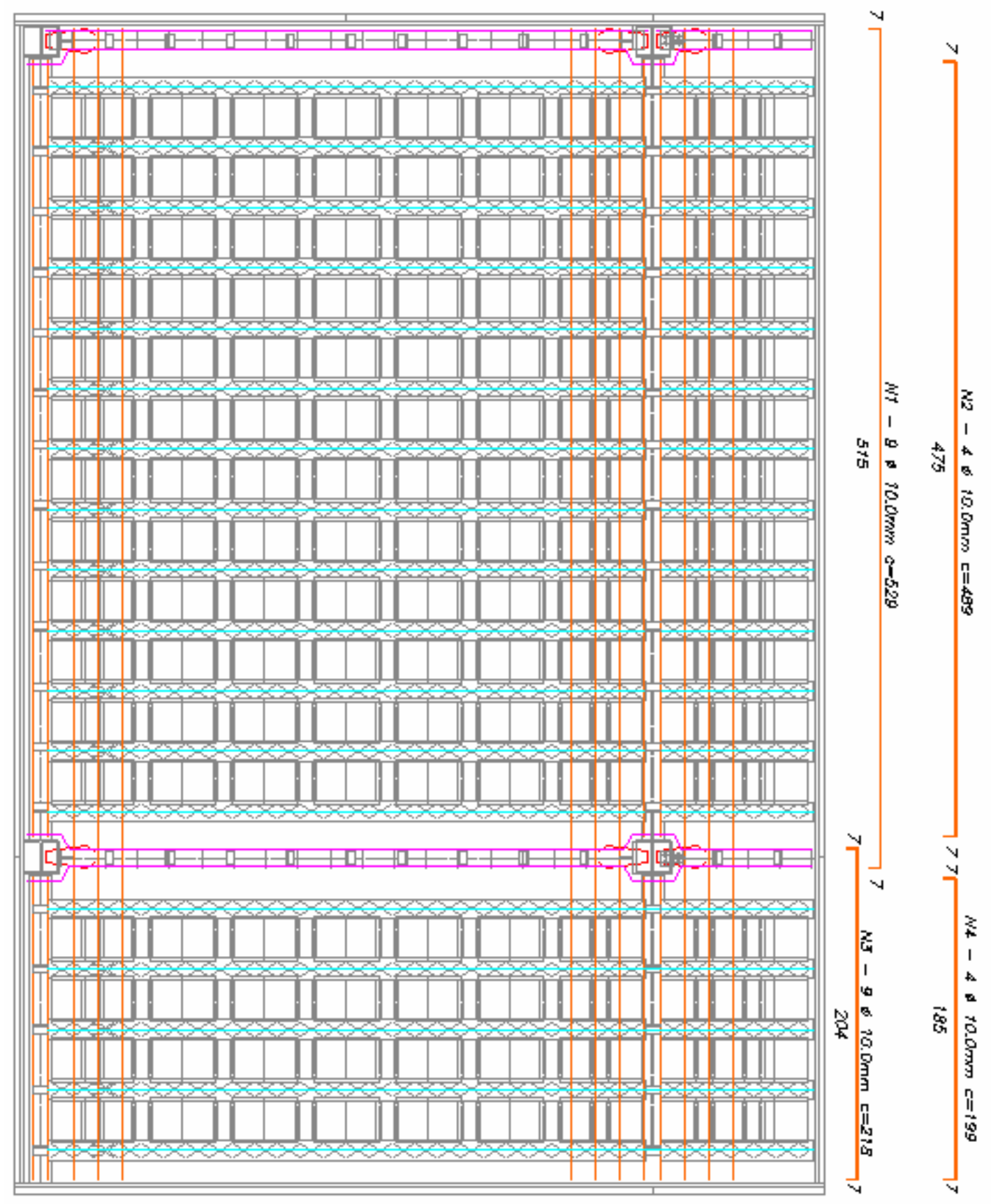

Figura A.14: Armadura da viga mista do pavimento tipo. 


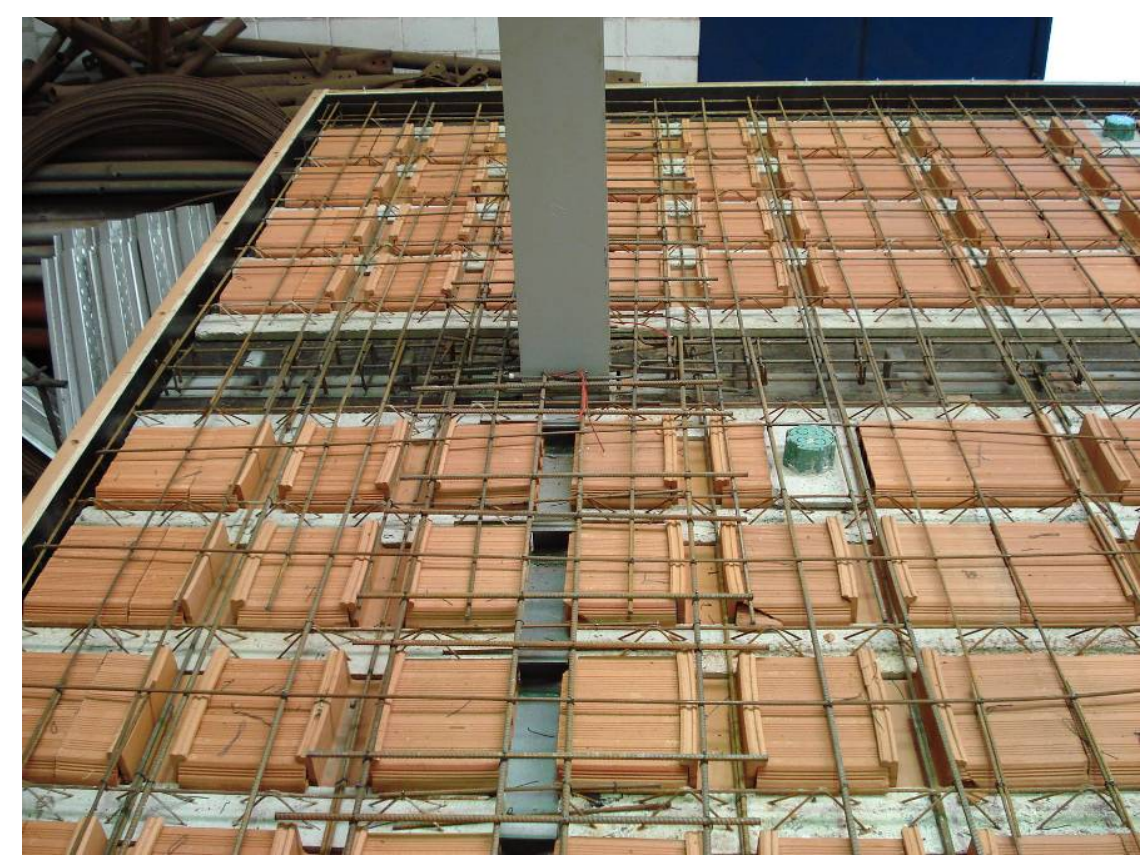

Figura A.15: Laje do pavimento tipo antes da concretagem.

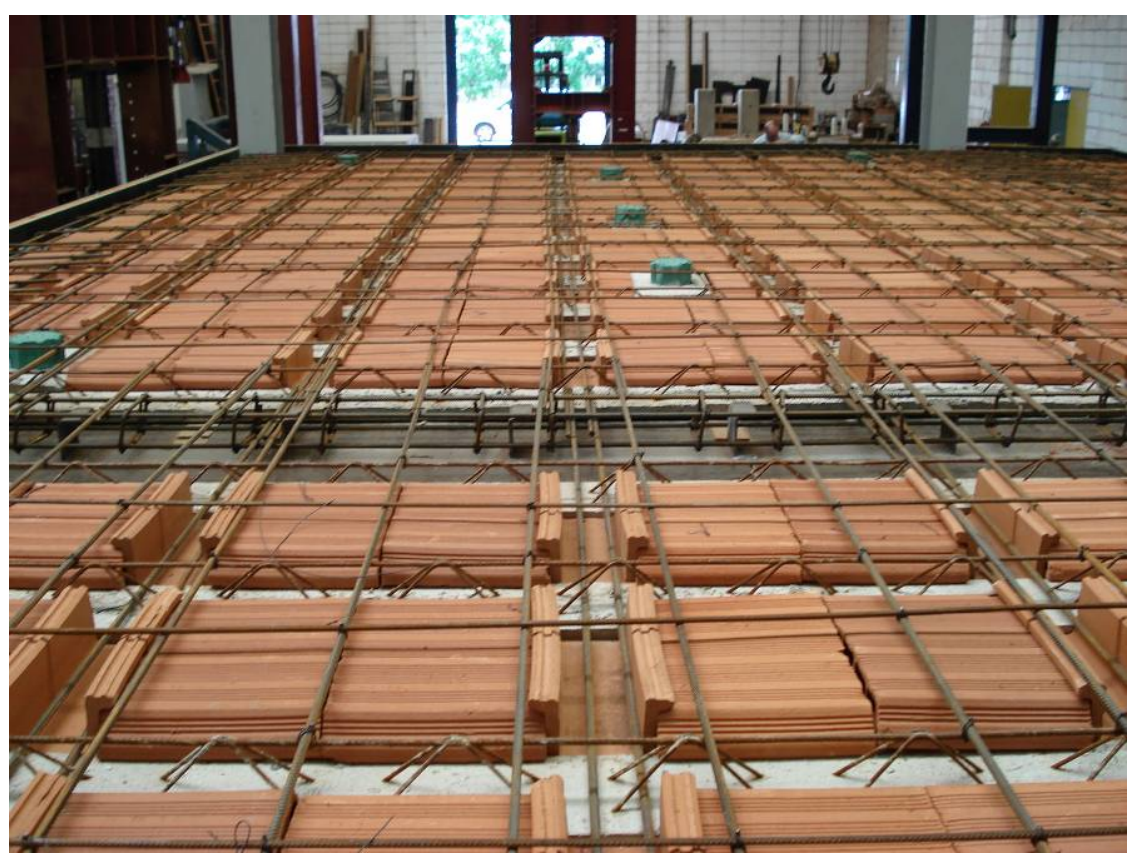

Figura A.16: Laje do pavimento tipo antes da concretagem. 


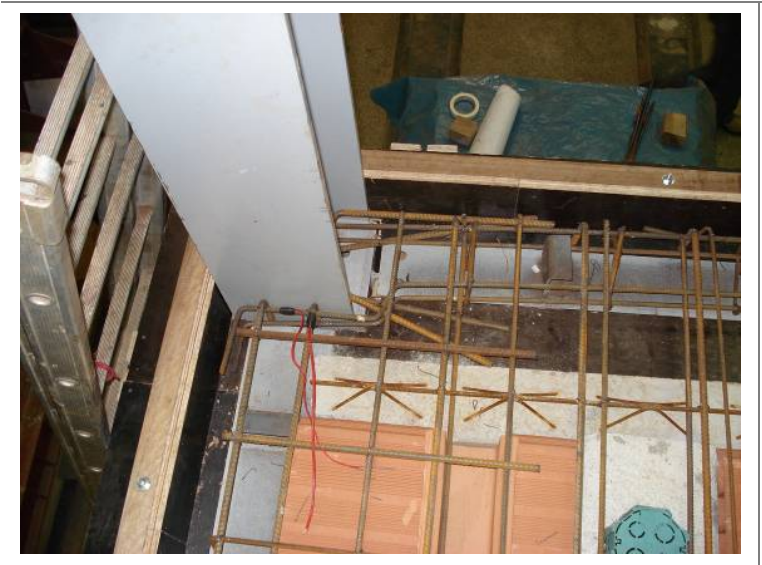

Nó 1

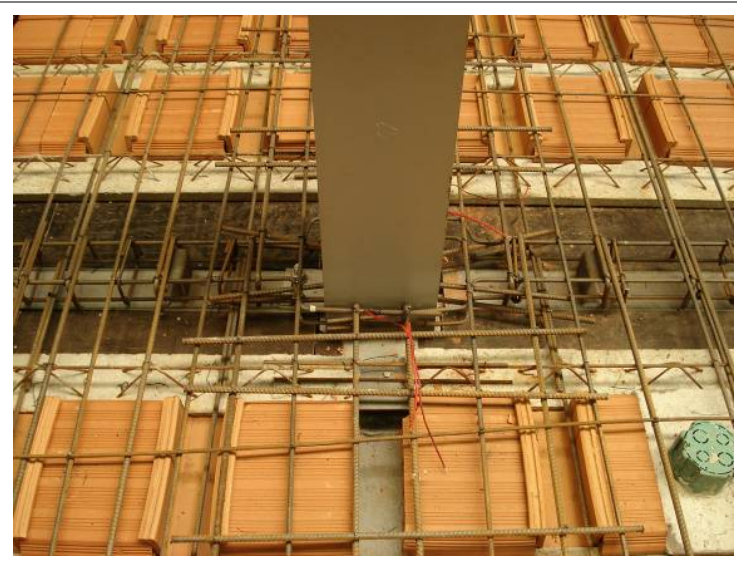

Nó 3

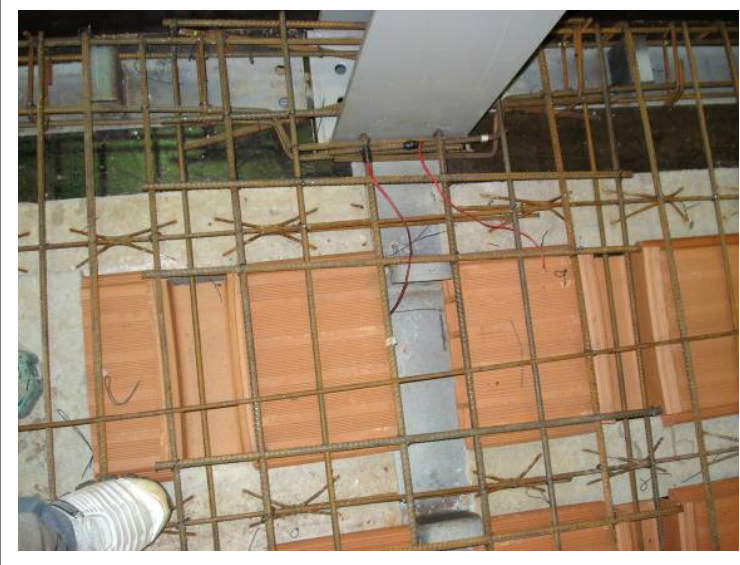

Nó 2

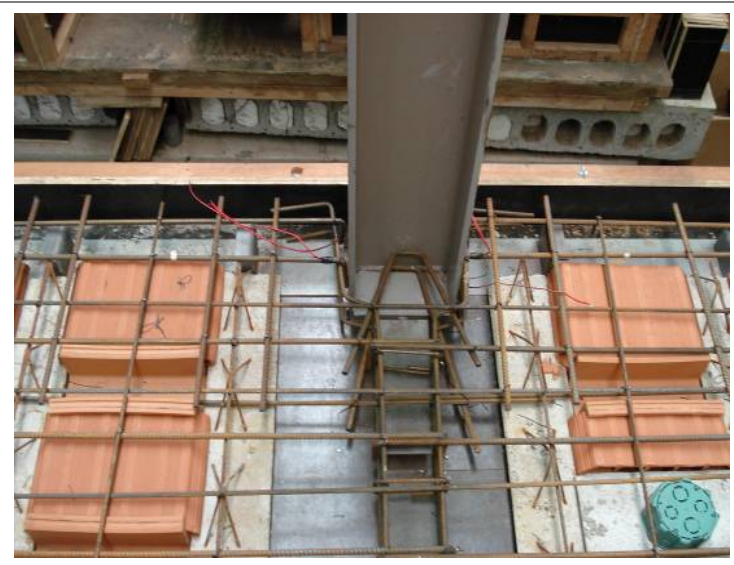

Nó 4

Figura A.17: Laje do pavimento tipo na região dos nós antes da concretagem. 


\section{APÊNDICE}

\section{RESULTADOS COMPLEMENTARES DA ETAPA DE CARREGAMENTO CONCENTRADO NO PAVIMENTO TIPO}

Neste apêndice serão apresentados resultados complementares, tais como os deslocamentos na laje e nas vigas ao término da etapa de carregamento concentrado na laje e nas vigas principais do pavimento tipo.

Os resultados para cada fase serão ilustrados separadamente, uma vez que as posições de leitura de alguns transdutores de deslocamentos foram alteradas em determinadas fases, em função da posição da carga concentrada na laje.

Nas Fases 1 e 2 do carregamento concentrado foram obtidos os deslocamentos na laje de acordo com as Linhas 1 e 2, além dos pontos no meio do vão entre apoios das vigas principais e da laje, conforme apresenta a Figura B.1.

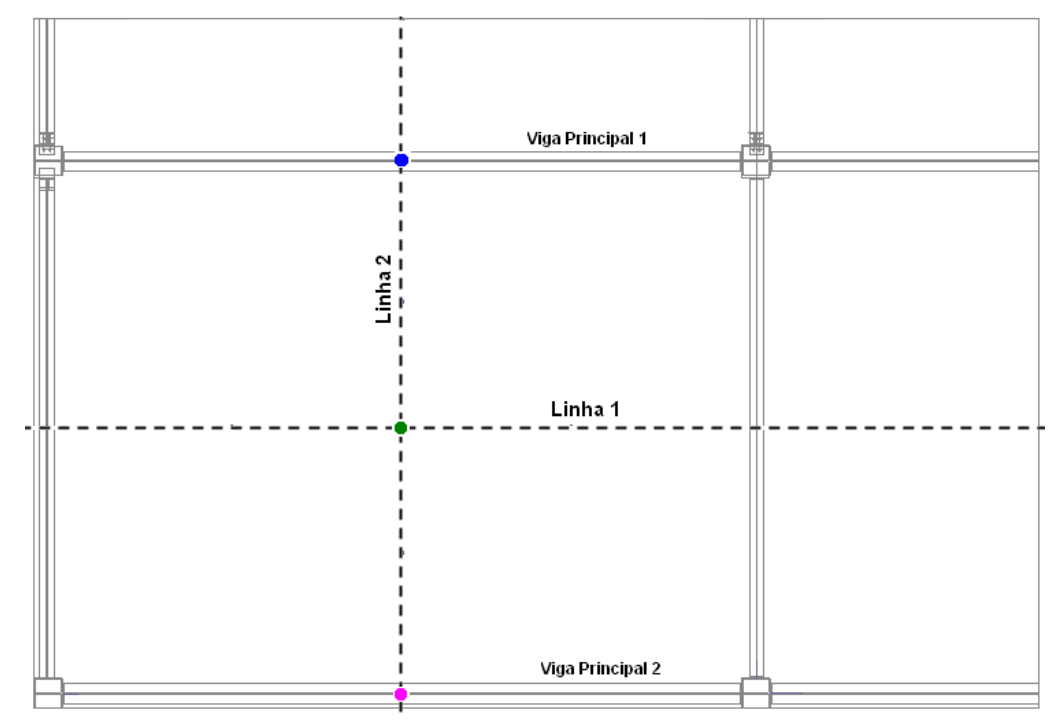

Figura B.1: Linhas de posição dos transdutores para aferição dos deslocamentos na laje. 
Apêndice B: Resultados complementares da etapa de carregamento concentrado no pavimento tipo

Os resultados nos pontos acima representados para o carregamento das Fases 1 e 2, bem com os respectivos esquemas de carregamento estão indicados abaixo:

- $\underline{1}^{a}$ Fase: força aplicada em dois pontos sobre a laje, no meio do vão segundo a direção da viga principal, com a reação de apoio final em cada ponto de $33,7 \mathrm{kN}(67,4 \mathrm{kN}$ no atuador).

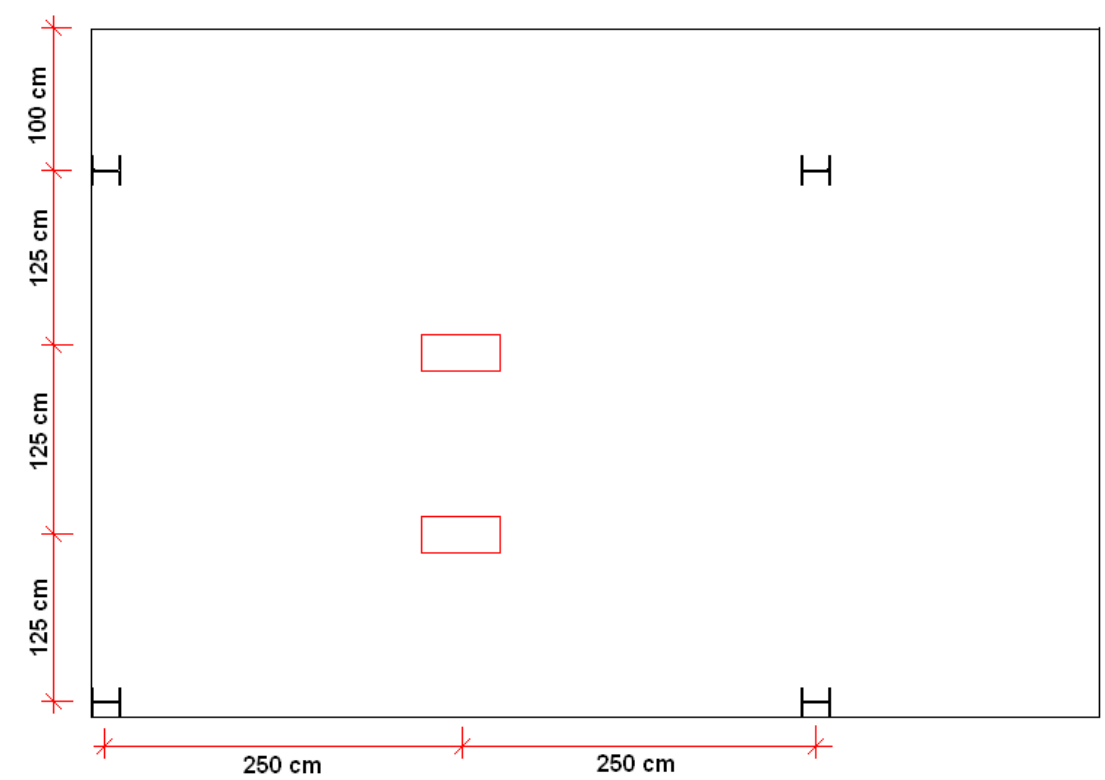

Figura B.2: Representação da Fase 1 do carregamento concentrado na laje.

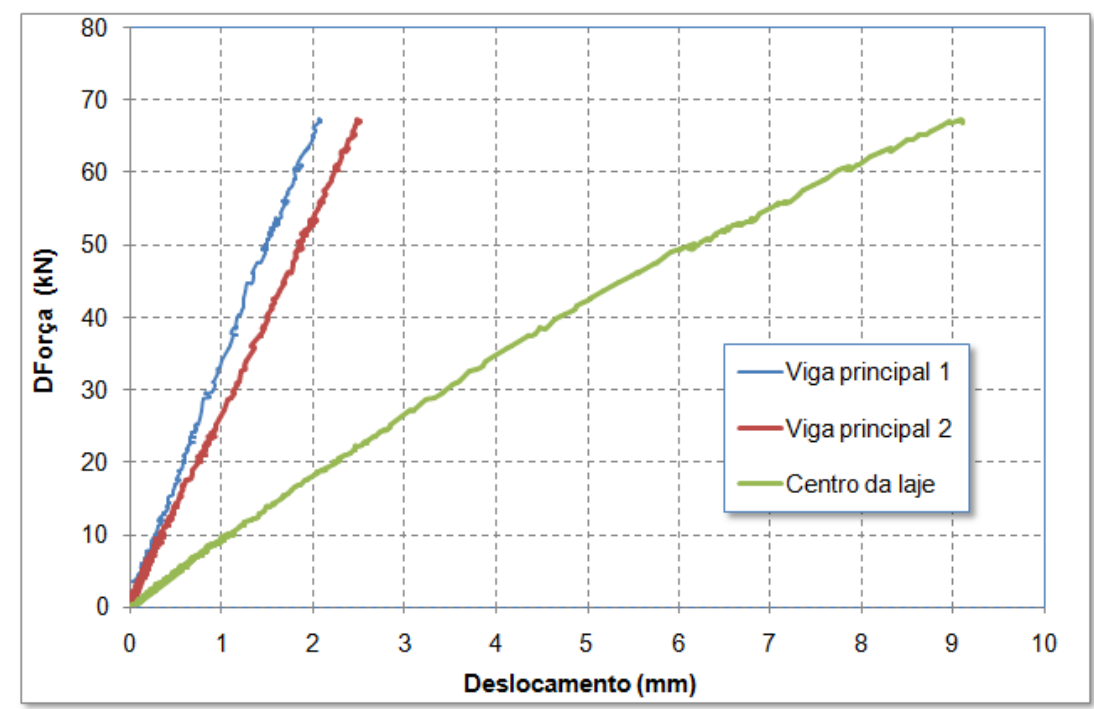

Figura B.3: Deslocamentos no meio do vão entre apoios das vigas principais e no centro da laje. 
Apêndice B: Resultados complementares da etapa de carregamento concentrado no pavimento tipo

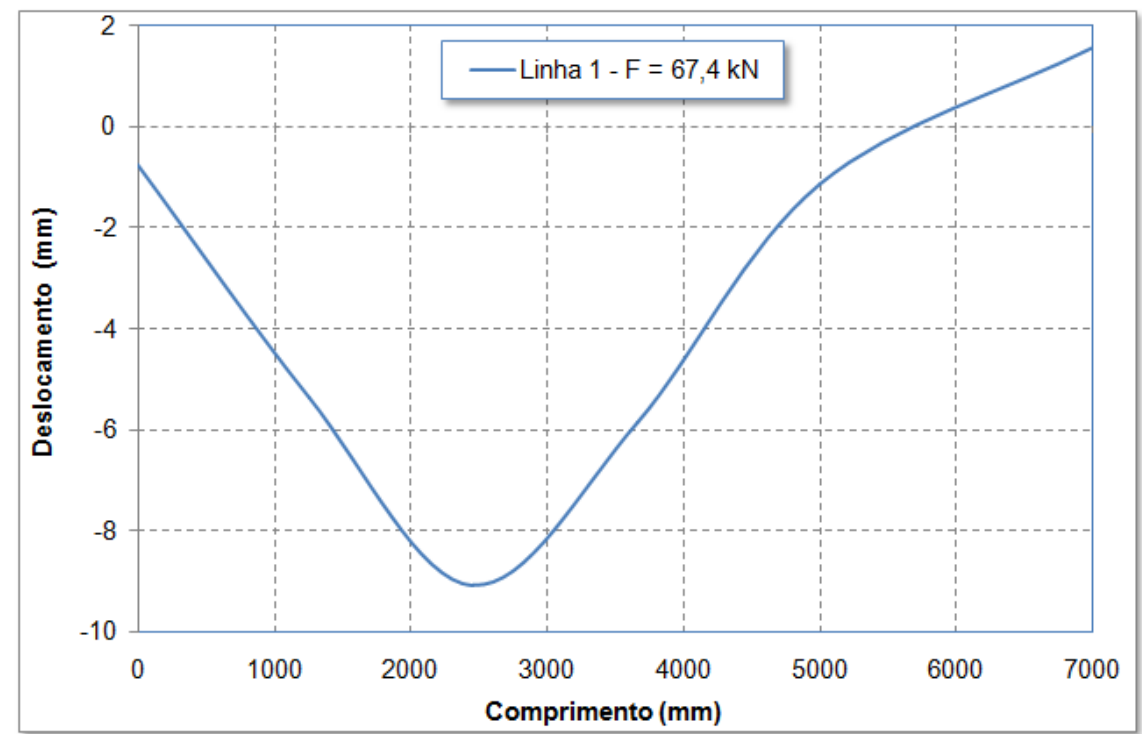

Figura B.4: Deslocamentos na Linha 1 da Fase 1 de carregamento concentrado na laje.

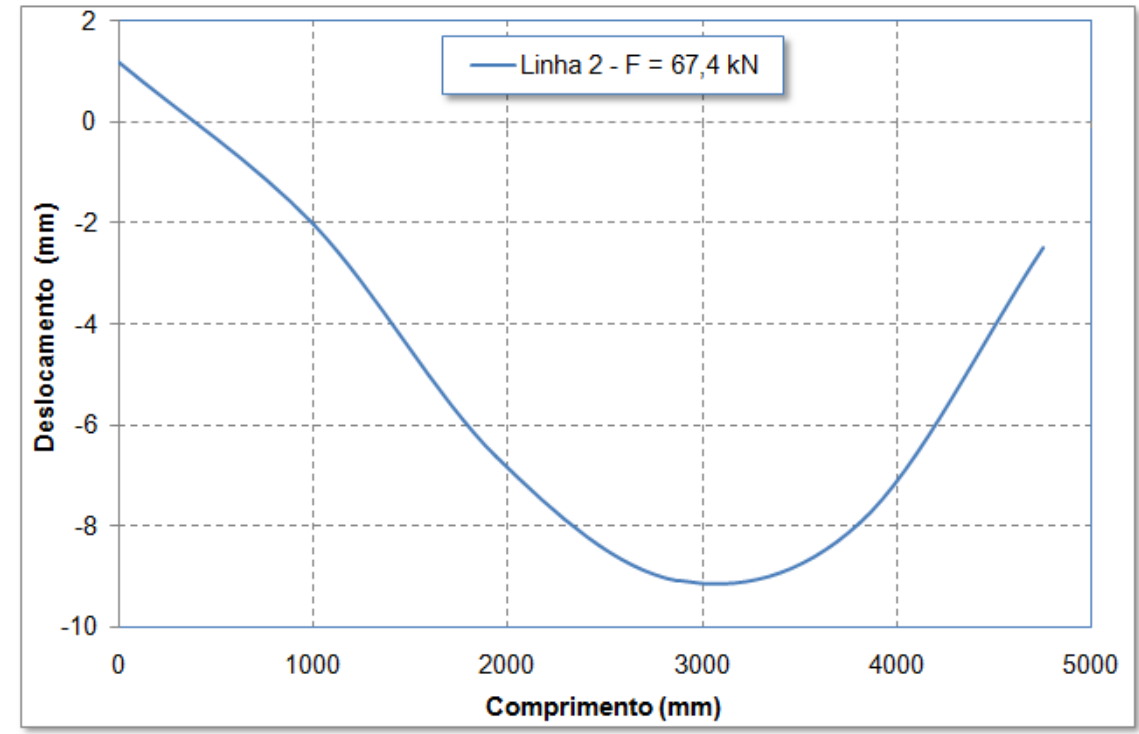

Figura B.5: Deslocamentos na Linha 2 da Fase 1 de carregamento concentrado na laje.

- $\underline{2}^{a}$ Fase: força aplicada no meio do vão na posição de cada viga principal, com a reação de apoio final em cada ponto de 49,4 kN $(98,8$ $\mathrm{kN}$ no atuador). 
Apêndice B: Resultados complementares da etapa de carregamento concentrado no pavimento tipo

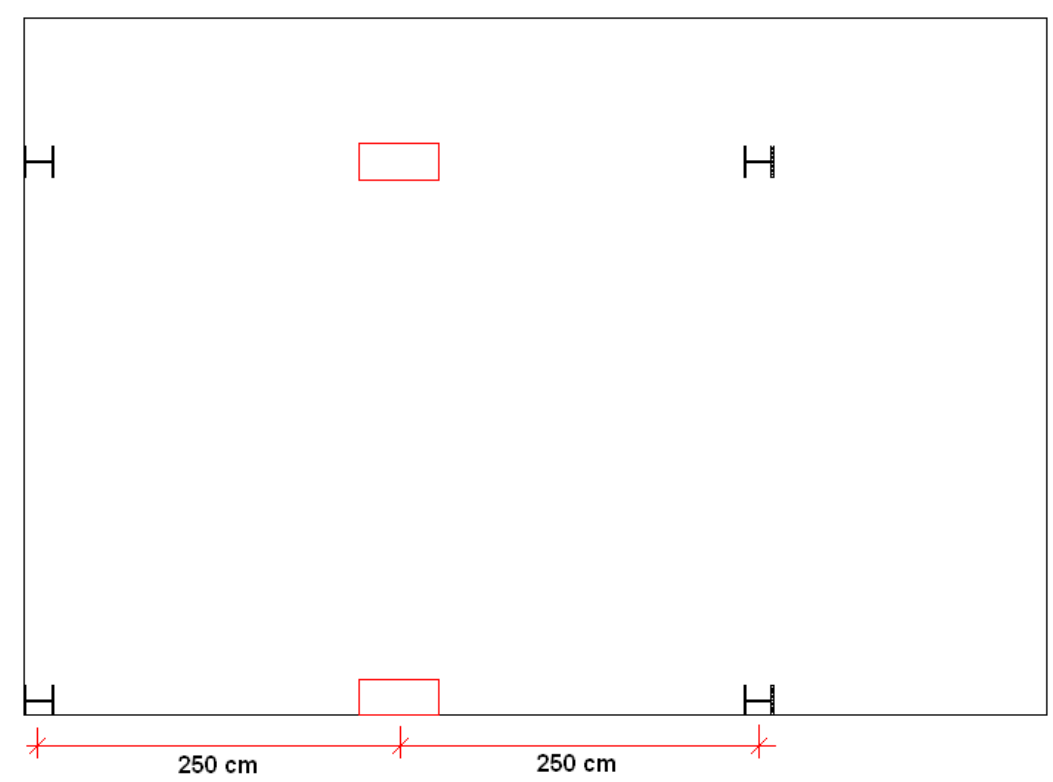

Figura B.6: Representação da Fase 2 do carregamento concentrado na laje.

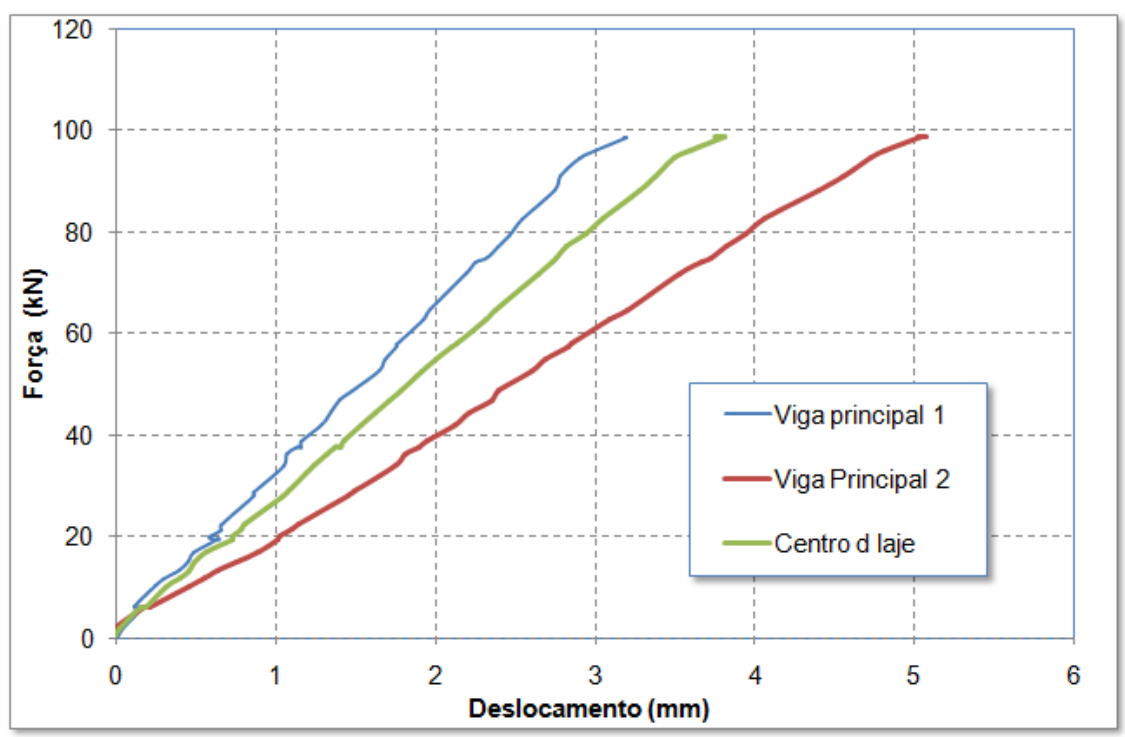

Figura B.7: Deslocamentos no meio do vão entre apoios das vigas principais e no centro da laje. 
Apêndice B: Resultados complementares da etapa de carregamento concentrado no pavimento tipo

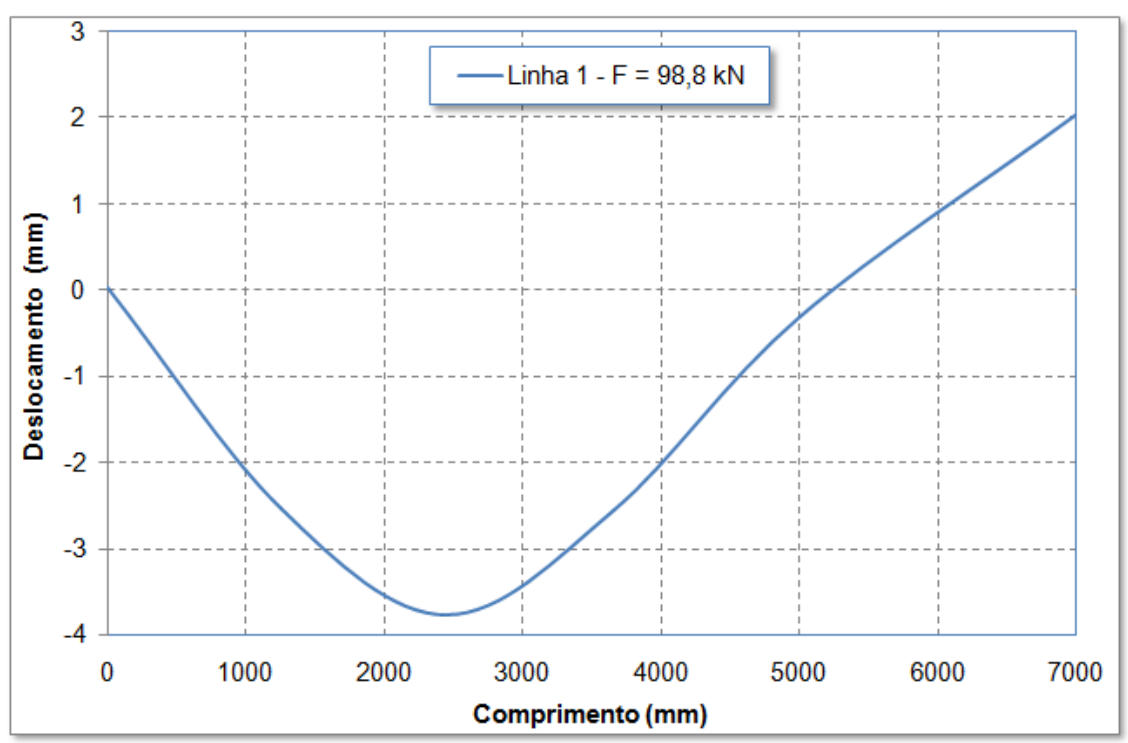

Figura B.8: Deslocamentos na Linha 1 da Fase 2 de carregamento concentrado na laje.

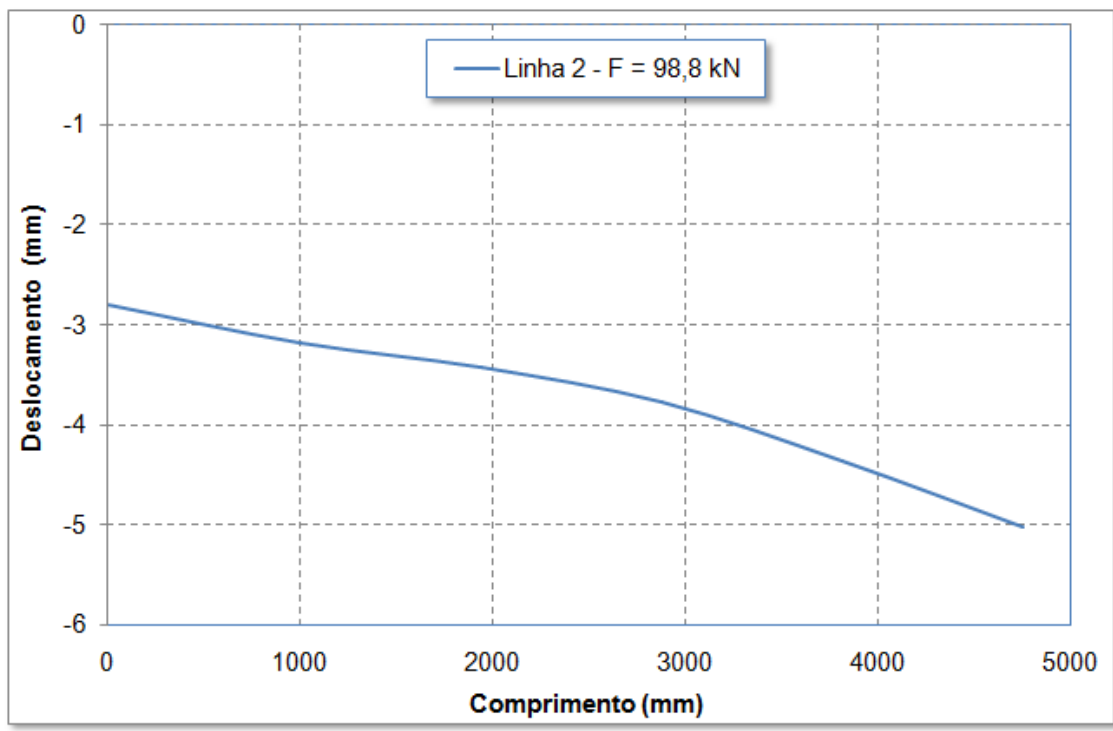

Figura B.9: Deslocamentos na Linha 2 da Fase 2 de carregamento concentrado na laje.

$\mathrm{Na}$ terceira fase do carregamento concentrado foram alteradas algumas posições de leitura, com o objetivo de medir os deslocamentos ao longo das vigas principais 1 e 2, além dos deslocamentos da laje nas linhas de transdutores 1 e 2, conforme ilustram as Figuras B.10 e B.11: 
Apêndice B: Resultados complementares da etapa de carregamento concentrado no pavimento tipo

- $\underline{3^{a} \text { Fase: }}$ força aplicada em dois pares de pontos sobre a laje, a cada terço de vão segundo a direção da viga principal, com a reação de apoio final $\left(F_{\max }\right)$ em cada ponto de $27,12 \mathrm{kN}(54,25 \mathrm{kN}$ em cada atuador).

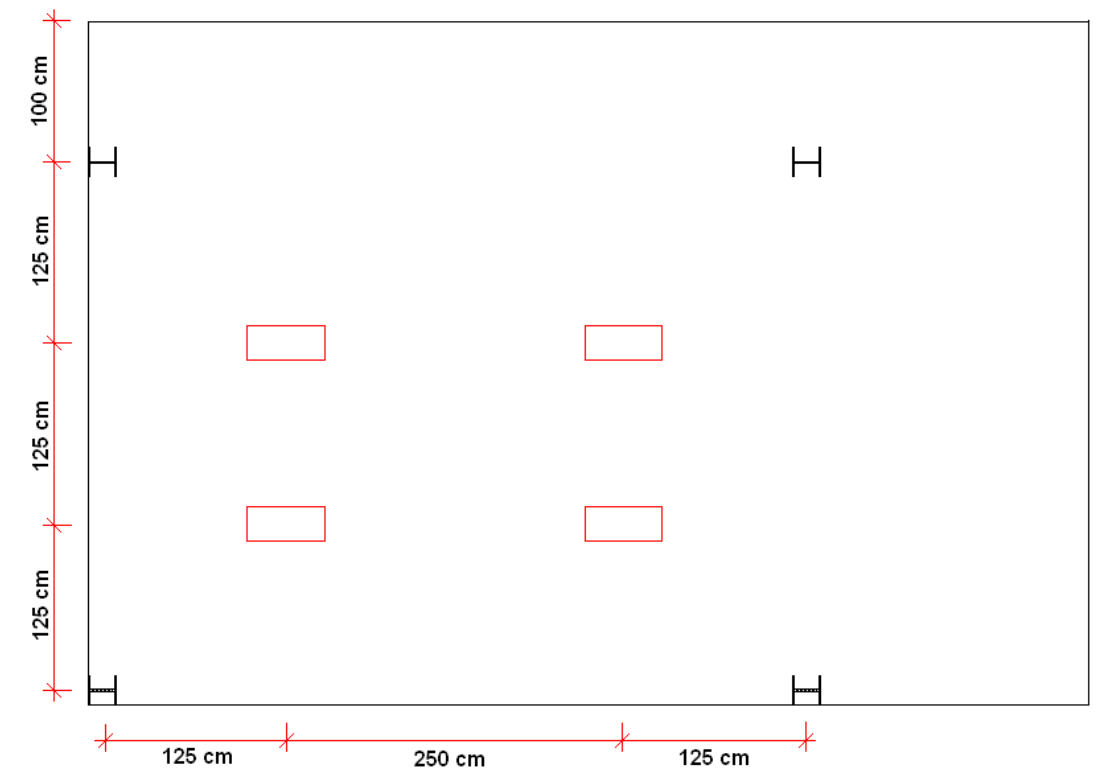

Figura B.10: Representação da Fase 3 do carregamento concentrado na laje.

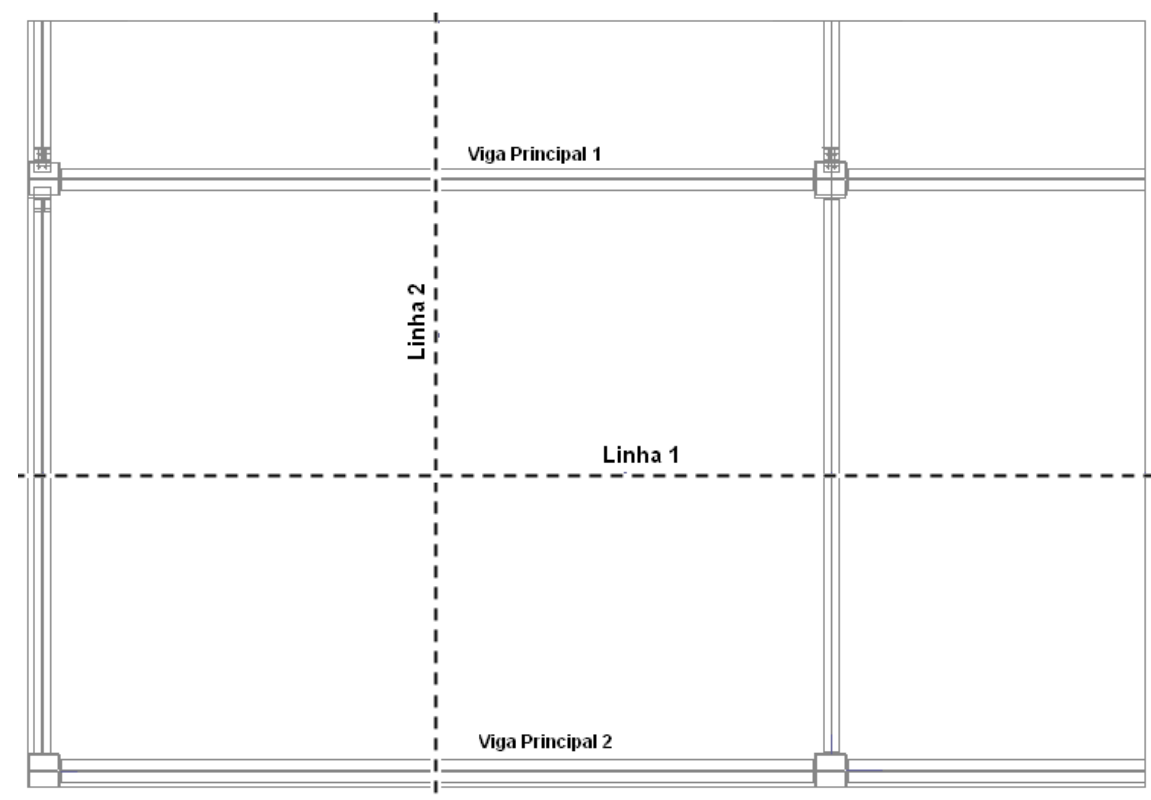

Figura B.11: Numeração das vigas principais e linhas de transdutores para leitura dos deslocamentos da Fase 3 de carregamento concentrado. 
Apêndice B: Resultados complementares da etapa de carregamento concentrado no pavimento tipo

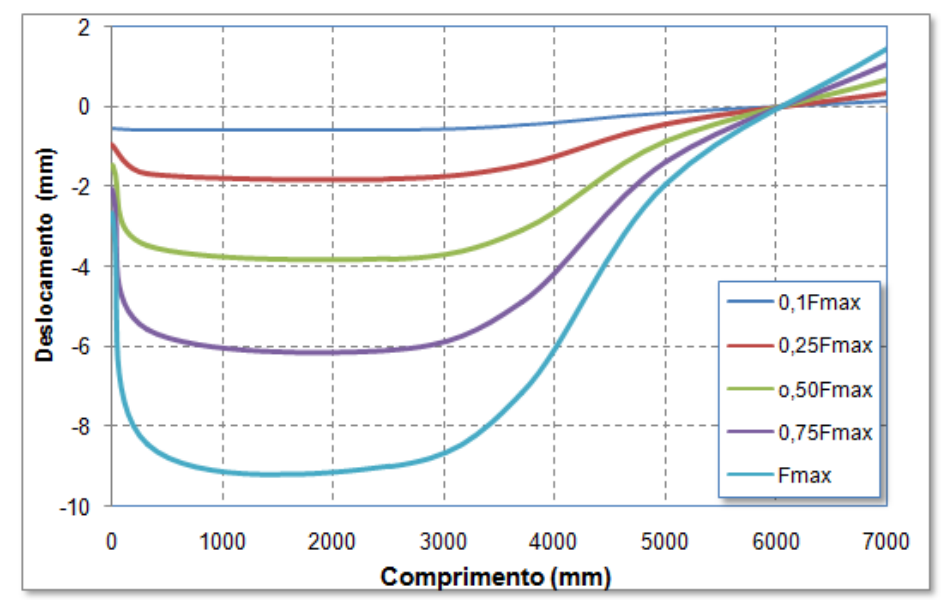

Figura B.12: Deslocamentos na Linha 1 da Fase 3 de carregamento concentrado na laje.

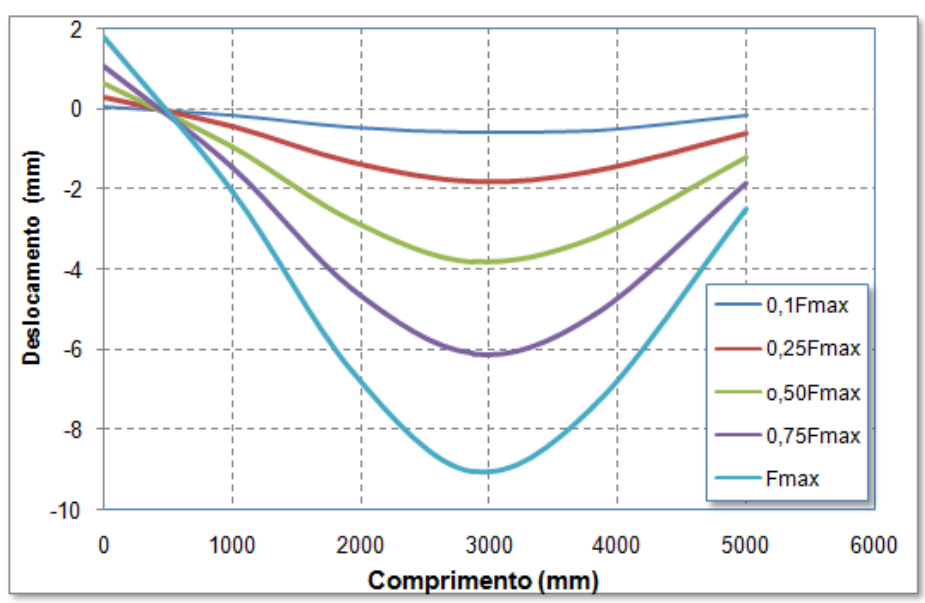

Figura B.13: Deslocamentos na Linha 2 da Fase 3 de carregamento concentrado na laje.

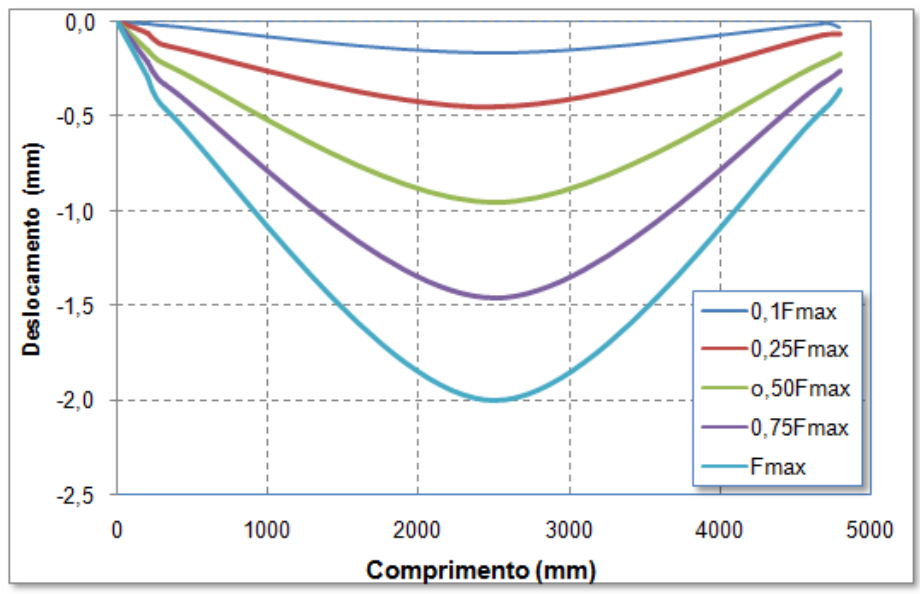

Figura B.14: Deslocamentos na viga principal 1 da Fase 3 de carregamento concentrado na laje. 
Apêndice B: Resultados complementares da etapa de carregamento concentrado no pavimento tipo

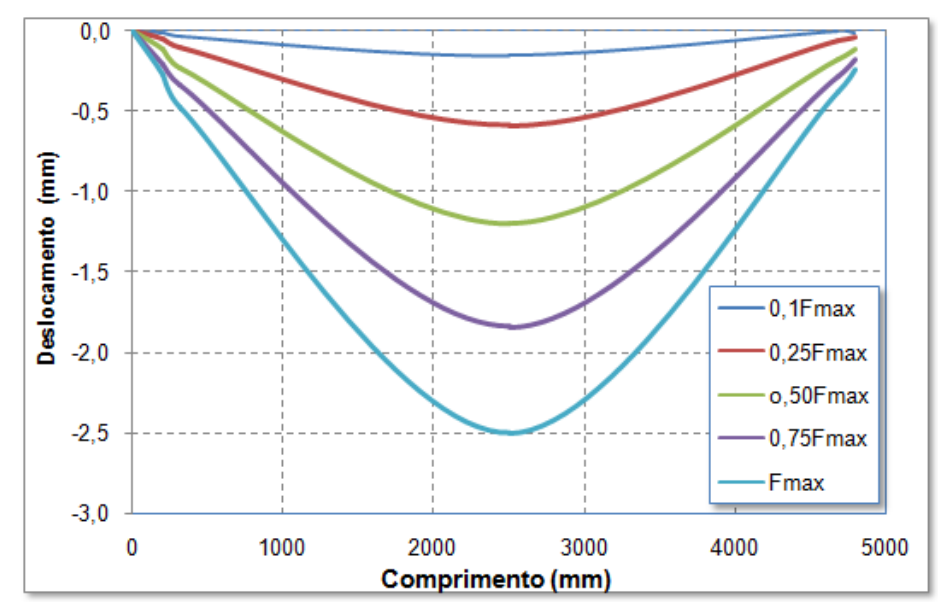

Figura B.15: Deslocamentos na viga principal 2 da Fase 3 de carregamento concentrado na laje.

Nas Fases 4 e 5 do carregamento concentrado, as posições de leitura dos transdutores de deslocamentos foram novamente alterados, com o objetivo de medir os deslocamentos das vigas 3 e 4, além dos deslocamentos da laje nas linhas de transdutores 1 e 2, conforme ilustra a Figura B.16.

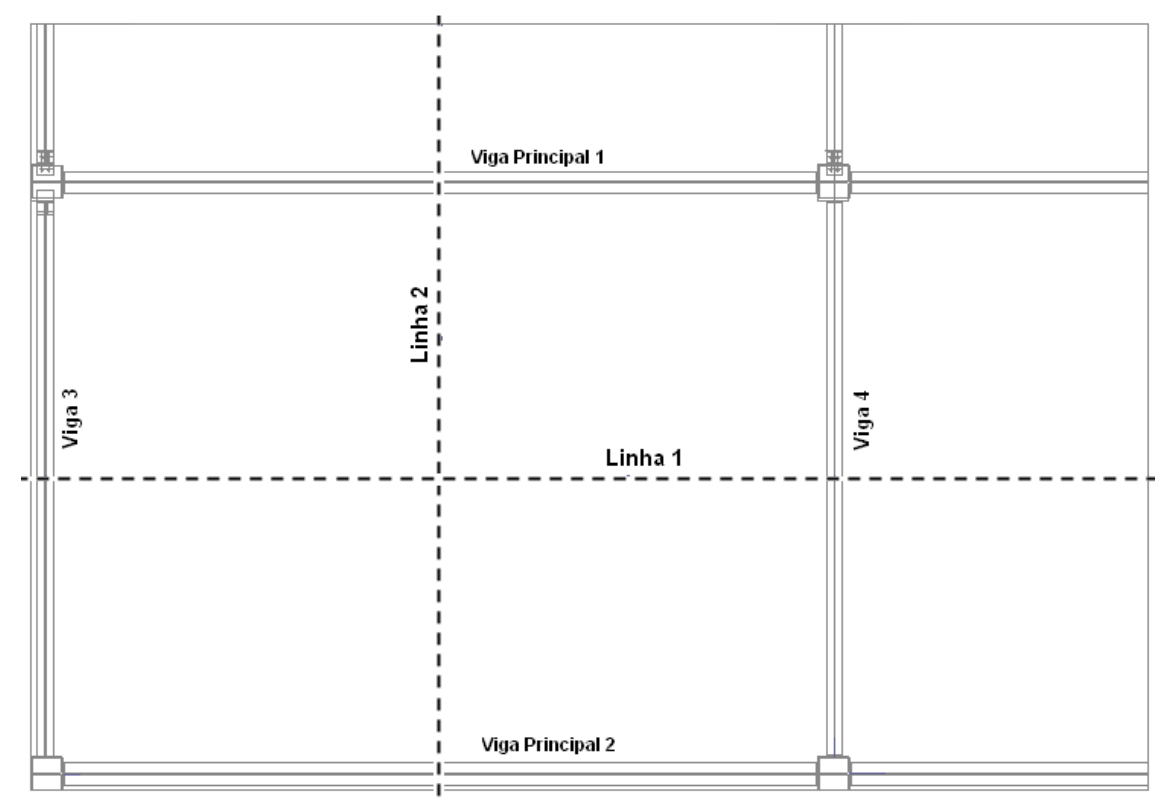

Figura B.16: Vigas principais, secundárias e linhas de transdutores para leitura dos deslocamentos das Fases 4 e 5.

- $4^{a}$ Fase: força aplicada em dois pontos sobre a laje, conforme a posição apresentada na Figura B.17, com a reação de apoio final $\left(F_{\max }\right)$ 
Apêndice B: Resultados complementares da etapa de carregamento concentrado no pavimento tipo

em cada ponto de $55,75 \mathrm{kN}(111,5 \mathrm{kN}$ no atuador).

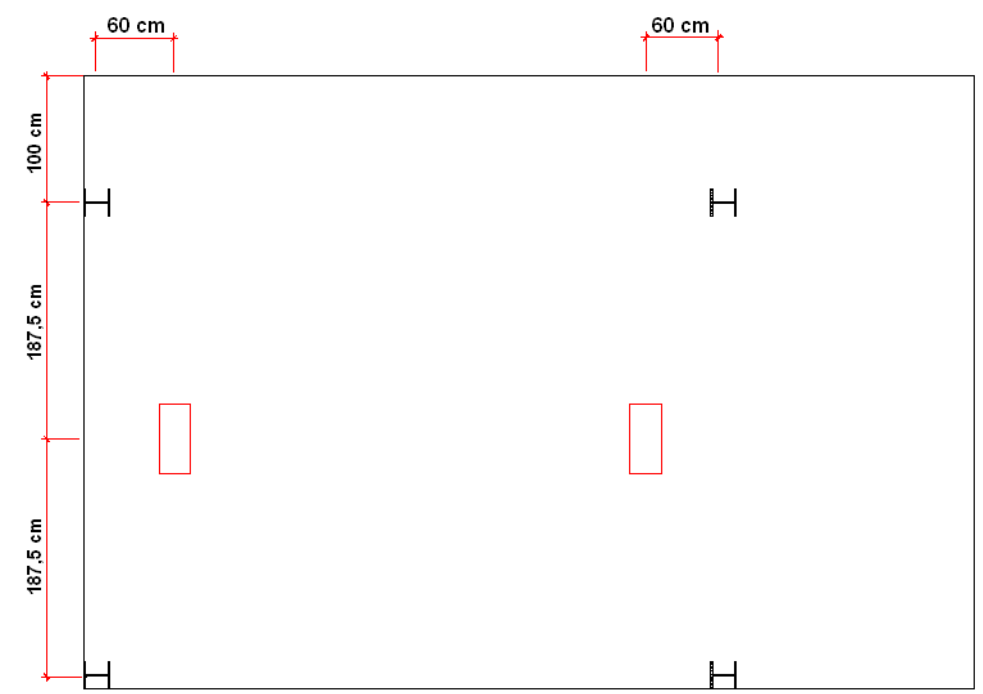

Figura B.17: Representação da Fase 4 do carregamento concentrado na laje.

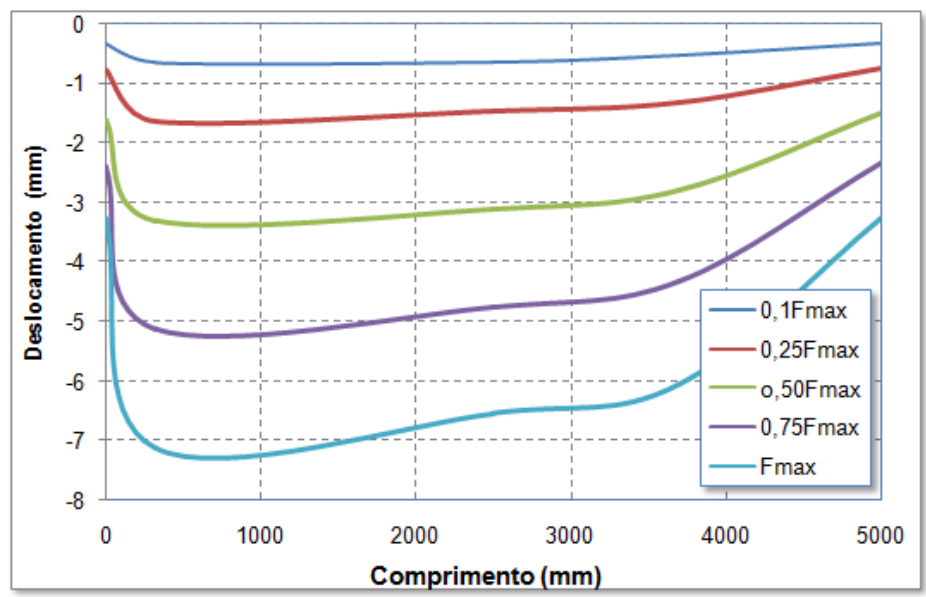

Figura B.18: Deslocamentos na Linha 1 da Fase 4 de carregamento concentrado na laje. 
Apêndice B: Resultados complementares da etapa de carregamento concentrado no pavimento tipo

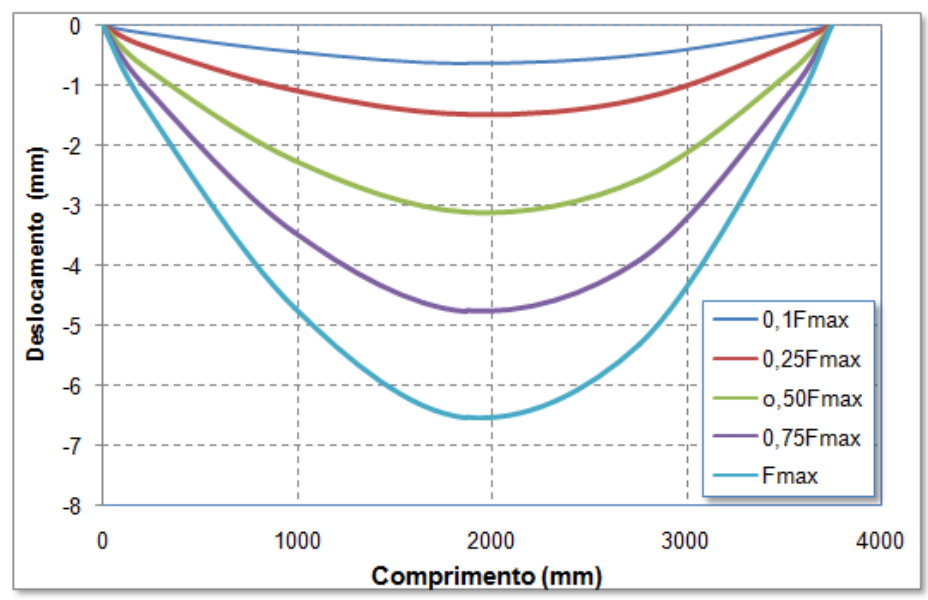

Figura B.19: Deslocamentos na Linha 2 da Fase 4 de carregamento concentrado na laje.

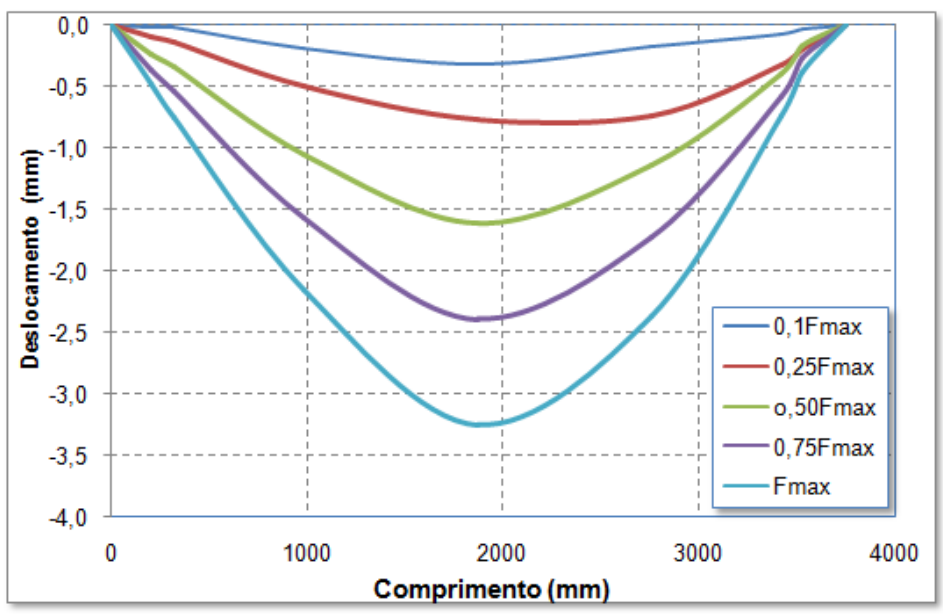

Figura B.20: Deslocamentos na viga 3 da Fase 4 de carregamento concentrado na laje.

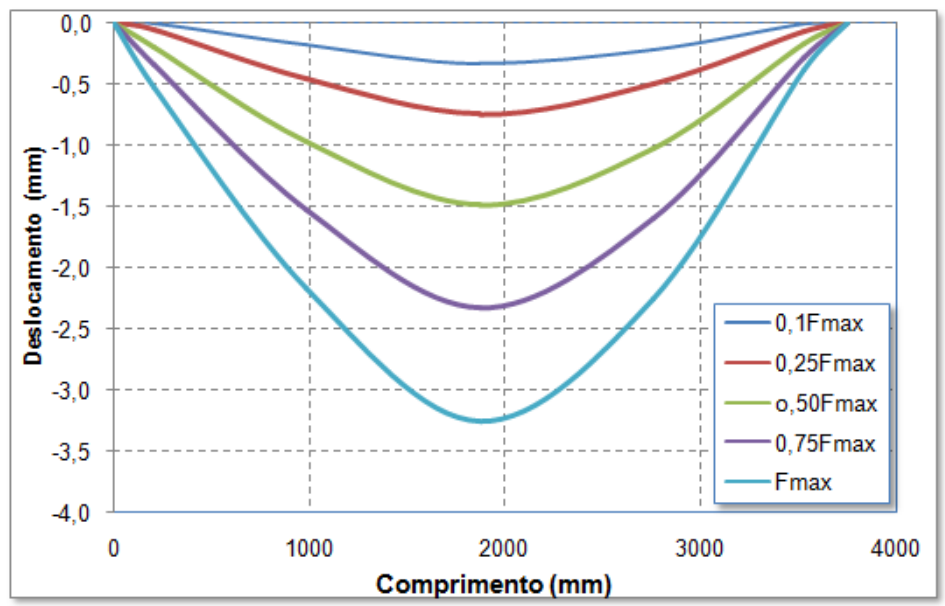

Figura B.21: Deslocamentos na viga 4 da Fase 4 de carregamento concentrado na laje. 
Apêndice B: Resultados complementares da etapa de carregamento concentrado no pavimento tipo

- $\underline{5^{a} \text { Fase: }}$ força aplicada em dois pontos sobre a laje, a cada terço entre os apoios na direção da viga principal, conforme ilustra a Figura B.22, com a reação de apoio final $\left(F_{\text {max }}\right)$ em cada ponto de $38,63 \mathrm{kN}(77,26$ $\mathrm{kN}$ no atuador).

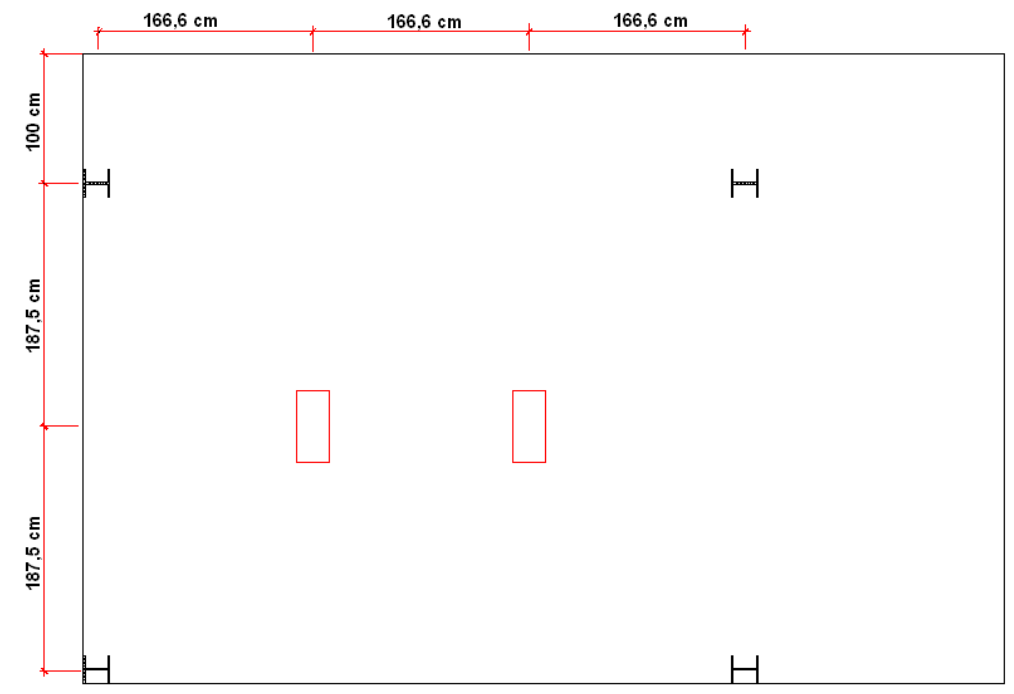

Figura B.22: Representação da Fase 5 do carregamento concentrado na laje.

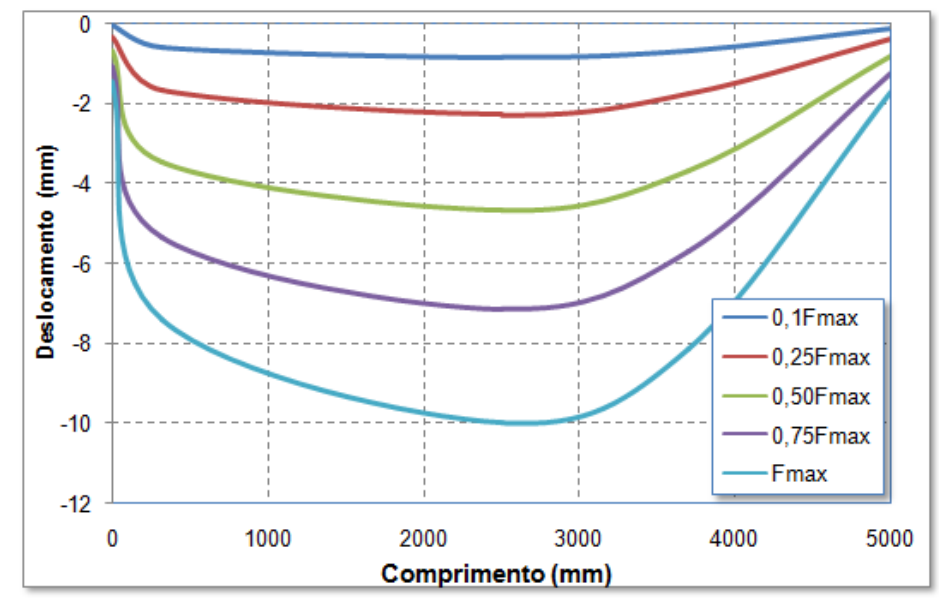

Figura B.23: Deslocamentos na Linha 1 da Fase 5 de carregamento concentrado na laje. 
Apêndice B: Resultados complementares da etapa de carregamento concentrado no pavimento tipo

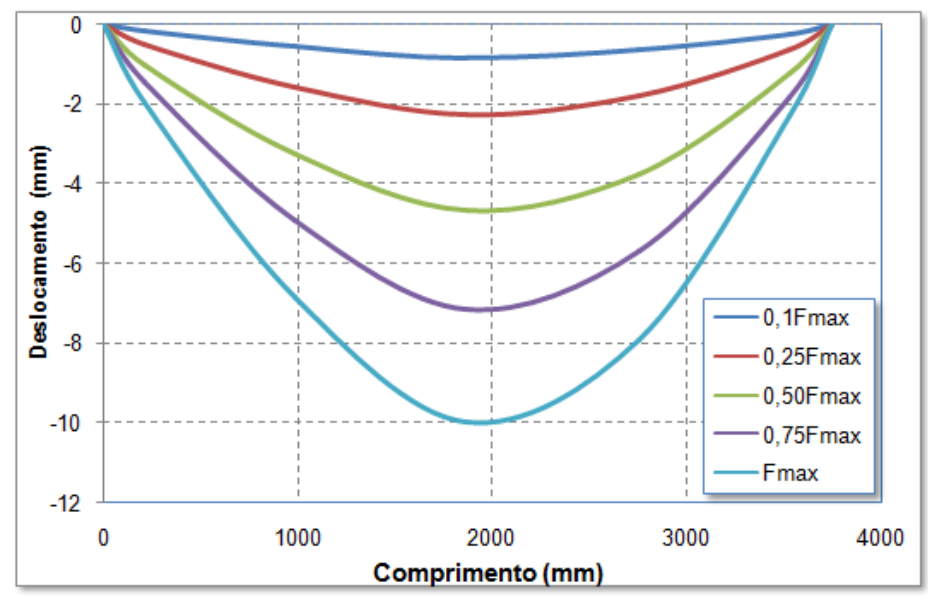

Figura B.24: Deslocamentos na Linha 2 da Fase 5 de carregamento concentrado na laje.

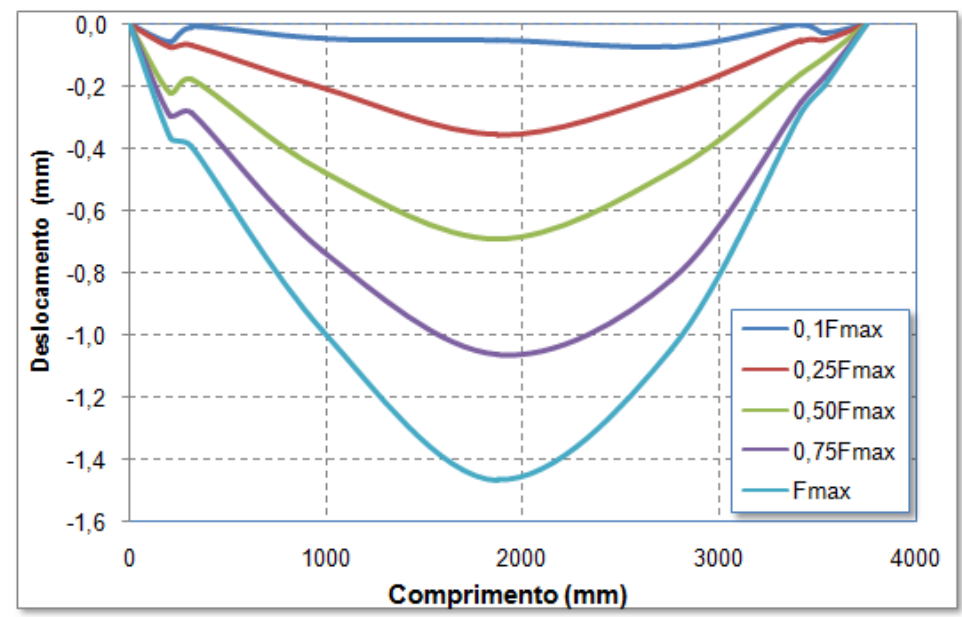

Figura B.25: Deslocamentos na viga 3 da Fase 5 de carregamento concentrado na laje.

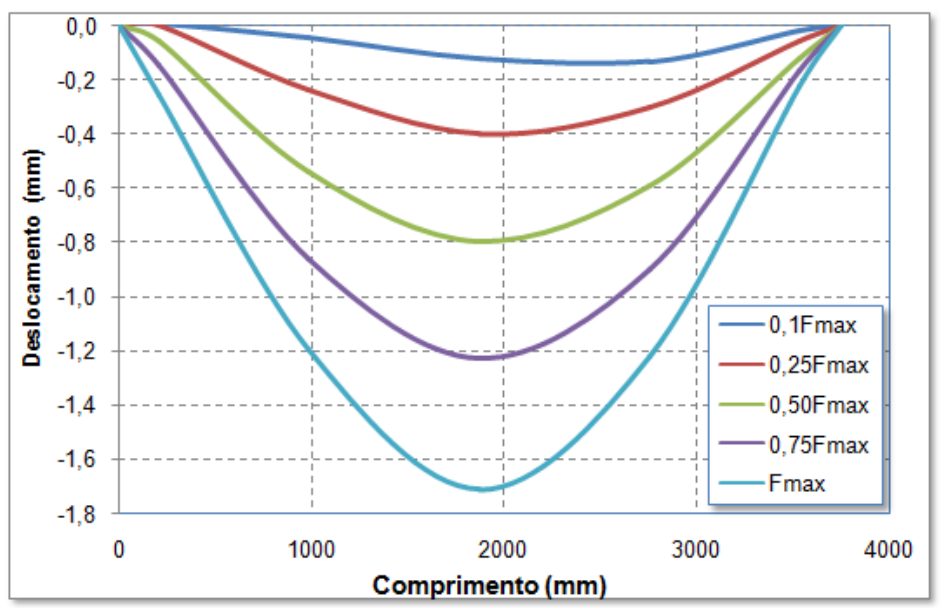

Figura B.26: Deslocamentos na viga 4 da Fase 5 de carregamento concentrado na laje. 
Apêndice B: Resultados complementares da etapa de carregamento concentrado no pavimento tipo

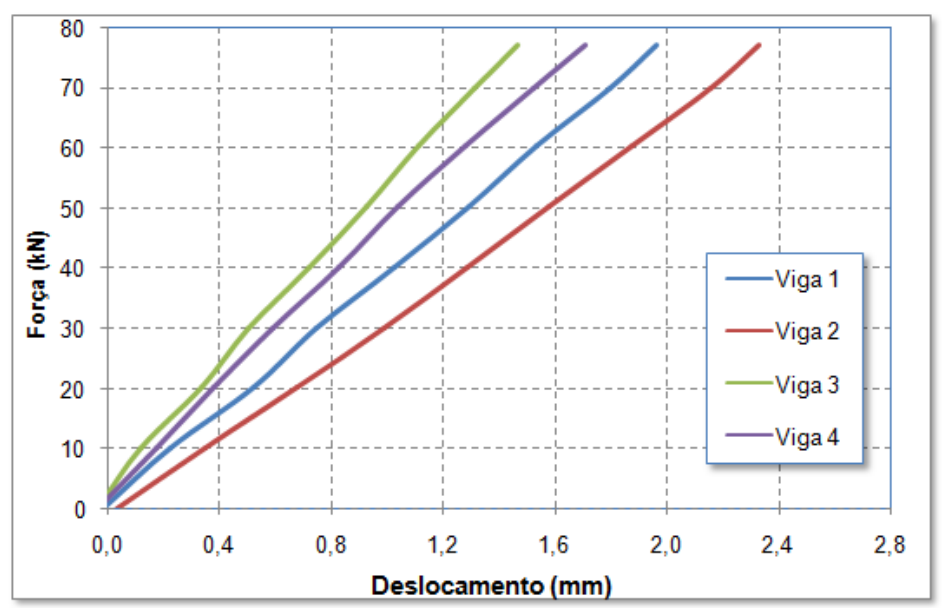

Figura B.27: Deslocamentos no centro dos vãos das vigas 1, 2, 3 e 4 da Fase 5 de carregamento concentrado na laje.

- $\mathbf{6}^{a}$ Fase: força aplicada em dois pontos sobre a viga principal, numa distância de $125 \mathrm{~cm}$ dos nós do pórtico, conforme ilustra a Figura B.28, com a reação de apoio final $\left(F_{\max }\right)$ em cada ponto de $70 \mathrm{kN}(140 \mathrm{kN} \mathrm{em}$ cada atuador).

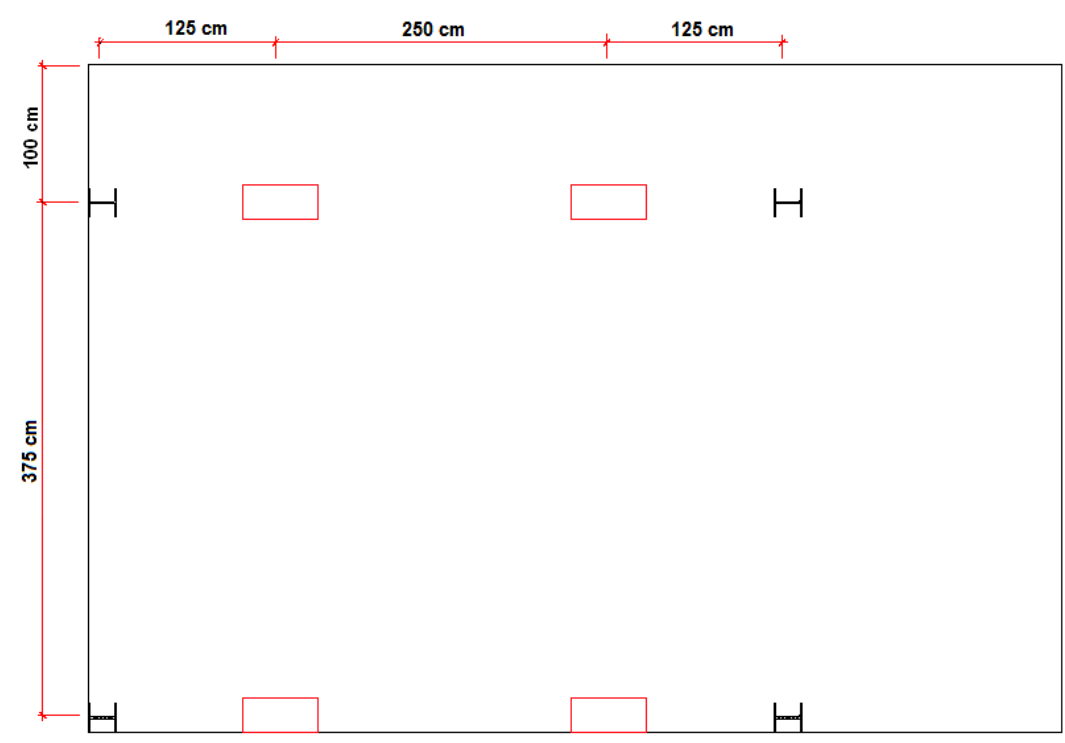

Figura B.28: Representação da Fase 6 do carregamento concentrado na laje. 
Apêndice B: Resultados complementares da etapa de carregamento concentrado no pavimento tipo

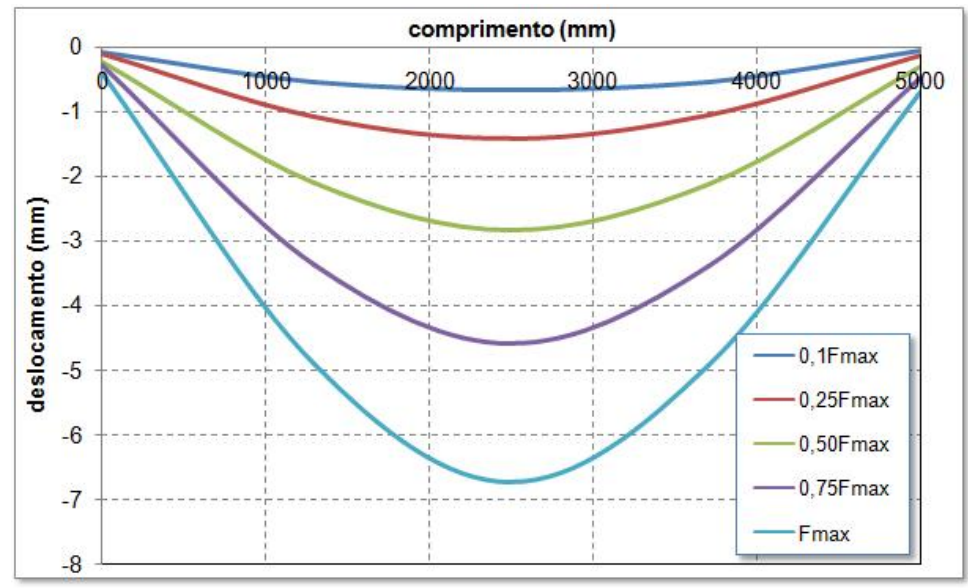

Figura B.29: Deslocamentos na Linha 1 da Fase 6 de carregamento concentrado na laje.

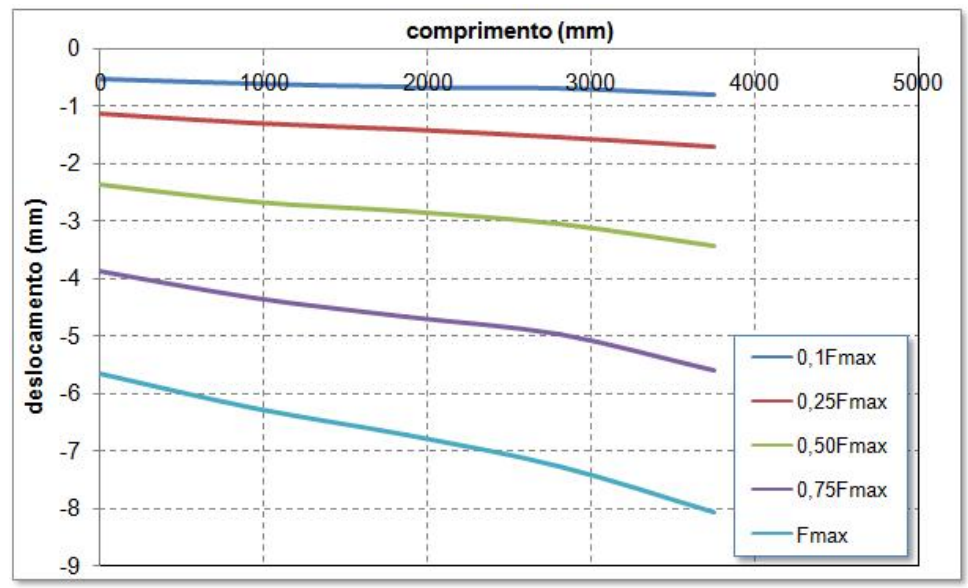

Figura B.30: Deslocamentos na Linha 2 da Fase 6 de carregamento concentrado na laje.

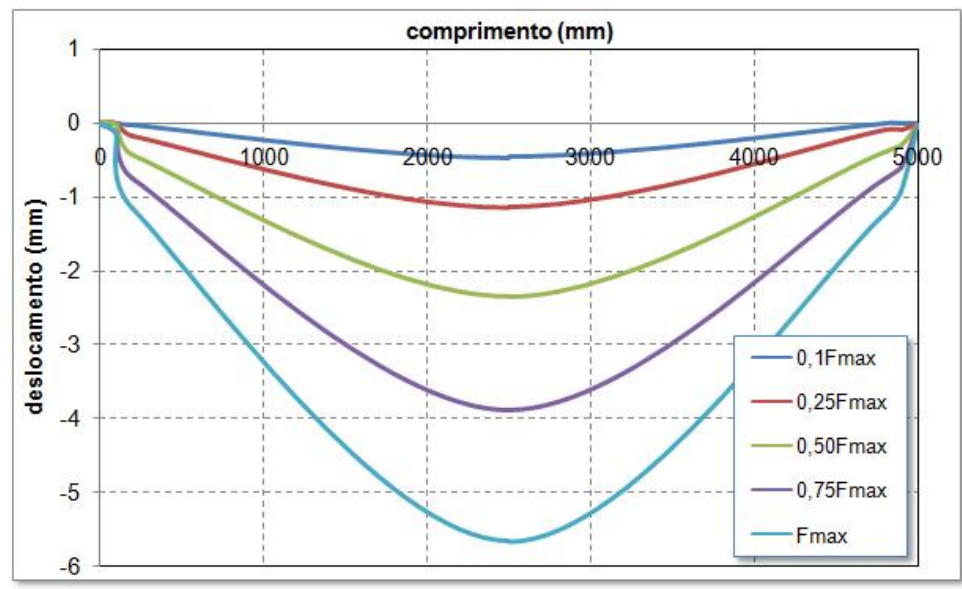

Figura B.31: Deslocamentos na viga principal 1 da Fase 6 de carregamento concentrado na laje. 
Apêndice B: Resultados complementares da etapa de carregamento concentrado no pavimento tipo

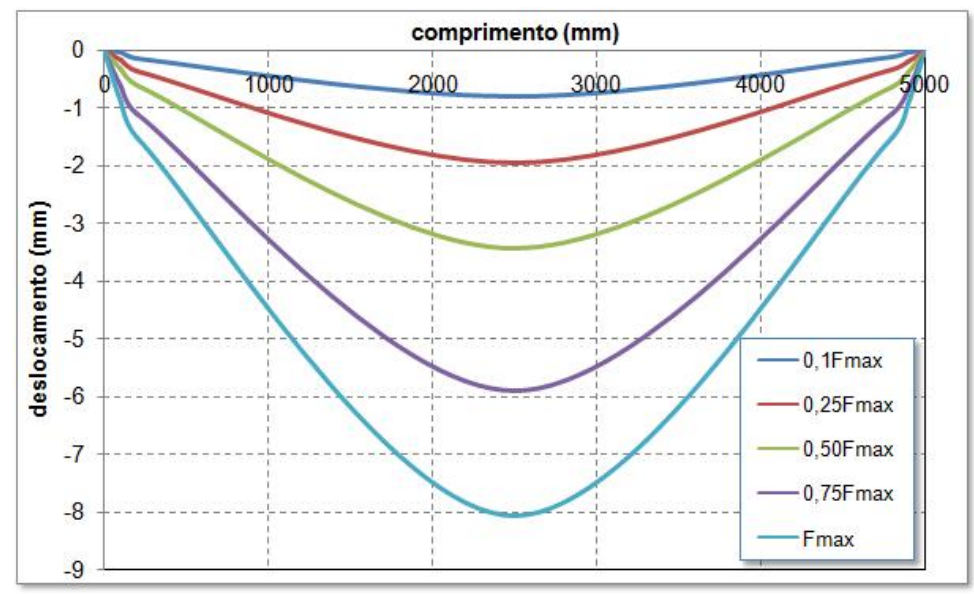

Figura B.32: Deslocamentos na viga principal 2 da Fase 6 de carregamento concentrado na laje.

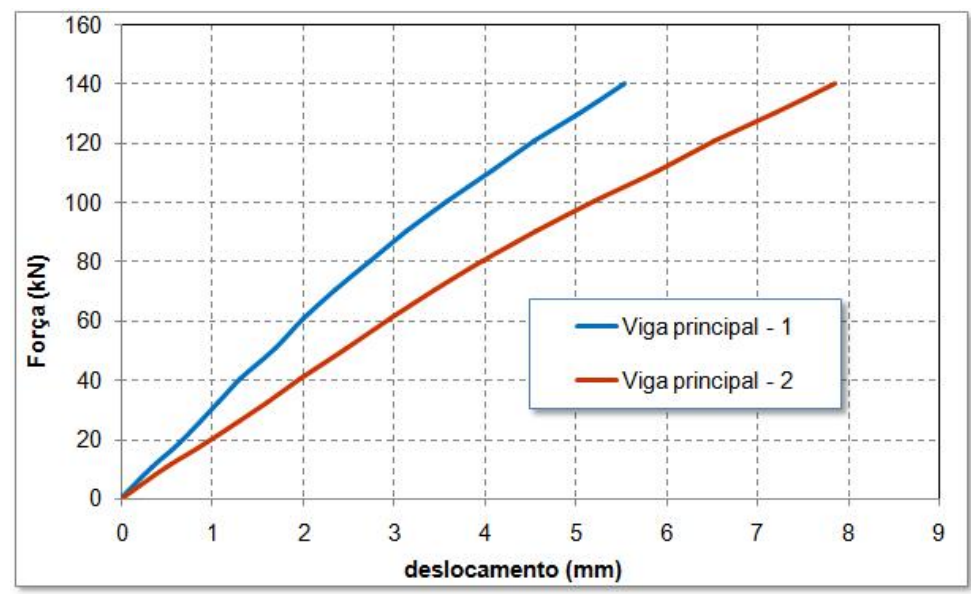

Figura B.33: Deslocamentos no centro dos vãos das vigas principais1 e 2 da Fase 6 de carregamento concentrado na laje.

- $\underline{7}^{a}$ Fase: força aplicada em dois pontos sobre a viga principal, numa distância de $125 \mathrm{~cm}$ e $250 \mathrm{~cm}$ dos nós do pórtico, conforme apresenta a Figura B.34, com a reação de apoio final $\left(F_{\max }\right)$ em cada ponto de 88 kN (176 kN em cada atuador). 
Apêndice B: Resultados complementares da etapa de carregamento concentrado no pavimento tipo

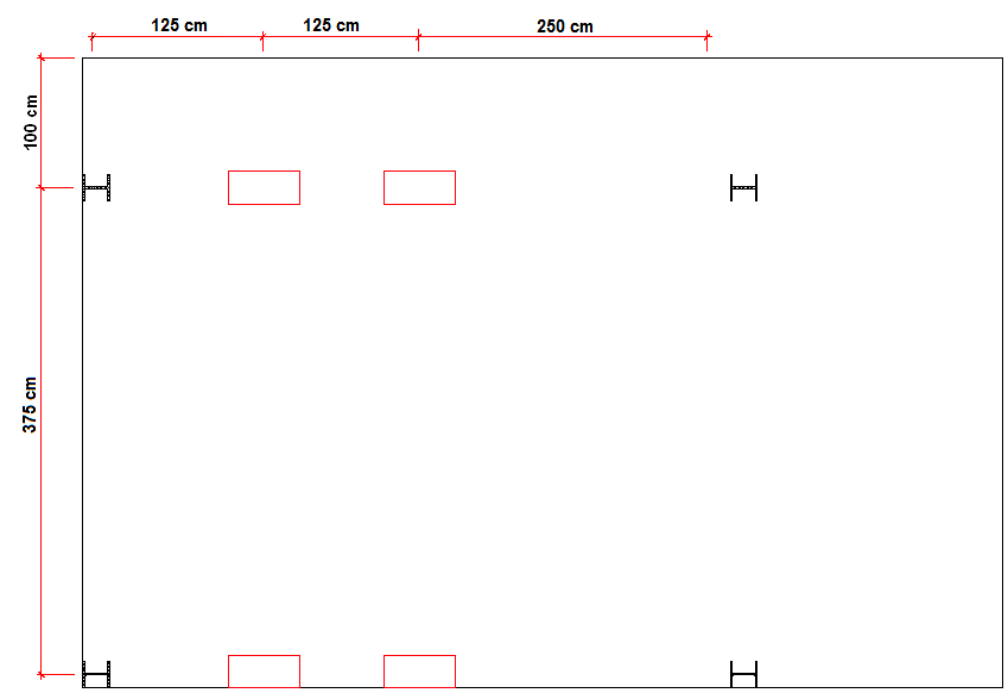

Figura B.34: Representação da Fase 7 do carregamento concentrado na laje.

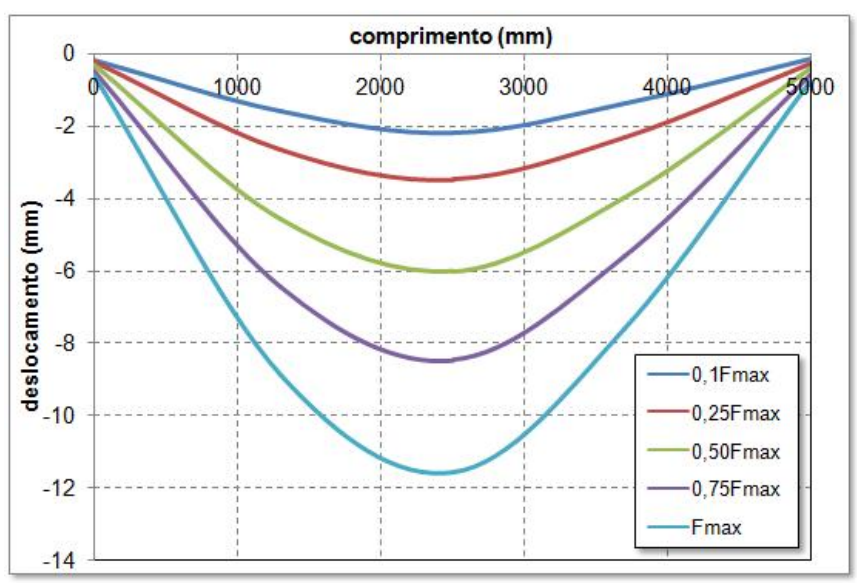

Figura B.35: Deslocamentos na Linha 1 da Fase 7 de carregamento concentrado na laje.

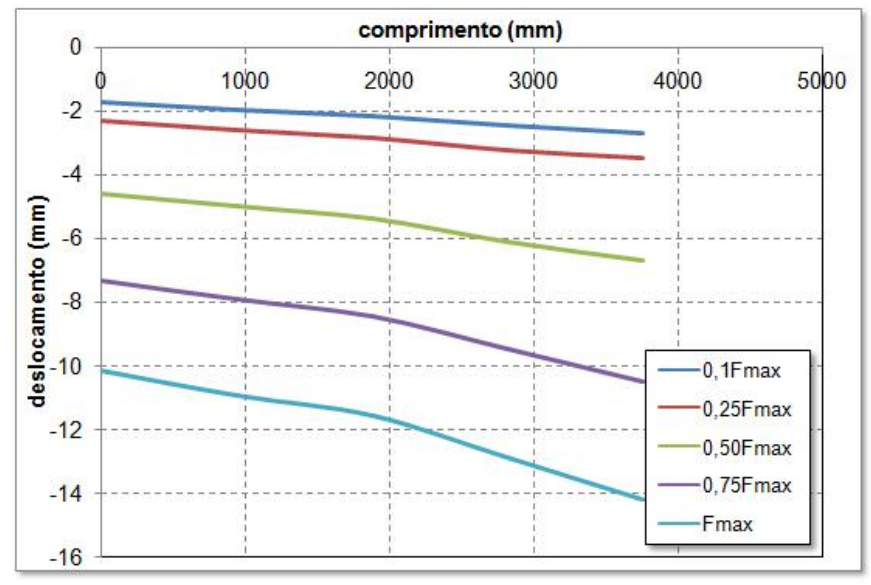

Figura B.36: Deslocamentos na Linha 2 da Fase 7 de carregamento concentrado na laje. 
Apêndice B: Resultados complementares da etapa de carregamento concentrado no pavimento tipo

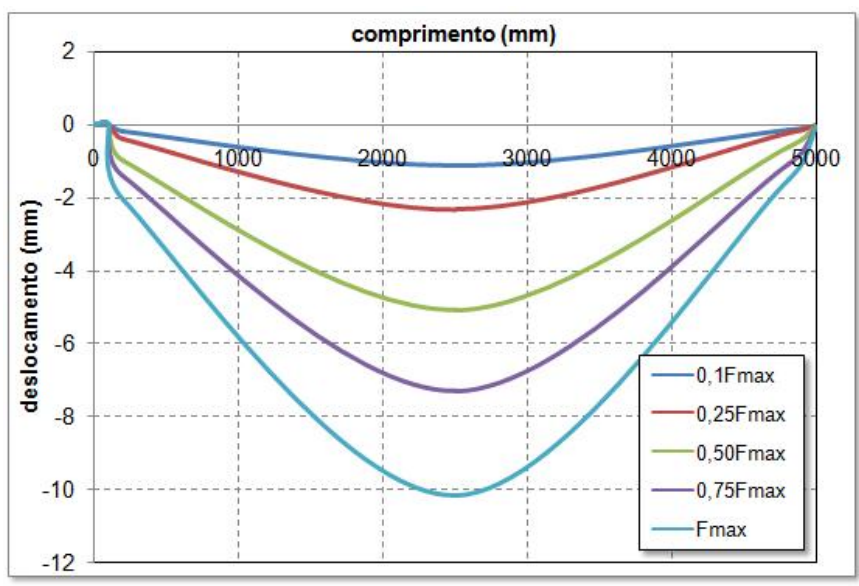

Figura B.37: Deslocamentos na viga principal 1 da Fase 7 de carregamento concentrado na laje.

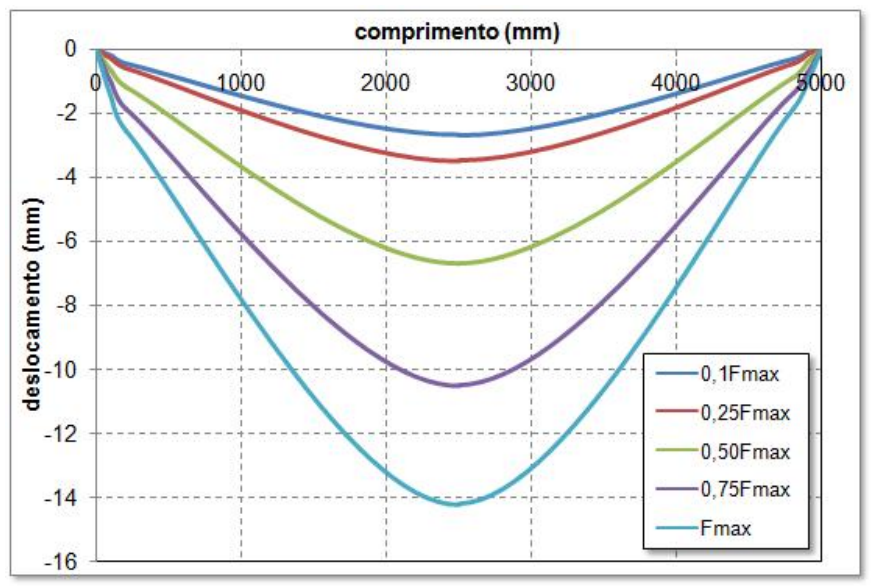

Figura B.38: Deslocamentos na viga principal 2 da Fase 7 de carregamento concentrado na laje.

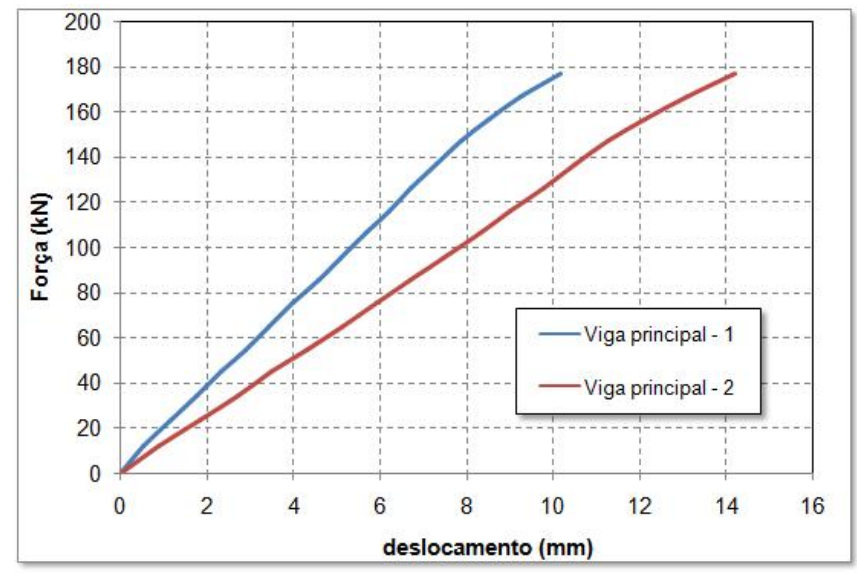

Figura B.39: Deslocamentos no centro dos vãos das vigas principais1 e 2 da Fase 7 de carregamento concentrado na laje. 
Apêndice B: Resultados complementares da etapa de carregamento concentrado no pavimento tipo

- $\boldsymbol{8}^{a}$ Fase: força aplicada em dois pontos sobre a viga principal, numa distância de $195 \mathrm{~cm}$ e $230 \mathrm{~cm}$ dos nós do pórtico, conforme ilustra a Figura B.40, com a reação de apoio final $\left(F_{\max }\right)$ em cada ponto de 110 kN (220 kN em cada atuador). Nesta etapa ocorreu o colapso da ligação 1 devido à abertura excessiva de fissuras na laje de concreto.

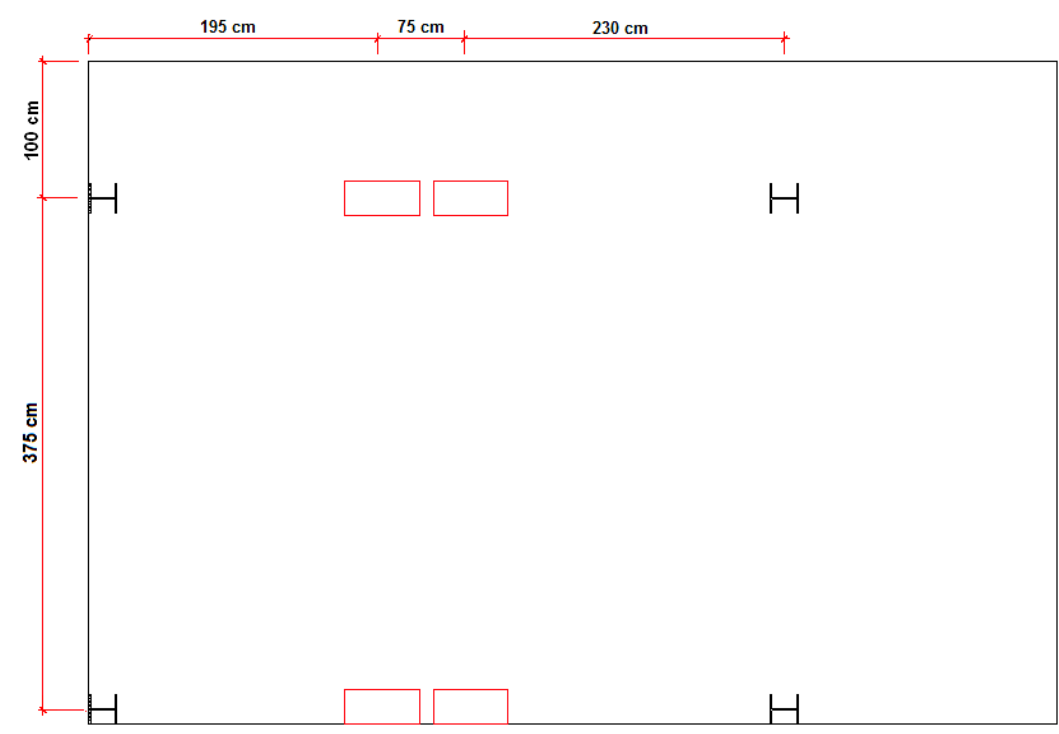

Figura B.40: Representação da Fase 8 do carregamento concentrado na laje.

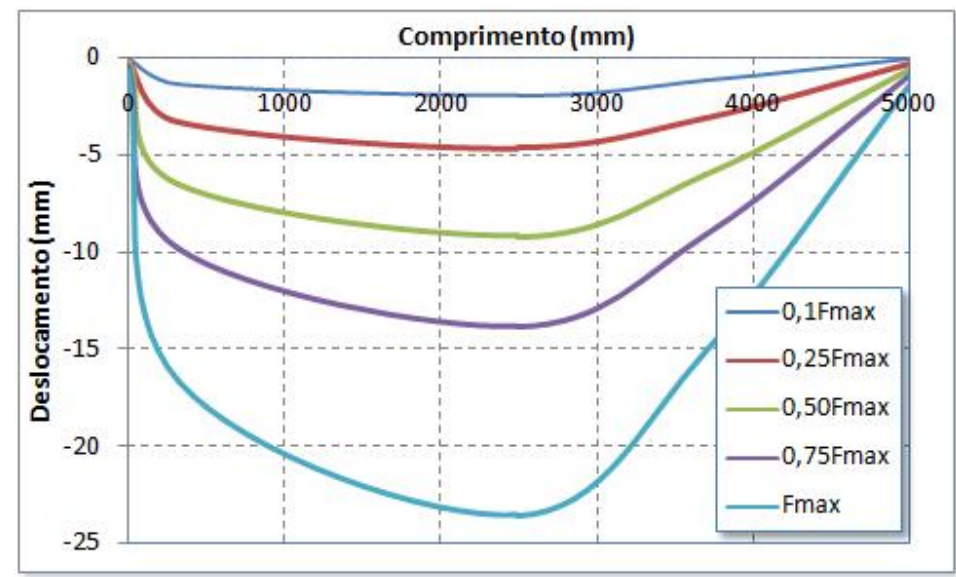

Figura B.41: Deslocamentos na Linha 1 da Fase 8 de carregamento concentrado na laje. 
Apêndice B: Resultados complementares da etapa de carregamento concentrado no pavimento tipo

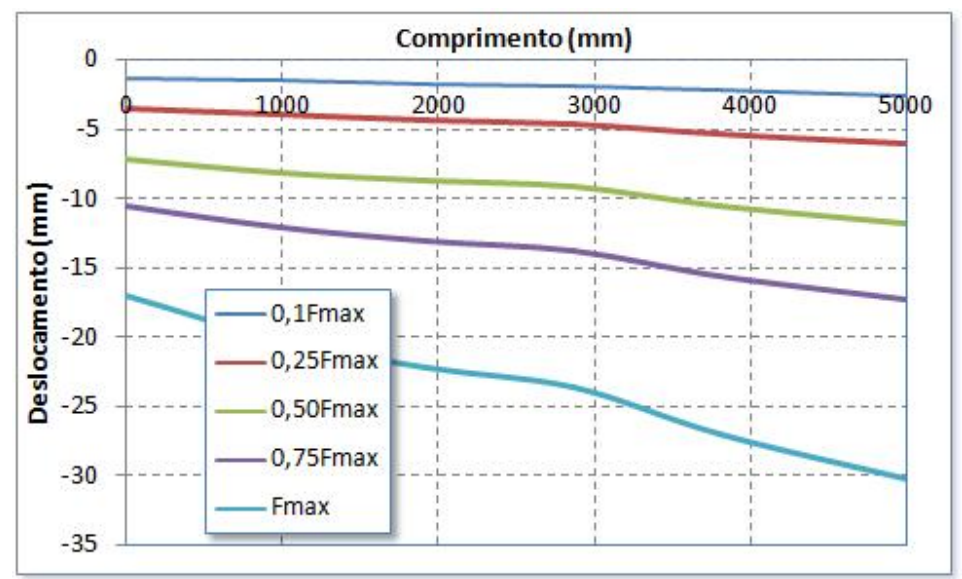

Figura B.42: Deslocamentos na Linha 2 da Fase 8 de carregamento concentrado na laje.

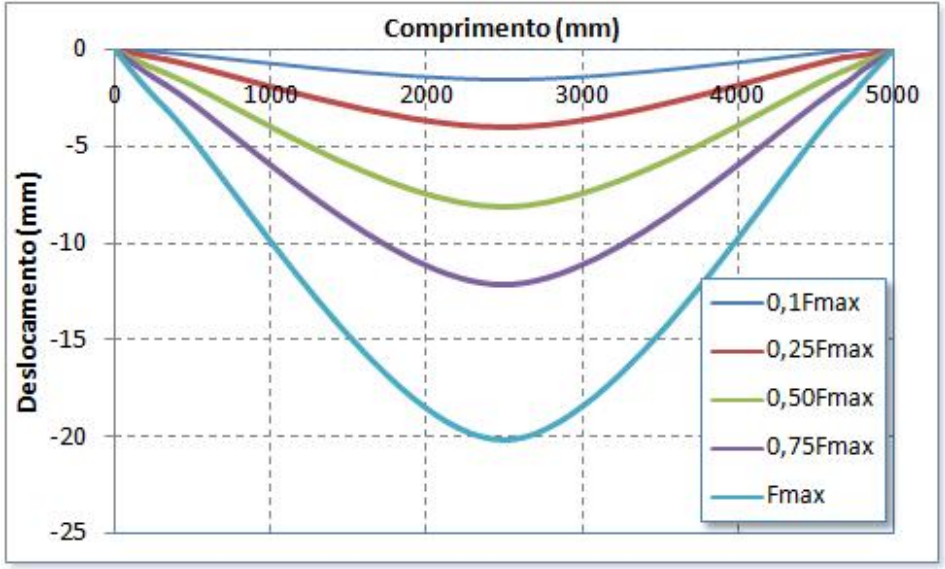

Figura B.43: Deslocamentos na viga principal 1 da Fase 8 de carregamento concentrado na laje.

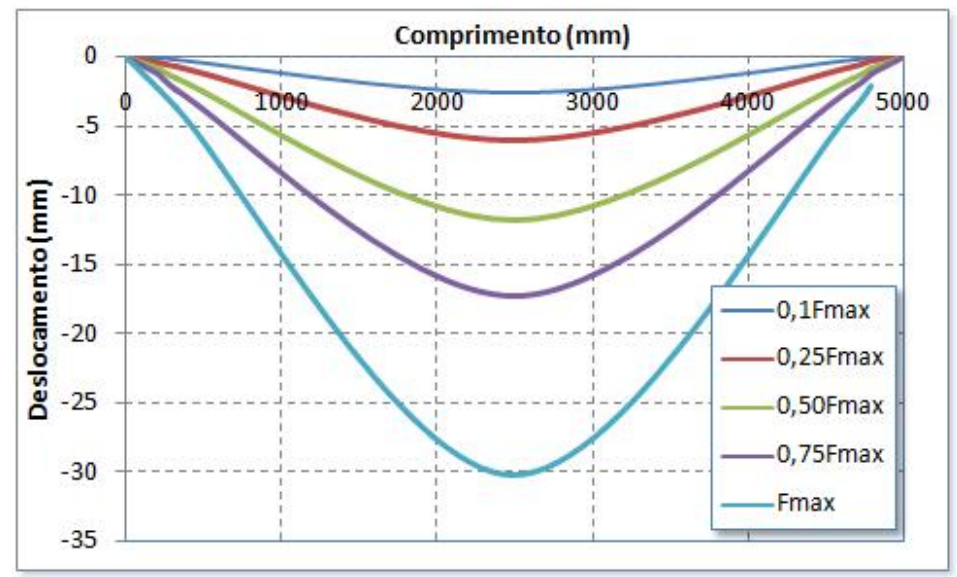

Figura B.44: Deslocamentos na viga principal 2 da Fase 8 de carregamento concentrado na laje. 
Apêndice B: Resultados complementares da etapa de carregamento concentrado no pavimento tipo

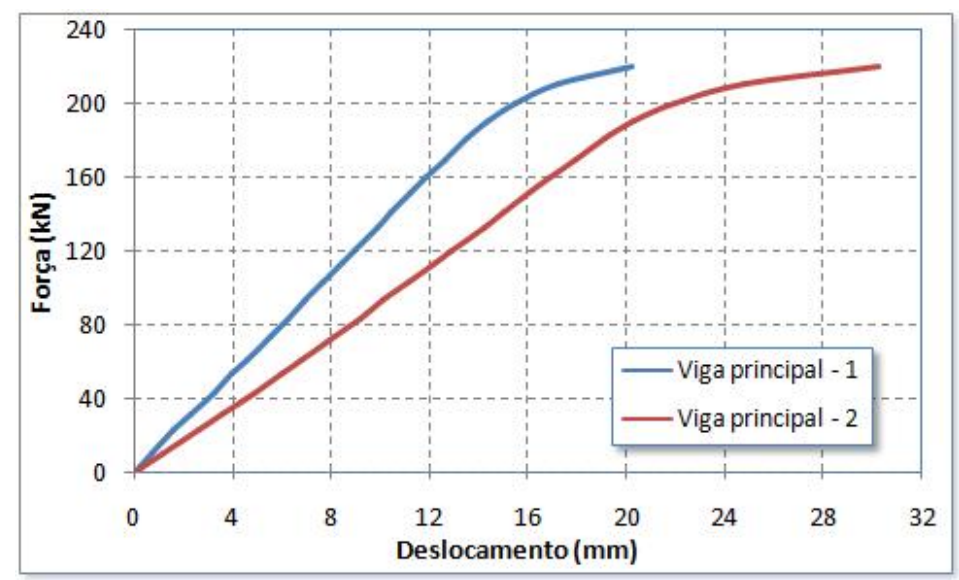

Figura B.45: Deslocamentos no centro dos vãos das vigas principais1 e 2 da Fase 8 de carregamento concentrado na laje.

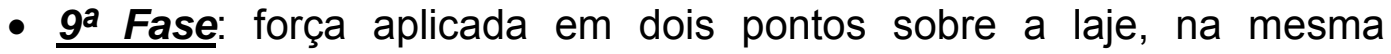
distância de $195 \mathrm{~cm}$ e $230 \mathrm{~cm}$ dos nós do pórtico da fase anterior, conforme apresenta a Figura B.46, com a reação de apoio final $\left(F_{\max }\right)$ em cada ponto de $55 \mathrm{kN}$ (110 kN em cada atuador). Esta última etapa foi concebida para atingir o colapso da laje do pavimento tipo.

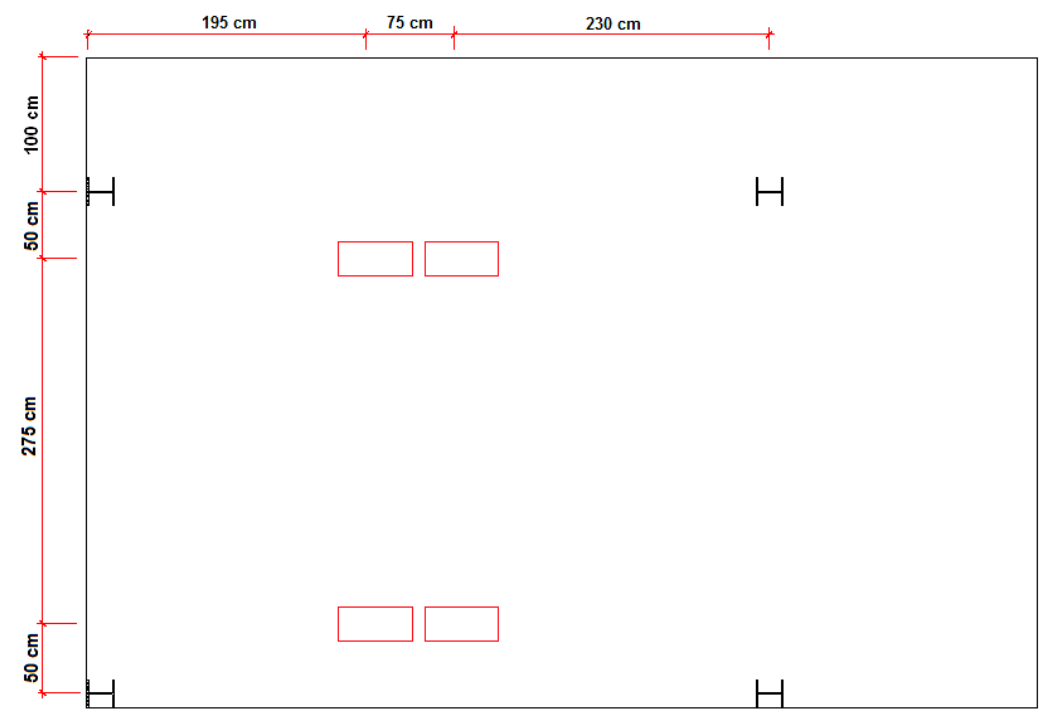

Figura B.46: Representação da Fase 9 do carregamento concentrado na laje. 
Apêndice B: Resultados complementares da etapa de carregamento concentrado no pavimento tipo

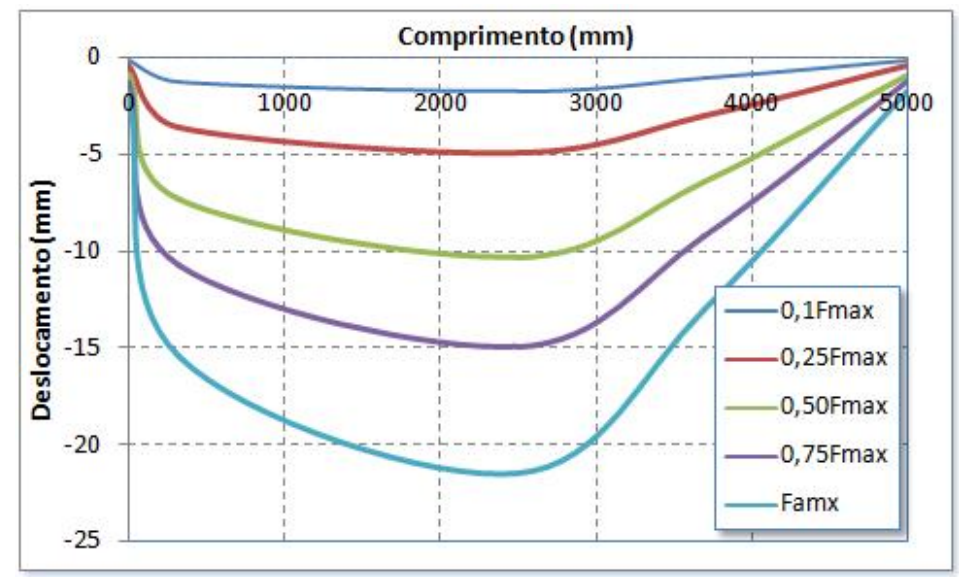

Figura B.47: Deslocamentos na Linha 1 da Fase 9 de carregamento concentrado na laje.

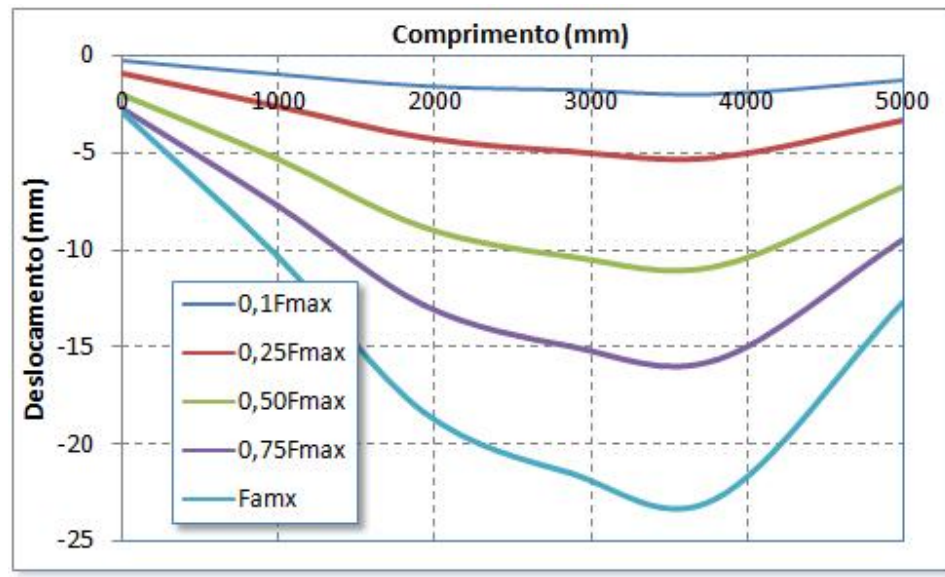

Figura B.48: Deslocamentos na Linha 2 da Fase 9 de carregamento concentrado na laje.

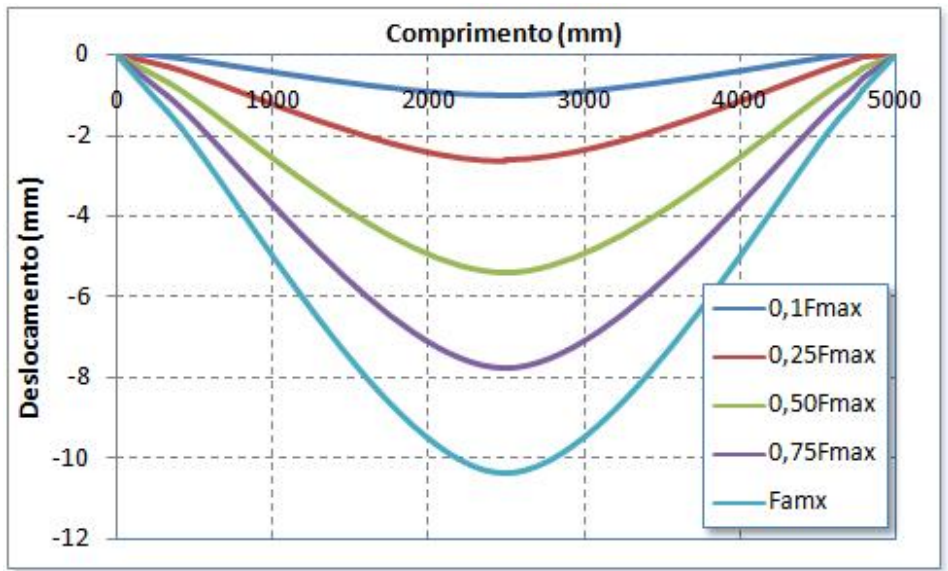

Figura B.49: Deslocamentos na viga principal 1 da Fase 9 de carregamento concentrado na laje. 
Apêndice B: Resultados complementares da etapa de carregamento concentrado no pavimento tipo

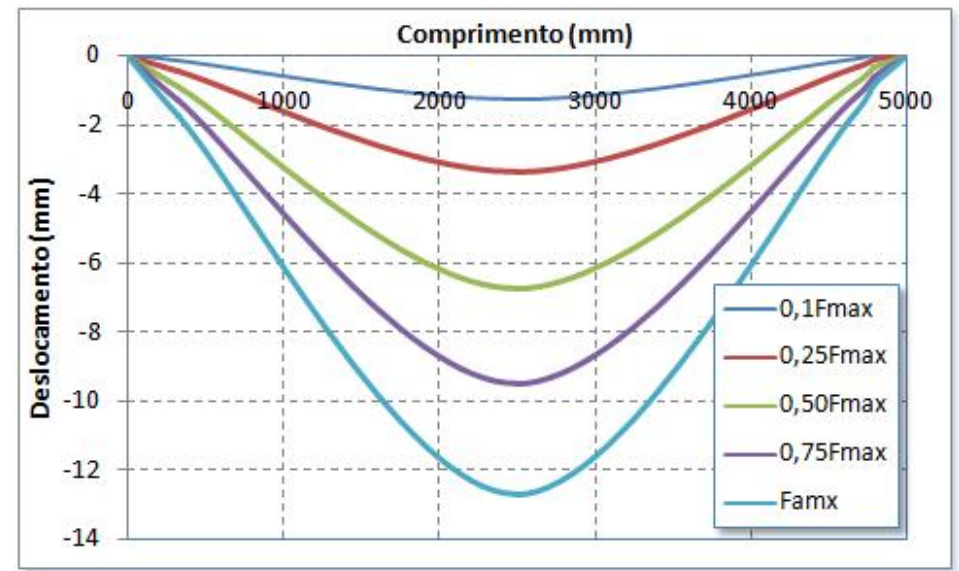

Figura B.50: Deslocamentos na viga principal 2 da Fase 9 de carregamento concentrado na laje.

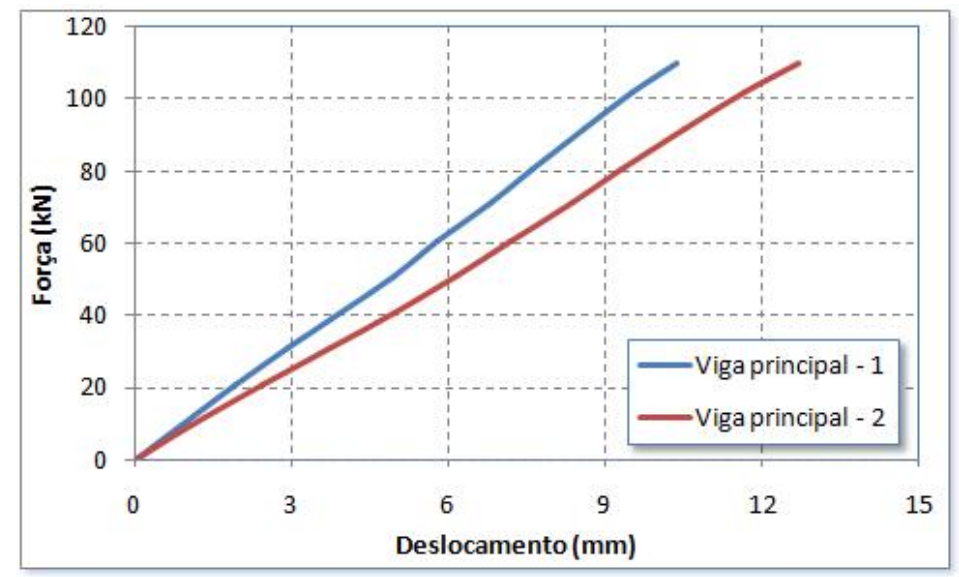

Figura B.51: Deslocamentos no centro dos vãos das vigas principais1 e 2 da Fase 9 de carregamento concentrado na laje.

A Figura B.52. ilustra a fissuração na laje ao término do carregamento.

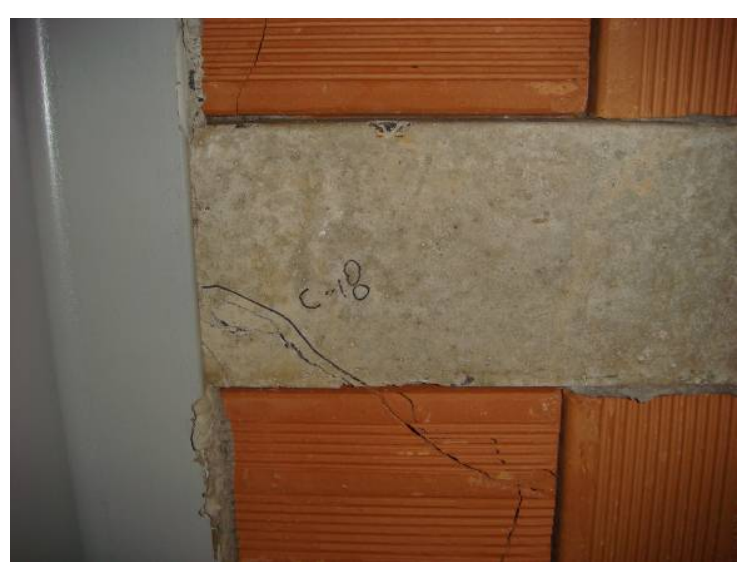

Fissuração da vigota e lajota

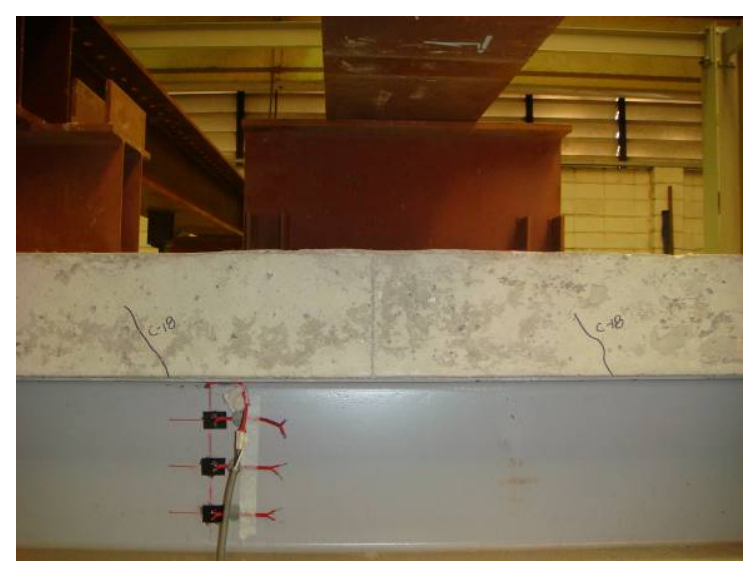

Fissuração na espessura da laje

Figura B.52: Fissuração na laje após a fase 9 de carregamento concentrado. 
